Mihai Nedelea

\title{
Erfordernisse und Möglichkeiten einer wachstumsorientierten Steuerpolitik in Rumänien
}




\title{
Mihai Nedelea
}

\section{Erfordernisse und Möglichkeiten einer wachstumsorientierten Steuerpolitik in Rumänien}

Die Wettbewerbsfähigkeit der Industrieunternehmen steht in engem Zusammenhang mit dem Modernitäts- und Gütegrad ihrer Sachkapitalbestände. In dieser Arbeit wird die in Rumänien nach der Wende getroffene Steuergesetzgebung kritisch beurteilt. Ihr Einfluß auf die unternehmerische Kapitalbildung wird anhand eines mikroökonomischen, neoklassischen Modells analysiert. Der Autor entwickelt zusätzlich ein Modell für den Liquiditätsentzugseffekt der Besteuerung. Die Analyse erfolgt in bezug auf die für Rumänien als repräsentativ betrachtete Textil- und Bekleidungsindustrie. Zum Schluß ergeben sich die steuerpolitischen Empfehlungen des Autors hinsichtlich der effizientesten Möglichkeiten für die Reduzierung der unternehmerischen Steuerlast.

\begin{abstract}
Abschluß der Universität Politehnica (Technische Hochschule) Bukarest als Dipl.Ingenieur (Maschinenbau). Zusätzliche kaufmännische Ausbildung an der Akademie für Wirtschaftsstudien Bukarest. Ingenieurtätigkeit (Konstruktion, Technologien) und Assistent im Fachbereich Management der Universität Politehnica Bukarest. Promotion an der TH Darmstadt, seit August 1994 Büroleiter von Klöckner Industrieanlagen GmbH in Bukarest.
\end{abstract}


Erfordernisse und Möglichkeiten einer wachstumsorientierten Steuerpolitik in Rumänien

Dargestellt am Beispiel der Textil- und Bekleidungsindustrie 


\section{Sozialökonomische Schriften}

Herausgegeben von BertRürup

Band 7

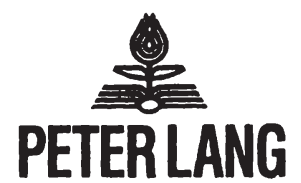

Frankfurt am Main. Berlin - Bern - New York. Paris - Wien

Mihail Nedelea - 978-3-631-75036-0 


\section{Mihai Nedelea}

\section{Erfordernisse und Möglichkeiten einer wachstumsorientierten Steuerpolitik in Rumänien}

Dargestelltam Beispiel der

Textil- und Bekleidungsindustrie

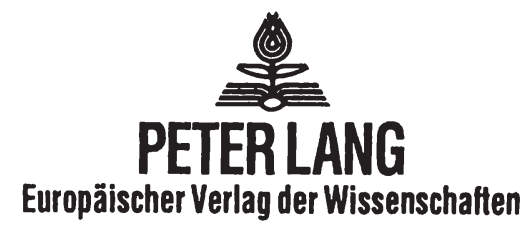


Die Deutsche Bibliothek - CIP-Einheitsaufnahme

Nedelea, Mihai:

Erfordernisse und Möglichkeiten einer wachstumsorientierten Steuerpolitik in Rumänien : dargestellt am Beispiel der Textilund Bekleidungsindustrie / Mihai Nedelea. - Frankfurt am Main ; Berlin ; Bern ; New York ; Paris ; Wien : Lang, 1995

(Sozialökonomische Schriften ; Bd. 7)

Zugl.: Darmstadt, Techn. Hochsch., Diss., 1994

ISBN 3-631-48381-3

Open Access: The online version of this publication is published on www.peterlang.com and www.econstor.eu under the international Creative Commons License CC-BY 4.0. Learn more on how you can use and share this work: http://creativecommons.org/ licenses/by/4.0.

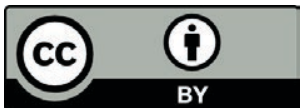

This book is available Open Access thanks to the kind support of ZBW - Leibniz-Informationszentrum Wirtschaft.

NE: GT

\author{
D 17 \\ ISSN 0172-1747 \\ ISBN 3-631-48381-3 \\ ISBN 978-3-631-75036-0(eBook) \\ (c) Peter Lang GmbH \\ Europäischer Verlag der Wissenschaften \\ Frankfurt am Main 1995 \\ Alle Rechte vorbehalten
}

Das Werk einschließlich aller seiner Teile ist urheberrechtlich geschützt. Jede Verwertung außerhalb der engen Grenzen des

Urheberrechtsgesetzes ist ohne Zustimmung des Verlages unzulässig und strafbar. Das gilt insbesondere für Vervielfältigungen, Übersetzungen, Mikroverfilmungen und die Einspeicherung und Verarbeitung in elektronischen Systemen. 


\section{GELEITWORT}

Herr Nedelea verfolgt mit seiner Arbeit zwei Ziele.

Zum einen bemüht er sich zu dokumentieren, inwieweit die seit dem Machtwechsel erfolgte Umgestaltung des rumänischen Steuersystems die zu einer marktwirtschaftlich orientierten Modernisierung unabdingbare Kapitalbildung schon positiv beeinflußt hat und zum anderen, wie aufgrund der institutionellen Besonderheiten dieses Landes eine wachstumsorientierte Unternehmenssteuerpolitik aussehen sollte und in welchen Schritten sie umgesetzt werden könnte.

Bemerkenswert an dieser Arbeit ist, daß es dem Verfasser gelingt, seine intimen Kenntnisse der rumänischen Verhältnisse mit modernen wirtschaftswissenschaftlichen, analytischen und methodischen Kenntnissen zu kombinieren.

Dies gereicht der Arbeit zum Vorteil, denn die von Herrn Nedelea formulierten Optionen sind somit einerseits theoretisch fundiert, andererseits aber - was von besonderer praktischer Wichtigkeit ist - hinsichtlich der institutionellen Besonderheiten seines Heimatlandes "erfahrungsgesättigt".

Es ist daher nur zu hoffen, daß diese Analyse eines jungen hoffnungsvollen, marktorientierten rumänischen Nachwuchswissenschaftlers nicht nur in der wirtschaftswissenschaftlichen Diskussion, sondern auch und gerade in der steuerpolitischen Diskussion seines Heimatlandes die gebührende Aufmerksamkeit findet.

(Prof.Dr.Dr.h.c. Bert Rürup) 
Mihail Nedelea - 978-3-631-75036-0 Downloaded from PubFactory at 01/11/2019 09:01:58AM via free access 


\section{INHALTSVERZEICHNIS}

Kapitel 1: Rumänien: Stand der Reform und wirtschaftliche Lage 1

1.1. 1989: Die Erbschaft der Planwirtschaft 1

1.2. Die politische Entwicklung nach $1989 \quad 8$

$\begin{array}{lr}\text { 1.2.1. Politischer Rahmen } & 8\end{array}$

1.2.2. Hauptziele der Wirtschaftspolitik nach $1989 \quad 11$

1.3. Preisreform und Geldpolitik 14

1.4. Außenhandels- und Währungspolitik 19

1.5. Entwicklung der rumänischen Volkswirtschaft nach 1989

1.6. Unternehmensreform 28

1.7. Stand der Privatisierung 31

1.8. Das Bankensystem 35

1.9. Die Finanzpolitik nach der Wende 38

1.10. Ausländische Investitionen in Rumänien nach $1989 \quad 44$

1.11. Defizite: Angebots- und Strukturpolitik 45

Kapitel 2: Die rumänische Textil- und Bekleidungsindustrie (TBI) 49

2.1. Bedeutung der rumänischen Textil- und Bekleidungsindustrie 49

2.2. Stärken - Schwächen Analyse der rumänischen Textil- und Bekleidungs$\begin{array}{ll}\text { industrie } & 65\end{array}$

2.2.1. Internationales Umfeld 65

2.2.1.1. Der Weltmarkt für Textilien, Bekleidung und Lederware 65

2.2.1.2. Anbieter und Angebotsbedingungen in der Welttextilwirtschaft 66

2.2.1.3. Tarifäre und nichttarifäre Hemmnisse für die Textil- und Bekleidungsexporte $\quad 69$

2.2.1.4. Rolle und Wettbewerbsvorteile der osteuropäischen Länder im $\begin{array}{ll}\text { Welttextilhandel } & 71\end{array}$

2.2.2. Nationales Umfeld der Textil- und Bekleidungsindustrie 79

2.2.3. Evaluation der rumänischen TBI nach 1989 und Identifizierung ihrer Schwachstellen $\quad 82$

2.3. Faktorausstattungsanalyse 101

2.4. Entwicklungsperspektiven der rumänischen TBI 116

Kapitel 3: Die Bedeutung der Steuern für die Investitionstätigkeit im Lichte $\begin{array}{ll}\text { der ökonomischen Theorie } & 121\end{array}$

3.1. Die Determinanten des Investitionsverhaltens 122

3.2. Makroökonomischer versus mikroökonomischer Ansatz 125 
$\begin{array}{ll}\text { 3.3. Erweiterungs- versus Ersatzinvestitionen } & 127\end{array}$

3.4. Der betriebswirtschaftliche Ansatz 128

3.5. Die neoklassische Investitionstheorie 129

$\begin{array}{ll}\text { 3.6. Der Akzeleratoransatz } & 138\end{array}$

3.7. Die Tobin's "q"-Theorie 139

3.8. Uncertainty-Theorien 139

3.9. Der Finanzierungsquellenansatz 143

3.10. Die Liquiditätstheorie 146

Kapitel 4: Von der Theorie zur Empirie: das Isomorphismusproblem 147

4.1. Zielsetzungen der Investoren in Rumänien 147

4.2. Kriterienraster zur Beurteilung der Praxisrelevanz der verschiedenen Modelle $\quad 150$

4.3. Analyse der Theorien des Investitionsverhaltens 152

4.4. Das der rumänischen Volkswirtschaft adäquate Modell 158

Kapitel 5: Wirkungsanalyse der Gewinn- und Dividendensteuer in der rumänischen Textil- und Bekleidungsindustrie $\quad 163$

5.1. Gesetzlicher Rahmen 163

5.1.1. Einführung 163

5.1.2. Das Gesetz Nr.12/1991 betreffend die Gewinnsteuer 164

5.1.3. Der Regierungsbeschluß Nr.804/1991 "Über die Gewinnsteuer" 167

5.1.4. Die Vorschriften des Finanzministeriums Nr.3614/ 26.04.1991 hinsichtlich der Berechnung der Gewinnsteuer 168

5.1.5. Das Gesetz Nr.40/1992 über die Dividendensteuer 172

5.1.6. Das neue Abschreibungsgesetz, vom 2. März 1994

5.1.7. Das Buchführungsgesetz Nr.82/1991 und das neue Buchführungssystem ab dem 1.01.1994 177

5.2. Wirkungen auf die Rentabilität und somit auf die Investitionsbereit$\begin{array}{ll}\text { schaft } & 180\end{array}$

5.2.1. Festlegung der mathematischen Form des Modells entsprechend dem steuerlichen Rahmen in Rumänien $\quad 180$

5.2.2. Schätzung der ökonomischen Abschreibungen in der rumänischen $\begin{array}{ll}\text { TBI } & 184\end{array}$

5.2.3. Berechnung des Barwerts der steuerlich zugelassenen Abschreibun$\begin{array}{ll}\text { gen } & 187\end{array}$

5.2.4. Berechnung der Preissteigerungsrate der TBI-spezifischen Maschinen $\begin{array}{ll}\text { und Anlagen } & 190\end{array}$

5.2.5. Berechnung der Kapitalbereitstellungskosten in der rumänischen Textil- und Bekleidungsindustrie 
5.2.6. Elastizitätsanalyse 194

5.3. Wirkungen auf die Liquidität der investierenden Unternehmen 204

5.3.1. Berechnung des maximalen Gewinnanteils, der reinvestiert werden kann 204

5.3.2. Berechnung des von der Gewinnbesteuerung verursachten zusätzlichen Finanzbedarfs einer Investitionskette 207

5.4. Möglichkeiten der Überwälzung der Gewinnsteuer 219

Kapitel 6: Gestaltung und Einfluß der Vermögen- und Kapitalverkehrssteuern 227

6.1. Gesetzlicher Rahmen 227

6.1.1. Die Gebühr für die Benutzung öffentlichen Bodens von juristischen $\begin{array}{ll}\text { Personen } & 227\end{array}$

6.1.2. Die Gebäudesteuer für juristische Personen 229

6.1.3. Die Kfz-Steuer für juristische Personen 229

6.1.4. Die Gesellschaftsteuer 229

6.1.5. Grund- und Gebäudeerwerbsteuern für juristische Personen 230

6.1.6. Die Steuer auf den Verkauf von Aktiva der staatlichen Unternehmen 232

6.2. Die Bedeutung der Vermögen- und Kapitalverkehrssteuern für die Investitionen

Kapitel 7: Besonderheiten des rumänischen Steuersystems für die ausländischen Investitionen

7.1. Wichtige gesetzliche Sonderbestimmungen betreffend die ausländischen Investitionen in Rumänien

7.2. Wirkungen der rumänischen steuerlichen Gesetzgebung und andere besondere Aspekte der Problematik der ausländischen Investitionen

Kapitel 8: Zusammenfassung und einige wirtschaftspolitische Folgerungen 
Mihail Nedelea - 978-3-631-75036-0 Downloaded from PubFactory at 01/11/2019 09:01:58AM via free access 


\section{ABKÜRZUNGSVERZEICHNIS}

$\begin{array}{ll}\text { Abb. } & \text { Abbildung } \\ \text { Abs. } & \text { Abschnitt } \\ \text { AG } & \text { Aktiengesellschaft } \\ \text { Art. } & \text { Artikel } \\ \text { Bd. } & \text { Band } \\ \text { BIP } & \text { Bruttoinlandsprodukt } \\ \text { BSP } & \text { Bruttosozialprodukt } \\ \text { bzw. } & \text { beziehungsweise } \\ \text { ca. } & \text { circa } \\ \text { d.h. } & \text { das heißt } \\ \text { DIW } & \text { Deutsches Institut für Wirtschaftsforschung } \\ \text { EG (EWG) } & \text { Europäische (Wirtschafts-)Gemeinschaften } \\ \text { ff. } & \text { fortfolgende } \\ \text { GmbH } & \text { Gesellschaft mit beschränkter Haftung } \\ \text { GUS } & \text { Gemeinschaft Unabhängiger Staaten } \\ \text { Hrsg. } & \text { Herausgeber } \\ \text { IWF } & \text { Internationaler Währungsfonds } \\ \text { Kap. } & \text { Kapitel } \\ \text { Kfz } & \text { Kraftfahrzeug } \\ \text { m.a.W. } & \text { mit anderen Worten } \\ \text { Mio. } & \text { Million(en) } \\ \text { MOE } & \text { Mittel- und Osteuropa } \\ \text { N.F. } & \text { Neue Folge } \\ \text { NIV } & \text { Neulich Industrialisierte Volkswirtschaften } \\ \text { No. } & \text { number (Englisch) } \\ \text { Nr. } & \text { Nummer } \\ \text { OECD } & \text { Organisation for Economic Cooperation and Development } \\ \text { Rbl. } & \text { Rubel } \\ \text { RGW } & \text { Rat für Gegenseitige Wirtschaftshilfe } \\ \text { rum. } & \text { rumänisch } \\ \text { S. } & \text { Seite } \\ \text { SITC } & \text { Statistic International Trade Classification } \\ \text { Tab. } & \text { Tabelle } \\ \text { TBI } & \text { Textil- und Bekleidungsindustrie } \\ \text { Tsd. } & \text { Tausende } \\ & \end{array}$


u.a. und andere

usw. und so weiter

vgl. vergleiche

Vol. volume (Englisch)

z.B. zum Beispiel

ZFB zusätzlicher Finanzierungsbedarf

z.T. zum Teil 


\section{TABELLENVERZEICHNIS}

Tabelle 1.1: $\quad$ Struktur der rumänischen Exporte, 1989.

Tabelle 1.2: Einheits- bzw. Kilogrammpreise der technologieintensiven Güter, erzielt von den osteuropäischen Exporteuren auf dem EG-Markt, im Verhältnis zu den Preisen der westlichen Güter, 1965-1985 (in \%).

Tabelle 1.3: $\quad$ Wirtschaftsstruktur Rumäniens 1989.

Tabelle 1.4: Monatliche Inflationsrate, 1991-1993.

Tabelle 1.5: Inflation in den MOE-Ländern: Änderung der Verbraucherpreise gegenüber dem Vorjahr in Prozent, 1989-1992.

Tabelle 1.6: Makroökonomische Indikatoren in Rumänien: Veränderungen gegenüber dem Vorjahr 1990, 1991 und 1992, in \%, preisbereinigt.

Tabelle 1.7: Durchschnittliche makroökonomische Indikatoren für die osteuropäischen Länder ohne UdSSR und Jugoslawien (Veränderungen gegenüber dem Vorjahr in \%, preisbereinigt).

Tabelle 1.8: Makroökonomische Indikatoren der osteuropäischen Länder, 1992.

Tabelle 1.9: Änderungen der Staatseinnahmen und Ausgaben in Rumänien gegenüber dem Vorjahr (in \%), inflationsbereinigt.

Tabelle 1.10: Entwicklung der Anteile unterschiedlicher Einnahmen- und Ausgabenarten im rumänischen Staatshaushalt, 1991-1993 (in \%).

Tabelle 1.11: Bruttoinlandsprodukt und Staatshaushalt in Rumänien, 1990-1992.

Tabelle 1.12: Ausländische Investitionen in Rumänien, 1990-1993.

Tabelle 2.1: Ausstattung der rumänischen Industrie mit Produktionsfaktoren - Ende 1991.

(und 2.1.bis)

Tabelle 2.2: $\quad$ Staffelung der Industriebranchen nach der Ausstattung mit Produktionsfaktoren.

Tabelle 2.3: Qualität der Produktionsprozesse in der rumänischen Industrie - 1991.

(und 2.3.bis)

Tabelle 2.4: $\quad$ Staffelung der Industriebranchen nach der Qualität der Produktionsprozesse.

Tabelle 2.5: Geldmäßige Effizienz der rumänischen Industriebranchen.

(und 2.5.bis)

Tabelle 2.6: $\quad$ Staffelung der Industriebranchen nach Finanzindikatoren.

Tabelle 2.7: Gewicht der verschiedenen Industriebranchen innerhalb der rumänischen Volkswirtschaft und Wettbewerbsfähigkeit im Außenhandel. 
Tabelle 2.8: Staffelung nach Wettbewerbsfähigkeit im Außenhandel und Gewicht innerhalb der rumänischen Volkswirtschaft.

Tabelle 2.9: Allgemeine Rangordnung der Industriebranchen.

Tabelle 2.10: Allgemeine Rangordnung der Industriebranchen ohne Gewichtung.

Tabelle 2.11: Die wichtigsten 10 Importeure von Textilien und Bekleidung im Jahr 1991.

Tabelle 2.12: Die wichtigsten 10 Exporteure von Textilien und Bekleidung im Jahr 1991.

Tabelle 2.13: Außenhandel der Bundesrepublik Deutschland mit Staatshandelsländern, in Mio. DM, ohne passive Veredelung.

Tabelle 2.14: Dynamik der Exporte, Wettbewerbsfähigkeitseffekt (Faktoranalyse) und Einfluß der Bekleidungsexporte darauf, 1972-1987.

Tabelle 2.15: Textilbezogener Handel der OECD mit der MOE/GUS-Ländern 1985 bis 1990 (Mio. US-\$).

Tabelle 2.16: Umwälzungen im Familienbudget in Rumänien, 1980-1992. Prozentmäßiger Anteil der Ausgaben für Ernährung und Bekleidung.

Tabelle 2.17: Anteile des Staatssektors in der rumänischen TBI-Produktion, 1992.

Tabelle 2.18: Auftragseingang der rumänischen TBI, 1989-1992.

Tabelle 2.19: Monatliche Preissteigerungsraten in Rumänien, 1991-1993, in \% .

Tabelle 2.20: Indizes der Verbraucherpreise in Rumänien (ausgewählte Produkte), 19911993.

Tabelle 2.21: Entwicklung der Exporte der rumänischen TBI, 1989-1992.

Tabelle 2.22: Exporte des Textilsektors, 1989-1992.

Tabelle 2.23: Anteile der Arbeiter und der Frauen in der Belegschaft der TBI, 1992 (in \%).

Tabelle 2.24: Ausbildungsbasis des Personals der rumänischen TBI.

Tabelle 2.25: Effizienz des Energieverbrauchs in Mio. Lei Produktionswert pro verbrauchte Mio. KWh (preisbereinigt), 1989-1992.

Tabelle 2.26: Effizienz des Rohstoffverbrauchs der TBI, 1989-1992.

Tabelle 2.27: Finanzkraftindikatoren der rumänischen und deutschen TBI 1991.

Tabelle 2.28: Maschinen- und Anlagenausstattung der rumänischen TBI - 1990.

Tabelle 2.29: Kapitalgütegrad in der rumänischen TBI, 1990-1992.

Tabelle 2.30: Produktion der rumänischen TBI, 1980-1989.

Tabelle 2.31: Bruttoanlageinvestitionen und Finanzierungsquellen in der rumänischen TBI, 1990-1992.

Tabelle 2.32: Einbehaltene Gewinne und Investitionen, 1990-1992.

Tabelle 2.33: Modernisierungs- und Investitionsbedarf in der rumänischen TBI, in Maschinen- und Anlageneinheiten.

Tabelle 2.34: Kapitalintensität der Branchen der rumänischen Industrie, 1992.

Tabelle 2.35: Investitionsbedarf der rumänischen TBI, 1993-1996.

Tabelle 3.1: Erhöhung des Finanzbedarfs in unterschiedlichen Besteuerungsfällen. 
Tabelle 4.1: Unterschiede zwischen Unternehmensgruppen nach ökonomischen Indikatoren.

Tabelle 4.2: Unterschiede zwischen Unternehmensgruppen mach Zielsetzungen.

Tabelle 4.3: Beurteilung der theoretischen Modelle.

Tabelle 5.1: Ökonomische Abschreibungen in der TBI, berechnet nach der Altersdistribution des Anlagevermögens Ende 1990.

Barwert der steuerlich zugelassenen Abschreibungen:

Tabelle 5.2: Textilindustrie, private Unternehmen.

Tabelle 5.3: Textilindustrie, staatliche Unternehmen.

Tabelle 5.4: Bekleidungsindustrie, private Unternehmen.

Tabelle 5.5: Bekleidungsindustrie, staatliche Unternehmen.

Tabelle 5.6: Lederindustrie, private Unternehmen.

Tabelle 5.7: Lederindustrie, staatliche Unternehmen.

Kapitalbereitstellungskosten:

Tabelle 5.8: Textilindustrie.

Tabelle 5.9: Bekleidungsindustrie.

Tabelle 5.10: Lederindustrie.

Tabelle 5.11: Systematik der Fälle für die Elastizitätsanalyse.

Tabelle 5.12: Kalkulationszinsen " $r$ " für unterschiedliche Gewinnsteuersätze.

Tabelle 5.13: Barwert der steuerlichen Abschreibungen für unterschiedliche Steuersätze und dementsprechend unterschiedliche Kalkulationszinssätze.

Tabelle 5.14: Elastizitätsanalyse der Kapitalbereitstellungskosten nach dem Gewinnsteuersatz "u" (Senkung).

Tabelle 5.15: Variation der Kapitalbereitstellungskosten nach dem Barwert der steuerlichen Abschreibungen " $\mathrm{z}$ " bei $\mathrm{u}=45 \%$.

Tabelle 5.16: Variation der Kapitalbereitstellungskosten nach dem Barwert der steuerlichen Abschreibungen " $\mathrm{z}$ " bei $\mathrm{u}=20 \%$.

Tabelle 5.17: Anlageninvestitionsbedarf in der rumänischen TBI, berechnet für die kommenden fünf Jahre, in Mio. US-\$.

Tabelle 5.18: Zusätzlicher Finanzierungsbedarf der Unternehmen der TBI im Fall einer Investitionskette, die nach fünf Jahren nur noch von den Überschüssen getragen wird, in Mio. US-\$.

Tabelle 5.19: Elastizitäten des zusätzlichen Finanzierungsbedarfs gegenüber seinen Einflußparametern.

Tabelle 6.1: Gesellschaftsteuer aufs Stammkapital. 
Mihail Nedelea - 978-3-631-75036-0 Downloaded from PubFactory at 01/11/2019 09:01:58AM via free access 


\section{ABBILDUNGSVERZEICHNIS}

Abbildung 1.1: Ausgangsbedingungen der osteuropäischen Länder für den Übergang zur Marktwirtschaft.

Abbildung 2.1: Deutsche Einfuhren von TBI-Produkten aus Osteuropa, 1989-1992.

Abbildung 2.2: $\quad$ Relativer Einheitswert der Bekleidungsprodukte.

Abbildung 2.3: $\quad$ Physische Produktion der rumänischen TBI, 1990-1993.

Abbildung 2.4: Kapazitätsauslastung TBI 1990-1992, in \%.

Abbildung 2.5: $\quad$ Beschäftigtenzahl TBI 1989-1992 (Tsd.).

Abbildung 2.6: Arbeitsproduktivität in der rumänischen TBI, preisbereinigt, 1989-1992.

Abbildung 2.7: Kapitalproduktivität der TBI, 1989-1992, preisbereinigt.

Abbildung 2.8: Bruttowertschöpfungskoeffizient in der rumänischen TBI, 1989-1992.

Abbildung 2.9: Bruttogewinne in der rumänischen TBI 1989-1992, inflationsbereinigt.

Abbildung 2.10: Bruttokapitalkoeffizient in der rumänischen TBI, 1989-1992.

Abbildung 2.11: Bruttoanlageinvestitionen in der rumänischen TBI, 1980-1989.

Abbildung 3.1: Ableitung einer Kurve der optimalen Vermögensanlage.

Abbildung 3.2: Wahl der optimalen Vermögenskombination.

Abbildung 3.3: Gliederung der Finanzierungsmöglichkeiten eines Unternehmens.

Abbildung 3.4: Modell einer Investitionskette.

Abbildung 7.1: Variation der "kritischen Quantität" CQ mit dem Kalkulationszinssatz "r".

Abbildung 7.2: Gewinnsteuer ohne Verlustausgleich.

Abbildung 7.3: Gewinnsteuer mit vollem Verlustausgleich. 
Mihail Nedelea - 978-3-631-75036-0 Downloaded from PubFactory at 01/11/2019 09:01:58AM via free access 
VERZEICHNIS DER RUMÄNISCHEN GESETZE, REGIERUNGSBESCHLÜSSE UND

\section{SONSTIGEN NORMEN UND VORSCHRIFTEN}

\section{GESETZE:}

Nr. 62/1968 "Über das Abschreibungsregime"

Nr. 25/1981 "Über die Gebäudesteuer"

Nr. 15/1990 "Über die Neuorganisation der staatlichen Wirtschaftsunternehmen als Selbstverwaltungsbetriebe und Handelsgesellschaften"

Nr. 31/1990 "Über die Handelsgesellschaften"

Nr. 36/1990 "Über die Bevollmächtigung der Regierung, das Steuersystem durch Regierungsordonanzen zu ändern"

Nr. 12/1991 "Über die Gewinnsteuer"

Nr. 33/1991 "Über die Banktätigkeit"

Nr. 34/1991 "Über das Statut der Nationalbank Rumäniens"

Nr. 35/1991 "Über die ausländischen Investitionen"

Nr. 55/1991 "Zur Ergänzung des Gesetzes Nr. 12/1991 über die Gewinnsteuer"

Nr. 58/1991 "Über die Privatisierung der Handelsgesellschaften"

Nr. 82/1991 "Über das Buchführungssystem"

Nr. 40/1992 "Über die Dividendensteuer"

Nr. 45/1992 "Über die Kraftfahrzeugsteuer"

Nr. 54/1992 "Über die Steuer auf den Verkauf von Aktiva der staatlichen Unternehmen" Nr.130/1992 "Über die Mehrwertsteuer"

Nr. 57/1993 "Zur Ergänzung des Gesetzes Nr. 35/1991 über die ausländischen Investitionen"

Nr. 69/1993 "Über die Gebühr für die Benutzung staatlichen Bodens für nichtlandwirtschaftliche Zwecke"

\section{REGIERUNGSBESCHLÜSSE:}

Nr.1284/1990 "Über die Abgabe von 1\% für die Unterstützung der nationalen Forschung und Entwicklung"

Nr.1295/1990 "Über die Grunderwerbsteuer"

Nr. 781/1991 "Über die Berechnung der Dividendensteuer"

Nr. 804/1991 "Über die Gewinnsteuer" 
Nr. 26/1992 "Über die Gebäudesteuer"

\section{REGIERUNGSORDONANZEN:}

Nr. 3/1992 "Über die Mehrwertsteuer"

Nr. 15/1992 "Über die Kreis- und Gemeindesteuern"

\section{VORSCHRIFTEN DES FINANZMINISTERIUMS:}

Nr. 3614/1991 Angesichts der Berechnung des steuerpflichtigen Gewinns

Nr. 2011/1993 Angesichts einiger Bilanzierungsregeln für 1992

Nr. 2324/1993 Angesichts der buchhalterischen Eintragung der Wiederbewertungen des Firmenvermögens

NORMEN DES FINANZMINISTERIUMS:

Nr. 150035/1992 Angesichts einiger Bilanzierungsregeln 


\section{KAPITEL 1: RUMÄNIEN: STAND DER REFORM UND WIRTSCHAFTLICHE LAGE}

\subsection{9: Die Erbschaft der Planwirtschaft}

Zwischen den Ländern des ehemaligen Ostblocks hat Rumänien wahrscheinlich - abgesehen von Albanien - unter der Mißwirtschaft der kommunistischen Partei am meisten gelitten. Nach dem zweiten Weltkrieg, als die Kommunisten die Macht übernahmen und das sowjetische Wirtschaftssystem einführten, war das Land noch agrarisch geprägt, mit einigen Ausnahmen (Bergbau, Ölförderung, Stahlindustrie, Lebensmittelindustrie, Rüstung und etwa Maschinenbau). Die nach stalinistischem Muster in der Folgezeit vorangetriebene Industrialisierung setzte ihren Schwerpunkt bei der Schwerindustrie. Es wird sich im folgenden zeigen, daß die Produktionsstruktur noch in stärkerem Maße, als dies in den übrigen ehemaligen osteuropäischen sozialistischen Ländern der Fall ist, von der Produktionsstruktur abweicht, die sich gebildet hätte, wenn Rumänien nach 1945 seine Entwicklungspolitik auf die Integration in die Weltwirtschaft ausgerichtet hätte (LÖSCH, 1993, S.95). Damit dürfte der Anpassungsbedarf im Rahmen der Transformation zur freien Marktwirtschaft besonders groß sein.

Wie jede Planwirtschaft nach sowjetischem Modell war die rumänische Volkswirtschaft 1989 durch das Staatseigentum an fast allen Produktionsmitteln gekennzeichnet. Der wirtschaftliche Entscheidungsprozeß war vertikal-hierarchisch und ganz stark politisch geprägt. Die Planung erfolgte zentral und hatte einen obligatorischen Charakter, wobei das Anreizsystem weitgehend politisch motiviert war (AHRENS, 1993, S.78). Die Konsequenzen eines derart strukturierten Wirtschaftssystems waren eine lange Reihe von Funktionsmängeln, die erhebliche Ungleichgewichte auf mikroökonomischer Ebene, Fehlallokationen von Produktionsfaktoren, Inovationsschwächen und wichtige Anreiz- und Kontrolldefizite mit sich brachten.

Sowohl die Arbeits- als auch die Gütermärkte waren streng kontrolliert und besaßen fast ausschließlich mono- und oligopolistischen Charakter. Es gab - und es gibt heute noch keinen Kapitalmarkt. Die Finanzströme der Unternehmen wurden vom Staat diktiert, die Finanzströme bei der Bevölkerung vom Staat streng beeinflußt und kontrolliert. Dadurch, daß es so gut wie keinen Wettbewerb gab und daß die Unternehmen nicht in Konkurs gehen konnten, herrschte in der ganzen Volkswirtschaft die ödste Verantwortungslosigkeit gegenüber den Käufern sowie gegenüber der Substanz der Unternehmen und dem Finanzsystem, die man sich nur vorstellen kann. 
Allerdings erlaubte das System der verbindlichen Planung am Anfang, in der Phase der extensiven Industrialisierung, eine operative Mobilisierung der Ressourcen für bestimmte Investitionsprojekte. Dazu halfen in den 70er Jahren auch die westlichen Kreditgeber, die, motiviert durch die sogenannte "Unabhängigkeit" Rumäniens gegenüber der Sowjetunion, dem Land den Zugang an Geld für übermäßige Investitionen in der Schwerindustrie erleichterten. Nach dem ersten Ölschock in 1974 meinte man in Osteuropa, daß dem kapitalistischen Westen durch die "brüderlichen" Nahostländer der Todesschlag gegeben sei. Deshalb sah man keinen Grund, Rationalisierungsinvestitionen vorzunehmen.

Aber der Übergang vom extensiven zum intensiven, vom quantitativen zum qualitativen Wachstum, von den billigen, einfachen, zu den hochwertigen Produkten, von den energieund rohstoffintensiven zu den forschungs- und know-how-intensiven Erzeugnissen konnte in Rumänien in der 70er Jahren wegen der systembedingten Funktionsschwächen nicht erfolgen. Die Konsequenz war eine kontinuierliche Abschottung der rumänischen Volkswirtschaft von der freien Welt. Da man politisch nicht willens war, Reformen für die Erhöhung der Wettbewerbsfähigkeit nach außen einzuleiten, hat man sich vom Außen isoliert. Die Produktivitäts- und Einkommenszuwächse verringerten sich, die Wettbewerbsfähigkeit der rumänischen Produkte sank allmählich und den Planungsbehörden fiel es immer schwerer, über Exporte genug Devisen für die Beschaffung der Rohstoffe zu erwirtschaften, um die riesigen Kombinate der Schwerindustrie zu erhalten. Es ist im Großen und Ganzen die Geschichte der 80er Jahre, als alle RGW-Länder sich im Handel langsam vom Westen abkoppelten und umso kräftiger miteinander zweitklassige Produkte austauschten. In Rumänien kam erschwerend der "Feldzug" für die Tilgung der Auslandsschulden hinzu, die das Land in den 70er Jahren angehäuft hatte. Dadurch wurde der Produktionsapparat erheblich überlastet und zum Teil zerstört, weil man inzwischen zwecks Einsparung von Devisen so gut wie keine Ersatzinvestitionen vornahm.

Beurteilt man die Wirtschaftspolitik des kommunistischen Regimes nach ihren eigenen Erfolgskriterien - kontinuierliches Wachstum des Industrieoutputs, hohe Investitionsquoten (aber nur in neuen oder erweiterten Kapazitäten, und nicht zur Erhaltung der bestehenden!) war sie bis 1980 mehr oder weniger erfolgreich. In den 80er Jahren fingen aber die schweren Probleme an. Seit 1981 wuchsen die Investitionen nominell kaum, real gar nicht. Der Wert der Industrieproduktion wuchs immer noch bis 1987, als die letzte Phase der wirtschaftlichen Strukturkrise, nämlich die Schrumpfungsphase, begann. Außer den allgemein bekannten prinzipiellen Widersprüchen des planwirtschaftlichen Lenkungssystems hat ein zusätzlicher Faktor, der erwähnt werden muß, an der Strukturkrise mitgewirkt: Seit 1980 sanken die Anlagenimporte Rumäniens aus Industrieländern von 702,8 Mio. US-\$ auf 142,3 Mio. US-\$ in 1989, also ungefähr um das Fünffache. Seit 1981 haben auch die Einfuhren von Brennstoff, Mineralien und Halbfabrikaten aus RGW- sowie Industrieländern ständig abgenommen. Das hatte ernste Konsequenzen für die Industrieinputs zur Folge. Von 1980 bis 1985 sind sie 
um 22\% gesunken (Quelle: Romanian Statistical Yearbook, 1991). In den 80er Jahren wurden den Unternehmen immer mehr Anträge auf Importe sowohl für "kritische" Rohstoffe und Halbfabrikate als auch für Erneuerungen, Instandhaltung und Ersatzinvestitionen abgelehnt, während die Exporte von Investitions- und Konsumgütern forciert wurden, um einen Überschuß der Außenhandelsbilanz von etwa 1,5 Mrd.US-\$ jährlich zu erzielen. Dies wäre auch ohne die Zerstörung des Produktionsapparats möglich gewesen, wenn man auf die Politik der extensiven Entwicklung, d.h. der Investition nur in neuen Produktionseinheiten, verzichtet und zugleich Wirtschaftsreformen eingeführt hätte. Eigentlich hat das planwirtschaftliche System seine eigene Zerstörung bewirkt.

AHRENS (1993, S.86) bezweifelt, ob alle osteuropäischen Länder alleine den Anforderungen an die Transformation der jeweiligen Wirtschaftsordnungen gerecht werden können. Er wies dabei auf "die immensen makroökonomischen Fehlentwicklungen und die umfangreichen mikroökonomischen Probleme, die sich vor allem in der Form einer verzerrten Preisstruktur und einer notwendigen Reform der Eigentumsordnung stellen" hin.

Mit 23,112 Mio. Einwohnern und 11,070 Mio. Erwerbstätigen war Rumänien 1989 nach Polen das zweitgrößte Land (und auch der zweitgrößte Markt) Osteuropas. Mit einem Bruttoinlandsprodukt pro Kopf von 2.488 US-\$ hätte man Rumänien am oberen Rand der Skala der Entwicklungsländer einstufen können. Für ein sozialistisches Land war aber in 1989 die Außenschuld von 529 Mio.US-\$ auffallend gering (vgl.Bulgarien - 10.220 Mio.US\$). Dabei hatte Rumänien damals auch Forderungen in Höhe von etwa 2,5 Mrd.US-\$ an bestimmte "brüderliche" Ländern, vor allem an Ägypten und an den Irak. Die Exporte bezifferten sich 1989 auf 6.262 Mio. US-\$ (Tabelle 1.1).

Diese Exportstruktur würde eher für ein Schwellenland, bzw. für ein mittelständig entwickeltes Land charakteristisch sein. Auch lag 1989 der Anteil des RGW- Handels im Außenhandel Rumäniens, trotz einer klaren Steigerungstendenz, "nur" bei 45\% (vgl. Bulgarien: $80 \%$ ). Das heißt allerdings nicht, daß alle aus Rumänien exportierten Waren auf den westlichen Märkten wettbewerbsfähig waren. Aus politischen Gründen hat man die Statistiken der Struktur der Ausfuhren nach Güterarten und Ländern vor 1989 nicht veröffentlicht. Vieles läßt vermuten, daß die Exporte von hochwertigen Gütern, mit höherem Wertschöpfungsanteil, sich in den 80er Jahren langsam in Richtung der RGW-Länder umorientierten, während in den Westen 1989 nur noch Rohstoffe und Halbfabrikate exportiert wurden, woran im allgemeinen viel weniger verdient wird. Hauptursache: die technologische und organisationelle Entwicklung, zusammen mit der Qualität der angebotenen Produkte, sind in dem Osten in den 80er Jahren fast stehen geblieben (bei manchen Produkten, wegen der unselektiven Kürzung der importierten Inputs, sogar verschlechtert), während der Westen sich weiter technologie- und qualitätsintensiv entwickelt hat. 
Tabelle 1.1: Struktur der rumänischen Exporte, 1989

\begin{tabular}{||l||c|c||}
\hline & Exporte (Mio.\$) & Anteil (\%) \\
\hline $\begin{array}{l}\text { Maschinen, Anlagen und Ver- } \\
\text { kehrstechnik }\end{array}$ & 1831,3 & 29,25 \\
\hline Brennstoffe, Mineralien, Metalle & 2012,5 & 32,13 \\
\hline $\begin{array}{l}\text { Chemische Produkte, Düngenmit- } \\
\text { tel, Kautschuk }\end{array}$ & 594,7 & 9,49 \\
\hline $\begin{array}{l}\text { Baumaterialien und Baurüstungen } \\
\text { Landwirtschaftliche Rohstoffe }\end{array}$ & 126,9 & 2,03 \\
\hline Lebensmittel & 35,1 & 0,56 \\
\hline Industrielle Konsumgüter & 267,3 & 4,27 \\
\hline Sonstiges & 1134,7 & 18,12 \\
\hline Insgesamt & 258,6 & 4,13 \\
\hline
\end{tabular}

(Nach Angaben vom Romanian Statistical Yearbook, S.601)

WINIECKI (1991, S.188) schlägt einen für diesen Tatbestand interessanten Maßstab vor: wie hoch waren die von den RGW-Ländern auf den westlichen Märkten für "engineering goods" erzielten Preise im Verhältnis zu den Preisen für die gleichen westlichen Güter? Tabelle 1.2 zeigt, daß der relative Wert der osteuropäischen technologieintensiven Güter für die meisten Länder stets abgenommen hat. Eine Ausnahme bildeten Rumänien und Polen, bei deren Exporten der höchste relative Wert (sozusagen die höchste Wettbewerbsfähigkeit) 1977 erreicht wurde und danach ebenfalls ständig absank.

Außer einer ungünstigen Struktur der Exporte weist Rumänien auch eine unausgewogene sektorielle Wirtschaftsstruktur aus: einen überdimensionierten Industriesektor sowie einen zu schmalen Dienstleistungssektor. Beurteilt man die rumänische Wirtschaftsstruktur gemäß der CHENERY-Hypothese (CHENERY \& TAYLOR, 1968), dann stellt man fest, genauso wie DÖHRN und HEILEMANN (1993, S.67) für Polen, Ungarn und die Tschechoslowakei, daß die Anteile der verschiedenen Wirtschaftssektoren im Bruttoinlandsprodukt Rumäniens stark von dem abweichen, was sich herausgegeben hätte, wenn das Land einen marktwirtschaftlichen Entwicklungspfad verfolgt hätte (Tabelle 1.3). 
Tabelle 1.2: Einheits- bzw. Kilogrammpreise der technologieintensiven Güter, erzielt von den osteuropäischen Exporteuren auf dem EG-Markt, im Verhältnis zu den Preisen der westlichen Güter, 1965- 1985 (in \%)

\begin{tabular}{||c|c|c|c|c|c|c|}
\hline \multicolumn{1}{|c|}{ Land } & 1965 & 1970 & 1975 & 1977 & 1980 & 1985 \\
\hline \hline Bulgarien & 32 & 39 & 36 & 34 & 30 & 25 \\
\hline $\begin{array}{l}\text { Tschechoslo- } \\
\text { wakei }\end{array}$ & 47 & 45 & 38 & 36 & 32 & 25 \\
\hline DDR & 58 & 47 & 48 & 44 & 37 & 33 \\
\hline Ungarn & 77 & 72 & 52 & 53 & 47 & 35 \\
\hline Polen & 36 & 36 & 36 & 44 & 34 & 23 \\
\hline Rumänien & 37 & 39 & 38 & 45 & 38 & 29 \\
\hline UdSSR & 46 & 43 & 30 & 30 & 29 & 23 \\
\hline
\end{tabular}

(Quelle: WINIECKI, 1991, S.188)

Tabelle 1.3: Wirtschaftsstruktur Rumäniens 1989

\begin{tabular}{||l||c|l||}
\hline Wirtschaftssektor & Anteil am BIP & $\begin{array}{l}\text { Normaler Anteil, gemäß } \\
\text { der CHENERY-Hypo- } \\
\text { these }\end{array}$ \\
\hline \hline Landwirtschaft & $14,2 \%$ & $9 \%$ \\
\hline Baugewerbe & $5,5 \%$ & $5 \%$ \\
\hline Bergbau und Energie & $5,2 \%$ & $6 \%$ \\
\hline Dienstleistungen & $11,1 \%$ & $43 \%$ \\
\hline Verarbeitendes Gewerbe & $49,5 \%$ & $22 \%$ \\
\hline
\end{tabular}

(Nach Angaben von DÖHRN \& HEILEMANN, 1993, S.59 und Romanian Statistical Yearbook, 1993, S.331 ff.)

Obwohl der Anteil der Industrie am Bruttosozialprodukt aufgrund der damaligen überhöhten Preise der Investitionsgüter überschätzt sein könnte (Im Abschnitt 2.2.3. dieser Arbeit wird der Anreiz, typisch für die Planwirtschaft, möglichst teuer zu produzieren, analysiert) ist die Überindustrialisierung trotzdem deutlich erkennbar. Auch MONTIAS (1991, S.179 ff.) schätzt, daß selbst nach 40 Jahren extensiver, halbautarkischer Industrialisierung das Gewicht 
der Schwerindustrie als unüblich groß angesehen werden darf. Er gibt für diese tiefgreifende Industrialisierung drei relevanten statistischen Angaben an:

- der prozentmäßige Anteil der landwirtschaftlichen Arbeitskräfte fiel von $74,1 \%$ in 1950 auf $28,2 \%$ in 1987 ;

- die Stahlproduktion stieg zwischen 1950 und 1989 von 0,5 Mio.t auf 14,4 Mio.t an;

- der Anteil des Bergbaus, der Chemie, der Metallurgie, des Maschinenbaus und der Elektronik am gesamten Produktionswert der rumänischen Industrie wuchs von $37,1 \%$ in 1950 auf $62,6 \%$ in 1989.

Immerhin hat diese Industrialisierung einen besonderen energie- und rohstoffintensiven Charakter gehabt. Die energieintensiven Zweige der Industrie - Metallurgie, Chemie, Baumaterialien - verfügten über etwa $45 \%$ des gesamten industriellen Anlagevermögens, bezogen die Hälfte der Energieressourcen, die der Industrie zugeteilt wurden, erzielten aber nur 18,9\% des gesamten Wertes der Industrieproduktion (Quelle: Romanian Statistical Yearbook, 1991). Das Niveau der Umweltverschmutzung, das dieser einseitigen Orientierung Schwerindustrie folgte, wäre in Industrieländern unakzeptabel gewesen. Die Konzentration des Schwefeldioxyds in der Atmosphäre war z.B. in Rumänien am Ende der 80er Jahre dreimal größer als in Westdeutschland.

Neben der Fehlentwicklung der Wirtschaftsstruktur erweist sich auch der desolate Stand des Kapitalstocks als ein erschwerender Faktor für die Ausgangslage der rumänischen Volkswirtschaft in Hinblick auf die Transformation. Die Konstellation der 80er Jahre war durch strenge Einschränkung der Anlageimporte, vor allem aus Industrieländern, sowie Forcierung der Ausfuhr der besten rumänischen Maschinen und Anlagen in die RGW-Länder (in den Westen ging es sowieso kaum noch) gekennzeichnet. Dadurch wurde die Modernisierung des volkswirtschaftlichen Kapitalstocks aufgeschoben und der Ersatz der verschlissenen und/oder obsoleten Maschinen erheblich verlangsamt. Die Angaben des Industrieministeriums für 1989 sind ernüchternd: $40 \%$ des Anlagevermögens waren damals schon völlig abgenutzt.

Die Lage wird dadurch erschwert, daß die gesetzlich zugelassenen Abschreibungsdauern in Rumänien deutlich höher als in westeuropäischen Ländern sind. Weiter stellte man am 1.Januar 1989 fest, daß im Herstellungsprozeß von 1000 repräsentativen Erzeugnissen, die etwa drei Viertel der industriellen Produktion ausmachten, ein Viertel der Produktionskapazitäten wegen technischem Ausfall unbenutzt geblieben war. Bei $60 \%$ dieser Produkte war das zu ihrer Herstellung benutzte Sachkapital zu etwa $85 \%$ abgeschrieben.

Aber selbst wenn der technische Stand des Anlagevermögens in Ordnung wäre, würde daraus nicht folgen, daß die damit produzierten Güter die Erzielung einer hohen Wertschöpfung erlauben würden. Im Rahmen der ökonometrischen Forschung wurde in der Zeit von 1985 bis 1992 in verschiedenen Studien versucht, die sogenannte "technische Effizienz" der Betriebe 
in Zentralverwaltungswirtschaften zu schätzen (siehe hierzu MURREL, 1991, S.59-76). Die gelieferten Werte waren in vielen Fällen überraschend hoch und machten etwa 86 bis 95,3\% von den westlichen Werten aus. Aber die technische Effizienz ist ein Maß für die Leistungsfähigkeit (oder Produktivität in physischen Einheiten) eines Betriebes bei gegebenem technologischen Ausrüstungsstand. Es ist tatsächlich bemerkenswert, wie die osteuropäischen Techniker mit dem gegebenen - hochverschlissenen - Sachkapital immer noch produzieren können. Die Entwicklungen nach der Wende haben gezeigt, daß solche Vergleiche wenig aussagekräftig sind. Die technische Produktivität ist bedeutungslos, wenn mit der gegebenen Qualität der hergestellten Produkte keine Wertschöpfung auf dem Weltmarkt zu erwirtschaften ist. Das beste Beispiel hierfür liefert KROKER (1993, S.8): In der DDR wurden allein die Privatisierungserlöse ursprünglich auf netto $600 \mathrm{Mrd}$.DM geschätzt. Wenn die Treuhandanstalt ihre Aufgaben mitte der 90er Jahre beenden wird, rechnet man schon mit Schulden von $250 \mathrm{Mrd}$.DM statt eines Vermögens. Der Nettovermögenswert der ostdeutschen Betriebe war also insgesamt negativ. Es gibt keinen Grund anzunehmen, daß die Lage in Rumänien anders sei. Da aber Rumänien sich voraussichtlich mit keinem westlichen Land wiedervereinigen wird, wird die rumänische Industrie auf dem heimischen Markt für eine bestimmte Zeit noch einen gewissen Schutz genießen (siehe hierzu das Assoziierungsabkommen mit der EG und das Freihandelsabkommen mit dem EFTA).

Zusammenfassend seien die drei Hauptaussagen von BORENSZTEIN, DEMEKAS und OSTRY (1993, S.2) zitiert:

- Rumänien, Bulgarien und die Tschechoslowakei waren, unter den MOE-Ländern, die am stärksten und starrsten zentralisiert. MOE bedeutet Mittel- und Osteuropa.

- In Rumänien hat die Volkswirtschaft genug Ressourcen gehabt, um - unter sehr schweren Bedingungen -Überschüsse der Außenhandelsbilanz zu generieren, die für den Ausgleich der Auslandsschulden ausreichend waren. Dies hat aber andersum gravierende interne Unausgewogenheiten verursacht.

- Der Produktionseinbruch hat in Rumänien schon vor der Wende angefangen. Als die Reformen begannen, war die Produktion schon etwas gesunken; dieser Prozeß hätte sich auch ohne die Reformen fortgesetzt.

Das innere Ungleichgewicht ist auch der Grund, warum Rumänien neben die UdSSR im Modell der Ausgangsbedingungen für den Übergang zur Marktwirtschaft von FISCHER \& GELB gesetzt werden sollte. (FISCHER und GELB hatten Rumänien überhaupt nicht eingestuft - siehe FISCHER \& GELB, 1991, S.93) Obwohl die Außenverschuldung Rumäniens genauso gering wie die der Tschechoslowakei ist, ist der Preis, der dafür bezahlt wurde, eine starke wirtschaftliche Strukturkrise - siehe Abb.1.1. 
Abbildung 1.1: Ausgangsbedingungen der osteuropäischen Länder für den Übergang zur Marktwirtschaft

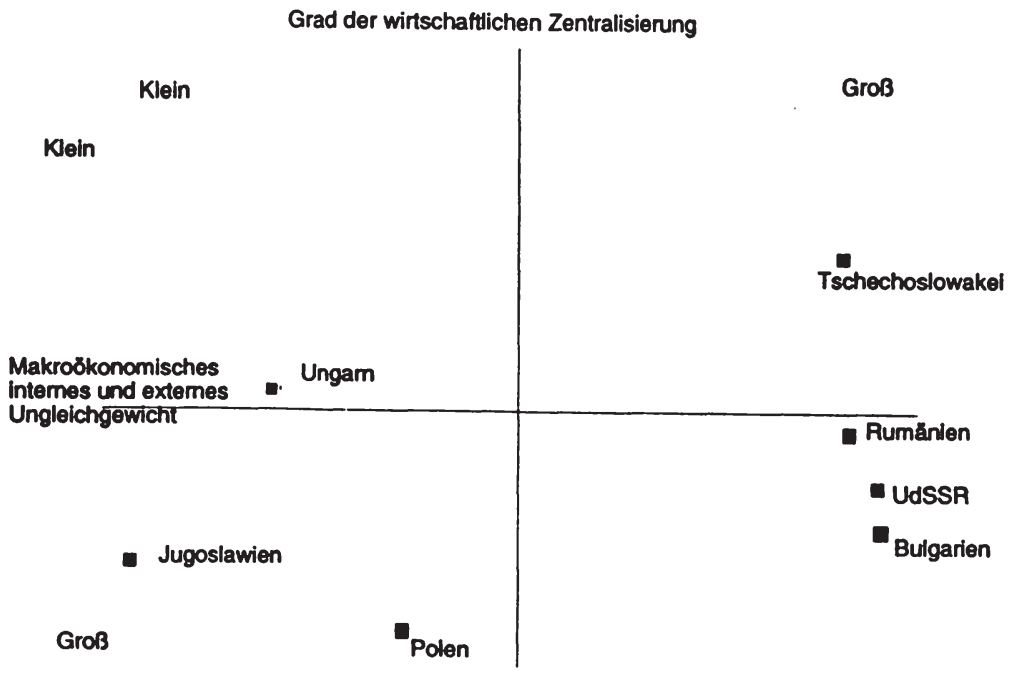

\subsection{Die politische Entwicklung nach 1989}

\subsubsection{Politischer Rahmen}

In der politischen Entwicklung in Rumänien nach der Wende lassen sich vier Phasen unterscheiden:

a) Dezember 1989 - Mai 1990 (erste freie Wahlen nach 1945): die künftigen politischen Strömungen kristallisieren sich heraus.

b) Mai 1990 - Oktober 1991: die Regierung Petre ROMAN. Diese Regierung wurde von der von ehemaligen Kommunisten dominierten "Nationalen Rettungsfront" gebildet und unterstützt. Trotzdem bekannte sie sich im Sommer 1990 endgültig für die Marktwirtschaft und begann auch tatsächlich, Maßnahmen in dieser Richtung zu ergreifen. Ein wichtiges Kennzeichen der rumänischen Transformation lautet: es gab anfangs keine Perestrojka. Bei der Reform der Institutionen war die Regierung ROMAN im Vergleich zu den nachfolgenden die aktivste. Die wichtigsten Institutionen des Rechtsstaates wurden geschaffen. Ob sie tatsächlich wie in einem traditionsgeprägten Rechtsstaat funktionieren, ist eine andere Frage. Demokratische Rechte wurden gewährt, das Prinzip des Privateigentums als tragende Säule der Volkswirtschaft anerkannt. Auf die politische und zivilrechtliche Reform wird hier nicht 
näher eingegangen; sie ist den Entwicklungen in den anderen osteuropäischen Ländern ähnlich. Es kann behauptet werden, daß die Regierung ROMAN in stärkerem Maße als die nachfolgenden die Grundlagen des Wirtschaftssystems reformiert hat: Die staatlichen Unternehmen wurden in Aktiengesellschaften mit staatlichem Kapital umgewandelt. Das Bankensystem wurde zweistufig umorganisiert, die Aufgaben der Nationalbank klar definiert und die Tätigkeit der Geschäftsbanken durch eine neue Gesetzgebung reglementiert. Der gesetzliche Rahmen der künftigen Privatisierung der Industrie - über Vouchers - wurde erarbeitet und gebilligt. Handelskammern und Handelsregister wurden etabliert. Der landwirtschaftliche Boden wurde an die ehemaligen Eigentümer bzw. an ihre Erben restituiert. Das Staatsmonopol über den Außenhandel wurde abgeschafft. Die freie Bildung von privaten Firmen in fast allen Bereichen der Wirtschaft in den üblichen Rechtsformen (AG, GmbH, KG und $\mathrm{KGaA}$ ) wurde per Gesetz zugelassen und reglementiert. Der Handels- und Dienstleistungssektor wurde entweder durch Verkauf oder Verpachtung weitgehend in private Hände überführt. Endlich versuchte das Gesetz Nr.35/1991 durch einige Vergünstigungen die ausländischen Investitionen im Lande anzureizen. Im Zuge dieses entschiedenen Reformprozesses teilte sich die Regierungspartei inoffiziell in zwei Flügel:

- Die "jungen" Technokraten, die zwar im kommunistischen Regime ihre Karriere begonnen hatten, aber eine Politik der schnellen marktwirtschaftlichen Öffnung, der vollständigen Demokratisierung und des Anschlusses des Landes an die westlichen Strukturen und Organisationen anstrebten, wurden von Petre ROMAN geführt. Diese Leute werden nach der offiziellen Trennung im Frühjahr 1992 die Demokratische Partei (DP) bilden;

- Die "alten" Mitglieder der zweitrangigen Nomenklatura blieben hinter dem Präsidenten ILIESCU. Sie setzen sich für eine Art Perestrojka, für die deutliche Verlangsamung der Reformprozesse, für die Bekämpfung der "westlichen Bevormundung", für den "sorgfältigen Umgang" mit dem Staatseigentum, gegen Eindringen des ausländischen Kapitals (das für ihre eigenen neugebildeten privaten Firmen eine unerwünschte Konkurrenz darstellen könnte), für die Verstärkung der Fiskalität und der staatlichen Kontrolle (sprich: Bürokratie) ein. Ihre politischen Forderungen wurden von populistischen und nationalistischen Argumenten begleitet. Im Frühjahr 1992 bildeten sie die Partei der Sozialen Demokratie (PSD).

Der entschlossene Reformkurs des Ministerpräsidenten ROMAN hat ihm das Amt gekostet. Nach Unruhen der Bergleute in Oktober 1991, die in die Ausplünderung des Regierungspalastes mündeten, war er gezwungen zurückzutreten.

c) Damit fing die dritte Phase der Koalitionsregierung Theodor STOLOJAN (Nationale Rettungsfront + Liberale Partei + Unabhängige) an. Das Programm dieser Regierung lautete, die Lage zu stabilisieren und zugleich Neuwahlen für das folgende Jahr vorzubereiten. Der Schwerpunkt der Wirtschaftspolitik verlagerte sich von der mikroökonomischen 
Ebene und vom Ordnungsrahmen auf die makroökonomische Steuerung der Volkswirtschaft, wobei in starkem Maße auf das geldpolitische Instrumentarium zurückgegriffen wurde. Diese sogenannte Stabilisierungsphase dauert bis heute ohne nennenswerte Erfolge an. Im Abschnitt 1.2.2. wird diese Stabilisierungspolitik näher untersucht werden.

d) Nach den Wahlen von Oktober 1992 bildete die Partei der Sozialen Demokratie, die etwa $35 \%$ der Stimmen gewonnen hatte, die Regierung Nicolae VACAROIU allein. Sie wird dabei von der Nationalen Unionspartei der Rumänen (NUPR - eine nationalistische Partei ohne klare wirtschaftspolitischen Vorstellungen), von der Agrarpartei (die ehemalige Nomenklatura der sozialistischen Landwirtschaft), von der Partei Großrumänien (National-Sozialisten) und von der Sozialistischen Arbeiterpartei (Kader der ehemaligen Kommunistischen Partei, die sich für das "chinesische Modell" einsetzen), bis heute stillschweigend unterstützt. Zusammen verfügen diese politischen Kräfte über 53\% der Parlamentsitze, den Rest teilen sich die Demokratische Konvention (eine Koalition von Liberalen, Christdemokraten und Sozialdemokraten westlicher Prägung sowie Vertretern der nationalen Minderheiten und Zivilrechtlern) und die Demokratische Partei von Petre ROMAN. Seitdem stocken die Reformen, weil in dieser Regierung die Reformgegner vereinigt sind. Das sind die Bürokraten und Direktoren der Staatsbetriebe, die von den Reformen - mindestens kurzfristig negativ berührt werden können, ferner diejenigen Arbeiter, denen der Verlust des Arbeitsplatzes droht, und die Haushalte mit niedrigeren Einkommen. Die Unterstützung der letzten Gruppe ist erstaunlich, weil die staatlichen Sozialleistungen, die Renten und Arbeitseinkommen kaum gestiegen sind, während die Preise für Grundnahrungsmittel, Strom und Heizung schon freigegeben wurden.

Obwohl die VACAROIU-Regierung nicht reformfreundlich ist, wird sie von den internationalen Finanzinstitutionen, vor allem von dem IWF gezwungen, marktwirtschaftliche Reformen fortzusetzen. So sieht z.B. das in November $1993 \mathrm{mit}$ dem IWF ausgehandelte Memorandum unter anderen vor, daß die rumänische Regierung 1994300 große Unternehmen privatisieren und die verdeckte Subventionierung unrentabler Betriebe aufgeben soll. Gleichzeitig darf der Anteil des Staatshaushaltsdefizits im Bruttoinlandsprodukt die Grenze von $4 \%$ nicht überschreiten. Sonst erhält das Land vom IWF keine weitere Finanzierung. Die Alternative der Unterstützung durch den sozialistischen Ostblock gibt es nicht mehr, somit muß sich die Regierung VACAROIU beugen.

Daß die Verlangsamung oder gar Einfrierung des Reformprozesses schlimme Folgen für die Entwicklung der Volkswirtschaft hat, steht außer Frage. Die besten Beispiele geben hierfür in Rumänien die Landwirte. Ihnen wurde zwar ihr früherer Grundbesitz zurückgegeben, die meisten von ihnen (etwa $82 \%$ ) erhielten aber bisher keine rechtswirksamen Eigentumstiteln, sondern nur vom Bürgermeister ausgestellte Bescheinigungen. Deshalb scheuen sie sich, in 
Bodenverbesserungen oder Bewässerungsanlagen zu investieren. Dieser Tatbestand verhinderte bislang die Entstehung eines funktionsfähigen Grundstückmarktes.

Der Vertrauensmalus der Regierung VACAROIU hat auch auf die Investitionsbereitschaft der übrigen Unternehmer einen sehr negativen Einfluß ausgeübt. LANG (1991, S.224 ff.) erklärt diesen Verhaltensmechanismus folgendermaßen: Die unternehmerischen Tätigkeiten werden in Richtung der kurzfristigen Gewinnmaximierung in risikoarme Geschäfte orientiert. Dagegen wird nicht in Vorhaben investiert, die eine langfristige Expansion, oder gar die Sicherung eines langfristig akzeptablen Gewinns versprechen. Der spekulative Handel weitet sich überall aus. Die Abnehmer neigen zur Hortung, was wiederum den Nachfrageüberhang vergrößert. Gewinne und sonstige Einkommen werden hauptsächlich konsumiert, in Devisen zwecks Sparens umgetauscht, oder exportiert ("capital flight"). Dadurch wird die Bekämpfung der Strukturkrise, die in erster Reihe auf Investitionen am Ort basiert, weiter aufgeschoben.

\subsubsection{Hauptziele der Wirtschaftspolitik nach 1989}

Selbst die reformfreundliche ROMAN-Regierung hat in Rumänien keine Schocktherapie verfolgt. Man glaubte sie den Menschen, die nach jahrzehntelangen Mangelwirtschaft arm und müde waren, nicht zumuten zu können. Auch fürchtete man mögliche Unruhen. Deswegen begann die Regierung ROMAN, die Preise schrittweise zu liberalisieren. Die nachfolgende Regierung STOLOJAN ordnete dann der makroökonomischen Stabilität die absolute Priorität zu. Sie versuchte, die Geldwertstabilität mit Hilfe der Geldpolitik, der Reduzierung des Budgetdefizits und einer auf Lohnkontrolle gerichteten Einkommenspolitik zu erreichen. Für das erklärte Hauptziel der makroökonomischen Stabilisierung nahm man Nullwachstum hin.

Die gegenwärtige Regierung VACAROIU plante für 1993 sogar eine Steigerung der Industrieproduktion von $10 \%$ bis $20 \%$ zu erzielen, 1.000 .000 neue Arbeitsplätze zu schaffen (?) und die Inflation unter $70 \%$ zu drücken. Tatsächlich ergab sich aber am Jahresende eine Geldentwertung von $314 \%$. Diese Regierung hat offensichtlich für sich selber noch keine ernsthafte wirtschaftspolitische Schritte beschrieben - in November 1993, ein Jahr nach ihrer Machtübernahme, hatte sie dem Parlament noch kein wirtschaftspolitisches Programm vorgelegt! Erst die Verhandlungen mit dem IWF haben sie gezwungen, ihre Vorstellungen zu präzisieren. Bis dahin lagen ihre Bemühungen eher im Bereich der Kaderpolitik (die Ersetzung der überbleibenden Anhänger der Demokratischen Partei mit PSD-treuen Funktionären), der Maximierung der Staatseinnahmen und der Erhaltung der alten Produktions- und Machtstrukturen. Die antiinflationäre Geldpolitik wurde zwar fortgesetzt, doch geschah dies 
unabhängig und zum Teil gegen den Willen der Regierung, durch die Nationalbank, die immer noch von Reformateuren geführt wird.

Die einzigen Errungenschaften der Regierung VACAROIU sind bisher die Einführung der Mehrwertsteuer, ein Paar andere fiskalpolitischen Maßnahmen (die im Kapitel 5 ausführlich untersucht werden), die letzte Stufe der Preisliberalisierung sowie die Fortführung der von den früheren Regierungen angefangenen Lohnkontrolle. Sie hat im Großen und Ganzen die Politik der Regierung STOLOJAN fortgesetzt, ohne einschneidende Reformschritte zu unternehmen. Deswegen beschränkt sich die weitere Darstellung auf die Politik der früheren Regierungen.

Abgesehen von der Festlegung eines bestimmten institutionellen Rahmens für die wirtschaftliche Tätigkeit hat die Regierung ROMAN wenig wirtschaftspolitische Erfolge auf der Mikroebene erzielt. Von der Verbesserung der Standortbedingungen, von einer Angebots-, Industrie- oder Strukturpolitik war selbst bei dieser reformwilligen Regierung kaum die Rede. Infolge der Empfehlungen der verschiedenen internationalen Finanzorganisationen, insbesondere des IWF, hat sich ein Standardrezept gebildet, das die Vorgehensweisen der osteuropäischen Regierungen geprägt hat. Dieses Rezept sieht vor, daß bei der Transformation der ehemaligen Planwirtschaften zuerst die Stabilisierung - darunter wird hauptsächlich die Inflationsdämpfung verstanden - erreicht werden muß. Die tatsächliche Transformation (sprich: Privatisierung) soll erst später hinzutreten. Die Stabilisierungspolitik sollte aus restriktiver Geld- und Finanzpolitik (einschließlich des Abbaus von Subventionen für Güter des Grundbedarfs) und aus einer weitgehenden Preisfreigabe bestehen. Als Ergänzungsmaßnahme wird die Einführung der "inneren Konvertibilität" mit festem Wechselkurs zu einer Leitwährung (in Rumänien US-\$) eingeplant, damit der Außenhandel soviel wie möglich liberalisiert wird. Den "Anker" des Stabilisierungspakets soll eine straffe Einkommenspolitik darstellen. Nominallohnsteigerungen über eine staatlich vorgeschriebene Lohnobergrenze hinaus sollen konfiskatorisch besteuert werden.

Alle drei Regierungen haben dieses Rezept angewendet, aber ohne Erfolg. Die Lohnindexierung, die die Stufen der Preisfreigabe begleitete, der Kostendruck und die monopolistische Struktur der Wirtschaft haben eine inflationistische Spirale verursacht, die die Erreichung des Hauptziels der Stabilisierungspolitik, nämlich der Geldwertstabilität, verhindert hat. Die Produktion ist ständig gesunken, hat Ende 1992 die Talsohle erreicht, in der sie seitdem verharrt.

Die Hoffnung auf den erwarteten Aufschwung wurde immer wieder enttäuscht. Auf die Preisliberalisierung folgte keine Angebotsreaktion, weil staatliche Unternehmen, die die Mehrheit bilden, auf die Preiserhöhungen anders reagieren als Privatunternehmen in Marktwirtschaften. Sie erhöhen einfach die Preise der Produkte, ohne quantitativ mehr anzubieten, 
und nutzen ihre Monopol- oder Oligopollage aus. Die Preisabsprachen zwischen staatlichen Produzenten und der Regierung wurden "Preisverhandlungen" genannt! Im Ergebnis wurde weniger und teurer produziert. Der unterentwickelte Markt konnte dieses Verhalten nicht konterkarieren.

Mittlerweile gibt es in den Industrieländern zahlreiche Stimmen, sogar innerhalb des IWF, die behaupten, die Erwartungen der "policy-makers" des IWF über die Geschwindigkeit der Angebotsreaktion und andere Änderungen im Verhalten der Unternehmen wären überoptimistisch gewesen (z.B. BRUNO, 1992, S.753). Der IWF gibt in seinem "World Economic Outlook" vom Oktober 1992, selbst zu: "Es ist immer klarer geworden, daß die makroökonomische Stabilisierung und die Systemreform Hand in Hand gehen: Die makroökonomische Stabilisierung muß so schnell wie möglich erreicht werden, um eine Beschleunigung der Inflation zu verhindern, die die Systemreform unmöglich machen könnte; aber ohne Systemreform, die die Grundlagen der Marktwirtschaft legen sollte, könnte die Fortsetzung der Stabilisierungspolitik paralysiert werden." (International Monetary Fund, 1992, S.45).

Das, was in Rumänien geschehen ist, rechtfertigt dieses Urteil. Abgesehen davon, daß es höchst fragwürdig ist, ob die nach Oktober 1992 eingesetzten Behörden ernsthaft daran interessiert sind, das System zu reformieren - bisher haben sie die Schritte der Systemreform, vor allem die Privatisierung, stets verzögert - muß anerkannt werden, daß die Politik der vorgeschalteten Stabilisierung die nachfolgende Systemtransformation erschwert. Wie vorhin schon gezeigt wurde, reagieren die staatlichen Betriebe nicht auf die restriktive Geldpolitik mit Anstrengungen für die strukturelle Anpassung, sondern stellen ihre Zahlungen an andere Staatsbetriebe einfach ein, wenn sie die Preise ihrer eigenen Produkte wegen der hohen Nachfrageelastizität nicht mehr erhöhen können. Der bereits schlechte Zustand der Bilanzen der Unternehmen des Staatssektors verschlechtert sich weiter. Die meisten Betriebe sind nunmehr miteinander durch zweifelhafte Forderungen verknüpft. Dadurch werden auch eigentlich finanziell gesunde und technisch angepaßte Unternehmen vom Bankrott bedroht. Der Mangel an Transparenz trägt auch bei, daß zwischen wettbewerbsfähigen und nicht wettbewerbsfähigen Unternehmen nicht mehr unterschieden werden kann, und dadurch wird die Hauptaufgabe der Systemtransformation, die Privatisierung, erheblich erschwert. Auf dieses Phänomen der "bad debts", in Rumänien auch Finanzblockage genannt, wird in diesem Kapitel später näher eingegangen. Bisher haben wir festgestellt, daß die Stabilisierung ohne Systemtransformation die Probleme nicht nur nicht löst, sondern sie gar erschwert. Unter den gegebenen Bedingungen der massiven Unausgewogenheit zwischen den Marktkräften, vermag die Freisetzung der Preise allein kaum das Angebot zu stimulieren. Ohne eine stabile Währung heizt sie nur die Spekulationen an und verhindert Vermögensbildung, wie es in der Weimarer Republik auch der Fall war (KREGEL \& MATZNER, 1992, S.37). 
Die Stabilisierungspolitik vernachlässigt, wenn sie als Hauptziel verfolgt wird, die Asynchronität zwischen der Umstrukturierung der Angebotsseite und der Reduzierung des Nachfrageüberhangs. Das Angebot schrumpft anstatt zu wachsen, so daß die Ungleichgewichte, selbst wenn sie zwischen Angebot und Nachfrage nicht mehr zu beobachten sind, sich auf andere Ebenen verschieben. In Rumänien ist die Produktion fast genau so schnell wie die Kaufkraft der Bevölkerung gesunken, der inflationistische Sog hat sich also kaum abgeschwächt. Zusammen mit der steigenden Arbeitslosigkeit bedeutet dies Stagflation.

Man hat in dieser Zeit vom Staat erwartet, daß er sich lediglich um die neue Gesetzgebung, die Reform des Finanzwesens und die Freigabe der Preise, sowie um die Reduzierung seiner Ausgaben kümmert. Es wurde dabei einerseits vergessen, daß die Staatsstrukturen sich nie von selbst auflösen und die oberen staatlichen Entscheidungsträger selber eingreifen müssen, um die Bürokratien abzubauen und die Unternehmen zur Privatisierung zu bringen. Andererseits versäumte es der IWF dem Staat die Aufgabe der Struktur- und Angebotspolitik zuzuweisen. Vor allem in diesen schweren Zeiten muß sich der Staat darum kümmern, daß den Unternehmen günstige Produktionsbedingungen verschafft werden, daß sie Chancen für ihre Sanierung erhalten und daß die von der Planwirtschaft geerbte Fehlstruktur nicht durch staatliche Maßnahmen perpetuiert wird. Auch die Gründung und der Markteintritt von neuen privaten Unternehmen muß mit allen Mitteln unterstützt werden. Für sie müssen sich Produktion und Investition lohnen.

CORBO (1992, S.407) bemerkt, daß, das künftige Wirtschaftswachstum, wie in Lateinamerika, auf der Expandierung der Exporte basieren muß. Um den Prozeß des exportinduzierten Wachstums anzuregen, muß man neben der traditionellen Stabilisierungspolitik, auch tiefgreifende Reformen der Politik und der Institutionen vornehmen. Diese Reformen müssen als Hauptziel die Stimulierung der Produktion und des Einsatzes von Produktionsfaktoren haben; sie müssen die Grenzen der Faktormobilität abbauen, sowie Ersparnis und Investition anreizen, um stetiges Wirtschaftswachstum zu ermöglichen. Dabei soll der Staat aus den wirtschaftlichen Tätigkeiten aussteigen, die der Privatsektor mit höherer Effizienz durchführen kann, und sich nur an die Aufgaben halten, die die noch schwachen Marktteilnehmer nicht erledigen können. Auch soll er sich ernsthaft für die Entmonopolisierung der volkswirtschaftlichen Angebotsseite einsetzen (siehe hierzu auch FISCHER \& GELB, 1991, S.97).

\subsection{Preisreform und Geldpolitik}

Die rumänischen Regierungen entschieden sich für Preisliberalisierung in mehreren Schritten. Dabei haben wahrscheinlich die sozialen Rücksichten und die Angst vor einem möglichen sozialen Ausbruch die wichtigste Rolle gespielt. Die erste Preisfreigabe erfolgte am 1. November 1990, die zweite am 1. April 1991, die dritte am 1. Mai 1992, die vierte am 1. 
September 1992 und die endgültige am 1. Mai 1993, als die Preise der letzten 12 Produkte des Grundbedarfs völlig frei gegeben wurden. Bei dieser Gelegenheit wurde auch die Kontrolle der sog. Handelsspanne aufgegeben. Darunter versteht man die Differenz zwischen dem Preis am Endverbraucher und dem Preis "ab Werk", die früher die Obergrenze von $30 \%$ über die gesamte Distributionskette nicht überschreiten durfte. Jede Stufe der Preisliberalisierung wurde von prozentualen Lohnerhöhungen oder von einheitlichen Kompensationen (derselbe Betrag für alle Lohnbezieher) begleitet, die aber die Effekte der Preissteigerungen nur zur Hälfte ausglichen. Die Steigerungsrate bzw. die Bruttokompensation wurde jeweils von der Regierung nach Beratungen mit den Gewerkschaften bestimmt.

Somit war die Lohnpolitik ziemlich restriktiv. Obwohl der Arbeitsmarkt vom Anfang an weitgehend dereguliert wurde und in kurzer Zeit nach der politischen Liberalisierung sich neue, unabhängige Gewerkschaften bildeten, haben die betrieblichen Lohnverhandlungen bisher keinen weiten Spielraum gefunden. Jede Erhöhung der Lohnsumme in Unternehmen mit staatlichem Kapital, die - abgesehen von den anläßlich der Stufen der Preisfreigabe zugesagten Indexierungen und Kompensationen - über die Produktivitätssteigerung hinaus geht, wird konfiskatorisch abgeschöpft. Hauptregel ist dabei, daß die Produktivität schneller steigt als die Reallöhne, ansonsten würde die Inflation verstärkt werden. Da die Produktivität gesunken ist, sind die Reallöhne auch gesunken. Zwischen Oktober 1990 und Juni 1993 sind die Verbraucherpreise um das 26,5-fache, die Nettogehälter jedoch nur um das 17,2-fache gestiegen. Das bedeutet also eine Senkung des Reallohnes auf $65 \%$ des ursprünglichen Niveaus (Quelle: Romania, Quarterly Statistical Bulletin, 2/1993, S.16-17). Die geringen Lohnkosten bringen also immer noch einen wichtigen Standortvorteil in Rumänien.

Charakteristisch für alle Stufen der Preisliberalisierung war auch, daß die daraufhin erfolgten Preissteigerungen immer stärker als erwartet ausfielen. In den ersten Stufen wurde der monopolistische Charakter der vorhandenen Produktionsstrukturen noch einigermaßen berücksichtigt, indem für einige Waren Preisobergrenzen gesetzt wurden. Die Mehrstufigkeit wurde mit dem Argument begründet, daß angesichts des großen - geerbten - Nachfrageüberhangs bei Produkten des täglichen Bedarfs, eine Freigabe aller Preise in einem Schritt einen unerträglichen Preisschock für die Mehrheit der Bevölkerung verursacht hätte. Andererseits hat die Erfahrung gezeigt, daß die Preisreglementierung einiger Konsumgüter anhaltende Schwarzmarktstrukturen generiert, die die Knappheit dieser Güter künstlich verstärkten. Inzwischen hat man erkannt, daß es viel vernünftiger ist, an die schlechter gestellten Bevölkerungsschichten Geldkompensationen zu zahlen.

Ein besonderes Problem stellte die Preisfreigabe bei den Rohstoffen dar. In manchen Zweigen der Industrie haben dadurch die Produktionskosten die Preise des Weltmarktes überschritten. Bei vielen Produkten geht der komparative Vorteil der im Lande vorhandenen Produktionsfaktoren (vor allem billige Arbeitskräfte) dadurch verloren, daß die veralteten 
Anlagen und die überholten Produkttechnologien einen überhöhten Energie- und Rohstoffverbrauch verlangen. Deswegen wurden die Differenzen zwischen den Weltmarkt- und den internen Preisen der rumänischen Bergbauprodukte weiter vom Staatshaushalt gedeckt. Der IWF (1992, S.47) macht auf die Nachteile der mehrstufigen Preisliberalisierung aufmerksam: "Die graduelle Preisfreigabe kann die Hortung und die Produktion auf Lager anreizen und zugleich die Anpassung der relativen Preise an die tatsächlichen Verhältnisse der Ausstattung mit Produktionsfaktoren verzögern; damit werden falsche Informationen für die Investitionsentscheidungen und für den Einsatz von Arbeitskräften generiert. "Die Hortung mit spekulativer Absicht wäre somit eine Ursache der anhaltenden Inflation, die die Stufen der Preisliberalisierung begleitet hat (Tabelle 1.4).

Tabelle 1.4: Monatliche Inflationsrate, 1991-1993 (in \%)

\begin{tabular}{|c||c|c||c|c||}
\hline Jahr & Insgesamt & $\begin{array}{l}\text { Nahrungsmit- } \\
\text { tel }\end{array}$ & Andere Waren & $\begin{array}{l}\text { Dienstleistun- } \\
\text { gen }\end{array}$ \\
\hline \hline 1991 & 10,3 & 12,0 & 8,9 & 8,6 \\
\hline \hline 1992 & 9,6 & 10,2 & 9,3 & 8,4 \\
\hline \hline $\begin{array}{c}1993 \\
\text { (Jan. } \\
\text {-Okt.) }\end{array}$ & 12,4 & 11,7 & 13.5 & 11,6 \\
\hline
\end{tabular}

(Quelle: Romania - Price Statistics Bulletin, Oct.1993, S.1)

Auch der Kostensog ist eine wichtige Ursache der Inflation. Die überaltete Technik verursacht einen übermäßigen Rohstoff- und Energieverbrauch sowie erhebliche Instandhaltungsund Reparaturkosten. Die monopolistische Lage der Anbieter von Energie, Gas, Wasser, Heizung, Kommunikationen usw. erlaubt ihnen, überdimensionierte Personalstrukturen zu behalten und sämtliche daraus resultierende Kosten auf die Preise abzuwälzen. Auch die anderen Unternehmen sind mit Personal traditionell überbesetzt. Der Liquiditätsmangel, verursacht durch die restriktive Geldpolitik und Finanzblockage, erlaubt den Unternehmen kaum, ihren Kapitalstock zu modernisieren, damit durch die Erhöhung der physischen Produktivität und die Senkung der Materialkosten mehr und billiger produziert werden kann. Die stetige Senkung der Produktion hat auch verhindert, daß Nachfrage und Angebot für eine längere Zeit zum Gleichgewicht kommen. Selbst die höheren Zinsen, mit denen die Nationalbank die Inflation zu bekämpfen versucht, werden einfach in die Kalkulation einbezogen, da sie alle Unternehmen fast gleichmäßig beeinflussen und wie eine allgemeine Produktionssteuer wirken. Auch die mehrmalige Abwertung der Währung hat, ohne die Ausfuhr spürbar zu stimulieren, durch die Verteuerung der Importe den Kostendruck verstärkt. 
WELFENS (1991, S.222) bemerkt, daß die Anpassungsinflation, veranlaßt von der Preisliberalisierung, chronisch werden kann, wenn der Anpassungsprozeß zu lange dauert und somit die Erwartungen der Marktkräfte auf höhere Preis- und Lohnsteigerungen eingestellt sind. Das ist genau der Fall in Rumänien. Die Wirkungen auf Ersparnis und Investition sind somit katastrophal. Ein Beispiel mag das verdeutlichen. 1993 betrug die Inflationsrate $314 \%$. Für Termineinlagen bieten die rumänischen Banken 1994 Zinsen von ca. 120\%, weil erwartet wird, daß infolge der Durchführung des IWF-Programms die Inflation sinkt. Aber die privaten Einleger glauben einfach nicht, daß die Inflationsrate 1994 sich unter dieser Grenze halten wird. Deswegen ziehen sie vor, ihre Lei gegen freie Devisen zu tauschen, um ihre Substanz zu erhalten. Außer der Dollarisierung der Ersparnisse, die viele unerwünschte Effekte bringen kann (siehe hierzu CALVO \& VEGH, 1993), hat dieses Verhalten der Haushalte zur Folge, daß die nicht gebrauchten Lei wieder in den Bargeldkreislauf eingespeist werden, und die Inflation wieder verstärken.

BRUNO (1992, s.758) ist der Meinung, daß für Rumänien und Bulgarien auch die ursprüngliche akute Knappheit an Devisen, die vom Anfang an eine besondere Währungspolitik verlangte, mit sukzessiven kräftigen Abwertungen zu den höheren Inflationsraten beigetragen hat.

Unter diesen Umständen haben die Regierungen nach 1989 die größte Bedeutung der Geldpolitik als Anker der Stabilisierung der Volkswirtschaft in der Anpassungskrise beigemessen. Die Nationalbank hat bis September 1991 eine strenge Kontrolle der Expandierung des inländischen Kreditvolumens vorgenommen. Diese Kontrolle erfolgte bis September 1991 über Plafonds, die den Handelsbanken gesetzt wurden. Trotzdem konnte die Nationalbank dem zunehmenden Druck seitens der Wirtschaft und der politischen Kräfte nicht länger widerstehen und entspannte im Oktober 1991 die Kreditkontrolle. Sie erlaubte dann den Handelsbanken, an die landwirtschaftlichen Unternehmen staatssubventionierte, zinsgünstige Kredite über die Plafonds hinaus zu vergeben. Die Kreditexpansion beschleunigte sich auch infolge der Reform des Währungskursmechanismus in November 1991. Damals hat die Regierung den Umtausch sämtlicher Devisenkontenbestände der rumänischen Unternehmen (staatlich und privat) zu einem abgewerteten Kurs der Lei erzwungen. Dadurch wurde eine große Menge Lei auf einmal in den Geldkreislauf eingespeist (CIUPAGEA, 1993).

Bis Oktober 1991 hatten sich schon eine große Menge dubioser Verbindlichkeiten ("bad debts") zwischen staatlichen Unternehmen angehäuft. Die Entspannung der Kreditkontrolle im Herbst 1991 hat die Finanzblockage zwar einigermaßen gemildert, keineswegs aber aufgehoben. In Mai 1992 schätzte der IWF in seinem "World Economic Outlook", daß Bulgarien und Rumänien die kleinsten Fortschritte in der Inflationsbekämpfung in Osteuropa gemacht hatten (IWF, 1992, S.30). In Zusammenarbeit mit der Nationalbank hat die Regierung STOLOJAN in April 1992 wieder angefangen, mit stärkeren Maßnahmen gegen die 
Inflation anzukämpfen. Der Akzent wurde dabei nicht mehr auf die Kreditkontrolle sondern auf die Kontrolle der Geldmengen und auf die Zinspolitik gesetzt. Der Geldmengenumschlag sollte dabei auch beschleunigt werden, es wurde aber dafür nichts getan.

Im Mai 1992 setzte die Nationalbank die Refinanzierungszinsen auf 60\% hoch. Man hoffte, daß dieser Schritt Ersparnis und Akkumulation stimulieren würde, die Geldressourcen der Bevölkerung dem Bankensystem zufließen würden, damit die Sachkapitalinvestitionen ohne zusätzliche Kreditschöpfung finanziert werden können und die Produktion auf Lager verhindert wird. Dieser Kurs hatte einen gewissen Erfolg: die monatliche Inflationsrate fiel von 10\% in März 1992 auf 3,4\% in August 1992. In September 1992 fing aber die Wahlkampagne an und die Politiker hatten nunmehr "wichtigere" Sorgen als die Inflationsbekämpfung. Auch gewöhnten sich die großen Staatsunternehmen langsam die hohen Zinsen in die Preise einzubauen, wobei sie ihre Marktdominanz ausnutzten. Andererseits haben die hohen Zinsen eher die Gründung von neuen privaten Unternehmen im produzierenden Gewerbe beeinträchtigt, als die finanzielle Disziplinlosigkeit der großen staatlichen zu bekämpfen. Am Ende des Jahres betrug die Inflationsrate etwa 200\%; die "hohen" nominellen Zinsen erwiesen sich also als real negativ.

Die Regierung VACAROIU kümmerte sich weniger darum, die Inflation zu bremsen. Es war die Nationalbank, die in November 1993 ein neues System der Refinanzierung mit Ausschreibung der Refinanzierungssummen einführte. Damit sind die Zinsen bei den Handelsbanken wieder höher geworden (bis zu 150\% für kurzfristige Darlehen), sie gleichen aber die Inflationsrate von 1993 - 314\% - immer noch nicht aus.

$\mathrm{Da}$ es den bisherigen Regierungen nicht gelungen ist, die Inflation zu stoppen, läßt sich in Tabelle 1.4 ablesen. Im Vergleich mit den anderen Reformländern des ehemaligen Ostblocks schneidet Rumänien in dieser Hinsicht besonders schlecht ab, wie es Tabelle 1.5 zeigt.

Diese Entwicklung bestätigt die These, daß in einem Land, in dem der marktwirtschaftliche Ordnungsrahmen nicht funktionsfähig ist, die Bekämpfung der Inflation allein durch monetäre Maßnahmen, etwa durch eine restriktive Geldpolitik, in Konkurrenz mit dem Ziel, die Unternehmen bis zur Privatisierung am Leben zu erhalten, geraten kann. Eine rein monetaristische antiinflationäre Geldpolitik hat wenig Erfolgschancen, wenn sie nicht von einer gesunden Angebotspolitik und von finanzieller Unterstützung durch das Ausland begleitet wird. Letztere sollten bewirken, daß mindestens das ursprüngliche Produktionsniveau vor der Wende gehalten wird. Rumänien steht daher eine große Herausforderung gegenüber: bisher hat sich die Inflation jedes Jahr erhöht. Abgesehen von den paralysierenden Folgen der Hyperinflation (siehe IWF, Okt. 1992, S.50), die das Land durchaus bedrohen könnte, wenn der Kurs der Regierung VACAROIU nicht so schnell wie möglich geändert wird, üben selbst 
Tabelle 1.5: Inflation in den MOE-Ländern: Änderung der Verbraucherpreise gegenüber dem Vorjahr in Prozent.

\begin{tabular}{||l||c|c|c|c||}
\hline Land & 1989 & 1990 & 1991 & 1992 \\
\hline \hline frühere CSFR & 1,4 & 10,0 & 58,0 & 11,0 \\
\hline Polen & 251,1 & 585,8 & 70,0 & 40,0 \\
\hline Ungarn & 17,1 & 28,4 & 35,0 & 21,0 \\
\hline Bulgarien & 6,4 & 26,3 & 334,0 & 90,0 \\
\hline Rumänien & 0,9 & 4,2 & 161,0 & 211,0 \\
\hline frühere UdSSR & 2,0 & 5,3 & 91,0 & 2000,0 \\
\hline \hline
\end{tabular}

(Quelle: FRÖHLICH \& LINK, 1993, S.22)

die bisherigen jährlichen Inflationsraten von 200-300\% auf Standortattraktivität, Ersparnis und Investition einen gravierenden Einfluß aus und können die Systemtransformation nur erschweren. Deswegen ist es unbedingt notwendig, so schnell wie möglich die mikroökonomischen Produktionsbedingungen zu verbessern und die Privatisierung zu beschleunigen.

\subsection{Außenhandels- und Währungspolitik}

Hauptziele der Reform im Außenhandelsbereich waren die Förderung der Exporte, bei gleichzeitiger weiteren Öffnung der rumänischen Volkswirtschaft zum Westen, trotz eines gewissen Schutzes der heimischen Industrie. Exporte und Importe wurden nach 1989 schrittweise liberalisiert. Export- und Importquoten wurden allmählich abgeschafft. Importe und Exporte für die Mehrheit der Produkte wurden freigegeben, mußten jedoch dem Handelsministerium angezeigt werden. Für eine gewisse Gruppe von Gütern müssen explizit Exportgenehmigungen beantragt werden. Dazu gehören insbesondere Produkte des Grundbedarfs und einige Rohstoffe, die von der rumänischen Industrie gebraucht werden. Zur Zeit gibt es keine mengenmäßigen Einschränkungen der Importe mehr, das einzige Problem ist die Verfügbarkeit von Devisen.

Die Monopole der staatlichen Außenhandelsunternehmen wurden nach der Wende sofort abgeschafft. Der Anteil der privaten Unternehmen am Gesamtvolumen des Außenhandels wuchs bis 1992 auf $29,3 \%$.

Die Importliberalisierung hat sofort eine Verschlechterung der Außenhandelsbilanz verursacht, denn die Importe nahmen zu, während die Exporte nicht Schritt halten konnten. 
Bald darauf brach auch der RGW zusammen. Der Handel mit den ehemaligen RGW-Ländern sank schneller als erwartet. Das war insbesondere durch die Aufgabe des Mechanismus der Gegengeschäfte begründet, die für beide Importeure und Exporteure einen bestimmten Schutz bedeuteten. Allerdings hatten die langfristigen Abkommen im Rahmen des RGW eine preisund qualitätsverzerrte Export- und Produktionsstruktur zementiert, wodurch die langjährige Abschottung dieser Länder vom Weltmarkt sich nur vertiefte (HABUDA, 1992, S.21).

Während die Importe stark gestiegen sind, sind die Exporte am Anfang sogar gesunken. Die Regierung versuchte mit fiskalischen Maßnahmen die Exporte zu stimulieren. $\mathrm{Zu}$ diesen Maßnahmen gehörten die Abschaffung der Umsatzsteuer für exportierte Produkte und das "draw-back"-System bei Zöllen. Weiterhin wurde den exportierenden Unternehmen erlaubt, die Einnahmen auf Devisenkonten zu halten, ohne sie gegen Lei umtauschen zu müssen. Diese Maßnahmen trugen tatsächlich zu einer stetigen, aber langsamen Erhöhung der Exporte bei, bis sogar ein positives Saldo der Außenhandelsbilanz im 3. Quartal 1992 erreicht wurde. Danach hat sich aber die Lage wieder verschlechtert und die Außenhandelsbilanz ist wieder defizitär geworden.

Am 1. Januar 1992 wurde der neue Zolltarif eingeführt, dessen Bestimmungen auf GATTNomenklatur, -Struktur, und -Höhe umgestellt sind. Die vorgesehenen Zolltarife rangieren von 0 bis $40 \%$ ad valorem, steigend von sehr kleinen oder Nullwerten für Rohstoffe bis auf 36-40\% für Produkte mit hohem Veredelungsgrad, um der heimischen Industrie einen bestimmten Protektionsgrad noch zu gewähren. Aber in den Beziehungen mit den EG- und EFTA-Ländern wird dieser Tarif nicht lange angewendet werden können, da der Assoziierungsvertrag bzw. das Freihandelsabkommen mit diesen Gemeinschaften, die 1992 unterzeichnet wurden, sieht vor, daß sich Rumänien innerhalb von 10 Jahren völlig den Importen aus diesen Ländern eröffnen muß (siehe hierzu auch Abs.2.2.1.3.). Für die rumänischen Exporte in die EG- und EFTA- Länder müssen die Zölle und mengenmäßigen Einschränkungen schneller abgeschafft werden.

Gemäß dem Assoziierungsabkommen hat die EG Einflußmöglichkeiten auf die rumänische Wirtschaftspolitik und kann zur Lösung von bestimmten Problemen beitragen (LANGHAMMER, 1993, S.242). Ohne eine konsequente Transformationspolitik wird Rumänien keinen verbesserten Marktzugang für seine Produkte in der EG nach Ablauf der ersten Vertragsperiode bekommen und also auch keine Vollmitgliedschaft.

Mit den ehemaligen RGW-Ländern, einschließlich der neuen, unabhängigen GUS-Republiken hat Rumänien nach der Wende neue Handelsabkommen unterzeichnet. Die Waren werden nunmehr zu Weltmarktpreisen auf Dollarbasis getauscht. Dabei spielen die Gegengeschäfte insbesondere mit den Staaten der ehemaligen UdSSR nach wie vor eine wichtige Rolle. Die ehemaligen RGW-Partner gewähren sich gegenseitig die Meistbegünstigungsklausel. 
Allerdings wurde in dieser kurzen Zeit seit 1989 der Schwerpunkt des rumänischen Außenhandels (der auch früher nicht ganz weit von den Industrieländern lag - siehe Abs.1.1.) deutlich auf die Beziehungen mit dem industrialisierten Westen, insbesondere mit den europäischen Industrieländern, verschoben. Politische und kommerzielle Bemühungen haben dazu beigetragen. "Bei stark geschrumpften Außenhandelsvolumina ist die erfolgreiche regionale Umlenkung des Außenhandels bemerkenswert; die wichtigen Handelspartner beider Länder (Bulgarien und Rumänien) sind nicht mehr frühere RGW-Staaten sondern die entwickelten westlichen Volkswirtschaften." (LÖSCH, 1993, S.111). Diese Entwicklung sollte für den allgemeinen Reformprozeß, abgesehen von den anfänglichen Schwierigkeiten, die sich aus der Konkurrenz mit den qualitativ besseren westlichen Produkten ergeben, einen positiven Effekt haben. Intensivere Außenhandelsbeziehungen mit dem Westen haben auch ordnungspolitisches Gewicht. Der von staatlichen Großunternehmen immer noch dominierte rumänische Markt wird unter Wettbewerbsdruck von außen gesetzt. Somit wird die Entmonopolisierung gefördert und die Entstehung marktgerechter Preise erleichtert. Die Öffnung zum Westen erzwingt also marktwirtschaftliche Verhaltensweisen und erhöht den Privatisierungsdruck.

Die jeweiligen Regierungen haben auch versucht, die Bemühungen für die Erhöhung der Exporte und den Ausgleich der Außenhandelsbilanz durch die Währungspolitik zu unterstützen.

Die wissenschaftliche Diskussion, ob die Einführung der freien Konvertibilität auf einmal am Anfang oder ganz am Ende im Transformationsprozeß erfolgen sollte, führte bisher zu keinem eindeutigen Ergebnis. Zum einen steht fest, daß solange die heimischen Unternehmen wegen Devisenknappheit nicht imstande sind, mit ihren ausländischen Konkurrenten auf den Weltmärkten um Produktionsfaktoren unter gleichen Bedingungen, das heißt nur in bezug auf Preise und Qualitäten, zu kämpfen, solange ihnen die Wahl ihrer Lieferanten durch Devisenbeschränkungen verzerrt wird, die Anpassung an das marktwirtschaftliche System wenig Erfolgschancen hat (WINIECKI, 1991, S.189).

Zum anderen ist auch klar, daß die Deklarierung der Konvertibilität nur von einer politischen Entscheidung abhängt; aber das Wichtigste ist nicht die Deklarierung sondern ihre Vorbereitung durch weitgehende Liberalisierung sowohl des Außenhandels als auch des Kapitalverkehrs (INOTAI, 1993, S.81). Mit anderen Worten, obwohl die Währungskonvertibilität für den Erfolg der Transformation lebenswichtig ist, könnte ihre voreilige Einführung die ganze Systemreform gefährden. Leider hatten die rumänischen Regierungen bisher nicht genug Entscheidungsspielraum, um selber den Zeitpunkt der Einführung der Konvertibilität zu bestimmen. 
Schon kurz nach der Wende ist klar geworden, daß die Devisenreserven des Landes es nicht erlaubten, einen freien, mit irgendeinem Währungskorb verbundenen Gleichgewichtskurs wenigstens ein Jahr lang fest zu halten. Auch die geringe Glaubwürdigkeit der rumänischen Regierungen gegenüber den internationalen Finanzinstitutionen, insbesondere nach dem brutalen Sturz der Regierung ROMAN, hat den Zugang zu den ausländischen Finanzierungsquellen erheblich eingeschränkt. Dadurch ist ein normaler Zugang zu freien Devisen, der in anderen osteuropäischen Ländern (Polen, Ungarn, Tschechoslowakei, später auch Bulgarien) eine wichtige Rolle als Stabilisierungsanker gespielt hat, für die rumänischen Unternehmen ausgeblieben.

Im Januar 1990 lag der offizielle Kurs des US-\$ bei 21 Lei (Schwarzmarktkurs 120 Lei). Bis in November 1991 wurde der Leu in mehreren Schritten offiziell abgewertet, bis auf 60 Lei für 1 US-\$. Im November 1991 wurde die innere, beschränkte Konvertibilität der nationalen Währung zusammen mit einer kräftigen Abwertung auf 180 Lei für 1 US-\$, eingeführt. Von nun an waren alle Unternehmen verpflichtet, ihre Devisen entweder durch direkte Exporte oder auf dem zwischenbanklichen Markt im sogenannten "Fixing-Verfahren", das heute noch angewendet wird, zu beschaffen. Die Devisenprobleme wurden dadurch bei weitem nicht gelöst. Erstens funktioniert das Fixingverfahren nicht wie eine Devisenausschreibung. Derjenige, der mehr Lei für den Dollar anbietet, wird dadurch nicht besser gestellt. Es ist eher eine Warteschlange, bei der der Kurs jeweils für den nächsten Tag von den Vertretern der Banken unter dem Diktat des Finanzministeriums festgelegt wird. Die Kunden werden der Reihe nach bedient, wobei auch der inoffizielle Machtkampf zwischen den Banken eine Rolle spielt. Insoweit kann man von keiner Konvertibilität reden. Der Ausdruck "FixingVerfahren" der STOLOJAN-Regierung hat wenig Verbindung mit der Realität, man auch nicht von einer Ausschreibung sprechen. Die Devisen werden dadurch von den Unternehmen ferngehalten, die die profitabelsten Außenhandelsgeschäfte tätigen würden, und demzufolge bereit wären, den Kurs zu zahlen, der sich in einer freien Ausschreibung ergeben würde.

Es ist nicht die einzige Verzerrung, die dieser Devisenmechanismus verursacht. Manche Unternehmen, die über Devisen verfügen, zahlen ihre Lei-Schulden gegenüber dem Staat, den Banken oder anderen rumänischen Unternehmen nicht, weil sie wissen, daß sie nicht in Konkurs gehen können. Gleichzeitig behalten ihre Devisen, ohne sie auf den "Fixing "-Markt zu bringen. So ist ein "grauer" Markt entstanden: Gegen eine Provision von 10-20\% stellen diese Unternehmen ihre Devisen anderen, importierenden Unternehmen zur Verfügung und umgehen so das Fixingverfahren. Die Importeure, die meistens private Firmen sind, spielen dabei mit, weil sie wissen, daß das Fixingverfahren üblicherweise ihre zu tauschenden Summen für mehr als 30 Tage zinslos bei den Banken blockiert.

Die Erlaubnis für die Exporteure, ihre Deviseneinnahmen zu behalten, reizt die Erzeuger von Halbfabrikaten an, ihre Produkte direkt zu exportieren, anstatt sie gegen Lei an weiterver- 
arbeitende rumänische Unternehmen zu verkaufen. Die meisten von diesen Halbzeugproduzenten sind von importierten Rohstoffen abhängig und je größer eine Summe in Lei ist, desto schwieriger ist es, sie in US-\$ umzutauschen. Ihr Verhalten ist also aus eigener Sicht durchaus vernünftig. Dadurch wird die Versorgung der höheren Veredelungsstufen mit Halbfabrikaten beträchtlich erschwert, und somit geht ein Teil des Bruttoinlandsprodukts verloren. Gegen diese Tendenz kämpften alle Regierungen mehr oder weniger erfolgreich durch Exportlizenzen und -verbote. Aber wenn z.B. die Stahlproduzenten nicht über genug Devisen verfügen, um Eisenerz und Koks zu importieren, und andererseits die Walzwerke, die Eisenbahnschienen erzeugen und exportieren, sämtliche Deviseneinnahmen für sich behalten und sogar spekulieren, droht die gesamte Veredelungskette zusammenzubrechen. Hauptursache dafür ist das allgemeine Mißtrauen in diese neue Art von Devisenbewirtschaftung, die das Fixingverfahren darstellt.

Die Nichtkonvertibilität trägt auch zur Erhaltung einer primitiven und kostspieligen Art des Handels bei: nämlich des Barters. Die Flexibilität und Anpassungsfähigkeit der rumänischen Unternehmen werden eingeschränkt, weil ihnen Gegengeschäfte aufgezwungen werden. Selbst westliche Firmen, die in Rumänien verkaufen wollen, sind oftmals gezwungen, Erzeugnisse rumänischer Unternehmen als Gegenleistung anzunehmen, die sie dann selber auf Drittmärkten verkaufen müssen.

Das Währungssystem, das im November 1991 eingeführt wurde, ist heute noch in Kraft. Keine prinzipiellen Änderungen wurden seither vorgenommen. Die Restriktionen für den Devisenerwerb durch Ausländer und inländische Privatpersonen gelten immer noch. Es gibt auch strenge Einschränkungen des Kapitalexports. Laut Gesetzes Nr.35/1991 dürfen die ausländischen Investoren jährlich einen Teil ihrer Gewinne in Lei, der $15 \%$ des ursprünglichen Wertes der Investition nicht überschreitet, in Devisen tauschen und ins Ausland transferieren. Wenn man die hohe Inflation berücksichtigt merkt man, daß, wenn am Ende der Bilanzperiode keine Wiederbewertung erfolgt, die $15 \%$ bei einer Inflation von $300 \%$ real $5 \%$ bedeuten können.

In dem Zeitraum von November 1991 bis Dezember 1993 hat sich die nationale Währung schrittweise um das Siebenfache bis auf 1250 Lei für 1 US-\$ abgewertet. Diese Entwicklung darf aber nicht als ein Prozeß zu einem Gleichgewicht hin verstanden werden. Das Finanzministerium und die Nationalbank, die die Fixierung des Kurses entscheidend beeinflussen, haben unter dem Druck der Devisennachfrage Schritt für Schritt nachgegeben. Bisher kann der Währungskurs sich immer noch nicht frei bilden; die Nachfrage überschreitet nach wie vor das Devisenangebot. Die Abwertungen haben die Exporte in den Westen wenig stimuliert, da es sich meistens um billige Waren handelt, die sich auf dem unteren, unelastischen Teil der Nachfragekurve befinden. Man hat den graduellen Charakter der Liberalisierung des Währungskurses, genauso wie bei der Preisfreigabe, mit dem Argument begründet, eine 
einmalige starke Abwertung würde die Importe unerträglich verteuern. Aber diese graduelle Vorgehensweise kann die Inflationsspirale nur beschleunigen, weil alle Unternehmen, die importierte Rohstoffe einsetzen, ständig neue Abwertungen erwarten und höhere Spannen über ihre Kosten hinaus aufschlagen.

\subsection{Entwicklung der rumänischen Volkswirtschaft nach 1989}

Bisher wurden die wichtigsten Komponenten der Wirtschaftspolitik in Rumänien nach der Wende dargelegt und kritisch bewertet. Nur die Finanzpolitik wurde bewußt außer acht gelassen, da sie später zusammen mit dem Bankensystem berücksichtigt wird. Die folgenden Zahlen müssen hauptsächlich im Zusammenhang mit dem Erbe der planwirtschaftlichen Zeit und mit der vorher geschilderten Wirtschaftspolitik der bisherigen drei Regierungen verstanden werden, aber auch mit dem Einfluß anderer Faktoren, die entweder nach der Wende eingetreten oder ins Bewußtsein gekommen sind. So z.B. hat man nach der Auflösung der alten Zentralverwaltungsstrukturen festgestellt, daß in den meisten Unternehmen das Management kaum fähig war, den neuen kommerziellen und strategischen Herausforderungen gerecht zu werden. Auch die Institutionen des Staates, vor allem die öffentliche Verwaltung, hatten nicht die Fähigkeit, die neuen Aufgaben, die der Aufbruch des kleinen Unternehmertums stellte, zu erledigen. Neue Herausforderungen sind im wirtschaftlichen Umfeld aufgetaucht:

- die Auflösung des RGW, die die Umorientierung des Außenhandels zum Westen verlangte, wobei die Produkte, die früher in RGW-Länder exportiert waren, den westlichen Standards qualitätsmäßig nicht entsprachen;

- der Devisenmangel;

- der Golfkrieg, der den Verlust von 500 Mio.US-\$ Forderungen an den Irak bedeutete;

- der Jugoslawienkrieg mit der Donaublockade;

- die sozialen Unruhen, der Gewerkschaftskampf und die Reduzierung der Arbeitszeiten;

- die freie Konkurrenz der ausländischen Produkte auf dem inländischen Markt.

All diese Faktoren haben auch zur Senkung des Inlandsprodukts und der Industrieproduktion, zur Inflation und zur Verschlechterung der Außenhandelsbilanz beigetragen. CALVO und CORICELLI (1993, S.33) fügen zu den Faktoren, die den Einbruch der Produktion bedingt haben, auch die Unfähigkeit des überkommenen Bankensystems, die Krediteinschränkungen und das Nichtvorhandensein eines Kapitalmarktes hinzu. Daraufhin wird später in diesem Kapitel eingegangen. Laut BRUNO (1992, S.761) gibt es auch nachfragebedingte Ursachen: Die inflationsbedingten Preisanstiegserwartungen regen die Hortung an und drosseln nach jeder Stufe der Preisfreigabe die Nachfrage deutlich. Auch die strenge Kontrolle der Löhne unter Freigabe der Preise übt denselben Effekt auf die Nachfrage aus. 
Die wichtigsten makroökonomischen Indikatoren der bisherigen volkswirtschaftlichen Evolution in der Transformationsphase werden in Tabelle 1.6 angegeben. Mit ihr sollte hauptsächlich im Vergleich mit anderen MOE-Ländern deutlich gemacht werden, ob die "Talsohle" der Durststrecke schon erreicht wurde, wie hoch die sozialen Kosten der Transformation sind, wie wettbewerbsfähig die rumänischen Exporte sind und welchen Erfolg die Stabilisierungspolitik der bisherigen Regierungen angesichts der Inflationsbekämpfung und des Finanzgleichgewichts hatte. Tabellen 1.6 bis 1.8 ermöglichen den Vergleich mit dem MOE-Durchschnitt sowie mit einzelnen osteuropäischen Ländern.

Tabelle 1.6: Makroökonomische Indikatoren in Rumänien: Veränderungen gegenüber dem Vorjahr (in \%, wenn nicht anders angegeben) - preisbereinigt

\begin{tabular}{||l||c|c|c||}
\hline & 1990 & 1991 & 1992 \\
\hline Bruttoinlandsprodukt & $-5,6 \%$ & $-12,9 \%$ & $-13,6 \%$ \\
\hline Bruttoinvestitionen & $-35 \%$ & $-26 \%$ & $-1,1 \%$ \\
\hline Industrieproduktion & $-13,5 \%$ & $-14,7 \%$ & $-16,1 \%$ \\
\hline Arbeitsproduktivität in der Industrie & $-19,4 \%$ & $-15 \%$ & $-13,4 \%$ \\
\hline Preisniveau & $+4,2 \%$ & $+161 \%$ & $+211 \%$ \\
\hline Arbeitslose (in \% der Erwerbspersonen) & - & $3 \%$ & $8,4 \%$ \\
\hline Haushaltsdefizit (in \% des BIP) & - & $1,9 \%$ & $4,4 \%$ \\
\hline Exporte & $-41,6 \%$ & $-4,8 \%$ & $+18,6 \%$ \\
\hline $\begin{array}{l}\text { Defizit der Bilanz der laufenden Posten } \\
\text { (in Mio.US-\$) }\end{array}$ & 3.254 & 1.012 & 1.506 \\
\hline
\end{tabular}

(Nach Angaben vom Romanian Statistical Yearbook, 1993)

Die statistischen Angaben für die Reformländer sind mit einigen Mängeln behaftet. Die private Wirtschaft ist nicht vollständig erfaßt, zumal diese Anbieter großes Interesse haben, nicht alles statistisch zu deklarieren. Auch die Schattenwirtschaft spielt eine nicht zu vernachlässigende Rolle. Dies muß vor allem beim Bruttoinlandsprodukt und bei den Arbeitslosenquoten berücksichtigt werden. 
Tabelle 1.7: Durchschnittliche makroökonomische Indikatoren für die osteuropäischen Länder ohne UdSSR und Jugoslawien (Veränderungen gegenüber dem Vorjahr, in \%, wenn nicht anders angegeben) - preisbereinigt

\begin{tabular}{||l||c|c|c||}
\hline & 1990 & 1991 & 1992 \\
\hline Bruttoinlandsprodukt & $-2,1 \%$ & $-13,7 \%$ & $-10,4 \%$ \\
\hline Preisniveau & $+16,4 \%$ & $+115,7 \%$ & $+47,8 \%$ \\
\hline Exporte & $-4,7 \%$ & $-20,4 \%$ & $+1 \%$ \\
\hline $\begin{array}{l}\text { Bilanz der laufenden Posten (in Mio. } \\
\text { US-\$) }\end{array}$ & +2.400 & -6.400 & -2.900 \\
\hline
\end{tabular}

(Nach Angaben von IWF, Jan. 1993, S.18)

Tabelle 1.8: Makroökonomische Indikatoren der osteuropäischen Länder, 1992

\begin{tabular}{||l||c|c|c|c|c||}
\hline & $\mathrm{H}$ & $\mathrm{PL}$ & $\mathrm{CS}$ & $\mathrm{BG}$ & $\mathrm{RO}$ \\
\hline \hline $\begin{array}{l}\text { Kumulierter Rückgang des } \\
\text { BIP gegenüber 1988 (in } \\
\% \text { ) }\end{array}$ & $-16,5$ & $-21,2$ & $-21,4$ & $-33,4$ & $-33,5$ \\
\hline $\begin{array}{l}\text { Leistungsbilanz, (in Mrd- } \\
\text { US-\$) }\end{array}$ & $+0,9$ & $-1,0$ & $+0,8$ & $-0,8$ & $-1,0$ \\
\hline $\begin{array}{l}\text { Inflationsrate (\%) } \\
\text { Reallöhne (Änderung ge- } \\
\text { genüber 1991 (\%) }\end{array}$ & +21 & 40 & 11 & 90 & 211 \\
\hline $\begin{array}{l}\text { Arbeitslosenquote (in \% } \\
\text { der Erwerbspersonen) }\end{array}$ & 13 & 15 & 8 & 15 & 8,5 \\
\hline
\end{tabular}

(Quelle: FRÖHLICH \& LINK, 1993, S.23)

Trotz alledem ist es nicht schwer zu erkennen, daß Rumänien die Stabilisierung bisher nicht gelungen ist. Aus einigen statistischen Zwischenrechnungen für 1993 (Romania - Quarterly Statistical Bulletin, No. 2/1993) ließe sich zwar eine Stabilisierung der Industrieproduktion auf dem schon erreichten, niedrigen Niveau vermuten, es gibt aber kein Zeichen für die Erholung, zumal die Produktion auf Lager wegen der laxeren Kreditpolitik der Regierung VACAROIU gegenüber den staatlichen Unternehmen wieder gestiegen ist. In vielen Sektoren überschritten in September 1993 die Lagerbestände die monatliche Produktion des Sektors. 
Im Vergleich mit den anderen osteuropäischen Reformländern (ohne die ehemaligen UdSSR und Jugoslawien) schneidet Rumänien mit Ausnahme bei der Arbeitslosigkeit fast immer schlechter ab. Die niedrigste Arbeitslosenquote gibt aber keinen besonderen Grund zur Zufriedenheit, sie deutet lediglich auf die Unvollständigkeit und Langsamkeit der Unternehmensreform hin. Angesichts des extrem schmalen Angebots an Umschulungsprogramme und der Unvollkommenheiten des Wohnungsmarktes darf auf keinen Fall eine besondere Mobilität des Faktors Arbeit unterstellt werden.

Der Transformationsprozeß war also bisher von keinem besonderen Erfolg begleitet. Es ist umso alarmierender, daß die Bemühungen sich bislang lediglich auf die Stabilisierung konzentrierten und die Strukturreform kaum in Angriff nahmen. Die Erfolge der Regierungen STOLOJAN und VACAROIU sind nur negativ zu beurteilen. Ihnen ist die Stabilisierung nicht gelungen. Deshalb haben sie die Systemreform stets aufgeschoben und versäumt, an die mikroökonomischen und systembedingten Grundlagen der Marktwirtschaft (Privateigentum, Konkursgesetzgebung, Anpassung des Finanz- und Zollsystems usw.) heranzugehen. Nach der offiziellen Meinung des IWF (Jan. 1993, S.16) ist die Langsamkeit des Reformprozesses die Ursache des kräftigen Rückganges der Produktion in Rumänien. Aus den bisherigen Darlegungen hat sich klar ergeben, daß Rumänien sich erst am Anfang des Weges zur freien Marktwirtschaft befindet. Es fehlen nicht nur wesentliche Bausteine des gesetzlichen Rahmens einer Marktwirtschaft (Börsegesetz, verschiedene Gesetze für die Banktätigkeit, Konkursgesetz, Abschreibungsgesetz, Gesetz der Schuldverschreibungen usw.), sondern der bestehende Staatsapparat ist noch nicht imstande, die existierende Gesetzgebung und die entsprechenden Rechte der Unternehmer und Arbeitnehmer zu sichern. Auch die Infrastrukturverbesserungen als Aufgabe des Staates stehen am Anfang, wodurch die Standortattraktivität Rumäniens negativ beeinflußt wird. Schließlich wurden Privatisierungsprozeß und - wenn überhaupt - Restitution seit der Amtsübernahme der Regierung VACAROIU mit der Begründung, man müsse die Wirtschaft zuerst stabilisieren (?) fast eingefroren.

Im folgenden wird versucht, die wichtigsten Unvollständigkeiten der rumänischen Transformation vorzuführen. Sie haben sowohl einen negativen Einfluß auf die Ergebnisse der endogenen Bemühungen der rumänischen Marktkräfte gehabt, als auch das Mißtrauen der westlichen Geldgeber geweckt. Das führte zu einem chronischen Kapitalhunger in der rumänischen Volkswirtschaft. Im großen und ganzen wurde bisher in Rumänien lediglich die Phase des Marktsozialismus einschließlich einer parlamentarischen Demokratie mit mehrerer politischen Parteien, freien Wahlen und Pressefreiheit, erreicht. 


\subsection{Unternehmensreform}

Nach FISCHER \& GELB (1991, S.98) ist die Unternehmensreform der Kern des Transformationsprozesses. Sie verlangt die Durchsetzung der Finanzdisziplin, die Reform des Managements und schließlich die genaue Definition und Übertragung der Eigentumsrechte an Privatpersonen. Da die Privatisierung zwischen 3 und 30 Jahre dauern kann und spezielle Probleme aufwirft, ist der erste Schritt, der schnell gemacht werden muß, die Umwandlung der Staatsunternehmen in Aktiengesellschaften, wobei am Anfang der Staat alle Anteile besitzt (die sogenannte Korporatisierung). Sie wurde in Rumänien während der Regierung ROMAN vorgenommen (Gesetz Nr.15/1990 "Über die Neuorganisation der staatlichen Wirtschaftsbetriebe als Selbstverwaltungsbetriebe und Handelsgesellschaften"). Die Selbstverwaltungsbetriebe sind Unternehmen der sogenannten "strategischen" Bereiche (natürliche Monopole, Gas-, Wasser-, Heizungs- und Stromversorgung, Telekom, Rüstungsindustrie, Bergbau usw.), die dem Staat vollständig gehören. Ihre Privatisierung ist nicht beabsichtigt; Ihre Gewinne fließen automatisch dem Staatshaushalt zu, wie ihre Verluste fast automatisch vom Staatshaushalt gedeckt werden. Ihr Muster bilden die französischen "Regies". Der Anreiz für die staatlichen Unternehmen ist sehr groß, als Selbstverwaltungsbetrieb umorganisiert zu werden, da diese Rechtsform erhebliche ökonomische Sicherheitsvorteile bietet, zumal die staatlichen Ministerien es nicht schaffen, alle Selbstverwaltungsbetriebe gründlich in ihrer Tätigkeit, vor allem in der Preisbildung, zu kontrollieren.

Die (Handels-)Gesellschaften sind durch das Gesetz Nr.31/1990 "Über die Handelsgesellschaften" reglementiert: Sie können in der Rechtsform der AG, GmbH, KG oder KGaA können gegründet werden. Es werden auch kleine Familienunternehmen ("Familienassoziationen mit Erwerbszweck") mit Kapital unter einer bestimmten Grenze, ohne eingestellte Arbeitskräfte und mit unbeschränkter Haftung zugelassen. Daraus folgt, daß Personengesellschaften nach westlichem Muster nicht gegründet werden können. Den Status der Kooperativen ("Genossenschaften") hat man kaum geändert.

Die neugegründeten Firmen, privat oder staatlich, müssen einer der oben aufgezählten Rechtsformen gehören. In $99 \%$ der Fälle orientieren sich die privaten Firmen an der Form der $\mathrm{GmbH}$; dagegen hat der Staat alle seine Unternehmen, die keine Selbstverwaltungsbetriebe geworden sind, in AG's umgewandelt. Dieser Prozeß, obwohl er bemerkenswert schnell abgeschlossen wurde, ist von einem gravierenden Fehler behaftet: Die Bewertung der Aktiva erfolgte ausschließlich nach dem buchhalterischen Verfahren mit dem Ergebnis der allgemeinen Überbewertung. Die neuesten und technisch bestens erhaltenen Anlagen (in Rumänien ganz selten zu finden) haben keinen Wert, wenn mit den damit produzierten Erzeugnissen auf den Märkten keine Wertschöpfung zu realisieren ist. Wenn sie niemand kaufen will, können diese Anlagen durchaus brandneu Schrott darstellen. Das Stammkapital dieser staatlichen AG's ist also eine formale Zahl. Sie sollten vielmehr nur nach der Fakto- 
renausstattung, nach den angeschlossenen Märkten und nach den Rentabilitätsaussichten bewertet werden. Die bürokratische Überbewertung mit dem falschen Gedanken, bei der Privatisierung zu einem besseren Verkaufspreis zu kommen, hat sie eigentlich deutlich erschwert.

Vor der Umorganisierung der staatlichen Unternehmen hatte man schon die ehemaligen Zentralen in sogenannten "Holdings" umgewandelt. Sie sind Aktiengesellschaften mit staatlichem Kapital genauso wie die früher von ihnen betreuten volkseigenen Betriebe geworden. Sie bieten letzteren unverbindlich kommerzielle, juristische und Beratungsleistungen. Da die ehemalige Zentrale keine Anteile am Kapital der früher unterstellten Unternehmen besitzt und die Verbindungen zwischen ihnen ganz locker geworden sind, bleibt der Name "Holding" ein Rätsel.

Gleichzeitig wurde in den ehemaligen Industrieministerien (in der Planwirtschaft gab es ein Ministerium für jede Branche der Industrie) ein massiver Personalabbau betrieben. AnschlieBend wurden sie in ein einziges Industrieministerium vereint. Die Unternehmen mit staatlichem Kapital erhielten eine bestimmte Autonomie: Sämtliche Entscheidungen über Produktpalette und Produktionsmengen, Verkauf und Beschaffung, Personalpolitik wurden ihnen überlassen. Strategische Entscheidungen, wie Beteiligungen an andere Unternehmen, Kreditaufnahme für wichtige Modernisierungsprojekte, Teilungen oder Verschmelzungen, Bildungen von Gemeinschaftsunternehmen mit ausländischen Investoren, bedürfen der Genehmigung des Industrieministeriums und des Staatseigentumsfonds (siehe 1.7.). Auch die Preiskontrolle wurde in manchen Bereichen nicht auf einmal aufgegeben (hier obliegt die Verantwortung hauptsächlich dem Finanzministerium).

Mit der Umorganisierung der Staatsunternehmen in marktwirtschaftliche Gesellschaftsformen wurde auch prinzipiell die erste Phase der Entflechtung abgeschlossen. Die meisten größeren Unternehmen und Kombinate teilten sich in mehrere Aktiengesellschaften. Dabei fand sowohl eine horizontale als auch eine vertikale Entflechtung statt. Werke mit demselben Profil, die im Lande verstreut lagen und rechtmäßig demselben Großunternehmen angehörten, wurden selbständige Unternehmen. Während die horizontale einen unmittelbaren positiven Effekt auf die Entmonopolisierung und Verstärkung des Wettbewerbs hatte und also ohne Bedenken zu begrüßen ist, brachte die vertikale Entflechtung mit sich zunächst auch Nachteile. Im Prinzip strebte man damit an, daß infolge einer höheren Unabhängigkeit die Produzenten die günstigsten Zulieferer und die Zulieferer die besten Kunden finden würden, Preise und Kosten viel besser die Stärken und Schwächen jedes Produzenten wiedergeben würden und ein neues, viel flexibleres Netz von Lieferbeziehungen sich herausbilden würde. Die Mobilität der Produkte und der vertraglichen Beziehungen ist aber in Rumänien aufgrund von Infrastrukturschwächen und mangelhafter kaufmännischen Tradition viel geringer als in den Industrieländern. Die verschiedenen Industrien sind weniger in Ballungszentren als in 
Westeuropa konzentriert. Sie wurden im Gegenteil bewußt von den Kommunisten gleichmäBiger auf das Land verteilt, weil die Beschäftigungsprobleme in der Politik der sozialistischen Industrialisierung eine größere Rolle als die Faktorausstattung gespielt haben. Es gab früher Zulieferer die landesweit monopolistisch organisiert waren (die Automobilindustrie ist z.B. stark abhängig von einem Produzent von Kühlern, von einem Produzent von Zinkverteilern usw.). Durch die vertikale Teilung sind auch lokale Monopole entstanden. Eine Gießerei z.B., die früher für alle Produktionsstätten eines vertikal integrierten Kombinats arbeitete, ist jetzt eine unabhängige AG geworden; Ihre Kunden können zwar bei einer anderen Gießerei im Lande bestellen, aber die Kosten würden wegen der schlechten Infrastruktur, der zweifelhaften Liefertreue usw. viel höher liegen.

Die vertikale Entflechtung hat in der Übergangsphase zweifelsohne Kostenerhöhungen verursacht (Acquisitions- und Transportkosten, aber auch den Verlust von Skalenerträgen vor allem in der Erzeugung von Halbfabrikaten, wo diese Effekte wichtig sind). Andererseits muß man ihre strukturellen Auswirkungen auf die Dauer positiv bewerten.

Die Korporatisierung mit der erhöhten Autonomie und Entflechtung der staatlichen Unternehmen war ein unbedingt notwendiger Schritt der Transformation, der aber bei weitem nicht genügte, um das System der freien Marktwirtschaft einzuführen. Die Unternehmen staatlichen Eigentums werden üblicherweise - selbst wenn viele Stimmen das Gegenteil behaupten nicht wie ein normales Geschäft in einem marktwirtschaftlichen Rahmen geführt, woraus ihre schwächere Leistungsfähigkeit sich ergibt. Ihre Strategien werden von sozialen Determinanten stark geprägt; Ihnen werden starre institutionelle und gesetzliche Einschränkungen, aber weiche Budgetrestriktionen auferlegt. Die Verfahren für die Ernennung der Direktoren und der Vorstandsmitglieder lassen viel Raum für politische Manipulationen. Die Autonomie des Managements bei Schlüsselfragen wie z.B. der Preispolitik, der Freisetzung von Personal und der Investition wird vom Industrieministerium, Staatseigentumsfonds und manchmal auch anderen Institutionen eingeschränkt. Entscheidungsbefugnis und Verantwortung sind bei den Unternehmen mit staatlichem Kapital voneinander getrennt (SCHMIEDING, 1993, S.12). Das Hauptinteresse der Arbeitnehmer wie der Manager ist nicht auf die Maximierung des Firmenwertes gezielt, weil ihr Status ähnlich ist. Beide Gruppen fühlen sich für die Erhaltung der Substanz nicht unbedingt verantwortlich. Auch die künftigen Eigentumsrechte sind nicht klar, was insbesondere für die Manager demotivierend wirken dürfte. Das Fehlverhalten wird auch dadurch angestachelt, daß die Unternehmen mit den politischen Instanzen weiterhin über Sonderkonditionen verhandeln können. Ihnen wird z.B. vom ebenfalls staatlichen Bankensystem eine schlechte Finanzdisziplin mit gravierenden Effekten für den ganzen Wirtschaftskreislauf nachgesehen. Eine weitere Änderung im Status dieser Unternehmen, nämlich die Privatisierung, sollte möglichst schnell erfolgen. Ohne Privatisierung wird der Finanzkreislauf als Teil des gesamten Wirtschaftskreislaufs nie richtig funktionieren können (CORICELLI \& MILESI-FERRETI, 1993, S.388). 


\subsection{Stand der Privatisierung}

Der Anteil des Staates an der gesamtwirtschaftlichen Wertschöpfung war vor der Wende in Rumänien extrem hoch. Zählt man die landwirtschaftlichen Produktionsgenossenschaften auch zum Staatssektor, was angesichts ihrer mangelnden Entscheidungsfreiheit durchaus vernünftig ist, wurden 1989 in Rumänien 95,5\% des Nettomaterialproduktes, 99,5\% des Bruttoproduktionswertes der Industrie und $85,6 \%$ des Bruttoproduktionswertes der Landwirtschaft von Staatsunternehmen realisiert (Quelle: Romanian Statistical Yearbook, 1991). Die Anerkennung der Notwendigkeit der Privatisierung ergab sich 1990 aus dem Programm der Regierung ROMAN, das den Übergang zur Marktwirtschaft als wirtschaftliches Hauptziel des neuen Regimes erklärte. Immerhin wurden die Diskussionen über Ausmaß und Tempo des Privatisierungsprozesses heftig kontrovers geführt. Neben dem Widerstand der alten Strukturen ergab sich eine starke Konkurrenz der Ziele, die bei der Privatisierung verfolgt werden mußten: Geschwindigkeit, Erlöse, Kapital- und Technologietransfer, Beseitigung der Managementlücke, Wettbewerbsfähigkeit, politische und soziale Akzeptanz.

Die Privatisierungsproblematik ist ein "politisches Minenfeld" (FISCHER \& GELB, 1991, S.98). Meistens haben die Arbeitnehmer, insbesondere die Arbeiter in den Staatsbetrieben, die Überzeugung, sie hätten substanzielle Ansprüche auf das Firmeneigentum. Die "spontane" Privatisierung in der Form des Verkaufs von Aktiva von und an "insiders" - Direktoren, ehemalige Bürokraten usw., meistens Mitglieder der ehemaligen Nomenklatura - schafft Ungerechtigkeiten. Nationalistische Gefühle können auch den Verkauf an Ausländer drosseln.

Es wird heiß diskutiert, ob man schnell oder langsam privatisieren müßte. Die Anhänger des Gradualismus behaupten, die Privatisierung sollte nach der Stabilisierung, unter vernünftigen Preisverhältnissen erfolgen, nachdem die neuen, marktwirtschaftlichen Verhaltensweisen sich herausgebildet haben und eine gewisse Schicht von Geschäftsleuten sich entstanden ist. "Wirkliche Eigentümer" werden benötigt, d.h. private Personen oder Organisationen, die auf längere Frist orientiert sind und deren Anteil an der Firma groß genug ist, um sie kontrollieren zu können.

Die Anhänger des schnellen Weges halten dem entgegen, daß es in Osteuropa zu viel Staatseigentum gibt, um die traditionellen Privatisierungsverfahren verwenden zu können. Zwischen 1980 und 1987 wurden weltweit weniger als 1000 Unternehmen privatisiert. Dagegen gab es Ende 1992 nur in der rumänischen Industrie 1817 Aktiengesellschaften mit staatlichem Kapital (Quelle: Romanian Statistical Yearbook, 1993). Sie geben zu, daß die schnelle Privatisierung die Einnahmen des Staates beim Verkauf mindern, aber sie argumentieren, daß die Vorteile einer schnellen und unwiderruflichen Umschichtung zur privaten Produktion diese Verluste bei weitem kompensieren würden. Eine weitgehende und rasche 
Reform des Eigentumssystems würde die Produktionseffizienz erhöhen und die schon bestehenden Kräfte des Widerstands gegen die Transformation (freigesetzte Arbeiter, Bürokraten usw.) ausgleichen. Auch würden die Steuereinnahmen bei effizienterer Wirtschaftstätigkeit ansteigen.

Bedingt von den politischen Verhältnissen (anfangs reformfreundlich, später reformbremsend), aber auch von technischen und institutionellen Einschränkungen, erfolgten die ersten Schritte der Privatisierung in Rumänien ganz schnell. Aber nach der Machtübernahme der Regierung VACAROIU wurde die Privatisierung so gut wie eingefroren. Im Bereich der Landwirtschaft wurden die Produktionsgenossenschaften in der ersten Hälfte von 1990 rasch aufgelöst. Ihre Nutzflächen wurden den ehemaligen Eigentümern oder ihren Erben restituiert. Jedoch wurden sie auf höchstens 10 Hektar pro Familie begrenzt. Die Staatsgüter wurden in Aktiengesellschaften umorganisiert.

Die sogenannte "kleine Privatisierung" der kleineren Staatsunternehmen, vorwiegend im Handels- und Dienstleistungsbereich, setzte ebenfalls schon früh vor einer umfassenden gesetzlichen Regelung ein. Es handelte sich dabei in vielen Fällen um den erfolgreichen Versuch ehemaliger Wirtschaftsfunktionäre, sich aus Teilen des Staatseigentums, die sie selber als "unergiebig" einstuften, zu bedienen. Hierbei sind Verkäufe von kleineren Aktiva der staatlichen Unternehmen (Läden, Verkaufseinrichtungen, Lagern, Hotels, aber auch Maschinen und Produktionsanlagen) in mehr oder weniger korrekten Versteigerungen zu erwähnen, aber auch deren Verpachtung an private Firmen. 1992 wurden 53,4\% sämtlicher Umsätze des Einzelhandels vom privaten Sektor realisiert. Mit Ausnahme der Post, der Kommunikationen und des öffentlichen Verkehrs befindet sich der Dienstleistungssektor weitgehend in privaten Händen. Der IWF stellt in seinem Bericht vom Oktober 1992 fest (IWF, Okt. 1992, S.48), es habe bemerkenswerte Fortschritte in der Privatisierung der kleinen Betriebe in der Tschechoslowakei, Polen, Ungarn und Rumänien gegeben. Das bezieht sich hauptsächlich auf den Einzelhandels- und Dienstleistungsbereich, aber auch auf Wohnungsbau, auf Speditionen und auf Kleinindustrie.

Im Sommer 1991 wurde das Privatisierungsgesetz (die "große Privatisierung") nach heftigen Diskussionen verabschiedet. 30\% des Kapitals der staatlichen Unternehmen sollen kostenlos an die Bevölkerung verteilt werden, während der Rest verkauft werden soll. Es wurden 5 Fonds des privaten Eigentums gegründet, die die $30 \%$ des staatlichen Aktienkapitals erhielten und verteilen sollen. Jeder Erwachsene bekam 5 Vouchers, mit denen er Aktien an die zu privatisierenden Unternehmen erwerben kann, wenn die Aktien zum Verkauf gegeben werden. Er kann sie auch bei einem Fond einlegen, um am Jahresende die durchschnittliche Dividende aus dem Fondsvermögen zu bekommen. Keine von diesen beiden Möglichkeiten wurde aber bis Ende 1993 eröffnet, da bis dahin diese Privatisierungsmaßnahmen nicht eingeleitet wurden. Die übrigen $70 \%$ des Aktienkapitals werden dem Staatseigentumsfonds 
zugeordnet, der sie innerhalb einer unpräzisierten Frist durch Verkauf privatisieren soll. Das Privatisierungsgesetz schließt die Bevorzugung der Belegschaft beim Aktienverkauf nicht aus; infolgedessen hat insbesondere unter den Wirtschaftsfunktionären das sogenannte MEBO (Management-Employees Buy-Out) Verfahren große Popularität gewonnen. KLÖS (1993, S.75) macht darauf aufmerksam, daß die soziale Akzeptanz in Gefahr geraten kann, wenn bei der Privatisierung Betriebsangehörige bevorzugt werden und somit die übrige Bevölkerung benachteiligt wird. Dadurch wird jegliche Gerechtigkeit aufgegeben.

Die Voucherprivatisierung bezieht die gesamte Bevölkerung in die Verteilung des Staatsvermögens ein, und ist also von der Akzeptanz her positiv. Sie erfordert aber längere Vorbereitungen. Wenn der Wille gegeben ist, können sie in anderthalb Jahren abgeschlossen sein, wie das Beispiel der Tschechoslowakei zeigt. Fraglich ist auch, ob die Betriebe unter der Verwaltung der Fonds effizient geleitet und umstrukturiert werden (CORNELSEN, 1993, S.39). ALTER (1992, S.19) weist auf einen weiteren Nachteil dieses Verfahrens hin: In den kommenden Jahren brauchen die maroden Staatsunternehmen wichtige Kapitalzuflüsse für Ersatz- und Modernisierungsinvestitionen. Die Verschenkung des Staatsvermögens an die Bevölkerung wird dieses Problem nicht lösen, sondern sogar erschweren, weil die Kapitalspritzen ausbleiben. Auch vermag die Voucherprivatisierung zu atomisierten Eigentumsdistributionen führen, die eine effektive Kontrolle verhindern und negative Konsequenzen für die Investitionsentscheidungen mit sich bringen.

Man kann aber zur Zeit in Rumänien das Ausmaß solcher negativen Effekte der Voucherprivatisierung aus dem einfachen Grund noch nicht abschätzen, weil sie noch nicht zustande gekommen ist. Von den staatlichen Aktiengesellschaften des verarbeitenden Gewerbes wurden 19922 (zwei) in einem Pilotprojekt privatisiert: eine Brauerei (durch Verkauf von Aktien über eine Bank) und eine Konfektionsfabrik (71\% der Aktien wurden an eine italienische Firma verkauft und 29\% auf Kredit an die Belegschaft). Der Staatseigentumsfonds hatte in seinem Programm für 1993 großspurig die Privatisierung von 1.100 kleinen, 100 mittelständigen und 4 großen staatlichen Aktiengesellschaften vorgesehen. Am 31.Oktober 1993 waren es 134 kleine und 5 mittelständige Unternehmen, die man tatsächlich privatisiert hatte (Quelle: RUDNITCHI, 1993). Keine Aktie wurde dabei gegen Vouchers verkauft. Erst 1994 sollen die Vouchers gegen Aktien - jedoch nur für große (!) Unternehmen - umgetauscht werden können. Der Verkauf soll durch spezialisierte Makleragenturen erfolgen, die es aber im Moment auch nicht gibt. Für 1994 ist die Privatisierung von 1930 kleinen, 403 mittelständigen und 35 großen Unternehmen geplant. Wenn man die bisherige Entwicklung und die Tatsache berücksichtigt, daß der Staatseigentumsfonds ein starker Stützpunkt der regierenden Partei der Sozialen Demokratie ist, sind diese Zahlen mit Vorsicht zu genießen.

Schätzungen des Anteils des privaten Sektors am Bruttoinlandsprodukt oder an der Industrieproduktion liegen weder beim Nationalen Statistischen Ausschuß, noch beim Industriemini- 
sterium noch bei der Rumänischen Entwicklungsagentur zur Zeit nicht vor. Ende 1992 waren $11,7 \%$ der Unternehmen der Industrie in Privat- und 24,9\% in Genossenschaftseigentum (alles kleine und mittelständige Betriebe); sie beschäftigten 1,5\% bzw. 6\% der Arbeitskräfte. $1,2 \%$ der Industrieunternehmen waren Gemeinschaftsunternehmen mit ausländischen privaten Investoren (staatlicher Anteil kleiner als 50\%); sie beschäftigten 1\% der Arbeitskräfte. 1993 sollten sich diese Anteile etwas erhöht haben obwohl nur etwa 10\% (!) des ursprünglichen Privatisierungsprogramms durchgeführt wurden.

Das Londoner Adam Smith Institut hat prognostiziert, daß man in Osteuropa für die Privatisierung der Industrie etwa 28 Jahre benötigen wird (KLÖS, 1993, S.79). Das Tempo, das in Rumänien vorgelegt wird, wird diesen Termin aber weit überschreiten. Die Erkenntnis sollte sich bei den rumänischen Politikern durchsetzen, daß der Hauptzweck der Privatisierung nicht die Generierung der sozialen Ungleichheit sondern die Entstehung eines funktionsfähigen Kapitalmarktes ist. Ohne ihn ist eine marktgerechte Allokation der Ressourcen unmöglich und auch die Investitionen werden erheblich beeinträchtigt.

Ohne einen artikulierten Kapitalmarkt wird die für eine erfolgreiche Transformation unbedingt notwendige Faktormobilität ausbleiben. Der Markt des landwirtschaftlichen Bodens ist z.B. zur Zeit von Verboten noch stark beeinträchtigt. So ist es nicht erlaubt, das rückübereignete Land zu verkaufen. Die Besitzer von landwirtschaftlichem Boden sind verpflichtet, ihn zu bebauen. Dadurch sollte die landwirtschaftliche Produktion sichergestellt werden. Diese Regel wirkt aber eher kontraproduktiv, weil die von ihm eingeführten Mobilitätshemmnisse die optimale Bodenallokation verhindern.

Ausländische private oder juristische Personen dürfen weder in Städten noch auf dem Land Boden kaufen. Ihnen werden Grundstücke nur verpachtet. Der Pachtzins wird aber oft willkürlich und unangemessen hoch angesetzt und wirkt so häufig abschreckend auf den potentiellen Investor.

Auf die Probleme des Finanzmarktes wird im Abs.1.8. näher eingegangen. Aber er funktioniert bei weitem nicht so schlecht wie der Immobilienmarkt, wo die institutionellen Voraussetzungen (Katastern, Übertragungsregeln, eindeutige Eigentumsverhältnisse) meistens fehlen und die Märkte noch extrem reguliert sind. Seit dem Frühjahr 1990 warten z.B. die ehemaligen Hausbesitzer, die während des kommunistischen Regimes von ihren Häusern ohne Gesetzesgrundlage vertrieben wurden, auf die Restitution zumindest eines Teils ihres widerrechtlich konfiszierten Eigentums. Die Änderung dieses Zustandes wird dadurch erschwert, daß für die gegenwärtigen Bewohner - häufig Minister und Parlamentarier - ein geeigneter Ersatz gefunden werden muß. 


\subsection{Das Bankensystem}

Im Bankensystem der Planwirtschaft kumulierte die Nationalbank die Funktionen der Zentralsowie einer Handelsbank. Das ganze Bankensystem war an sich stabil: die Bestimmung von Preisen, fixen Zinsen, sowie die administrative Allokation der Kredite und Subventionen seitens der Planungsbehörde sicherten allen Unternehmen stets die benötigte Liquidität. Die Zuteilung von Krediten erfolgte direkt; das Bankensystem verhielte sich wie ein verlängerter Arm der Planungsbehörde. Die Zinsen hatten mit den tatsächlichen Rentabilitäten wenig gemeinsam. Fast sämtliche Produktionstätigkeiten wurden von Staatsunternehmen ausgeübt, also vom Staat garantiert. Darum waren die Banken nicht befugt, die Qualität der Aktiva zu kontrollieren. Bankleute waren eine Mischung von Buchhältern und Notaren. Sie haben sämtliche Transaktionen sorgfältig registriert und die zentralen Planer mit zusätzlichen Informationen über die ökonomische Ströme versorgt. Sie übermittelten auch Daten, deren Weitergabe nicht im Interesse der Betriebe war, weil sie zur Ausweitung der Planauflagen führen konnten.

1991 wurde auch in Rumänien das zweistufige Bankensystem eingeführt, indem die Zentralbank von den Handelsbanken durch entsprechende, per Gesetz gebilligte Statuten getrennt wurde. Die Nationalbank erhielt eine hohe Autonomie. Ihre Hauptaufgabe lautete, "die Geldund Kreditpolitik des Landes im Rahmen der Wirtschafts- und Finanzpolitik des Staates zu bestimmen und so durchzuführen, daß die Stabilität der nationalen Währung gewährt bleibt" (Gesetze Nr.33/1991 "Über die Banktätigkeit" und Nr.34/1991, "Über das Statut der Nationalbank Rumäniens"). Die Nationalbank ist bisher tatsächlich unabhängig geblieben; der heute führenden Partei der Sozialen Demokratie ist trotz heftiger Auseinandersetzungen nicht gelungen, den Gouverneur durch einen parteitreuen Funktionär zu ersetzen. So kamen die währungspolitischen Maßnahmen der Nationalbank oftmals in Konflikt mit anderen wirtschaftspolitischen Schritten der Regierung. Es mußten Kompromisse gemacht werden, wie z.B. bei der Entspannung der restriktiven Kreditpolitik in November 1991 und im Frühjahr 1993.

Hinzu kommt auch, daß die Nationalbank über wenige und grobe Instrumente der Geldpolitik verfügt: Kreditkontingente, Einlagenpolitik, Mindestreservepolitik. Die Kreditkontingente wurden im November 1993 durch ein System der täglichen Versteigerung der Refinanzierungskredite für die Geschäftsbanken ersetzt. Diskontgeschäfte und Offenmarktoperationen können, obwohl sie im Gesetz Nr.34/1991 erwähnt sind, mangels entsprechender Wertpapiere (Handelswechsel, Aktien, Obligationen) und der notwendigen Gesetze und Institutionen, die die Entstehung und den Verkehr dieser Wertpapiere regeln sollten, noch nicht getätigt werden. 
Seit 1991 wurden mehrere neue Geschäftsbanken gegründet (Eximbank, Postbank), manche auch mit privatem (Dacia Felix - die erste hundertprozentig private rumänische Bank nach 1948) und/oder Auslandskapital (Türkisch-Rumänische Bank, Interkonfessionelle Bank usw.).

Außer den oben genannten Regelungen, wurden auch einige Maßnahmen für die Sanierung der Bilanzen der staatlichen Geschäftsbanken vorgenommen. Die Nationalbank hat in dieser Richtung einige Vorsichtsmaßnahmen durchgesetzt. Anfang 1992 wurden per Gesetz die Altschulden der Unternehmen mit staatlichem Kapital (Stand: 31.12.1990) mit dem Überschuß des Budgets der Sozialen Sicherung ausgeglichen. Damals handelte es sich meistens um Kredite für in der Zeit der Planwirtschaft angefangene Erweiterungsinvestitionen, die sich nicht mehr rentierten, aber die Bilanzen der Unternehmen weiter belasteten, und für die Banken aussichtslose Forderungen darstellten.

Während der Regierung STOLOJAN sind tatsächlich die Eigenmitteln des Bankensektors (bestehend aus eingezahltem Kapital, Risikofonds und Reservefonds) relativ zur Vorperiode gestiegen: Die Kapitalkonten der Banken deckten Ende 1992 12,4\% der von ihnen gewährten Kredite (ohne die Kredite an die Regierung), gegenüber 7,4\% im Jahr zuvor. Der staatliche Bankensektor ist trotzdem unterkapitalisiert. Nach dem oben erwähnten Ausgleich, hat sich seine Bilanzlage infolge der weichen Budgetrestriktionen, die den staatlichen Unternehmen auferlegt sind, wieder verschlechtert. Die Weigerung des Präsidenten der Rumänischen Außenhandelsbank, für aussichtslose Kredite an staatlichen Unternehmen weiterhin Regierungsgarantien zu akzeptieren, hat ihn vor kurzem das Amt gekostet. Die dubiose Bilanzlage der staatlichen Banken erschwert ihre Privatisierung erheblich; auch die negative Differenz zwischen den vom Finanzministerium zugelassenen Nominalzinsen und der tatsächlichen Inflationsrate wirkt in derselben Richtung der Entkapitalisierung. Um Verluste zu vermeiden, verzögern die Banken die Zahlungs- und Abrechnungsvorgänge und erzielen damit Zinsgewinne. Eine einfache Überweisung kann zwei bis drei Wochen dauern; in der Zwischenzeit benutzen die Banken die entsprechende Gelder, ohne Zinsen zu zahlen. Nicht nur rumänische Unternehmen, aber auch ausländische Investoren haben sich oftmals über diesen Tatbestand beschwert (POPESCU, 1994). Der andere Grund, warum die Banken, trotz der negativen Realzinsen, Gewinne erwirtschaften und der Bankensektor insgesamt einer der profitabelsten der Volkswirtschaft ist, war die Erweiterung der Spanne zwischen Zinsen auf Darlehen und Zinsen auf Einlagen. Eine derartige große Spanne ermöglicht zwar die Rekapitalisierung der Banken. Dies geschieht aber nur auf Kosten der wirtschaftlichen Erholung, weil diese "finanzielle Repression" den Anreiz zu sparen nach unten und die Investitionskosten nach oben drückt (BEGG \& PORTES, 1993, S.398). Der Sparzins ist tatsächlich so niedrig geworden, daß die private Ersparnis dramatisch geschrumpft ist.

Die Finanzdisziplin wurde auch von den Banken selber unterminiert, indem sie sich scheuten, bestimmte Kredite als uneinbringbar zu deklarieren. Solange es Kreditobergrenzen gab, hat 
der kontinuierliche Zufluß von Krediten an unrentablen Unternehmen die Kreditverfügbarkeit für gesunde Unternehmen stark gedrosselt und dadurch ihre Investitionen und ihre Produktion eingeschränkt.

Selbst wenn die Kreditportfolien der Banken bereinigt werden tauchen die selben Probleme wieder auf, wie die Erfahrung nach dem Ausgleich vom Frühjahr 1992 gezeigt hat. Die Banken sind großzügig bei der Kreditvergabe an staatliche Unternehmen und kaum in der Lage, die Kreditwürdigkeit ihrer Kunden einzuschätzen. Die Mehrheit ihres Personals wurde im ehemaligen planwirtschaftlichen System geschult, in dem Rentabilitäts- und Risikoprobleme eine ganz geringe Rolle spielten. Diese Schwierigkeiten werden von dem fehlerhaften zwischenbanklichen Informationssystem und den inadäquaten Kontrollmechanismen verstärkt. Obwohl die Kreditvergabe an Privatkunden streng reglementiert ist, erlauben Schlupflöcher und Korruption z.B. mit derselben Garantie Kredite bei mehreren Banken aufzunehmen. Angesichts dieser Sachlage nehmen die privaten Unternehmer Bankkredite wenig in Anspruch. Diese Tatsache erschwert den neugegründeten privaten Unternehmen den Zugang zum geschäftlichen Umfeld. Das selbe Problem gibt es z.B. auch in Ungarn und Polen (WHITMORE, 1991, S.70).

Nicht nur die privaten Unternehmen haben aber Schwierigkeiten, wenn sie langfristige Kredite beantragen, sondern auch die staatlichen Unternehmen, wenn es um die Modernisierung ihres Kapitalstocks geht. Sie haben zusätzlich eine Reihe von bürokratischen Hürden zu nehmen. Staatseigentumsfonds, Industrieministerium, Regierung, Finanzministerium, Eximbank (wenn es um Auslandskredite geht) und schließlich ein interministerieller Ausschuß müssen ihre Zustimmung geben, nachdem die angesprochene Bank sich bereit erklärt hat, den Kredit zur Verfügung zu stellen. Dies spricht bei der Investitionsentscheidung der Unternehmen deutlich gegen die Kreditfinanzierung. Auch die Nominalzinsen von 150\%$180 \%$, obwohl sie bisher kleiner als die Inflationsrate waren, üben eine abschreckende Wirkung aus. Man legt keinen großen Wert mehr auf die Durchführbarkeitsstudien, wenn man Inflation, Entwicklung der Löhne und der Märkte sowie die Entwicklung der Kosten nicht vorausschätzen kann, weil alles in großem Maße von der Politik einer labilen Regierung abhängt.

Unter den heutigen Verhältnissen ist zu erwarten, daß Bankensystem und Kreditmarkt nicht imstande sind, den notwendigen Investitionsprozeß, der mit der Umstrukturierung und Transformation verbunden ist, richtig zu unterstützen. Die einzigen nennenswerten Finanzierungsquellen dürften im Moment die eigenen Gewinne der Unternehmen sowie ausländische Investoren sein. Es würde aber ein großer Fehler sein, sich nur auf diese zwei Möglichkeiten zu verlassen. Erstens bedarf es in Rumänien enormer Infrastrukturinvestitionen, die ohne eine erfolgreiche Zusammenarbeit zwischen Staat, Bankensystem und internationalen Finanzinstitutionen nicht durchgeführt werden können, um den potentiellen Investoren richtige 
Standortbedingungen zu sichern. Dafür muß das Bankensystem weiter modernisiert und den marktwirtschaftlichen Anforderungen angepaßt werden. Auch auf kürzere Sicht wird man ohne ein funktionsfähiges Bankensystem nicht auskommen können. HARDY \& LAHIRI (1992, S.779) zeigen, daß die Krise des Bankensektors die negativen Effekte aller Typen von Instabilitäten während der Transformation in Osteuropa verstärkt. Solange Ressourcen für die vollständige Umstrukturierung des Bankensektors nicht mobilisiert werden, sind und bleiben die Reformkosten erhöht. Auch CALVO \& CORICELLI ([28], S.33) bezeichnen den Kreditmarkt als eine Schlüsselinstitution in Osteuropa, der stark unterentwickelt ist. Ihre statistische Analyse für Polen begründet die Behauptung, daß $20 \%$ des Produktionsverfalls auf die Kreditkontraktion zurückzuführen ist.

In der nächsten Zeit sind für ein normales Funktionieren des rumänischen Bankensystems der Aufbau des langfristigen Kapitalmarktes und ein Zahlungs- und Clearingsnetz nach westlichen Maßstäben unbedingt notwendig. Der Kapitalmarkt soll die Schlüsselrolle in der Mobilisierung der Ersparnisse und in der Erhöhung der Effizienz der Ressourcenallokation spielen. Das zwischenbankliche Netz müßte die Allokation der Ersparnisse innerhalb des Bankensystems ermöglichen, die Wirkung der Instrumente der marktwirtschaftlichen Monetärkontrolle verstärken und Korruption und Veruntreuung vorbeugen.

Daneben muß unbedingt die Gesetzgebung erweitert und weiter angepaßt werden. Eine Regelung für Wechselgeschäfte und andere schnellere Zahlungsinstrumente muß eingeführt werden. Man diskutiert seit 1991 darüber, aber die Geschäftsbanken weigern sich mangels Fachkenntnisse diese Instrumente einzuführen. Ein Börsengesetz und die Einrichtung einer Wertpapierbörse, die daraus folgt, ist für die Entstehung eines artikulierten Kapitalmarktes, der den Kreditmarkt erweitern soll, unbedingt notwendig. Gleichzeitig müßten die meisten staatlichen AG's für den Verkauf ihrer Aktien - bzw. Tausch gegen Vouchers - vorbereitet werden. Zusätzlich wird so schnell wie möglich eine gesetzliche Regelung der Finanzierung durch Obligationen gebraucht, bisher wurde diese Finanzierungsform von keinem rumänischen Unternehmen benutzt. Allerdings ist es fraglich, ob die staatlichen Unternehmen in den Augen der Bevölkerung eine ausreichende Bonität haben, um dieses Finanzierungsinstrument nutzen zu können.

\subsection{Die Finanzpolitik nach der Wende}

Im folgenden Abschnitt wird die Finanzpolitik lediglich von der Ausgaben- und Defizitseite her analysiert, da die Einnahmenseite, vor allem die Fiskalpolitik, im Kapitel 5 eingehend untersucht wird. 
Die Finanzpolitik befand sich nach der Wende unter dem Druck der stetigen Senkung des Bruttoinlandsprodukts, die wiederum die Minderung der Staatseinnahmen verursachte. Die Finanzlage wurde durch die Tatsache verkompliziert, daß die Inflation eine richtige Festlegung der notwendigen Ausgaben für jeden Teil des Haushalts unmöglich machte. Die labilen politischen Verhältnisse sowie die Unfähigkeit der Finanzbürokratie, sich an die Anforderungen des Rechtsstaates und der freien Marktwirtschaft, vor allem an die Operativität und an die Transparenz anzupassen, haben dazu geführt, daß der Staatshaushalt für ein Jahr jeweils im März oder April desselben Jahres verabschiedet wurde. Die Struktur des Staatshaushaltes und insbesondere des Budgets der sozialen Sicherung haben sich nach der Wende verständlicherweise geändert (Tabellen 1.9 und 1.10).

Tabelle 1.9: Änderungen der Staatseinnahmen und Ausgaben gegenüber dem Vorjahr (in \%) inflationsbereinigt.

\begin{tabular}{||l|c|c||}
\hline \multicolumn{1}{|c|}{ Staatseinnahmen } & 1992 & $\begin{array}{c}1993 \\
\text { (1.Halbjahr, gegenüber } \\
\text { dem 1.Halbjahr 1992) }\end{array}$ \\
\hline \hline Insgesamt: - darunter: & $-11,7$ & $-18,6$ \\
\hline Gewinnsteuern & $-3,2$ & $-28,4$ \\
\hline Lohnsteuern & $-14,5$ & $-1,7$ \\
\hline Umsatzsteuern & $-26,2$ & $-18,8$ \\
\hline Zölle & $+52,9$ & $+15,9$ \\
\hline \hline Staatsausgaben & & $-15,0$ \\
\hline $\begin{array}{l}\text { Insgesamt: } \\
\text { - darunter: }\end{array}$ & $-2,7$ & $-13,3$ \\
\hline $\begin{array}{l}\text { Ausbildung, Krankenfürsorge, } \\
\text { Sozialhilfe u.ä. }\end{array}$ & $-18,3$ & $-8,9$ \\
\hline Verteidigung & $-19,6$ & $+14,1$ \\
\hline Polizei und innere Sicherheit & $-4,9$ & $+1,9$ \\
\hline $\begin{array}{l}\text { Öffentliche Verwaltung auf Lan- } \\
\text { desebene und Justiz }\end{array}$ & $+1,1$ & \\
\hline $\begin{array}{l}\text { Wirtschaftliche Maßnahmen (vor } \\
\text { allem Subventionen) }\end{array}$ & & \\
\hline
\end{tabular}

(Quelle: Romania - Quarterly Statistical Bulletin, No. 2/1993, S.94-96, eigene Berechnungen) 
Tabelle 1.10: Entwicklung der Anteile unterschiedlicher Einnahmen- und Ausgabenarten im Staatshaushalt, 1991-1993 (in \%)

\begin{tabular}{|l||c|c|c|}
\hline & 1991 & 1992 & $\begin{array}{c}1993 \\
\text { (1.Halbjahr) }\end{array}$ \\
\hline \hline Staatseinnahmen insgesamt: & 100 & 100 & 100 \\
\hline $\begin{array}{l}\text { darunter: } \\
\text { Gewinnsteuern }\end{array}$ & 21,1 & 23,1 & 19,7 \\
\hline Lohnsteuern & 34,6 & 33,6 & 35 \\
\hline Umsatzsteuern & 36,7 & 30,7 & 32,2 \\
\hline Zölle & 3,3 & 5,8 & 8,2 \\
\hline \hline Staatsausgaben insgesamt: & 100 & 100 & 100 \\
\hline $\begin{array}{l}\text { - darunter: } \\
\text { Ausbildung, Krankenfürsorge, Kul- } \\
\text { tur, Sozialhilfe, Sport u.ä. }\end{array}$ & 34,8 & 29,2 & 29 \\
\hline Verteidigung & 14,5 & 12 & 9,4 \\
\hline Polizei und innere Sicherheit & 3,7 & 3,6 & 4,9 \\
\hline $\begin{array}{l}\text { Öffentliche Verwaltung auf Landes- } \\
\text { ebene und Justiz }\end{array}$ & 2,9 & 3,0 & 3,1 \\
\hline Wirtschaftliche Maßnahmen & 35,2 & 40,2 & 42,6 \\
\hline
\end{tabular}

(Quelle: Romania - Quarterly Statistical Bulletin, No. 2/1993, S.94-96, eigene Berechnungen)

Aus Tabelle 1.9 kann man ablesen, daß die Ausgaben weniger als die Einnahmen gesunken sind, das Haushaltsdefizit hat sich also entsprechend erhöht. Alle Regierungen haben sich gescheut, Subventionskürzungen vorzunehmen; das Gegenteil ist festzustellen, indem der Anteil der sogenannten "wirtschaftlichen Maßnahmen" mit der Zeit sogar gestiegen ist. Ihre Verringerung wurde nicht in Angriff genommen, weil man sich vor den sozialen Kosten des Subventionsabbaus fürchtete. Gleichzeitig sind die Einnahmen proportional mit dem Bruttoinlandsprodukt gesunken, nicht aber die Ausgaben für die soziale Verträglichkeit der Reformen (Siehe Tabelle 1.11.).

Die Senkung der Staatsquote in 1991 ist auf den Übergang zu einem neuen institutionellen Rahmen des Staatshaushalts zurückzuführen, bei dem die Sozialversicherung vom übrigen Haushalt getrennt wird. Wie es früher gezeigt wurde, konnte das Ziel der Regierung STOLOJAN, das Defizit des Staatshaushalts unter $2 \%$ des BIP zu halten, nicht erreicht werden. 
Tabelle 1.11: Bruttoinlandsprodukt und Staatshaushalt, 1990-1992

\begin{tabular}{||l|c|c|c||}
\hline & 1990 & 1991 & 1992 \\
\hline BIP (Mrd.Lei) & 844 & 2198,9 & 5982,3 \\
\hline \hline Staatseinnahmen (Mrd.Lei) & 307 & 496,8 & 1363,9 \\
\hline Ihr Anteil am BIP (\%) & 36,4 & 22,6 & 22,8 \\
\hline \hline Staatsausgaben (Mrd.Lei) & 310,9 & 537,9 & 1626,9 \\
\hline Ihr Anteil am BIP (\%) & 36,8 & 24,5 & 27,2 \\
\hline \hline Haushaltssaldo (Mrd.Lei) & $-3,9$ & $-41,1$ & $-263,0$ \\
\hline Sein Anteil am BIP (\%) & $-0,5$ & $-1,9$ & $-4,4$ \\
\hline \hline $\begin{array}{l}\text { Saldo des Budgets der Sozialversicherung } \\
\text { (Mrd.Lei) }\end{array}$ & - & $+9,0$ & $+64,5$ \\
\hline Sein Anteil am BIP (\%) & - & $+0,4$ & $+1,1$ \\
\hline \hline $\begin{array}{l}\text { Saldo des konsolidierten Nationalhaushalts } \\
\text { (Mrd.Lei) }\end{array}$ & - & $-32,1$ & $-198,5$ \\
\hline Sein Anteil am BIP (\%) & - & $-1,5$ & $-3,3$ \\
\hline
\end{tabular}

(Quellen: Romanian Statistical Yearbook 1991 und 1993, Quarterly Statistical Bulletin No. 2/1993 und eigene Berechnungen)

Die Hauptursache liegt nahe: da der größte Teil des produktiven Vermögens immer noch in staatlichem Besitz ist, stammen die Staatseinnahmen noch überwiegend von den Staatsbetrieben. Der Niedergang der Staatswirtschaft macht alle Budgetplanungen - und die entsprechenden Vereinbarungen mit dem IWF - zunichte. Andererseits bedeutet die zunehmende Verschuldung der Staatsbetriebe bei den Staatsbanken und untereinander eine wirkliche "Zeitbombe" (SCHMIEDING, 1993, S.17). Obwohl die Zunahme des Haushaltsdefizits einen verstärkenden Einfluß auf die Inflation hatte, hat man keine andere Lösung gefunden. Auch die anteilsmäßige Erhöhung der finanzieller Unterstützung der schwachen Unternehmen hat dazu beigetragen, eine "Metastasierung" - eine Erweiterung der Finanzblockage, die die ganze Wirtschaft erstickt hätte - zu verschieben. Der Schuldenausgleich vom Frühjahr 1992 hat auch die Erhöhung der Staatsverschuldung bewirkt. Dieser Schritt war damals eine Lösung; leider erwies sie sich im nachhinein als zu kurzfristig, für das Frühjahr 1994 wird ein ähnlicher Ausgleich von der Regierung VACAROIU geplant. Solange das Staatseigentum in der Produktion und im Finanzwesen den größeren Anteil hat und es keine Konkursgesetzgebung gibt, wird sich dieses Problem zyklisch wiederholen. Die Zunahme der Verbindlichkeiten zwischen Unternehmen stellt für sie eine Möglichkeit dar, strengeren Finanzkontrollen seitens des Staates auszuweichen. Die Unternehmen praktizieren 
dieses Vorgehen seit den fünfziger Jahren; solche Ausgleichsverfahren wie im Frühling 1992 gab es damals auch; nur, weil sie öfter vorgenommen wurden, hatten sie nicht denselben Umfang wie nach der Wende. Ein Teil von den zunehmenden Verbindlichkeiten kann entlang Unternehmenketten ausgeglichen werden; verbleibt aber der Teil, der die Nettoverschuldung des Unternehmensektors gegenüber dem Bankensystem darstellt, meistens "nonperforming loans" oder uneinbringliche Kredite. Diese "schlechten Schulden" sind die unmittelbare Folge der Tolerierung hoffnungsloser Unternehmen innerhalb des Wirtschaftssystems. Die Verbindlichkeitsketten, die von ihnen ausgehen, zwingen selbst wettbewerbsfähige Unternehmen in die Liquiditätskrise. Mit der Zeit erstreckt sich diese Verflechtung bis zu einem Punkt, wo ein einziger Bankrott den ganzen Wirtschaftskreislauf paralysieren kann, weil auch die Banken nicht genug kapitalisiert sind, um den Konkurs einiger wichtigen Kunden überleben zu können. Diese Metastasierung des Kredits zwischen Unternehmen kann nicht durch eine restriktive Geld- und Kreditpolitik (z.B. durch Kreditplafonds) bekämpft werden. Wenn A nicht an B zahlt dann bezahlt B seine Zinsen für seine aufgenommenen Kredite nicht an die Bank. Obwohl die nominelle Kreditmasse nicht wächst und obwohl sie in den von der Politik bestimmten Grenzen bleibt nehmen die "schlechten Schulden" zu.

Altschulden können auch eine Erbschaft der Planwirtschaft sein: durch sie wurden entweder nach der Wende unumsetzbar gewordene Waren oder von der Wende angefangene, unvollendete Investitionen finanziert, die jetzt nicht mehr rentierlich sind.

PORTES (1992, S.668) bemerkt dazu, daß die Einleitung von Konkursverfahren nach dem Erlaß der entsprechenden Gesetze nicht die richtigen Verantwortlichen treffen würde, wenn davor kein Ausgleich stattfindet. Der Ausgleich sollte - wie in Rumänien im Frühling 1992 die Unterscheidung zwischen unliquiden und insolventen Unternehmen ermöglichen. Allerdings führt PORTES an anderer Stelle zusammen mit BEGG aus (PORTES \& BEGG, 1993, S.402): Soweit die Einstellung der Regierung gegenüber den hoffnungslosen Unternehmen ("lame ducks") und die Eigentumsfrage bei Aktiengesellschaften nicht geklärt werden, setzen derartige Ausgleiche an den Symptomen und nicht an die Ursache an. Neue schlechte Schulden werden schnell wieder erscheinen. Darum sollte man den Ausgleich in dem Transformationsprozeß möglichst später einplanen.

Der Ausgleich erhöhte die Staatsverschuldung, was der IWF im Februar 1992 stark kritisierte (vgl. PISULLA, 1993, S.216). Die Kritik hätte aber nicht an diesen Faktum ansetzen dürfen sondern daran, daß die Regierung und das Parlament die relative finanzielle Gesundung infolge des Ausgleichs nicht sofort nutzten, um die Konkursgesetzgebung einzuführen. Sie wußten jedoch, daß dies in einer relativ kurzen Zeit zu erhöhter Arbeitslosigkeit geführt hätte, die sie politisch nicht verkraften konnten. Auf Kosten der Geldwertstabilität und der Gesundheit der Staatsfinanzen nahm man also einen gewaltigen Schuldenerlaß vor. Er führte 
zu keinem anderen Ergebnis als das Problem auf den Rücken der kommenden Regierungen zu verschieben.

Abschließend muß gesagt werden, daß die Finanzpolitik der rumänischen Regierungen nicht ohne jegliche Unterstützung seitens der internationalen Finanzorganisationen verlaufen ist. Gegen die Ansätze des IWF in den osteuropäischen Ländern kann man Kritik äußern: Der Fonds versucht vor allem mit makroökonomischen Instrumenten wie Inflationsbekämpfung, Defizitabbau und Währungsabwertung wirtschaftliche Fehlentwicklungen zu korrigieren. Das sind aber alles indirekte, prinzipiell marktwirtschaftliche Eingriffe, die normalerweise wirkungslos bleiben wenn sie in noch nicht-marktwirtschaftlichen Systemen angewendet werden. Aber man darf nicht vergessen, daß der IWF seine Bereitschaft vom Anfang an erklärte, Rumänien zu unterstützen, zumal Rumänien den Ruf eines Landes hatte, das seine Schulden zahlt. Die im Rahmen der IWF-üblichen Bereitschaftskreditvereinbarungen Rumänien gewährten "stand by" Kreditlinien, waren proportional der Größe des Landes (380,5 Mio.SZR zwischen April 1991 und April 1992, sowie 314 Mio.SZR zwischen Mai 1992 und April 1993). Hinzu kam eine Kompensationsfinanzierung für Ölimporte (247,7 Mio.SZR) und für unerwartete externe Störungen (131 Mio. SZR) im ersten Zeitraum.

Leider signalisierte Rumänien nach der Ablösung der Regierung STOLOJAN durch die Art und Weise, in der sich die Regierung VACAROIU verhielte, nicht mehr seine Entschlossenheit, durch wirtschaftspolitische Reformen seine Kreditwürdigkeit zu erhöhen und die Voraussetzungen dafür zu schaffen, daß sich private Investitionen rentieren. Nationalistische Akzente gegen das "Diktat" des IWF sowie der stockende Verlauf der Verhandlungen mit der rumänischen Regierung deuten auf die Unfähigkeit der Vertretern der neuen Macht hin, in marktwirtschaftlichen Kategorien zu denken. Nur der Druck durch die Öffentlichkeit und durch den Staatspräsidenten hat die Regierung VACAROIU gezwungen, nach einer achtmonatigen Verzögerung im Dezember 1993 ein Memorandum mit dem IWF zu unterzeichnen, in dem sie sich verpflichtet, gegen die Zusage von weiteren Krediten die Privatisierung $\mathrm{zu}$ beschleunigen, die Bedingungen für ausländische Investitionen zu verbessern und die Staatsausgaben zu senken. Aber der rumänische Staatsapparat ist nicht einmal imstande, die zugesagten Kredite den Unternehmen, Gebietskörperschaften u.a. rechtzeitig zur Verfügung zu stellen. Für sie kam das Problem hinzu, die Bedingungen für die Kreditinanspruchname, vor allem die Zusammenstellung einer umfangreichen Dokumentation, zu erfüllen. 1991 sagte die Weltbank zusätzlich Rumänien Kreditlinien in Höhe von 230 Mio.US-\$ zu - nur 3 Mio.US-\$ davon wurden tatsächlich in Anspruch genommen! 1992 lagen die entsprechenden Zahlen bei 500 Mio.US-\$, bzw. 39 Mio.US-\$. Somit war der rumänische Koeffizient der Inanspruchnahme der Kreditlinien mit 7,8\%, 4,4 mal kleiner als im Durchschnitt für Osteuropa (Quelle: BUSCH \& FRÖHLICH, 1993, S.62). 


\subsection{Ausländische Investitionen in Rumänien nach 1989}

Die Gründe, warum Rumänien ausländische Kapitalinvestitionen in dieser Phase der Transformation braucht, sind vielfältig. Nach ALTER (1992, S.18) geht der Sach- und Humankapitalbedarf in den osteuropäischen Reformländern weit über ihre Möglichkeiten hinaus. Die Mobilisierung der heimischen Ersparnisse sollte nicht vernachlässigt werden, aber alle Schätzungen des Investitionsbedarfs in Osteuropa zeigen, daß es äußerst gefährlich für ein solches Land wäre, sich nur auf die endogen generierten Investitionsströme zu verlassen. Man braucht nur den desolaten Zustand des Sachkapitals, die veralteten Technologien, die ideologisch bedingte Isolierung der rumänischen Forschung und Entwicklung von der übrigen Welt und den großen Mangel an Marketing-, Management- und Finanzierungskenntnisse in den rumänischen Unternehmen zu berücksichtigen, um vom Realismus solcher Urteile überzeugt zu werden. Der Kollaps der Anlageinvestitionen nach der Wende kommt erschwerend hinzu, von dem dramatischen Rückgang der F\&E-Tätigkeiten ganz zu schweigen. Gegenüber 1985 sind die Investitionen preisbereinigt 1990 auf 59,2\%, und dann weiter 1991 auf 43,9\% und 1992 auf 43,4\% gesunken (Quelle: Romanian Statistical Yearbook, 1993, S.380).

Neben dem Finanz- und Anlagekapitaltransfer bringen die westlichen Investoren auch ein fortschrittliches Know-How auf vielen Ebenen mit: Produktideen, modernes Managementwissen, Marketing, Controlling u.v.a. Dadurch wird den rumänischen Unternehmen geholfen, auch die Humankapitallücke zu schließen. Häufig stellt der Investor auch die von ihm gewonnenen Märkte zur Verfügung, so daß viele Arbeitsplätze gesichert werden.

Rumänien bietet einige attraktive Standortbedingungen: äußerst niedrige Arbeitskosten (Durchschnittslohn im Oktober 1993: 100 DM), Gewinnsteuererlaß in den ersten 2 bis 5 Jahren der Aktivität (gestaffelt nach der Branche, wo investiert wird), Zoll- und Mehrwertsteuerfreiheit für das investierte Sachkapital, Zollfreiheit für alle importierten Rohstoffe in den ersten zwei Jahren, Freiheit des Gewinntransfers ins Ausland, technisch gut ausgebildete Arbeitskräfte, Bevorzugung der ausländischen Firmen im Vergleich zu den einheimischen usw. Trotzdem ist die bisherige Entwicklung der ausländischen Investitionen in Rumänien entmutigend (Tabelle 1.12). Auch in dieser Hinsicht liegt das Land weit hinter den Reformrennern Tschechien, Ungarn und Polen. Im Jahre 1993 sind die ausländischen Investitionen anscheinend politisch bedingt - sogar gesunken.

Dagegen nähert sich mittlerweile die Investitionssumme in Ungarn der 7 Milliarden-Grenze. Die vorher genannten Standortvorteile Rumäniens reichen offensichtlich nicht aus. Einerseits dürfte es an den Unvollkommenheiten der Rahmenbedingungen in Rumänien liegen: die 
Tabelle 1.12: Ausländische Investitionen in Rumänien, 1990-1993

\begin{tabular}{|c||c|c||}
\hline Jahr & Investiertes Kapital (Mio.US-\$) & Anzahl der Firmen \\
\hline \hline 1990 & 107,7 & 1.529 \\
\hline 1991 & 156,3 & 6.368 \\
\hline 1992 & 269,1 & 12.780 \\
\hline 1993 & 227,4 & 8.457 \\
\hline Insgesamt & 760,5 & 29.137 \\
\hline
\end{tabular}

(Nach Angaben der Rumänischen Entwicklungsagentur)

Währung ist nicht frei und somit wird der Gewinntransfer erschwert (auch erhöhen die häufigen Abwertungen der rumänischen Währung die Wahrscheinlichkeit des Währungskursver lustes beim Tausch); sämtliche Infrastruktur ist mangelhaft (siehe auch ferner Abs.2.2.2.); es gibt keinen Kapitalmarkt und damit wird die Möglichkeit einer Liquidation der Investition erheblich in Frage gestellt; die Auslandsfinanzierung ist fast unmöglich, das Bankensystem funktioniert unzufriedend für westliche Standards; selbst die Lebensqualität und die Wohnbedingungen entsprechen kaum den Anforderungen der westlichen Geschäftsleute. Andererseits gibt es auch Gründe, die an das politische Element knüpfen: das Mißtrauen sowohl in dem Willen als auch in der Fähigkeit der heutigen Regierung, weitere Reformen in Richtung der freien Marktwirtschaft voranzutreiben; eine Lohnsteuer von $60 \%$, die ausländische Fachleute, die sich länger als 183 Tage im Jahr in Rumänien aufhalten, zahlen müssen; die häufigen, unkalkullierbaren Zoll- und Akzisenänderungen; die stillschweigende Zusammenarbeit der Regierungspartei mit den national-kommunistischen politischen Kräften -all dies erhöht die "option value of waiting" (PORTES, 1992, s.663). Es ist klar, daß die Garantien der heutigen Regierung für die potentiellen westlichen Investoren nicht viel wert sind und daß außerdem das Umfeld für die Tätigkeit vieler ausländischen Investoren noch nicht reif ist. Die künftige Wirtschaftspolitik sollte sich daran orientieren.

\subsection{Defizite: Angebots- und Strukturpolitik}

In Abschnitt 1.1. wurde dargelegt, daß die sektorielle Struktur der rumänischen Volkswirtschaft deutlich fehlentwickelt ist. Auch innerhalb der Sektoren (Industrie, Landwirtschaft) ist die Unausgewogenheit ziemlich groß. Sie zeigt sich bei der Betrachtung der Indikatoren Netto- und Bruttokapitalproduktivität, Nettogewinn- und Wertschöpfungsquote, die sich im Abs.2.1. aus Tabellen 2.3 und 2.5 ablesen lassen. Demnach ist der Ausgleich der Grenzproduktivitäten, der einem volkswirtschaftlichen Optimum entspräche, noch weit entfernt. In der Textil- und Bekleidungsindustrie sowie der Elektrotechnik und der Industrie der Baumate- 
rialien kann noch investiert werden, während Maschinenbau und Chemie gesundschrumpfen sollten.

Die Struktur des Anlagevermögens ist infolge der verbindlichen Zentralplanung völlig anders als die Struktur, die sich durch private Investitionen zum Zweck der Gewinn- bzw. Firmenwertmaximierung ergeben hätte. Der Industriesektor muß grundlegend reformiert werden, vor allem um den unangemessen hohen Rohstoff- und Energieverbrauch zu reduzieren. Der Anteil des Dienstleistungssektors am BIP soll steigen. Die Umweltschäden müssen in die Kostenstruktur und dadurch in die Rentabilitätsrechnungen miteinbezogen werden.

Diese aus westlicher Sicht ungewöhnliche sektorielle und branchenmäßige Struktur des Anlagevermögens spiegelte sich in der Allokation anderer Produktionsfaktoren, wie z.B. des Bodens und der Finanzmitteln, sowie in der Struktur des Humankapitals wider. SCHMIEDING (1993, S.11) versucht, dieses Problem durch ein Gedankenexperiment zu veranschaulichen: man stelle sich die Probleme vor, vor denen westdeutsche Firmen stünden, wenn sie eines Tages entdecken müßten, daß ihr gesamtes Personal für den An- und Verkauf, für Werbung und Finanzierung, für Rechnungswesen und Rechtsfragen zusammen mit allen Rechtsanwälten, Richtern, Bankiers und staatlichen Beamten und Angestellten eine mehrjährige Reise zum Mars angetreten hätte. Zwar würden einige findige Lückenbüßer rasch reich; aber die Wirtschaftsleistung insgesamt ginge zurück.

Daneben leidet die rumänische Volkswirtschaft an vielen anderen Strukturmängeln: fehlende oder unterentwickelte Finanzmärkte; unzufriedendes Funktionieren der Arbeitsmärkte angesichts der Lohnfindung und -differenzierung; anhaltende Monopole und Monopsone; zu viel Staatseigentum; Unsicherheiten angesichts der Restitution. All diese Mängel der unterschiedlichen Strukturen innerhalb der rumänischen Volkswirtschaft perpetuieren die Rigiditäten und verhindern Marktsignale und Information, ihre stimulierende und koordinierende Aufgabe zu erfüllen. Die innere strukturelle Anpassung wurde durch den Kollaps eines Teiles der früheren Außenhandelsbeziehungen und durch die innere Transformationskrise erschwert. Sie haben die Kapitalakkumulation fast blockiert (ohne Kapitalakkumulation kann es keine Kapitalreallokation geben!). In diesem unvollkommenen Marktrahmen genügen die Konzentration auf die Stabilisierungspolitik, die Erklärung der Freiheit der Märkte und das Abwarten, bis die Marktkräfte die Umstrukturierung erfolgreich bewirken, nicht. Die Anstöße, die von dem sich bildenden Privatsektor ausgehen, wirken, wenngleich sie stark sind, nicht schnell genug, um den Verfall der Produktion in den (ehemaligen) staatlichen Unternehmen zu kompensieren.

Allerdings muß immer wieder festgestellt werden, daß in Rumänien unter Wirtschaftspolitik nicht das gleiche wie z.B. in den EG-Ländern verstanden wird. Den meisten heutigen Verantwortlichen der rumänischen Wirtschaftspolitik - Regierung, Staatseigentumsfonds, 
Industrie-, Finanz- und Handelsministerium - fällt es besonders schwer, sich von den Modellen des Marktsozialismus zu befreien (Ausnahmen: die Nationalbank, die Fonds des privaten Eigentums). Um durch Schaffung von Beamtenstellen die politische Klientele zu befriedigen, werden immer wieder neue Institutionen gegründet, die die Wirtschaftspolitik tragen sollen: der zentrale Ausschuß für Reform und Strategien, die Umstrukturierungskommission, der Ausschuß für die Förderung der ausländischen Investitionen, u.v.a. Ihre Tätigkeiten beschränken sich auf sterile Konferenzen und Berichterstattungen über unterschiedliche staatlichen Unternehmen oder Unternehmensgruppen, ohne an die Beseitigung der Ursachen der Krise zu gehen nämlich an das staatliche Eigentum und an die Standortbedingungen für private Investitionen. Der "Sozialismus ohne Planung" konterkariert die Wirkung der Budgetrestriktionen in den Firmen, weil die Eigentums- und Kontrollfragen nicht geklärt sind. Die Verfolgung des politischen Ziels, wirtschaftlich ungesunde Arbeitsplätze auf kurze Sicht zu erhalten, anstatt neue, sichere Arbeitsplätze durch Angebotspolitik zu ermöglichen, mündet in weiche Budgetrestriktionen für die staatlichen Firmen. Nach wie vor benutzt die rumänische Regierung (und neuerdings der Staatseigentumsfonds) die Steuereinnahmen und die Dividenden von rentablen Unternehmen, um durch Umverteilung die insolventen zu retten. Dadurch wird nicht nur die Erreichung einer optimalen Wirtschaftsstruktur sondern auch die Privatisierung der besten Unternehmen verschoben. Den "guten" Unternehmen werden Investitionsmittel entzogen, die ihre internationale Wettbewerbsfähigkeit verstärken würden. Die Entstehung einiger gesunder Wirtschaftspfeiler, die in der Transformationszeit stabilisierend wirken würde, wird dadurch erheblich erschwert.

Andererseits wird der Zugang neuer privater Anbieter am Markt durch unterschiedliche Faktoren erschwert. Nicht nur die schwerfällige Bürokratie überall da, wo die privaten Unternehmer in Kontakt mit staatlichen Behörden kommen (Zoll, Finanzamt, Handelsregister, Stadtpräsidien, Notariat usw.), sondern auch der "crowding-out" Effekt bei Krediten wirkt in dieser Richtung. Der Markteintritt der "newcomer" wird von dem überproportionalen Anteil der dubiosen Kredite an nicht-zahlenden staatlichen Unternehmen am gesamten Kreditangebot eingeschränkt.

Somit besteht kein Zweifel mehr, daß die bisherige Wirtschaftspolitik den Reformprozeß nicht weiter bringen kann. Die Erfahrung der 80er Jahre in den freien Marktwirtschaften zeigt, daß in solchen Fällen die Hauptziele der Wirtschaftspolitik die Förderung der industriellen Umstrukturierung, die Entwicklung von neuen Industrien, den Transfer von im Lande nicht existierenden Know-How und die Sicherung eines unternehmer-, inovations- und risikofreundlichen Geschäftsklimas einschließen sollen. Die Strukturpolitik sollte die Flexibilität des Wirtschaftssystems erhöhen. Dadurch würde die Faktormobilität steigen, und somit würde sich die Ressourcenallokation verbessern. Die Strukturpolitik sollte auch auf die Effizienz und Unternehmerfreundlichkeit der öffentlichen Verwaltung, den technologischen 
Wandel, die Verbesserung der Qualität der Produktionsfaktoren, die Eliminierung der Starrheiten der Finanzmärkte und der steuerinduzierten Verzerrungen abzielen.

Vorsicht ist dabei angebracht. WINIECKI (1991, S.190) macht darauf aufmerksam, daß die ersten vierzig Jahre von planwirtschaftlicher Industrialisierung in Osteuropa lediglich "eine eigenartige Klasse von schon anfangs veralteten Maschinen" entstehen ließen. Die Strukturund Industriepolitik müßte sich deswegen darauf beschränken, Dimensionen und Funktionsfähigkeit der Märkte zu verstärken, während die primäre Verantwortung für die industrielle Entwicklung von den Unternehmen selbst getragen werden soll. Anders ausgedrückt, die Industrie soll "Hilfe zur Selbsthilfe" bekommen (OECD, 1991, S.18). Hierbei spielen neben den öffentlichen Infrastrukturinvestitionen und Umschulungsprogrammen für Arbeitslose, neben Deregulierung und Wettbewerbspolitik, neben industrieller Entflechtung und Privatisierung die Instrumente der Fiskalpolitik eine entscheidende Rolle. 
KAPITEL 2:

DIE RUMÄNISCHE TEXTIL- UND BEKLEIDUNGSINDUSTRIE (TBI)

\subsection{Bedeutung der rumänischen Textil- und Bekleidungsindustrie}

Angesichts des hohen Umstrukturierungsbedarfs, der sich aus der problematischen Lage der rumänischen Volkswirtschaft in der Zeit des Übergangs zur Marktwirtschaft ergibt, stellt sich aus der Sicht des Wirtschaftspolitikers zuerst die Frage: Was muß getan werden, damit die schon längst bestehende, aber erst durch die ersten Schritte der Liberalisierung in vollem Umfang enthüllte Strukturkrise abgefedert wird? Die negativen Effekte der Strukturkrise wurden infolge der ersten marktwirtschaftsorientierten Reformen deutlicher gemacht: die Unausgewogenheiten zwischen den unterschiedlichen Sektoren und Zweigen traten ganz klar zutage; die Branchen, die vor der Wende subventioniert wurden, gerieten nach den jeweiligen Stufen der Freisetzung der Preise in erhebliche Schwierigkeiten; somit verschwand die früher versteckte Subventionierung des verarbeitenden Gewerbes durch staatlich fixierte, niedrige Preise für Energie und Rohstoffe; der dadurch entstandene Preisdruck verursachte einen inflationären Anschub, hauptsächlich von dem Kostendruck dieser Produktionsfaktoren bedingt.

Da die Industrie nicht mehr staatlich geplant war, gewann sehr schnell die Ausstattung jeder Branche mit Produktionsfaktoren an Bedeutung: Rohstoffe, Energieversorgung, gebildete Arbeitskräfte, Maschinen und Anlagen, gut gelegener Boden. Rohstoffe, Energie und Sachkapital waren nunmehr fast so teuer wie auf dem Weltmarkt (manche sogar teurer, aufgrund der monopolistischen Position derer Anbieter); demzufolge haben sich die Erzeugerpreise der Industrie auch den Weltmarktpreisen angenähert, und, in (zu) vielen Fällen, wurden letztere auch überschritten - hauptsächlich wegen der veralteten, energie- und rohstoffintensiven Technologien. Dies war natürlich von wichtigen Umsatzeinbußen auf den internationalen Märkten begleitet. Somit gewannen die Effizienzparameter der Produktion ganz stark an Bedeutung: spezifischer Rohstoff- und Energieverbrauch, Arbeits- und Kapitalproduktivität usw.

Letztendlich, obwohl die Rolle der Preise und Kosten als Informationsträger immer noch durch versteckte Eingriffe des Staates ins Finanzwesen der Unternehmen (Subventionen im Bergbau, im öffentlichen Verkehr und in der Lebensmittelindustrie, zinsgünstige Kredite an staatliche Betriebe, staatlicher Ausgleich der sog. "bad debts") verfälscht wird, und obgleich die Beurteilung der finanziellen Lage eines rumänischen Unternehmens nach westlichen Standards immer noch nicht sehr sinnvoll ist (wegen der fehlenden Konkursgesetzgebung, des durchaus schlechten Funktionierens des Bankensystems und der historisch bedingten Unter- 
kapitalisierung) gewannen nach der Wende auch die Finanzindikatoren des Unternehmens eine wichtige Rolle.

Damit erhielt der Wirtschaftspolitiker bessere Ansatzpunkte für die Beurteilung der heutigen Lage der rumänischen Volkswirtschaft nach marktwirtschaftlichen Kriterien. Die Transformationskrise in Rumänien ist aber auf keinen Fall eine typisch kapitalistische Überproduktionskrise, wo der nachfrageorientierte Ansatz behilflich sein könnte. Wenn etwas getan werden muß, um das Sinken des Bruttoinlandsprodukts zu stoppen und die Strukturkrise zu überwinden, dann geht es um die Verbesserung der Produktionsbedingungen, also um Angebotsund insbesondere Industriepolitik. Und für die Angebotspolitik macht es natürlich Sinn herauszufinden, welche Unternehmensgruppen (nach Größen, nach Produktionsprofil, nach Regionen u.v.a.) am Start die besten Produktionsbedingungen und die besten Perspektiven haben, wo also der wirtschaftspolitische Eingriff am ergiebigsten sein könnte, das heißt wo mit der kleinsten politisch verursachten Störung des marktwirtschaftlichen Gleichgewichts das Ziel des gewünschten Anschubs für eine günstige Entwicklung erreicht werden kann.

Es gibt also gute Gründe dafür, in dieser Phase des Übergangs zur Marktwirtschaft die wirtschaftspolitischen Instrumente auf die wirtschaftlichen Tätigkeiten zu richten, die die besten Chancen für die künftige Entwicklung haben. Eine nivellierende Politik, die die relativen "Renner" zugunsten der Problemindustrien vernachlässigen würde - gleichgültig, ob diese Politik auf sozialen, strategischen oder Prestigeargumenten basiert - würde zweifelsohne die Strukturkrise und den Rückgang des allgemeinen Wohlstands und (somit) des Lebensstandards der Bevölkerung unberührt lassen, mit dem unerwünschten Ergebnis der Erschöpfung des Geduldpotentials der Menschen für die Transitionsphase. Die chaotischen Ausbrüche sozialer Wut, die im Endeffekt entstehen würden, würden jegliche Hoffnungen für die Demokratisierung und Liberalisierung der rumänischen Gesellschaft vernichten. Dagegen kann nur eine Wirtschaftspolitik, die auf den Stärken der rumänischen Volkswirtschaft basiert, die Gesundung ihrer Struktur bringen.

Um diese Frage ist in den letzten zwei Jahren auch in Rumänien eine heiße Diskussion entstanden. So vertritt z.B. das rumänische nationale Institut für Wirtschaftsforschung die Meinung, es bedürfe einer Strukturpolitik angesichts der Regierung, die die Prioritäten durch eine Staffelung der Industrien nach bestimmten Kriterien setzen sollte. An diese Prioritäten sollten hauptsächlich die für den staatlichen Eingriff benutzten wirtschaftspolitischen Instrumente anknüpfen (MIHAESCU, 1993, S.12).

Der Workshop "Economic Interpenetration Between Central and Eastern Europe", das im Oktober 1991 in Brüssel von der Generalabteilung für Wirtschaft und Finanzen der Europäischen Gemeinschaft organisiert wurde, kam zu dem Ergebnis, daß die Umstrukturierung der 
mittel- und osteuropäischen Industrien nicht ohne die Identifizierung der sogenannten Schlüsselindustrien erfolgen kann. Dafür sollten Parameter, wie:

- die Ausstattung mit Produktionsfaktoren,

- Qualitätsindikatoren der Exporte,

- $\quad$ Arbeits- und Kapitalproduktivität,

- Wertschöpfung,

gemäß der Weltmarktpreise berechnet werden.

In der "Romanian Case Study", die bei dieser Gelegenheit vorgestellt wurde, vertritt M.JACKSON die Meinung, die Umstrukturierung der rumänischen Industrie sollte in Bezug auf die Exportorientierung erfolgen, wobei die Interessen der ausländischen Investoren, die sich an entwickelnden, exportorientierten Industrien beteiligen, explizite berücksichtigt werden sollten.

Angesichts der angebrachten Struktur- und Industriepolitik in mittel- und osteuropäischen Ländern sind auch andere Stellungnahmen zu erwähnen:

- D.LINOTTE (1992) ist, wie der Verfasser dieser Arbeit, der Meinung, daß der keynesianische Ansatz nicht tauglich ist, und schlägt einen neoklassischen Ansatz vor, basierend auf einem allgemeinen Gleichgewichtsmodell der Industrie. Im Ergebnis lautet die Hauptaufgabe der Strukturpolitik Einschränkung der Entwicklung des 1. Sektors (Produktionsmittel) und Beschleunigung der Entwicklung des 2.Sektors (Konsumgüterindustrie). In diesem Fall könnte die Bevölkerung Konsumebenen erreichen, die höhere Indifferenzkurven tangieren, obwohl der volkswirtschaftliche Output gesunken ist. Dadurch wäre auch der negative Effekt des Produktionsrückgangs auf den allgemeinen Wohlstand minimiert.

- Dagegen gibt es unter den OECD-Experten (OECD, 1991, S.136) auch die Meinung, die Spezialisierung im Außenhandel sollte auf der bestehenden Industriestruktur und auf der geschichtlichen Entwicklung der verschiedenen Industrien basieren.

- Das rumänische INCE (Nationalinstitut für Wirtschaftsforschung) wiederum nahm folgende Stellung bezüglich der zu empfehlenden Industriepolitik in der Transitionsphase ein (MIHAESCU, 1993, S.16 ff., eigene Übersetzung):

"a) die Strukturpolitik im Bereich der Industrie sollte die notwendigen Bedingungen für die Vorbereitung der Umorientierung schaffen, mit anderen Worten, das Gleichgewicht zwischen den positiven Effekten und den Transformationskosten stets zu behalten;

b) die industrielle Strukturpolitik solle die Wettbewerbsvorteile der bestehenden Industriekapazitäten möglichst intensiv ausnutzen." 
Bemerkenswert bei all diesen Konzeptionen ist, daß die Textil- und Bekleidungsindustrie allen o.a. Anforderungen entspricht. Sie ist exportorientiert und für die Interessen der ausländischen Investoren offen und sehr gut geeignet; sie gehört überwiegend zum 2.Sektor (Konsumgüter) und hat eine geschichtlich lange (für rumänische Verhältnisse) Erfahrung und Entwicklungstradition. Durch die Generierung von freien Devisen ist diese Industrie auch imstande, einen wichtigen Beitrag zur Erhaltung des Gleichgewichts während der Übergangsphase zur Marktwirtschaft zu leisten; letztendlich hat sie gegenüber den ausländischen Wettbewerbern wichtige komparative Vorteile, die später erläutert werden sollen.

In den Zeiten der zentralen Planwirtschaft (1948-1989) war in Rumänien, wie in den anderen mittel- und osteuropäischen Ländern (MOE) auch, "die Forcierung der Textil- und Bekleidungsproduktion Ausdruck dafür, daß in diesen Ländern die - knappen - Devisen für den Import von Investitionsgütern benötigt wurden, somit die Versorgung der heimischen Bevölkerung mit Textilien und Bekleidung weitgehend aus eigener Produktion zu erfolgen hatte; zudem hatte der Export von Textilien und Bekleidung Devisen zu bringen" (BREITENACHER, 1989, S.67). Dieses Zitat von einem berühmten deutschen Textilökonomen enthüllt aber nur einen Teil der Gründe für die extensive Entwicklung der Textil- und Bekleidungsindustrie (TBI) in Rumänien. Eine weitere Rolle haben sozial- und regionalpolitische Urteile gespielt: der Wunsch, Arbeitsplätze für Frauen zu schaffen, als Komplement in den Gebieten, wo sich die Schwerindustrie entwickelte, sowie der Versuch, mit kleinerem Investitionsaufwand die Industrie in traditionell landwirtschaftliche Zonen einzusiedeln.

Zur Zeit gibt es in Rumänien 387 Unternehmen im Bereich der TBI, fast gleichmäßig über das ganze Land verteilt (Zahl Ende 1992, vom Industrieministerium angegeben). Gemäß der von der Weltbank benutzten Einteilung der Länder nach dem Entwicklungsstand der Textilund Bekleidungsindustrie (BREITENACHER, 1989, S.166) befindet sich die rumänische TBI in der sog. diversifizierten Phase. Sie ist durch größere Produktionsmengen mit einer breiteren Produktpalette gekennzeichnet, wobei in bezug auf Qualität und technische Komplexität des Herstellungsprozesses größere Ansprüche gestellt werden. Zum Teil wird mit Beteiligung größerer Produzenten aus den Industrieländern produziert (z.B. Steilmann in Rumänien). Es gibt schon eine stärkere vertikale Integration, und auch eine eigene Faserherstellung (in Rumänien sind die Produktionskapazitäten für Fasern, im Vergleich mit anderen MOELändern, sogar groß). Außer den MOE-Ländern befinden sich einige fortgeschrittene ASEAN-Länder und einige nordafrikanische Länder (aber erst am Anfang) in dieser Phase. Die nächsten Phasen sind die goldene (Korea, Taiwan, Singapur und Hongkong) und die reife Phase (Japan, Italien, BRD und USA).

Im folgenden wird versucht, die Bedeutung dieser historisch gewachsenen TBI relativ zu den übrigen Branchen der rumänischen Volkswirtschaft, im Hinblick auf die benötigte Setzung der Prioritäten der Industriepolitik in der Umstrukturierungsphase, zu quantifizieren. 
Die Kriterien für den Vergleich der verschiedenen Industrien stammen von Dr.Corneliu RUSSU, vom Nationalen Institut für Wirtschaftsforschung (Vorstudie Nr.24/1992). Der Verfasser dieser Arbeit hat zwei zusätzliche Kriterien beigefügt, die relevant für die Bedeutung einer industriellen Branche sein dürften: den Verflechtungsgrad mit den anderen Industrien (siehe BREITENACHER, 1981, S.20) und die Gleichmäßigkeit der Regionalverteilung (siehe MÜHLECK, 1992, S.71). Beides sind Kriterien, die eine gewisse soziale Relevanz besitzen, indem sie angeben, inwieweit Arbeitsplätze in anderen Industrien von der TBI abhängig sind, bzw. inwieweit eine Krise der TBI das Wirtschaftsleben ganzer Gebiete lahmlegen könnte. Die statistischen Angaben basieren auf Berechnungen des rumänischen Industrieministeriums vom Ende des Jahres 1991 (unveröffentlicht). Die mathematische Bearbeitung, im Grunde eine Variante des Rangverfahrens, und die Bedeutungskoeffizienten der jeweiligen Kriterien stammen vom Verfasser dieser Arbeit.

Die Hauptnachteile des folgenden Beurteilungsverfahrens sind:

- die Privatwirtschaft konnte, mangels statistischer Angaben, nicht erfaßt werden. Dieser Satz bedarf einer Erklärung: die privaten Unternehmen können nur über die Statistiken der Finanzbehörde erfaßt werden, da sie nicht verpflichtet sind, ihre Produktionszahlen dem Industrieministerium mitzuteilen. Dagegen hat das Informationssystem des Finanzministeriums nur fiskalische Zwecke, und ist nicht nach Industriezweigen, sondern nach Kreisen (judeţe) organisiert; hinzu kommt auch, daß die privaten Firmen immer mehrere Geschäftsfelder am Handelsregister angeben, so daß es außerordentlich schwierig ist, im Rahmen des heutigen statistischen Systems ihre Meßzahlen nach spezifischen Tätigkeiten zu trennen.

- die Nahrungs- und Genußmittelindustrie fehlt, weil sie dem Landwirtschaftsministerium unterstellt ist.

Unter diesen Vorbehalten kann die folgende Analyse trotzdem ein interessantes Bild über die Struktur der rumänischen Industrie und deren Schwerpunkte liefern.

Die Kriterien wurden in 4 Kategorien gruppiert:

- erste Kategorie: Ausstattung der Branche mit Produktionsfaktoren, mit den Indikatoren:
a) Beschäftigtenzahl
- Gewicht 0,15
b) Stammkapital
- Gewicht 0,20
c) Nettoanlagevermögen
- Gewicht 0,20
d) Produktionskapazität
- Gewicht 0,10 
e) Abhängigkeit vom Import von Rohstoffen und Energie, d.h. Anteil dieser Importe im gesamten Bedarf

- Gewicht 0,15

f) Prozentmäßiger Anteil der Knappheit an Rohstoffen unter den Faktoren, die den Produktionsrückgang in den ersten 2 Jahren nach der Wende verursacht haben (gemäß der faktoriellen Analyse des Industrieministeriums)

- Gewicht 0,15

g) Gewicht der Knappheit an Energie unter den Faktoren, die denselben Produktionsrückgang verursacht haben (ebenfalls gemäß der faktoriellen Analyse des Industrieministeriums)

- Gewicht 0,05

Die Beschäftigtenzahl ist sowohl aus sozialen Gründen, als auch aufgrund der Schwierigkeit, qualifiziertes Personal zu beschaffen, oder vorhandenes Personal umzuschulen, wichtig.

Die Produktionskapazität ist nicht so relevant, da die bestehenden Kapazitäten sich in jedem Fall erheblich anpassen müssen - manche werden zunehmen können, andere werden abgebaut werden müssen.

Da die rumänische Währung - Lei - eine nur beschränkte Konvertibilität besitzt, ist es leicht zu verstehen, warum die Abhängigkeit einer Branche von Importen so relevant ist. Zwar dürfen die rumänischen Unternehmen im sogenannten zwischenbanklichen Fixingverfahren Lei gegen freie Devisen umtauschen, aber wegen der unzulänglichen Devisenreserven des Landes bedeutet dies eine zinslose Paralysierung von wichtigen Summen über eine Zeit die bis zu 4 oder 5 Monaten dauern kann. Das Gewicht der Probleme der Energieversorgung ist kleiner, weil mittlerweile die chronische Knappheit an Energie nicht mehr dramatisch ist, wegen der Stillegung der Produktion in einigen energieintensiven Betrieben.

Die Zahlen werden wie folgt bearbeitet: die Industrie, die den jeweils ungünstigsten Indikator aufweist, wird mit 1 notiert. Die Noten der anderen Industrien stellen das Verhältnis zwischen ihrem jeweiligen Indikator und dem gleichen Indikator der am schlechtesten gestellten Industrie dar (wenn das Anwachsen des Indikators eine günstige Entwicklung bedeutet), oder das Umgekehrte von diesem Verhältnis (wenn das Indikator sinken müßte, damit sich die Lage verbessert). Für jede Industrie werden dann die Noten mit den Gewichten der Indikatoren multipliziert und anschließend addiert (Tabellen 2.1 und 2.1.bis). 
Tabelle 2.1: Ausstattung mit Produktionsfaktoren - Ende 1991

\begin{tabular}{||l|c|c|c|c|c|c|c||}
\hline Indikator & $\begin{array}{l}\text { Ma- } \\
\text { schi- } \\
\text { nen- } \\
\text { bau }\end{array}$ & TBI & $\begin{array}{l}\text { Holz, } \\
\text { Mö- } \\
\text { bel, } \\
\text { Papier }\end{array}$ & Chemie & $\begin{array}{l}\text { Elektro- } \\
\text { technik }\end{array}$ & $\begin{array}{l}\text { Metal- } \\
\text { lurgie }\end{array}$ & $\begin{array}{l}\text { Bau- } \\
\text { mate- } \\
\text { rialien }\end{array}$ \\
\hline $\begin{array}{l}\text { a)Beschäf- } \\
\text { tigte (Tsd.) }\end{array}$ & 645 & 586 & 410 & 328 & 282 & 242 & 99 \\
\hline $\begin{array}{l}\text { b)Stamm- } \\
\text { kapital } \\
\text { (Mrd.Lei) }\end{array}$ & 207 & 46 & 36 & 199 & 57 & 218 & 31 \\
\hline $\begin{array}{l}\text { c)Nettoanla- } \\
\text { gevermögen } \\
\text { (Mrd.Lei) }\end{array}$ & 151 & 35 & 36 & 129 & 35 & 121 & 27 \\
\hline $\begin{array}{l}\text { d)Produkti- } \\
\text { onskapazität } \\
\text { (Mrd.Lei) }\end{array}$ & 108 & 91 & 46 & 98 & 48 & 70 & 14 \\
\hline $\begin{array}{l}\text { e)Importab- } \\
\text { hängigkeit } \\
\text { (\%) }\end{array}$ & 10 & 20 & 11 & 30 & 7 & 82 & 12 \\
\hline $\begin{array}{l}\text { f)Rohstoff- } \\
\text { knappheit } \\
\text { (\%) }\end{array}$ & 32 & 37 & 26 & 45 & 31 & 34 & 22 \\
\hline $\begin{array}{l}\text { g)Energie- } \\
\text { knappheit } \\
\text { (\%) }\end{array}$ & 17 & 16 & 26 & 18 & 13 & 20 & \\
\hline
\end{tabular}

Es ist ersichtlich daß, infolge der planwirtschaftlichen Entwicklung mit dem Kern in der Schwerindustrie, die Produktionsfaktoren mit Priorität dem Maschinenbau, der chemischen und der metallurgischen Industrie zugeordnet wurden (Tabelle 2.2). Die geringe Importabhängigkeit der Industrien mit höherem Veredelungsgrad (Maschinenbau und Elektrotechnik) ist ein Ergebnis der importsubstituierenden Strategie der 70er und 80er Jahre. 
Tabelle 2.1.bis: $\quad$ Ausstattung mit Produktionsfaktoren - Noten

\begin{tabular}{|c|c|c|c|c|c|c|c||}
\hline Ind. & $\begin{array}{l}\text { Ma- } \\
\text { schi- } \\
\text { nen- } \\
\text { bau }\end{array}$ & TBI & $\begin{array}{l}\text { Holz, } \\
\text { Mö- } \\
\text { bel, } \\
\text { Papier }\end{array}$ & $\begin{array}{l}\text { Che- } \\
\text { mie }\end{array}$ & $\begin{array}{l}\text { Elektro- } \\
\text { technik }\end{array}$ & $\begin{array}{l}\text { Metal- } \\
\text { lurgie }\end{array}$ & $\begin{array}{l}\text { Bau- } \\
\text { mate- } \\
\text { rialien }\end{array}$ \\
\hline a) & 6,51 & 5,92 & 4,14 & 3,31 & 2,85 & 2,44 & 1 \\
\hline b) & 6,68 & 1,48 & 1,16 & 6,41 & 1,84 & 7,03 & 1 \\
\hline c) & 5,59 & 1,30 & 1,33 & 4,78 & 1,29 & 4,48 & 1 \\
\hline d) & 7,71 & 6,50 & 3,28 & 7,00 & 3,43 & 5,00 & 1 \\
\hline e) & 8,20 & 4,10 & 7,45 & 2,73 & 11,70 & 1 & 6,83 \\
\hline f) & 1,41 & 1,22 & 1,73 & 1 & 1,45 & 1,32 & 2,05 \\
\hline g) & 1,53 & 1,63 & 1 & 1,44 & 2,00 & 1,30 & 1,37 \\
\hline $\begin{array}{l}\text { Ergeb- } \\
\text { nis }\end{array}$ & 5,72 & 2,97 & 2,87 & 4,07 & 3,47 & 3,58 & 2,05 \\
\hline
\end{tabular}

Tabelle 2.2: Staffelung nach der Ausstattung mit Produktionsfaktoren

\begin{tabular}{||l|c|c||}
\hline \multicolumn{1}{|c|}{ Industrie } & Note & Rang \\
\hline Maschinenbau & 5,72 & 1 \\
\hline Chemie & 4,07 & 2 \\
\hline Metallurgie & 3,58 & 3 \\
\hline Elektrotechnik & 3,47 & 4 \\
\hline TBI & 2,97 & 5 \\
\hline Holz, Möbel, Papier & 2,87 & 6 \\
\hline Baumaterialien & 2,05 & 7 \\
\hline
\end{tabular}

Jedoch sind gewisse Vorbehalte gegenüber der Aussagefähigkeit dieser Indikatorengruppe und der entsprechenden Rangordnung angebracht. Die Beschäftigtenzahlen sind üblicherweise als Folge der ehemaligen Planwirtschaft eher aufgebläht; die Bewertung der Aktiva als Grundlage des eingeschriebenen Stammkapitals ist wiederum fragwürdig, da die buchhalterischen Werte, und nicht die Fähigkeit, Gewinne zu erbringen im Bewertungsverfahren maßgebend waren. Ferner wurde den Preisen, zu denen bestimmte Rohstoffe im Lande zu 
erhalten sind, keine Rechnung getragen. Die o.a. Staffelung spiegelt die historische Entwicklung der rumänischen Industrie wider, die entsprechend der Marx'schen These der Priorität des 1.Sektors (Produktionsmittel) gelenkt wurde.

\section{- zweite Kategorie: Qualität der Produktionsprozesse.}

Diese Gruppe enthält Indikatoren für die materielle Effizienz des Einsatzes von Rohstoffen, Energie, Sachkapital, Arbeitskräften und für den Grad der Umweltverschmutzung:

a)Verwertungsgrad der eingesetzten Rohstoffe (Gewicht 0,2):

\section{Bruttoproduktionswert \\ Rohstoffaufwand}

b)Verwertungsgrad der eingesetzten Energie (Gewicht 0,05):

\section{Bruttoproduktionswert Verbrauchte MWh}

c)Bruttokapitalproduktivität (Gewicht 0,15 ):

\section{Bruttoproduktionswert \\ Bruttoanlagevermögen}

d)Nettokapitalproduktivität (Gewicht 0,15):

\section{Bruttoproduktionswert} Nettoanlagevermögen

e)Arbeitsproduktivität (Gewicht 0,1):

\section{Bruttoproduktionswert Beschäftigtenzahl}

f)Kapazitätauslastungsgrad (Gewicht 0,2);

g)Umweltverschmutzende Emissionen und Imissionen (Gewicht 0,15).

Für die Transformationsphase am wichtigsten sind die Kapazitätsauslastung (sie ist ein Indikator für die Chancen und Perspektiven der jeweiligen Industrie), die Rohstoffprobleme (angesichts des Verlustes der billigen Rohstoffquellen im RGW) und der Umweltschutz (der früher völlig vernachlässigt wurde (Tabellen 2.3 und 2.3.bis). 
Tabelle 2.3: Qualität der Produktionsprozesse - 1991

\begin{tabular}{|c|c|c|c|c|c|c|c|}
\hline Indikator & $\begin{array}{l}\text { Ma- } \\
\text { schi- } \\
\text { nen- } \\
\text { bau }\end{array}$ & TBI & $\begin{array}{l}\text { Holz, } \\
\text { Möbel } \\
\text { und } \\
\text { Papier }\end{array}$ & $\begin{array}{l}\text { Che- } \\
\text { mie }\end{array}$ & $\begin{array}{l}\text { Elektro- } \\
\text { technik }\end{array}$ & $\begin{array}{l}\text { Metal- } \\
\text { lurgie }\end{array}$ & $\begin{array}{l}\text { Bau- } \\
\text { mate- } \\
\text { rialien }\end{array}$ \\
\hline $\begin{array}{l}\text { a)Roh- } \\
\text { stoffverwer- } \\
\text { tung (Produk- } \\
\text { tionswert/ } \\
\text { Wert der ein- } \\
\text { gesetzten } \\
\text { Rohstoffe) }\end{array}$ & 1,90 & 5,97 & 2,39 & 1,20 & 1,51 & 1,04 & 1,61 \\
\hline $\begin{array}{l}\text { b)Energiever- } \\
\text { wertung } \\
\text { (Mio.Lei- } \\
\text { /MWh) }\end{array}$ & 29,00 & 69,54 & 15,90 & 11,00 & 49,00 & 7,25 & 9,80 \\
\hline $\begin{array}{l}\text { c)Bruttokapi- } \\
\text { talprodukti- } \\
\text { vität (Brutto- } \\
\text { produktions- } \\
\text { wert/ Wert } \\
\text { des eingesetz- } \\
\text { ten Kapitals) }\end{array}$ & 1,00 & 3,25 & 0,98 & 0,96 & 2,12 & 2,00 & 1,16 \\
\hline $\begin{array}{l}\text { d)Nettokapi- } \\
\text { talprodukti- } \\
\text { vität (Netto- } \\
\text { produktions- } \\
\text { wert/ Wert } \\
\text { des eingesetz- } \\
\text { ten Kapitals) }\end{array}$ & 0,68 & 1,77 & 1,29 & 0,80 & 1,36 & 1,75 & 0,53 \\
\hline $\begin{array}{l}\text { e)Arbeitspro- } \\
\text { duktivität } \\
\text { (Tsd.Lei/- } \\
\text { Besch.) }\end{array}$ & 184 & 161 & 129 & 383 & 183 & 300 & 155 \\
\hline $\begin{array}{l}\text { f)Kapazitäts- } \\
\text { auslastung } \\
(\%)\end{array}$ & 71,30 & 73,40 & 71,60 & 48,18 & 66,71 & 54,14 & 55,00 \\
\hline $\begin{array}{l}\text { g)Umweltver- } \\
\text { schmutzung } \\
\text { (Tsd.to) }\end{array}$ & 777 & 95,4 & 4608 & 1196 & 97,82 & 5754 & 1420 \\
\hline
\end{tabular}


Tabelle 2.3.bis: Qualität der Produktionsprozesse - Noten

\begin{tabular}{||c|c|c|c|c|c|c|c||}
\hline Ind. & $\begin{array}{l}\text { Ma- } \\
\text { schi- } \\
\text { nen- } \\
\text { bau }\end{array}$ & TBI & $\begin{array}{l}\text { Holz, } \\
\text { Mö- } \\
\text { bel, } \\
\text { Papier }\end{array}$ & $\begin{array}{l}\text { Che- } \\
\text { mie }\end{array}$ & $\begin{array}{l}\text { Elektro- } \\
\text { technik }\end{array}$ & $\begin{array}{l}\text { Metal- } \\
\text { lurgie }\end{array}$ & $\begin{array}{l}\text { Bau- } \\
\text { mate- } \\
\text { rialien }\end{array}$ \\
\hline a) & 1,83 & 5,74 & 2,30 & 1,15 & 1,45 & 1 & 1,55 \\
\hline b) & 4,00 & 9,59 & 2,19 & 1,52 & 6,75 & 1 & 1,35 \\
\hline c) & 1,04 & 3,38 & 1,02 & 1 & 2,21 & 2,08 & 1,21 \\
\hline d) & 1,28 & 3,34 & 2,43 & 1,51 & 2,57 & 3,30 & 1 \\
\hline e) & 1,43 & 1,25 & 1 & 2,97 & 1,42 & 2,33 & 1,20 \\
\hline f) & 1,48 & 1,52 & 1,49 & 1 & 1,38 & 1,12 & 1,14 \\
\hline g) & 7,41 & 60,3 & 1,25 & 4,81 & 58,8 & 1 & 4,05 \\
\hline $\begin{array}{l}\text { Ergeb- } \\
\text { nis }\end{array}$ & 2,46 & 12,1 & 1,67 & 1,90 & 10,58 & 1,66 & 1,66 \\
\hline
\end{tabular}

Bei den Kriterien der Qualität der Produktionsprozesse, mit Druck auf der Effizienz der Verwertung der eingesetzten Produktionsfaktoren, schneiden die Industrien mit höherem Veredelungsgrad und, implizite, höherem technischen Niveau, am besten ab. Es sind, in dieser Rangfolge, die TBI, die Elektrotechnik und der Maschinenbau. Diese sind auch, in derselben Rangfolge, die am wenigsten umweltschädlichen Industrien.

Tabelle 2.4: Staffelung nach der Qualität der Produktionsprozesse

\begin{tabular}{||l|l|c||}
\hline \multicolumn{1}{|c|}{ Industrie } & Note & Rang \\
\hline TBI & 12,11 & 1 \\
\hline Elektrotechnik & 10,58 & 2 \\
\hline Maschinenbau & 2,46 & 3 \\
\hline Chemie & 1,90 & 4 \\
\hline Holz, Möbel, Papier & 1,67 & 5 \\
\hline Metallurgie & 1,66 & $6 / 7$ \\
\hline Baumaterialien & 1,66 & $6 / 7$ \\
\hline
\end{tabular}


- dritte Kategorie: Die geldmäßige Effizienz der Produktionsprozesse.

Diese Gruppe enthält nur zwei Indikatoren, die als gleichbedeutend (Gewicht jeweils 0,5 ) beurteilt wurden:

a)Nettogewinnquote:

\section{Nettogewinne \\ $\overline{\text { Bruttoproduktionswert }}$}

b)Wertschöpfungsquote:

\section{Bruttowertschöpfung \\ Bruttoproduktionswert}

Der erste Indikator ist aus betriebswirtschaftlicher, der zweite aus volkswirtschaftlicher Sicht wichtiger.

Tabelle 2.5: Geldmäßige Effizienz der Produktionsprozesse

\begin{tabular}{||l|c|c|c|c|c|c|c||}
\hline \hline Indikator & $\begin{array}{l}\text { Ma- } \\
\text { schi- } \\
\text { nen- } \\
\text { bau }\end{array}$ & TBI & $\begin{array}{l}\text { Holz, } \\
\text { Mö- } \\
\text { bel, } \\
\text { Papier }\end{array}$ & $\begin{array}{l}\text { Che- } \\
\text { mie }\end{array}$ & $\begin{array}{l}\text { Elektro- } \\
\text { technik }\end{array}$ & $\begin{array}{l}\text { Metal- } \\
\text { lurgie }\end{array}$ & $\begin{array}{l}\text { Bau- } \\
\text { mate- } \\
\text { rialien }\end{array}$ \\
\hline $\begin{array}{l}\text { a)Nettoge- } \\
\text { winnquote } \\
\text { (\%) }\end{array}$ & 0,5 & 10,3 & 2,0 & 2,2 & 5,0 & 3,2 & 4,3 \\
\hline $\begin{array}{l}\text { b)Wertschöp- } \\
\text { fungsquote } \\
(\%)\end{array}$ & 30,0 & 41,3 & 44,8 & 20,9 & 37,0 & 17,5 & 39,0 \\
\hline
\end{tabular}

Die finanzielle Analyse (die Tabellen 2.5 und 2.5.bis) ergibt ein Bild, das die Umwälzungen, die Unausgewogenheiten und den Kampf um die Marktmacht in der heutigen rumänischen Industrie widerspiegelt. Auch sind der vorhin genannte Preisdruck bei Rohstoffen und Energie, die sinkende Kaufkraft der Bevölkerung und das geringe Investitionspotential der Unternehmen dafür verantwortlich, daß der Maschinenbau und die Chemie solche kleine Gewinnquoten ausweisen. Dagegen überrascht wiederum die TBI durch ihre - verhältnismäßig gesunde Lage. 
Tabelle 2.5.bis: Geldmäßige Effizienz - Noten

\begin{tabular}{||c|c|c|c|c|c|c|c||}
\hline \hline Ind. & $\begin{array}{l}\text { Maschi- } \\
\text { nenbau }\end{array}$ & TBI & $\begin{array}{l}\text { Holz, } \\
\text { Möbel, } \\
\text { Papier }\end{array}$ & Chemie & $\begin{array}{l}\text { Elektro- } \\
\text { technik }\end{array}$ & $\begin{array}{l}\text { Metal- } \\
\text { lurgie }\end{array}$ & $\begin{array}{l}\text { Bau- } \\
\text { mate- } \\
\text { rialien }\end{array}$ \\
\hline a) & 1 & 20,6 & 4,0 & 4,4 & 10,0 & 6,4 & 8,6 \\
\hline b) & 1,71 & 2,36 & 2,56 & 1,19 & 2,11 & 1 & 2,23 \\
\hline $\begin{array}{l}\text { Ergeb- } \\
\text { nis }\end{array}$ & 2,71 & 22,36 & 6,56 & 5,59 & 12,11 & 7,4 & 10,83 \\
\hline
\end{tabular}

Tabelle 2.6: Staffelung nach Finanzindikatoren

\begin{tabular}{||l|c|c||}
\hline \multicolumn{1}{|c|}{ Industrie } & Note & Rang \\
\hline TBI & 22,36 & 1 \\
\hline Elektrotechnik & 12,11 & 2 \\
\hline Baumaterialien & 10,83 & 3 \\
\hline Metallurgie & 7,40 & 4 \\
\hline Holz, Möbel, Papier & 6,56 & 5 \\
\hline Chemie & 5,59 & 6 \\
\hline Maschinenbau & 2,71 & 7 \\
\hline
\end{tabular}

- vierte und letzte Gruppe: Die Indikatoren des Gewichts innerhalb der rumänischen Volkswirtschaft und der Wettbewerbsfähigkeit im Außenhandel.

Es sind, einerseits, die Anteile jeder Industrie in der Summe der Umsätze, der Exporte und der Bruttowertschöpfungen der Volkswirtschaft, und, andererseits, der Rang jeder Industrie auf der Skala der Verflechtungsgrade mit den anderen Branchen und auf der Skala der gleichmäßigeren Verteilung im Landesgebiet. Die Industrie mit dem höchsten Konzentrationsgrad wurde mit 1 , die mit dem niedrigsten mit 7 notiert (Tabellen 2.7, 2.7.bis und 2.8). 
Tabelle 2.7: Gewicht innerhalb der rumänischen Volkswirtschaft und Wettbewerbsfähigkeit im Außenhandel

\begin{tabular}{||l|c|c|c|c|c|c|c||}
\hline Indikator & $\begin{array}{l}\text { Ma- } \\
\text { schi- } \\
\text { nen- } \\
\text { bau }\end{array}$ & TBI & $\begin{array}{l}\text { Holz, } \\
\text { Mö- } \\
\text { bel, } \\
\text { Papier }\end{array}$ & $\begin{array}{l}\text { Che- } \\
\text { mie }\end{array}$ & $\begin{array}{l}\text { Elektro- } \\
\text { technik }\end{array}$ & $\begin{array}{l}\text { Metal- } \\
\text { lurgie }\end{array}$ & $\begin{array}{l}\text { Bau- } \\
\text { mate- } \\
\text { rialien }\end{array}$ \\
\hline $\begin{array}{l}\text { a)Anteil an } \\
\text { den Umsätzen } \\
\text { (\%) }\end{array}$ & 8,59 & 5,60 & 1,82 & 8,61 & 3,06 & 6,73 & 2,57 \\
\hline $\begin{array}{l}\text { b)Anteil an } \\
\text { den Exporten } \\
\text { (\%) }\end{array}$ & 21,32 & 11,44 & 12,86 & 21,42 & 1,80 & 15,38 & 3,84 \\
\hline $\begin{array}{l}\text { c)Anteil an } \\
\text { der Wert- } \\
\text { schöpfung } \\
\text { (\%) }\end{array}$ & 6,43 & 5,00 & 1,66 & 4,40 & 2,73 & 4,17 & 2,06 \\
\hline
\end{tabular}

Tabelle 2.7.bis: Gewicht innerhalb der rumänischen Volkswirtschaft und Wettbewerbsfähigkeit im Außenhandel - Noten

\begin{tabular}{||c|c|c|c|c|c|c|c||}
\hline Indikator & $\begin{array}{l}\text { Ma- } \\
\text { schi- } \\
\text { nen- } \\
\text { bau }\end{array}$ & TBI & $\begin{array}{l}\text { Holz, } \\
\text { Mö- } \\
\text { bel, } \\
\text { Papier }\end{array}$ & $\begin{array}{l}\text { Che- } \\
\text { mie }\end{array}$ & $\begin{array}{l}\text { Elektro- } \\
\text { technik }\end{array}$ & $\begin{array}{l}\text { Metal- } \\
\text { lurgie }\end{array}$ & $\begin{array}{l}\text { Bau- } \\
\text { mate- } \\
\text { rialien }\end{array}$ \\
\hline a) & 4,72 & 3,08 & 1 & 4,73 & 1,68 & 3,70 & 1,41 \\
\hline b) & 11,84 & 6,36 & 7,14 & 11,90 & 1 & 8,54 & 2,13 \\
\hline c) & 3,87 & 3,01 & 1 & 2,65 & 1,64 & 2,51 & 1,24 \\
\hline $\begin{array}{l}\text { d)Verflech- } \\
\text { tungsgrad mit } \\
\text { anderen } \\
\text { Zweigen }\end{array}$ & 6 & 2 & 1 & 7 & 4 & 5 & 3 \\
\hline $\begin{array}{l}\text { e)Regional- } \\
\text { verteilung }\end{array}$ & 5 & 7 & 4 & 2 & 6 & 1 & 3 \\
\hline Ergebnis & 7,68 & 4,55 & 3,76 & 7,36 & 2,30 & 5,39 & 2,14 \\
\hline
\end{tabular}


Dabei waren die Gewichte der jeweiligen Indikatoren:

$$
\begin{aligned}
& \text { a }-0,1 \\
& \text { b }-0,4 \\
& \text { c }-0,2 \\
& \text { d }-0,2 \\
& \text { e }-0,1
\end{aligned}
$$

Bei dieser Gruppe von Indikatoren war der größte Druck auf die Exportfähigkeit aufgrund der Tatsache, daß für die Modernisierungsprozesse, die im Rahmen der Umstrukturierung stattfinden sollen, und für die angestrebte freie Konvertibilität der rumänischen Währung ein wichtiges Exportpotential benötigt wird. Gemäß der letzten Art von Kriterien ist die Rangordnung der Industrien die folgende (Tabelle 2.8):

Tabelle 2.8: Staffelung nach Wettbewerbsfähigkeit im Außenhandel und Gewicht innerhalb der Volkswirtschaft

\begin{tabular}{||l|c|c||}
\hline \multicolumn{1}{|c|}{ Industrie } & Note & Rang \\
\hline Maschinenbau & 7,68 & 1 \\
\hline Chemie & 7,36 & 2 \\
\hline Metallurgie & 5,39 & 3 \\
\hline TBI & 4,55 & 4 \\
\hline Holz, Möbel, Papier & 3,76 & 5 \\
\hline Elektrotechnik & 2,30 & 6 \\
\hline Baumaterialien & 2,14 & 7 \\
\hline
\end{tabular}

Gewichtet man jetzt die Kriteriengruppen wie folgt:

- Faktorausstattung: 0,3

- Qualität der Produktionsprozesse: 0,2

- Geldmäßige Effizienz: 0,35

- Wettbewerbsfähigkeit und Gewicht: 0,15

und addiert man die somit gewichteten Noten jeder Industrie (die Noten sind durchaus addierbar, da sie relative Verhältnisse zwischen denselben Charakteristika der Industrien widerspiegeln, und keine absolute Größen), ergibt sich die folgende allgemeine Rangordnung, die als Prioritätsliste für die Struktur- und Industriepolitik im Rahmen der wirtschaftlichen Reform denkbar wäre (Tabelle 2.9): 
Tabelle 2.9: Allgemeine Rangordnung

\begin{tabular}{||l|c|c|}
\hline \multicolumn{1}{|c|}{ Industrie } & Note & Rang \\
\hline TBI & 11,82 & 1 \\
\hline Elektrotechnik & 7,74 & 2 \\
\hline Baumaterialien & 5,06 & 3 \\
\hline Metallurgie & 4,81 & 4 \\
\hline Chemie & 4,66 & 5 \\
\hline Maschinenbau & 4,31 & 6 \\
\hline Holz, Möbel, Papier & 4,06 & 7 \\
\hline
\end{tabular}

Selbst wenn diese Gewichtung zugunsten der geldmäßigen Effizienz aufgegeben wird, schneidet die Textil- und Bekleidungsindustrie auch ohne Gewichtung am besten ab (Tabelle 2.10):

Tabelle 2.10: Allgemeine Rangordnung ohne Gewichtung

\begin{tabular}{||l|c|c||}
\hline \multicolumn{1}{|c|}{ Industrie } & Note & Rang \\
\hline TBI & 41,99 & 1 \\
\hline Elektrotechnik & 28,46 & 2 \\
\hline Chemie & 18,92 & 3 \\
\hline Maschinenbau & 18,57 & 4 \\
\hline Metallurgie & 18,03 & 5 \\
\hline Baumaterialien & 16,68 & 6 \\
\hline Holz, Möbel, Papier & 14,86 & 7 \\
\hline
\end{tabular}

Es gibt also sehr gute Gründe um zu behaupten, die Textil- und Bekleidungsindustrie, gefolgt von der Elektrotechnik habe auf längere Sicht gute Entwicklungsperspektiven. Ein gutes Funktionieren der TBI während der Transformationsphase würde zweifelsohne einen wichtigen Beitrag zur Einhaltung des Gleichgewichts der Außenhandelsbilanz leisten (Schon Ende 1992 bestanden 40,2\% der EG-Importe aus Rumänien aus Textilien, Bekleidung und Schuhen). Der arbeitsintensive Charakter der Bekleidungsindustrie kann auch einen Anreiz für die Produktionsverlagerung aus den Industrieländern bieten. Dadurch würden neue Arbeitsplätze 
geschaffen, die die von den anderen Industrien freigesetzten Arbeitskräfte absorbieren würden. Eine Struktur- und Industriepolitik der Regierungen der kommenden Jahre, ohne die TBI prioritär zu berücksichtigen, wäre also ganz verfehlt.

\subsection{Stärken - Schwächen Analyse der rumänischen Textil- und Bekleidungsindustrie}

\subsubsection{Internationales Umfeld}

\subsubsection{Der Weltmarkt für Textilien, Bekleidung und Lederware}

Der Weltmarkt für Textilien, Bekleidung und Lederware ist ein Markt mit großen Absatzproblemen, gekennzeichnet durch hohe Wettbewerbsintensität und zahlreiche Beschränkungen des freien Handels. Es ist ein Markt für reife Produkte, der sich in den 70er und 80er Jahren unterdurchschnittlich entwickelt hat.

Die Nachfrage nach Textilien und Bekleidung hat sich weltweit schwächer entwickelt als der Absatz anderer Industrieerzeugnisse. In den Ländern der dritten Welt stieg sie im Durchschnitt zwar stärker als die Ausgaben für den privaten Verbrauch, aber in den Industrieländern wuchs sie unterproportional. Die Weltproduktion von Textilien stieg zwischen 1970 und 1986 um durchschnittlich 1,9\% jährlich an, während bei der gesamten Industrieproduktion die Wachstumsquote jährlich 3,4\% betrug (siehe VIEHWEG, 1989, S.16). Dieser Unterschied ist darauf zurückzuführen, daß in den Industrieländern, die nach wie vor den größten Teil der Produktion und des Welthandels mit Textilien und Bekleidung betreiben (1985 lieferten sie $64,7 \%$ der auf dem Weltmarkt umgesetzten Textilien und 43,6\% der Bekleidung), die Einkommenselastizität solcher Produkte kleiner eins ist. Somit sind in den Industrieländern Textilien und Bekleidung im allgemeinen inferiore Güter.

Hinzu kommt auch, daß die internationale Wettbewerbsintensität wegen des Marktzutritts immer neuer Anbieter aus Entwicklungsländern stets zugenommen hat. Andererseits hat der Zusammenbruch der Sowjetunion auch den Verlust eines bedeutenden Absatzmarktes, insbesondere für die ehemaligen RGW-Länder, verursacht.

Die wichtigsten Importeure von Textilien und Bekleidung sind in der Tabelle 2.11 angegeben: 
Tabelle 2.11: Die wichtigsten 10 Importeure von Textilien und Bekleidung im Jahr 1991

\begin{tabular}{||lc|lc||}
\hline \multicolumn{2}{|c|}{ Textilien } & Mrd.US-\$ & \multicolumn{3}{c||}{ Land } & Mrd.US-\$ \\
\hline BRDeutschland & 12,112 & USA & 27,699 \\
\hline Hong Kong & 12,102 & BRDeutschland & 24,051 \\
\hline USA & 7,339 & Japan & 9,396 \\
\hline Frankreich & 7,083 & Frankreich & 8,828 \\
\hline Großbritanien & 6,605 & Hong Kong & 8,579 \\
\hline Italien & 5,737 & Großbritanien & 7,296 \\
\hline Japan & 4,327 & Niederlande & 5,239 \\
\hline Belgien & 3,558 & Belgien & 3,835 \\
\hline Niederlande & 3,533 & Schweiz & 3,545 \\
\hline VR China & 3,369 & Italien & 3,418 \\
\hline
\end{tabular}

(Quelle: Jahrbuch der Textilindustrie, Gesamttextil, 1993)

Den größten Anteil an den Textilimporten der Welt hat die Europäische Wirtschaftsgemeinschaft, die also der wichtigste Kunde für Textil- und Bekleidungserzeugnisse in der Welt ist.

\subsubsection{Anbieter und Angebotsbedingungen in der Welttextilwirtschaft}

Bemerkenswert ist die Tatsache daß, insbesondere bei Textilien, die wichtigsten Exporteure fast dieselben sind wie die wichtigsten Importeure - mit einigen nennenswerten Ausnahmen: Taiwan und Südkorea (Tabelle 2.12).

Basierend auf den komparativen Lohnkostenvorteilen der Länder der Dritten Welt, auf derer Rohstoffbasis, auf der staatlichen Förderung des Textil- und Bekleidungssektors sowie auf der Entwicklung von weltumspannenden Informations-, Beschaffungs- und Absatzstrategien, haben sich in den letzten Jahrzehnten erhebliche Verschiebungen in der Struktur der Anbieterländer vollzogen (siehe BREITENACHER, 1992, S.73). Immer wieder treten neue TBIAnbieter auf dem Weltmarkt auf. Ständig neue Produktionszentren sind insbesondere in Ostasien aufgetaucht. Aber auch innerhalb dieses Gebietes fanden deutliche Verschiebungen der Investitionsschwerpunkte statt. Hong Kong übernahm in den 60er Jahren die führende Rolle von Japan. Danach bauten Südkorea, Taiwan und Singapur rasch ihre Kapazitäten aus, 
Tabelle 2.12: Die wichtigsten 10 Exporteure von Textilien und Bekleidung im Jahr 1991

\begin{tabular}{|c|c|c|c|}
\hline \multicolumn{2}{|c|}{ Textilien } & \multicolumn{2}{|c|}{ Bekleidung } \\
\hline$\underline{\text { Land }}$ & Mrd.US-\$ & $\underline{\text { Land }}$ & Mrd.US-\$ \\
\hline BR Deutschland & 13,197 & Hong Kong & 17,960 \\
\hline Hong Kong & 9,793 & Italien & 11,752 \\
\hline Italien & 9,386 & VR China & 8,999 \\
\hline VR China & 7,734 & BR Deutschland & 7,490 \\
\hline Südkorea & 7,296 & Südkorea & 7,418 \\
\hline Taiwan & 7,030 & Frankreich & 4,772 \\
\hline Japan & 6,524 & Taiwan & 4,307 \\
\hline Belgien & 6,336 & Portugal & 3,597 \\
\hline Frankreich & 5,815 & Türkei & 3,478 \\
\hline USA & 5,457 & Großbritanien & 3,393 \\
\hline
\end{tabular}

(Quelle: Jahrbuch der Textilindustrie, Gesamttextil, 1993)

gefolgt von Malaysia, den Philipinnen, Indonesien, Thailand und der VR China. Die nächste Welle wird wahrscheinlich von Vietnam, Kambodscha und Laos ausgehen.

Nicht nur Ostasien wies eine bemerkenswerte Entwicklung der Textil- und Bekleidungsproduktion auf, sondern auch einige Mittelmeerländer, vor allem Portugal und die Türkei, die bereits auf die Stelle des 8. bzw. 9. Exporteurs der Welt gestiegen sind.

Den anderen traditionell wichtigen Zentren der Textil- und Bekleidungsproduktion, Indien, Pakistan und Lateinamerika gelang es überhaupt nicht, mit dieser stürmischen Entwicklung Schritt zu halten. In Lateinamerika hat die Verschuldungsproblematik die Lage der TBI erheblich erschwert (siehe ebenfalls BREITENACHER, 1992, S.74).

In den Staatshandelsländern hat sich die TBI auch extensiv entwickelt, insbesondere aus den im Paragraphen 2.1 angegebenen Gründen. "Nach groben Schätzungen dürfte derzeit etwa ein Drittel sämtlicher in der Welt produzierten Textilien in Staatshandelsländern gefertigt werden; für Bekleidung könnte der entsprechende Anteilswert noch höher liegen, insbesondere wenn man sich die rasante Produktionsentwicklung in Chinas Bekleidungsindustrie vergegenwärtigt (BREITENACHER, 1989, S.69 - bezogen auf 1989). 
In der Produktion der marktwirtschaftlichen Länder erhöhte sich in den letzten 20 Jahren der Anteil der Entwicklungsländer auf ca.40\% bei Textilien und ca. $50 \%$ bei Bekleidung. Dabei haben die lateinamerikanische, nordamerikanische und westeuropäische TBI an Bedeutung verloren. Trotzdem besteht nach wie vor der größte Teil der TBI-Kapazitäten in diesen Regionen.

Von 1973 bis 1985 wuchsen die Anteile der Entwicklungsländer auf dem Weltmarkt für Textilien und Bekleidung kontinuierlich. Dies erscheint umso bemerkenswerter, als in diesem Zeitraum die mengenmäßigen Beschränkungen gegen Importe aus Entwicklungsländern zugenommen haben. Allerdings haben sich in den letzten Jahren beide Tendenzen infolge der Wiedererstärkung der Wettbewerbsfähigkeit der TBI in den Industrieländern abgeschwächt. Es ist das Ergebnis der Anpassungsprozesse, die sich in den 80er Jahren insbesondere in Westeuropa und Japan vollzogen haben: der Übergang zu neuen, modischen Produkten, breiteren Angebotspaletten, neuen Marketingkonzepten, flexibleren Fabrikationsverfahren, kleineren Losgrößen (was wiederum die Produktionskosten nach oben treibt), hochwertigen Stoffen, größeren Anteilen der Industrietextilien (Produkte mit hohem Forschungsanteil).

In den letzten zwei Jahrzehnten konnten die Entwicklungsländer vor allem bei Bekleidung ihre Handelsbilanz gegenüber den Industrieländern verbessern. Ihr Handelsüberschuß hat sich in diesem Bereich stets erhöht. Dagegen weisen die Industrieländer im Textilbereich einen (kleineren) Überschuß im Handel mit den Entwicklungsländern aus (Quelle: BREITENACHER, 1992, S.77). Zwei Ursachen sind dafür zu nennen:

- Viele Entwicklungsländer versuchen, statt Textilien (Garne und Gewebe), eher Fertigprodukte (Bekleidung, Strick- und Wirkwaren) zu exportieren. Ihre Textilindustrien wurden deswegen in die Rolle des Zulieferers gedrängt; sodann wuchsen die Textilexporte dieser Länder schwächer als ihre Bekleidungsexporte;

- Die Textiltechnologie erzielte in den Industrieländern in den 80er Jahren bemerkenswerte Erfolge; die Produktivität und Qualität ihrer Textilproduktion und dadurch auch ihre Wettbewerbsfähigkeit erhöhten sich; ihre Textilimporte wurden auf "freier marktwirtschaftlicher Weise" gebremst.

Für die vorhin beschriebenen Verlagerungstendenzen gilt ein allgemeines Schema: Die Standortverlagerung der lohnintensiven Bekleidungsproduktion in die Entwicklungs- und Schwellenländer fing schon in den 50er Jahren an. Die Verlagerung der Textilienproduktion fing später (etwa Anfang der 60er Jahre) an, aber bei weitem nicht so stark wie bei der Bekleidung. Schließlich wurde die Produktion von Chemiefasern - eine äußerst kapitalintensive Branche - im Rahmen der "großen" Industrialisierung in den Entwicklungs- und Schwellenländern aufgebaut. Die Erhöhung der Fertigungstiefe fand also in der TBI dieser Länder rückwärts statt. Die Versorgung der heimischen Bekleidungsindustrie mit Geweben und Garnen in besseren Bedingungen und, somit, die Erhöhung der Wettbewerbsfähigkeit der 
gesamten "Textilpipeline" waren damit angestrebt. Als Ergebnis produzierten die Entwicklungs- und Schwellenländer 1990 ca. 50\% der Bekleidung, ca. $40 \%$ der Baumwoll- und Wollgewebe und Baumwollgarne und 35\% der Chemiefasern der Welt (ohne die ehemaligen RGW-Länder).

\subsubsection{Tarifäre und nichttarifäre Hemmnisse für die Textil- und Bekleidungsexporte}

Wegen des starken Wettbewerbs, der den Weltmarkt für Textil- und Bekleidungsprodukte kennzeichnet, sind die meisten nationalen Märkte gegen die ausländische Konkurrenz entweder durch hohe Zölle (z.B. USA: 72\%-90\% bei Textilien und Bekleidung, 25\%-30\% bei Schuhen, $35 \%-50 \%$ bei Lederwaren) oder durch mengenmäßige Beschränkungen abgeschirmt. Rumänien wurde in die Kategorie der Entwicklungsländer eingestuft und ist dadurch ein Genießer des Allgemeinen Präferenzsystems (APS). Aber bei den Textil- und Bekleidungsprodukten gelten besondere Regelungen, die unter das Welttextilabkommen (WTA) fallen. Im Rahmen des GATT wurde dieses Welttextilabkommen von den Industrieländern durchgesetzt, mit der Begründung, die Anpassung ihrer Textil- und Bekleidungsindustrien zu dem immer stärker werdenden Wettbewerb aus Billiglohnländern bräuche Zeit. Sodann verpflichteten sich alle Staatshandelsländer und ein großer Teil von den Entwicklungs- und Schwellenländern im Rahmen von Selbstbeschränkungsabkommen jeweils gegenüber der EWG, Japan, Kanada und den USA, das Wachstum ihrer Ausfuhren in die Industrieländer für verschiedene Warengruppen auf bestimmte durchschnittliche Zuwachsraten zu beschränken. Dem vereinbarten Mengenzuwachs lagen gewisse Überlegungen hinsichtlich der zu erwartenden Nachfrageentwicklung in den Industrieländern zugrunde (siehe BREITENACHER, 1989, S.90).

Im Durchschnitt betrug die Steigerungsrate für Textil- und Bekleidungsprodukte in die Europäische Gemeinschaft in der Laufzeit des WTA IV (Mitte 1986 bis Mitte 1991) etwa $3 \%$ jährlich. Da die wichtigsten Kunden der osteuropäischen TBI die EG-Länder, gefolgt von den osteuropäischen Ländern selbst und von Nordamerika sind, waren die Regelungen des WTA natürlich von kardinaler Bedeutung für die Expansion der Textil- und Bekleidungsexporte dieser Länder.

Immerhin haben sich nach der Liberalisierung der politischen Verhältnisse in den ehemaligen RGW-Ländern auch die Bedingungen des Zugangs ihrer Textil- und Bekleidungserzeugnisse auf die westlichen Märkte einigermaßen verbessert. Der erste Schritt der neuen Handelspolitik der EG gegenüber Osteuropa (BÖHNLEIN \& HEITGER, 1991, S.130-133) war 1989 die Aufhebung der nichttarifären Hemmnisse für polnische und ungarische Importe für das Jahr 1990, obwohl diese Restriktionen in Spanien und Portugal weiterhin bestanden. Diese Maßnahme wurde 1990 auch für das Jahr 1991 getroffen, wobei auch Bulgarien, Rumänien 
und die Tschechoslowakei davon profitierten. Allerdings blieb für die EG bei den Textilimporten eine Hintertür offen: Falls die osteuropäischen Einfuhren wirtschaftliche Schwierigkeiten in den EG-Staaten verursachen würden, könnten die nicht-tarifären Hemmnisse sofort wiedereingeführt werden.

Diese Aufhebung mit vorübergehendem Charakter wurde von der Unterzeichnung der Assoziationsverträge Polens, Ungarns, Rumäniens, Bulgariens und der Tschechoslowakei gefolgt. Nunmehr gibt es einen institutionalisierten Rahmen für die gegenseitige Aufhebung der tarifären und nicht-tarifären Hemmnisse. Die Verträge sehen hauptsächlich die stufenweise Einführung des freien Warenverkehrs vor, mit der Errichtung einer Freihandelszone innerhalb von zehn Jahren (DIW, Nr. 50/1991, S.701-704 und RUDNITCHI, 1993). Die EG verpflichtet sich dafür, größere und schnellere Schritte zu machen, indem sie im Bereich der Importe von Industriegütern - mit der Ausnahme von Textilien, Stahl und Kohle - die noch bestehenden Mengenbeschränkungen sofort aufhebt und alle Zölle innerhalb von fünf Jahren stufenweise abbauen wird. Bei Textilien und Stahl werden die Mengenbeschränkungen zuerst beibehalten, aber die Quoten sukzessive erhöht und die Zölle reduziert. Dieser Bereich soll auch spätestens in sechs Jahren für die Zölle und in fünf Jahren für die Mengenbeschränkungen liberalisiert werden.

Dagegen stehen den assoziierten Länder längere Fristen zur Verfügung (maximal 10 Jahre), um in kleineren Schritten die Liberalisierung durchzuführen. Diese Partnerländer haben also nur vier bis fünf Jahre mehr Zeit, bevor sie ihre Märkte den EG-Produkten völlig öffnen müssen. Bezüglich des schwierigen Prozesses der Anpassung dieser Volkswirtschaften an die marktwirtschaftlichen Regeln und des Anschlusses an das westliche Technologieniveau, den diese Länder vor sich haben, ist diese Frist nicht sehr lang, insbesondere wenn man berücksichtigt, daß den Industrieländern der Prozeß der Anpassung ihrer Textil- und Bekleidungsindustrien an die veränderten internationalen Wettbewerbsverhältnisse in 30 Jahren noch nicht völlig gelungen ist, so daß sie immer noch auf Einfuhrbeschränkungen angewiesen sind. Der Textiliensektor war bei den Verhandlungen für diese Assoziationsverträge der schwierigste Punkt, der nur dadurch geklärt wurde, daß Griechenland und Portugal zusätzliche EG-Hilfe zur Strukturanpassung zugesagt wurde.

Die Zugeständnisse der EG hätten nämlich deswegen großzügiger sein können (z.B. die sofortige Abschaffung der Einfuhrquoten), da für die Partnerländer Agrarprodukte, Textilien, Stahl sowie Kohle fast die Hälfte ihrer Lieferungen in die EG ausmachen (also für sie sehr wichtig sind), während der Anteil dieser Länder an den EG-Einfuhren dieser Waren nur etwa $2 \%$ beträgt (für die EG also eine Bagatelle ist).

Das Ausmaß der Vergünstigungen wird auch durch die beibehaltene sogenannte Rettungsklausel eingeschränkt, die den EG-Ländern die Möglichkeit gewährt, über Preisregelungen 
ihre Märkte vor preisgünstigeren Angeboten zu schützen. Somit scheint die Liberalisierung des Handels unter den Assoziationsverträgen viel weniger effektiv zu sein, als anfangs versprochen (ROLLO \& SMITH, 1993, S.174).

Immerhin bedeuten diese Verträge einen wichtigen Wettbewerbsvorteil für die fünf - mittlerweile sechs -mittel- und osteuropäischen (MOE) Länder (Polen, Ungarn, Tschechien, Slowakei, Rumänien, Bulgarien), vor allem weil die ehemaligen UdSSR-Republiken einen solchen Status noch nicht bekommen haben, und den "normalen" Regelungen des WTA für ihre Exporte in die Industrieländer unterworfen sind. Hinzu kommt auch, daß die o.g. sechs Länder Freihandelsabkommen, mit ganz ähnlichen Bestimmungen wie bei den Assoziationsverträgen, mit den EFTA-Ländern unterzeichnet haben (dies gilt für die GUS- Staaten wiederum nicht). Auch haben die Vereinigten Staaten allen ehemaligen RGW-Ländern nach 1989 die Meistbegünstigungsklausel gewährt. Dadurch genießen die osteuropäischen Länder insbesondere gegenüber ihren Konkurrenten aus Schwellenländern (die meisten Mittelmeerländern sind schon mit der EG assoziiert), aus den GUS-Staaten und der VR China, auf mittlerer Sicht einen institutionellen Vorsprung. Es ist aber nachteilig für sie, daß inzwischen neue Zollgrenzen zwischen ehemaligen RGW-Ländern entstanden sind (GASS, 1993).

\subsubsection{Rolle und Wettbewerbsvorteile der osteuropäischen Länder im Welttextilhandel}

Vor den politischen Umwälzungen im Jahre 1989 wurden die gesamten Ein- und Ausfuhren der Staatshandelsländer fast ausschließlich von staatlichen Außenhandelsunternehmen abgewickelt, die das Ein- und Ausfuhrmonopol hatten. Die Preisbildung orientierte sich nur in geringem Maße an den tatsächlichen Kosten. Man arbeitete mit Verrechnungspreisen; deswegen tauchte die Diskussion über Dumping seitens dieser Länder immer wieder auf.

Die Exportpolitik der Staatshandelsländer, gestützt auf diese von den Planbehörden fixierten Preise, war dementsprechend aggressiv. Ein gutes Beispiel dafür ist die Tabelle 2.13, die den Außenhandel der BR Deutschland mit diesen Ländern 1986 und 1987, ohne Lohnveredelung, schildert. Die entsprechenden Textilhandelsbilanzen anderer Industrieländer mit den Staatshandelsländern sehen nicht viel anders aus. Der Außenhandel war für die BRD insgesamt defizitär. Besonders augenfällig ist das Ungleichgewicht dieser Bilanz mit Rumänien, der Tschechoslowakei und der VR China.

Die Öffnung des Ostens, sowie der steigende Preisdruck auf die Unternehmen der TBI in Westeuropa haben einen tiefgreifenden Strukturwandel in der Produktion und im Handel mit Textilprodukten sowohl im Osten als auch im Westen eingeleitet und weiter gefördert. Eine zunehmende Handelsverflechtung zwischen den beiden Seiten ist entstanden und entwickelt sich weiter, obwohl überall in Europa die Zahl der Beschäftigten im Textil- und Bekleidungs- 
Tabelle 2.13: $\quad$ Außenhandel der BRD mit Staatshandelsländern, in Mio.DM, ohne passive Veredelung

\begin{tabular}{||l||c|c||c|c||}
\hline \multicolumn{1}{||c|}{ Land } & $\begin{array}{l}\text { BRD- } \\
\text { Einfuhr } \\
1986\end{array}$ & $\begin{array}{l}\text { BRD- Aus- } \\
\text { fuhr 1986 }\end{array}$ & $\begin{array}{l}\text { BRD- } \\
\text { Einfuhr } \\
1987\end{array}$ & $\begin{array}{l}\text { BRD- Aus- } \\
\text { fuhr 1987 }\end{array}$ \\
\hline \hline Bulgarien & 64,5 & 39,1 & 51,1 & 51,6 \\
\hline Polen & 82,5 & 65,1 & 75,5 & 51,9 \\
\hline Rumänien & 145,4 & 10,0 & 130,8 & 7,6 \\
\hline CSSR & 245,7 & 70,8 & 231,2 & 70,7 \\
\hline Ungarn & 81,4 & 174,0 & 85,4 & 146,5 \\
\hline UdSSR & 31,6 & 298,6 & 44,9 & 278,8 \\
\hline Jugoslawien & 830,2 & 428,8 & 889,8 & 444,0 \\
\hline China & 829,7 & 11,2 & 1132,9 & 21,6 \\
\hline \hline Total & 2311,0 & 1097,6 & 2641,6 & 1072,7 \\
\hline
\end{tabular}

(Nach Angaben von NEUNDÖRFER \& STAHR, 1989, S.74)

sektor abnimmt. Das große Lohngefälle zwischen West und Ost wird insbesondere dabei über Vergabe von Lohnfertigung von West nach Ost benutzt. In wichtigem Maße hat dazu auch der Bürgerkrieg im ehemaligen Jugoslawien beigetragen (ADAMICEK, 1991, S.154), indem die zahlreichen Verträge mit dem wichtigsten Lohnveredelungsland Europas aufgelöst und wiederum mit Unternehmen in Ungarn, der Tschechoslowakei, Polen und Slowenien geschlossen wurden. Gemäß GÄLLI (1992, S.12) sind die ersten Ausweichversuche der deutschen Textilunternehmer nach Nordafrika an ungenügender Qualität und Liefertreue gescheitert; "die kurze Entfernung zu den neu zugänglichen Nachbarn im Osten sowie ihr Preis/Leistungsangebot erwiesen sich in vielen Fällen als so überzeugend, daß auch Konkurrenten aus Fernost Zunehmend das Nachsehen haben".

Die hohe Standortunabhängigkeit der textilindustriellen Fertigung ist tatsächlich ein - für die MOE-Länder - wichtiger Vorteil dieser Branche, insbesondere bei der Bekleidungsproduktion. Und die kleinen Lohnkosten sind nicht der einzige Standortvorteil dieser Länder. Die Marktnähe zu vielen Verbrauchern in Ost und West, die Anwesenheit einer Textilmaschinenproduktion (insbesondere in Tschechien, Polen und Rumänien), die mit der TBI zur Realisierung von Produkt- und Prozessinnovationen zusammenarbeiten kann, dürften weitere Vorteile sein. BREITENACHER (1992, S.25) sieht eine der Schwächen der deutschen TBI in der geringen Auslandsfertigung. Insbesondere für solche wenig kapitalintensiven Zweige wie die 
Bekleidungs- und die Maschenindustrie wäre eine Ausweitung der Auslandsfertigung der Unternehmen aus der EG angebracht. Die damit verbundenen Vorteile wären: die Vermeidung des Risikos, das oft Direktinvestitionen in Entwicklungsländern behaftet sowie die Flexibilität der Verlagerung der Lohnveredelung im Notfall auf andere Länder, dargestellt am Beispiel Bürgerkrieg Jugoslawien.

Der Textilhandel zwischen Ost und West ist aber auch ohne die passive Lohnveredelung gestiegen. Wichtigster Grund dafür ist der Zusammenbruch der früher bevorzugten Handelsbeziehungen zwischen den RGW-Ländern und insbesondere der Verlust des riesigen sowjetischen Marktes. Als der RGW aufgelöst wurde, galten nunmehr für den Warenverkehr zwischen seinen ehemaligen Mitgliedern Weltmarktpreise in US-\$. Dies bedeutete eine Verteuerung der Waren, die sich die ehemaligen Ostblockländer am Anfang nicht leisten konnten. Und weil sie sowieso freie Währungen dafür zahlen sollten, kauften sie lieber im Westen ein.

Demzufolge mußten die osteuropäischen Textilanbieter den größten Teil ihrer früher auf die RGW-Länder gerichteten Angebote jetzt auf die westlichen Märkte und Qualitätsstandards umstellen. Dieser Prozeß ist ihnen in unterschiedlichem Maße gelungen; ihre Exporte in die OECD-Länder und insbesondere in die EG, nunmehr ihr wichtigster Handelspartner, sind immerhin gestiegen. Ein zweiter Grund könnten die ersten Liberalisierungsmaßnahmen (Absetzung der Zölle und Aufstockung der Einfuhrquoten) der EG für die Textil- und Bekleidungsimporte sein. Allerdings ist fragwürdig, inwieweit die MOE-Länder schnell genug darauf reagiert haben.

Abbildung 2.1 zeigt die Entwicklung der deutschen Einfuhren von Textilien und Bekleidung aus Osteuropa und der GUS zwischen 1989 und 1992.

Es ist bekannt (BREITENACHER, 1989, S.110 ff.) daß der wichtigste - und geöffnetste Markt der EG für Textilerzeugnisse der MOE-Länder, sozusagen ein Modellmarkt, die BR Deutschland ist. Dementsprechend bietet Abb.2.1 nicht nur ein Bild über die Dynamik der Textilexporte in die Bundesrepublik, sondern auch über den Marktanteil jedes osteuropäischen Lieferlandes.

Die wichtigsten Konkurrenten der MOE- und GUS-Länder bei ihren Bemühungen, ihre Textilexporte in die Industrieländer zu steigern, sind in erster Reihe die ostasiatischen Länder (VR China, Hong Kong, Südkorea, Taiwan, Singapur, Thailand, Malaysia, die Philipinnen und Indonesien) und einige Mittelmeerländer wie z.B. die Türkei, Marokko und Tunesien. 


\section{Abb.2.1: Deutsche Einfuhre von TBI- Produkten aus Osteuropa 1989-1992}

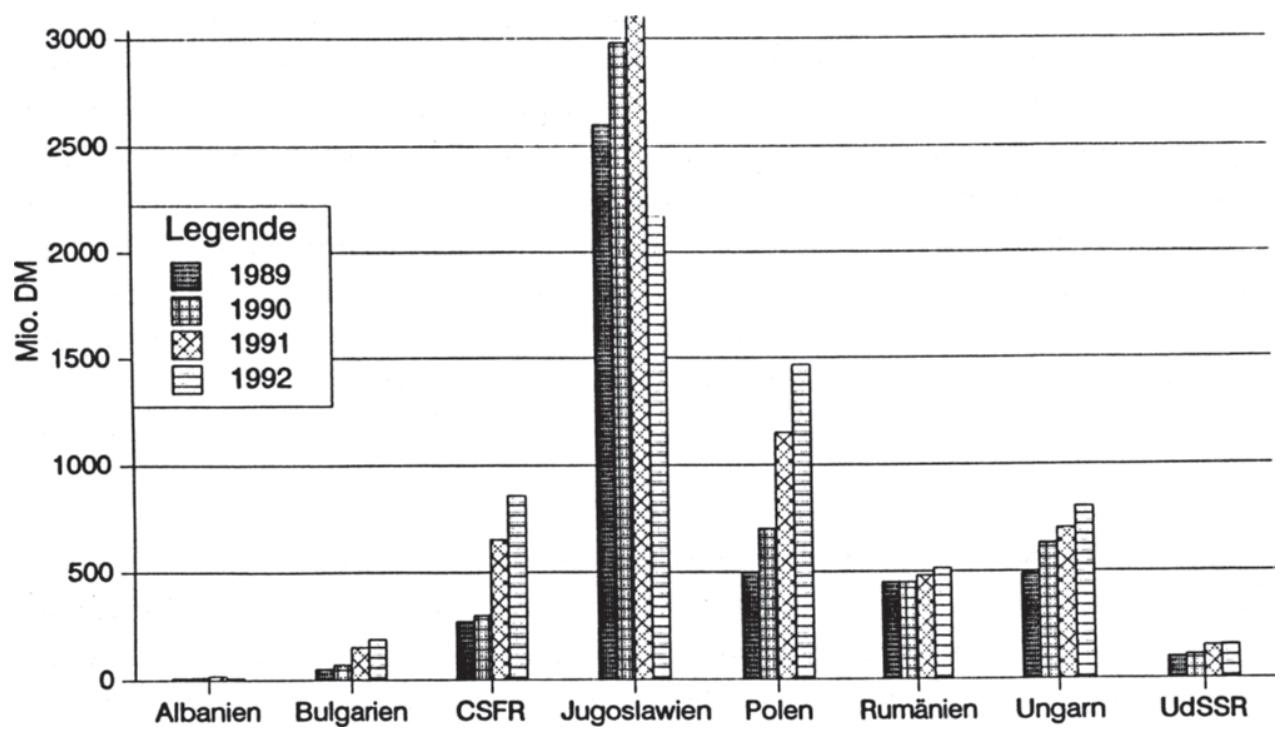

(Quelle: GÄLLI, 1992, S.25)

Die Lage der ostasiatischen Länder ist unterschiedlich. Hong Kong, Südkorea, Taiwan und Singapur gehören bereits zu den "neulich industrialisierten Volkswirtschaften" (NIV). Gemäß der Klassifizierung der Weltbank befinden sich diese Länder in der "goldenen Phase" der Entwicklung ihrer TBI, sind also, im Vergleich mit den MOE-Ländern, einen Schritt weiter. Sie haben eine technisch anspruchsvollere Textil- und Bekleidungsproduktion, mit einer sehr erfolgreichen Exporttätigkeit. Sie stellen auch wichtige Mengen von Chemiefasern her. Charakteristisch ist auch die Breite ihrer Produktpalette, wobei sie sogar einen gewissen Grad von Produktionsverlagerung ins Ausland erreicht haben (BREITENACHER, 1989, S.166 ff.).

Es gibt eine sehr interessante komparative Analyse für die Entwicklung der Exporte von drei MOE-Ländern (die Tschechoslowakei, Polen und Ungarn) und von drei NIV's -Hong Kong, Südkorea und Taiwan (HOEN \& VAN LEEUWEN, 1991). Durch Faktoranalyse wird darin gezeigt, daß in dem Zeitraum 1972-1987 der Wettbewerbsfähigkeitseffekt fast immer einen positiven Beitrag zur Erhöhung der Exporte der NIV geleistet hat, während bei den drei o.g. RGW-Ländern die Entwicklung ganz umgekehrt war. So ist im untersuchten Zeitraum die internationale Wettbewerbsfähigkeit der RGW ständig gesunken. Die Verteilung der Wett- 
bewerbsfähigkeitseffekte auf verschiedene Warengruppen zeigt dagegen, daß die Bekleidungsexporte beider Ländergruppen fast immer einen negativen Einfluß auf die Wettbewerbsfähigkeit der gesamten Exporte ausgeübt haben. Dieser negative Einfluß war bis 1984 viel kleiner für die NIV als für die drei ausgewählten RGW-Länder. Allerdings näherte sich der Einfluß der Bekleidungsexporte auf den Wettbewerbsfähigkeitseffekt beider Ländergruppen zwischen 1984 und 1987 stark an - siehe Tabelle 2.14.

Tabelle 2.14: Dynamik der Exporte, Wettbewerbsfähigkeitseffekt (Faktoranalyse) und Einfluß der Bekleidungsexporte darauf: 1972-1987.

\begin{tabular}{||l|l|l|l||}
\hline & $\begin{array}{l}\text { Wachstum der } \\
\text { Exporte (Mio.\$) }\end{array}$ & $\begin{array}{l}\text { Davon: auf den } \\
\text { Wettbewerbsfähig- } \\
\text { keitseffekt zurück- } \\
\text { zuführen (\%) }\end{array}$ & $\begin{array}{l}\text { Einfluß der Be- } \\
\text { kleidungsexporte } \\
\text { auf den Wettbe- } \\
\text { werbsfähigkeits- } \\
\text { effekt } \\
(\%)\end{array}$ \\
\hline $1972 / 1975$ & $\underline{\text { RGW NIV }}$ & $\underline{\text { RGW } \quad \underline{\text { NIV }}}$ & $\underline{\text { RGW }} \quad \underline{\text { NIV }}$ \\
\hline $1975 / 1978$ & $+942+2281$ & $+11,8 \%+55,3 \%$ & $+19 \% \quad+99,3 \%$ \\
\hline $1978 / 1981$ & $+355+2299$ & $-51,7 \%+67,7 \%$ & $-84,4 \%+70,4 \%$ \\
\hline $1981 / 1984$ & $-322-30$ & $-81,7 \%+772 \%$ & $-287 \%-11,8 \%$ \\
\hline $1984 / 1987$ & $+1499+7791$ & $-41,5 \%+18,1 \%$ & $-26,3 \%-19,8 \%$ \\
\hline
\end{tabular}

(Nach Angaben von HOEN \& VAN LEEUWEN, 1991, S.371)

Die Bekleidungsexporte der RGW-Länder haben also in der ersten Hälfte der 80er Jahre wegen der sinkenden Wettbewerbsfähigkeit stark gelitten, insbesondere weil -so BREITENACHER (1989, S.85) - "der Textil- und Bekleidungssektor dieser Länder - trotz niedriger Preise - vielfach nicht verstanden hat, sich den differenzierten und anspruchsvollen Wünschen der westlichen Verbraucher anzupassen." Allerdings, insbesondere durch die Erhöhung der Qualität und des durchschnittlichen Einheitswertes der Erzeugnisse, ist es diesen Ländern gelungen, das Wettbewerbsfähigkeitsgefälle gegenüber den NIV fast auszugleichen - siehe Abbildung 2.2. zur Entwicklung des Einheitswertes der Produkte der RGW-Länder. 
Abb.2.2: Relativer Einheitswert der Bekleidungsprodukte

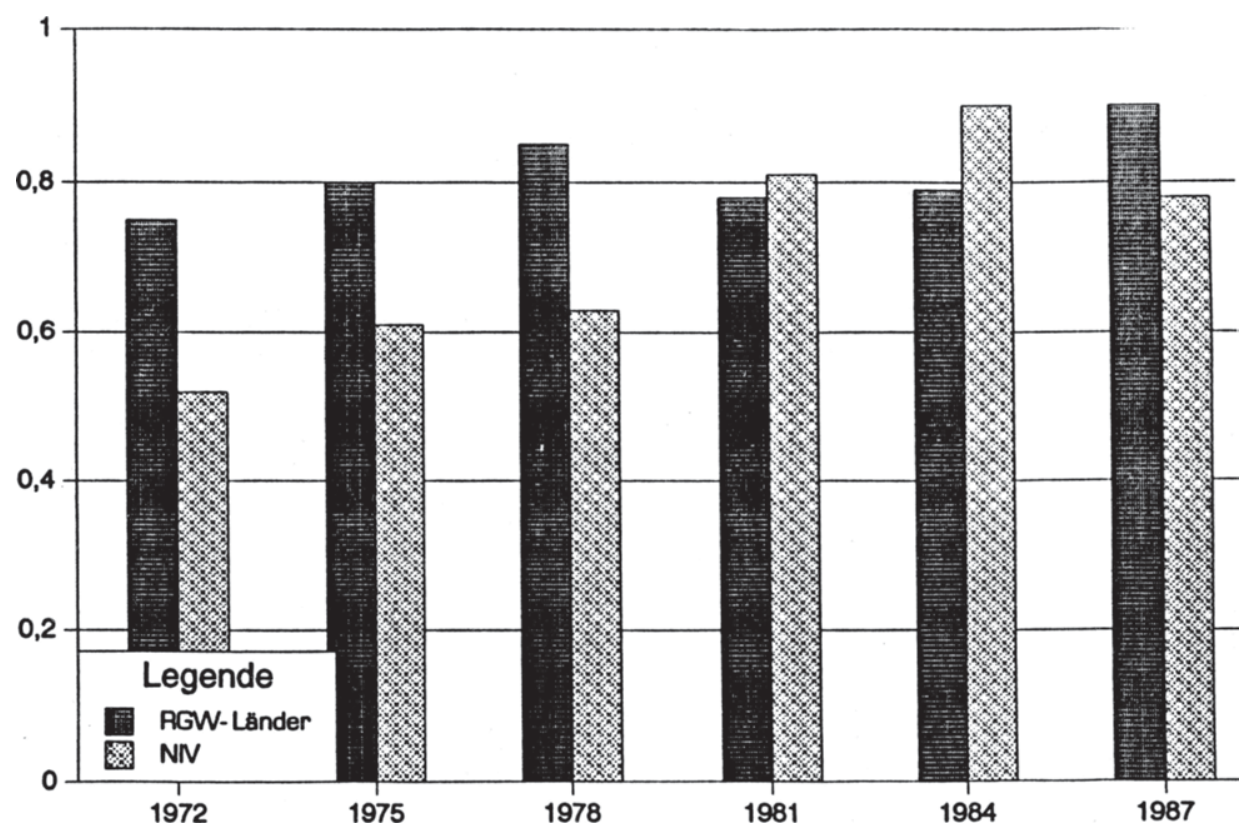

(Nach Angaben von HOEN \& VAN LEEUWEN, 1991, S.376)

Der Übergang zu wertvolleren Produkten - das sogenannte "product upgrading" - hat also den Vorsprung der NIV bezüglich der Chancen auf den westlichen Märkten (die Hauptabnehmer der Textil- und Bekleidungsprodukte von beiden Länderkategorien sind die OECDLänder) verringert. Tatsächlich wuchsen die Exporte der MOE- und GUS-Länder in die OECD-Länder, vor allem bei Bekleidung, im Zeitraum 1985-1990 ganz deutlich (Tabelle 2.15).

Obwohl der Beitrag von Osteuropa an der gesamten Textil- und Bekleidungseinfuhr der OECD mit 3,4\% immer noch klein ist, symptomatisch ist er aber zwischen 1988-1990 von $3,2 \%$ auf 3,4\% gestiegen, während der Anteil der Fernostländer in diesem Zeitraum von $35,5 \%$ auf 33,6\% gesunken ist (GÄLLI, 1992, S.19). Verantwortlich dafür sind in erster Linie die letzten Festlegungen der Quoten im Rahmen des Welttextilabkommens, die die ostasiatischen Exporte Länder nach wie vor stark beschränken.

Noch deutlicher war die Expansion der MOE/GUS Textilexporte in die Europäische Gemeinschaft, während die Anteile des Fernost wiederum rückgängig waren. Der Textil- und 
Bekleidungshandel zwischen West- und Osteuropa ist von der geographischen Nähe sehr stark begünstigt. Von 1985 bis 1990 wuchsen die Exporte der MOE/GUS Länder in die EG

Tabelle 2.15: $\quad$ Textilbezogener Handel der OECD mit den MOE/GUS Ländern 1985 bis 1990 (Mio. US-\$)

\begin{tabular}{||l||c|c|c|c||c||}
\hline Exporte-SITC & 1985 & 1988 & 1989 & 1990 & $\begin{array}{l}\text { Verände- } \\
\text { rung \% } \\
\text { p.a. } \\
1985 / 90\end{array}$ \\
\hline \hline $\begin{array}{l}\text { 26:Textile Fa- } \\
\text { sern und Abfälle }\end{array}$ & 961 & 1294 & 1679 & 728 & $-5,4$ \\
\hline $\begin{array}{l}\text { 65:Textile Garne } \\
\text { und Gewebe }\end{array}$ & 1572 & 2355 & 2668 & 3349 & 16,3 \\
\hline $\begin{array}{l}\text { 84:Bekleidung } \\
\text { und Accessoires }\end{array}$ & 554 & 602 & 837 & 1256 & 17,8 \\
\hline $\begin{array}{l}\text { 26/65/84: } \\
\text { Textilbezogen } \\
\text { insgesamt }\end{array}$ & 3086 & 4251 & 5185 & 5333 & 11,6 \\
\hline
\end{tabular}

\begin{tabular}{||l||c|c|c|c||c||}
\hline $\begin{array}{l}\text { Importe- } \\
\text { SITC }\end{array}$ & 1985 & 1988 & 1989 & 1990 & $\begin{array}{l}\text { Verände- } \\
\text { rung \% } \\
\text { p.a. } \\
1985 / 90\end{array}$ \\
\hline \hline $\begin{array}{l}\text { 26: Textile Fa- } \\
\text { sern und Abfälle }\end{array}$ & 248 & 483 & 562 & 506 & 15,3 \\
\hline $\begin{array}{l}\text { 65:Textile Garne } \\
\text { und Gewebe }\end{array}$ & 669 & 1079 & 1091 & 1291 & 14,0 \\
\hline $\begin{array}{l}\text { 84:Bekleidung } \\
\text { und Accessoires }\end{array}$ & 1728 & 3176 & 3322 & 4473 & 20,9 \\
\hline $\begin{array}{l}\text { 26/65/84: } \\
\text { Textilbezogen } \\
\text { insgesamt }\end{array}$ & 2646 & 4737 & 4975 & 6270 & 18,8 \\
\hline
\end{tabular}

(Nach Angaben von GÄLLI, 1992, S.22) 
mit $21 \%$ jährlich bis auf zuletzt 5,4 Mrd.US-\$ zu. Der MOE/GUS-Anteil in den Textil- und Bekleidungsimporten der EG wuchs 1988 bis 1990 von 5,2\% auf 5,6\%, während der Fernostanteil im selben Zeitraum von $19,4 \%$ auf $19 \%$ absank.

Aufgrund ihrer spezifischen Wettbewerbsvorteile haben also die osteuropäischen Länder schon angefangen, Marktanteile der ostasiatischen Länder auf dem EG-Textilmarkt zu gewinnen. Es geht hier nicht nur um die stärker entwickelten vier "Drachen" (Südkorea, Taiwan, Hong Kong und Singapur), sondern auch um die anderen -Indonesien, Malaysia, die Philipinnen, Thailand - deren Textilindustrien sich gemäß der Weltbankklassifikation zwischen der grundlegenden und der diversifizierten Phase ihrer Entwicklung befinden. Es ist zu erwarten, daß diese letzte Gruppe von den MOE/GUS Ländern auf dem EG-Textilmarkt überspringen wird. Hauptgründe dafür wären: die absolute Marktnähe der letzteren, ihre geringe Lohnkosten, ihre relativ besser qualifizierten Arbeitskräfte und ihre Erfahrungen im Textilmaschinenbau.

Die Textil- und Bekleidungsproduzenten aus der EG, Nordamerika und Japan sind unter normalen Umständen keine Konkurrenten für die MOE/GUS Länder, da sie im Prinzip andere Marktsegmente decken, infolge der Spezialisierung der Hersteller in den Industrieländern auf hochwertige und modische Produkte, auf neue und "intelligente" Stoffe usw. Dagegen bleibt die Konkurrenz der Mittelmeerländer bedeutsam: 1992 exportierten z.B. die MOE/GUS Länder Textilien und Bekleidung in die BRD für 6,16 Mrd.\$, und die Mittelmeerländer für 6,04 Mrd.\$, wovon die Türkei mit 4,05 Mrd.\$ bei weitem der stärkste Anbieter war (Quelle: Gesamttextil, 1993). In diesem Konkurrenzkampf sind die osteuropäischen Wettbewerbsvorteile mit der Produktqualität und der Lieferzuverlässigkeit verbunden.

Zusammenfassend läßt sich sagen, daß aufgrund einiger spezifischer Vorteile der osteuropäischen Länder (auf die im Paragraphen 2.3. am Beispiel Rumäniens näher eingegangen wird), die Textil- und Bekleidungsimporte der EG aus asiatischen Ländern zunehmend von osteuropäischen und Mittelmeerländern verdrängt werden. Die kostengünstiger produzierenden Länder rund um die EG werden in einem weitergefaßten europäischen Wirtschaftsraum erfaßt. Auch die ausländischen Investitionen der westeuropäischen Textil- und Bekleidungsunternehmen nahmen in diesem Raum schneller zu, als diejenigen der gesamten westlichen Industrie (siehe hierzu z.B. SPINANGER, 1993, S.109).

Unter diesen Bedingungen kann die osteuropäische Textil- und Bekleidungsindustrie (besonders letztere) auf mittlere Sicht gute Entwicklungschancen haben. Nichts spricht dagegen, daß diese Länder ihre sogenannten "Leichtindustrien" (die, neben der TBI, auch die Schuh- und Lederindustrie enthalten, die, im Grunde genommen, dieselben Charakteristika wie die TBI im Lichte der bisherigen Diskussion ausweisen) zu einer tragenden Säule der Transformation und des Außenhandels in der Übergangsphase entwickeln. 


\subsubsection{Nationales Umfeld der Textil- und Bekleidungsindustrie}

Die wichtigsten Eigenschaften des rumänischen sozio-ökonomischen und institutionellen Umfeldes wurden, nach bestimmten Merkmalen strukturiert, im Kapitel 1 dargelegt. Im vorliegenden Paragraphen geht es vielmehr um die bedeutendsten Restriktionen (ökonomischer, wirtschaftspolitischer, finanzieller oder infrastruktureller Art), die die Entwicklung der Textil- und Bekleidungsindustrie beeinträchtigen vermögen.

Die erste wichtige Restriktion für die rumänische TBI war in den Jahren 1990 bis 1993 der Binnenmarkt selbst. Der Verfall der Produktion in fast allen Sektoren der Volkswirtschaft, begleitet von der Freisetzung der Preise bei strenger Kontrolle der Löhne und Gehälter hat einen enormen Druck auf den Endverbrauch von Konsumgütern ausgeübt. Zwischen Oktober 1990 und Juli 1993 sind zum Beispiel die Nettogehälter im Durchschnitt 17 mal, die Preise für Industriewaren (ohne Nahrungs- und Genußmittel) dagegen 29,3 mal gestiegen (Quelle: NATIONAL STATISTICS COMISSION OF ROMANIA, Oct. 1993, und ebenda, No.2/1993). Diese Entwicklung hat gravierende Umwälzungen - im Sinne der Erhöhung des Anteils der Ausgaben für Ernährung (wo die Konsumnachfrage viel inelastischer ist und trotz Preiserhöhungen wenig sinkt) auf Kosten der Anteile anderer Ausgabentypen, einschließlich der Bekleidung - im durchschnittlichen Familienbudget der Rumänen mit sich gebracht (Tabelle 2.16).

Tabelle 2.16: $\quad$ Umwälzungen in Familienbudget, 1980-1992. Prozentmäßiger Anteil der Ausgaben für Ernährung und Bekleidung.

\begin{tabular}{||l||c|c||c|c||}
\hline Familientyp & $\begin{array}{c}\text { Ernährung } \\
1980\end{array}$ & $\begin{array}{c}\text { Bekleidung } \\
1980\end{array}$ & $\begin{array}{c}\text { Ernährung } \\
1992\end{array}$ & $\begin{array}{c}\text { Bekleidung } \\
1992\end{array}$ \\
\hline Arbeitnehmer & 45,6 & 17,2 & 55,9 & 13,7 \\
\hline Landwirte & 63,7 & 12,6 & 75,1 & 7,3 \\
\hline Rentner & 58,0 & 9,3 & 66,9 & 6,9 \\
\hline
\end{tabular}

(Quelle: ROMANIAN STATISTICAL YEARBOOK, 1993, S.206-207)

Es ist kein Wunder daß unter diesen Umständen die Einkommenselastizität der Nachfrage für Textil-, Bekleidungs- und Ledererzeugnisse in dem angegebenen Zeitraum kleiner eins war. Während das durchschnittliche Gehalt in 1992 5,75 mal höher war als in 1990, sind die nominelle Umsätze der TBI nur 3,4 mal in derselben Zeit gestiegen. Somit ergibt sich eine nominelle Elastizität von ungefähr 0,6. Dies hat aber keineswegs zu einer Überproduktionskrise geführt, da aufgrund von Rohstoffmangel auch die physische Produktion zurückge- 
gangen ist. Die Preise sind in derselben Zeitspanne bei Textilien und Bekleidung insbesondere wegen der Verteuerungen der Produktionsfaktoren etwa 10,6 mal gestiegen.

Eine zweite Restriktion von der Verbraucherseite ist der starke Wettbewerb, der auf dem rumänischen Textil- und Bekleidungsmarkt herrscht. Nicht nur 387 Unternehmen mit staatlichem Kapital (oder staatlicher Beteiligung), sondern auch eine hohe Zahl privater Produzenten, Kooperativen und Importeure kämpfen auf diesem Markt. Neben der begrenzten Kaufkraft der Bevölkerung, ist dies ein zweiter wichtiger Grund für die starke Exportorientierung der rumänischen TBI.

Der inländische Markt ist nach den üblichen Regeln geschützt: die Zölle bewegen sich in einem Rahmen von 3-10\% (für Rohstoffe) bis auf 30-40\% (für Bekleidung und Schuhe). Auf die verzollte Ware kommt zusätzlich die Mehrwertsteuer von $18 \%$ hinzu. Importquoten gibt es nicht; die einzige mengenmäßige Einschränkung der Importe stellt der Währungstausch dar, da die rumänische Währung nicht frei konvertierbar ist. Zahlreiche Zollpräferenzen werden im Rahmen des Allgemeinen Präferenzsystems (APS) den Importen aus Entwicklungsländern gewährt. Selbst bei diesen verhältnismäßig hohen Zöllen für Bekleidung und Schuhe bildet die billige Massenware aus Taiwan, der Türkei und Syrien eine wichtige Konkurrenz für die rumänischen Erzeugnisse, vor allem weil solche Produkte massiv von "Touristen", den Zoll umgehend, ins Land gebracht werden. Aus den Industrieländern werden fast ausschließlich hochwertige Garne und Gewebe, sowie Industrietextilien und Stoffabfälle importiert, die in den meisten Fällen in der wiederum in den Westen exportierten Bekleidung zu finden sind. Hochwertige und modische Schuhe und Bekleidung aus dem Westen sind für die rumänische Industrie (noch) nicht bedrohlich, da sie aufgrund der hohen Preise nur von einer ganz dünnen Schicht der Bevölkerung gekauft werden können.

Der Wettbewerb läßt sich auch auf dem Markt der Industrietextilien spüren, wo die Abnehmer, die ihre Produkte hinterher exportieren und somit über Devisen verfügen, bereits die Wahl zwischen dem heimischen und dem ausländischen Angebot haben. Dies gilt auch für die Bekleidungsindustrie als Abnehmer von Garnen und Geweben, die sich schon sehr stark an der Lohnveredelung orientiert hat.

Seitens der Lieferanten von Rohstoffen, Energie und anderen Vorleistungen läßt sich die Bekleidungs- und Lederwarenindustrie weniger beeinflussen, da sie weder energie- noch rohstoffintensiv ist. Dagegen haben die primären Veredelungsstufen der "Textil- und Lederpipeline" - Spinnereien, Webereien, Gerbereien - mit den aggressiven periodischen Verteuerungen der Leistungen der staatlichen Monopole (Energie, Gas, Wasser, Heizung, Kommunikationen) größere Schwierigkeiten. 
Auch die Beziehungen zwischen Abnehmern und Lieferanten in der Veredelungskette leiden sehr stark unter der im Kapitel 1 geschilderten Finanzblockage. Im Notfall stellen die in Liquiditätsschwierigkeiten geratenen staatlichen Firmen ihre Zahlungen an einander ein, weil sie aus Erfahrung wissen, daß die in kurzer Zeit entstehende, landesdeckende Verflechtung von Verbindlichkeiten droht, das ganze Finanzsystem zu ersticken. Die Regierung hat bisher durch mehrmalige Finanzspritzen die Impulse für den Wiederausgleich gegeben (siehe Kap.1). Immerhin bleiben in der Zwischenzeit, bis der Ausgleich erfolgt, wichtige Teile der Produktion still.

Ein weiteres Problem, das den Unternehmen der Textilindustrie die Lage erschwert, sind die Infrastrukturschwächen. Besonders in diesem international stark verflochtenen Sektor der Industrie, in der TBI, sind die schnellen und effizienten Verbindungen mit dem Ausland von großer Bedeutung. Die Liefertreue ist bei Lohnaufträgen eine der wichtigsten Bedingungen; die saisonbedingten Schwankungen der qualitativen und mengenmäßigen Nachfrage verlangen eine gut funktionierende Beschaffungs- und Distributionslogistik. Die Unternehmen in der Provinz haben immer noch keine vollständigen direkten telefonischen Verbindungen mit dem Ausland - dies war in der kommunistischen Zeit sogar streng verboten! -; sie können zwar direkt angerufen werden, aber nicht direkt anrufen. Die Bahn funktioniert noch einigermaßen akzeptabel, aber es gibt so gut wie keine Autobahnen (124 Km im ganzen Land), und die Grenzübergangspunkte reichen nicht aus.

In vielen Ländern, wo in verschiedenen Phasen der wirtschaftlichen Entwicklung die TBI eine Priorität der Regierungspolitik bildete (Südkorea, Taiwan, den Philippinen, Indonesien, Pakistan, Tunesien) wurden Beihilfeprogramme zur Modernisierung der Textilindustrie auferlegt. Diese Programme enthielten in erster Linie Kreditverbilligungen und Devisenerleichterungen. In Rumänien gibt es für die TBI nichts ähnliches. Der Textilsektor, der in hohem Maße von Importen abhängig ist, findet es besonders schwer, sich die benötigten Devisen zu beschaffen. Das sogenannte "Fixingverfahren" (der Tausch von Lei gegen Devisen) ist eher eine Warteschlange als, wie offiziell behauptet, eine Währungsausschreibung. Die zu tauschenden Gelder bleiben 2 bis 3 Monate lang bei den Banken zinslos liegen, bis sie endlich in freie Devisen umgetauscht werden. Der Bedarf wird täglich zu 2 bis maximal 20\% gedeckt. Auch die ständigen Abwertungen der heimischen Währung führen dazu, daß die Importe sich immer verteuern und die Modernisierungsvorhaben erschwert werden. Die Textil- und Bekleidungsexporte, abgesehen von der lohnveredelten Ware, werden dagegen durch diese Abwertung kaum stimuliert. Aufgrund der geringen Verkaufspreise liegen die rumänischen Textilien, Bekleidung und Lederwaren auf dem unteren, unelastischen Teil der Nachfragekurve; ihre Verbilligung durch Abwertung der Währung im exportierenden Land vermindert die Umsätze, statt sie zu erhöhen. 
Als ob die Importe von Maschinen und Anlagen nicht teuer genug wären, werden sie weiter mittels der Mehrwertsteuer von 18\%, der Zolltarife von 10 bis $20 \%$, und der einheitlichen Abgabe von 0,5\% für die Modernisierung der Zolleinrichtungen verteuert. J.SEROUSSI, der Vorsitzende des Verbandes der ausländischen Investoren in Rumänien, Geschäftsmann im Textilbereich, hat sich schon über diese Tatbestände geklagt (1993). Nach der Wende hat die zunehmende Macht der Zollbehörden (der Anteil der Zolleinnahmen am gesamten Staatshaushalt stieg von 3,7\% im 2.Quartal 1991 auf 8,2\% im 2.Quartal 1993, was auf eine wachsende fiskalische Rolle der Zölle hindeutet - Quelle: NATIONAL STATISTICS COMISSION OF ROMANIA, No. 2/1993, S.94) und das völlig abschreckende Benehmen der Zollbeamten, die ungeheuerliche Bürokratie und Korruption, die dort herrschen, nicht wenige potentielle Investoren schon am "Eingangstor" des Landes abgehalten.

Die Exporte der TBI werden dagegen durch das "draw-back"-System erleichtert, das erlaubt, die Zollausgaben für importierte Rohstoffe beim Export des Fertigproduktes erstattet zu bekommen. Nicht nur der lohnarbeitende Teil der Bekleidungs- und Lederwarenindustrie, sondern auch die rohstoffimportierende Textilerzeugung profitieren von dieser Vergünstigung, die 1990 in Kraft getreten ist. Aber auch im Exportbereich verursacht der Eingriff der Regierung Wettbewerbsverzerrungen: die Verwaltung und Verteilung der Exportquoten seitens des Handelsministeriums hat wegen der bürokratischen Hindernisse sogar dazu geführt, daß manche Quoten unausgenutzt geblieben sind.

Die größte Abnormalität liegt aber darin, daß die Textil- und Bekleidungsindustrie nicht auf der Prioritätsliste der Regierung für die Industrie- und Strukturpolitik in der Transformationsphase steht. Eine augenfällige wirtschaftliche Realität - die erstrangige Bedeutung der TBI wird damit völlig außer Betracht gelassen und andere Industriesektoren werden, aufgrund ihrer sozialen Explosionsgefahr, durch präferenzielle Kredite und Subventionen unterstützt. Dies gilt insbesondere für die Industrien, die in riesigen Kombinaten konzentriert sind, von welchen in manchen Ortschaften fast die gesamte aktive Bevölkerung wirtschaftlich abhängig ist. Die TBI ist dagegen in kleineren Einheiten organisiert und gleichmäßig über das Land verteilt. Vielleicht sind die Arbeitnehmer der TBI - überwiegend Frauen - für den Sozialund Gewerkschaftskampf schlechter gewappnet.

\subsubsection{Evaluation der rumänischen TBI nach 1989 und Identifizierung ihrer Schwachstellen.}

Mit einer wertmäßigen Produktion von 327,7 Mrd.Lei machte die Textilindustrie 1992 4,9\% der gesamten rumänischen Industrieproduktion aus. Die Bekleidungsindustrie stellte mit 136,6 Mrd.Lei, und die Schuh- und Lederindustrie, mit 112,7 Mrd.Lei, weitere 2,1\%, bzw.1,7\% dar. Die sogenannte Leichtindustrie realisierte also $8,7 \%$ der gesamten Indu- 
strieproduktion (aber 40,2\% der Exporte in die EG!). 1989 waren es immerhin noch 12,9\% der Industrieproduktion. Der Rückgang dieses Anteils ist sowohl auf den Verfall der physischen Produktion in der TBI als auch auf den im Vergleich mit anderen Industrien viel kleineren Preisanstieg der Textil- und Bekleidungserzeugnisse zurückzuführen. Die Dynamik der physischen Produktion nach 1989 ist in Abbildung 2.3 angegeben.

Abb.2.3: Physische Produktion der rumänischen TBI, 1990-1993

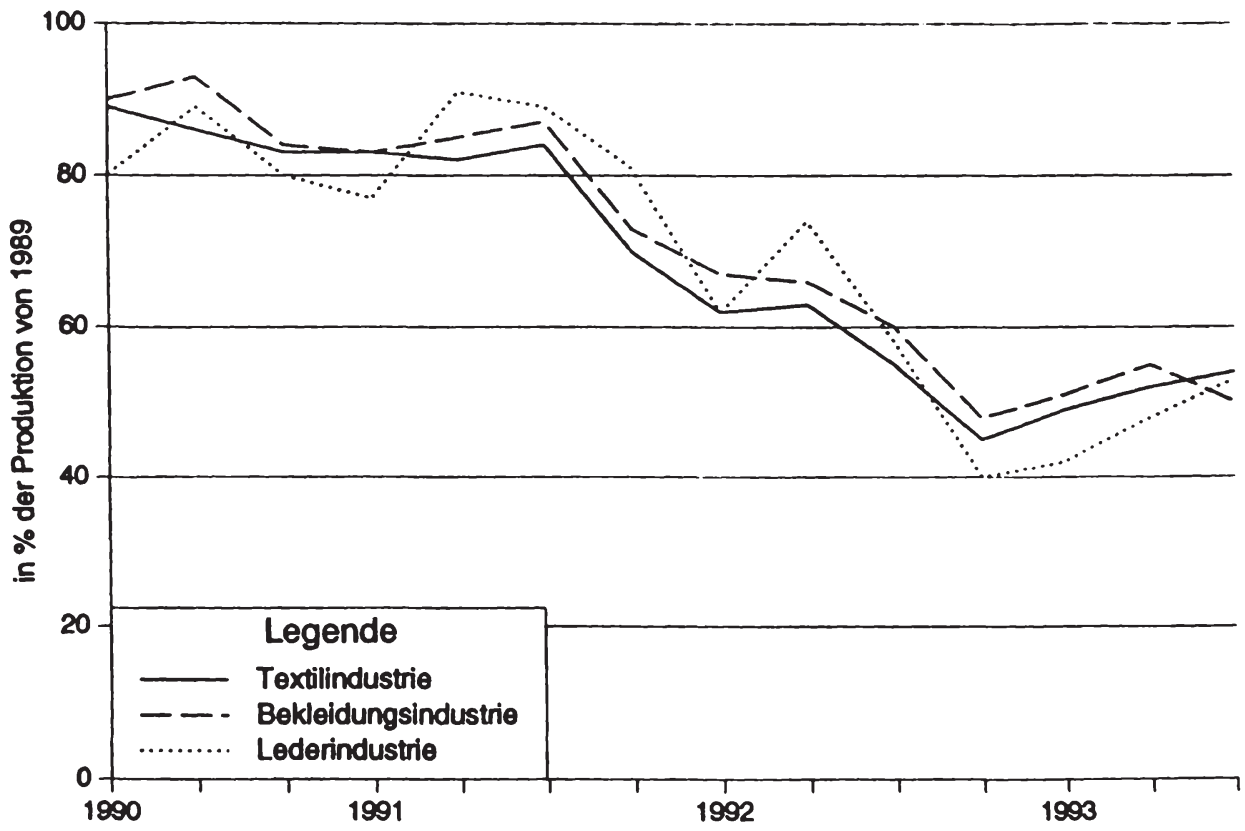

(Quelle: ebenda, S.9)

Die Entwicklung in den ersten zwei Quartalen des Jahres 1993, sowie die Angaben in (NATIONAL STATISTICS COMISSION OF ROMANIA, Nov. 1993) deuten auf eine Stabilisierung auf diesem niedrigen Niveau hin. Diese Zahlen - und somit auch die Produktion, 3 Jahre nach der Wende - müssen aber, wie schon GÄLLI für Ungarn bemerkt (1991, S.156), etwas nach oben korrigiert werden, weil sie von der - insbesondere im Bekleidungssektor - weit verbreiteten Schattenwirtschaft absehen. Mit der Ausnahme einiger wenigen Gemeinschaftsunternehmen mit westlichen Partnern und der Handwerkerkooperativen sind 
die Unternehmen der TBI immer noch in Staatsbesitz. Die Anteile der Produktion im Staatssektor werden in Tabelle 2.17 angegeben.

Tabelle 2.17: $\quad$ Anteile des Staatssektors in der TBI- Produktion

\begin{tabular}{|l|c|c|c|}
\hline Produktion 1992 & Textilindustrie & $\begin{array}{l}\text { Bekleidungsindu- } \\
\text { strie }\end{array}$ & $\begin{array}{l}\text { Schuhe und Leder- } \\
\text { waren }\end{array}$ \\
\hline $\begin{array}{l}\text { Insgesamt } \\
\text { (Mrd.Lei) } \\
\text { - darunter: }\end{array}$ & 327,7 & 136,6 & 112,7 \\
\hline $\begin{array}{l}\text { staatliche Unter- } \\
\text { nehmen, in Mrd. } \\
\text { Lei }\end{array}$ & 296,3 & 76 & 106,9 \\
\hline $\begin{array}{l}\text { staatliche Unter- } \\
\text { nehmen, in \% }\end{array}$ & 90,4 & 55,6 & 94,9 \\
\hline
\end{tabular}

(Nach ROMANIAN STATISTICAL YEARBOOK, 1993, S.490 und Angaben des Industrieministeriums)

Außer der wenig kapitalintensiven Bekleidungsindustrie, wo die Privatisierung weiter fortgeschritten ist, ist die TBI also nach wie vor fest in den Händen des Staates.

Der Rückgang der Produktion ist der Senkung des Auftragseingangs gefolgt (Tabelle 2.18). Diese Senkung wurde wiederum insbesondere von der preisinduzierten Nachfragesenkung verursacht. Wie schon gezeigt, haben die Verteuerungen den Anteil der Ausgaben für Ernährung, Heizung, Energie und Transport (alles inelastische Nachfragekurven) zulasten des Anteils der Ausgaben für Bekleidung erhöht (siehe hierfür die Tabellen 2.16, 2.19 und 2.20), obwohl die Verbraucherpreise für Textilien und Lederware nicht so schnell wie die anderen Preise gestiegen sind.

Tabelle 2.18: Auftragseingang 1989-1992

\begin{tabular}{||l|c|c|c|c||}
\hline & 1989 & 1990 & 1991 & 1992 \\
\hline \hline Für den Export (Mio.US-\$) & 1007 & 692 & 439 & 387 \\
\hline $\begin{array}{l}\text { Für das Inland (Mrd.Lei - preis- } \\
\text { bereinigt) }\end{array}$ & 115 & 85 & 84 & 67 \\
\hline
\end{tabular}

(Nach Angaben des Industrieministeriums) 
Tabelle 2.19: Monatliche Preissteigerungsraten in Rumänien 1991-1993, in \%

\begin{tabular}{||c||c|c|c|c||}
\hline & Allgemein & $\begin{array}{l}\text { Nahrungs- und } \\
\text { Genußmittel }\end{array}$ & $\begin{array}{l}\text { Andere indu- } \\
\text { strielle Waren }\end{array}$ & $\begin{array}{l}\text { Dienstleistun- } \\
\text { gen }\end{array}$ \\
\hline \hline 1991 & 10,3 & 12,0 & 8,9 & 8,6 \\
\hline 1992 & 9,6 & 10,2 & 9,3 & 8,4 \\
\hline $\begin{array}{c}\text { Jan.-Okt. } \\
1993\end{array}$ & 12,4 & 11,7 & 13,5 & 11,6 \\
\hline
\end{tabular}

(Quelle: NATIONAL STATISTICS COMISSION OF ROMANIA, Oct. 1993, S.1)

Tabelle 2.20: Indizes der Verbraucherpreise (ausgewählte Produkte). Oktober $1990=100$.

\begin{tabular}{||l||c|c|c||}
\hline & Dez.1991 & Dez.1992 & Okt.1993 \\
\hline \hline Nahrungs- und Genußmittel & 298,7 & 1568 & 4735,6 \\
\hline Andere industrielle Waren, darunter: & 270,6 & 1212 & 4293,3 \\
\hline - Bekleidung & 263,7 & 1064 & 3479,7 \\
\hline - Schuhe & 311,4 & 1549 & 4880,6 \\
\hline - Treibstoff & 131,3 & 642,6 & 3879,8 \\
\hline - Strom, Gas, Heizung & 377,2 & 592,7 & 3601,1 \\
\hline
\end{tabular}

(Nach Angaben von ebenda, S.2-3 und ROMANIAN STATISTICAL YEARBOOK, 1993, S.387)

Unter diesen Umständen war es selbstverständlich, daß die rumänische TBI versuchte, durch Erhöhung ihrer Ausfuhren den Umsatzeinbruch im Lande zu kompensieren. Das, was ihr eigentlich gelungen ist, zeigt Tabelle 2.21.

Augenfällig bei dieser Statistik ist zuerst der hohe negative Einfluß, den die Auflösung des RGW 1990 und der Zusammenbruch des sowjetischen Marktes auf die rumänischen Exporte ausgeübt haben. Somit ist für die rumänische TBI ein riesiger Markt stark und schnell geschrumpfen (50\% der Exporte der rumänischen TBI gingen 1989 in die RGW-Länder).

Es gibt aber auch viele andere Gründe für die Senkung der Exporte. Die Tatsache, daß zwischen 1991 und 1992 die Textilexporte zurückgegangen, während die Bekleidungsexporte gestiegen sind, könnte den falschen Eindruck erwecken, die rumänische TBI habe inzwischen 
Tabelle 2.21: $\quad$ Entwicklung der Exporte der rumänischen TBI

\begin{tabular}{||l||c|c|c|c|c||}
\hline & 1989 & 1990 & 1991 & 1992 & $\begin{array}{c}1993 \\
\text { (erste 6 } \\
\text { Monate) }\end{array}$ \\
\hline \hline $\begin{array}{l}\text { Textilindustrie (Mio.Ru- } \\
\text { bel) }\end{array}$ & 155,8 & 120,4 & 27,9 & - & - \\
\hline $\begin{array}{l}\text { Textilindustrie } \\
\text { (Mio.US-\$) }\end{array}$ & 161,5 & 120,3 & 143 & 112 & 43 \\
\hline \hline $\begin{array}{l}\text { Bekleidung (Mio.Rubel) } \\
\text { (Mekleidung (Mio.US-\$) }\end{array}$ & 213,2 & 127,3 & 50,4 & - & - \\
\hline \hline $\begin{array}{l}\text { Schuhe und Lederware } \\
\text { (Mio.Rubel) }\end{array}$ & 141,8 & 78 & 24 & - & 107 \\
\hline $\begin{array}{l}\text { Schuhe und Lederware } \\
\text { (Mio.US-\$) }\end{array}$ & 80,5 & 61 & 68,4 & 68 & 27 \\
\hline
\end{tabular}

(Nach Angaben des Industrieministeriums)

die Strategie verfolgt, lieber Produkte höheren Veredelungsgrades als Garne oder Gewebe auszuführen. Eigentlich geht es aber darum, daß, während die Textilindustrie kapital- und forschungsintensiv ist, die Bekleidungsindustrie arbeitsintensiv ist. Durch stetige Erweiterung der passiven Lohnveredelung ist die Devisenlage der Bekleidungsindustrie viel besser geworden als die der Textilindustrie, wo nicht nur für Importe von Rohstoffen, sondern auch für Modernisierungen der teueren Anlagen Devisen in höherem Maße benötigt werden. Die Erhöhung der Bekleidungsexporte zwischen 1991 und 1992 ist gänzlich auf die Lohnverarbeitung zurückzuführen.

Im allgemeinen ist aber der Trend der Exporte der TBI rückläufig. Der rumänischen TBI ist die notwendige Umorientierung von 50\% ihrer Exporte vom östlichen zum westlichen Standard nicht gut gelungen. Erstens - so auch das Industrieministerium - sind mit der vorhandenen Technik ganz schwer Erzeugnisse herzustellen, die auf den westlichen Märkten wettbewerbsfähig sind. 1989 gab es immer noch drei Qualitätsstandards: für Exporte in den Westen, in sozialistische Länder und für den rumänischen Markt. Es fehlen hochwertige Produkte, in erster Reihe höher veredelte Gewebe aus feinen und sehr feinen Garnen, Strickwaren mit Jacquard-Modellen und Intarsien usw. Auch sind die Industrie- und technischen Textilien, eine Produktgamme, deren Markt ständig in der Welt expandiert, wenig in der Fabrikation vertreten. 
Zweitens ist die Versorgung mit Informationen ungenügend (sowohl in Richtung der Marketing- und Distributionskenntnisse als auch der neuen Technologien und Materialien). Dafür ist fast ausschließlich die kommunistische Erbschaft verantwortlich: die Textilfach- und Kaufleute wurden in den 80er Jahren allmählich, anfangs aufgrund der Devisenersparnis, später aber auch um den Kontakt mit den "imperialistischen Ideologien" zu vermeiden, vom Ausland isoliert. Viele Textilien sind forschungs- und technologieintensive Produkte; angesichts des antiintellektuellen Benehmens des Ceauşescu-Regimes ist es kein Wunder, daß in dieser Richtung wenig Fortschritte gemacht wurden. Auch die fleißige Belegung der staatlichen Außenhandelsunternehmen mit Angehörigen des Sicherheitsdienstes hat einen ähnlich zerstörenden Einfluß auf ihre Kreativität, Flexibilität und Anpassungsfähigkeit gehabt.

Drittens haben die gravierenden Änderungen auf den Exportmärkten auch die interindustriellen Verflechtungen der "Textilpipeline" tangiert. Normalerweise liefert die Textilindustrie den größten Teil ihrer Produktion (Garne, Gewebe, Bände, Netze usw.) an die weiteren Veredelungsstufen, die Bekleidungs- und die Lederwarenindustrie. Die Produktion des Textilsektors ist stets gesunken, wie in Abb.2.3 abzulesen ist. Aber auch der Anteil der Lieferungen der Textilindustrie an die anderen Industrien (darunter hauptsächlich an die Bekleidungsbranche) ist in ihrem gesamten Produktionswert von 57,8\% 1989 auf 52,8\% 1992 gesunken (Angaben des Industrieministeriums), wobei der Anteil der Lieferungen an Endverbraucher von $27,4 \%$ auf $36,7 \%$ gestiegen ist. Ein qualitatives Phänomen zeichnet sich hier ab: aufgrund ihrer stärkeren Exportorientierung hat die Bekleidungsindustrie anteilsmäßig (aber auch absolut) an einem Teil der Lieferungen der vorgelagerten Textilbranche verzichtet. Es gab mehrere Gründe dafür: Garne und Gewebe wurden immer teurer; die Chemiefasern rumänischer Produktion sind teurer als auf dem Weltmarkt geworden; die Lieferungsfristen wurden - insbesondere aufgrund von Beschaffungs- und Devisenproblemen - von der Textilindustrie nicht immer eingehalten; endlich, da die Bekleidungsindustrie ihre Inputs in Lei bezahlte, aber für ihre exportierten Produkte freie Devisen bekam, erhöhte sich der Druck der Lieferanten nach oben um mindestens einen Teil der gelieferten Stoffe und Garne in freien Devisen bezahlt zu bekommen.

Die Bekleidungsindustrie hat also weniger Vorprodukte der heimischen Textilindustrie eingesetzt und dafür mehr auf die passive Lohnveredelung gesetzt, wo der ausländische Partner den Stoff zur Verfügung stellt. Somit hat sich die Kupplung zwischen Textil- und Bekleidungsindustrie gelockert. Ähnliche Phänomene sind auch in anderen MOE-Ländern zu beobachten (siehe z.B. GÄLLI, 1991, S.159, für Ungarn). In kleinerem Maße gibt es diese Lockerung auch in der Lederwarenindustrie, zwischen den Gerbereien und den Konfektionswerken. Die Bekleidungsindustrie orientierte sich mehr an der direkten Kooperation mit ausländischen Partnern. Dagegen setzte die Textilindustrie mehr auf die Belieferung des heimischen Marktes. In der Tat haben die Senkung des Lebensstandards und somit die Anreize zur Heimarbeit, die Verbreitung der Schattenwirtschaft und der privaten Beklei- 
dungshersteller die inländische Nachfrage für Garne und Stoffe nicht stark sinken lassen. Trotzdem ist wegen der Nichtkonvertibilität der rumänischen Währung die Textilindustrie schlechter gestellt: sie braucht Devisen für ihre Rohstoffimporte, aber ihre Erzeugnisse sind nicht sehr exportfähig, was man am Rückgang dieser Exporte leicht ablesen kann (Tabelle 2.21). Allerdings ist dieser Rückgang nur von den Baumwollgeweben bedingt; bei allen anderen Gewebesortimenten sind die Exporte des Textilsektors spätestens 1991 oder 1992 wieder angestiegen (Tabelle 2.22). Diesen Produktbereichen ist die Umstellung auf die westlichen Märkte vielleicht nicht besser gelungen als den Baumwollgeweben, aber sie sind viel weniger von importierten Rohstoffen abhängig.

Tabelle 2.22: $\quad$ Exporte des Textilsektors, 1989-1992 (bei Rubel inflationsbereinigt)

\begin{tabular}{|l|c|c|c|c||}
\hline & 1989 & 1990 & 1991 & 1992 \\
\hline \hline Baumwollgarne (Tsd.US-\$) & - & 73 & 1770 & 4200 \\
\hline Baumwollgarne (Tsd.Rbl.) & 16084 & 9094 & 98 & - \\
\hline \hline Baumwollgeweben (Tsd.US-\$) & 52038 & 23607 & 24778 & 16100 \\
\hline Baumwollgewebe (Tsd.Rbl.) & 1527 & 297 & 95 & - \\
\hline \hline Seidegewebe (Tsd.US-\$) & 4109 & 2684 & 7501 & 5700 \\
\hline \hline $\begin{array}{l}\text { Dünne Flachs- und Hanfgewebe } \\
\text { (Tsd.US-\$) }\end{array}$ & 3413 & 2381 & 3612 & 5200 \\
\hline $\begin{array}{l}\text { Dünne Flachs- und Hanfgewebe } \\
\text { (Tsd.Rbl.) }\end{array}$ & 13441 & 7931 & 1323 & - \\
\hline \hline Wollgewebe (Tsd. US-\$) & 12192 & 5525 & 13029 & 18580 \\
\hline \hline Teppiche (Tsd.US-\$) & 133 & 1926 & 2738 & 1300 \\
\hline Teppiche (Tsd.Rbl.) & 2891 & 5437 & 420 & - \\
\hline \hline Maschenware (Tsd.US-\$) & 70918 & 59258 & 33967 & 54000 \\
\hline Maschenware (Tsd.Rbl.) & 79038 & 48872 & 18079 & - \\
\hline \hline Andere Produkte (Tsd.US-\$) & 18774 & 25355 & 55746 & 6920 \\
\hline Andere Produkte (Tsd.Rbl.) & 42808 & 48754 & 7899 & - \\
\hline \hline Insgesamt (Mio.US-\$) & 161,5 & 120,8 & 143,1 & 112 \\
\hline Insgesamt (Mio.Rbl.) & 155,8 & 120,4 & 27,9 & - \\
\hline
\end{tabular}

(Nach Angaben des Industrieministeriums) 
Die TBI insgesamt ist nicht in hohem Maße von importierten Rohstoffen abhängig. Gemäß den Angaben des Industrieministeriums waren 1992 nur 20,8\% (1989: 23,4\%) des Bedarfs an Rohstoffen der TBI über Importe gedeckt -überwiegend rohe Baumwolle und Baumwollgarne, aber auch Chemiefasern und Farbstoffe, Klebstoffe und andere Veredelungsmaterialien. Auch die Importe der Lederwarenindustrie beziehen sich hauptsächlich auf Rindsleder und verschiedene Betriebs- und Hilfsmitteln.

Das Land verfügt über eine bedeutende Produktionskapazität von zellulosischen (Produktion 1991: 38.000 to) und synthetischen Fasern (Produktion 1991: 163.000 to, zweiter Rang im ehemaligen RGW nach der GUS). Rumänien ist der 18. größte Produzent von Wolle der Welt: $28.000 \mathrm{t}$ in 1992, das heißt $1,20 \mathrm{Kg} / \mathrm{Kopf}$ der Bevölkerung (Quelle: NATIONALER STATISTISCHER AUSSCHUSS RUMÄNIENS, Aug. 1993, S.63). Die wichtigste Schwäche (die anderen können durch Erhöhung der Inlandsproduktion korrigiert werden) der Rohstoffbasis der rumänischen TBI ist die Importabhängigkeit bei Baumwolle. Mit der Auflösung des RGW konnte man die Baumwolle aus Zentralasien nicht mehr über Barter beschaffen; sie ist entsprechend teurer geworden und wird nunmehr fast ausschließlich gegen Devisen verkauft. Die Anpassung an die neuen Bedingungen ist noch nicht vollendet. Die Baumwollimporte sind von $72.700 \mathrm{t}$ in 1989 auf $40.000 \mathrm{t}$ in 1992 gesunken; dementsprechend hat sich auch die Produktion von Baumwollgeweben von 684,2 Mio.qm in 1989 auf 294 Mio.qm in 1992 verringert (Angaben des Industrieministeriums). Es gibt also auch Angebotsursachen für den Rückgang der Produktion.

Die Engpässe bei der Rohstoffbeschaffung waren aber nicht der einzige Einflußfaktor für die Produktionssenkung in der Textilindustrie. Die physische Produktion ist auch bei Wollgeweben von 123,7 Mio.qm in 1989 auf 60 Mio.qm in 1992 gesunken, obwohl hier die Rohstoffbasis im Lande vorhanden ist. Abbildung 2.3 zeigt Produktionsrückgänge in allen drei Sektoren der TBI an. Außerdem ist der Auslastungsgrad der vorhandenen Kapazitäten deutlich zurückgegangen (Abb.2.4).

Diese Reduzierung erhöht wiederum die Stückkosten durch die Erhöhung der anteilsmäßigen Fixkosten. Die Modernisierung - der Übergang zu moderneren Produkten, erzeugt mit moderneren Maschinen - empfiehlt sich in dieser Lage. Auch die nominelle Arbeitszeit ist in dieser Industrie chronisch minder ausgelastet (zu 74,9\% im Textil- und zu 76,3\% im Ledersektor - siehe NATIONAL STATISTICS COMISSION OF ROMANIA, Nov. 1993, S.5).

Unter diesen Umständen sind die Unternehmen zum Stellenabbau übergegangen (Abb.2.5). 
Abb.2.4: Kapazltätsauslastung TBI, 1990-1992, in \%

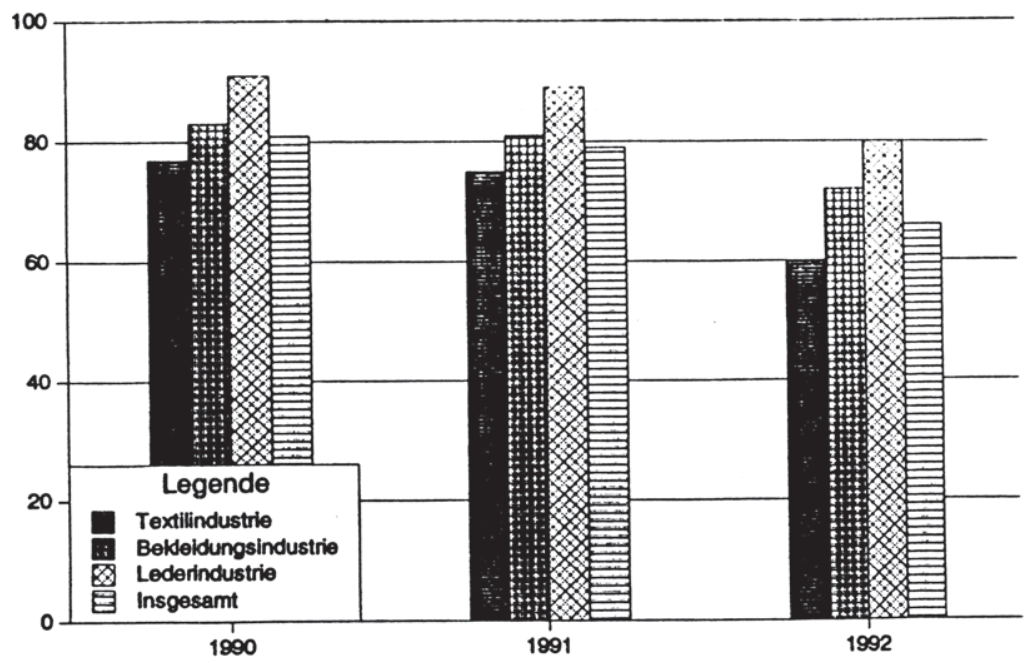

(Nach Angaben des Industrieministeriums, die sich auf die Faktorenausstattung 1989 beziehen)

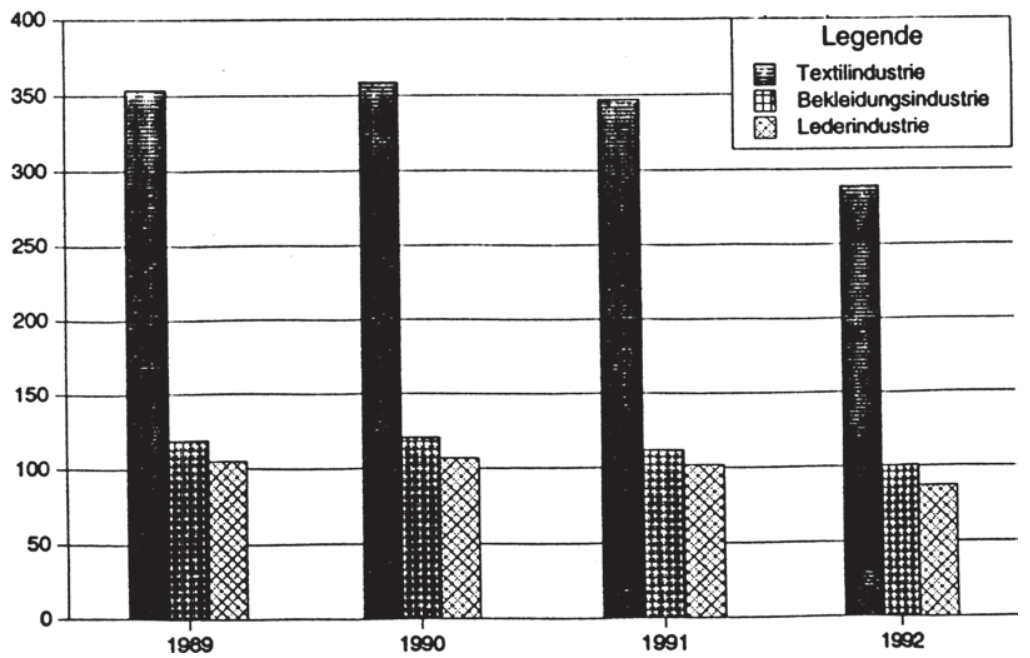

(Nach Angaben des Industrieministeriums) 
Aus diesen Zahlen wird auch klar, daß die Struktur der TBI, wie sie ursprünglich geplant wurde, diese von ihren komparativen Vorteilen nicht profitieren läßt: die arbeitsintensive Bekleidungsindustrie hat dreimal weniger Beschäftigte als die arbeitssparende Textilindustrie! Wenngleich die Kapazitäten der Textilindustrie größer sind, kann dieser Unterschied die offensichtliche Überbelegung mit Personal der Textilindustrie nicht rechtfertigen. Es ist eine Krankheit, an der auch andere MOE-Länder leiden (siehe GÄLLI, 1992, S.17). Andererseits müßte die Zahl der Beschäftigten in der staatlichen Bekleidungsindustrie mit etwa 1,8 multipliziert werden, um die Gesamtzahl der Beschäftigten zu erhalten, da die privaten Firmen in diesem Bereich schon fast $45 \%$ des inländischen Produktionswertes ausmachen.

Der Grund der Senkung der Personalzahlen in den letzten Jahren ist nicht etwa die Erhöhung der Kapitalintensität. Im Gegenteil, die Summe der Investitionen nach 1989 ist - im Vergleich mit dem Bedarf - ganz gering. Es geht eigentlich um die Reduzierung der Überbelegung mit Personal und dann auch um die Einengung der Produktion in manchen Unternehmen, die entweder die Rohstoffquellen oder die Märkte einigermaßen verloren haben.

Die Struktur der Belegschaft ist von dem hohen Anteil der Arbeiter und der Frauen gekennzeichnet. Tabelle 2.23 erlaubt den Vergleich der rumänischen mit den entsprechenden Zahlen für Deutschland.

Tabelle 2.23: $\quad$ Anteile der Arbeiter und der Frauen in der Belegschaft der TBI, in 1992 (in \%)

\begin{tabular}{||l||c|c|c|c||}
\hline \hline Industriesektor & $\begin{array}{l}\text { Rumänien- } \\
\text { Arbeiter }\end{array}$ & $\begin{array}{l}\text { Rumänien- } \\
\text { Frauen }\end{array}$ & $\begin{array}{l}\text { BRD- Ar- } \\
\text { beiter }\end{array}$ & BRD- Frauen \\
\hline \hline Textil & 91,4 & 75,7 & 75 & 50,1 \\
\hline Bekleidung & 91,8 & 84 & 77,9 & 80,5 \\
\hline Lederware & 92 & 69,4 & $?$ & $?$ \\
\hline $\begin{array}{l}\text { Verarbeitendes Ge- } \\
\text { werbe insgesamt }\end{array}$ & 86,8 & 42,2 & 66,9 & 27,8 \\
\hline
\end{tabular}

(Nach Angaben von ROMANIAN STATISTICAL YEARBOOK, 1993, S.160-162 und MÜHLECK, 1992, S.80)

Die Unterschiede zwischen den rumänischen und deutschen Zahlen deuten auf das große Entwicklungs- und Technologiegefälle zwischen den beiden Ländern. In der rumänischen Industrie, und insbesondere in der TBI ist der Einsatz an Forschung, Entwicklung und fortgeschrittener Technologie entsprechend den hohen Arbeiteranteilen kleiner. Auch die höheren Anteile der Frauen in Rumänien zeigen, daß dort diese, auf dem Arbeitsmarkt 
schlechter gestellte Gruppe aufgrund der wichtigen Rolle der Handarbeit vermehrt eingestellt wird. Es darf aber daraus nicht geschlossen werden, daß die Arbeitskräfte der rumänischen TBI grundsätzlich unqualifiziert sind. Die Lage des Ausbildungssystems für den TBI- Bereich wird in der Tabelle 2.24 geschildert.

Tabelle 2.24: $\quad$ Ausbildungsbasis des Personals der rumänischen TBI

\begin{tabular}{||l||c|c|c|c|c|c||}
\hline & $1980 /$ & $\begin{array}{l}1985 / \\
1986\end{array}$ & $\begin{array}{l}1989 / \\
1990\end{array}$ & $\begin{array}{l}1990 / \\
1991\end{array}$ & $\begin{array}{l}1991 / \\
1992\end{array}$ & $\begin{array}{l}1992 / \\
1993\end{array}$ \\
\hline \hline $\begin{array}{l}\text { Berufsschu- } \\
\text { len }\end{array}$ & 46 & 57 & 56 & 37 & 50 & 51 \\
\hline $\begin{array}{l}\text { Schüler in } \\
\text { Berufs- } \\
\text { schulen }\end{array}$ & 23585 & 41077 & 47785 & 37713 & 50076 & 40174 \\
\hline $\begin{array}{l}\text { Abiturienten } \\
\text { der Berufs- } \\
\text { schulen }\end{array}$ & 10592 & 19903 & 20668 & 13760 & 18891 & n.v. \\
\hline $\begin{array}{l}\text { Meister- } \\
\text { schulen }\end{array}$ & 33 & 24 & 6 & 8 & 9 & 11 \\
\hline $\begin{array}{l}\text { Schüler in } \\
\text { Meister- } \\
\text { schulen }\end{array}$ & 3631 & 1667 & 311 & 825 & 914 & 776 \\
\hline $\begin{array}{l}\text { Abiturienten } \\
\text { der Meister- } \\
\text { schulen }\end{array}$ & 2363 & 729 & 153 & 186 & 359 & n.v. \\
\hline $\begin{array}{l}\text { Studenten } \\
\text { von } \\
\text { "Leicht- } \\
\text { industrie" }\end{array}$ & 2972 & 2696 & 3241 & 2943 & 2849 & 2792 \\
\hline $\begin{array}{l}\text { Hochschul- } \\
\text { abschlüsse }\end{array}$ & 610 & 500 & 474 & 487 & 429 & n.v. \\
\hline
\end{tabular}

(Quelle: ROMANIAN STATISTICAL YEARBOOK, 1993, S.274-286)

In Wirklichkeit sind die Arbeitskräfte aller Qualifikationsebenen - wie in der gesamten rumänischen Industrie - sehr geschickt wenn es darum geht, mit ganz knappen Mitteln, mit eigentlich zu verschrottenden Maschinen und Anlagen, ohne Ersatzteile, mit den billigsten Rohstoffen und Betriebsmitteln, die Produktion von der Technik her zu erhalten. In den 80er Jahren, dem Jahrzehnt der Tilgung der ausländischen Schulden, haben sie nur unter diesen 
Bedingungen gearbeitet, da die Importe extrem reduziert waren (man hat nur noch Rohstoffe importiert, als ob Betriebsmittel, Ersatzteile, neue Technologien keine Produktionsfaktoren gewesen wären!); auch standen sie stets unter "Sabotage"-Verdacht, weil trotz ihrer Bemühungen die Produktion manchmal ausfiel. Die Qualifikationsmängel der Belegschaft der TBI sind sozusagen "marktwirtschaftsbedingt": es fehlen grundsätzlich Marketing-, Strategie- und Qualitätssicherungskenntnisse.

Trotz der Bemühungen der Belegschaft und trotz einer akzeptablen Qualität der Ausbildung der Arbeitskräfte ist die Arbeitsproduktivität nach 1989 gesunken (Abb. 2.6).

\section{Abb,2,6: Arbeitsproduktivität in der rumänischen TBI, preisbereinigt, 1989-1992}

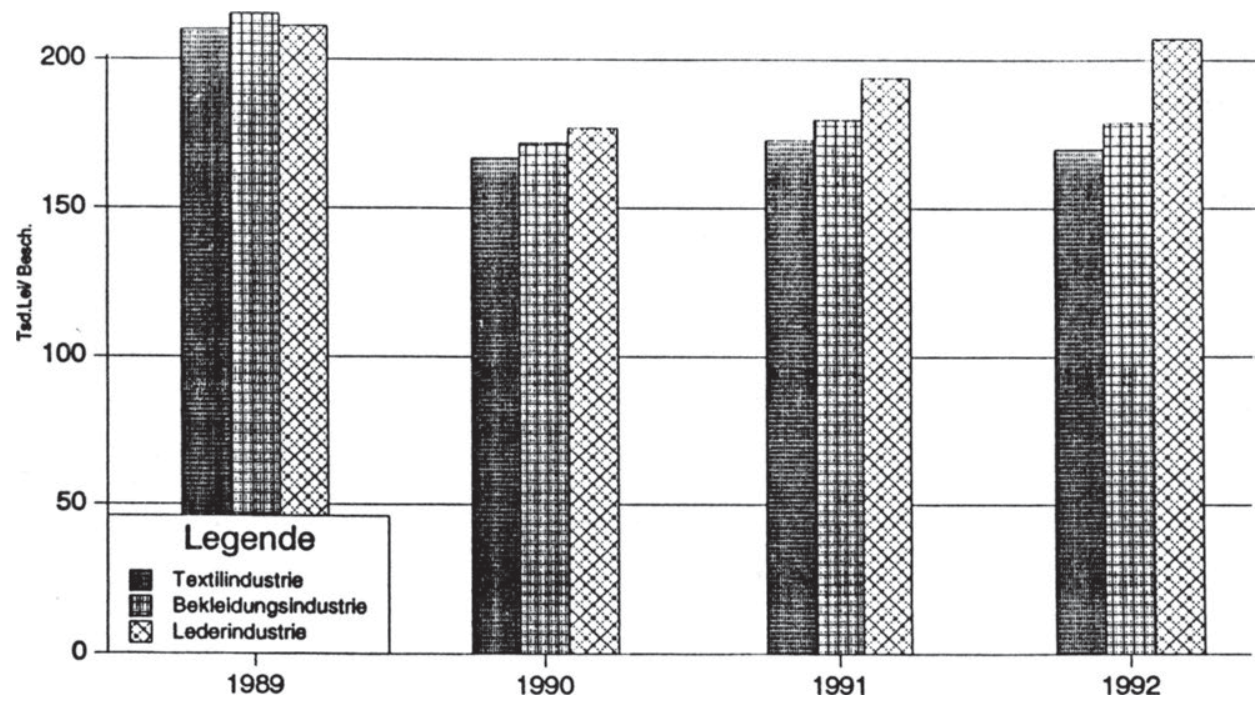

(Nach Angaben des Industrieministeriums) 
Der große Schock war auch hier zwischen 1989 und 1990, wegen der bekannten Ursachen: Verlust billiger Rohstoffquellen und des RGW-Rubelmarktes (auch über 1991 erstreckt), Freisetzung der Rohstoffpreise, und alles nicht von einem proportionalen Stellenabbau begleitet. Danach war die Talsohle erreicht und die Arbeitsproduktivität begann infolge des Stellenabbaus und der Schließung einiger ganz unproduktiven Kapazitäten wieder zu steigen (siehe hierzu auch DIW Nr. 47/1991, S.665). Der Aufschwung der Produktivität in Richtung des ursprünglichen Wertes wurde aber von der ungünstigen Entwicklung der Preise für Textilien und Bekleidung gedämpft. Es ist symptomatisch, daß bei Schuhen und Lederwaren, wo die Preise zwischen Oktober 1990 und Oktober 1993 48,8 mal gestiegen sind, der Wiederanstieg der Produktivität deutlicher war als bei Textilien und Bekleidung, wo der Preisanstieg nur 34,8 mal, weniger als der Industriedurchschnitt, betrug.

Der spezifische Energieverbrauch ist sogar nach 1989 gesunken (Tabelle 2.25). Diese Erhöhung der Effizienz war einigermaßen von der Steigung (36 mal zwischen Okt.1990 und Okt.1993, weniger aber als der Industriedurchschnitt) der Energiepreise (Strom, Gas und Heizung) erzwungen. Auch ist mit der Autonomie den Unternehmen erlaubt worden, die Benutzung der Produktionsanlagen nicht mehr zu forcieren, als es vor 1989 verlangt wurde. Demzufolge wurden insbesondere die ältesten und energieintensivsten Anlagen stillgelegt.

Tabelle 2.25: $\quad$ Effizienz des Energieverbrauchs, in Mio.Lei Produktionswert (preisbereinigt) pro verbrauchte Mio.KWh

\begin{tabular}{||l|c|c|c|c||}
\hline \hline Effizienz & 1989 & 1990 & 1991 & 1992 \\
\hline \hline Textilindustrie & 46,8 & 48,9 & 51,9 & 57,2 \\
\hline Bekleidungsindustrie & 322,7 & 320,6 & 321,3 & 322,2 \\
\hline Lederindustrie & 105,4 & 100,5 & 118,6 & 118,5 \\
\hline Insgesamt & 66,7 & 64,4 & 75,5 & 84,1 \\
\hline
\end{tabular}

(Nach Angaben des Industrieministeriums)

Es ist auch sichtbar, daß die Textilindustrie, die die energieintensivste Stufe der Textilveredelung enthält, viel mehr an Energie verbraucht als die Bekleidungsindustrie. Die Lederindustrie liegt irgendwo dazwischen, weil sie die ganze "Lederpipeline" von der Gerberei bis zur Schuhkonfektion beinhaltet. Die ganze TBI verbraucht aber sowieso im Vergleich mit dem nationalen Industriedurchschnitt wenig: der Textilsektor 2 mal, der Bekleidungssektor 5 mal und der Ledersektor 7,8 mal weniger (siehe auch Paragraph 2.1). 
Beim Rohstoffverbrauch ist die Lage etwas komplizierter. Ein Merkmal der TBI ist ihre Rohstoffintensität. Die Produzenten, die eine hohe Effizienz im Rohstoffverbrauch erreichen, haben also einen wichtigen Wettbewerbsvorteil. Ohne eine gute Organisation, eine einwandfreie Führung des Produktionsprozesses und, vor allem, gute technische Ausstattung ist dieses Ziel aber nicht erreichbar. Tabelle 2.26 gibt die Indikatoren der Rohstoffintensität an.

Tabelle 2.26: $\quad$ Effizienz des Rohstoffverbrauchs der TBI, 1989-1992

\begin{tabular}{||l||c|c|c|c||c||}
\hline $\begin{array}{l}\text { Produktion pro Roh- } \\
\text { stoffuerbrauch }\end{array}$ & 1989 & 1990 & 1991 & 1992 & zum Vergleich: \\
\hline \hline $\begin{array}{l}\text { Kg Baumwollgarn pro 1 } \\
\text { to Baumwollfasern }\end{array}$ & 935 & 919 & 922 & 926 & $\begin{array}{c}\text { Tschechoslowakei } \\
\text { 1988: 938 }\end{array}$ \\
\hline $\begin{array}{l}\text { Kg Wollgarne pro 1 to } \\
\text { Wollfasern }\end{array}$ & 926 & 917 & 921 & 922 & $\begin{array}{c}\text { Belgien 1988: } \\
930\end{array}$ \\
\hline $\begin{array}{l}\text { Kg Flachs- und Hanf- } \\
\text { garne pro } \\
\text { 1 to Fasern }\end{array}$ & 771 & 763 & 757 & 760 & $\begin{array}{c}\text { Polen 1988: } \\
772\end{array}$ \\
\hline $\begin{array}{l}\text { qm Baumwollgewebe } \\
\text { pro 1 to Baumwollgarne }\end{array}$ & 6385 & 5482 & 5600 & 5650 & $\begin{array}{c}\text { Deutschland 1989: } \\
7000\end{array}$ \\
\hline $\begin{array}{l}\text { qm Wollgewebe pro 1 } \\
\text { to Wollgarne }\end{array}$ & 3981 & 3279 & 3341 & 3356 & $\begin{array}{c}\text { England 1988: } \\
4167\end{array}$ \\
\hline $\begin{array}{l}\text { qm Flachs- und Hanfge- } \\
\text { webe pro 1 to Garne }\end{array}$ & 3312 & 3226 & 3333 & 3390 & $\begin{array}{c}\text { Polen 1988: } \\
3743\end{array}$ \\
\hline $\begin{array}{l}\text { qm Seidengewebe pro 1 } \\
\text { to Garne }\end{array}$ & 8905 & 8292 & 8460 & 8621 & Deutschland 1989: \\
9608
\end{tabular}

(Nach Angaben des Industrieministeriums)

Ähnlich wie bei der Arbeitsproduktivität ist die Effizienz des Rohstoffeinsatzes 1990 dramatisch gesunken und hat dann in den nächsten Jahren angefangen, den ursprünglichen Einbruch wieder aufzuholen, ohne das Anfangsniveau bis $1992 \mathrm{zu}$ erreichen.

Der Verfall der Effizienz ist hier eher auf den Verzicht auf die dreistufige Teilung der Produktqualitäten (Export Westen, Export Osten, Inlandsmarkt) zurückzuführen. Bei der Produktion für den heimischen Markt wurde nach der außenwirtschaftlichen Eröffnung zu höheren Qualitätsstandards übergegangen, mit höherem (sprich: normalem) Rohstoffeinsatz. 
Dieser Schritt war von der Konkurrenz der ausländischen Textilien und Bekleidung erzwungen worden. Die ehrgeizigen Rohstoffverbrauchsnormen der planwirtschaftlichen Zeit führten zusammen mit der technischen Leistungsfähigkeit der vorhandenen Anlagen dazu, daß die Textil- und Bekleidungsprodukte für den rumänischen Markt mit einem unterdimensionierten Verbrauch an Material hergestellt waren und demnach beim Waschen schrumpften. Um auf dem inländischen Markt bleiben zu können, mußten die Unternehmen zurück zu den, dem Maschinenpark entsprechenden, Rohstoffmengen kehren.

Bisher wurde nur die Effizienz der physisch eingesetzten Produktionsfaktoren (Arbeitskraft, Energie, Rohstoffe, ohne Sachkapital) untersucht. Die Erforschung der Entwicklung der kostenorientierten Standortbedingungen, in Währungseinheiten ausgedrückt, würde aber einen Blick auf einige komparative Vorteile der rumänischen TBI ermöglichen. Die rumänische Währung wurde zwischen Oktober 1990 und Oktober 1993 vom offiziellen Kurs 60 Lei pro 1 US-\$ zum "Fixing-"Kurs 1095 Lei für 1 US-\$ kräftig abgewertet, um mit der Inflation Schritt zu halten und gleichzeitig die Exporte zu erleichtern. Mit einem monatlichen Durchschnittsgehalt von 54.730 Lei brutto in Juni 1993 (etwa 55 US-\$) waren die Arbeitskräfte der TBI die "billigsten" im Lande (Quelle: NATIONAL STATISTICS COMISSION OF ROMANIA, No.2/1993, S.17). Das höchste Durchschnittsgehalt wird in der Energie- und Gaswirtschaft mit 154.130 Lei gezahlt. Die Lohnquote in der Bruttowertschöpfung der TBI betrug 1991 (letzte Angaben des rumänischen Nationalen Ausschusses für Statistik) 50,82\% (Quelle: ebenda, S.17, und ROMANIAN STATISTICAL YEARBOOK, 1993, S.349). Diese Zahl dürfte in den Jahren 1992 und 1993 wegen der restriktiven Lohnpolitik der Regierung und des hohen Anteils der Zinsaufwendungen in der Wertschöpfung sogar gesunken sein. In der Bundesrepublik Deutschland lag diese Quote 1990 bei $56 \%$ für das Bekleidungs- und $61 \%$ für das Textilgewerbe (Quelle: MÜHLECK, 1992, S.124).

Auch beim Vergleich mit den Lohnkosten der TBI anderer MOE/GUS-Länder schneidet die rumänische TBI sehr gut ab. Die direkten Lohn- und Personalzusatzkosten je Arbeitnehmer und Monat betrugen 199295 DM in Rußland, 173 DM in Bulgarien, 118 DM in Rumänien, 367 DM in Polen, 401 DM in der Tschechoslowakei und 662 DM in Ungarn (Quelle: GASS, 1993, S.18). Die rumänische Arbeitsstunde kostet also 0,67 DM, das heißt 36 mal weniger als in Deutschland und $6 \mathrm{mal}$ weniger als in Hong Kong! (Quelle: BREITENACHER, 1989, S.69).

Die Preise der anderen Produktionsfaktoren sind auch gestiegen, aber unterproportional zu dem durchschnittlichen Preisindex. Letzterer lag in Oktober 1993 bei 4291,3 (Oktober 1990 $=100$ ). Energie, Gas und Heizung haben sich dagegen in demselben Zeitraum nur $36 \mathrm{mal}$ verteuert. Mit der Stillegung vieler Produktionskapazitäten der Schwerindustrie hat Rumänien mittlerweile schon einen Überschuß an Energie; Rumänien ist auch Erdgas- und Ölproduzent; zusätzliches Erdgas wird aus Rußland und Turkmenistan importiert. 
Die Baumwoll- und Chemiefaserpreise (wichtigste importierte Rohstoffe) sind 1990, nach der Auflösung des RGW, auf Weltmarktniveau gestiegen, wo sie seitdem geblieben sind. Auch die Inlandspreise bei synthetischen und zellulosischen Fasern, Wolle, Flachs und Hanf haben sich den Weltmarktpreisen angenähert, ohne aber sie zu erreichen. Ursache hierfür ist das Verbot bzw. die strenge Lizenzkontrolle der Rohstoff- und Halbfabrikatexporte seitens der Regierung für die ganze rumänische Industrie. Der Preisschock wurde also überstanden, allerdings mit einer Einbuße von etwa $50 \%$ in der physischen Produktion, wobei es im Moment ganz schwer zu sagen ist, wieviel von diesem Rückgang auf die Erhöhung der Faktorpreise und wieviel auf den Quasi-Verlust der RGW-Märkte zurückzuführen ist.

Die Kapitalproduktivität ist im untersuchten Zeitraum ebenfalls gesunken (siehe Abb.2.7), und zwar stärker als die Arbeitsproduktivität. Dies ist nicht die Folge einer Substitution von Arbeit durch Kapital (obwohl der Kapitalkoeffizient durch Stellenabbau zugenommen hat), sondern des Produktions- und Umsatzrückgangs.

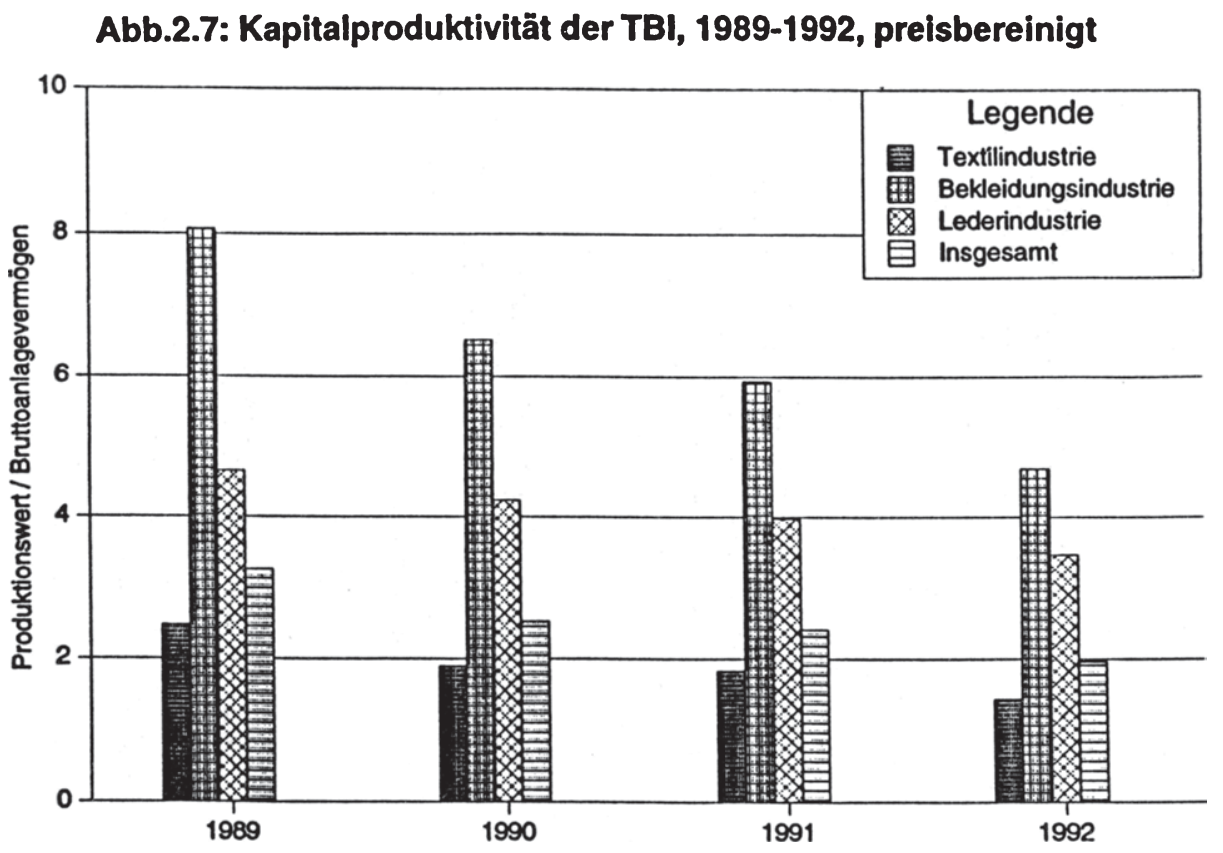

(Nach Angaben des Industrieministeriums) 
Es wäre aber verfehlt, aus dieser ungünstigen Entwicklung der Kapitalproduktivität den Schluß zu ziehen, die Produktionskapazitäten seien in der TBI überhöht und müßten folglich abgebaut werden. Dieser Rückgang ist auf die Qualität und den Gütegrad des Sachkapitals zurückzuführen. Dieses Problem wird im Paragraphen 2.3 näher untersucht. Die neuen Märkte können mit der mit dem vorhandenen Anlagevermögen erreichten Produktqualität nicht gewonnen, die alten Märkte nicht mehr behalten werden.

Für volkswirtschaftliche Zusammenhänge ist auch der Bruttowertschöpfungskoeffizient dieser Branche ganz bedeutend, indem er angibt, mit welcher Effizienz die volkswirtschaftlichen Ressourcen in diesem Sektor benutzt werden. Als Verhältnis zwischen Bruttowertschöpfung und Bruttoproduktionswert ist dieser Indikator in den letzten Jahren kaum gesunken Abb.2.8.

\section{Abb.2.8: Bruttowertschöpfungskoeffizient in der rumänischen TBI, 1989-1992}

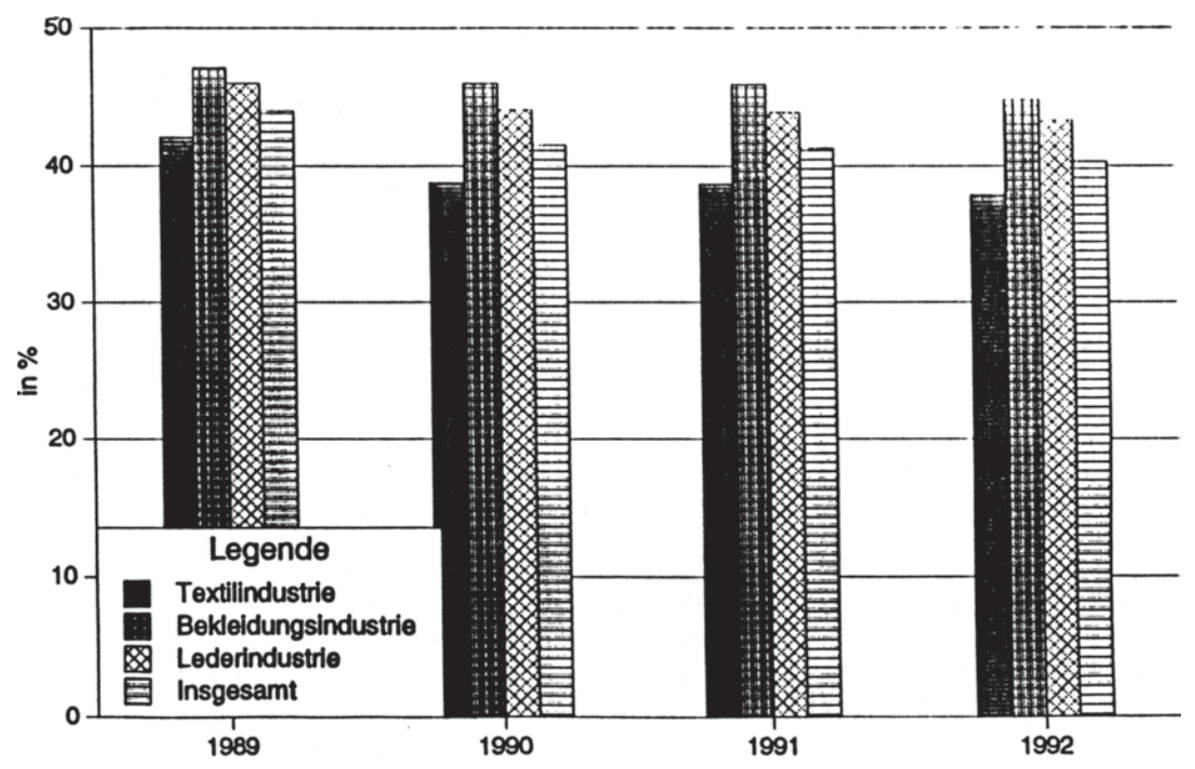

(Nach Angaben des Industrieministeriums) 
Wenn man berücksichtigt, daß dieser Koeffizient 1990 in der deutschen Textilindustrie bei 33,7\% und in der Bekleidungsindustrie bei 30,4\% lag (Quelle: Gesamttextil, 1993), kommt man zur Erkenntnis, daß trotz der Teuerung der Produktionsfaktoren und des Umsatzrückgangs, in der rumänischen TBI noch Raum für eine weitere "Abspeckung" bleibt. Vergleicht man zwischen den Textil- und Bekleidungsindustrien beider Länder auch den Finanzkraftindikator (Verhältnis der Bruttowertschöpfung zu den Lohnkosten), stellt man ähnliche Bedingungen in den Textilsektoren, aber eine viel bessere Lage der rumänischen Bekleidungsindustrie fest (Tabelle 2.27).

Tabelle 2.27: Finanzkraftindikatoren 1991

\begin{tabular}{|l|c|c|}
\hline & Deutschland & Rumänien \\
\hline \hline Textilindustrie & 1,490 & 1,465 \\
\hline Bekleidungsindustrie & 1,112 & 1,250 \\
\hline
\end{tabular}

Nach Angaben von ROMANIAN STATISTICAL YEARBOOK, 1993, S.158, NATIONAL STATISTICS COMISSION OF ROMANIA, No. 2/1993, S.16 und GÄLLI, 1992, S.97)

Schließlich ist die Gewinnlage maßgebend für die wirtschaftliche Gesundheit der untersuchten Branche. Infolge des Preisschocks bei Rohstoffen, der organisatorischen Probleme der Transformation, der Management- und Informationskrise, der Reduzierung der Arbeitszeit und der Senkung der Arbeitsdisziplin, der Spaltung einiger sinnvoll integrierter Betriebe, sind die Kosten gestiegen und die Erlöse gesunken. Sodann hat auch die Masse der erwirtschafteten Bruttogewinne (preisbereinigt) abgenommen (Abb.2.9).

Andere wichtige Faktoren haben auch zu dieser ungünstigen Entwicklung beigetragen und sich in den Bilanzen der Firmen zu Buche geschlagen: die Kettenreaktion der Zahlungseinstellungen infolge der sogenannten "bad debts", geschildert im Kapitel 1, mit einem Zyklus von 12 bis 16 Monaten, immer wieder durch die Lösung der staatlichen Finanzspritzen abgeklärt, hat für jede Runde erhebliche Zinsaufwände mit sich gebracht. Die Perpetuierung hoher Lagerbestände (in September 1993 lagen z.B. diese bei Geweben beim Zweifachen der monatlichen Landesproduktion) hat auch die Kosten erhöht und die Bilanzkennzahlen vieler Unternehmen verschlechtert. Die hohe Lagerhaltung nimmt einen wichtigen Teil des ohnehin unzulänglichen Umlaufvermögens der Unternehmen für unproduktive Zwecke in Anspruch, erschwert dadurch die Wiederholung des Produktionszyklus und erhöht wiederum die Gefahr der Liquiditätskrise. Es ist allgemein bekannt, daß die staatlichen Unternehmen von den planwirtschaftlichen Zeiten einen unzureichenden Anteil der Liquiditäten in den Bilanzsummen geerbt haben (siehe HOANTA, 1993). 
Abb2.9: Bruttogewinne in der rumänischen TBI 1989-1992, In Prelsen von 1990

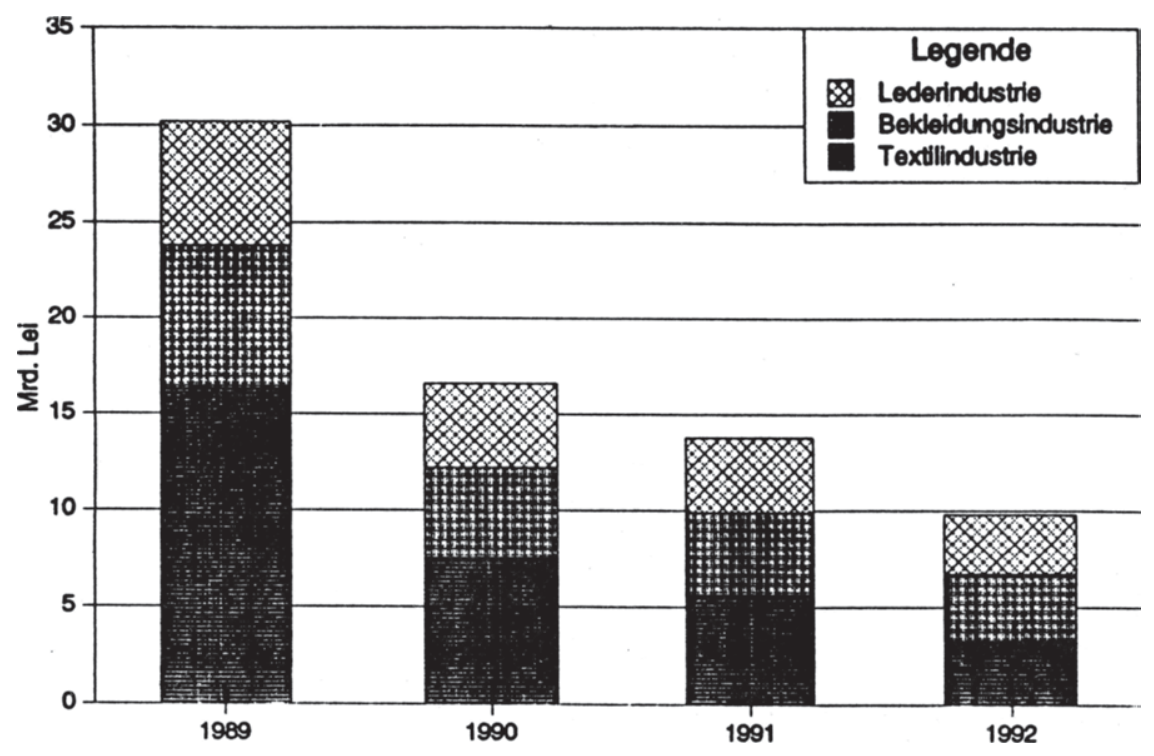

(Nach Angaben des Industrieministeriums)

Im Zuge der forcierten Investitionspolitik hat der sozialistische Staat (und hinterher auch der neue Staat, als Eigentümer, durch seine Fiskal- und Dividendenpolitik) den Unternehmen die erwirtschafteten Überschüsse fast völlig abgenommen und gleichzeitig über Finanzeingriffe auch die Liquiditäten dieser Unternehmen an der Untergrenze gehalten. Nach der Wende wurde auch kaum berücksichtigt, daß die freie Marktwirtschaft eine höhere Liquidität der Unternehmen benötigt als die Planwirtschaft, deren steife Zahlungs- und Abrechnungsmechanismen immer über dieselben Kanäle liefen. Weiter entzieht das Bankensystem mit seinen maroden Zahlungssystemen (eine einfache Zahlung zwischen 2 Unternehmen kann bis 3 Wochen dauern) wichtige Liquiditäten - im Oktober 1993 waren es 320 Mrd.Lei, zwei Drittel des Produktionswertes der TBI im ganzen Jahr 1992 (!), die zwischen den Konten unterwegs waren (Quelle: POPESCU, 1994).

Die finanziellen Schwierigkeiten, die sich auf die Gewinnlage der Unternehmen negativ auswirken, sind also hauptsächlich durch die endogene Unterkapitalisierung jedes Unternehmens und die wichtigen Störungen, die die "bad debts" und das schlechte Funktionieren des Bankensystems von außen induzieren, verursacht. 


\subsection{Faktorausstattungsanalyse}

Eine Zusammenfassung der Stärken und Schwächen der rumänischen TBI sollte aber in Anlehnung an die Faktorausstattungshypothese erfolgen. Diese Hypothese hat bei den theoretischen Überlegungen zu den Standortvor- und -nachteilen und somit zur Wettbewerbsfähigkeit vieler nationaler Textilindustrien große Bedeutung erlangt. Die Hypothese besagt im Grunde genommen, daß ein Land bei jenen Gütern besonders wettbewerbsfähig ist, bei deren Produktion die im Land reichlich vorhandenen Produktionsfaktoren besonders intensiv ausgenutzt werden können.

Die drei grundlegenden Produktionsfaktoren sind ungelernte Arbeit, Ausbildungskapital und Sachkapital. Die Textilindustrie kann mit einer gegebenen Investitionssumme überdurchschnittlich viel Arbeitsplätze zur Verfügung stellen; deswegen wird daraus geschlossen, daß Länder wie Rumänien, die ein großes Reservoir von Arbeitskräften haben, bei der Herstellung von Textilien Standortvorteile haben. In der Tat ergibt sich aus den bisherigen Ausführungen daß mit den ersten zwei Produktionsfaktoren Rumänien besonders gut bzw. gut ausgestattet ist, zumal gegen geringere Kosten. Auch die anderen Faktoren, die auf die Wettbewerbsfähigkeit Einfluß nehmen (BREITENACHER, 1981, S.130), bewegen sich in befriedigenden Grenzen. Das Wirtschaftsklima im allgemeinen ist viel gesünder als vor der Wende und, selbst wenn es nicht so günstig wie in Ungarn und in der Tschechischen Republik ist, läßt sich vermuten, daß die heutige populistische Regierung mit ihrer halbherzigen Reformpolitik die positive Energie der marktwirtschaftlichen Impulse nicht mehr lange bremsen können wird. Das Ausmaß von Genehmigungsvorschriften ist für die Gründung neuer Unternehmen, insbesondere mit Auslandskapital, kein nennenswertes Hindernis; im Gegenteil, die Gesetzgebung versucht die Gründung von Unternehmen des verarbeitenden Gewerbes anzureizen. Eine wichtige Schwachstelle wäre hier die Trägheit und Korruption der Verwaltungsorgane: dies ist auch eine politische Frage. Die Normen betreffend den Umweltschutz sind bei weitem nicht so streng wie in der EG, und in der Textilproduktion sind die Emissionen sowieso nicht bedeutend. Die Rohstoffkosten sind mittlerweile auf Weltmarktniveau (außer bei Wolle, Flachs und Hanf, die billiger geblieben sind); Energie, Kommunikations- und Transportkosten sind zwei bis drei mal billiger als in Deutschland, wenn auch die Qualität der angebotenen Leistungen nicht dieselbe ist. Die Nähe zum künftig riesigen russischen Absatzmarkt, aber auch zu der EG -insbesondere zu Deutschland und Italien, den wichtigsten TBI-Produzenten, aber auch Importeuren, der EG - ist auch ein auf mittlerer Sicht wichtiger Standortvorteil.

Es zeigt sich also, daß die heutigen Schwierigkeiten der rumänischen TBI - vor allem die Verschlechterung der Finanzlage und der Kapazitätsauslastung infolge der Umsatzsenkung hauptsächlich auf den übrig bleibenden Produktionsfaktor Sachkapital und einigermaßen (was die Management- und Marketingkenntnisse betrifft) auf das Ausbildungskapital zurückzu- 
führen sind. Tatsache ist, daß die rumänische TBI an Unterkapitalisierung leidet. Diese Unterkapitalisierung bedeutet aber nicht nur den zu geringen Anteil der liquiden Mitteln in der Bilanzsumme, wie vorhin gezeigt. Vielmehr ist darunter zu verstehen, daß die Struktur, die Qualität, die Funktionalität und der Gütegrad des vorhandenen Kapitalstocks den Herausforderungen der marktwirtschaftlichen Eröffnung nicht entspricht. Die Eigenschaften des Sachkapitals der rumänischen TBI sollten deshalb näher untersucht werden.

Eine Synthese des Instituts für die Leichtindustrie in Bukarest (unveröffentlicht) zeigt ein desolates Bild des Anlagevermögens dieser Branche (Tabelle 2.28).

Tabelle 2.28: $\quad$ Maschinen- und Anlagenausstattung der rumänischen TBI - 1990

\begin{tabular}{||l|c|l|l|c|}
\hline Branche & $\begin{array}{l}\text { Gesamtzahl } \\
\text { der Maschi- } \\
\text { nen und } \\
\text { Anlagen; } \\
\text { - darunter: }\end{array}$ & $\begin{array}{l}\text { zwischen 10 } \\
\text { und 20 Jah- } \\
\text { ren alt }\end{array}$ & $\begin{array}{l}\text { älter als 20 } \\
\text { Jahre }\end{array}$ & $\begin{array}{l}\text { völlig abge- } \\
\text { schrieben }\end{array}$ \\
\hline \hline Baumwolleverarbeitung & 56360 & $47,4 \%$ & $36,6 \%$ & $27,7 \%$ \\
\hline Wolleverarbeitung & 11958 & $28,6 \%$ & $20,6 \%$ & $26,8 \%$ \\
\hline Seideverarbeitung & 11405 & $46,5 \%$ & $35,6 \%$ & $29,2 \%$ \\
\hline $\begin{array}{l}\text { Flachs- und Hanfver- } \\
\text { arbeitung }\end{array}$ & 6268 & $67,2 \%$ & $13 \%$ & $10,7 \%$ \\
\hline Maschenware & 41609 & $58,2 \%$ & $16,9 \%$ & $17,1 \%$ \\
\hline Bekleidung & 65952 & $54,6 \%$ & $5,8 \%$ & $48,9 \%$ \\
\hline Lederwaren & 27857 & $27,4 \%$ & $50,1 \%$ & $52,8 \%$ \\
\hline \hline Insgesamt TBI & 221409 & $48,6 \%$ & $23,5 \%$ & $30,2 \%$ \\
\hline
\end{tabular}

(Quelle: Institut für Leichtindustrie Bukarest)

Selbst bei den überhöhten, vom Gesetz Nr.62/1968 (immer noch in Kraft) fixierten Nutzungsdauern (zwischen 15 und 25 Jahren), ist der Anteil der völlig abgeschriebenen Anlagen, die immer noch arbeiten, phantastisch hoch: $30,2 \%$ für die gesamte TBI, aber ganz extrem für die Bekleidungsindustrie $(48,9 \%)$ und für die Lederindustrie $(52 \%)$.

Die rumänische TBI befindet sich somit etwa 15-20 Jahre hinter den gleichen Branchen der Industrieländer. Der technische und moralische Verschleiß übt direkten Einfluß auf die Qualität und die Diversifizierung der Produkte, sowie auf den Rohstoff- und Energiever- 
brauch, auf die Produktivität und die Stückkosten aus. Wenn nichts gemacht wird, wird die rumänische Textil- und Bekleidungsindustrie immer weniger produzieren (weil die alten Maschinen umso öfter kaputt gehen werden) und zwar mit immer höheren Kosten wegen den obsoleten Technologien. Auch die veraltete Struktur des Sachkapitals mit seinen bescheidenen Fertigungsmöglichkeiten ermöglicht nicht die Realisierung von moderneren Produkten in kleineren Losgrößen, unter höheren Flexibilitätsbedingungen und in einer breiteren Produktpalette. Die im Paragraphen 2.2.3 ausgewiesene, ungünstige Entwicklung der Kapitalproduktivität ist auch Ausdruck für die Anpassungsschwierigkeiten des Textil- und Bekleidungsangebots, die mit dem veralteten Kapitalstock in Zusammenhang stehen. Auch der Bruttokapitalkoeffizient - das Verhältnis zwischen Bruttoanlagevermögen und Bruttowertschöpfung deutet, durch seine Erhöhung, auf eine Senkung der Effizienz des Sachkapitals dieser Branche hin (Abb.2.10).

Abb.2.10: Bruttokapitalkoeffizient in der rumänischen TBI, 1989-1992

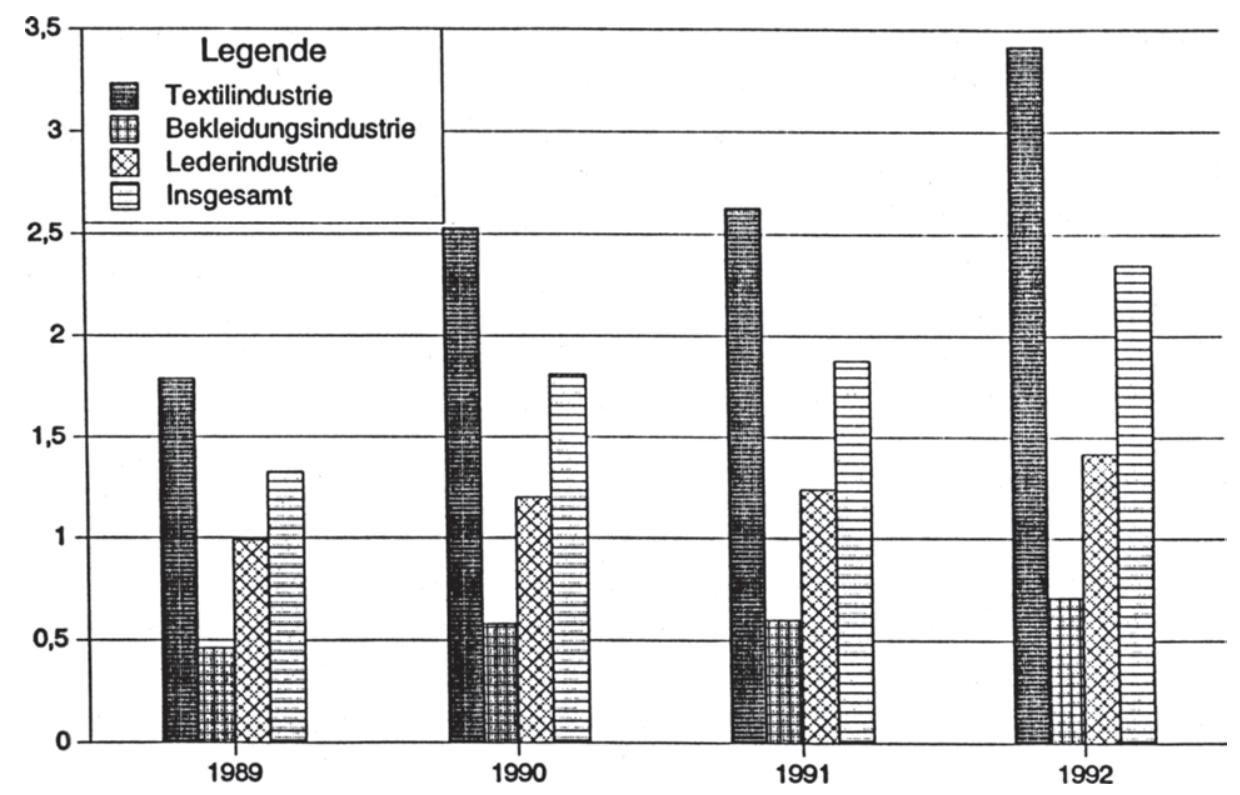

(Quelle: Eigene Berechnungen nach Angaben des Industrieministeriums) 
Die beim Industrieministerium vorliegenden Angaben erlauben auch die Berechnung des Kapitalgütegrads, verstanden als Verhältnis der volkswirtschaftlichen Buchwerte zu den volkswirtschaftlichen Neuwerten, das heißt zwischen den aggregierten Restwerten und den aggregierten Nominalwerten der vorhandenen Anlagen (Tabelle 2.29).

Tabelle 2.29: $\quad$ Kapitalgütegrad in der rumänischen TBI, 1990-1992

\begin{tabular}{||l|c|c|c|}
\hline & 1990 & 1991 & 1992 \\
\hline \hline Textilindustrie & 0,520 & 0,528 & 0,528 \\
\hline Bekleidungsindustrie & 0,563 & 0,583 & 0,602 \\
\hline Lederindustrie & 0,444 & 0,452 & 0,408 \\
\hline \hline Insgesamt TBI & 0,517 & 0,525 & 0,523 \\
\hline
\end{tabular}

(Eigene Berechnungen nach Angaben des Industrieministeriums)

Gemäß der allgemeinen Auffassung spiegelt ein Kapitalgütegrad größer als 0,5 eine normale Investitionstätigkeit wider (bei 0,5 finden nur Ersatzinvestitionen statt), während ein Gütegrad kleiner als 0,5 die Schrumpfung der Branche signalisieren sollte. Anscheinend gäbe es nur für die Lederindustrie Gründe, sich Sorgen zu machen. Es müssen aber zwei weitere Probleme berücksichtigt werden. Erstens sind selbst die höheren Zahlen der Bekleidungsindustrie zu klein, wenn ein richtiger Wirtschaftsaufschwung gewünscht wird, was für die osteuropäischen Länder der Fall ist. In der Verbrauchsgüterindustrie der BR Deutschland lag der Kapitalgütegrad selbst im schweren Nachkriegsjahr 1950 bei 0,574 , ist danach auf 0,696 in 1960 gestiegen und dann auf 0,649 in 1970 gesunken.

Zweitens hängt der Kapitalgütegrad von der gesetzlich erlaubten Abschreibungsmöglichkeit ab. Sind die vom Gesetz zugelassenen Nutzungsdauern überhöht, wie es in Rumänien tatsächlich der Fall ist (zumal die einzige Abschreibungsmethode das Linearverfahren ist), erweist ein viel älteres Anlagevermögen denselben Kapitalgütegrad wie ein - nach internationalem Gebrauch - gut erhaltenes Sachkapital. Mit anderen Worten, wenn alle Anlagen einer Branche 10 Jahre alt sind, und ihre gesetzlich erlaubte Nutzungsdauer 20 Jahre beträgt, ist der Kapitalgütegrad 0,5, genauso wie im Falle einer Branche, wo alle Anlagen 5 Jahre alt sind, bei einer gesetzlich erlaubten Nutzungsdauer von 10 Jahren. Auch werden die völlig abgeschriebenen Anlagen, die aber immer noch arbeiten - ein typisches Phänomen in der osteuropäischen Industrie - vom Kapitalgütegrad nicht erfaßt. Aus diesen Gründen soll in der Beurteilung der Sachkapitalausstattung der rumänischen Industrie das größere Gewicht auf die Altersdistribution in der Tabelle 2.28 gesetzt werden. 
Wie ist man aber in diese Situation geraten? Die heutige Ausstattung ist das Ergebnis einer von dem normalen Trend der intensiven Entwicklung und qualitativen Verbesserung abweichenden Evolution, die fast alle Sektoren der osteuropäischen Volkswirtschaften charakterisiert hat.

Die intensive Entwicklung der Textil- und Bekleidungsindustrie, mit Druck auf der Verbesserung der Effizienzparameter, fand eigentlich nur in den marktwirtschaftlichen Ländern statt, insbesondere in den Industrie- und Schwellenländern. In der ersten Hälfte der 80er Jahre vollzog sich unter dem Druck der Weltwirtschaftskrise ein neuer Investitionszyklus in den westlichen Textil- und Bekleidungsindustrien, der nicht nur aus Ersatzinvestitionen bestand, sondern auch auf Verfahrensverbesserungen und Rationalisierung gerichtet war (VIEHWEG, 1989, S.17). Diesbezüglich seien z.B. die mikroelektronischen Steuerungen und die Computersteuerung in der ganzen Textilfabrikation, der Übergang zum Open-End Spinnverfahren, zu den schützenlosen Webstühlen (Greifer-, Projektil-, Luft- und Wasserjetwebmaschinen), die die Herstellung breiterer Stoffe, in mehreren Farben und mit einer drei mal höheren Produktivität ermöglichen, sowie die Spezial- und Sondernähmaschinen und die speziellen Transportsysteme (Hängeförderanlagen) in der Bekleidungsindustrie, erwähnt.

In Rumänien wurde inzwischen die Textil- und Bekleidungsproduktion, die durch Exporte den Feldzug der Tilgung der Auslandsschulden unterstützen mußte, stark forciert, ohne die mindestens zur Erhaltung des Produktionspotentials benötigten Investitionen zu tätigen (Abb.2.11).

Angesichts der relativen Geldwertstabilität der 80er Jahre sind diese Zahlen auch ohne Preisbereinigung aussagekräftig genug. Im Textilbereich sind also von 1980 bis 1985 die Investitionen stark gesunken, im Bekleidungssektor gewachsen und im Ledersektor stagniert. Dies entspricht einer kurzsichtigen Strategie der Reduzierung, ohne Rücksicht auf die Konsequenzen, der Importe für die nicht direkt exportierenden Branchen. Demzufolge hat die Qualität der rumänischen Stoffe abgenommen und sie konnten umso weniger exportiert bzw. in Exportprodukte eingebaut werden. Nach 1985 haben die Investitionen im Textilsektor angefangen, wieder anzusteigen, ohne aber das Ursprungsniveau von 1980 erreichen zu können. Diese Investitionspolitik des sozialistischen Staates hat zur starken Veralterung des Sachkapitals und zur Senkung der Qualität der Textilien geführt.

Der Anstieg der Investitionen im Bekleidungsbereich ist hauptsächlich eine Folge der Verbreitung der Lohnveredelungsverträge, wo normalerweise der westliche Partner, unter Berücksichtigung des maroden Zustandes der Maschinen im rumänischen Partnerunternehmen, auch die benötigten Maschinen zur Verfügung stellte. 


\section{Abb.2.11: Bruttoanlageinvestitionen in der rumänischen TBI, 1980-1989}

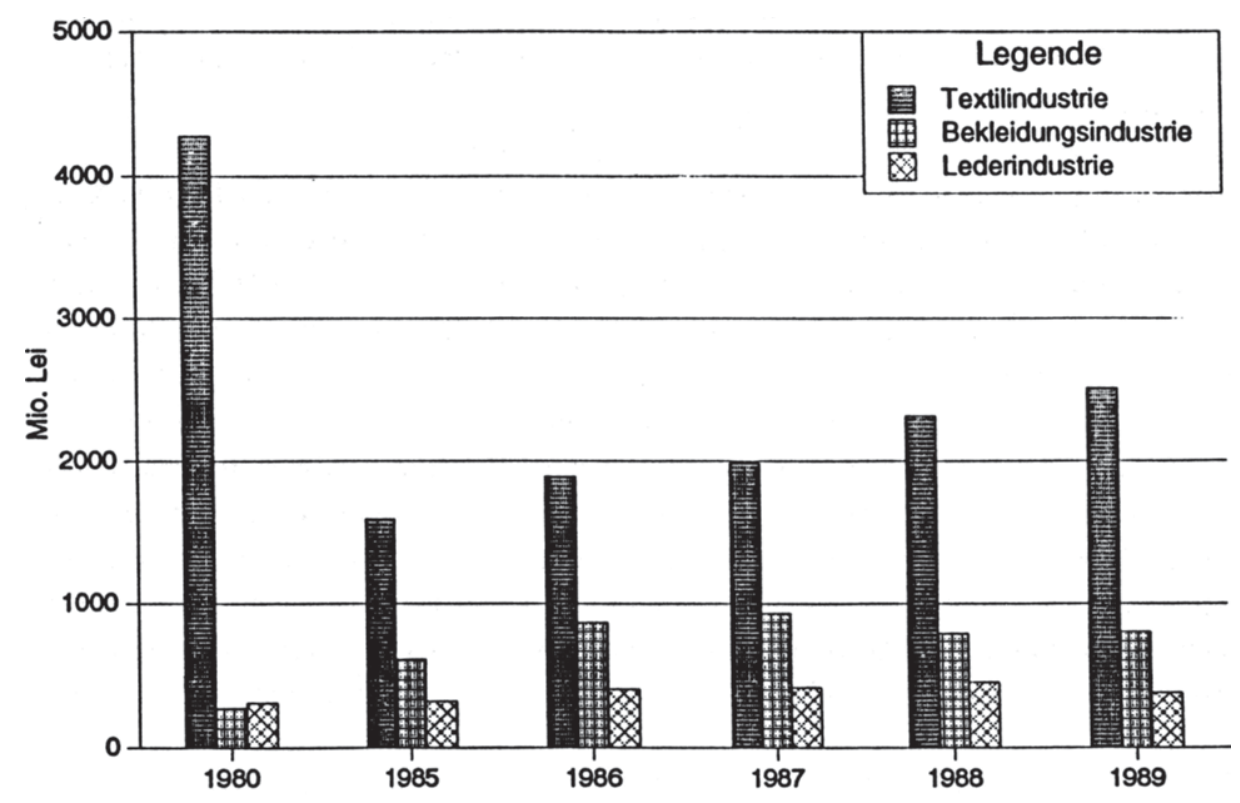

(Nach Angaben von ROMANIAN STATISTICAL YEARBOOK, 1993, S.376)

$\mathrm{Daß}$ die getätigten Bruttoanlageinvestitionen für die Erhaltung des 1980 vorhandenen Produktionspotentials nicht ausreichten, zeigt sich aus der Entwicklung der Produktionszahlen 1980-1989 (Tabelle 2.30).

Mit der Ausnahme der Bekleidung und, einigermaßen, der Wollgewebe, ist die Produktion der TBI in allen Produktgruppen entweder stagniert oder gesunken. Es muß auch berücksichtigt werden, daß zwischen 1983 und 1989117 brandneue Betriebe der TBI, für eine totale Investitionssumme von 2934 Mio.Lei eingeweiht wurden. Die Produktionskapazitäten wurden also ausgeweitet, ohne daß die physische Produktion angestiegen ist (Ausnahme: Bekleidungsindustrie). Es ist der Beweis dafür, daß die damalige Führung der rumänischen geplanten Wirtschaft keinen anderen Pfad der wirtschaftlichen Entwicklung als die extensive Ausweitung der physischen Kapazitäten, ohne qualitative Anpassung an die neuen Herausforderungen der Märkte, verstand oder wählen konnte. Um die triumphierende Industrialisierung weiter zu betreiben, ließ man die bestehenden Produktionskapazitäten verfallen, und finanzierte mit den von ihnen erwirtschafteten Bruttoüberschüssen andere, neue Produktionsstellen. 
Tabelle 2.30: Produktion der rumänischen TBI, 1980-1989

\begin{tabular}{|c|c|c|c|c|c|c|c|}
\hline & M.E & 1980 & 1985 & 1986 & 1987 & 1988 & 1989 \\
\hline Baumwollgarne & $\begin{array}{l}\text { Tsd. } \\
\text { to. }\end{array}$ & 183 & 170 & 181 & 172 & 165 & 158 \\
\hline Wollgarne & $\begin{array}{l}\text { Tsd. } \\
\text { to. }\end{array}$ & 74 & 72 & 77 & 76 & 76 & 67 \\
\hline $\begin{array}{l}\text { Flachs- und Hanfgar- } \\
\text { ne }\end{array}$ & $\begin{array}{l}\text { Tsd. } \\
\text { to. }\end{array}$ & 45 & 38 & 38 & 36 & 36 & 34 \\
\hline Baumwollgewebe & $\begin{array}{l}\text { Mio. } \\
\text { qm. }\end{array}$ & 748 & 695 & 727 & 705 & 689 & 709 \\
\hline Wollgewebe & $\begin{array}{l}\text { Mio. } \\
\text { qm. }\end{array}$ & 128 & 128 & 137 & 135 & 133 & 141 \\
\hline $\begin{array}{l}\text { Flachs-, Hanf- und } \\
\text { Jutegewebe }\end{array}$ & $\begin{array}{l}\text { Mio. } \\
\text { qm. }\end{array}$ & 148 & 140 & 149 & 149 & 140 & 123 \\
\hline Seidegewebe & $\begin{array}{l}\text { Mio. } \\
\text { qm. }\end{array}$ & 130 & 135 & 138 & 142 & 140 & 142 \\
\hline Strickwaren & $\begin{array}{l}\text { Mio. } \\
\text { Stk. }\end{array}$ & 296 & 279 & 285 & 274 & 258 & 260 \\
\hline Strümpfe & $\begin{array}{l}\text { Mio. } \\
\text { Paar }\end{array}$ & 235 & 244 & 260 & 253 & 241 & 240 \\
\hline Bekleidung & $\begin{array}{l}\text { Mrd. } \\
\text { Lei }\end{array}$ & 31 & 47 & 50 & 50 & 47 & 46 \\
\hline Schuhe & $\begin{array}{l}\text { Mio. } \\
\text { Paar }\end{array}$ & 113 & 112 & 116 & 113 & 109 & 118 \\
\hline
\end{tabular}

(Quelle: ebenda, S.498)

Nach 1989 sind die Anlageinvestitionen angesichts des Investitionsbedarfs, der sich aus dem desolaten Stand der überwiegenden Mehrheit der bestehenden Anlagen ergab, und infolge der neuen Autonomie der staatlichen Unternehmen, wieder gestiegen. 1989 hat man noch 3.700 Mio. Lei in die TBI investiert; 1990 waren es 3.000 Mio. Lei, zuzüglich 77,6 Mio. US-\$ (Währungskurs: 1 US-\$ = 60 Lei); die Investitionssumme sank aber einigermaßen 1991 mit 3.194 Mio. Lei (preisbereinigt) und 57,6 Mio. US-\$, um in 1992 auf 1.505 Mio.Lei (preisbereinigt) und 8,6 Mio. US-\$ extrem zu fallen (Tabelle 2.31). 
Tabelle 2.31: $\quad$ Bruttoanlageinvestitionen in der rumänischen TBI, 1990-1992 (preisbereinigt)

\begin{tabular}{||l||c|c|c||}
\hline & Jahr & Mio.Lei & Mio.US-\$ \\
\hline \hline Insgesamt TBI & 1990 & 3000 & 77,6 \\
- davon: & 1991 & 3194 & 57,6 \\
\hline 1) Modernisierung der Anlagen und der & 1992 & 1505 & 8,6 \\
Produkte für die Erhöhung der Exporte & 1990 & 300 & 7,1 \\
& 1991 & 198 & 5,3 \\
\hline 2) Umprofilierung der Produktionskapazitä- & 1992 & 167 & 1,0 \\
ten & 1990 & - & - \\
& 1991 & 114 & - \\
\hline 3) Verbesserung der Technologien für die & 1990 & 71 & - \\
Reduzierung des Rohstoffs- und Energiever- & 1991 & 2285 & 46,3 \\
brauchs & 1992 & 921 & 6,6 \\
\hline 4) Fertigstellung von vor 1989 angefangenen & 1990 & 700 & 10,0 \\
Investitionen für die Erhöhung der Produk- & 1991 & 445 & 6,0 \\
tion von Primärressourcen und Recycling & 1992 & 155 & 1,0 \\
\hline 5) Umweltschutzinvestitionen & 1990 & - & - \\
& 1991 & 114 & - \\
\hline
\end{tabular}

Tabelle 2.31 bis: Finanzierungsquellen der Bruttoanlageinvestitionen in der rumänischen TBI, 1990-1992

\begin{tabular}{||l||c|c|c||}
\hline \hline & 1990 & 1991 & 1992 \\
\hline \hline Aus einbehaltenen Gewinnen: & & & \\
- in Mio. Lei & 3000 & 2281 & 714 \\
- in Mio. US-\$ (a) & - & - & 6,5 \\
- in Mio. US-\$ (b) & 14,4 & 10,2 & 0,6 \\
\hline Aus Krediten: & & & \\
- Inland (Mio.Lei) & - & 912 & 792 \\
- Ausland (Mio.US-\$) & 61,0 & 46,4 & 1,5 \\
\hline Auslandsinvestitionen & 2,2 & 1,0 & - \\
\hline
\end{tabular}

Erklärung: (a) - an der rumänischen Außenhandelsbank, und, angefangen mit November 1991, im "Fixing"-Verfahren beschaffene Devisen

(b) - durch eigene Exporte erwirtschaftete Devisen

(Nach Angaben des Industrieministeriums und eigenen Berechnungen - für beide Tabellen) 
In den Jahren 1990 und 1991 gab es also eine bestimmte Investitionswelle. Die vorliegenden Zahlen lassen vermuten, daß die Teilnehmer hauptsächlich die Unternehmen waren, die 1989 noch exportierten (siehe den überwiegenden Anteil der durch eigene Exporte erwirtschafteten Devisen in der Finanzierung der Anlagenimporte) und/oder einigermaßen international kreditwürdig waren, bzw. Regierungsgarantien für die aufgenommenen Kredite kriegten. 1992 fingen aber die Tilgungen der Kredite für diese Unternehmen an, während die anderen nicht imstande waren, aus den unterschiedlichsten Gründen, gemäß ihres Bedarfs zu investieren. Der Investitionsbedarf wurde mit den 1990 und 1991 vorgenommenen Investitionen bei weitem nicht gedeckt, wie es später in diesem Paragraphen gezeigt wird. Auch die Gründung von "joint ventures" mit staatlichen Unternehmen wurde 1992 eingestellt. Eine bestimmte Kreditknappheit, sowie die Schrumpfung der zur Finanzierung von Investitionen herangezogenen Nettogewinne können auch festgestellt werden. In Tabelle 2.32 wird die Summe der zur Finanzierung von Investitionen benutzten Gewinne mit der Bruttogewinnmasse jedes Jahres (preisbereinigt) verglichen:

Tabelle 2.32.

\begin{tabular}{||l|c|c|c|c|}
\hline & 1989 & 1990 & 1991 & 1992 \\
\hline \hline $\begin{array}{l}\text { Investitionen, finanziert aus } \\
\text { einbehaltenen Gewinnen } \\
\text { (Mio.Lei) }\end{array}$ & - & 3000 & 2281 & 714 \\
\hline Bruttogewinnmasse (Mio. Lei) & 31500 & 17000 & 14200 & 10100 \\
\hline $\begin{array}{l}\text { Anteil der Investitionen in der } \\
\text { Bruttogewinnmasse (\%) }\end{array}$ & - & 17,6 & 16,1 & 7,1 \\
\hline
\end{tabular}

(Nach Angaben des Industrieministeriums und eigenen Berechnungen)

Wie angedeutet, konnte nur ein geringer Anteil der Bruttogewinne zur Finanzierung der Investitionen eingesetzt werden - aus dem Bruttogewinn muß in staatlichen Unternehmen zuerst eine $45 \%$-ige Gewinnsteuer an den Staatshaushalt abgeführt, und nur danach können bis zu 50\% des Nettogewinns für Investitionen einbehalten werden. Die übrigen $50 \%$ des Nettogewinns müssen zwischen dem Fonds für die Motivierung der Mitarbeiter (bis zu 10\% des Nettogewinns) und den Dividenden an Staats- und Privateigentumsfonds geteilt werden. Die privaten Unternehmen brauchen die letzten zwei Abgaben nicht zu bezahlen, verfügen allerdings über viel kleineren Gewinnmassen. Zwischen 1990 und 1992 sind die Gewinne infolge der im Paragraphen 2.2.3 angegebenen Ursachen - stets gesunken. Weil der Anteil der Investitionen in diesen Gewinnsummen aufgrund des staatlichen Drucks ganz gering ist, sind auch die Investitionen bis auf Werte, die selbst die Erhaltung der heutigen Wettbewerbs- 
fähigkeit in Frage stellen gesunken, den riesigen Umstrukturierungsbedarf nicht zu erwähnen.

Auch bekamen 1991 die staatlichen Unternehmen der TBI die Möglichkeit wieder, langfristige Kredite aufzunehmen - allerdings in unzulänglichen Mengen. Auch wenn diese Kredite mit 2,4 Mrd. Lei in 1991 und 6,1 Mrd. Lei in 1992 (laufende Preise) einer gesamten Summe von etwa 9,5 Mio. US-\$ gleichwertig waren, sanken die Auslandskredite von 46,4 Mio. US-\$ auf 1,5 Mio. US-\$ von 1991 bis 1992 . Wichtige Teile der IWF "stand by" Kreditvolumina blieben vor allem wegen der schwerwiegenden Bürokratie der Regierungsgremien bei der Beurteilung der Investitionsprojekte und bei der Erteilung der Regierungsoder Finanzministeriumsgarantien unbeansprucht. Auch der provisorische Charakter der STOLOJAN-Regierung und, basierend darauf, ihre Weigerung, entschiedene Reformschritte zu unternehmen, beeinflußten die internationale Kreditwürdigkeit Rumäniens in negativem Sinne. Symptomatisch ist auch, daß 1992 keine westliche Firma sich mehr traute, ein "joint venture" mit einem staatlichen Unternehmen in Rumänien zu gründen (nach letzten Angaben gibt es wieder welche in 1993, wobei der deutsche Bekleidungsproduzent Steilmann der wichtigste Investor ist).

Aus der Struktur der nach der Wende getätigten Investitionen ergibt sich auch, daß diese nicht marktgerecht genug verteilt waren. Zwar ist die Reduzierung des Rohstoff- und Energieverbrauchs in Zeiten von Preisschocks bei diesen Produktionsfaktoren ganz wichtig; es darf aber nicht vergessen werden, daß es auf den internationalen Märkten Qualitätsschwellen gibt, unter denen die Produkte, egal wie billig, sich nicht mehr verkaufen lassen. In dieser wichtigeren Richtung wurde bisher ganz wenig getan.

Zusammenfassend ist der Hauptgrund für die bisherige bescheidene Investitionstätigkeit in der TBI der Kapital- und Kreditmangel. Auf dem heimischen Kreditmarkt ist es äußerst schwer, langfristige Kredite aufzunehmen. Internationale Kredite sind vor allem wegen der Gesetzgebung, die es den rumänischen Unternehmen nicht erlaubt, mit Grund und Boden zu bürgen, sehr schwer zu bekommen. Und die Gewinnmasse als übrig gebliebene Finanzierungsquelle ist von Steuern und erzwungenen Dividendenzahlungen überstrapaziert.

Alle vom Verfasser dieser Arbeit befragten Fachleute und Führungskräfte der Betriebe der TBI, des Industrieministeriums und des Instituts für Leichtindustrie waren der Meinung, der Investitionswille sei in jedem Betrieb da, weil alle merken, daß, wenn sie ihr Angebot qualitativ, preislich und kostenmäßig zu den Anforderungen der Märkte nicht anpassen, sie aus den Märkten ausscheiden werden. So hat z.B. die Abteilung für Textil- und Bekleidungsindustrie innerhalb des Industrieministeriums eine "Synthese der strategischen Ziele der Umstrukturierung und Weiterentwicklung der rumänischen TBI" den Unternehmen vorgeschlagen, in der von: 
- $\quad$ dem Stopp der Produktions- und der Umsatzsenkung durch die Anpassung der Produktsortimente und -qualitäten an die heutigen marktwirtschaftlichen Anforderungen;

- der Umstrukturierung der Produktion durch ihre Umorientierung und qualitative Anpassung bezüglich der neuen Bedingungen in der Rohstoffbeschaffung;

- der Modernisierung und technologischen Verbesserung der Fabrikation innerhalb der bestehenden Kapazitäten gezielt auf die Erhöhung der Produktivität, die Reduzierung der Kosten, die Verbesserung des Umweltschutzes und die Zunahme der Exporte;

- der Modernisierung mit Druck auf den primären Textil- und Lederveredelungsstufen (Spinnereien, Webereien, Textilveredelung, Gerbereien), um den sekundären Veredelungsstufen marktgerechte Halbfabrikate anbieten zu können;

gesprochen wird.

All dies setzt eine kräftige Investitionstätigkeit voraus, die das Institut für Leichtindustrie schon 1990 in technischen Einheiten wie folgt ausgedrückt hat (Tabelle 2.33):

Verglichen mit Tabelle 2.28, stellt dieses Programm eher einen minimalen Investitionsbedarf dar. Daß es bisher nicht möglich gewesen ist, selbst diese minimalen Investitionen zu unternehmen, zeigt sich aus der Entwicklung der tatsächlichen Investitionstätigkeit in der rumänischen TBI in Tabelle 2.31. 1991 z.B. wurden Investitionen in Höhe von etwa 100 Mio. US-\$ vorgenommen. Davon hätte man 1353 Anlagen modernisieren und 6749 Anlagen neu beschaffen müssen - offensichtlich unmöglich, wenn man berücksichtigt, daß in dieser Zahl 5990 teure Webstühle und Spinnrotoren enthalten sind.

Außer der bisher dargelegten Investitionsmotivation, gibt es aber auch andere auslösende Faktoren. GERSTENBERGER (1983) unterscheidet zwischen drei Kategorien von Faktoren für die Anpassung des Kapitalstocks an veränderte Rahmenbedingungen:

- die Entwicklung der Nachfrage aus dem In- und Ausland nach den Erzeugnissen der verschiedenen Wirtschaftszweige (für die rumänische TBI geht es um eine qualitativ anders gewordene, von Mode und Ästhetik viel stärker geprägte Nachfrage);

- die technologische Entwicklung (an den technischen Umwälzungen der 80er Jahre bei Stoffen, Farben, Klebstoffen und insbesondere Industrietextilien hat die rumänische TBI nicht teilgenommen);

- Verschiebungen in den relativen Preisen zwischen dem Produktionsfaktor Kapital und den übrigen Produktionsfaktoren Arbeit, Energie und Rohstoffe (die überproportionalen Verteuerungen bei Rohstoffen und Energie haben das Anlagekapital in Rumänien relativ verbilligt. Es lohnt sich jetzt, teurere Anlagen zu beschaffen, die weniger repetitive Produktionsfaktoren verbrauchen, vorausgesetzt man hat die Anschubfinanzierung). 
Tabelle 2.33: Modernisierungs- und Investitionsbedarf der rumänischen TBI, in Maschinen- und Anlageneinheiten

Maschinen und Anlagen, die modernisiert werden müssen

\begin{tabular}{||l||c|c|c||}
\hline Industriezweig & 1991 & 1992 & 1993 \\
\hline \hline Baumwollspinnereien und -webereien & 1348 & 605 & 810 \\
\hline Seidespinnereien und -webereien & 1 & - & - \\
\hline Hanf und Flachsspinnereien und -webereien & 1 & 22 & 53 \\
\hline Maschensektor & 3 & 15 & 25 \\
\hline
\end{tabular}

Maschinen und Anlagen, die neu beschaffen werden müssen

\begin{tabular}{||l|c|c|c||}
\hline Industriezweig & 1991 & 1992 & 1993 \\
\hline \hline Baumwollspinnereien und -webereien & 4642 & 2073 & 3785 \\
\hline Wollspinnereien und -webereien & 122 & 423 & 2330 \\
\hline Seidespinnereien und -webereien & 206 & 375 & 1379 \\
\hline $\begin{array}{l}\text { Hanf- und Flachsspinnereien und -weberei- } \\
\text { en }\end{array}$ & 4 & 483 & 2754 \\
\hline Maschensektor & 439 & 910 & 4000 \\
\hline Bekleidungssektor & 387 & 982 & 3510 \\
\hline Ledersektor & 949 & 856 & 20369 \\
\hline
\end{tabular}

(Quelle: Synthese des Instituts für Leichtindustrie, unveröffentlicht)

Insgesamt wird die Kapitalintensität nicht unbedingt steigen müssen; z.B. wenn es darum ginge, die bestehenden, veralteten Anlagen mit neuen Anlagen vom selben Typ zu ersetzen, die aber funktionsfähig sind und viel kleinere Ausfallraten erweisen.

Die nominelle Kapitalintensität (Bruttoanlagevermögen pro Beschäftigten) würde sich wegen der Inflation zwar erhöhen, nichts steht aber für die relative Kapitalintensität (verglichen mit den anderen Industriebranchen) fest. Eine Analyse der Entwicklung der Kapitalintensität in der rumänischen TBI wäre von vielen Mängeln behaftet. Vom Anfang an würde man auf das Problem der staatlich fixierten Preise stoßen, die die Kapitalintensität künstlich erhöhten (anders als in der Marktwirtschaft, besteht in den Unternehmen innerhalb der Planwirtschaft 
der Anreiz, möglichst teure Produkte zu entwickeln und zu produzieren, um mit weniger Anstrengungen den wertmäßigen Plan erfüllen zu können). Je komplizierter ein Produkt ist z.B. eine Maschine -desto mehr Spielraum hat man, um aufgrund hoher Fabrikationskosten und des "mark-up pricing"-Verfahrens, einen höheren Preis für das Produkt von der Planbehörde genehmigt zu bekommen. Auch deswegen waren die Preise der in den ehemaligen Planwirtschaften hergestellten Maschinen und Anlagen, relativ zu den damaligen Energie-, Rohstoff- und Personalkosten überhöht.

Während die Werte des Anlagevermögens vor 1989 wegen des oben dargestellten Mechanismus als überhöht betrachtet werden müssen, gilt dasselbe auch für die Beschäftigtenzahlen, da das typische Planwirtschaftsunternehmen mit Personal überbelegt war.

Die Angaben nach 1989 - und, insbesondere, diejenigen nach der letzten Preisliberalisierung - reichen nicht aus, um eine saubere Analyse der Kapitalintensität mit aussagekräftigen Ergebnissen zu betreiben. Jedoch kann man, ohne zu grobe Störungsfaktoren einzubeziehen, die Kapitalintensität der TBI mit denjenigen der anderen Branchen vergleichen (Tabelle 2.34).

Tabelle 2.34: $\quad$ Kapitalintensität der Branchen der rumänischen Industrie - 1992

\begin{tabular}{||l|c||}
\hline Industrie & Kapitalintensität (Mio. Lei/ Besch.) \\
\hline \hline Nahrungs- und Genußmittel & 3,505 \\
\hline TBI - darunter: & 0,918 \\
- Textilindustrie & 1,210 \\
- Bekleidungsindustrie & 0,578 \\
- Lederindustrie & 0,639 \\
\hline Möbel, Holz und Papier & 1,868 \\
\hline Chemie & 7,156 \\
\hline Baumaterialien & 2,423 \\
\hline Metallurgie & 11,018 \\
\hline Maschinenbau & 2,404 \\
\hline Elektrotechnik & 2,151 \\
\hline
\end{tabular}

(Nach Angaben von ROMANIAN STATISTICAL YEARBOOK, 1993, S.162 und S.363) 
Aus Tabelle 2.34 läßt sich ablesen, daß in der Tat der Textilsektor zweimal so viel Sachkapital für einen Arbeitsplatz braucht als die Bekleidungs- oder die Lederindustrie; dementsprechend wird der Investitionsbedarf hier höher sein (siehe auch BREITENACHER, 1992, S.27). Allerdings bleibt die Kapitalintensität dieses relativ kapitalaufwendigeren Sektors immer noch hinter der Kapitalintensität der nächsten Industrie auf diesem Skala, den Baumaterialien. Nach NEUNDÖRFER (1992) wäre angesichts der höheren Kapitalintensität des Textilsektors (Spinnereien, Webereien, Veredelungsstätten), die eine geringere Standortflexibilität ermöglicht, auf kurze Sicht nicht mit ausländischen Investitionen in Osteuropa in diesem Bereich zu rechnen. Es gibt aber keinen Grund, da in Osteuropa in Branchen investiert wird, die viel kapitalintensiver sind (Nahrungs- und Genußmittel, Petrochemie, Möbelindustrie), daß dieses Argument in der Vernachlässigung des Textilsektors von den ausländischen Investoren eine wichtige Rolle spielt. Eigentlich ist es umgekehrt: Gerade weil in der TBI der geldmäßige Investitionsbedarf pro Betriebsstätte geringer als in anderen Industrien ausfällt und die Marktaussichten für Exporte relativ gut sind, sollten sich die Investitionen schneller amortisieren. Dies gilt sowohl für die ausländischen Investoren, als auch für die inländischen Unternehmen.

Es gibt auch zahlreiche andere Argumente, die eine beschleunigte Investitionstätigkeit in der rumänischen TBI rechtfertigen würden. Gemäß WORTHINGTON (1992, S.316) beeinflußt die Intensität des Wettbewerbs auf dem Markt der Textil- und Bekleidungsprodukte die Investition sowohl durch Nachfragekanäle - die Nachfrage wird in Osteuropa nach der Erreichung der Talsohle des Bruttosozialprodukts wieder steigen, was in Polen, Ungarn und der Tschechischen Republik bereits geschehen ist - als auch durch die Preise der Produktionsfaktoren, während die Investitionsentscheidungen selbst eine Rückwirkung auf die auf dem Markt angebotenen Mengen ausüben. Die Anlageinvestitionen üben auf die Produktivität einer Volkswirtschaft den wichtigsten Entwicklungseffekt aus. So gibt PROBST (1978, S.24) an, daß in der TBI der Bundesrepublik die jährliche Rate der Effizienzsteigerung des Kapitals zwischen 1950 und 1965 durchschnittlich 15\% betrug. Diese Qualitätsverbesserung des Kapitalstocks durch Investition hat in der TBI der BRD eine durchschnittliche jährliche Produktionssteigerung von 4,31\% ermöglicht (Faktoranalyse). Weitere 1\% der Steigerungsrate wurden von der Abnahme des Durchschnittsalters der Kapitalgüter mit jährlich 0,24 Jahren verursacht. In diesem Zusammenhang wären auch die SOLOWsche Theorie des "embodiment-effect" (SOLOW, 1971, S.24-47), der investitionsinduzierte technische Fortschritt von OPPENLÄNDER (1976) und die Theorie des "learning by doing" von ARROW (1962) zu erwähnen. Nicht nur die Neu- und Rationalisierungsinvestitionen sind Faktor des technischen Fortschritts, der Erhöhung der Qualität und der Produktivität sondern auch die Ersatzinvestitionen - so PROBST (1978, S.36). Die beste Lösung in einer normalen Wirtschaftsentwicklung ist eine technik- und finanzgerechte Kombination der drei Investitionsarten; in der heutigen Lage der rumänischen TBI sollten die längst versäumten Ersatz- und Rationalisierungsinvestitionen Priorität haben. Auf jeden Fall dürften die 
Wirkungen der Investitionen in Rumänien hinsichtlich des Wachstums, der Effizienzsteigerung und der Produktivität aufgrund der geringeren Kapitalintensität, der marktungerechten Orientierung der heutigen Produktpalette, die wiederum vom Sachkapital abhängig ist, und der bisher vernachlässigten Produktionsorganisation höher sein als in den Industriestaaten. Eine wichtige empirische Unterstützung solcher Theorien, die die Bedeutung der Investitionen für das Wirtschaftswachstum unterstreichen, liefern DE LONG und SUMMERS (1991). Infolge einer eingehenden statistischen Bearbeitung welt- und zeitumfassender Angaben finden sie heraus, daß die schnell wachsenden Länder diejenigen sind, wo die Anbieter der Produktionsanlagen die günstigsten angebotsseitigen Bedingungen genießen und dementsprechend die Anlageinvestitionen erleichtert werden.

Schließlich muß man betonen, daß, wenn die notwendigen Investitionen nicht so schnell wie möglich getätigt werden, die wirtschaftliche Erholung ganz ernst in Frage gestellt werden kann. In Nachkriegsdeutschland "reichte damals eine relativ geringe Investition aus, um einen großen Kapazitätseffekt auszulösen, da oft wenige Maschinenaggregate ausreichten, ganze Produktionsanlagen instandzusetzen", jetzt aber "dürften angesichts des maroden Zustandes der gesamten Kapitalanlagen in den neuen Bundesländern massivere Investitionen vonnöten sein, um eine gleiche Erhöhung des Güterangebots zuwege zu bringen" (EHRET und PATZIG, 1991, S.119). Die Lage ist überall in Osteuropa die selbe (vgl. GÄLLI, 1992, S.16-17 für sämtliche MOE/GUS-Länder, ebenfalls GÄLLI, 1991, S.147-148 für Polen und ADAMICEK, 1991, S.155, für die ehemalige Tschechoslowakei). Seit 1990 konkurrieren alle Länder des ehemaligen Ostblocks um Auslandskredite und -kapital für die Ergänzung der von ihren Volkswirtschaften in ungenügendem Umfang erwirtschafteten Gewinnmassen, die zum Ersatz und zur Erneuerung ihres Kapitalstocks, verstanden als "alle dauerhaften Anlagen und Einrichtungen, die zur Erzielung des Produktionsergebnisses notwendig sind" (EINHOFF, 1975, S.6), benutzt werden sollen. In diesem Rennen ist Rumänien später als z.B. Polen oder Ungarn gestartet und die bisherigen Ergebnisse nach der Wende auf dem Gebiet der Investitionen in der TBI sind wenig ermutigend; wenn man z.B. den Modernisierungsgrad der rumänischen TBI (Anteil der Anlageinvestitionen der letzten 2 Jahrgänge im gesamten Anlagevermögen) betrachtet, stellt man fest daß gerade in Rumänien, wo ein großer Nachholbedarf besteht, ganz wenig in dieser Hinsicht getan wurde. In Rumänien beläuft sich dieser Modernisierungsgrad auf 6\% (eigene Berechnung nach Angaben des Industrieministeriums).

Der vom rumänischen Industrieministerium geschätzte, geldmäßige Investitionsbedarf Tabelle 2.35 -erscheint, verglichen mit dem technischen Bedarf, angegeben in Tabelle 2.33, eher als unrealistisch (sprich: unterschätzt). Um auf ein glaubhaftes Bild zu kommen, sollte man in Verbindung mit den durchschnittlichen Preisen der Textilmaschinen und -anlagen, die Zahlen etwa mit 3 multiplizieren. Um den Vergleich mit den anderen Tabellen in diesem Kapitel zu erleichtern, wurden die Zahlen inflationsbereinigt. 
Tabelle 2.35: Investitionsbedarf der rumänischen TBI, 1993-1996 (Preise von Oktober 1990; Währungskurs 1 US-\$ = 60 Lei)

\begin{tabular}{|c|c|c|}
\hline & 1993 & 1994 bis 1996 \\
\hline $\begin{array}{l}\text { Gesamter Investitionsbedarf } \\
\text { - davon Finanzierungsquel- } \\
\text { len: }\end{array}$ & $\begin{array}{l}2986 \text { Mio. Lei; } \\
\text { davon: } \\
\text { 35,2 Mio. US-\$ }\end{array}$ & $\begin{array}{l}9445 \text { Mio. Lei; } \\
\text { davon: } \\
\text { 105,1 Mio.US-\$ }\end{array}$ \\
\hline $\begin{array}{l}\text { Eigene Finanzie- } \\
\text { rungsquellen der Unterneh- } \\
\text { men (hauptsächlich einbe- } \\
\text { haltene Gewinne) }\end{array}$ & $\begin{array}{l}1435 \text { Mio. Lei; } \\
\text { davon: } \\
\text { 29,3 Mio. US-\$ }\end{array}$ & $\begin{array}{l}4478 \text { Mio. Lei; } \\
\text { davon: } \\
83,2 \text { Mio. US-\$ }\end{array}$ \\
\hline Kredite und Auslandskapital & $\begin{array}{l}1551 \text { Mio. Lei; } \\
\text { davon: } \\
\text { 5,9 Mio. US-\$ }\end{array}$ & $\begin{array}{l}4967 \text { Mio. Lei; } \\
\text { davon: } \\
21,9 \text { Mio. US-\$ }\end{array}$ \\
\hline Staatshaushalt & 39 Mio. Lei & 104 Mio. Lei \\
\hline
\end{tabular}

(Nach Angaben des Industrieministeriums)

Anderseits würden selbst diese nach Ansicht des Verfassers dieser Arbeit unterschätzten Investitionsbeträge, im Vergleich mit dem Jahr 1992, einen Sprung auf das Zweifache bedeuten -was angesichts der heutigen Stagnationspolitik der in Oktober 1992 angetretenen Regierung kaum zu erwarten ist.

Ein DIW-Beitrag (1988, S.28) deutet darauf hin, daß in den Branchen, die (wie die rumänische TBI) ungenügend mit Eigenkapital ausgestattet sind, die Anpassungsverzögerungen zum Kapitalstockbedarf entsprechend größer sind. Hinzu kommt erschwerend das Phänomen der "bad debts" und der chronischen Liquiditätskrisen. Ende 1992 hatte der gesamte TBI-Sektor Forderungen in Höhe von 76,7 Mrd.Lei und Verbindlichkeiten von 61,8 Mrd.Lei (Währungskurs: 1 US- $\$=180$ Lei). Auf die Finanzierungsprobleme wurde im Kapitel 1 und wird weiter im Kapitel 5 eingegangen.

\subsection{Entwicklungsperspektiven der rumänischen TBI}

Die Textil- und Bekleidungsindustrien der osteuropäischen Länder haben insgesamt ähnliche Perspektiven. Die kleinen Familienbetriebe, sowie die von größeren Kombinaten getrennten Unternehmen, auf Nischenprodukte spezialisiert, und die integrierten Großbetriebe, sind alle ganz stark darauf eingestellt, zuerst über Lohnarbeit für westliche Unternehmen, genaue Marktinformation und schrittweise Übernahme von westlichem Know-How, die ausländi- 
schen Märkte zu betreten bzw. ihre Anteile darin zu erhöhen. Die neu entstandene textile Entwicklungs- und Investitionsachse erstreckt sich von Westeuropa bis nach Moskau und dann südwärts bis in die neuen Republiken Zentralasiens. Für Polen schätzt z.B. GÄLLI (1991, S.151), daß der staatlich unterstützte Aufschwung der Privatindustrie, die niedrigen Löhne, der große Binnenmarkt mit einem wichtigen Nachholbedarf an modischer Ware sowie die Nähe zur EG gute Voraussetzungen für eine weitere Entwicklung der Bekleidungs- und auch der Textilindustrie bieten. Allerdings wurde von amerikanischen Experten 1991 geschätzt, daß in den fünf folgenden Jahren in der TBI Investitionen im Gesamtwert von rund 700 Mio. US-\$ durchgeführt werden müssen (zum Vergleich, wurde dieser Bedarf in Rumänien, wo die TBI über größere Produktionskapazitäten als in Polen verfügt, vom Industrieministerium auf etwa 207 Mio.US-\$ für 1993-1996 geschätzt). In Polen wurde auch das Steuersystem hinsichtlich seines Einflusses auf die TBI untersucht, mit dem Ergebnis, daß es größere Investitionen eher unattraktiv macht. In der ehemaligen Tschechoslowakei sieht ADAMICEK (1991, S.155) ein eher geringes Interesse westeuropäischer Textilunternehmen an Kapitalbeteiligungen zum Ausbau und Modernisierung der tschechischen und slowakischen Kapazitäten aufgrund ihrer eigener angespannten Lage. Dagegen haben die Bekleidungsunternehmen aufgrund ihrer Nähe zum EG-Markt insbesondere bei modischer Ware viel bessere Chancen.

Die spezifischen Perspektiven der rumänischen TBI sollen in erster Reihe in Anlehnung an ihren Stärken beurteilt werden. Darunter zählen:

- die geographische Lage Rumäniens, marktnah sowohl zu der GUS, zu den EG-, zu den EFTA-, als auch zu den nahöstlichen Ländern;

- der neulich unterschriebene Assoziierungsvertrag mit der EG, der Freihandelsvertrag mit der EFTA und die Gewährung der Meistbegünstigungsklausel seitens der USA alles Dokumente, die den Zugang der rumänischen Textilprodukte zu diesen Märkten erheblich erleichtern;

- $\quad$ eine gewisse Erfahrung in der Produktion von Massenware und in der passiven Lohnveredelung;

- $\quad$ der - verglichen mit anderen Industrien - kleinere Investitionsbedarf;

- die extrem niedrigen Lohnkosten.

Es ist interessant zu merken, daß gerade die Faktoren, die die Krise der westdeutschen TBI verursacht haben, nämlich die Aufwertung der D-Mark und die Senkung der Einkommenselastizität der Textilien und Bekleidung aufgrund der Erhöhung des Lebensstandards, in Rumänien sich umgekehrt entwickeln. Der Leu (Einzahl von Lei) wertet sich stets ab und der Lebensstandard sinkt ebenfalls.

Die TBI ist bisher keineswegs unter die besondere Aufmerksamkeit der rumänischen Regierung gefallen. Trotz der im Paragraphen 2.1 dargestellten besonderen Bedeutung der TBI 
wurde sie nicht einmal auf der Prioritätsliste für die Regierungsgarantien der ausländischen Kredite gestellt. Von anderen Instrumenten einer Industriepolitik, die auf mikroökonomischen Niveau ansetzen sollte, ist also nicht die Rede, und nicht zuletzt deswegen, weil der größte Teil der TBI in Rumänien noch genug rentabel ist, um keine Subventionierung zu brauchen.

Unabhängig davon, ob es in der Zukunft Investitionszuschüsse und -zulagen oder andere Finanzhilfen geben wird, ob die außenwirtschaftliche Protektion steigen oder sinken wird also ob der Staat der TBI helfen wird (er sollte sie wenigstens nicht stören - siehe Kap.5) kann man entsprechend dem heutigen Stand der Theorie und der Erfahrungen in anderen sich industriell entwickelnden Ländern einige Aussagen über die Perspektiven der rumänischen TBI machen.

Gemäß seiner Rolle in der Befriedigung der menschlichen Bedürfnisse steigt der Bekleidungsverbrauch bei niedrigen Einkommen (der rumänische Fall) zunächst überproportional, und dann proportional mit den Einkommen. Mit dem weiteren Zuwachs des Einkommens wächst endlich der Bekleidungsverbrauch nur noch unterproportional (der Fall der Industrieländer) - so BREITENACHER (1981, S.33). In kurzer und mittlerer Frist ist also von nun an eine günstige Entwicklung der heimischen Nachfrage zu erwarten. Mit der langsamen Erholung der anderen Branchen der rumänischen Industrie wird die Nachfrage für Industrietextilien (siehe VIEHWEG, 1989, S.16) auf längere Frist steigen, und damit wird die TBI weitere Luft bekommen, vorausgesetzt, daß auf diesem Gebiet aus dem Westens mindestens technisches Know-How investiert wird. Auf jeden Fall wird in dem Moment eine Strategie der Importsubstitution für Industrietextilien, gestützt auf ausländischen Investitionen, denkbar sein (SCHILD, 1992).

Da erwartet wird, daß in Osteuropa die Pro-Kopf-Einkommen und dadurch die Ausgaben für Textilien und Bekleidung anwachsen, wird sich die Nachfrage in den osteuropäischen Ländern dementsprechend diversifizieren. Da sich die Produktion aller Modelle und Varianten im Inland wegen des relativ kleinen Marktes nicht lohnen würde, werden die osteuropäischen Länder immer mehr Textilien und Bekleidung miteinander handeln. Es ist auch mit einer Expansion der Textil- und Bekleidungsexporte zu rechnen, die die Konsequenzen des Zusammenbruchs von 1990 mildern, wenn nicht einholen dürfte.

Eine andere Richtung der Exportentwicklung, auf die bereits in vielen osteuropäischen Ländern stark zurückgegriffen wird, ist die passive Lohnveredelung. Sie hat insbesondere in arbeitsintensiven Bereichen, wie der Bekleidungsindustrie, wo der Druck der Lohnkosten die westlichen Produzenten zur Auslandsfertigung zwingt, sehr gute Zukunftschancen, allerdings nur, bis sich die Lohnkosten in Osten und Westen ausgleichen sollen. Da aber ein solcher Ausgleich nicht einmal auf mittlere Sicht zu erwarten ist, bleibt die passive Veredelung für die rumänische TBI eine sehr gute Überlebenschance. 
Wiederum sollten die rumänischen Textil- und Bekleidungsproduzenten ihren Angriff auf die Märkte der Industrieländer fortsetzen. Obwohl Textilien geringe Preiselastizitäten bei der Ausfuhr ausweisen, kann ihr Export selbst unter restriktiven Bedingungen, wie diejenigen, die vom Welttextilabkommen fixiert werden, trotzdem expandieren und erfolgreich und profitabel sein. Grundlage dafür ist eine gesunde "supply-side policy", die auf die Verbesserung der Produktions- und Angebotsbedingungen abzielen sollte, wie z.B. in Indonesien und Thailand (HILL \& SUPHACHALASAI, 1992). Dafür soll sich aber auch der Staat unbedingt einsetzen.

Außer einer Erhöhung der Exporte, ist auch - sollte die Wirtschaftspolitik vernünftig werden - ein Anstieg der Auslandsinvestitionen in die rumänische TBI zu erwarten. Die westlichen Investoren hätten dabei zweierlei Motive:

den Absatz: man investiert, um bereits erschlossene Absatzmärkte zu sichern oder auszuweiten und neue Märkte zu erschließen;

den Kostenabbau: die Produktion wird, unter Einhaltung der bisherigen Technik und/oder Sortiments, an einen Standort verlagert, der, verglichen zu den Industrieländern, komparative Kostenvorteile hat.

Obwohl angesichts des typisch osteuropäischen Lohnkostenvorteils der Anreiz bestünde, die Bedeutung der zweiten Investitionsart zu überschätzen, muß man berücksichtigen, daß die westlichen absatzorientierten Auslandsinvestitionen in Entwicklungs- oder sogar Industrieländern einen immer größeren Anteil besitzen (siehe auch SPINANGER, 1993). Diese Entwicklung basiert auf der Erfahrung, daß große Absatzmärkte im Ausland sich auf Dauer nicht allein durch Exporte bedienen lassen. Marktanteile im Ausland lassen sich langfristig nur dann halten, wenn der Schritt vom Export zur Auslandsproduktion unternommen wird. Dies ist auch häufig darum notwendig, weil im Zuge der Industrialisierung der Abnehmerländer, ihre Protektionsmaßnahmen immer kräftiger werden, um die Importe durch die heimische Produktion zu ersetzen. Durch Auslandsinvestitionen können protektionistische Maßnahmen umgangen werden.

Die deutschen Auslandsinvestitionen im Textil- und Bekleidungsgewerbe betrugen 19881336 Mio.DM (etwa 763 Mio.US-\$). Damit machten sie ungefähr 0,7\% der sämtlichen deutschen Investitionen ins Ausland aus. Vergleichen wir diese Zahl mit dem in Tabelle 2.35 für Rumänien geschätzten Investitionsbedarf, selbst 3 mal nach oben korrigiert (also etwa 621 Mio.US-\$ für 1993-1996), und berücksichtigt man auch, daß die Bundesrepublik nicht das einzige Industrieland ist, das in Rumänien Investitionen vornehmen könnte, stellen wir fest, daß es Auslandskapital geben könnte, vorausgesetzt es wird durch geschickte Maßnahmen von Rumänien angezogen. Gegen diese Schätzung sprechen allerdings die Folgen der deutschen Wiedervereinigung und der heutigen Rezession in Westeuropa: "auch westdeutsche Textilunternehmer [prüfen] angesichts der weltweit herrschenden Überkapazitäten für die 
Textilproduktion jede Investition bzw. Produktionserweiterung genauestens und [nehmen] diese nur dann in Angriff [,] wenn sie vom wirtschaftlichen Erfolg überzeugt sind" (VON NETZER, 1992). Da es aber in Osteuropa nicht um Kapazitätserweiterung, sondern um Kapazitätserhaltung über Rehabilitierung geht, die wegen der o.g. Motive für die ausländischen Investoren interessant sein dürfte, und da die benötigten Beträge niedriger sind als in anderen Industriebranchen, bestehen noch viele Gründe für Optimismus. Der Kapazitätsabbau wird nicht aus konjunkturellen, sondern aus strukturellen Gründen notwendig sein, und nur dort, wo die Lage keine weitere Hoffnungen erlaubt.

Die Strategien, die diese Unternehmen in der Zukunft verfolgen werden, haben eine Gemeinsamkeit - die Herstellung von Produkten, die von der Qualität und dem Design her Chancen haben, auf den Weltmärkten umgesetzt zu werden. Darum müssen unbedingt der bestehende Kapitalstock, die Technologien und die Produkte angepaßt werden. Die anderen Aspekte (Kapitalintensität, Forschungsanteil, Rationalisierung usw.) sind in den o.g. Zielen enthalten. Auf jeden Fall aber dürfen die Unternehmen durch die Fiskalpolitik zumindest nicht behindert werden. 
KAPITEL 3: DIE BEDEUTUNG DER STEUERN FÜR DIE INVESTITIONSTÄTIGKEIT IM LICHTE DER ÖKONOMISCHEN THEORIE.

\begin{abstract}
Aus Kapitel 2 hat sich die Schlußfolgerung ergeben, die Produktionskapazitäten der rumänischen Industrie seien - was für den Ostblock keine Ausnahme bilden sollte - in erheblichem Maße veraltet, bzw. abgenutzt. Falls die rumänischen Unternehmen aus ihren (internen und/oder externen) Märkten nicht ausscheiden sollten, bedürfen sie vieler und baldiger Investitionen, die eine höhere Produktivität, Kostenvorteile und hinreichende Produktqualitäten ermöglichen müßten.
\end{abstract}

Eine Steuerpolitik, die auf die Effizienzsteigerung der industriellen Produktionskapazitäten mittels verstärkter Investitionstätigkeit abzielt, müßte auf jeden Fall auf einem - mit den rumänischen Verhältnissen zu vereinbarenden - theoretischen Modell des Zusammenhangs zwischen Steuern und Investitionen basieren. Infolge einer kritischen Übertragung auf die rumänische Wirklichkeit sollte man, anhand verschiedener Teilmodelle, die Wirkungen der unterschiedlichen rumänischen Steuern untersuchen können, um letztendlich einen "policymix" für die Erfüllung des o.g. Zieles gestalten zu können.

Dementsprechend ist die Untersuchung in diesem Kapitel wie folgt gestaltet:

- $\quad$ erstens werden die verschiedenen Determinanten der Investitionen, wie sie in den wichtigeren Ansätzen erklärt werden, dargestellt;

- $\quad$ zweitens werden einige bedeutenden Fragen angesichts des Rahmens, auf den sich diese Untersuchung des Zusammenhangs Steuern - Investitionen beschränken sollte geklärt bzw. angesprochen, wie z.B. ob es um einen mikro- oder makroökonomischen Ansatz bzw. um Ersatz- oder Erweiterungsinvestitionen geht;

- drittens wird auf die wichtigsten Theorien eingegangen, die im Laufe der Zeit aus der wissenschaftlichen Diskussion entstanden sind: die neoklassische Investitionstheorie, die Akzeleratortheorie und das Kapitalstockanpassungsprinzip, die betriebswirtschaftlichen Ansätze, die auf die Kapitalwertmethode bauen, die neuere Theorie des Tobin's "q";

gesondert werden die Risikoaspekte als wichtige Einflußgrößen auf die ausländischen Investitionen betrachtet, und die Finanzierungs- und Liquiditätsaspekte, die für die Investitionen inländischer Gesellschaften von erheblicher Bedeutung sind. 


\subsection{Die Determinanten des Investitionsverhaltens}

Betrachtet man das Problem der Evaluation von Investitionsdeterminanten in einer wissenschaftlich abgerundeten Weise - empirische Überprüfung verschiedener Hypothesen und Auswahl derjenigen, die sich am besten bestätigen lassen - gibt es bisher zwei Vorgehensweisen: bei der einen versucht man, anhand Korrelations- und Regressionsanalysen grob spezifizierte Investitionsfunktionen zu schätzen, bei der anderen dagegen handelt es sich um Befragungen in Unternehmen selbst.

Die Regressionsanalysen werden durchgeführt, um die verschiedensten Investitionstheorien anhand statistischer Reihen zu prüfen, bei denen die Investitionen als abhängig von der Expansion der Nachfrage (Akzeleratorprinzip) (z.B. LANGE, 1962, S.95 ff.), der Liquidität (ebenda, S.99 ff.), oder den Gewinnen (ALBACH, 1970, S.39 ff.) angesehen werden.

Die Befragungen versuchen dagegen, aus einer großen Zahl von Investitionsentscheidungen die Gemeinsamkeiten heraus zu kristallisieren. Ergebnis ist jeweils eine Vielzahl von Investitionsdeterminanten, die jedoch "kaum zu Investitionsfunktionen zusammengeführt werden können" (SIEDENBERG, 1976, S.16). Gemäß SIEDENBERG sind also Aussagen über das quantitative Ausmaß der Einwirkung bestimmter Parameter schon vom Ansatz her in diesem Fall nicht möglich.

Trotzdem können, wie bei KATONA (1960, S.248 ff.), aus Befragungen interessante Schlüsse gezogen werden. Es gäbe, so KATONA, nicht das Motiv der Investition, sondern eine Verflechtung von Motiven, deren Gewichte unter anderen von der wirtschaftlichen Lage der Unternehmung, der Konjunktur, des Alters des Industriezweiges (ganz wichtig im Fall Rumäniens), der Marktform, der Größe der Unternehmung sowie den Entscheidungsträgern abhängig sind. Daran schließt sich auch der Ansatz von SIEDENBERG, der zwischen langfristigen und kurzfristigen Zielen der Investitionspolitik des Unternehmens unterscheidet, an. So können z.B. Maßnahmen, die zur kurzfristigen Erwirtschaftung großer Gewinne führen, auf die Dauer zu einem Verlust an Marktanteilen und künftigen Gewinnen leiten. Die Investitionsentscheidung wäre also ein Abfindungsprozess zwischen der "Sicherung einer langfristigen Gewinnerzielung auf Normalniveau", die eine "Überlebenssicherung" gewährleistet, der permanenten Liquiditätserhaltung und der Nutzung kurzfristiger Gewinnchancen.

Neben diesen strategischen Komponenten der Investitionsentscheidung, unterscheidet SIEDENBERG, in Anhang an WÄCHTER (1969, S.82 ff.) auch zwischen unipersonalen und multipersonalen Zielfindungen. Sobald nicht eine Person allein alle Entscheidungen eines Unternehmens trifft, können die Ziele der Eigentümer und der Manager auseinander fallen. 
Dieser Tatbestand läßt sich mühelos auch für den Fall der rumänischen staatlichen Betrieben bestätigen. Eine Erweiterung dieses Ansatzes finden wir bei ATKINSON \& STIGLITZ (1980, S.151), die von "managerial discretion" sprechen. In ihrer extremen Form bedeutet diese diskretionäre Tendenz, daß die Manager ihren eigenen Nutzen zu maximieren versuchen, indem sie mehr investieren, als es für die Maximierung des Firmenwertes nötig wäre. Auch SCHUMPETER schließt sich solchen nichtmonetären Erklärungen des Investitionsverhaltens an, indem er dem Gewinn auch den Willen zur Macht, das Prestigebedürfnis und die Schaffensfreude als Hauptmotive der "neuen Kombinationen von Produktionsfaktoren" beifügt (1952, S.138).

Obwohl diese letzten, stark mit subjektiven bzw. nichtökonomischen Faktoren verbundenen Erklärungsversuche eine gewisse Relevanz auch für Rumänien haben dürften, würde ihre Berücksichtigung einer Untersuchung des Zusammenhangs Steuern - Investitionen wenig Raum schaffen. Die Wirtschaftspolitik stellt in erster Linie auf ökonomische Parameter ab, durch deren Beeinflussung sie die Volkswirtschaft entweder von Krankheiten zu heilen oder vor Krankheiten zu schützen versucht. Ob, wie erwähnt, empirisch getestet oder nicht, bezieht sich die Mehrzahl der Investitionstheorien auf ökonomischen Größen.

So gibt z.B. WITTMANN (1975, S.148) an, die Investitionen dürften von den Zinskosten, den Gewinnen, der Entwicklung der Nachfrage, der Liquidität und dem Kapitalstock abhängig sein. Ganz wichtig scheint aber, dem Ansatz von DOMAR \& MUSGRAVE (1944) gemäß, auch die Wahrscheinlichkeitsverteilung der erwarteten Gewinne und Verluste. All diese Einflußgrößen können entweder betriebswirtschaftlich oder volkswirtschaftlich untersucht werden.

Die erste Betrachtungsweise neigt eher dazu, "wie" und nicht "warum" Investitionen getätigt werden (Kapitalwertmethode) zu erklären; trotzdem bietet der betriebswirtschaftliche (sowie der mikroökonomische) Ansatz die Möglichkeit, die Reaktionen eines Unternehmens gegenüber wirtschaftspolitischen Maßnahmen (also auch gegenüber Steuern) abzuleiten. Ganz sinnvolle Konzepte, wie z.B. die Nutzenmaximierung (der Unternehmer richtet sich nicht unbedingt nach der Gewinnmaximierung, sondern nach der Maximierung seiner Nutzenfunktion, die auch sein Streben nach Sicherheit und stetiger Liquidität berücksichtigt) (SCHNEIDER, 1964, S.3), oder die zusammenfassende Aussage, daß Investitionen grundsätzlich "nur dann getätigt werden, wenn sie entweder zur Sicherung der Rentabilität des bereits existierenden Kapitalbestandes notwendig sind oder wenn erwartet werden kann, daß die Investitionen selbst eine zumindest ausreichende Rentabilität erzielen" (BARTHEL \& FASSING, 1980, S.316) lassen sich vornehmlich aus betriebswirtschaftlichen Betrachtungsweisen ableiten. Die Einbeziehung der Liquiditäts- und Finanzierungsprobleme in die Untersuchung der Investitionsdeterminanten ist ebenfalls dem betriebswirtschaftlichen Ansatz zu 
verdanken. Auf die Möglichkeiten und Grenzen dieses Ansatzes soll später noch eingegangen werden.

Modernere Ansätze räumen der Risikoproblematik eine größere Bedeutung ein, indem sie den Einfluß der Unsicherheit auf die Investitionsbereitschaft untersuchen. Eine Realinvestition wird als eine Option auf einen bestehenden finanziellen Kapitalstock angesehen. Die Durchführung der Realinvestition würde mit sich Investitionskosten bringen, die von den künftigen Erträgen zumindest überschritten werden müssen ("strike price of the option"). Anhand eines bestimmten Investitionskriteriums wird der optimale Zeitpunkt bestimmt, wann der Unternehmer von der Investitionsoption Gebrauch machen kann. Dabei spielt auch der Optionswert des Wartens ("option value of waiting") eine wichtige Rolle. MAC DONALD \& SIEGEL (1986, S.331-349) führen eine derartige Analyse anhand eines ganzzähligen Modells durch; PINDYCK (1987) und BERTOLA (1987) gehen mit der Analyse in den stetigen Zahlenbereich über. DIXIT (1989, S.620-638) und PINDYCK (1991, S.1110-1148) gehen einen Schritt weiter, indem sie in ihre jeweiligen Uncertainty-Modelle auch den quasiirreversiblen Charakter der Realinvestitionen miteinbeziehen. So betrachtet z.B. DIXIT (1989) die Entscheidungen eines Unternehmens für den Marktein- bzw. -austritt unter stochastischer Variation der Outputpreise und kommt zum Ergebnis, daß es unterschiedliche Schwellenpreise der angebotenen Produkte gibt. Der obere Schwellenpreis, der die Realinvestition als rentabel erscheinen ließe, setzt sich aus den variablen Kosten des Produktes und dem verteilten Zinsaufwand, entsprechend dem investierten Kapital, zusammen. Dagegen bildet sich der untere Schwellenpreis, der den Ausstieg des Investors aus dem Markt veranlassen würde, aus der Differenz zwischen den o.g. Größen. Dadurch entsteht ein Hysteresis-Effekt, der ein Maß für die Irreversibilität einer Realinvestition darstellt. Das Kernproblem wäre einen modelltheoretischen Pfad der optimalen irreversiblen Kapitalakkumulation unter Berücksichtigung verschiedener Risiken zu finden. Dies versucht PINDYCK (1991). Der unwiderrufliche Charakter der Investition in Kapitalgüter hat in seinem Modell einen verstärkenden Einfluß auf die von dem Investor eingeschätzten Risiken. Letztere werden weiter durch die Volatilität der Preise, der Zinsen, der Währungskurse, der Zölle, Steuern und anderen staatlichen Maßnahmen erhöht (PINDYCK, 1991, S.1141).

Angesichts der Vielfalt der Investitionstheorien könnte man, wie z.B. BECKMANN (1970, S.131), folgern, daß eine völlig überzeugende Erklärung der Investition noch aus steht. Wie noch später gezeigt werden soll, werden tatsächlich auch die modernsten Theorien empirisch zugleich bestätigt und verneint. Der Versuch, die Ziele der Unternehmen, ihre Dynamik, das Verhalten der Unternehmen in ihrem Umfeld und die aggregierten Investitionen in ein geschlossenes System zu binden, ist bisher gescheitert. Die Folgerung liegt nahe: es gibt keine eindeutigen und allgemein verwendbaren Investitionstheorien. Die Zielsetzungen der Unternehmen (und daher ihre Strategien) ändern sich räumlich und zeitlich unter dem Einfluß inner- und außerbetrieblicher Faktoren, die zum Teil auch nichtökonomischer Natur sind. 
"Vielmehr soll ein gedankliches Dreieckverhältnis konstruiert werden, ein Reaktionsraum aus Entscheidungssubjekt, Entscheidungsobjekt (Investition) und Entscheidungsfeld, in dem Ströme von Impulsen im zeitlichen Ablauf die Motivation einer Entscheidung entstehen lassen." (HEDERER, 1971, S.21).

Da es die Investitionstheorie nicht gibt, bleibt der Politik nur die Lösung, sich das zur entsprechenden Realität passende Modell vom vielfältigen theoretischen Angebot auszusuchen.

\subsection{Makroökonomischer versus mikroökonomischer Ansatz.}

Auf die Frage, auf welcher Ebene der Zusammenhang Steuern - Investitionen sich am besten untersuchen läßt, ist in jeder Referenzarbeit der bisherigen Theorie eingegangen worden. Die Kriterien zur Wahl eines von den zwei möglichen Ansätzen sollten mit den folgenden Aspekten verbunden sein:

- $\quad$ ob es sich um eine politische oder analytische Arbeit handelt;

- $\quad$ ob feste Hypothesen über das Verhalten der Unternehmer vorliegen oder nicht;

- ob der Untersucher eher zur klassischen (bzw. neoklassischen) oder zur keynesianischen Wirtschaftstheorie neigt;

- ob statistische Reihen angesichts des untersuchten Prozesses in ausreichender Menge verfügbar sind und, in derselben Gedankenordnung;

- $\quad$ ob ein makroökonomisches Modell, zur Untersuchung der berücksichtigten Prozesse angepaßt, vorliegt bzw. entwickelt werden kann. Zuerst muß gesagt werden daß obwohl die Investitionstätigkeit sowohl bei der Konjunkturforschung als auch bei der Erforschung des langfristigen Wachstums im Mittelpunkt der wissenschaftlichen Diskussion steht - die Besteuerung bei den meisten wirtschaftstheoretischen Erklärungsversuchen für die Investitionstätigkeit eigentlich nur als Randproblem behandelt wird.

JATZEK und LEIBFRITZ (1982, S.17) sehen den Grund dafür darin, daß "die Besteuerung ihre Wirkung nur indirekt über andere Einflußfaktoren der Investitionen entfaltet, ihre Bedeutung also erst bei detaillierteren Erklärungsansätzen zum Vorschein kommt". Dieser Tatbestand würde also einen apriorischen Anreiz liefern, von der makroökonomischen "hinunter" zur mikroökonomischen Untersuchungsebene zu rücken. Angesichts der angeblich indirekten Wirkung der Besteuerung (durch den Kapitalnutzungspreis - so die neoklassische Investitionstheorie, die die beiden Autoren auch benutzen) wäre also eine eingehendere Analyse auf mikroökonomischer (bzw. betriebswirtschaftlicher) Ebene für die Erzielung aussagekräftiger Ergebnisse unabdingbar. 
Dieselbe Meinung vertritt SCHNEIDER (1964, S.1), der zwei mögliche Ansätze unterscheidet: den Ausgang von einer makroökonomischen Investitionsfunktion oder von der Reaktion des einzelnen Unternehmens auf die Besteuerung. SCHNEIDER gibt zu, daß der erste Ansatz den großen Vorteil hätte, zu Ergebnissen zu führen, die für den Wirtschaftspolitiker unmittelbar verwendbar wären. Es muß hier unterstrichen werden: in quantitativer Hinsicht auf Landesebene, was leider die mikroökonomischen Ansätze, u.a. wegen des Aggregationsproblems, nicht erbringen können.

Die Schwierigkeit bei den makroökonomischen Ansätzen ist aber die Formulierung einer Investitionsfunktion, die gleichzeitig empirisch bewiesen und - im Hinblick auf die Steuern aussagekräftig genug sein sollte.

Hinzu kommt auch, daß - so FROMM und SCHINK (1973) - das Aggregationsproblem - das bei einem zunächst mikroökonomischen Vorgehen auftreten kann - auf dem Gebiet der Investitionstheorie nicht die entscheidende Bedeutung zu haben scheint, wie z.B. im Bereich der Konsumtheorie. Vielmehr sollte die Makropolitik auf die Mikroentscheidungen abstellen. Wenn z.B. von IncentiveWirkungen gesprochen wird, werden diese immer auch auf mikroökonomischer Ebene zu prüfen sein (SIEDENBERG, 1976, S.13).

Daher wählen die meisten Autoren den mikroökonomischen Ansatz, um die Reaktionen des Unternehmers (oder des Unternehmens, als "black-box" gesehen) abzuleiten. Weiter: für eine gründliche Untersuchung, die der Politik dienen soll, muß der Ansatz partialanalytisch im doppelten Sinne verlaufen: es wird nicht nur angenommen, daß die Preis-Absatz Funktion und die Faktor-Angebotsfunktion unverändert bleiben (und daher agiert der Unternehmer als Gewinnmaximierer und Mengenanpasser), sondern es wird auch jeweils nur eine Steuer betrachtet.

Es werden Modelle eines Unternehmens konstruiert, das sich in Hinblick auf ein vorgegebenes Ziel (Gewinnmaximierung, Nutzenmaximierung, Kapitalbedarfdeckung, Liquiditätssicherung usw.) immer rational verhält. Entweder hat es alle nötigen Informationen über die Zukunft, oder es können Aussagen über sein Verhalten unter Unsicherheit gemacht werden. Diese Art Ansätze zur Erklärung des Einflusses der fiskalpolitischen Parameter hat die längste Tradition: BROWN (1948), MUSGRAVE (1944), H.SCHNEIDER (1964), HELLIWELL (1968), JORGENSON (1963). Während den ersten vier Ansätzen der empirische Nachweis gänzlich fehlt, weist der letzte einen qualitativen Sprung auf, indem die entwickelte Theorie, die grundsätzlich auf festen Hypothesen im Hinblick auf das Verhalten des Unternehmers basiert, sich auch von der Empirie bestätigen läßt.

Die makroökonomische Betrachtung wird nur wieder ganz bedeutend, wenn man die Investitionsfähigkeit untersucht. Die Liquiditäts- und Finanzierungseffekte, die normalerweise 
durch geldpolitische oder finanzpolitische Maßnahmen mit Geldmengeneffekt ausgelöst werden, müssen immer sowohl auf individualwirtschaftlichem als auch auf aggregiertem Gebiet untersucht werden. Den mikroökonomischen Abschätzungen müssen also gesamtwirtschaftliche Überlegungen folgen.

\subsection{Erweiterungs- versus Ersatzinvestitionen.}

Auf das Gebiet der Ersatzinvestitionen haben sich bisher wenige theoretische Ansätze konzentriert, obwohl natürlich auch die Erneuerung des Kapitalstocks in Hinsicht auf Konjunktur und Wachstum eine gewisse Bedeutung haben dürfte. Es gibt allerdings auch in diesem Bereich einige Ansätze, die die Ersatzinvestitionen ausdrücklich berücksichtigen.

Hauptsächlich lassen sich diese in drei Kategorien einteilen. Der erste - und älteste - Ansatz unterstellt einen proportionalen Zusammenhang zwischen dem Kapitalstock und den Ersatzinvestitionen, mit der Begründung, jede Erweiterungsinvestition ziehe Ersatzinvestitionen in unendlicher Reihe nach sich, deren Summe in einer Periode ein bestimmter Anteil des Kapitalstocks derselben Periode sein sollte.

Die Kritik an diesem Ansatz bedient sich u.a. der zeitlichen Schwankungen der Erweiterungsinvestitionen. Da bei den Ersatzinvestitionen die Schwankungen viel weniger ausgeprägt sind (LEIBINGER (1985, S.136) z.B. gibt an, die Ersatz- und Rationalisierungsinvestitionen würden etwa $70 \%$ der Bruttoinvestitionen im verarbeitenden Gewerbe ausmachen, und daher schwächen sie den Einfluß kurzfristiger Nachfrageschwankungen auf die Investitionstätigkeit insgesamt ab), könnte sich dieser Anteil nicht konstant halten. Außerdem wird de facto die Ersatzinvestition nicht gleich nach ihrer entsprechenden Erweiterungsinvestition getätigt, sondern erst nach Ablauf der Nutzungsdauer, und dabei ist nicht die technische, sondern die ökonomische Nutzungsdauer relevant, deren Festlegung eine Frage der unternehmerischen Politik ist. Also werden die Ersatzinvestitionen nicht automatisch gemäß der Altersstruktur des bestehenden Kapitalstocks unternommen, sondern auch vom Zinssatz (oder Zinserwartungen), technischen Fortschritt usw. beeinflußt.

Eine fundierte Ablehnung der Proportionalitätshypothese wurde zum ersten Mal von FELDSTEIN und FOOT (1971) geliefert. Darin versuchen die Autoren anhand empirischer Daten zu beweisen, daß die Ersatzinvestitionen von den Finanzierungsmöglichkeiten, dem Wachstumswillen, dem Auslastungsgrad der Kapazitäten und dem Rationalisierungsdruck auf kurzer Sicht determiniert werden. Daraus resultiert die "Pufferrolle" der Ersatzinvestitionen: wenn die Zukunftserwartungen positiv genug sind, und die Liquiditätslage dagegen eingeengt ist, versucht man die Erweiterungsinvestitionen soweit wie möglich durchzuführen, um die Marktchancen nicht ungenutzt zu lassen. Stattdessen verlegt man den Zeitpunkt der 
Ersatzinvestitionen in die Zukunft. Umgekehrt würde in rezessiven Phasen die zur Verfügung stehende Liquidität nicht in Erweiterungs- sondern in vorgezogenen Ersatzinvestitionen getätigt. Eine wichtige Folgerung dieser Erklärung ist, daß die Ersatzinvestitionen von der Liquiditätslage, während die Nettoinvestitionen von den Gewinn- und Markterwartungen abhängig sind, da, wie gesehen, in der Allokation der Finanzmittel die Ersatzinvestitionen eine untergeordnete Priorität genießen. FELDSTEIN und FOOT weisen daher darauf hin, daß die Untersuchungen der Einflüsse der fiskalpolitischen Parameter auf die Investitionen unbedingt auch die Liquiditätsfrage berücksichtigen müssen. Ein anderes Ergebnis, das für diese Arbeit auch von Bedeutung sein sollte, ist daß gleichzeitig mit diesem Wettbewerb zwischen Ersatz- und Erweiterungsinvestitionen eine weitere Einflußgröße die Ersatzinvestitionen bedingt: "For any given level of capacity utilization, the greater the average age of the capital stock, the more incentive for replacement there is likely to be" (FELDSTEIN \& FOOT, 1971, S.57).

Der dritte Erklärungsansatz beruht auf der Hypothese, die Unternehmen ließen sich bei Ersatz- und Erweiterungsinvestitionenvon den gleichen Bestimmungsgründen leiten. Eine analytische Unterscheidung zwischen beiden Investitionsarten wäre daher ohne Belang. Die Kritik an diesen Ansatz bedient sich der Tatsache, daß die Erweiterungsinvestitionen mit einem größeren Risiko verbunden sind, da sie nicht einen bekannten Markt berühren, sondern darauf abzielen, Marktanteile zu erhöhen oder sich an neue Märkte anzuschließen.

\subsection{Der betriebswirtschaftliche Ansatz}

Der betriebswirtschaftliche Ansatz ist grundsätzlich analytisch-normativ. Sein Hauptzweck ist es, anhand finanzmathematischer Analysen zu finden, wie sich der betriebliche Investor bei gegebenen steuerlichen (oder anderen) Einflußgrößen verhalten sollte. Aussagen darüber, wie sich die Investoren unter dem Einfluß der Steuern tatsächlich verhalten, sind daher nicht möglich. In der Literatur sind zahlreiche solcher Untersuchungen zu finden, wie z.B. WAGNER (1979) und (1980), MELLWIG (1980) und (1985), und BAAN (1980). Abgesehen von den Ansätzen, die sich mit Finanzierungs- und Liquiditätsproblemen beschäftigen (diese werden innerhalb dieser Arbeit später berücksichtigt), bildet bei all diesen Ansätzen die Kapitalwertmethode deren Rückgrat.

Obwohl sie empirisch makroökonomisch nicht überprüft werden können, bieten die betriebswirtschaftlichen Ansätze wichtige Vorteile, wie z.B.:

die Möglichkeit der beliebigen Zerlegung in Teilmodelle zwecks partieller Analysen; die Schaffung der Grundlagen der mikroökonomischen Ansätze - z.B. übernimmt die neoklassische Investitionstheorie die Diskontierungsmethode vom ganzzähligen zum stetigen Bereich; 
- die Festsetzung des Rahmens des rationalen Verhaltens der Unternehmer.

Ihr größter Nachteil ist, daß sie keine Basis für die quantitative Messung der Wirkungen unterschiedlicher Steuern / fiskalpolitischer Maßnahmen auf die Makroebene liefern.

\subsection{Die neoklassische Investitionstheorie}

In ihrer Referenzarbeit "The Investment Decision" (1966), unterscheiden MEYER und KUH hauptsächlich zwei Arten von Investitionstheorien: die Marginalitätstheorien - ihrer Meinung nach, ein Gebilde aus Mathematik und elementarer hedonistischer Psychologie - und die Akzeleratortheorien. Als dieses Buch veröffentlicht wurde, gab es die neoklassische Investitionstheorie - die in der wissenschaftlichen Debatte bisher die Hauptrolle gespielt hat - in ihrer heutigen Form noch nicht. Ihre Entwicklung hat aber gezeigt, daß sie der ersteren Kategorie angehört. Ihre Anfangshypothesen sind charakteristisch für ihren marginalistischen Ansatz:

- $\quad$ Alle künftigen Produkt- und Faktorpreise sowie die künftigen Ausbringungsmengen sind bekannt, und somit auch die Einzahlungen, die jedes bestimmte Investitionsobjekt in der Zukunft erbringen wird.

- Alle Anschaffungsausgaben sind ebenfalls sowohl in der Gegenwart als auch für die Zukunft bekannt.

- $\quad$ Es gibt keine Technologieeinbrüche.

- Das Angebot an Finanzmitteln ist entweder beim gegebenen Marktzins unbegrenzt oder der Marktzins spiegelt in einer bestimmten Weise die Finanzmarktstruktur wider.

In der neoklassischen Theorie hat das Unternehmen das Ziel, seinen Kapitalwert W zu maximieren. Die Theorie ist also mit der Kapitalwertmethode (Abs.3.4.) verwandt. Der wesentliche Unterschied besteht aber darin, daß mit der Kapitalwertmethode nur Aussagen über die Vorteilhaftigkeit einzelner Investitionen abgeleitet werden können, ohne gleichzeitig die Reaktionen der Unternehmen auf die Änderungen der Vorteilhaftigkeit ableiten zu können. Dagegen verbindet die neoklassische Theorie diese Vorteilhaftigkeit mit produktionstheoretischen Hypothesen, und ermöglicht damit direkte Aussagen über die Art und den Umfang der Reaktionen der Investoren. Das Ziel, den Kapitalwert zu maximieren,ist praktisch identisch mit dem Ziel, den Gewinn jederzeit zu maximieren.

Die folgende Darstellung dieses Modells basiert grundsätzlich auf der Präsentation von SIEDENBERG (1976, S.97-108). 
Der Periodenüberschuß $Z(t)$ in Periode $t$ wird bestimmt durch die Differenz zwischen den Einzahlungen in Höhe des Umsatzes und den Auszahlungen für die Bezahlung des variablen Faktors und für die Investitionsgüterkäufe in der jeweiligen Periode:

$$
Z(t)=p Q(t)-w L(t)-q I(t)
$$

wobei: $\quad \mathrm{p}=$ Preis der produzierten Güter

$\mathrm{Q}=$ Menge der produzierten Güter

$\mathbf{w}=$ Preis des eingesetzten variablen Faktors

$\mathrm{L}=$ Menge des eingesetzten variablen Faktors

$\mathrm{q}=$ Preis der gekauften Investitionsgüter

$I$ = Menge der gekauften Investitionsgüter

Zusätzlich müssen auch die Zahlungen an direkten Steuern berücksichtigt werden. Angenommen, $\mathrm{pQ}$, wL und $\mathrm{qI}$ bleiben gleich, folgt daraus daß die Gewinnsteuern nicht überwälzbar sind. In einem ersten Ansatz werden die steuerliche Berücksichtigung der Abschreibungen, der Fremdkapitalzinsen und der Preisänderungen der Investitionsgüter einbezogen. Somit taucht der erste wesentliche Mangel dieser Methode auf: die Gewinnsteuerregelungen unterscheiden fast überall (auch in Rumänien) zwischen ausgeschütteten und nichtausgeschütteten Gewinnen. Diesen Mangel könnte man anhand der Unterstellung, das Verhältnis zwischen einbehaltenen und ausgeschütteten Gewinnen sei konstant umgehen.

Der Periodenüberschuß wird also:

$$
Z(t)=p Q(t)-w L(t)-q I(t)-T C(t)
$$

wobei:

$$
T C(t)=u\left[p Q(t)-w L(t)-q\left(v d-w r-x q^{\prime} / q\right) K(t)\right]
$$

\begin{tabular}{|c|c|}
\hline$K(t)$ & Kapitalstock zu Beginn der Periode t; \\
\hline $\mathrm{u}$ & Gewinnsteuersatz; \\
\hline $\mathbf{v}$ & $\begin{array}{l}\text { steuerlich berücksichtigungsfähiger Prozentsatz der Abschrei- } \\
\text { bung; }\end{array}$ \\
\hline w & steuerlich abzugsfähiger Teil der Zinsbelastung; \\
\hline $\mathrm{x}$ & $\begin{array}{l}\text { steuerlich zu berücksichtigender Teil der Preisänderungen der } \\
\text { Investitionsgüter; }\end{array}$ \\
\hline d & Abschreibungssatz; \\
\hline$=$ & Zinssatz; \\
\hline & Preisänderungen der Investitionsgüter. \\
\hline
\end{tabular}

und: 
Die Zielfunktion der Unternehmen ist also:

$$
\begin{gathered}
w=\int_{0}^{\infty} e^{-r t} Z(t) d t= \\
\int_{0}^{\infty} e^{-r t}\left\{p Q(t)-w L(t)-q I(t)-u\left[p Q(t)-w L(t)-q\left(v d-w r-x q^{\prime} / q\right) K(t)\right]\right\} d t
\end{gathered}
$$

(wobei von der ganzzähligen betrieblichen Kapitalwertrechnung zur stetigen mikroökonomischen Integralrechnung übergegangen wurde).

Diese Zielfunktion soll unter folgenden Nebenbedingungen maximiert werden:

- es gibt eine Produktionsfunktion:

$$
F(Q, L, K)=0
$$

- Ersatzinvestitionen werden in Höhe eines festen Prozentsatzes d vom Kapitalstock vorgenommen:

$$
\Delta K(t)-I(t)+d \cdot K(t)=0(3.7)
$$

wobei:

$$
\begin{array}{ll}
\mathbf{K}(t)= & \text { Veränderung des Kapitalstocks in Periode " } t " \\
\mathbf{I}(\mathrm{t})= & \text { Bruttoinvestitionen in Periode } t
\end{array}
$$

Die Maximierung der Funktion (3.5) unter den Nebenbedingungen (3.6) und (3.7) erfolgt mit Hilfe des Lagrangeschen Multiplikatorverfahrens.

Nach der Benutzung dieser Methode erhält man als Optimalbedingung:

$$
\left|\frac{\partial Q}{\partial K}\right|=\frac{q}{p}\left[\frac{1-u v}{1-u} d+\frac{1-u w}{1-u} r-\frac{1-u x}{1-u} \frac{q^{\prime}}{q}\right](3.8)
$$

wobei: 


$$
c=q\left[\frac{1-u v}{1-u} d+\frac{1-u w}{1-u} r-\frac{1-u x}{1-u} \frac{q^{\prime}}{q}\right](3.9)
$$

ein Ausdruck für die Kosten der Kapitalbereitstellung (capital user costs, Kapitalnutzungspreis) ist.

Als Verhaltensregel für den Einsatz des Faktors Kapital ergibt sich also: Es sind solange zusätzliche Kapitalgüter einzusetzen (Investitionsgüter zu beschaffen), bis die Grenzproduktivitätsbedingung:

$$
\frac{\partial Q}{\partial K}=\frac{C}{p}(3.10)
$$

erfüllt ist.

Diese Bedingung impliziert, daß ein Unternehmen seinen höchsten Kapitalwert und zugleich sein Gewinnmaximum zu jedem Zeitpunkt erreicht, wenn das zusätzliche Produkt aus dem Einsatz einer zusätzlichen Kapitaleinheit gleich ist dem Verhältnis von Kapitalbereitstellungskosten und dem Verkaufspreis dieses Produktes. Die Unternehmen werden, m.a.W., so lange investieren, bis das bewertete partielle Grenzprodukt den Grenzkosten des Einsatzes des Faktors Kapital gleich ist:

$$
p \partial Q=c \partial K(3.11)
$$

Bisher war aber die Produktionsfunktion nicht spezifiziert. In der neoklassischen Theorie wird dafür die Cobb-Douglas Funktion mit konstanten Niveaugrenzprodukten gewählt (sowie z.B. JORGENSON \& STEPHENSON, 1967):

$$
Q=K^{\alpha} L^{1-\alpha} ;(0<\alpha<1)(3.12)
$$

Die Produktionsfunktion ist also linearhomogen. Nach partieller Ableitung nach $\mathrm{K}$ erhält man:

$$
\frac{\partial Q}{\partial K}=\alpha K^{\alpha-1} L^{1-\alpha}(3.13)
$$

Da nun gilt: 


$$
\frac{Q}{K}=K^{\alpha-1} L^{1-\alpha}
$$

läßt sich (3.13) auch schreiben als:

$$
\frac{\partial Q}{\partial K}=\alpha \frac{Q}{K}(3.14)
$$

wobei:

$$
\alpha=\frac{\partial Q}{Q}+\frac{\partial K}{K}
$$

die partielle Produktionselastizität des Faktors Kapital darstellt. Gleichung (3.8) wird also:

$$
\frac{C}{p}=\alpha \frac{Q}{K}(3.15)
$$

Gleichung (3.8) entspricht aber der Maximum-Bedingung; $K$ ist also als gewünschter Kapitalstock zu betrachten. Nach K aufgelöst ergibt sich die Höhe des optimalen Kapitalstocks zum Zeitpunkt t:

$$
K^{*}(t)=\alpha \frac{p Q(t)}{C}(3.16)
$$

Die Höhe des optimalen Kapitalstocks hängt folglich ab:

- von der partiellen Produktionselastizität des Faktors Kapital;

- vom Preisniveau der produzierten Güter;

- von der Menge der produzierten Güter und

- von den Kapitalbereitstellungskosten.

Ohne Rücksicht auf die Anpassungsverzögerungen lautet die neoklassische Investitionsfunktion somit:

$$
I_{t}=\alpha \frac{p Q(t)}{C}-(1-d) K_{t}(3.17)
$$


Es wurde ersichtlich, daß die Größe, durch die die Steuern die Investitionsentscheidung (auf Makroebene) beeinflussen, die Kapitalbereitstellungskosten c sind. Ihre Erhöhung bzw Senkung senkt bzw. erhöht den optimalen (gewünschten) Kapitalstock , und die induzierten Investitionen gleichen (mit einer gewissen Zeitverzögerung) den tatsächlichen an den optimalen Kapitalstock an. Die Untersuchung der Steuereinflüsse setzt also die eingehende Berücksichtigung der Kapitalbereitstellungskosten voraus.

In einer Wirtschaft ohne Steuern $(u=0)$ :

$$
c=q\left(r-q^{\prime} / q\right)+q d
$$

setzen sich damit die Kapitalbereitstellungskosten aus der Realzinsbelastung sowie den Abschreibungen zusammen. Unter Einbeziehung einer Gewinnsteuer von Satz u, und den weiteren Annahmen:

$-\mathrm{v}=1$ (die Abschreibungen sind in vollem Umfang steuerlich absetzbar);

- $w=1$ (Fremdkapitalzinsen auch abzugsfähig);

$-\mathrm{x}=0$ (keine Besteuerung auf Kapitalgewinne);

werden die Kapitalbereitstellungskosten nach demselben Lagrangeschen Multiplikatorverfahren berechnet:

$$
C=q\left(r+d-\frac{q^{\prime}}{q}\right)(1-k-u z)(1-u)^{-1}(3.19)
$$

wobei:

- $\mathbf{k}=$ Prozentsatz eines möglichen Steuerabzugs für Investitionen und:

$$
z=\int_{0}^{\infty} e^{-r s} D(s) d s(3.20)
$$

- $D(s)=\quad$ der Teil der steuerlich zulässigen Abschreibungssumme, der für Steuerzwecke von einem Investitionsgut abgeschrieben werden darf, das s Perioden alt ist;

- $z=\quad$ der Gegenwartwert aller steuerlich erlaubten Abschreibungen eines Investitionsgutes. Bei erlaubter Sofortabschreibung der gesamten Anschaffungs- oder Herstellungskosten ist $\mathrm{z}=1$.

Die Benutzung der Formel (3.19) ermöglicht - im Gegensatz zur ursprünglich von JORGENSON in (1963) verwendeten Formulierung - die Analyse von drei wesentlichen fiskalpolitischen Variablen:

- dem Steuersatz u und seiner Variation;

- den Abschreibungsmöglichkeiten ( $\mathrm{z}$ ) und ihrer Variation;

- der Variation von Investitionskosten (k). 
Falls der Zins von der Gewinnbesteuerung beeinflußt werden sollte, gilt:

$$
r=(1-u) \rho
$$

wobei

$$
\rho=\text { cons } t,
$$

sollte der Kalkulationszinsfuß vor der Besteuerung sein. Daher:

$$
c=q\left[(1-u) \rho+d-\frac{q^{\prime}}{q}\right](1-u z)(1-u)^{-1}(3.21)
$$

Modernere Ansätze, wie z.B. diejenigen von KING (1977) oder ATKINSON \& STIGLITZ (1980, S.146-147) beschäftigen sich auch mit der Analyse der Kapitalbereitstellungskosten für verschiedene Finanzierungsalternativen.

KING berechnet die Kapitalbereitstellungskosten ohne den Kapitalwert zu maximieren und unter der Annahme, der Preis der Investitionsgüter sei gleich eins. Er geht von der Effizienzbedingung aus:

Grenzwertprodukt $=$ Grenzkosten der Investition

$$
G W P=\frac{\partial Q}{\partial K} p=q(r+d)(3.22)
$$

(ohne Besteuerung), und:

$$
G W P-r-d-u\left(G W P-r-d^{*}\right)=0(3.23)
$$

(bei Besteuerung und voller steuerlicher Abzugsfähigkeit der Zinsen, sowie q=1).Dann:

$$
\begin{aligned}
& G W P(1-u)-r+u r-d+u d^{*}=0 \Rightarrow \\
& \Rightarrow G W P=r+\frac{d-u d^{*}}{1-u}=c(3.24)
\end{aligned}
$$

wobei mit $d^{*}$ der steuerliche Abschreibungssatz gekennzeichnet wurde. Für 
ergibt sich wieder $c=r+d$, also eine Indifferenzbedingung: wenn die steuerlichen gleich den ökonomischen Abschreibungen sind, beeinflußt der Gewinnsteuersatz bzw. seine Änderung bei Preisstabilität die Investition nicht.

Mehr relevant für Rumänien dürften die Formeln sein, die KING unter Mitberücksichtigung der Inflation (q'/q) herausfindet:

- ohne Besteuerung:

$$
c=r+d\left(1+q^{\prime}\right)-q^{\prime}
$$

- mit Besteuerung, Fremdfinanzierung und volle steuerliche Abzugsfähigkeit der Zinsausgaben:

$$
c=r+\frac{d\left(1+q^{\prime}\right)-q^{\prime}-u d^{*}}{1-u}(3.26)
$$

mit der Indifferenzbedingung:

$$
d^{*}=d\left(1+q^{\prime}\right)-q^{\prime}
$$

- mit Besteuerung und Eigenfinanzierung über Kapitalerhöhung und anschließend Vollausschüttung der Dividenden:

$$
c=\frac{1}{1-u}\left[\frac{1-m}{u^{*}} r-q^{\prime}+d\left(1+q^{\prime}\right)-u d^{*}\right](3.27)
$$

wobei der ausschüttungsbedingte Steuerfaktor:

$$
u^{*}=1-m
$$

bei der Doppelbelastung der ausgeschütteten Dividenden, oder:

$$
u^{*}=\frac{1-m}{1-u}
$$

beim Vollanrechnungsverfahren, und $m$ der marginale Einkommensteuersatz des Dividendenbeziehers sind.

Beim Vollanrechnungsverfahren läßt sich die Indifferenzbedingung wiederum schreiben: 


$$
d^{*}=d\left(1+q^{\prime}\right)-q^{\prime}
$$

(der inflationsbereinigte ökonomische Abschreibungssatz).

- schließlich, mit Besteuerung und Eigenfinanzierung über Gewinnthesaurierung:

$$
C=\frac{1}{1-u}\left[\frac{1-m}{1-z} I-q^{\prime}+d\left(1+q^{\prime}\right)-u d^{*}\right](3.28)
$$

wobei $\mathrm{z}$ der Kapitalgewinnsteuersatz ist.

Für eine Besteuerungsneutralität sollen die Bedingungen:

$$
\begin{aligned}
\mathrm{m}=\mathrm{u}, \mathrm{z}=0, \text { oder }(1-\mathrm{z})(1-\mathrm{u}) & =1-\mathrm{m}, \text { und zugleich } \\
d^{*} & =d\left(1+q^{\prime}\right)-q^{\prime}
\end{aligned}
$$

erfüllt sein.

Aus diesen Rechnungen läßt sich zeigen daß, bei Preissteigerungen, das Steuersystem investitionspolitisch dann neutral ist, wenn Abschreibungen zu Wiederbeschaffungspreisen steuerlich erlaubt - $d\left(1+q^{\prime}\right)$ - aber gleichzeitig nur die realen Zinsausgaben steuerlich abzugsfähig sind (-q'). Dies entspricht dem Fall des indexierten Steuersystems.

JORGENSON hat selbst (1965) seine Theorie für den Zeitraum 1947-1960 auf die USA übertragen und empirisch überprüft. Mit Hilfe von verbesserten Investitionsfunktionen wie derjenigen von KLEIN (1974):

$$
I(t)=\alpha_{0}\left(\frac{p Q}{C}\right)+\alpha_{t}\left(\frac{p Q}{C}\right)_{t-1}+\beta K_{t-1}
$$

haben auch FELDSTEIN und FLEMING (1971) diese Theorie in Großbritannien getestet, mit einem Ergebnis, das mit ihr vereinbar ist: Abschreibungserleichterungen und die unterschiedliche Besteuerung von einbehaltenen und ausgeschütteten Gewinnen haben einen großen Beitrag (45\% bzw. 15\%) zur Anregung von Nettoinvestitionen in der Zeit 1954-1971 geleistet.

In Deutschland wurde der JORGENSONsche Ansatz in jüngerer Zeit anhand des ökonometrischen Grundmodells der Wirtschaftsforschungsinstitute auch mit der Erzielung aussagekräftiger Konklusionen eingesetzt. Schließlich sei erwähnt, daß auch in einer Wirtschaft, 
die nicht gerade hochentwickelt ist, dieser Ansatz sich gut bewährt hat (vgl. ANASTASSIOU, 1990, für Griechenland).

\subsection{Der Akzeleratoransatz}

In seiner rigiden Form, besagt das Akzeleratorprinzip, daß die zeitliche Änderung des Kapitalstocks eine Linearfunktion der Outputänderungsrate ist. Es beinhaltet also keine motivationelle Hypothese - eine Tatsache die, von der Firmenebene aus gesehen, als eine wichtige Schwäche gelten sollte. Wie MEYER und KUH (1966, S.14) bemerkt haben, verhält sich der typische Unternehmer wie ein Thermostat. Er merkt sich, wenn die Produktionskapazitäten hinter der Entwicklung der Nachfrage geblieben sind, und trifft folglich Maßnahmen um diese Deffizienz zu beseitigen. Diese Theorie ist einfach, direkt und fertig für die empirische Überprüfung.

Sie ist aber auch mit den unterschiedlichsten Mängeln behaftet. Fragwürdig ist z.B. die Hypothese daß, die Firmen keine Überschußkapazitäten besitzen dürfen, bevor sie Nettoinvestitionen vornehmen. Diese Bedingung ist schwer mit der Feststellung vereinbar, daß in der Realität Überschußkapazitäten bei fast allen Unternehmen zu finden sind. Eine andere problematische Unterstellung ist, daß die Firmen in beliebiger Menge Gelder zur Finanzierung ihrer Kapitalstockerweiterungen aufnehmen können. Diese Schwäche gilt aber auch für die neoklassische Investitionstheorie.

Trotz ihrer Einfachheit - oder vielleicht gerade deswegen - findet diese Theorie auch in jüngeren Zeiten ihre Anhänger - wie z.B. LEIBINGER (1985, S.133): "Ökonometrische Analysen bestätigen in ihrer Mehrzahl die dominierende Rolle der Nachfrageentwicklung für das private Investitionsverhalten. So schneidet auch in einer jüngeren Studie von CLARK, der die wichtigsten Investitionshypothesen für die USA in den Jahren 1954-1978 testete, die Akzeleratorhypothese am besten ab, während der Kapitalnutzungspreis (Zinssätze und Steuern) weniger bedeutsam ist". CHRIST (1963) zeigt aber, daß beide Ansätze neoklassische Investitionstheorie und Akzeleratortheorie - in ihren ökonometrischen Ergebnissen nicht grundsätzlich verschieden sind. Die Hauptunterschiede liegen - abgesehen von der dahinter liegenden Theorie - zum einen darin, daß EISNER (Akzeleratortheorie) Umsätze und JORGENSON Produktionswerte benutzt, und zum anderen der erste Ansatz Raten adimensionale Größen - während der zweite monetäre Werte verwendet. 


\subsection{Die Tobin's "q"-Theorie}

Die "q" Theorie von TOBIN (1968) versucht die Anpassungen des volkswirtschaftlichen Kapitalstocks durch "q" zu erklären - den Bruch zwischen dem Kapitalwert einer Firma und den Wiederherstellungskosten ihres Sachvermögens, einschließlich des Bodens. Wenn der tatsächliche gleich dem gewünschten Kapitalstock ist, $q=1$, dann beschränken sich die Investitionen auf den Ersatz der verschlissenen Sachanlagen (evtl. zuzüglich einer erwarteten Wachstumskomponente, in einer wachsenden Wirtschaft).

Dennoch, wenn Veränderungen der Kapitalbereitstellungskosten und anderer exogenen Variablen unerwartet sind und es auch Anpassungsverzögerungen gibt, oder wenn die Dauer der Anpassungsverzögerung unsicher ist, braucht $\mathrm{q}$ nicht gleich eins zu sein, um den Gleichgewichtzustand zu signalisieren. Im einfacheren Fall aber induziert $\mathbf{q}$ größer eins Erweiterungsinvestitionen, während q kleiner eins sie lähmt.

Tobin's q Theorie stellt die modernere Fortsetzung und Entwicklung der neoklassischen Investitionstheorie dar. So beweist z.B. HAYASHI (1982), daß der TOBINsche Ansatz gleich dem JORGENSONschen ist, zuzüglich dem Einbau der Anpassungskosten (adjustment costs). SUMMERS (1981) baut die Besteuerung in die "q"-Theorie ein und kommt zur Schlußfolgerung, daß die erfolgreichsten Maßnahmen für den Erfolg der Investitionstätigkeit diejenigen sind, die die Beschaffungskosten der neuen Anlagen verbilligen. Die Inflation, so SUMMERS, reduziert die Kapitalakkumulation, soweit das Steuersystem angesichts der Realund Nominalzinsen nicht indexiert wird.

Weitere wichtige Beiträge im Rahmen der Tobin's q Theorie liefern ABEL (1982), POTERBA und SUMMERS (1983), FUNKE (1987 und 1989), und SUMNER (1989). Hauptsächlich geht es um Verfeinerungen der TOBINschen Theorie und um ihre empirische Überprüfung oder Einbau in makroökonomische Modelle.

\subsection{Uncertainty-Theorien.}

Die Ansätze, die zur Lösung des Problems der Unsicherheit entwickelt worden sind, können in zwei Gruppen geteilt werden:

Auf der einen Seite stehen die Spieltheorie und ihre verwandten Ansätze. Sie versuchen, dem Unternehmen unter unsicheren Bedingungen optimale Entscheidungsstrategien zu empfehlen.

Die andere Gruppe enthält die Ansätze, die das Entscheidungsproblem anhand Indifferenzkurvensystemen zu lösen versuchen. Sie beinhalten also Hypothesen über die Nutzenfunktion des 
Unternehmens, die erlaubt, seine Entscheidung zu erklären und auch die Reaktionen der Unternehmen auf gewisse Datenänderungen zu antizipieren. Dabei kommen verschiedene Zielvariablen, wie Unternehmenskapitalwert, Gewinn und Verlust, Einkommen, Endvermögen und Eigenkapitalrendite in Betracht. Diese Zielvariablen sind allerdings miteinander stark verbunden. Die Hauptannahme lautet: "der Unternehmer strebe nach einer optimalen Kombination von erwarteter Höhe und Sicherheit seines monetären Ziels".(SIEVERT, 1989, S.196).

$\mathrm{Da}$ in der ökonomischen Realität diese zwei Größen gegenläufig sind, läßt sich die Folgerung herleiten: abnehmende Sicherheit muß durch zunehmend höhere Einkommenserwartungen kompensiert werden, soll ein bestimmtes Nutzenniveau gehalten werden.

Der erste nennenswerte Ansatz in dieser Richtung stammt von DOMAR und MUSGRAVE (1944). Die folgende Darstellung dieses Modells basiert auf der Version von MUSGRAVE (1974, S.276-281). Nach der Bestimmung der Wahrscheinlichkeit, verschiedene (positive oder negative) Erträge aus einer Investition zu erzielen, legt der Investor seine Wertschätzung in Form einer Wahrscheinlichkeitsverteilung fest. Der Investor richtet seine Aufmerksamkeit auf die mathematische Erwartung des prozentualen Ertrags y, den Durchschnittsertrag, den er langfristig zu erzielen erwartet. Er ist auch an der Gewinnkomponente g von y und an seiner Risikokomponente $\mathbf{r}$ interessiert.

Sind die erwarteten Ertragsraten $q_{1}, q_{2}, \ldots q_{k}, q_{k+1}, \ldots q_{n}$ derart, daß $q_{i}$ immer kleiner $q_{i+1}$ und $\mathrm{q}_{\mathrm{k}}=0$, und ist die Wahrscheinlichkeit des Eintritts von $\mathrm{q}_{\mathrm{i}}=\mathrm{p}_{\mathrm{i}}$, so daß gilt:

$$
\sum_{i=1}^{n} p_{i}=1
$$

so erhalten wir folgende Definitionen:

$$
\begin{gathered}
r=-\sum_{i=1}^{k} q_{i} p_{i} \\
g=\sum_{i=k+1}^{n} q_{i} p_{i} \\
y=\sum_{i=1}^{n} q_{i} p_{i}=g-r
\end{gathered}
$$

Da die Werte aller $q$ von Anfang an bis $q_{k}$ negativ sind, ist $r$ positiv. 
Jetzt muß der Investor entscheiden, in welcher Kombination er die verschiedenen Vermögensanlagen zu halten wünscht. Um die Relevanz dieses Ansatzes für die ausländischen Kapitalinvestitionen in Rumänien darzulegen, sei angenommen, daß dem ausländischen Investor zwei Opportunitäten offenstehen: die Investitionsprogramme $\mathrm{X}$ in der Tschechischen Republik, und $\mathrm{Z}$ in Rumänien. Sei $\mathrm{X}$ von einem geringeren Risiko behaftet, verspreche aber $Z$ höhere Erträge.

Abbildung 3.1: $\quad$ Ableitung einer Kurve der optimalen Vermögensanlage

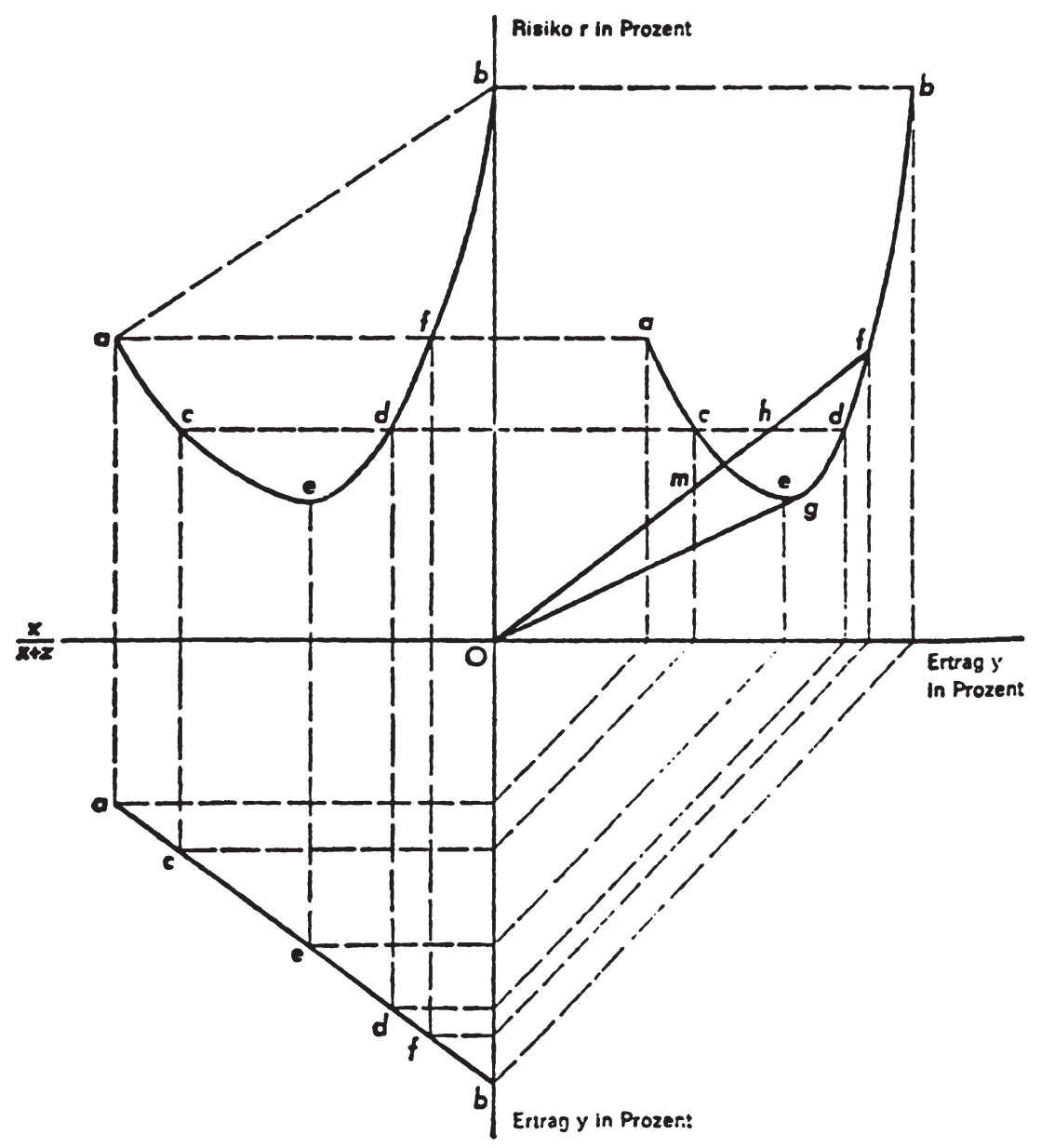

(Quelle: MUSGRAVE, 1974, S.278) 
Im linken unteren Quadranten der Abb.3.1 messen wir vertikal den Ertrag jeder möglichen Kombination von $\mathrm{X}$ und $\mathrm{Z}$. Auf der Abszisse messen wir den Anteil des gesamten Investitionsprogramms $X+Z$, der der Investition $X$ zugesprochen wird. Das Gewicht von $X$ nimmt $\mathrm{zu}$, wenn wir uns in diesem Quadranten nach links bewegen. Die Investition $\mathrm{Z}$ verspricht den größeren Ertrag. Die Erträge der verschiedenen Kombinationen von $\mathrm{X}$ und $\mathrm{Z}$ liegen auf einer Gerade von a nach b, da der Ertrag jeder Kombination jeweils dem gewogenen Durchschnitt des Ertrages der beiden Investitionsvarianten entspricht.

Im linken oberen Quadranten der Abb.3.1 werden vertikal das Risiko jeder möglichen Kombination und die Investitionskombinationen wiederum horizontal gemessen. Wenn die gesamten Finanzmitteln in $\mathrm{Z}$ investiert werden, so ist das Risiko gleich der Ordinate von b; wird nur in $\mathrm{X}$ investiert, so gibt die Ordinate von a das Risiko an. Die riskantere Investition $\mathrm{Z}$ bietet auch den größeren Ertrag. Wenn weniger in $\mathrm{X}$ und mehr in $\mathrm{Z}$ investiert wird, nimmt das gesamte Risiko wegen des Streuungseffekts ab. Da jedoch die Investition $\mathrm{Z}$ die mit dem höheren Risiko ist, wird bei sukzessiver Erhöhung von $\mathrm{Z}$ das gesamte Risiko irgendwann steigen. Wir erhalten somit eine Kurve aeb, die das gesamte Risiko abhängig vom Bruch $\mathrm{X} /(\mathrm{X}+\mathrm{Z})$ zeigt.

Schließlich sind die Risiken und Erträge der verschiedenen kombinierten Investitionsprogramme im rechten oberen Quadranten dargestellt. Das Risiko wird auf der Ordinate und der Ertrag auf der Abszisse gemessen. Die Kombinationen, die sich links von e befinden, können ausgeschlossen werden, da jeder rechts von e eine überlegene Kombination mit dem gleichen Risiko, aber höherem Ertrag gegenübersteht. Die Kurve eb ist somit der Ort der mit höchstem Ertrag und geringstem Risiko ausgestatteten Kombinationen, aus denen der Investor auswählen kann. Vom Punkt e an, behält der Investor lieber Bargeld, was der Geraden Og entsprechen sollte.

Diese optimale Investitionskurve wird in Abb.3.2 wiederholt. Die Entscheidung des Investors unter allen Punkten auf der Kurve OGB wird durch seine Präferenz zwischen dem Risiko $r$ und dem Einkommen y bestimmt. Das Indifferenzkurvensystem der Abb.3.2, das diese Präferenz ausdrückt, basiert auf der Annahme, daß die zur Verfügung stehenden Mitteln eine konstante Summe bilden. Die Form der Indifferenzkurven ergibt sich aus der Annahme, daß der Grenznutzen des Einkommens mit steigendem Einkommen sinkt und das Grenzleid des Risikos mit zunehmendem Risiko steigt.

Auf der Grundlage dieses Präferenzsystems und der optimalen Investitionskurve OGB wird der Investor diejenige Kombination wählen, die ihn die höchstmögliche Indifferenzkurve erreichen läßt. In Abb.3.2 geschieht das beim Punkt M. 
Abbildung 3.2: Wahl der optimalen Vermögenskombination

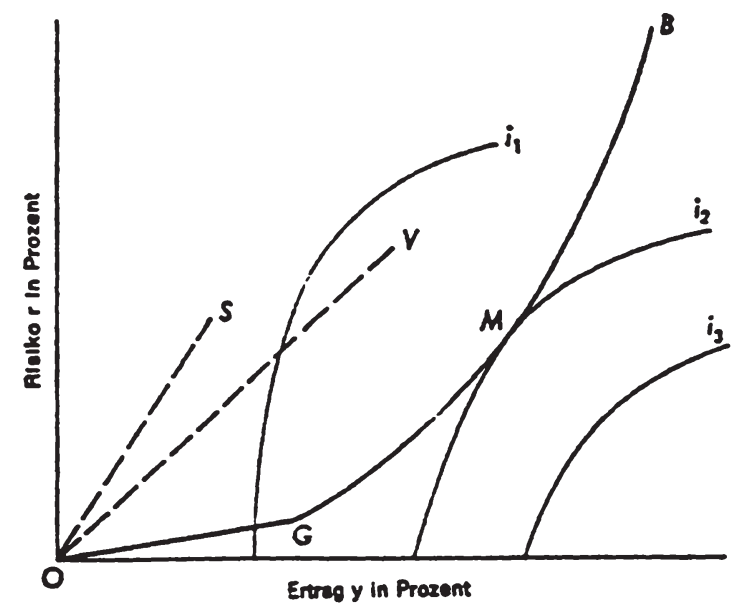

(Quelle: MUSGRAVE, 1974, S.281)

\subsection{Der Finanzierungsquellenansatz.}

In der betrieblichen Investitionsplanung kann man jederzeit zwei Teile unterscheiden: den physischen und den finanziellen. Die im ersten Teil aufgeführten und nach ihrer Vorteilhaftigkeit - oder Dringlichkeit - geordneten Investitionen müssen immer mit den Finanzierungsmitteln verglichen werden. Diese Auseinandersetzung ist ausschlaggebend für die Entscheidung, welche von den Investitionsprojekten auch tatsächlich durchgeführt werden sollen.

Weiterhin soll die neoklassische Annahme der unbegrenzten Finanzierungsmitteln verlassen werden. Es ist allgemein bekannt, daß einige der wichtigsten Probleme des Wiederaufbaus in Osteuropa die Knappheit der Finanzmitteln und das schlecht funktionierende Bankensystem sind.

Zahlreiche Aufsätze gehen in der Literatur auf das Problem des Einflusses der Besteuerung auf die Wahl der Finanzierungsform ein. Die Modalität der Untersuchung stellt entweder auf die betriebswirtschaftliche (WÖHE und BIEG (1984, S.331 ff.) oder auf volkswirtschaftliche (hier zählen NICKELL (1978, S.203-210), KING (1977), FELDSTEIN, GREEN und SHESHINSKI (1979) u.a.) Betrachtungsweise ab. JORGENSON (1971) teilt die Ansätze, die sich mit den finanziellen Überlegungen bei Investoren beschäftigen, in zwei Kategorien ein: 
diejenigen, die hauptsächlich die Finanzierung aus "external funds" analysieren - beginnend mit dem MODIGLIANI-MILLER Theorem des optimalen Finanzierungsprogramms und der optimalen Finanzierungsquellen unter bestimmten Besteuerungsbedingungen, und diejenigen, die die Finanzierung aus "internal funds" als entscheidend annehmen, angeregt von MEYER $\&$ KUH und DUESENBERRY.

SCHNEIDER (1964, S.157-163) betont, daß die Anschaffung einer Anlage, egal wie hoch ihre im voraus berechnete Rentabilität sein möchte, nur dann sinnvoll ist, wenn dadurch der Fortbestand des Unternehmens von der finanziellen Seite auch nicht in Frage gestellt wird. Das Unternehmen wird die Investition nur dann vornehmen, wenn es in jedem Zeitpunkt genügend Zahlungsmitteln besitzt oder sich beschaffen kann, um die mit der Investition verbundenen Zahlungsverpflichtungen erfüllen zu können. Gelinge dies dem Unternehmen nicht, wäre dann die Liquidation von wenigstens einem Teil des Betriebsvermögens notwendig, was zu hohen Zusatzkosten und dadurch zu Verlusten führen würde.

Die Besteuerung bringt im wesentlichen in dieser Situation zwei Wirkungen mit sich: durch die Steuerzahlung erhöht sich der Finanzbedarf einer Investition. Bei gegebenen Eigenmitteln des Unternehmens steigt die Verschuldung und damit die Zinszahlungen, zudem müssen ungünstige Kredite aufgenommen werden (siehe die hohen Zinsen in Rumänien, und die Verzögerungen, mit denen diese Kredite aufgegeben werden). Dadurch vermindert sich der Gewinn, der mit der Anlage erzielt wird, so daß eine zusätzliche Rentabilitätswirkung neben die Liquiditätswirkung eintritt.

Im folgenden wird vereinfachend unterstellt, daß das Unternehmen den Finanzbedarf dieser Investition vollständig durch eine eigene Einlage deckt. Soweit Zinskosten anfallen, werden sie als in den laufenden Kosten enthalten gedacht.

Im Lebenslauf eines Unternehmens müssen auch die Reinvestitionen berücksichtigt werden. Zur Vereinfachung der Darstellung sollen die folgenden Annahmen gemacht werden: Die Nutzungsdauer einer Anlage betrage $t$ Jahre. Während der ersten $t$ Jahre führt der Unternehmer in jedem Jahr Nettoinvestitionen in Höhe von I Geldeinheiten durch. Im Jahr $(t+1)$ beginnen die Reinvestitionen, sie betragen ebenfalls I GE jährlich, so daß die Investitionsausgaben in jedem Jahr gleich hoch sind. Wird mit jeder Anlage in jedem Jahr dieselbe Menge zu denselben Durchschnittskosten erzeugt und ist der Preis für die Erzeugnisse konstant, dann nimmt der Cash-Flow G linear bis zum Jahr $\mathrm{t}$ zu.

In Abb.3.4 ist der Cash-Flow im Jahr $\mathbf{k}$ gerade so groß wie die Investitionsausgaben geworden; wenn diese Investitionskette rentabel sein soll, muß $\mathrm{k}$ immer kleiner als $\mathrm{t}$ sein. 
Abbildung 3.4: Modell einer Investitionskette

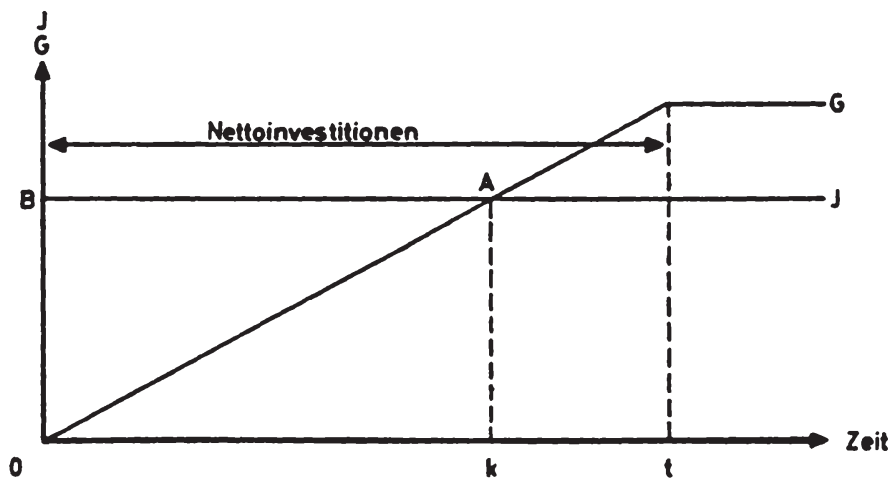

(Quelle: H. SCHNEIDER, 1964, S.160)

Vom Jahr $\mathrm{k}$ an können die Investitionsausgaben aus den laufenden Cash-Flows $\mathbf{G}$ gedeckt werden, es ist also nicht notwendig, von $\mathbf{k}$ an zusätzliches Eigen- oder Fremdkapital aufzunehmen.

Die Investitionsausgaben in den ersten $\mathrm{k}$ Jahren betragen insgesamt $\mathrm{I}(\mathrm{k}+1)$. Bleiben die Jahresgewinne voll im Unternehmen, können sie daher voll zur Deckung der Investitionsausgaben herangezogen werden, dann ist der Finanzbedarf insgesamt

$$
K B=I(k+1)-g \frac{k(k+1)}{2}
$$

wobei die zwischenzeitliche Verzinsung vernachlässigt wird. g ist die jährliche Zunahme des Cash-Flows.

Der Finanzbedarf einer Investition ist hier definiert als der Teil der Investitionsausgaben, den der Unternehmer nicht aus den anfallenden Gewinnen decken kann, er ist in Abb.3.4 also das Dreieck OAB. Da das Jahr $k$ so bestimmt wird, daß

$$
\mathrm{g} \mathrm{k}=\mathrm{I}
$$

vereinfacht sich der Ausdruck für den Finanzbedarf zu

$$
K B=\frac{I}{2}(k+1)
$$

Hätte der Unternehmer seine Nettoinvestitionen nicht auf $t$ Jahre verteilt, sondern im Jahre O zusammen vorgenommen, dann wäre der Finanzbedarf - unter den gemachten Annahmen - 


$$
\mathrm{I}(\mathrm{t}+1)
$$

groß gewesen. Durch die zeitliche Verteilung der Investitionsausgaben gelingt es also, den Finanzbedarf um mehr als $50 \%$ zu senken.

Die Steuerzahlung bindet zusätzliche Zahlungsmitteln und erhöht auf diese Weise den Finanzbedarf eines Investitionsvorhabens. Wie groß die Erhöhung des Finanzbedarfs ist, hängt u.a. von der Ausgestaltung der Steuer ab.

Der große Vorteil dieses Ansatzes ist, daß er eine mögliche Lösung eines Problems vorschlägt, mit dem sich die fiskalpolitische Literatur schon lange beschäftigt. So fragt z.B. WEYDERT (1968) wie die Verteilung des fiskalischen Drucks auf die Unternehmen erfolgt, um eine optimale Investitionstätigkeit zu erlauben, nachdem man das notwendige Steueraufkommen festgelegt hat?

\subsection{Die Liquiditätstheorie}

Die Liquiditätstheorie ist keine in sich geschlossene Theorie, sondern vielmehr eine Mischung von Ansätzen, beginnend mit TINBERGEN (1938) der zum ersten mal gezeigt hat, daß die Finanzengpässe die Investitionen drosseln, egal wie hoch die erwarteten Gewinne sein möchten. Als volkswirtschaftliche Fortsetzung derartiger Ansätze wie der von SCHNEIDER in Abs.3.9, stellt die Liquiditätstheorie auf die kurzfristige Gewinnsituation als wichtigste Bestimmungsgröße für die Investitionsfähigkeit ab. Bei einem unvolkommenen Kapitalmarkt bietet die Innenfinanzierung Kostenvorteile. Erst nachdem die Möglichkeiten zur Innenfinanzierung ausgeschöpft sind, geht das Unternehmen zur Fremdfinanzierung über, die aber mit wachsendem Verschuldungsgrad aufgrund höherer Risikozuschläge immer teurer wird.

Die Besteuerung kann die Investitionsfähigkeit in vielfältiger Weise beeinflussen: durch die Gewinnsteuern (Steuersätze, Abschreibungen, Investitionsförderungsmaßnahmen), durch die steuerliche Behandlung der Schuldzinsen und Aktienemissionen (Einfluß auf die Kosten der unterschiedlichen Finanzierungsformen); durch Kostensteuern oder Steuern vom Umsatz, die nicht überwälzt werden können; durch Vermögensteuern; schließlich sogar durch die Lohnsteuer, falls die Unternehmen von den Gewerkschaften gezwungen werden können, das Nettoniveau der Löhne zu behalten. 
KAPITEL 4:

\section{VON DER THEORIE ZUR EMPIRIE: DAS ISOMORPHISMUS- PROBLEM}

In ihrem engen Zusammenhang gesehen, dienen Kapitel 3 und 4 folgenden zwei Zwecken:

- $\quad$ zum einen, ein mit Rumänien isomorphes Modell des Zusammenhangs Steuern Investitionen auszuwählen oder durch die Kombination mehrerer wichtiger und kompatibler Ansätze ein gemischtes Modell, das sich danach in mehrere Teilmodelle für partialanalytische Untersuchungen zerteilen ließe, zusammen zu fassen;

- $\quad$ zum anderen diejenigen Parameter, durch die das Steuersystem die Investitionstätigkeit beeinflussen vermag (die sogenannten steuerlichen Investitionsdeterminanten) zu entdecken, um nach ihnen die Analyse in den folgenden Kapiteln zu richten.

Vom Kapitel 3 ergab sich eine Vielzahl von Ansätzen, aus denen ein für Rumänien geeignetes Modell ausgewählt (oder kombiniert) werden soll, um daraus die steuerlichen Investitionsdeterminanten zu kristallisieren.

$\mathrm{Zu}$ diesem Zweck ist Kapitel 4 wie folgt gestaltet:

- zuerst werden die Zielsetzungen unterschiedlicher Kategorien von Investoren in Rumänien vorgestellt. Ihr Vergleich mit den in den jeweiligen Modellen unterstellten Zielsetzungen bietet ein erstes Kriterium für die beabsichtigte Auswahl;

- basierend auf der rumänischen Realität wird danach ein Kriterienraster für die Beurteilung verschiedener Modelle eingeführt;

- $\quad$ letzlich erfolgt anhand dieses Kriterienrasters die kritische Würdigung, die Wahl der für diese Untersuchung geeigneten Modelle und die Aufzählung der steuerlichen Investitionsdeterminanten.

Das so erhaltene Modell wird später, im Kapitel 5, entsprechend den herausgefundenen steuerlichen Investitionsdeterminanten, zur Untersuchung ihrer jeweiligen Wirkungen benutzt werden.

\subsection{Zielsetzungen der Investoren in Rumänien.}

Wie schon früher gezeigt wurde, befindet sich der Transformationsprozess in Richtung Marktwirtschaft in Rumänien, mindestens von den Eigentumsverhältnissen her, in seiner Anfangsphase. Daher muß man, und die Untersuchung wird weiterhin davon geprägt sein, 
grundsätzlich zwischen : a) den inländischen staatlichen Unternehmen (hauptsächlich mittlerer und oberer Größe), b) den ausländischen Investoren (derselben Größe wie a)), und c) den inländischen privaten Unternehmen, die immerhin im Textil- und Bekleidungsbereich schon $20 \%$ der industriellen Produktion erzeugen, $13 \%$ des Kapitals ausmachen, aber überwiegend kleiner Dimensionen sind, unterscheiden. Angesichts der vielfältigen Unterschiede zwischen den drei Kategorien kommt man zur Kenntnis, daß sie, was ihre Investitionsdeterminanten angeht, gesondert betrachtet werden müssen (siehe Tabellen 4.1. und 4.2).

Tabelle 4.1: Unterschiede nach ökonomischen Indikatoren

\begin{tabular}{||c||c|c|c||}
\hline $\begin{array}{c}\text { AUSMASS } \\
\text { von: }\end{array}$ & $\begin{array}{c}\text { Staatliche } \\
\text { Firmen }\end{array}$ & $\begin{array}{c}\text { Ausländische } \\
\text { Investoren }\end{array}$ & $\begin{array}{c}\text { Kleine pri- } \\
\text { vate Firmen }\end{array}$ \\
\hline \hline Nachfrage & $\mathrm{xxx}$ & $\mathrm{xxx}$ & $\mathrm{x}$ \\
\hline $\begin{array}{c}\text { Kapital- } \\
\text { gütegrad }\end{array}$ & $\mathrm{x}$ & $\mathbf{x x x}$ & $\mathrm{x}$ \\
\hline Gewinnen & $\mathrm{x}$ & $\mathrm{xx}$ & $\mathbf{x}$ \\
\hline $\begin{array}{c}\text { Finanzie- } \\
\text { rungs- } \\
\text { quellen }\end{array}$ & $\mathrm{x}$ & $\mathrm{xx}$ & $\mathbf{x x x}$ \\
\hline $\begin{array}{c}\text { Risikobe- } \\
\text { reitschaft }\end{array}$ & $\mathrm{x}$ & $\mathrm{x}$ & 0 \\
\hline
\end{tabular}

Tabelle 4.2: Unterschiede nach Zielsetzungen

\begin{tabular}{||c||c|c|c||}
\hline $\begin{array}{c}\text { RELEVANZ } \\
\text { von: }\end{array}$ & $\begin{array}{c}\text { Staatliche } \\
\text { Firmen }\end{array}$ & $\begin{array}{c}\text { Ausländische } \\
\text { Investoren }\end{array}$ & $\begin{array}{c}\text { Kleine pri- } \\
\text { vate Firmen }\end{array}$ \\
\hline \hline Nachfrage & $\mathbf{x x x}$ & $\mathbf{x x x}$ & $\mathbf{x x x}$ \\
\hline $\begin{array}{c}\text { Kapital- } \\
\text { gütegrad }\end{array}$ & $\mathbf{x x x}$ & $\mathbf{x}$ & $\mathbf{x x}$ \\
\hline \begin{tabular}{c} 
Gewinnen \\
\hline $\begin{array}{c}\text { Finanzie- } \\
\text { rungs- } \\
\text { quellen }\end{array}$
\end{tabular} & $\mathbf{x x x}$ & $\mathbf{x x x}$ & $\mathbf{x x x}$ \\
\hline Risiken & $\mathbf{x x}$ & $\mathbf{x x x}$ & $\mathbf{x}$ \\
\hline
\end{tabular}


Erklärung der Zeichen:

$$
\begin{aligned}
\mathbf{x x x} & =\text { groß, bzw. sehr relevant } \\
\mathbf{x x} & =\text { mittelgroß, bzw. einigermaßen relevant } \\
\mathbf{x} & =\text { klein, bzw. wenig relevant } \\
0 & =\text { sehr klein }
\end{aligned}
$$

Die Tabellen sollen verdeutlichen, daß die drei Kategorien unterschiedliche Ausgangpositionen und somit unterschiedliche Zielprioritäten haben. So genießen die inländischen staatlichen Unternehmen immer noch einen wichtigen Marktanteil (im In- und Ausland), der aber droht, schnell in der Zukunft zu schrumpfen, wenn die richtigen Maßnahmen für die Modernisierung des Sachkapitals usw. nicht getroffen werden. Ihre Gewinne sind nicht groß, reichen zur Zeit noch zum ökonomischen Überleben, aber nicht für die Finanzierung der Modernisierung und der während der letzten fast 25 Jahren versäumten Ersatzinvestitionen. Da die Quellen für die Finanzierung dieser Vorgänge völlig ungenügend sind (siehe auch Kap.1 und 2), wird den Gewinnen als Finanzierungsquelle eine große Bedeutung beigemessen. Dagegen ist die Risikobereitschaft ziemlich klein, nicht unbedingt wegen einer ausserordentlichen Verantwortung im Umgang mit dem öffentlichen Eigentum, sondern von der "klassischen" Anpassungsträgheit großer industrieller Organisationen der ehemaligen Planwirtschaft verursacht.

Für die ausländischen Firmen, die in Rumänien entweder Betriebe oder Geschäftsstellen errichten, oder aber Gemeinschaftsunternehmen mit rumänischen Partnern bilden, sieht das Bild anders aus. Sie besitzen immer noch wichtige Märkte, die allerdings wie bei ersteren zu schrumpfen drohen. Daher haben sie ein doppeltes Interesse in Rumänien: auf lange Sicht sich die Erschließung des rumänischen Marktes und, um diesen Prozeß durchführen zu können, jedes Jahr einen "genügenden" Gewinn zu erzielen. Alternativ planen sie die umgekehrte Strategie: keine Rücksicht auf den rumänischen Markt, aber substantielle Gewinne durch die Nutzung der sehr geringen rumänischen Lohnstückkosten zu erwirtschaften. In beiden Fällen ist der Gewinn sehr wichtig, aber nicht gerade als Finanzierungsquelle, wie bei den inländischen Unternehmen, weil diese Firmen sich ihre langfristigen Finanzmitteln auf den internationalen Finanzmärkten beschaffen können. Sie leiden auf jeden Fall an den erheblichen Unvollkommenheiten des rumänischen Finanzmarktes, wenn auch nicht in demselben Maße wie ihre rumänischen Kollegen. Die Risiken, die sie in einer ihnen nicht so gut bekannten rumänischen Umwelt eingegangen sind, sind aber für sie ganz relevant. Natürlich leiden sie auch nicht an derselben Veralterung ihres Kapitalstocks wie die rumänischen Unternehmen.

Schließlich unterscheiden sich die kleinen rumänischen privaten Firmen von ihren größeren inländischen Konkurrenten hauptsächlich durch ihre viel höhere Risikobereitschaft, durch ihren (noch) geringeren Marktanteil und durch die positive Dynamik ihrer Marktanteile und 
Gewinne. Die "0" im Feld der Größe ihrer Finanzierungsquellen in Tabelle 4.1. soll bedeuten daß es ihnen in dieser Hinsicht nicht schlecht, sondern ganz schlecht geht. Der Kapitalgütegrad ist für sie dagegen von geringerer Bedeutung, da die meisten dieser Firmen auf dem Konfektionsgebiet tätig sind.

Als Zusammenfassung könnte man behaupten, daß bei den rumänischen Firmen, egal ob groß oder klein, der Investitionswille, aber ganz wenig die Investitionsfähigkeit gegeben ist. Grob gesehen, gilt für die ausländischen Investoren das Gegenteil.

\subsection{Kriterienraster zur Beurteilung der Praxisrelevanz der verschiedenen Modelle.}

Jeder Prozess der Abstraktion und Modellierung muß den Gegebenheiten der realen Umwelt Rechnung tragen; insbesondere auf dem Gebiet der Wirtschaftswissenschaften, wo die Dynamik der Untersuchungsgegenstände so überwältigend ist, dürfen Paradigmen auf keinen Fall unkritisch angenommen und benutzt werden. Im folgenden werden die Kriterien festgelegt, nach denen der Isomorphismus und die Anwendbarkeit dieses oder jenes Modells im wirtschaftlichen Raum Rumäniens geprüft werden sollen. Die wichtigsten Beurteilungskriterien sind mit den folgenden Fragen verbunden:

sind die Anfangshypothesen der verschiedenen Ansätze überhaupt mit der rumänischen Realität vereinbar? Dabei sollen die Unvollkommenheiten der rumänischen Märkte, die Nicht-Konvertibilität der Währung, die stolpernde Entwicklung der Finanzmärkte, die Quasi-Abwesenheit eines Kapitalmarktes und die Eigentumsverhältnisse in Rumänien mitberücksichtigt werden.

stimmen die Zielsetzungen der investierenden Unternehmen, die in verschiedenen Ansätzen unterstellt werden, mit den in Abschnitt 4.1. dargelegten Zielsetzungen überein?

- $\quad$ sind die untersuchten Ansätze überhaupt für die Analyse der Wirkungen der zur Zeit gegebenen steuerlichen Parameter (so wie die rumänische Gesetzgebung sie festgelegt hat) und für die Vorausschätzung der Konsequenzen der möglichen oder (unter einer bestimmten wirtschaftspolitischen Zielsetzung) gewünschten fiskalpolitischen Maßnahmen geeignet? In diesem Sinne ist ein Ansatz brauchbar, wenn er die Möglichkeit gibt:

- die steuerlichen Investitionsdeterminanten zu enthüllen;

- jede Determinante durch Partialanalysen oder Teilmodelle in ihren Wirkungen zu untersuchen;

- der Politik wirksame Instrumente zu vermitteln.

besitzt schließlich ein Ansatz den hinreichenden Abstraktionsgrad, um diejenigen Einzelheiten ausländischer Steuersysteme, die für Rumänien nicht relevant sind, unberücksichtigt $\mathrm{zu}$ lassen? 
Hinzu kommt auch, daß das Modell keine analytische Unterscheidung zwischen Ersatz- und Erweiterungsinvestitionen enthalten soll. Dafür gibt es folgende Gründe:

Die Investitionen, die vor den rumänischen Unternehmen stehen, haben doppelten Charakter: auf der einen Seite sind sie natürlich Ersatzinvestitionen, weil das künftige Überleben dieser Unternehmen davon abhängt, ob sie in möglichst kurzer Zeit die auf lange Dauer versäumten Ersatzinvestitionen nachholen können, um sodann ihr Sachkapital den Erforderungen der Märkte der neunziger Jahre hinsichtlich der Produktqualitäten und -kosten anzupassen. Andererseits sind sie Ersatzinvestitionen da sie, wie in der Puffertheorie von FELDSTEIN und FOOT (1971, S.49 ff.) viel abhängiger von der Liquidität als von den Expansionschancen sind. Weiter sind sie auch abhängig von dem Durchschnittsalter des Sachkapitals.

Andererseits sind sie Bruttoinvestitionen, da sie hauptsächlich von den von der Wende an erwirtschafteten Gewinnen und Abschreibungen finanziert werden. In der Zeit der Planwirtschaft bildeten die Abschreibungen kalkulatorische Rechengrößen, deren entsprechende Finanzbeträge nicht den Unternehmen, sondern der zentralen Planbehörde zur Verfügung standen. Sie haben u.a. zur extensiven Entwicklung der Planwirtschaft gedient, das heißt, zur Errichtung neuer Industriebetriebe oder Prestigeprojekte. Die Abschreibungen, die jetzt gebucht werden, können höchstens die Erhaltung des Sachkapitals in seinem aktuellen Zustand (abgesehen von der Inflation) sichern, was die oben dargestellte Zielsetzung der Unternehmen auf keinen Fall befriedigen könnte. Daher gewinnen die beabsichtigten Investitionen auch einen Nettocharakter.

Zusammenfassend wird sich die Untersuchung unter Berücksichtigung der Cash-Flow Aspekte, die zum einen von den Gewinnen und zum anderen von den Abschreibungen bedingt sind, weiter auf Bruttoinvestitionen konzentrieren. Den Nettoinvestitionen wird somit indirekt Rechnung getragen werden, aber nicht den Ersatzinvestitionen als solchen. Der Unterschied zwischen Ersatz- und Erweiterungsinvestitionen wird im folgenden keine Rolle mehr spielen, da im Grunde genommen die Qualitätssteigerung des volkswirtschaftlichen Kapitalstocks angestrebt wird.

Es mag als überraschend erscheinen, daß vom Modell nicht verlangt wird, die quantitative Messung der Wirkungen unterschiedlicher Steuern / fiskalpolitischer Maßnahmen auf der gesamtwirtschaftlichen Ebene zu ermöglichen. Der Grund dafür ist, daß ein makroökonomisches Modell für die Wirtschaft Rumäniens zur Zeit fehlt. Die Schaffung eines derartigen Modells ist auf kurze Sicht auch nicht zu erwarten, da in diesen ersten vier Jahren der Transformation keine glaubwürdigen und relevanten statistischen Indikatorenreihen angesammelt werden konnten. Auch wenn die statistischen Angaben, die sich auf die Zeit vor 1990 beziehen, glaubwürdig wären, wären sie dennoch nicht brauchbar, da sie eine andere Wirtschaftsordnung und daher andere Mechanismen des Konsums, der Investition, der 
Preisbildung usw. widerspiegeln. Um Zahlenreihen zu bilden, die lang genug wären, um ihre ökonometrische Verarbeitung zu ermöglichen, reichen die vier Jahren beginnend mit 1990 offensichtlich nicht aus.

Zum Schluß dieses Abschnitts wäre noch eine Anmerkung angebracht: da in dieser Arbeit keine Rede von der Konjunkturpolitik sein wird, ist der Zeitvollzug der Investitionen (die "lag"-Problematik) nicht sehr interessant. Es ist natürlich erwünscht, daß die Effekte der fiskalpolitischen Maßnahmen möglichst schnell in Kraft treten; von einer zeitlichen Steuerung der Investitionen kann aber abgesehen werden, da die heutige Krise der rumänischen Wirtschaft vielmehr struktureller als konjunktureller Natur ist.

\subsection{Analyse der Theorien des Investitionsverhaltens.}

Zur Erleichterung und Überschaubarkeit der Analyse der im Kapitel 3 dargestellten Modelle soll Tabelle 4.3 . benutzt werden.

Die Zahlen vom Tabellenkopf haben folgende Bedeutung:

1 - Betriebswirtschaftlicher Ansatz

2 - Neoklassische Investitionstheorie

3 - Akzeleratoransatz

4 - TOBIN's "q" Theorie

5 - Risikoansatz von DOMAR und MUSGRAVE

6 - Finanzierungsquellenansatz von SCHNEIDER

7 - Volkswirtschaftliche Liquiditätstheorie

Der Grad der Befriedigung der jeweiligen Kriterien sei auf einem 3-Stern Skala gemessen:

$* * *=$ sehr befriedigend

** = einigermaßen befriedigend

* = wenig befriedigend

- = gar nicht befriedigend

Im folgenden werden die Gründe der jeweiligen Einschätzungen für jeden Ansatz erklärt.

1) Der betriebswirtschaftliche Ansatz ist im Prinzip mit jeder industriellen Gesellschaft, in der es Betriebe gibt, in seinen Anfangshypothesen vereinbar. Der Einspruch, die Unternehmen in ehemaligen sozialistischen Ländern würden sich wegen ihrer Eigentumslage nicht gemäß dem gesunden Unternehmerdenken - in die Richtung der Gewinnmaximierung (bzw. der Kapitalwertmaximierung) orientieren, muß als unfundiert zurückgewiesen werden. In dieser Arbeit werden nur die Unternehmen, die überleben wollen, behandelt. Auch darf nicht vergessen werden, daß auch die rumänischen staatlichen Unternehmen in absehbarer Zukunft, im Zuge des Privatisierungsprozesses in private Hände gelangen sollen. 
Tabelle 4.3: Beurteilung der theoretischen Modelle

\begin{tabular}{||l||c|c|c|c|c|c|c||}
\hline $\begin{array}{l}\text { Ansatz/Kriterien der } \\
\text { Beurteilung }\end{array}$ & 1 & 2 & 3 & 4 & 5 & 6 & 7 \\
\hline \hline $\begin{array}{l}\text { a)Kongruenz der An- } \\
\text { fangshypothesen mit ru- } \\
\text { mänischer Wirklichkeit }\end{array}$ & $* * *$ & $* *$ & $*$ & $*$ & $* * *$ & $* * *$ & $*$ \\
\hline $\begin{array}{l}\text { b)Kongruenz der unter- } \\
\text { stellten Zielsetzungen mit } \\
\text { denen der Investoren in } \\
\text { Rumänien }\end{array}$ & $* * *$ & $* * *$ & $* *$ & $*$ & $* * *$ & $* * *$ & $*$ \\
\hline $\begin{array}{l}\text { c)Kompatibilität zum } \\
\text { rumänischen Steuersy- } \\
\text { stem }\end{array}$ & $*$ & $* * *$ & - & - & $* * *$ & $* * *$ & $*$ \\
\hline $\begin{array}{l}\text { d)Enthüllt die steuerli- } \\
\text { chen Investitionsdetermi- } \\
\text { nanten }\end{array}$ & $*$ & $* *$ & - & $*$ & $* *$ & $* *$ & $*$ \\
\hline $\begin{array}{l}\text { e)Ermöglicht die Unter- } \\
\text { suchung jeder Determi- } \\
\text { nante durch Partialanaly- } \\
\text { sen oder Teilmodelle }\end{array}$ & $* *$ & $* *$ & - & - & $* * *$ & $* * *$ & - \\
\hline $\begin{array}{l}\text { f)Vermittelt der Politik } \\
\text { wirksame Instrumente }\end{array}$ & $*$ & $* * *$ & - & $*$ & $* * *$ & $* * *$ & $*$ \\
\hline $\begin{array}{l}\text { g)Eignung zur Voraus- } \\
\text { schätzung der Konse- } \\
\text { quenzen unterschiedlicher } \\
\text { Steuerpolitiken }\end{array}$ & $*$ & $* * *$ & - & - & $* * *$ & $* *$ & $*$ \\
\hline
\end{tabular}

Aus diesem Argument wird klar, daß der BWL-Ansatz auch von den unterstellten Zielsetzungen der Unternehmen her sehr gut zur rumänischen Realität paßt. Er eignet sich dann auch für jedes Steuersystem der Welt, wenn man das einzelne Unternehmen betrachtet. Andererseits erklärt dieser Ansatz eher "wie" als "warum" Investitionen getätigt werden. Daher ist sowohl die Möglichkeit der Enthüllung der steuerlichen Investitionsdeterminanten mittels dieses Modells, als auch seine wirtschaftspolitische Verwendbarkeit beschränkt. Partialanalysen sind hierdurch, was die steuerpolitischen Implikationen angeht, zu allgemein.

2) Dagegen erfüllt die neoklassische Investitionstheorie fast alle Kriterien am besten. Die Zielsetzungen der Investoren in Rumänien, ob in- oder ausländisch, so wie sie im Abschnitt 4.1. dargelegt wurden, passen in diese Theorie sehr gut hinein. Sogar die indirekten Steuern soweit man die Meinung vertritt, daß sie nicht überwälzbar seien - können in die In- 
vestitionsfunktion über die Kapitalbereitstellungskosten "c" eingebaut werden, indem sie die Investitionsgüter verteuern (Steigerung von q). Die Kapitalbereitstellungskosten sind ein viel aussagekräftiger Indikator, der auch auf der gesamtwirtschaftlichen (oder branchenwirtschaftlichen) Ebene seine Bedeutung besitzt, als der Kapitalwert einer einzelnen hypothetischen Investition, der vom BWL-Ansatz lediglich geliefert wird. Die Lieferung einer (wenn auch in ihrer theoretischen Form sehr vereinfachten) volkswirtschaftlichen Investitionsfunktion ermöglicht - mindestens in qualitativer Weise -die Vorausschätzung der volkswirtschaftlichen Effekte fiskalpolitischer Maßnahmen. Das angebotene Spektrum der steuerlichen Investitionsdeterminanten ist breit genug und jede von ihnen kann und ist auch bereits mit Hilfe dieses Modells untersucht worden (z.B. beschleunigte Abschreibungen, Investitionsfreibeträge usw.). Die Wirtschaftspolitik der entwickelten Industrieländer und der sich schnell entwickelnden Schwellenländer hat sich in den letzten zwanzig Jahren dieses Modells intensiv bedient.

Die einzige Frage, deren Antwort nicht sofort klar wird, ist ob die marginalistischen Hypothesen dieses Modells (mit Sicherheit bekannte Produkt- und Faktorpreise, sowie künftige Einzahlungen und Anschaffungsausgaben, perfekter Finanzmarkt) in Rumänien auch zutreffen oder nicht. Was die ersteren Hypothesen betrifft, soll man der Tatsache Rechnung tragen, daß diese Abstraktionen in allen Vorteilhaftigkeitsrechnungen von Investitionen gemacht werden, ob in der Markt- oder in der Planwirtschaft. Diese Theorie basiert also auf einer universellen Methode, die die wichtigste Rolle in jedem Prozeß der Investitionsentscheidung spielt. Es ist also keine eigene Schwäche der neoklassischen Investitionstheorie. Mehr noch: interessanterweise unterstellt diese Theorie keine vollkommene Konkurrenz auf den Konsum- und Investitionsgütermärkten: das Unternehmen kann das Produktionsvolumen $\mathrm{Q}(\mathrm{t})$ entweder als Datum oder als variierbare Größe betrachten, je nachdem, ob seine Marktmacht kleiner oder größer ist. Haupteinwand gegen die Übertragung dieses Modells auf Rumänien bleibt also die Hypothese des vollkommenen Finanzmarktes. Die günstige Evolution der von geschickten steuerpolitischen Maßnahmen beeinflußten Kapitalbereitstellungskosten (capital user costs) oder der Umsatz- und Erlöschancen mag in diesem Modell bei den heimischen Unternehmen einen starken Investitionswillen induzieren (obwohl im Abschnitt 4.1. schon gezeigt wurde, daß dieser Wille ohnehin vorhanden ist); die gewünschte Investitionstätigkeit kann aber trotzdem wegen des unzulänglichen Finanzierungsangebots und anderer system- und personenbezogener Unvollkommenheiten unterbleiben. Für die ausländischen Investoren sollte dies, wie schon erwähnt, kein großes Hindernis sein, da sie sich auf den (angeblich) vollkommenen internationalen Finanzmärkten finanzieren können. Für die rumänischen Unternehmen ist eine solche Kreditaufnahme durch:

die Nichtkonvertibilität der rumänischen Währung;

die Scheu des rumänischen Finanzministeriums und der rumänischen Banken, langfristige Kredite zu garantieren;

die geringen Plafonds, die die westlichen Kreditversicherer Rumänien zuteilen; 
- die unzureichende Bonität der rumänischen (und auch allgemein osteuropäischen) Unternehmen nach den in der Marktwirtschaft üblichen Kriterien von ihren Finanzstrukturen her usw.;

erheblich erschwert. Aus diesem Grund bilden in Rumänien die Unternehmen, die Kredite für ihre Modernisierung bekommen haben, eher die Ausnahme als die Regel.

3) Die Kompatibilität der Hypothesen der Akzeleratortheorie mit der rumänischen Wirklichkeit kann bestritten werden; es gibt Argumente, die jeweils dafür oder dagegen sprechen. Der "Thermostat-Gedanke" (siehe MEYER \& KUH, 1966, S.14) aber, der eine quasi-automatische Anpassung der Produktionskapazitäten der Unternehmen an die Nachfrageentwicklung unterstellt, ist auf die rumänischen unvollkommenen Märkte eher unübertragbar.

Der entscheidende Nachteil aber, der den Akzeleratoransatz für die vorliegende Untersuchung unbrauchbar machen dürfte, ist, daß bei ihm keine steuerliche Einflußfaktoren erwähnt werden, und ihr eventueller Einbau in das sehr einfache mathematische Modell kaum durchführbar ist.

Dieser Mangel führt dazu, daß die Kriterien c) - g) von diesem Modell überhaupt nicht erfüllt werden.

4) Die TOBIN's "q" Theorie stellt eine wissenschaftlich sehr gut begründete Erweiterung, Verfeinerung und auch Verlängerung der neoklassischen Investitionstheorie dar (sozusagen, ein qualitativer Sprung von der Mikro- zur Makroebene). Trotz all ihrer Stärken ist sie aber für die vorliegende Untersuchung unbrauchbar, da ihre analytischen Instrumente - und auch ihre Hypothesen - mit volkswirtschaftlichen Größen operieren, deren Berechnung in Rumänien unmöglich ist, oder die es sogar nicht gibt.

Dieser Hauptnachteil wird aus der folgenden Formel für den steuerlich angepaßten Wert des marginalen q klar (vgl. FUNKE, RYLL \& WILLENBOCKEL, 1987):

$$
Q_{m, d}(t)=\frac{V(t)+\mu(t)[B(t)-A(t)]}{\mu(t)[1-k(t)-z(t)] K_{\text {rep }}(t)}
$$

wobei:

- $\mathrm{V}(\mathrm{t})=\quad$ der aggregierte Marktwert des Eigenkapitals der Aktiengesellschaften;

$-\mu(t)=\quad$ die KINGsche Steuerdiskriminierungsvariable (entspricht dem $u^{*}$ in Abs.3.5) für das Steuersystem;

- $\mathbf{B}(\mathrm{t})=\quad$ die aggregierten Dauerschulden und Rücklagen der Aktiengesellschaften; 
$-\mathbf{k}(\mathrm{t})=\quad$ Durchschnitt der in der Periode $\mathrm{t}$ gewährten steuerlichen Investitionsfreibeträge und -abzüge;

$-\mathbf{z}(\mathrm{t})=\quad$ der Steuersatz auf Kapitalwertsteigerung;

- $K_{\text {rep }}(t)=$ das gesamte Sachvermögen (Anlagen, Gebäuden und Vorräte) zu Wiederherstellungskosten.

Schon die erste Größe V(t) macht klar, daß dieser Ansatz für Rumänien, wo es noch keinen Kapitalmarkt gibt, zu verfeinert ist.

Die Berechnung des Hauptindikators "q" in Rumänien könnte nur mit sehr grober Annäherung erfolgen, da die Größen, die dazu benötigt werden (siehe oben), in Rumänien entweder ohne Belang oder kaum kalkulierbar sind. Damit ist auch die Aussagekraft dieses Indikators erheblich vermindert, und so bleiben auch die Kriterien c) bis g) so gut wie unerfüllt.

5) Bei der restriktiven Annahme gleicher Besteuerungssysteme in zwei beliebigen Ländern (die allerdings unter Berücksichtigung des starken Wettbewerbs um Investitionen zwischen osteuropäischen Ländern keine grobe Approximation sein sollte), kann man, anhand des Risikoansatzes von DOMAR und MUSGRAVE, den Einfluß der Gewinnsteuer, Vermögensteuer und anderer steuerlicher Kennzeichen wie z.B. des Verlustausgleichs und der Progressivität untersuchen. Unter Einbeziehung unterschiedlicher steuerlicher Einflußfaktoren ändert sich dabei der Verlauf der optimalen Vermögenskurve und somit die vom Investor gewünschte Vermögensstruktur. Neben dieser analytischen Teilbarkeit bietet dieser Ansatz auch den wesentlichen Vorteil, an die Hauptursache der zögernden Entwicklung der ausländischen Investitionen in Osteuropa, nämlich die Risikoscheu der Investoren, anzuknüpfen.

Im Laufe der Zeit haben sich in der wissenschaftlichen Diskussion weitere Entwicklungen und Verfeinerungen dieses Modells, wie z.B. von FELDSTEIN (1970) oder STIGLITZ (1969) ergeben. Im Zuge ihrer Entwicklung konzentrieren sie sich aber immer stärker auf die Portfolioanalyse der Vermögensanlagen, und ihre Hypothesen werden mit der wirtschaftlichen Realität Rumäniens (kein Kapitalmarkt) immer weniger vereinbar.

Dementsprechend kann man schlußfolgern, daß dieser Ansatz die folgenden Kriterien sehr gut erfüllt:

Kriterium a) - weil die Risikoaspekte für die ausländischen Investoren in Rumänien eine sehr wichtige Rolle spielen;

- Kriterium b) - weil die Auslandsinvestitionen in Rumänien mit höheren Risiken behaftet sind, dafür aber auch höhere Gewinne versprechen; 
Kriterien c),e),f),g) - weil man durch Partialanalysen wichtige Hinweise für die Fiskalpolitik erhalten kann.

Allerdings gelten diese Aspekte insbesondere für die ausländischen Investoren (siehe Abschnitt 4.1.). Auch wird Kriterium d) nicht vollständig erfüllt, da es steuerliche Investitionsdeterminanten gibt, die sich dieser Art von Analyse entziehen (z.B. die Möglichkeiten der Abschreibung).

6) Aus den Ausführungen im Paragraphen 4.2. resultiert, daß die Liquidität für die inländischen investierenden Unternehmen eine ganz bedeutende Rolle spielen dürfte. Wegen der dort schon erwähnten Gründe und zusätzlich wegen der hohen Zinsen und der großen bürokratischen Schwierigkeiten im Umgang mit dem heimischen Bankensystem ist die langfristige Kreditaufnahme von den rumänischen Unternehmen praktisch unerwünscht. Die Finanzierung über weitere Aktienemissionen ist den staatlichen Unternehmen, bis zur Privatisierung, normalerweise nicht erlaubt. Aber auch die privaten rumänischen Unternehmen können wegen der geringen Ersparnisse der Bevölkerung von der Beteiligungsfinanzierung nicht viel erwarten - nach 40 Jahren kommunistischer Einkommenspolitik und anschließend 3 Jahren Inflation. Es wurde ersichtlich, daß die einzige sichere und nennenswerte Finanzierungsquelle für rumänische Investoren die einbehaltenen Gewinne sind. Diese Art Finanzierung ist eng mit dem Begriff der Liquidität gebunden.

Der im Kapitel 3 vorgeführte Finanzierungsquellenansatz von SCHNEIDER spricht aus dem Herzen jedes rumänischen Managers. Seine Hypothese des Liquiditätsmangels ist mit den Gegebenheiten in der rumänischen Industrie sehr gut vereinbar; die unterstellte Zielkonstellation (Der Wille besteht, aber Mittel sind nicht vorhanden) stimmt auch mit dieser Lage überein. Das Modell eignet sich zur Untersuchung unterschiedlicher Steuerarten (siehe Tabelle 4.3), bei unterschiedlichen Abschreibungsregelungen. Die Kostensteuern können auch ohne große Schwierigkeiten ins Modell eingebaut werden.

Die Analyse anhand dieses Modells bringt ein einziges Problem mit sich: man kann z.B. zum Ergebnis kommen, daß eine gewisse steuerpolitische Maßnahme in einem durchschnittlichen Unternehmen so und so viel Geld für Investitionen freisetzen würde. Dieses Modell allein kann aber keine Informationen darüber liefern, wieviel von diesen freigesetzten Mitteln auch danach tatsächlich investiert werden. Es besagt also nichts über den Investitionswillen als Komponente der Investitionsbereitschaft. Da die andere Komponente der Investitionsbereitschaft die Investitionsfähigkeit ist, die von diesem Modell ausschließlich untersucht wird, ist dieses Modell mit der neoklassischen Investitionstheorie, die sich mit dem Investitionswillen beschäftigt, komplementär. Für die Untersuchung der inländischen Unternehmen ergänzen sich diese zwei Ansätze sehr gut. 
7) Was die volkswirtschaftliche Liquiditätstheorie angeht, bietet sie offensichtlich zuwenig Anknüpfungsmöglichkeiten zu den rumänischen Gegebenheiten. Ihre bisherigen Anwendungen stützen sich auf makroökonomische Modelle, die es, wie im Abschnitt 4.2. schon erläutert wurde, in Rumänien nicht gibt und auf kurze Sicht auch nicht geben kann. Ihre Anfangshypothesen tangieren nur einen Teil der Zielsetzungen und der Probleme, die vor den Investoren in Rumänien stehen. Auch die von dieser Theorie identifizierten steuerlichen Investitionsdeterminanten reichen nicht aus, und partielle Analysen oder steuerliche Anreizmaßnahmen können kaum eingebaut werden.

\subsection{Das der rumänischen Volkswirtschaft adäquate Modell.}

Eine erste Frage ergibt sich schon aus dem Titel dieses Abschnitts: Warum Wahl der Modelle und nicht des Modells? Wenn man aber das Kriterienraster, das im Abs.4.2. festgelegt worden ist, und die entsprechende Tabelle im Abs.4.3., betrachtet, stellt man fest, daß keines von den existierenden Modellen auf den gesamten Prozeß der Investitionen in Rumänien übertragbar ist. So ist z.B. der Akzeleratoransatz von seinen Anfangshypothesen her mit der rumänischen Lage nicht vereinbar, und eignet sich auch nicht zum Einbau der steuerlichen Parameter. Basierend auf dem betriebswirtschaftlichen Ansatz, bietet die neoklassische Investitionstheorie trotz ihrer vereinfachenden, marginalistischen Ausgangshypothesen eine gute Grundlage für die Untersuchung. Die Gewinnchancen und die Kapitalbereitstellungskosten sollen für alle Investoren in Rumänien, ob heimisch oder ausländisch, relevant sein.

Dagegen ist die Verfeinerung des neoklassischen Ansatzes, die Tobin's "q"-Theorie, zu stark auf die Gegebenheiten der seit Jahrhunderten funktionierenden westlichen Märkte konzentriert, um auf den rumänischen Markt übertragbar zu sein. Hinzu kommen auch zwei Aspekte, die die vorliegende Untersuchung komplizieren werden, die aber nicht vernachlässigt werden können: die besondere Bedeutung der Risikoeinschätzungen für die ausländischen Investoren, und die schwere Liquiditätslage der inländischen. Diese Aspekte werden jeweils von entsprechenden Theorien, nicht aber in integrierter Weise mit der Gewinnmotivation behandelt. Es gibt also keinen Ansatz, der das im Abs.4.2. vorgeführte Kriterienraster gänzlich befriedigt. Hauptgrund dafür ist der atypische Charakter der rumänischen Wirtschaft (kein entwickeltes Industrieland, kein Entwicklungsland, auch keine Planwirtschaft mehr, aber trotzdem eine Industriewirtschaft), der dazu führt, daß die Probleme seines wirtschaftlichen Umbaus wenig gemeinsam mit den Problemen haben, die während der wirtschaftlichen Entwicklung der westlichen Welt aufgetaucht sind.

Es können zum einen theoretische Modelle gezielt für die Transformationsphase der ehemaligen Ostblockländer entwickelt werden, die aber wegen ihrer mangelhaften empirischen Überprüfbarkeit auf keiner soliden Basis stehen; oder aber man versucht, typisch 
marktwirtschaftliche Modelle auf diese Länder zu übertragen; allerdings waren die Ergebnisse solcher Versuche bisher mindestens fragwürdig (siehe z.B. den monetaristischen Ansatz von Geoffrey SACHS in Polen).

Der einzige Weg, der übrig bleibt, ist also diejenigen Modelle zu finden, die sich in ihren Anfangshypothesen den verschiedenen Teilsystemen der rumänischen Wirtschaft am stärksten annähern, und sie getrennt anzuwenden. Sollte dieses Vorgehen zu widersprüchlichen wirtschaftspolitischen Folgerungen führen, wäre dann die subjektive Arbeit der Wirtschaftspolitik, die Prioritäten zu setzen, notwendig.

Die Suche nach den Wirkungen der Steuern auf Arbeits- und Kapitaleinsatz, sowie auf Konsum und Ersparnis, und insbesondere nach den Reaktionen der Wirtschaftssubjekte auf die Besteuerung, ist ein wichtiger Bestandteil der Steuerlehre, mit großer Bedeutung für Wirtschaftstheorie und -politik. Der Zusammenhang Steuern - Investitionen berührt beide Aspekte: die Reaktion des Investors als Wirtschaftssubjekt, sowie ihre Konsequenzen für die Kapitalbildung. RECKTENWALD (1984, S.394) unterscheidet zwischen Inzidenzwirkungen (auf Einkommen), Preiswirkungen und Substitutionswirkungen (Reaktionen mit dem Ziel der Steuerabweichung) der Besteuerung. Darunter mißt er den Inzidenzwirkungen der Steuern die Eigenschaft zu, einen wichtigeren Einfluß auf Arbeitseinsatz, technischen Fortschritt und Kapitalstock einerseits, auf Konsum, Ersparnis, Liquidität und Investition andererseits, zu haben.

Die Analytik von RECKTENWALD führt, strikt unternehmensbezogen, ANDEL fort (1983, S.127). Nach ihm entfalten die üblichen Steuern dreierlei Wirkungen: auf die Liquidität, auf die Rentabilität und auf den Auslastungsgrad der Unternehmen. Im Grunde genommen, sind das alles Entscheidungswirkungen des Steuerrechts (siehe hierzu D.SCHNEIDER, 1990, S.497). Die Relevanz der ersten zwei Arten von Wirkungen für die Investitionsentscheidungen kann nicht in Frage gestellt werden; sie gehören zu den Inzidenzwirkungen. Auch der gegebene bzw. erwartete Auslastungsgrad eines Investitionsobjektes spielt zweifelsohne im Entscheidungsprozess über künftige Investitionen eine nicht unbedeutende Rolle. Leider läßt sich eine Analyse des Zusammenhangs zwischen der Besteuerung und dem Auslastungsgrad der Unternehmen ohne ein makroökonomisches Modell, das die kontraktiven Effekte der Besteuerung auf die Nachfrage und somit die Umsätze oder auf das Angebot an Produktionsfaktoren quantitativ verdeutlichen sollte, nicht durchführen.

Wie vorhin schon gesagt, kann eine Totalanalyse der Steuerinzidenz in Rumänien (auf primäre Einkommen, dann auf Umverteilung, Nachfrage, Umsätze usw.) mangels statistischer Angaben und mangels eines derartigen, zuverlässigen Modells nicht durchgeführt werden. So STROBEL - Deutschland betreffend -: "Eine differenzierte Analyse, in der die verschiedenen steuerlichen Details berücksichtigt werden und in der von den kompliziertesten Alternativbe- 
dingungen ausgegangen wird, scheitert in aller Regel an rechnerischen Schwierigkeiten. Die Notwendigkeit zur analytischen Vereinfachung zwingt dazu, den Alternativenkomplex so weit wie möglich einzuengen und nach Möglichkeit nur wenige Alternativenmerkmale partialanalytisch als Variable zu betrachten." (STROBEL, 1977, S.273).

Demzufolge ist für Fragen der steuerlichen Belastung einzelner Wirtschaftssubjekte und ihrer Reaktion auf die Besteuerung die mikroökonomische Analyse einzusetzen. Im Rahmen der mikroökonomischen Partialanalyse wird nicht berücksichtigt, daß die Reaktionen der Wirtschaftssubjekts auch Reaktionen anderer Wirtschaftssubjekte hervorrufen, die zurückwirken können. Solche "feed-back"-Prozesse könnte man vollständig nur im Rahmen einer Totalanalyse erfassen; aber die zur Zeit vorliegenden mikroökonomischen Totalmodelle lassen sich für eine Steuerwirkungsanalyse unter rumänischen Verhältnissen nicht verwenden. Sie sind auf die Marktform der vollkommenen Konkurrenz beschränkt und dementsprechend wird darin "der Gewinnsteuer keine Rolle im Hinblick auf Existenz- und Eindeutigkeitsfragen eingeräumt" (SCHNEIDER \& NACHTKAMP, 1977, S. 357).

Schließlich ist sich der Verfasser dieser Arbeit bewußt, daß eine Analyse, die den Anspruch erhebt, die Gesamtheit der für die Investitionsentscheidungen relevanten Variablen zu erfassen, nicht vollständig ist, ohne auch die Größen "Absatzmenge - Q" und "Absatzpreis p" als variabel und damit von der Steuer beeinflußbar zu betrachten. Theoretisch bietet die neoklassische Investitionstheorie auch diese Möglichkeit an; empirisch dürfte dies aber kaum durchführbar sein.

Es kann also im nächsten Kapitel nur der unmittelbare Teil der Inzidenzwirkungen der Besteuerung analysiert werden: die Rentabilitäts- und die Liquiditätswirkungen, anhand der im Kapitel 3 präsentierten und in diesem Kapitel gewürdigten und ausgewählten Modelle. Die Effekte auf die Risikobereitschaft sollten als eine weitere Dimension der Rentabilitätswirkungen in einer früheren Phase der Investitionsentscheidung betrachtet werden. Wie im Abschnitt 4.3 schon gezeigt wurde, ist der Hauptnachteil des neoklassischen Modells hinsichtlich seiner Übertragbarkeit auf Rumänien in der Annahme über die unbegrenzten Möglichkeiten der Finanzierung zu sehen. Der eng begrenzte und teilweise von der übrigen Welt wegen der Nichtkonvertibilität isolierte rumänische Finanzmarkt stört allerdings hauptsächlich die heimischen Investoren, nicht die ausländischen. Für letztere gewinnt aber, durch die in Kapitel 1 geschilderte wirtschaftliche und politisch-institutionelle Lage Rumäniens bedingt, der Risikoaspekt eine überragende Bedeutung. Gewinnchancen werden immer - wie der Ansatz von DOMAR \& MUSGRAVE es auch zeigt - mit den Risiken gewogen, von denen sie behaftet sind.

Fazit: Für die Untersuchung des Einflusses der Steuern auf die Investitionen wird also im folgenden allgemein die neoklassische Investitionstheorie verwendet, die aber, im Hinblick 
auf die heimischen Unternehmen, ob staatlich oder privat, mit dem Finanzierungsquellenansatz, und im Hinblick auf die ausländischen Investoren, mit dem Risikoansatz ergänzt wird. Aus dem bisherigen Gang der Untersuchung ergaben sich die folgenden steuerlichen Einflußfaktoren auf die Investitionen, nach denen die vorliegende Arbeit weiterhin durchgeführt und gestaltet werden soll:

- die Gewinnsteuern, mit ihren folgenden Merkmalen:

- Steuersatz,

- Bemessungsgrundlagen,

- gesetzliche Erleichterungen,

- Verlustvor- und -rücktragsmöglichkeiten;

- die gesondert gestaltete rumänische Dividendensteuer;

- die Grund-, Gebäude- und KFZ-Steuer als einzige vermögensbelastende Steuern in Rumänien;

- die Kapitalverkehrsteuern: Grund- und Gebäudeerwerbsteuer, Gesellschaftsteuer, sowie die Steuer auf den Verkauf von Aktiva der staatlichen Unternehmen, insbesondere in bezug auf die Neugründung von privaten Unternehmen, mit rumänischem, ausländischem oder gemischtem Kapital.

Es sind nämlich die Steuern, die entweder in den mathematischen Formeln des neoklassischen bzw. Liquiditätsmodells explizit vertreten sind, oder aber die relevanten Variablen (z.B. die Liquidität oder das Risiko) in den ausgewählten Modellen unmittelbar beeinflussen.

Als brauchbarste für diese Untersuchung der Steuerwirkungen hat sich eine Klassifizierung der Steuern erwiesen, die ebenfalls von STROBEL (1977, S.273) stammt: erfolgsbezogene Steuern, vermögensbezogene Steuern und dann sonstige Steuern, bezogen auf Absatz und Beschaffung, sowie auf die Nutzung und Einsatz von Produktionsfaktoren. Die Gliederung des Kapitels 5 spiegelt genau diese Analytik wider. 
Mihail Nedelea - 978-3-631-75036-0 Downloaded from PubFactory at 01/11/2019 09:01:58AM via free access 


\section{KAPITEL 5: WIRKUNGSANALYSE DER GEWINN- UND DIVIDENDEN- STEUER IN DER RUMÄNISCHEN TEXTIL- UND BEKLEI- DUNGSINDUSTRIE}

\subsection{Gesetzlicher Rahmen}

\subsubsection{Einführung}

Der gesetzliche Rahmen der rumänischen Fiskalität ist unter schweren Bedingungen in der Transitionsphase entstanden. Vor allem mangelte es, kurz nach dem Umsturz von Ceausescu, im Dezember 1989, an Erfahrung auf diesem Gebiet. Die zentrale Lenkung im Rahmen der Planwirtschaft und das überall herrschende Staatseigentum hatten die Steuern zu einfachen Geldflüssen reduziert, die der Staat zwischen seinen Konten ablaufen ließ. Nicht nur spielten die Steuern damals kaum noch eine wirtschaftspolitische Rolle, sie besaßen auch keinen fiskalischen Inhalt mehr, da der Staat sich sowieso beliebig aus der Kasse eines jeden seiner Unternehmen bedienen durfte. Kurz gefassen waren die Steuern im sozialistischen Staat eine Formsache.

Die Einführung der neuen fiskalischen Gesetzgebung begann mit dem Gesetz Nr. 36/1990, wodurch die damalige Regierung vom Parlament die Vollmacht erhielt, ab dem 1.01.1991 Steuern je nach Bedarf durch Regierungsordonanzen festzulegen. Diese Vollmacht erstreckte sich auf 6 Monate, nach deren Ablauf die Regierung verpflichtet war, Vorschläge für die den von ihr eingeführten Steuern entsprechenden Gesetze dem Parlament vorzulegen. Diese Vollmacht wurde vom Parlament mit mehreren Anlässen verlängert, bis zum Frühjahr 1993. Seitdem bedarf jede neue Steuer eines vom Parlament gebilligten Gesetzes.

Wie es im folgenden zu zeigen sein wird, war der Prozeß der Reform der fiskalischen Gesetzgebung in Rumänien von zahlreichen Fehlern begleitet (z.B. die ursprüngliche progressive Gewinnsteuer); auch konnte man nach der Machtübernahme der Regierung VACAROIU feststellen, daß nunmehr auf der Prioritätsliste der Regierung und des Parlaments hinsichtlich der Fiskalpolitik nicht mehr die Einführung eines modernen, marktwirtschaftskonformen, sozialorientierten und investitionsfreundlichen Steuersystems auf dem ersten Platz rangierte, sondern die Maximierung der Steuereinnahmen, um die veralteten Wirtschafts- und Staatsstrukturen erhalten zu können.

Es wird sich auch in den folgenden Ausführungen zeigen, daß das rumänische Steuersystem, obwohl es versucht, über bestimmte Steuerstundungen Kapitalinvestitionen, insbesondere vom 
Ausland, anzureizen, nicht als investitionsfreundlich sondern sogar als substanzverzerrend bezeichnet werden kann.

Die Trägheit, mit der die rumänischen Staatsstrukturen - sowohl in der Gesetzgebung als auch auf der exekutiven Ebene - auf die Anforderungen der Modernisierung und des internationalen Wettbewerbs um Auslandskapital zwischen den osteuropäischen Volkswirtschaften reagiert haben, läßt darauf schließen, daß unter den rumänischen politischen Entscheidungsträgern auf dem fiskalischen Gebiet nicht nur das Fachwissen, sondern auch Organisation und Benevolenz fehlen. Die Regierung VACAROIU kassiert seit zwei Jahren fleißig in den ersten 4 Monaten des Jahres allerlei Steuern ein, ohne über einen festgesetzten Staatshaushalt zu verfügen. Der Staatshaushalt für 1993 wurde erst im April 1993 gebilligt, derjenige für 1994 hat mitte April 1994 immer noch nicht dem Parlament vorgelegen. Das als Anreiz für die Investitionen höchst wichtige Abschreibungsgesetz wurde seit dem Frühling 1992 über fast zwei Jahre hinweg aufgeschoben, und erst im März 1994 verabschiedet. Die heutige Wirtschaftspolitik in Rumänien ist offensichtlich weit davon entfernt, über die Verbesserung der Angebotsbedingungen in der Wirtschaft, die Überwindung der derzeitigen Strukturkrise zu versuchen.

Die folgende Übersicht der rumänischen Gesetzgebung basiert im Abschnitt 5.1.3. auf der Übersetzung der Rumänischen Entwicklungsagentur (1992, S.157-159). Die Auswahl der wichtigen Bestandteile der übrigen Gesetze und Verordnungen (Abschnitte 5.1.2. und 5.1.4. bis 5.1.7.) und ihre Übersetzung, sowie die eingebauten Kommentare stammen vom Verfasser dieser Arbeit.

\subsubsection{Das Gesetz Nr.12/1991 betreffend die Gewinnsteuer}

Obwohl dieses Gesetz die für Investitionen total ungünstige progressive Besteuerung vorsah, bleibt es immer noch in seinen Hauptbestimmungen in Kraft, wobei man später zu einer proportionalen Steuer überging. Relevant für die vorliegende Arbeit sind die folgenden Bestimmungen:

Artikel 3: Die Gewinnsteuer wird monatlich berechnet und entsprechend dem vom Anfang des Jahres kumulierten Gewinn in den Staatshaushalt monatlich eingezahlt.

Artikel 5: (über das Gesetz Nr.55/1.08.1991 hinzugefügt): Die steuerpflichtigen Unternehmen, die nach dem 1.01.1991 gegründet worden sind, bleiben wie folgt gewinnsteuerfrei:

a) Die Unternehmen im Bereich der Industrie, Land- und Bauwirtschaft, 5 Jahre ab dem Gründungstag;

b) Die Unternehmen im Bereich der Förderung von Rohstoffen mineraler Art, des Verkehrs- und Kommunikationswesens, 3 Jahre ab dem Gründungstag; 
c) Die Dienstleistungsunternehmen, 1 Jahr ab dem Gründungstag;

d) Die Handelsunternehmen, 6 Monate ab dem Gründungstag. [...]

Diese Bestimmungen gelten nicht für Selbstverwaltungsbetriebe und für Gesellschaften mit mehrheitlich staatlichem Kapital.

Artikel 7: Die Tätigkeit der Unternehmen, die gemäß Art.5 Steuerfreiheit genießen, soll sich nach dem Ende dieser Steuerfreiheit auf eine Dauer fortsetzen, die mindestens gleich der Steuerfreiheitsfrist ist. Ansonsten sind diese Unternehmen verpflichtet, die gestundete Gewinnsteuer retroaktiv zu zahlen, berechnet für die ganze Dauer der Steuerfreiheit.

Kommentar: Die Gleichgültigkeit, mit der Regierung und Parlament sich auf eine Regel eingelassen haben, die die "insiders" - sprich: die neuen Reichen von der alten Nomenklatura - zur Steuerhinterziehung nahezu einlädt, ist für die politischen Verhältnisse in Rumänien charakteristisch. Die meisten privaten Unternehmer, die klein sind und klein bleiben wollen, gründen jede 6 Monate eine neue $\mathrm{GmbH}$. Der einzige Anspruch des Finanzministeriums ist dabei, daß zwei GmbH's nicht dieselben Teilhaber haben dürfen. Es genügt also, einen von den z.B. 5 Teilhaber zu wechseln, um eine neue Gesellschaft gründen zu können, die Gewinnsteuerfreiheit genießen darf. So kommt es daß die (fast) gleichen Firmen, die die gleiche Tätigkeit, in den gleichen Räumen, mit den gleichen Mitarbeitern ausüben, schon den fünften Namen tragen, wobei die früheren Firmen, dem Gesetz entsprechend, nicht aufgelöst wurden, aber keine Gewinne mehr erwirtschaften, weil sie buchhalterisch von der zuletzt begründeten Firma "ausgebeutet" werden. Einige Zahlen sind dafür illustrativ: Ende 1992 existierten (wenigstens auf dem Papier) in Rumänien 199.902 Gesellschaften mit privatem Kapital, 21.056 Joint-Ventures (Gemeinschaftsunternehmen), 7.885 Gesellschaften mit mehrheitlich staatlichem Kapital und 859 Selbstverwaltungsbetriebe; also, eine private GmbH (die meisten haben diese Rechtsform angenommen) je 100 Einwohner! (GRIGORIE, 1993).

Auch der heutige Staatsminister für die Wirtschaftsreform, Mircea COSEA, gab zu, daß diese Bestimmung einen per Gesetz verstärkten günstigen Rahmen für die Korruption und die Steuerhinterziehung hat entstehen lassen. Eine Umorientierung des Steuersystems sei notwendig, um den größeren Firmen und wichtigeren Investoren, ob staatlich oder privat, Möglichkeiten für die Entwicklung einzuräumen (COSEA, 1994).

Artikel 9: Die Steuer auf Gewinne, die zur Finanzierung von Investitionen für die Erweiterung und Modernisierung der Anlagen und Technologien oder für den Umweltschutz benutzt werden, wird um $50 \%$ herabgesetzt. Dies geschieht unter der Bedingung, daß diese Beträge (die der Herabsetzung entsprechen) zu diesem Zweck tatsächlich verwendet werden. 
Kommentar: Das Finanzministerium hat hinterher präzisiert, daß die im Laufe des Jahres investierte Summe, auf die sich diese Herabsetzung bezieht, den tatsächlichen Gewinn nicht überschreiten darf.

Die Berechnung und der Ausgleich der nach Reduzierung erhaltenen Summen mit dem Staatshaushalt oder mit dem Lokalhaushalt wird bis am 31. Januar des nächsten Jahres gemacht und spiegelt sich in der Bilanz des Geschäftsjahres wider.

Kommentar: Diese Erleichterung für investierende Unternehmen entspricht dem in der finanzwissenschaftlichen Literatur definierten Steuerabzug für Investitionen. Die Reduzierung wird direkt bei der Steuerschuld gemacht, und nicht - wie bei einem Investitionsfreibetrag vor der Festlegung der Besteuerungsgrundlage. Aufgrund der Tatsache, daß dieser Steuerabzug erst nach Abschluß der Bilanz, das heißt im nächsten Jahr, gewährt wird, wirkt er sich nur im nachhinein positiv auf die Rentabilität des laufenden Jahres aus, und verursacht im laufenden Jahr keinen günstigen Liquiditätseffekt. Angesichts der bisher hohen Inflation in Rumänien, die Wirkung des Steuerabzugs war umso stärker, desto später im Verlaufe des Jahres die Investitionen getätigt worden sind. Ein Beispiel hierbei: für eine Investition in Höhe von 10.000.000 Lei, vorgenommen in März 1992, durfte das Unternehmen im Januar $19930,5 \times 45 \%$ x 10.000.000=2.250.000 Lei von seiner für 1993 gezahlten Gewinnsteuer erstattet bekommen. Zwischen März 1992 und Januar 1993 sind aber die Preise etwa 2,5 mal gestiegen, die zurückerhaltene Summe war also entsprechend weniger wert.

Im Fall einer proportionalen Gewinnsteuer, für Unternehmen, die Gewinne machen, hat der Steuerabzug denselben Effekt wie der Investitionsfreibetrag. Für Verluste erzielende Unternehmen dagegen, hat letzterer einen günstigeren Rentabilitätseffekt wenn die Möglichkeit des Verlustvortrags eingeräumt wird (was der Fall Rumäniens wäre).

Artikel 21: Das Finanzministerium erhält die Vollmacht, die maximalen steuerlich abzugsfähigen Aufwendungen für soziale, kulturelle und sportliche Veranstaltungen und Einrichtungen bei Selbstverwaltungsbetrieben und Gesellschaften mit ausschließlich staatlichem Kapital, jährlich im Gesetz des Staatshaushalts festzulegen.

Kommentar: Im Artikel 21 werden keine Befugnisse des Finanzministeriums, auch bei den privaten Unternehmen Grenzen zur Abzugsfähigkeit derartigen Aufwendungen festzusetzen, vorgesehen. Das ist offensichtlich ein Versäumnis, das das Ministerium selbst in seinen Vorschriften Nr.3614/1991, weiter erwähnt, korrigiert. Das gleiche gilt auch für Gesellschaften, die sich nur teilweise in staatlichem Besitz befinden.

Das Finanzministerium wird auch Vorschriften für die Berechnung der Gewinnsteuer und für die notwendige Formularistik ausgeben. 


\subsubsection{Der Regierungsbeschluß Nr. 804/1991 "Über die Gewinnsteuer"}

Dieser Regierungsbeschluß hat nachhaltig den Hauptfehler des Gesetzes Nr.12/1991, nämlich die Progressivität der Gewinnsteuer, korrigiert. Zugleich werden auch die steuerpflichtigen Unternehmen besser definiert.

Artikel 1: Selbstverwaltungsbetriebe, (Handels)gesellschaften, Kooperativen, Finanz- und Kreditinstitute, andere Wirtschaftsunternehmen mit eigener Rechtspersönlichkeit einschließlich jener mit ausländischem Kapital sowie Wirtschaftsunternehmen anderer juristischen rumänischen oder ausländischen Personen, die Gewinne aus der ausgeübten Tätigkeit ziehen und im vorliegenden Regierungsbeschluß als steuerpflichtige Unternehmen bezeichnet werden, sind gesetzmäßig verpflichtet, Gewinnsteuer ins Budget der zentralen Staatsverwaltung oder in die Lokalbudgets einzuzahlen.

Artikel 2: Die Gewinnsteuer wird in progressiven Sätzen, abhängig von der Höhe des Gewinns, wie folgt, berechnet:

- $30 \%$ von dem steuerpflichtigen Gewinn bis 1.000 .000 Lei;

- $45 \%$ von dem steuerpflichtigen Gewinn über 1.000.000 Lei.

Der steuerpflichtige Gewinn wird als Differenz zwischen den realisierten Einkünften und den im Anhang Nr. 2 dieses Beschlusses vorgesehenen Aufwendungen bestimmt.

Kommentar: In der Praxis, werden die ersten 1.000.000 Lei vom Gewinn mit 30\% besteuert, und nur die Differenz zwischen dem totalen Gewinn und der Summe von 1.000.000 Lei, mit 45\%. Mittlerweile ist aber wegen der stetigen Abwertung der rumänischen Währung die Million-Grenze symbolisch geworden, da im Frühjahr 1994 1.000.000 Lei zu 1.000 DM gleichwertig waren. Im folgenden kann man also von einem einheitlichen Gewinnsteuersatz von $45 \%$ ausgehen. Die dadurch entstandene Approximation ist vernachlässigbar.

Dieser Beschluß enthält auch die zur Berechnung der Bemessungsgrundlage der Gewinnsteuer abzugsfähigen Aufwendungen:

1. Produktions- und Vertriebskosten, berechnet gemäß der gesetzlichen Vorschriften.

2. Gebühr für die Benutzung von staatlichem Boden.

3. Kfz-Steuern für juristische Personen.

4. Aufwand für Berufsausbildung und Betriebspraktikum.

5. Ausgaben für Forschungsverträge [...] die in die am Punkt 1. ausgewiesenen Kosten nicht eingebaut wurden.

6. Provisionen an Außenhandelsunternehmen.

7. Werbungs- und Protokollaufwand, in den vom Finanzministerium jährlich festgesetzten Grenzen. 
8. Von dem Unternehmen bezahltes, und in den Produktions- und Vertriebskosten nicht erhaltenes Kindergeld.

9. Einzahlungen in den Reservefonds und in andere, vom Gesetz vorgesehene Sonderfonds. (Kommentar: die es zur Zeit offiziell nicht gibt!).

10. Verluste vergangener Jahre, falls diese bis zum Datum der Veranlagung der Gewinnsteuer nicht ausgeglichen werden konnten.

11. Zuwendungen und Schenkungen mit humanitärem Charakter sowie auch Aufwendungen für die Finanzierung von sozialen, kulturellen, wissenschaftlichen und sportlichen Tätigkeiten, in den von dem Finanzministerium jährlich festgesetzten Grenzen.

12. Andere Aufwendungen, von den in Kraft befindlichen Regelungen anerkannt (Kommentar: die es wiederum nicht gibt!).

\subsubsection{Die Vorschriften des Finanzministeriums Nr.3614/26.04.1991 hinsichtlich der Berechnung der Gewinnsteuer}

Diese Vorschriften stellen eigentlich die für diese Untersuchung brauchbarste Verordnung dar. Einerseits füllen sie die eklatanten Lücken des Gesetzes 12/1991 und des Regierungsbeschlusses 804/1991 (wo z.B. das Problem der Abzugsfähigkeit der Akzisen und anderer Umsatzsteuern total versäumt wird), andererseits schränken sie aber wichtige vom Gesetz erlaubte Steuervorteile (wie z.B. den Verlustvortrag) erheblich ein. Somit wird wieder eine der wichtigsten Unzulänglichkeiten der rumänischen Steuerpraxis klar: zu viele wichtige Punkte, die im Gewinnsteuergesetz geklärt werden sollten, werden der schwankenden Regierungspolitik überlassen. Die zur Zeit der Planwirtschaft eingebürgte Gepflogenheit, über Regierungsbeschlusse und Verordnungen die Wirtschaft zu lenken, die nicht selten dem Gesetz widersprechen, schlägt sich also auch in der Steuerpraxis nieder; das Ergebnis ist die Instabilität des rechtlichen Rahmens, in dem das Wirtschaftsleben abläuft, mit ungünstigen Wirkungen auf die Investitionsbereitschaft.

Relevant für die vorliegende Untersuchung dürften folgende Bestimmungen sein:

Kapitel 1: Die steuerpflichtigen Unternehmen und die Berechnung des steuerpflichtigen Gewinns.

Abs.2: Der steuerpflichtige Gewinn wird als Differenz zwischen den totalen Einkünften, aus Haupt- und Nebentätigkeiten, und den totalen Aufwendungen, die von der um die Erzielung der Einkünfte ausgeübten Tätigkeit verursacht worden sind, einschließlich der gezahlten Umsatzsteuern berechnet. 
Abs.3: Die totalen Einkünfte, die zur Berechnung des steuerpflichtigen Gewinns miteinbezogen werden müssen, setzen sich aus der Summe aller Entgelte für gelieferte Produkte und Dienstleistungen, aus eingenommenen Mieten, Pachten, Provisionen, aus Dividenden von Kapitalbeteiligungen, aus Zinsen und Penalitäten, aus Subventionen sowie aus Einkünften anderer Art, zusammen.

Abs.4: Die zur Berechnung des steuerpflichtigen Gewinns abzugsfähigen Aufwendungen sind:

die Produktions- und Vertriebskosten: Rohstoffe, Betriebsmittel, halbfertige Güter, Transport-, Lagerungs- und Acquisitionskosten, Brennstoff-, Strom- und Wasserkosten, Abschreibungen, sonstige Materialkosten, Löhne, Sozialversicherungsbeiträge, die Einzahlungen in den Forschungs- und Entwicklungsfonds (vorübergehend), Mieten, Pachten, Zinsen, Bestandsteuern, und sonstige im Gesetz vorgesehene Aufwendungen (Kommentar: welche? in welchem Gesetz?).

abzugsfähig sind auch die Kosten von Geschäftsreisen, Transport der Mitarbeiter zum und vom Betrieb, andere Prämien und Leistungen des Unternehmens an die Mitarbeiter, aber nur innerhalb einer Grenze, die jährlich vom Finanzministerium festgelegt wird.

Kommentar: Da das Finanzministerium diese Grenzen in engem Zusammenhang mit dem jährlichen Staatshaushalt festlegt, und da in den letzten zwei Jahren dieser Staatshaushalt mit großer Verzögerung (für 1993 erst im Monat April 1993!) vom Parlament gebilligt worden ist, kann man davon aus gehen, daß die Unternehmen mindestens im ersten Quartal gearbeitet haben, ohne ihre Aufwendungen und Steuerzahlungen planen zu können - eine Tatsache, die sich natürlich ungünstig auf das Geschäftsklima ausgewirkt hat.

Abs.5: Bis zur Billigung eines neuen Gesetzes in dieser Hinsicht, dürfen die zulässigen Abschreibungen wie folgt berechnet werden:

a) Die Selbstverwaltungsbetriebe und die Gesellschaften mit staatlichem Kapital werden nach wie vor die Abschreibungen gemäß dem Gesetz Nr.62/1968 berechnen.

Kommentar: Dieses Gesetz läßt nur die lineare Abschreibungsmethode zu. Auch sind die in diesem Gesetz vorgeschriebenen Nutzungsdauern sehr hoch. Erst im Frühjahr 1994 hat das Parlament das neue Abschreibungsgesetz gebilligt, das auch die degressive Abschreibungsmethode erlaubt (siehe ferner 5.1.6).

b) Die anderen Unternehmen dürfen die jährlichen Abschreibungen anhand der im Gesetz Nr.62/1968 normierten Nutzungsdauern berechnen, die aber mit bis zu $40 \%$ verkürzt werden dürfen. 
Abs.6: Anmerkungen zu den anderen gewinnsteuerlich abzugsfähigen Aufwendungen (siehe 5.1.3.)

a) Den Ausgaben für Forschung und Entwicklung dürfen beigerechnet werden:

- $\quad$ Die Abgabe von $1 \%$ für die Unterstützung der nationalen Forschung und Entwicklung gemäß dem Regierungsbeschluß Nr.1284/1990 - eine Art Umsatzsteuer mit speziellem Zweck;

- Die Beträge, die das Unternehmen für Forschungsaufträge bezahlt hat, die auf die Entwicklung, Modernisierung, Erneuerung der Produkte und Technologien, Umweltschutz und Arbeitsschutz gerichtet sind, und nicht in die Produktionskosten eingebaut wurden (Kommentar: mittlerweile nicht mehr! - seit der Einführung des neuen Buchführungssystems besteht für solche Aufwendungen Aktivierungspflicht - siehe 5.1.6).

b) Die Summe der abzugsfähigen Werbungs- und Protokollkosten dürfen $1 \%$ der Differenz zwischen den gesamten jährlichen Einnahmen und den Produktions- und Vertriebskosten, zuzüglich der gezahlten Umsatzsteuern, nicht überschreiten. Der überschreitende Betrag wird direkt aus dem Nettogewinn bezahlt. [...]

d) Höchstens 5\% der am Punkt b) definierten Differenz darf jährlich von den Aktiengesellschaften und Selbstverwaltungsbetrieben, gemäß dem Gesetz Nr.31/1990 "Über die (Handels)gesellschaften", aus dem Bruttogewinn abgezogen werden und zur Bildung des Reservefonds des Unternehmens benutzt werden, bis der Reservefonds im folgenden Verhältnis mit dem Eigenkapital steht:

- $\quad 20 \%$ bei Aktiengesellschaften, die durch die Umwandlung der Volkseigentumsbetriebe in (Handels)gesellschaften entstanden sind, und bei Selbstverwaltungsbetrieben;

- $\quad 25 \%$ bei Gesellschaften mit ausländischer Kapitalbeteiligung.

Kommentar: Eine gewisse steuerfreie Rückstellung wurde also damals erlaubt. Die $20 \%$ und $25 \%$ Sätze wurden im Gesetz Nr.31/1990 festgelegt, wobei das Finanzministerium volle Macht genießt, die Intensität der Ausnutzung dieses potentiellen Finanzierungsvorteils einzuschränken, indem es die Geschwindigkeit der Bildung dieser Rückstellung (auf rumänisch "gesetzlicher Reservefonds" genannt) begrenzen kann. Auch dürfen die Unternehmen diesen Reservefonds nicht zur Finanzierung von Sachkapital heranziehen sondern sind verpflichtet, ihn dem inflationären Werteverzehr zu opfern.

Typisch für die oben erwähnte Art, den Wirtschaftsprozeß von der Exekutive her durch Beschlüsse und Verordnungen, die den Gesetzen widersprechen, zu lenken, ist der augenfällige Widerspruch zwischen diesen Vorschriften und dem Artikel 131 der Gesetzes Nr.31/1990 über die (Handels)gesellschaften. In diesem Artikel steht fest, daß der Reservefonds mindestens $20 \%$ bzw. 25\% des Eigenkapitals der Gesellschaft ausmachen soll, 
indem mindestens 5\% der Gewinne der Gesellschaften jährlich in den Reservefonds eingelegt werden müssen. Viele Unternehmen versuchen derzeit in Rumänien von diesem offensichtlichen Mangel des Gesetzes zu profitieren, indem sie höhere Anteile der Bruttogewinne von der Steuer absetzen und sich auf das Gesetz Nr.31/1990 berufen, wobei das Finanzministerium höhere Macht gegenüber der Gesetzgebung zu genießen scheint (PETREA, 1993).

e) Bei der Berechnung des steuerpflichtigen Gewinns dürfen die Unternehmen den Verlust des Basisjahres nur mit den Gewinnen der nächsten zwei Jahren ausgleichen. Auch wenn danach ein Teil des Verlustes noch unausgeglichen bleibt, darf er nicht mit dem Gewinn des dritten Jahres verrechnet werden.

Kommentar: Somit schränkt das Finanzministerium die Möglichkeit des Verlustvortrags, die im Gesetz Nr.12/1991 "Über die Gewinnsteuer" unbegrenzt eingeräumt wurde, erheblich ein. Der Verlustrücktrag ist nicht erlaubt; allerdings würde er, angesichts der starken Inflation, keinen großen Nutzen stiften. Die Vorschriften des Finanzministeriums Nr.2011/5.01.1993 angesichts einiger Bilanzierungsregeln für 1992 schränken die Möglichkeit des Verlustvortrags noch stärker ein. Es wird vorgesehen, daß die Verluste mit erster Priorität vom Reservefonds (der o.g. Rücklage) gedeckt werden müssen.

f) Selbstverwaltungsbetriebe und Gesellschaften mit 100\%-iger Staatsbeteiligung dürfen von den sämtlichen Einkünften eine Summe, die $1 \%$ der jährlichen Summe aller bezahlten Löhne und Gehälter nicht überschreitet, zur Finanzierung von Sozial-, Kultur- und Sporteinrichtungen und -veranstaltungen ausgeben. Dieser Aufwand wird bei Berechnung der Gewinnsteuer von der Bemessungsgrundlage abgezogen. Bei den anderen Unternehmen beträgt der maximal abzugsfähige Aufwand für dieselben Zwecke 2,5\% von der unter Punkt b) definierten Differenz.

Kapitel 3 Steuerherabsetzung (siehe 5.1.2, Artikel 9)

[...] Falls die Summe, die der 50\%-igen Herabsetzung der Gewinnsteuer entspricht, im Basisjahr nicht zwecks Finanzierung von Investitionen erschöpft wurde, darf die Differenz auf das nächste Jahr verschoben werden. Im nächsten Jahr soll diese Differenz vor allen anderen Quellen zur Finanzierung von Investitionen benutzt werden. Falls diese Differenz im nächsten Jahr auch nicht erschöpft wird, ist der verbleibende Teil am Ende des nächsten Jahres zusammen mit der Gewinnsteuer an die Staatskasse zu entrichten. [...]

Kommentar: Wie es schon aus dem oben erwähnten Artikel deutlich wird, ist der Begriff "Investitionen" im physischen Sinne zu verstehen, also ohne die Finanzanlagen. Seit dem Frühjahr 1994 wird deshalb kräftig diskutiert, ob man nicht, gemäß der Empfehlungen des 
Internationalen Währungsfonds, die Beteiligungen an andere Gesellschaften miteinbeziehen sollte, um den Privatisierungsprozeß zu unterstützen.

Kapitel 4: Steuerfreie Unternehmen (siehe 5.1.2, Artikel 5).

[...] Die Unternehmen, die durch die Fusion, Splitterung oder Rechtsformänderung bereits existierender Unternehmen entstanden sind, sind keine neugegründeten Unternehmen im Sinne des Gesetzes, und haben demnach keinen Anspruch auf Steuerfreiheit. [...]

Kommentar: Somit wird ein wichtiges Versäumnis des Gesetzes korrigiert. Den sogenannten "Joint Ventures", den Tochtergesellschaften ausländischer Unternehmen und den Investitionen der ausländischen Privatpersonen wird allerdings die Steuerfreiheit nicht entzogen, da die Beteiligungen von ausländischem Kapital gemäß dem Gesetz Nr.35/1991 über die ausländischen Investitionen steuerlich gesondert behandelt werden. Die Formulierung ist trotzdem unklar: man hätte vor "bereits existierender", "im Lande" einfügen müssen, um Mißdeutungen zu vermeiden.

[...] Die neugegründeten Unternehmen werden in die von Punkt a) bis d) definierten Klassen der Steuerfreiheit gemäß ihrem Profil eingegliedert. Falls das Profil eines Unternehmens mehrere Tätigkeiten umfaßt, die unterschiedlichen Steuerfreiheitsklassen entsprechen, ist die Tätigkeit, die den größten Teil der Umsätze ausmacht, für die Eingliederung maßgebend. [...]

\subsubsection{Das Gesetz Nr.40/1992 über die Dividendensteuer}

Dieses Gesetz sieht eine zusätzliche steuerliche Belastung der ausgeschütteten Dividenden vor. Im Falle der Gesellschaften, die sich gänzlich im Staatsbesitz befinden, kassiert der Staatshaushalt diese Dividendensteuer, und danach werden die Dividenden, die dem Staat als Aktionär zufließen, in einen der 4 regionalen Fonds des privaten Eigentums (30\% davon) und in den Staatseigentumsfonds (70\% davon) (siehe Kapitel 1 dieser Arbeit) eingeschüttet. Die privaten Gesellschaften sind natürlich nicht verpflichtet, an die Eigentumsfonds Dividenden zu zahlen; wenn sie aber an ihre Aktionäre Dividenden ausschütten, werden sie ebenfalls ein zweites Mal, gemäß dieses Gesetzes, besteuert.

Somit werden gemäß Artikel 1 sämtliche Dividenden, die von Gesellschaften, unabhängig von deren Eigentumsstrukturen, ausgeschüttet werden, mit $\mathbf{1 0 \%}$ besteuert.

Artikel 2 enthält eine sehr wichtige Bestimmung: die Gesellschaften mit mehrheitlicher Beteiligung des Staates dürfen aus dem Nettogewinn maximal 10\% den Mitarbeitern als 
Beteiligung an den Gewinnen zahlen, und höchstens 50\% aus demselben Nettogewinn einbehalten, um damit den Fonds für die Selbstfinanzierung von Entwicklung und Modernisierung (d.h. von Investitionen) zu bilden. Also mindestens $40 \%$ des Nettogewinns müssen an die Eigentumsfonds als Dividenden ausgeschüttet werden, wobei sie zuvor mit $10 \%$ besteuert werden.

Diese Bestimmung ist von kardinaler Bedeutung für den Spielraum der Selbstfinanzierung bei Gesellschaften mit staatlichem Kapital. Eine Verwechslung der Kompetenzen ist auch hier zu finden. Die Dividendenpolitik solcher Gesellschaften sollte, der Flexibilität halber, ein Entscheidungsparameter der Regierung und der Eigentumsfonds sein, und nicht per Gesetz vom Parlament festgelegt werden.

Wie gesehen, werden die mit staatlichem oder privatem Kapital erwirtschafteten Überschüsse zweimal besteuert: zuerst die Gewinne und dann die ausgeschütteten Dividenden. Da es in Rumänien keine artikulierte Einkommensteuer gibt (nur Lohn(Quellen)steuer), werden die an physische Personen ausgezahlten Dividenden nicht weiter besteuert.

Die von juristischen Personen eingenommenen Dividenden (z.B. auf Beteiligungen an anderen Gesellschaften) werden im rumänischen Buchführungssystem als Finanzeinkommen bezeichnet und gewinnerhöhend verbucht. Dementsprechend, je tiefer die Verschachtelung, desto konfiskatorischer die Besteuerung, da es in Rumänien kein Schachtelprivileg gibt (das Problem wurde bisher nicht einmal von der Presse aufgegriffen!).

\subsubsection{Das neue Abschreibungsgesetz, vom 2.März 1994}

Dieses für die Kapitalakkumulation sehr wichtige Gesetz ließ lange auf sich warten. Da ein großer Teil der rumänischen Politiker den dramatischen Verschleiß und Werteverzehr, die seit der Zeit der Planwirtschaft dem volkswirtschaftlichen Kapitalstock anhaften, aus welchen Gründen auch immer noch nicht wahrnehmen wollen, und vielleicht weil vielen von ihnen der Begriff der Abschreibungen noch nicht klar ist, hat das Parlament die Besprechung des Entwurfes dieses Gesetzes, schon aus der Zeit der Regierung ROMAN - 1991 - stammend, stets aufgeschoben. Endlich wurde das Projekt im März 1994 dem Parlament vorgelegt, und wurde ohne irgendwelche Diskussionen gebilligt. Immerhin hatte es vor diesem "Ereignis" einige Signale von der Seite der reformfreudigen Presse und der Verbände der privaten Arbeitgeber gegeben, die den schnellen Übergang zu moderneren Abschreibungsverfahren forderten (z.B. PANTEA, 1993).

Ohne Zweifel kann man dieses Gesetz als viel investitionsfreundlicher als seinen Vorgänger bezeichnen. Folgendes spricht dafür: 
außer der linearen Abschreibungsmethode, werden auch die degressive und die sog. beschleunigte Abschreibung zugelassen. Bei der degressiven Abschreibung, wird gemäß der vorgeschriebenen Nutzungsdauer ein Abschreibungssatz berechnet. Er beträgt z.B. bei einer Anlage, mit einer zugelassenen minimalen Nutzungsdauer von 10 Jahren, $1: 10=10 \%$. Dieser Abschreibungssatz wird dann mit 1,5 - für Anlagen mit einer Nutzungsdauer von 2 bis (einschließlich) 5 Jahren - mit 2 - für Nutzungsdauern zwischen 5 und 10 Jahren - und mit 2,5 - für Nutzungsdauern über 10 Jahre multipliziert. Es ergibt sich die sog. jährliche Abschreibungsquote. Sie wird dann im Rahmen der Abschreibungsmethode jedes Jahr mit dem Restwert der Anlage multipliziert, um die Abschreibungssumme für dieses Jahr zu bestimmen. Beispiel: eine Maschine mit einer Nutzungsdauer von 10 Jahren: Abschreibungssatz 10\%; Multiplikator 2; im ersten Jahr werden $2 \times 10 \%=20 \%$ abgeschrieben; im zweiten Jahr, $20 \%$ x $80 \%$ (Restwert) $=16 \%$; weiter:

3.Jahr: $20 \%$ x $64 \%=12,8 \%$

4.Jahr: $20 \% \times 51,2 \%=10,24 \%$

5.Jahr: $20 \% \times 40,96 \%=8,192 \%$

6.Jahr: $20 \% \times 32,768 \%=6,554 \%$

7.Jahr: $20 \% \times 26,214 \%=5,243 \%$

8.Jahr: $20 \% \times 20,971 \%=4,194 \%$

9.Jahr: $20 \% \times 16,777 \%=3,355 \%$

10.Jahr: $16,777 \%-3,355 \%=13,422 \%$ (den Restwert).

Bei der beschleunigten Abschreibung dürfen im ersten Jahr bis zu $50 \%$ des Anschaffungswertes abgesetzt werden. Der Rest wird in den verbliebenen Jahre der Nutzungsdauer nach dem Linearverfahren abgeschrieben. Beispiel: eine Maschine mit einer Nutzungsdauer von 5 Jahren:

1.Jahr: $50 \%$

2.Jahr: $12,5 \%$

3.Jahr: $12,5 \%$

4.Jahr: $12,5 \%$

5.Jahr: $12,5 \%$

die Entscheidung, ob innerhalb eines Unternehmens linear oder degressiv abgeschrieben wird, wird der Versammlung der Aktionäre, bzw. dem Vorstand (in Selbstverwaltungsbetrieben) überlassen. Die degressive Abschreibungsmethode darf nur mit spezieller Genehmigung des Finanzministeriums (Anmerkung: unter welchen Bedingungen? welches sind die Gründe, die einen Antrag darauf rechtfertigen würden? - keine Spezifikation!) angewendet werden.

für bei Reparaturen irgendwelcher Art und Umfang eingesetzte Ersatzteile besteht keine Aktivierungspflicht, sowie für Teile, die kleinen Modernisierungen der 
Maschinen während Kapitalreparaturen dienen. Diese eher unklare Formulierung (was bedeutet klein?) überläßt eigentlich den Unternehmen einigermaßen die Aktivierungswahl für einige Komponenten des Sachkapitals. Der Unterschied zwischen Erhaltungsund Herstellungsaufwand (siehe hierzu WÖHE 1980, S.642) wird sowieso von den heute geltenden Buchführungsregeln nicht klar definiert.

Obwohl im o.g. Sinne fortschrittlich, leidet dieses Abschreibungsgesetz trotzdem an den allgemeinen Krankheiten der rumänischen Gesetzgebung, insbesondere in den letzten zwei Jahren: Unklarheit und Unvollständigkeit, zum Teil auch Widersprüchlichkeit. Es wird z.B. festgelegt, daß die Versammlung der Aktionäre das "Abschreibungsregime" wählen darf. Bedeutet dies, daß infolge ihrer Wahl, die Unternehmen ausschließlich eines oder das andere Verfahren verwenden dürfen? Dürfen die Unternehmen z.B. einen Teil der Anlagen nach der Linear- und den Rest nach der degressiven Methode abschreiben? Wenn nicht, soll die Versammlung der Aktionäre dann für jede Maschine das Abschreibungsverfahren gesondert bestimmen? Mangels einer klaren Antwort, werden wir im folgenden die Hypothese eines einheitlichen "Abschreibungsregimes" innerhalb eines Betriebes verfolgen, da sie dem Geist der bisherigen Gesetzgebung in Rumänien nach der Wende eher entspricht.

Ein anderes Problem wird aus der einfachen arithmetischen Darlegung des degressiven Abschreibungsverfahrens ersichtlich: ohne die Möglichkeit eines Übergangs vom degressiven zum linearen Verfahren, zu einem Zeitpunkt, den das Unternehmen selbst bestimmen sollte, verliert die vom rumänischen Gesetz erlaubte degressive Methode gegen das Ende der Nutzungsdauer genau ihren degressiven Charakter, und wandelt sich in ihr Gegenteil um. Die Kurve der Abschreibungsbeträge bekommt also ein "Bauch" in der zweiten Hälfte der Nutzungsdauer. Der Liquiditätsvorteil des degressiven Verfahrens geht zu schnell verloren im oben angegebenen Beispiel wird die Abschreibung nach dem degressiven Verfahren schon nach dem 4. Jahr kleiner und also weniger vorteilhaft als die Abschreibung nach dem linearen Verfahren. Dagegen fällt plötzlich im 10.Jahr eine 3 mal größere Abschreibung an, was den Anforderungen einer investitionsfreundlichen Besteuerung und einer möglichst "glatten" Finanzierung (ohne Höhen und Tiefen) überhaupt nicht gerecht wird. Man kann aber dagegen nichts machen, weil das Gesetz "die Änderung, während der normierten Lebensdauer der absetzbaren Gegenstände, der anhand der Bestimmungen des vorliegenden Gesetzes festgelegten Nutzungsdauern und Abschreibungsregimen" ausdrücklich untersagt.

Man könnte bestreiten, ob die Aktivierungspflicht für den Gründungsaufwand, für die F\&EAusgaben, für Computerprogramme, für Patente, Lizenzen und ähnliche unkörperliche Aktiva investitionsfreundlich sei. Im Gesetz findet man auch hier einen augenfälligen Widerspruch: diese als Investitionen eingestuften Ausgabenarten müssen aktiviert werden. Das Gesetz schreibt aber vor, daß ihre Absetzung über maximal 5 Jahre erfolgen soll. Wenn der Staat vermeiden möchte, daß die Unternehmen über überhöhten Abschreibungsaufwand ihre 
Gewinne herabsetzen und somit weniger Steuern zahlen, sollte er eine minimale Absetzungsdauer für derartige Aktiva vorschreiben. Eigentlich geht es dem Staat aber vielmehr darum, seine eigenen Unternehmen zu zwingen, durch Abschreibungen einen Fonds für Ersatzinvestitionen zu bilden (den sog. Entwicklungsfonds), damit der Entkapitalisierung der staatlichen Unternehmen Grenzen gesetzt werden. Der Gesetzgeber hat wahrscheinlich vor Auge die Anstrengungen der "Volkseigentumsbetriebe" gehabt, über minimierten Abschreibungsaufwand höhere Rentabilitäten nachzuweisen, damit die Direktoren und andere höhere Angestellten extra prämiiert werden. Auch in der heutigen Eigentums- und Interessenkonstellation besteht in staatlichen Unternehmen die Gefahr, daß Insiders, anstatt sich um das Überleben des Unternehmens zu kümmern, tief in ihre Substanz über erhöhte Löhne, kompensiert durch niedrige oder gar keine Abschreibungen, eingreifen. Somit werden die Zukunftschancen des Unternehmens natürlich schwer in Frage gestellt; dies geht aber Direktoren, die nur noch 2-4 Jahre bis zur Rente warten müssen, ganz wenig an. Gegen dieses Phänomen der Selbstvernichtung des staatlichen Eigentums werden zahlreiche Bestimmungen dieses neuen Abschreibungsgesetzes gerichtet, die ganz genau angeben, in welchen Ausnahmefällen die staatlichen Unternehmen von den Abschreibungen befreit werden. Hiermit ließ sich ein weniger bekannter Widerspruch des staatlichen Eigentums erkennen, der nur über eine engere Kontrolle der Vertreter des Staates eingehalten werden kann: die Abschreibungen sind ein Recht für die privaten Unternehmer, für die sie eine wichtige Regenerierungs- und Entwicklungsquelle darstellen, aber eine schwere Pflicht für die Angestellten des staatlichen Eigentums, die sie daran hindert, sich beliebig von der wirtschaftlichen Substanz des staatlichen Unternehmens zu bedienen.

Schließlich muß man erkennen, daß die Festlegung neuer Nutzungsdauern, für jede Maschinen- und Anlageart, der Regierung obliegt, nachdem sie sich mit den nationalen Arbeitgeberverbänden beraten hat. Dieser Prozeß hat natürlich noch nicht angefangen - nach dem heutigen Tempo wird es wahrscheinlich noch 2 Jahre dauern, bis die im Gesetz Nr.62/1968 festgelegten Nutzungsdauern entsprechend den Anforderungen einer modernen Marktwirtschaft verkürzt werden. Immerhin dürfen bis dahin die Unternehmen mit (mehrheitlich) privatem Kapital, laut der Vorschriften Nr.3614/26.04.1991 des Finanzministeriums, bei der Berechnung der Abschreibungen die im Gesetz Nr.62/1968 vorgeschriebenen minimalen Nutzungsdauern mit bis zu $40 \%$ verkürzen. Auch darf man nicht vergessen, daß die Unvollständigkeiten des Gesetzes der Regierung genug Spielraum überlassen, so daß sie durch ihrer Verantwortung obliegende Verordnungen - Beschlüsse und Vorschriften - seine positiven Effekte nicht nur lähmen, sondern sogar stornieren kann. Neben der Aufgabe der Festlegung, per Regierungsverordnung, alle 5 Jahre, der zulässigen Nutzungsdauern - hier kann z.B. die Lobby einiger Direktoren von staatlichen Unternehmen, die aus bestimmten Gründen, an kleineren Abschreibungen interessiert werden kann, eine durchaus zerstörende Rolle spielen - sollte man hier auch die Befugnis der Regierung erwähnen, die Multiplikatoren von 1,5, 2 und 2,5 von der degressiven Abschreibungsmethode zu ändern. 


\subsubsection{Das Buchführungsgesetz Nr.82/1991 und das neue Buchführungssystem ab dem 1.01.1994}

Das Buchführungsgesetz ist für die vorliegende Arbeit zu allgemein. Es überläßt alle wichtigen Bestimmungen, die über den Kontenplan und über die entsprechenden Buchungsund Bewertungsverfahren die ausgewiesenen Gewinne, die Steuerzahlungen und den Finanzierungsspielraum beeinflussen könnten, dem Finanzministerium, das somit über eine erhebliche Macht verfügt, den wirtschaftlichen Aufbau zu fördern oder zu behindern. Das Buchführungsgesetz beschränkt sich auf allgemeinen Vorschriften, die nicht selten wegen eben dieser Allgemeinheit überflüssig werden - wie z.B. Artikel 7:

"Die buchhalterische Erfassung der beweglichen und unbeweglichen Güter erfolgt mit dem Anschaffungswert, den Selbsterstellungskosten oder dem Marktwert, je nach dem."

Relevanter für die vorliegende Untersuchung sollten die Eigenschaften des neuen, ab dem 1.01.1994 eingeführten, Buchführungssystems sein (siehe z.B. DRAGAN, 1993). Das alte System war eine wenig geänderte Form seines planwirtschaftlichen Vorgängers, wobei lediglich die Namen der Konten "in die Sprache der Marktwirtschaft" übersetzt waren, ohne aber daß die Verfahren an die neuen Anforderungen angepaßt wurden. Ein Bericht der Weltbank machte 1993 den Staatseigentumsfonds darauf aufmerksam, daß das damalige rumänische Buchführungssystem auf die Erhöhung der Steuereinnahmen und nicht auf die Erleichterung der Firmenentwicklung, oder mindestens auf das zweckmäßige und objektive Wiederspiegeln der wirtschaftlichen Situation der Firma, gerichtet war (LIONACHESCU, 1993). Auf folgende Brennpunkte wurde im Bericht eingegangen:

Die Abschreibungsmethoden waren völlig obsolet, charakteristisch für die Planwirtschaft. Es wurde nur die lineare Abschreibungsmethode zugelassen, daneben waren auch die vom Abschreibungsgesetz Nr.62/1968 festgelegten zulässigen Nutzungsdauern weitgehend überhöht (z.B. bei Gebäuden über 100 Jahre - vgl. mit dem internationalen Durchschnitt: 40 Jahre). Auch berücksichtigt die steuerliche Nutzungsdauer bei Betriebsgebäuden ihren Zusammenhang mit dem Fertigungsprozeß überhaupt nicht).

Gewinnmindernde Rückstellungen (für dubiose Forderungen, für Risiken, für ihrer Höhe nach ungewisse Schulden, für drohende Verluste, für aufgeschobene Reparaturen, usw.) waren im offiziellen Kontenplan nicht vorgesehen und also nicht erlaubt. Da der Staat für die Unternehmen nicht mehr wie früher volle Verantwortung übernimmt, ist es auch logisch daß man ihnen erlaubt, sich gegen Risiken mit marktwirtschaftlichen Mitteln zu wehren. 
Die Bewertung der Vorräte war nur nach der FIFO-Methode erlaubt (das heißt, zu historischen Kosten). Die hohen Inflationsraten bewirkten, daß die Umsätze gegenüber den Anschaffungen überbewertet waren, und die Gewinne dementsprechend künstlich aufgebläht wurden. Dieser Effekt setzte in Industriebranchen mit längeren Kapitalumschlagszeiten stärker ein, und hat die Lage der Großindustrie in der Transitionskrise zusätzlich erschwert. Es ist auch ein Grund, warum sich die Investoren in der Übergangsphase vornehmlich für Handelstätigkeiten und für die Produktion von Gütern des täglichen Verbrauchs entschieden haben.

Im Abschnitt 5.1.6. wurde gezeigt, daß mit der Billigung des neuen Abschreibungsgesetzes das erste o.g. Problem mindestens zum Teil gelöst (bzw. eruiert, was die überhöhten Nutzungsdauern angeht) wurde. Außerdem sieht das neue Buchführungssystem die Benutzung von Rückstellungen vor, deren Gewicht im Geschäftsvolumen der Firma und deren Bildungszweck vom Finanzministerium geregelt werden sollen (was bislang noch nicht geschehen ist). Ihre Bildung mindert den Gewinn, ihre Auflösung erhöht ihn wiederum. Immerhin bedeutet die Möglichkeit der Bildung von Rückstellungen - insoweit sie nicht, nach dem in Rumänien eingebürgten Stil, von dem Finanzministerium direkt durch irgendwelche Vorschriften annuliert bzw. stark eingeschränkt wird - ein nicht zu vernachlässigender Liquiditätsvorteil. Dem dritten Problem wurde eine international übliche Lösung gegeben, indem das LIFO (Last In First Out) Bewertungsverfahren erlaubt wurde. So werden die Anschaffungen zu neueren (sprich: höheren) Preisen bewertet, den nominellen Gewinn mindernd und dadurch die Folgen der Inflation mildernd.

Zur Finanzierung von Investitionen sind die Unternehmen buchführungsmäßig verpflichtet, den sogenannten Entwicklungsfonds einzurichten. Seine Bildungsquellen sind: die Abschreibungen, die einbehaltenen Nettogewinne, die Verkaufserlöse von eigenen sachlichen Aktiva, Verschrottungserlöse, sowie der Steuerabzug für die im vorigen Jahr vorgenommenen Investitionen. Aus dem Entwicklungsfonds können sämtliche Arten von Investitionen finanziert werden, einschließlich der Beteiligungen an andere Unternehmen oder F\&EInvestitionen. Genauso wie in den westlichen Industrieländern werden die Differenzen zwischen Veräußerungswert und Buchwert bei gebrauchten sachlichen Aktiva als Einkommen eingestuft und dementsprechend besteuert, bevor sie in den Entwicklungsfonds eingeschüttet werden. Dies gilt auch für Wertpapiere, deren Kursgewinne auch besteuert werden sollen. Im Prinzip ist es ja auch richtig so, damit die Spekulationen nicht von der Besteuerung befreit bleiben. Nur unter inflationären Bedingungen, wie es in Rumänien der Fall ist, werden dadurch, wenn kurz zuvor keine Wieder(auf)bewertung der entsprechenden Aktiva stattgefunden hat, inflationäre Scheingewinne besteuert.

Ein anderes - sehr ernstes - Problem, das das neue Buchführungssystem prinzipiell genauso wenig wie das alte gelöst hat, ist die Besteuerung der Kursgewinne bei Devisenbeständen. 
Soll z.B. eine Firma auf ein unverzinsliches Girokonto am 1.01.1991 100.000 US-\$ eingelegt haben, als der Wechselkurs zu 35 Lei für ein Dollar war, würden seine Devisenbestände im Dezember wegen der stetigen Abwertung der rumänischen Währung nunmehr 18.000.000 Lei gleich sein. Der vom Buchführungssystem ausgewiesene Scheingewinn von 14,5 Mio.Lei wird demzufolge mit $45 \%$ besteuert, was schließlich ein Substanzverzehr von 6.375.000 Lei (zum Wert vom Dezember 1991) für die Firma bedeutet. Dieser Tatbestand bringt eine sehr ernste Einschränkung der Ersparnis - und also des Eigenfinanzierungsspielraumes - mit sich, ganz zu schweigen von dem schwerwiegenden Eingriff in die Substanz der Unternehmen. Die Beschwerden der Unternehmen wurden zum ersten Mal Ende 1993 vom Finanzministerium in Betracht gezogen (bis dahin wurden die Bilanzen ohne Rücksicht auf das geschilderte Phänomen geschlossen, was in beträchtlichem Maße zur Entkapitalisierung der rumänischen Unternehmen beigetragen hat), und es wurde den Unternehmen erlaubt, ausnahmsweise, die Wechselkursgewinne direkt in den Reservefonds umzubuchen, ohne sie als "Finanzeinkommen" auszuweisen.

Ein ähnliches Problem stellte sich schon im Frühjahr 1991, nach den ersten zwei Stufen der Preisfreigabe, für die Abschreibungen der Sachkapitalbestände. Da die Abschreibungen zum Anschaffungswert angesichts des inflationären Prozesses in kurzer Zeit zu klein geworden sind und zur Besteuerung von inflationsbedingten Scheingewinnen geführt hätten, sorgte das Finanzministerium etwa jedes Jahr für eine neue Wiederbewertung des Sachkapitals in staatlichen Unternehmen (den privaten Unternehmen wurden diese Wiederbewertungen empfohlen, jedoch nicht erzwungen). HENDERSHOTT und CHENG-FU (1981, S.97) zeigen, daß im Fall der Inflation, die planmäßige Abschreibung beim nicht-aktualisierten Anschaffungswert zu einem Überhang der wirtschaftlich sinnvollen gegenüber der steuerlich erlaubten Abschreibung führt, mit dem Ergebnis, einer höheren Steuerbelastung, die an der Steigerung der Kapitalbereitstellungskosten erkannt werden kann (weil sich die Ersatzinvestitionen im Schritt mit der Inflation verteuern, ohne von entsprechenden Abschreibungssummen gedeckt zu werden - siehe auch FRANZEN, MEYER \& ZIEMER, 1973, S.20-24). Auch WAGNER (1978, S.223-236) benutzt ein an das Prinzip der Quellenerhaltung gebundenes Modell, um den Eingriff in die wirtschaftliche Substanz des Unternehmens in solchen Fällen zu veranschaulichen.

Bei den Wiederaufwertungen (Aktualisierungen heißen sie im rumänischen buchhalterischen Sprachgebrauch) wurden die Aufwertungsdifferenzen bei abschreibungsfähigem Vermögen in den Reservefonds eingeschüttet, ohne den Gewinn zu berühren, während die Aufwertungsdifferenzen bei Finanzanlagen und Grundstücken zur Erhöhung des Eigenkapitals der Unternehmen herangezogen wurden (ebenfalls gewinneutral). (siehe hierzu RISTEA, 1993, und auch die Vorschriften Nr.2324/27.01.1993 des Finanzministeriums angesichts der buchhalterischen Eintragung der Wiederbewertungen des Firmenvermögens). 
Die beiden letzten Probleme beziehen sich auf Buchführungs- und Bilanzierungsregeln, die die Substanzerhaltung des Unternehmens im inflationären Umfeld ermöglichen sollten. Es gibt in der internationalen Praxis -in lateinamerikanischen Ländern mit hohen Inflationsraten oder etwa in westeuropäischen internationalen Konzernen, die Töchtern in solchen Ländern haben verschiedene Systeme, die den Einfluß der Inflation auf die Substanzerhaltung abblenden: die Methode der realen Kapitalerhaltung ("Current Purchase Power Accounting"), der absoluten Substanzerhaltung ("Current Cost Accounting") und der Nettosubstanzerhaltung (siehe hierzu auch BECKER, 1992, S.548). Die (allerdings mit Verzögerungen) von der Regierung angeordneten Maßnahmen zur Anpassung der Buchwerten unterschiedlicher Aktiva an die inflationäre Preisentwicklung sind zweifelsohne mit den Prinzipien der substanziellen Kapitalerhaltung konform; nur fragt man sich warum ihre Anwendung stets von periodischen Entscheidungen der Regierung abhängt, anstatt institutionalisiert zu werden, wenigstens in der Form einer Wahlmöglichkeit. Im Fall der Inflation sind sie sowieso notwendig, während ihre Anwendung in Zeiten der Geldwertstabilität auf die Steuerschuld keinen Einfluß hat.

\subsection{Wirkungen auf die Rentabilität und somit auf die Investitionsbereitschaft}

\subsubsection{Festlegung der mathematischen Form des Modells entsprechend dem steuerlichen Rahmen in Rumänien}

Da bei der Berechnung der Kapitalbereitstellungskosten eine wichtige Zahl von steuerlichen Parametern miteinbezogen wird, und weil, was wichtiger ist, die Kapitalbereitstellungskosten ein Schlüsselsignal für Investitionsentscheidungen sind, sind sie als Indikator für die relativen Investitionsanreize zwischen verschiedenen Ländern mehr geeignet, als ein einziger Steuerparameter, wie z.B. der nominelle Körperschaftssteuersatz.

Im folgenden werden, anhand des im Paragraphen 3.5. - "Die neoklassische Investitionstheorie" - dargelegten mathematischen Modells, die entsprechenden Formeln für unterschiedliche mögliche Arten von Kapitalinvestitionen festgelegt, unter Berücksichtigung der Bestimmungen der rumänischen fiskalischen Gesetzgebung, die im Paragraphen 5.1. vorgestellt wurden.

Im neoklassischen Modell besitzt Formel 3.19 den höchsten Grad an Allgemeinheit: 


$$
c=q\left(r+d-\frac{q^{\prime}}{q}\right)(1-k-u z)(1-u)^{-1}(3.19)
$$

$\begin{array}{lll}\text { wobei: } & -\mathrm{q}= & \text { Preis der Kapitalgüter; } \\ -\mathrm{r}= & \text { Kalkulationszinssatz; } \\ -\mathrm{d}= & \text { "ökonomischer" Abschreibungssatz; } \\ -\mathrm{q} / \mathrm{q}= & \text { Preissteigerungsrate der Kapitalgüter; } \\ -\mathrm{k}= & \text { Prozentsatz des Steuerabzugs für Investitionen; } \\ -\mathrm{u}= & \text { Gewinnsteuersatz; } \\ -\mathrm{z}= & \text { Barwert der steuerlich zugelassenen Abschreibungen. }\end{array}$

Angenommen, der Preis der Kapitalgüter sei gleich eins, würden die Kapitalbereitstellungskosten in Prozentpunkten ausgedrückt werden.

Der einzusetzende Zinssatz " $r$ " ist normalerweise von der Höhe der verschiedenen Steuern abhängig, da in dieser Formel lediglich der Nettozinssatz zu berücksichtigen ist. Der Grenzertrag einer Kapitaleinheit, gleich den Kapitalbereitstellungskosten, muß nämlich neben Kapitalabnutzung und steuerlicher Belastung - den Nettozinssatz, verstanden als die noch ausreichende Mindestrentabilität für den Kapitalgeber, im Grenzfall decken. Bezeichnet "i" den nominellen Bruttozinssatz, der bei den jeweiligen Finanzierungsarten zu berücksichtigen ist, dann ist:

Fall 1: Kreditfinanzierung:

$$
r=i(1-u)(\text { Forme15.1) }
$$

Fall 2: $\quad$ Finanzierung über einbehaltene Gewinne:

$$
r=i(1-m)(5.2)
$$

wobei "m" im rumänischen Steuersystem, wo es keine Einkommensteuer gibt, dem Satz der Dividendensteuer von $10 \%$ entspricht, der die Alternative der Gewinnausschüttung belasten würde;

Fall 3: Finanzierung über Aktienemission und anschließend Vollausschüttung der Dividenden: 


$$
r=i \frac{1-m_{1}}{u^{*}}(5 \cdot 3)
$$

wobei: $\quad$ a) $m_{1}=0$ in Rumänien, wo es keine Besteuerung von Zinsen gibt;

b)

$$
u^{*}=\frac{1-m^{*}}{1-u}(5.4)
$$

ist der ausschüttungsbedingte Steuerfaktor. Wiederum werden, da es in Rumänien keine Einkommensteuer gibt, die ausgeschütteten Gewinne zuerst mit dem üblichen Gewinnsteuersatz ( $u=45 \%$ ) belastet und dann, bei der Ausschüttung, mit weiteren $10 \%$. Es ist als ob die Dividenden beim Dividendenbezieher voll angerechnet würden, wobei sein marginaler Einkommensteuersatz mit $10 \%$ höher als der Gewinnsteuersatz wäre. Also:

$$
m^{*}=(1008+108) u=1,1 \cdot 458=49,58(5.5)
$$

Eine kurze Analyse der Anlagemöglichkeiten, die einem rumänischen Investor - bzw. einem ausländischen Investor in Rumänien - Ende 1993 zur Verfügung stehen, ergibt folgendes:

- $\quad$ es gibt keine Wertpapierbörse, kann also nicht von Aktienkursen und durchschnittlichen, befriedigenden Dividenden gesprochen werden;

- die staatlichen festverzinslichen Wertpapiere (staatliche Obligationen) bieten einen eher unattraktiven Zins an - 85\%;

- dagegen bieten die Geschäftsbanken viel günstigere Zinsen. Die sechs wichtigsten rumänischen Geschäftsbanken (Rumänische Handelsbank, Rumänische Entwicklungsbank, Bank Dacia Felix, Bank der Landwirtschaft, Postbank und Creditbank) bieten im Durchschnitt für 1 Jahr-Termineinlagen 138,33\% für physische Personen, und $116,27 \%$ für juristische Personen an;

die Kreditaufnahme ist teurer - der Zins liegt im Durchschnitt bei etwa $157 \%$ für 1 Jahr-Kredite.

Falls die Finanzierung einer Investition über Kreditaufnahme erfolgt, gleichgültig ob die Firma staatlich oder privat ist, muß der Bruttozinssatz " $\mathrm{i}$ " gleich dem durchschnittlichen Zins für Jahresanleihen sein, den die Bank auch anderswo erzielen könnte. Also:

$$
r=i(1-u)=157 \%(1-45 \%)=86,35 \%
$$


Falls eine Firma die einbehaltenen Gewinne zur Finanzierung heranzieht, dann ist durch den Bruttozinssatz "i" der durchschnittliche Zins zu verstehen, der für 1 Jahr-Einlagen zu bekommen ist. Die sicherste - und, vom Zins her, ergiebigste - Alternative, die der Eigentümer des Unternehmens zur geplanten Investition haben, ist nämlich die Termineinlage. Der Dividendensteuersatz " $\mathrm{m}$ " von $10 \%$ gilt sowohl für die privaten Unternehmen (deren Besitzer private Personen sind und keiner Einkommensteuer unterliegen), als auch für die staatlichen Unternehmen, deren Besitzer - die Eigentumsfonds, rumänischer Pendant zur ostdeutschen Treuhand - auch von der Gewinnsteuer befreit sind.

Nur der Bruttozinssatz " $\mathrm{i}$ " ist unterschiedlich zwischen privaten Unternehmen (deren Teilhaber die Alternative des Bruttozinses für Termineinlagen für physische Personen ( $\mathrm{i}=$ $138,33 \%$ ) haben) und staatlichen Unternehmen (die Eigentumsfonds kriegen, für Termineinlagen, nur den Zins für juristische Personen, $\mathrm{i}=116,27 \%)$. Ergo:

- für private Unternehmen:

$$
\mathrm{r}=\mathrm{i}(1-\mathrm{m})=138,33 \%(1-10 \%)=124,5 \%
$$

- für staatliche Unternehmen:

$$
r=i(1-m)=116,27 \%(1-10 \%)=104,64 \%
$$

Im letzten Fall, wo die Investition über Aktienemission finanziert wird, gelten wiederum zwei rechnerische Bruttozinsen, je nachdem ob die Aktien an private Einleger verkauft werden (mit $\mathrm{i}=138,33 \%$ ) oder die Kapitalerhöhung von den Eigentumsfonds finanziert wird (dann gilt wieder $\mathrm{i}=116,27 \%)$. Also:

- mit privatem Verkauf der Aktien:

$$
r=i \frac{1-m_{1}}{u^{*}}=138,338 \frac{1-0}{\frac{1-49,58}{1-458}}=150,668
$$

- durch Beteiligung der Eigentumsfonds:

$$
r=i \frac{1-m_{1}}{u^{*}}=116,27 \frac{1-0}{\frac{1-49,5 \%}{1-458}}=126,63 \%
$$

Im Fall der Verschachtelung der Gesellschaften würde für eine einfache Beteiligung $m_{1}=$ $\mathrm{u}=45 \%$ sein; dann, würde die Dividendenbesteuerung desto stärker ausfallen, je tiefer die Verschachtelung, weil die von einer Muttergesellschaft von der Tochter eingenommenen Dividenden in der rumänischen Buchführung als "Finanzeinkommen" eingestuft werden und, 
ohne jegliche Anrechnung der von der Tochter schon bezahlten Gewinnsteuer, den Gewinn der Muttergesellschaft erhöhen. Da aber das Phänomen der Verschachtelung der Kapitalgesellschaften in der rumänischen Volkswirtschaft kein nennenswertes Ausmaß erreicht hat, wird im folgenden von diesem Fall abgesehen.

Die übrigen Variablen in Formel 3.19 sind teilweise bekannt (der Steuerabzug für Investitionen $\mathrm{k}=50 \%$; der Gewinnsteuersatz $\mathrm{u}=45 \%$ ) oder werden in den folgenden Abschnitten in bezug auf die rumänische Textil- und Bekleidungsindustrie berechnet.

\subsubsection{Schätzung der ökonomischen Abschreibungen in der rumänischen TBI}

Die "richtigen" - ökonomischen - Abschreibungen sind, gemäß COEN (1975), diejenigen, auf die das Neu- und Ersatzinvestitionsverhalten der Firmen deutet.

Demzufolge könnte man die tatsächlichen Ersatzkapitalinvestitionen (eventuell getrennt in Maschinen und Strukturen) über eine ausreichend lange Zeitspanne in Werteinheiten ausdrücken, und ihr Verhältnis zu dem (nach den gleichen Regeln) bewerteten volkswirtschaftlichen Anlagevermögens jedes Jahr als "ökonomischen" Abschreibungssatz bezeichnen. Diese Berechnung könnte je nach Bedarf, für die ganze Industrie oder für einzige Branchen davon gemacht werden.

Nun ist es natürlich schwer, wie es der Artikel von COEN auch zeigt, zwischen Neu- und Ersatzinvestitionen deutlich zu unterscheiden.

Eine weitere Schwierigkeit besteht darin, daß es in Rumänien keine statistischen Investitionsreihen gibt, die für einen solchen Zweck aussagekräftig genug wären. Die statistischen Angaben, die sich auf die Zeit vor 1990 beziehen, sind für eine solche Art von Analyse unbrauchbar, da die Neu- und Ersatzinvestitionen, die sie erfassen, nicht von den Unternehmen selbst im Zuge ihrer Anpassung an die veränderten - marktwirtschaftlichen Rahmenbedingungen entschieden wurden, sondern von den politisch motivierten Planbehörden; diese Zahlen spiegeln also kein marktgerechtes Investitionsverhalten der betroffenen Unternehmen wider.

BOADWAY (1980) geht davon aus, daß die Ersatzinvestitionen in der neoklassischen Investitionstheorie überwiegend als einen Bruchteil des bestehenden Kapitalstocks angenommen worden seien:

$$
\mathrm{EI}=\mathrm{d} * \mathrm{~K}(\mathrm{t}) \text {, }
$$

wobei der Prozentsatz $d$ von der ökonomischen Nutzungsdauer abhängt (EI = Ersatzinvestitionen; $K(t)=$ der in Betracht gezogene Kapitalstock). Auch die Übertragung dieser 
Hypothese auf die rumänische Industrie stößt auf wichtige Schwierigkeiten. Sie entspricht einem marktgerechten Verhalten der Unternehmen, die darum besorgt sind, daß wegen Überalterung und Verschleiß ihrer Produktionsanlagen, ihre Erzeugnisse keine Qualitätseinbußen und ihre physische Produktivität keine Senkung hinnehmen müssen. Wie schon gezeigt, waren die rumänischen Planbehörden kurzsichtig genug, um eine solche Politik nicht zu verfolgen. Ein Bruchteil - gemäß einer nach modernen Kriterien berechneten ökonomischen Nutzungsdauer - von dem Restwert des heutigen Anlagevermögens der TBI würde eigentlich ein Bruchteil von ganz wenig bedeuten. Tatsächlich würde man feststellen, daß bei nach Kriterien der internationalen Wettbewerbsfähigkeit verkürzten ökonomischen Nutzungsdauern zwischen $60 \%$ und, in manchen Produktbereichen, sogar 98\% der Maschinen und Anlagen schon ausgelaufen sind und so schnell wie möglich physisch ersetzt werden müssen. Dies gilt teilweise sogar dann, wenn man die heutigen, hohen steuerlich zulässigen Nutzungsdauern anwendet (siehe Tabelle 2.28). Die nach der Regel von der Formel 5.6. hypothetisch vorgenommenen Ersatzinvestitionen könnten lediglich den Fortbestand eines kleinen Teiles der heutigen Produktionskapazität sichern. Angenommen - wie es Kapitel 2 vermuten läßt die rumänische TBI habe eine gute Marktlage und etwa günstigere Angebotsbedingungen, dann sollte sie sich um die Erhaltung ihrer ursprünglich geplanten Produktionskapazität kümmern.

Ein weiteres Argument, das dafür spricht, daß in der rumänischen Industrie die ökonomischen (sprich: ökonomisch vernünftigen) Abschreibungen viel höher liegen, als das bisherige Ersatzinvestitionsverhalten der rumänischen Unternehmen es vermuten läßt, ist daß die alten Maschinen und Anlagen in ihren letzten Lebensjahren schneller verschleißen. Dementsprechend sollte ein älterer Kapitalstock höhere ökonomische Abschreibungen hervorrufen.

Im folgenden wird unter "ökonomischen" Abschreibungen der Abschreibungsaufwand verstanden, der den Ersatz der heute bestehenden Produktionsanlagen der TBI durch Maschinen des gleichen Typs, also ohne Modernisierung und ohne Kapazitätserweiterung, bis zu einem Kapitalgütegrad von 0,5 finanzmäßig decken würde. Bei der Berechnung des Kapitalgütegrads sollte die ökonomische Nutzungsdauer der Länder mit einer erfolgreichen Textil- und Bekleidungsindustrie verwendet werden, im Gegensatz zu der überhöhten, von den rumänischen Planbehörden festgelegten Nutzungsdauer. Die in der rumänischen TBI lange Zeit versäumten Ersatzinvestitionen stellen zusammen mit den künftig zu tätigenden Abschreibungen die für diese Arbeit relevanten ökonomischen Abschreibungen als Teil der Kapitalbereitstellungskosten dar. Die Ersatzinvestitionen, die in der Zukunft getätigt werden sollen, sind in Prozent ausgedruckt und auf einen angemessenen Zeithorizont verteilt. Dagegen sind die potentiellen Investitionen für Modernisierung und Kapazitätserweiterung nicht durch die ökonomischen Abschreibungen gedeckt. 
In der Berechnung der ökonomischen Abschreibungen für die rumänische TBI wurde von den Angaben des Instituts für Leichtindustrie Bukarest ausgegangen. Eine Synthese davon ist in Tabelle 2.28 angegeben. Dort wird die Einteilung der Maschinen und Anlagen der rumänischen TBI nach Altersgruppen (zwischen 10 und 20 Jahre, über 20 Jahre) angezeigt. In jeder Altersgruppe wurde für jeden Anlagentyp eine gleichmäßige Distribution des Alters der Anlagen in Jahren unterstellt. Jeder Anlageart wurde dann eine bestimmte ökonomische Nutzungsdauer beigemessen, die aus der Verkürzung der vom Gesetz Nr.62/1968 zugelassenen Nutzungsdauern um $40 \%$ (gemäß der Vorschriften des Finanzministeriums Nr.3614/26.04.1991, die den Unternehmen mit privatem Kapital diese Möglichkeit einräumen) entstanden ist. Dabei wurde angenommen, daß die Schätzungen des Finanzministeriums der Realität entsprechen, wonach die im Gesetz Nr.62/1968 festgelegten Nutzungsdauern um $40 \%$ reduziert werden sollten, um sie den international üblichen anzunähern. Man könnte davon ausgehen, daß diese neuen Nutzungsdauern ökonomisch "richtig" sind, obwohl den staatlichen Unternehmen die steuerliche Anwendung noch nicht gestattet ist.

Es wurde dann für jeden Typ von Anlagen ermittelt, wieviele von den bestehenden Anlagen die ökonomisch richtige Nutzungsdauer überschritten haben. Damit erhielt man den Prozentsatz, der innerhalb der nächsten 5 Jahre - ein angemessener Zeithorizont für die Alterssanierung der TBI - ersetzt werden müsste. Zugleich wurde für jede Art von Anlagen und Maschinen eine jährliche ökonomische laufende Abschreibungsquote berechnet, die sich aus der neuen Nutzungsdauer ergibt, nach der Hypothese der linearen Abnutzung, nach der Formel:

$$
\mathrm{LAQ}=1 / \mathrm{n}
$$

wobei: $\quad-$ LAQ $=\quad$ laufende Abschreibungsquote (die sich ergeben hätte, falls kein Nachholbedarf in der Altersdistribution des Anlagevermögens bestünde)

- $\mathrm{n}=\quad$ die ökonomische Nutzungsdauer der Maschinen und Anlagen des betroffenen Typs.

Schließlich wurden die verschiedenen Typen von Maschinen und Anlagen gemäß ihrer Vertretung im Anlagevermögen der TBI gewichtet und ein abgewogener Durchschnitt von den zu ersetzenden Prozentsätzen, sowie von den laufenden Abschreibungsquoten kalkuliert. Die Endformel lautet:

$$
d=\frac{P q}{5}+L A Q(5.8)
$$


wobei: $\quad-d=\quad$ der ökonomische Abschreibungssatz;

- P\% = der innerhalb der nächsten 5 Jahre zu ersetzende Prozentsatz des Anlagevermögens der betroffenen Branche;

- LAQ $=$ die durchschnittliche laufende Abschreibungsquote.

Die Ergebnisse dieser Berechnungen sind in Tabelle 5.1 zusammengestellt.

Tabelle 5.1: Ökonomische Abschreibungen in der TBI, berechnet nach der Altersdistribution des Anlagevermögens Ende 1990.

\begin{tabular}{|l||c|c|c||}
\hline & Textil & Bekleidung & Leder \\
\hline \hline $\begin{array}{l}\text { Zu ersetzender Prozentsatz des } \\
\text { Anlagevermögens (innerhalb } \\
\text { der nächsten 5 Jahre) }\end{array}$ & $70,76 \%$ & $74,66 \%$ & $76,70 \%$ \\
\hline $\begin{array}{l}\text { Jährliche laufende Abschrei- } \\
\text { bungsquote }\end{array}$ & $9,12 \%$ & $15,625 \%$ & $10,26 \%$ \\
\hline $\begin{array}{l}\text { Okonomischer Abschreibungs- } \\
\text { satz d }\end{array}$ & $23,27 \%$ & $30,56 \%$ & $25,60 \%$ \\
\hline
\end{tabular}

(Quelle: eigene Berechnungen nach den Angaben des Instituts für Leichtindustrie Bukarest)

Die ermittelten Werte sollen in der Berechnung der Kapitalbereitstellungskosten, je nach Branche der TBI, verwendet werden.

\subsubsection{Berechnung des Barwerts der steuerlich zugelassenen Abschreibungen}

Hierbei muß zwischen privaten und staatlichen Unternehmen unterschieden werden. Ersteren ist es gestattet, die Nutzungsdauer, die sich aus den seit 1968 immer noch geltenden AfATabellen (Gesetz Nr.62/1968) ergibt, um 40\% zu verkürzen. Letzteren wird diese Möglichkeit nicht eingeräumt. Sie müssen die alten AfA-Tabellen verwenden, bis die Regierung, die von Vertretern der Arbeitgeberverbände beraten wird, neue AfA-Tabellen entsprechend dem neuen Abschreibungsgesetz erstellt. Man kann sichergehen daß bis dahin weitere 2 Jahre vergehen werden wenn man die Geschwindigkeit kennt, mit der die Regierung VACAROIU ihren Verpflichtungen nachkommt.

Bei der Berechnung des Barwerts der steuerlich zulässigen Abschreibungen - " $\mathrm{z}$ " in der Formel 3.19 - muß man also für jede Branche der TBI eine durchschnittliche Nutzungsdauer berechnen, gemäß der Gewichtung der unterschiedlichen Typen von Maschinen und Anlagen und der existierenden AfA-Tabellen. Diese Nutzungsdauer wird dann für die privaten Unternehmen um $40 \%$ herabgesetzt (hier wurde vereinfachend unterstellt, die Privatisierung wäre 
in den drei Branchen der TBI gleichmäßig durchgeführt worden). Der Barwert " $z$ " wird nun für jede Branche - Textil-, Bekleidungs- und Lederindustrie - entsprechend der ermittelten Nutzungsdauer und den Bestimmungen des neuen Abschreibungsgesetzes (Abschnitt 5.1.6) nach dem nunmehr erlaubten degressiven Verfahren berechnet.

Ein besonderes Problem wirft dabei der angenommene Wert des Nettozinssatzes - " $r$ " - auf, der auch in die Berechnung des Barwerts der steuerlich zulässigen Abschreibungen einzusetzen ist. Verschiedene Nettozinssätze haben sich im Abschnitt 5.2.1. in unterschiedlichen Finanzierungsfällen ergeben. Ihnen wird auch im folgenden Rechnung getragen. Tabellen 5.2 bis 5.7 geben die unter den o.a. Bedingungen berechneten Werte von " $\mathrm{z}$ " an.

Tabelle 5.2: Textilindustrie - private Unternehmen

\begin{tabular}{||l||c|c|c|c|c||}
\hline \hline Finanzierungsfall & $\mathrm{n}$ Jahre & $\mathrm{k}$ & $\mathrm{d}^{*}$ & $\mathrm{r}$ & $\mathrm{z}$ \\
\hline \hline Kredit & 11,28 & 2,5 & $22,15 \%$ & $86,35 \%$ & $38 \%$ \\
\hline Einbehaltene Gewinne & 11,28 & 2,5 & $22,15 \%$ & $124,5 \%$ & $34 \%$ \\
\hline Aktienemission & 11,28 & 2,5 & $22,15 \%$ & $150,7 \%$ & $32 \%$ \\
\hline
\end{tabular}

Tabelle 5.3: Textilindustrie - staatliche Unternehmen

\begin{tabular}{||l|c|c|c|c|c||}
\hline \hline Finanzierungsfall & n Jahre & $\mathrm{k}$ & $\mathrm{d}^{*}$ & $\mathrm{r}$ & $\mathrm{z}$ \\
\hline \hline Kredit & 18,8 & 2,5 & $13,3 \%$ & $86,35 \%$ & $25 \%$ \\
\hline Einbehaltene Gewinne & 18,8 & 2,5 & $13,3 \%$ & $104,6 \%$ & $23 \%$ \\
\hline Aktienemission & 18,8 & 2,5 & $13,3 \%$ & $126,6 \%$ & $22,5 \%$ \\
\hline
\end{tabular}

Tabelle 5.4: Bekleidungsindustrie - private Unternehmen

\begin{tabular}{||l|c|c|c|c|c||}
\hline Finanzierungsfall & $\begin{array}{c}\mathrm{n} \\
\text { Jahre }\end{array}$ & $\mathrm{k}$ & $\mathrm{d}^{*}$ & $\mathrm{r}$ & $\mathrm{z}$ \\
\hline \hline Kredit & 6,4 & 2 & $31,25 \%$ & $86,35 \%$ & $49,6 \%$ \\
\hline Einbehaltene Gewinne & 6,4 & 2 & $31,25 \%$ & $124,5 \%$ & $45,1 \%$ \\
\hline Aktienemission & 6,4 & 2 & $31,25 \%$ & $150,7 \%$ & $43,1 \%$ \\
\hline
\end{tabular}


Tabelle 5.5: Bekleidungsindustrie - staatliche Unternehmen

\begin{tabular}{||l|c|c|c|c|c||}
\hline \hline Finanzierungsfall & $\begin{array}{c}\mathrm{n} \\
\text { Jahre }\end{array}$ & $\mathrm{k}$ & $\mathrm{d}^{*}$ & $\mathrm{r}$ & $\mathrm{z}$ \\
\hline \hline Kredit & 10,67 & 2,5 & $23,43 \%$ & $86,35 \%$ & $39,8 \%$ \\
\hline Einbehaltene Gewinne & 10,67 & 2,5 & $23,43 \%$ & $104,6 \%$ & $37,4 \%$ \\
\hline Aktienemission & 10,67 & 2,5 & $23,43 \%$ & $126,6 \%$ & $35,4 \%$ \\
\hline
\end{tabular}

Tabelle 5.6: Lederindustrie - private Unternehmen

\begin{tabular}{||l||c|c|c|c|c||}
\hline \hline Finanzierungsfall & $\begin{array}{c}\mathrm{n} \\
\text { Jahre }\end{array}$ & $\mathrm{k}$ & $\mathrm{d}^{*}$ & $\mathrm{r}$ & $\mathrm{z}$ \\
\hline \hline Kredit & 10,08 & 2,5 & $24,8 \%$ & $86,35 \%$ & $41,6 \%$ \\
\hline Einbehaltene Gewinne & 10,08 & 2,5 & $24,8 \%$ & $124,5 \%$ & $37,3 \%$ \\
\hline Aktienemission & 10,08 & 2,5 & $24,8 \%$ & $150,7 \%$ & $35,4 \%$ \\
\hline
\end{tabular}

Tabelle 5.7: Lederindustrie - staatliche Unternehmen

\begin{tabular}{||l||c|c|c|c|c||}
\hline \hline Finanzierungsfall & $\begin{array}{c}\mathrm{n} \\
\text { Jahre }\end{array}$ & $\mathrm{k}$ & $\mathrm{d}^{*}$ & $\mathrm{r}$ & $\mathrm{z}$ \\
\hline \hline Kredit & 16,79 & 2,5 & $14,89 \%$ & $86,35 \%$ & $27,4 \%$ \\
\hline Einbehaltene Gewinne & 16,79 & 2,5 & $14,89 \%$ & $104,6 \%$ & $25,5 \%$ \\
\hline Aktienemission & 16,79 & 2,5 & $14,89 \%$ & $126,6 \%$ & $23,8 \%$ \\
\hline
\end{tabular}

Erklärung: Mit dem Degressionskoeffizient " $k$ " wird gemäß dem neuen Abschreibungsgesetz die jährliche lineare Abschreibungsquote $1 / \mathrm{n}$ multipliziert, um den degressiven $\mathrm{Ab}$ schreibungssatz $d^{*}$ zu erhalten. Demnach werden im ersten Jahr steuerlich $d^{*}(\%)$ des Anschaffungswertes abgesetzt, $d^{*}(\%)$ vom Restwert im zweiten Jahr u.s. w.. Im letzten Jahr nach der gesetzlichen Nutzungsdauer -wird der Restwert abgesetzt, ohne die Möglichkeit des Übergangs zu einer anderen Abschreibungsmethode beim selben Objekt zu haben. 


\subsubsection{Berechnung der Preissteigerungsrate der TBI-spezifischen Maschinen und Anlagen}

Die bislang neuesten Angaben über die Preisentwicklung unterschiedlicher Produktionsbranchen, die von dem rumänischen Nationalen Statistischen Ausschuß veröffentlicht wurden, beziehen sich auf das Jahr 1992. Das ganze rumänische System der Beschaffung von statistischen Bruttoangaben sowie ihre Verarbeitung und Veröffentlichung ist nach planwirtschaftlichen Kriterien organisiert und entspricht den Anforderungen einer modernen Volkswirtschaft nicht mehr. Die erheblichen Verzögerungen (das statistische Vierteljahresheft Nr.3/1993 ist erst im März 1994 erschienen, und das statistische Jahrbuch Rumäniens 1994 mit Angaben für 1993 - wird gewöhnlich vor Oktober 1994 nicht veröffentlicht werden), mit denen die Informationen verwertet und veröffentlicht werden, sind eine Folge dieses Tatbestandes.

Im Jahr 1992 sind die Preise der Maschinen und Anlagen für die Textil-, Bekleidungs- und Lederindustrie 2,348 mal, also um 134,8\%, gestiegen (Quelle: Rumänien - Laufende statistische Informationen, Nr. 1/1993, S.7). Diese Zahl darf aber nur mit angemessener Vorsicht angewendet werden. Erstens ist für die Investoren, die Ende 1993 oder Anfang 1994 schätzen wollen, wie hoch die Renditen ihrer Investitionsobjekte im Jahr 1994 liegen müssen, damit sie wenigstens die Kapitalbereitstellungskosten decken, nicht unbedingt die Preisentwicklung im vorigen Jahr von Bedeutung, sondern die Inflationsrate, die sie für das kommende, bzw. laufende Jahr vorausschätzen. Die erwartete Inflationsrate hängt nicht nur von subjektiven Urteilen des Investors, sondern auch von wirtschaftspolitischen Variablen ab wie z.B. den Leitzinsen der Zentralbank oder der Lohnpolitik - die sich in einer Transitionswirtschaft sehr schnell ändern können. Im folgenden wird angenommen, die Investoren würden sich mangels aktuellerer Informationen am Preisindex von 1992 orientieren.

Zweitens sollten die Maschinen- und Anlageinvestitionen vornehmlich in Importen bestehen, da die rumänische TBI-Maschinenindustrie verständlicherweise in Qualität und Umfang nur einen begrenzten Teil des Modernisierungsbedarfs der TBI decken kann. Dabei sind für den Investor nicht mehr die Entwicklung der Preise der rumänischen Maschinen und Anlagen wichtig, sondern die Indizes ihrer Weltmarktpreise in Zusammenhang mit der Abwertungsrate der rumänischen Währung. Der Jahresindex der in Lei umgerechneten internationalen Preise der TBI-spezifischen Maschinen und Anlagen dürfte von dem Index der internen Preise abweichen.

Was die externen Angebotspreise - in freien Devisen - der TBI-Maschinen und Anlagen betrifft, kann man für diesen begrenzten Zeitraum vereinfachend von Preisstabilität ausgehen. Dagegen ist der Kurs des US-\$, in Lei ausgedrückt, heftig gesprungen. Während er im Dezember 1991 bei 180 Lei lag, betrug er ein Jahr später bereits 600 Lei. Bis Dezember 
1993 kletterte er auf 1250 Lei. Die Abwertungsrate der rumänischen Währung betrug also 1992 durchschnittlich 233,3\% und 1993 108,3\%. Angesichts der im Kapitel 1 geschilderten Gegebenheiten der rumänischen Geldpolitik, aber auch der jüngsten positiven Ergebnisse mit der Vereinheitlichung des Schwarzmarkts- mit dem offiziellen Dollarkurs, wird man 1994 keine höhere Abwertung erwarten als 1993.

Geht man, gemäß der Schätzung des Instituts für Leichtindustrie - in derselben, unveröffentlichten Untersuchung, die bereits im Kapitel 2 erwähnt wurde - davon aus, daß der Ersatz- und Modernisierungsbedarf des Textilzweiges zu etwa einem Viertel von der rumänischen Maschinenindustrie gedeckt werden kann, dann sollte die branchendurchschnittlich erwartete Preissteigerungsrate bei textilspezifischen Maschinen und Anlagen nach der folgenden Formel berechnet werden:

$$
\mathrm{q} / \mathrm{q}=0,25 \mathrm{RPR}+0,75 \mathrm{IPR}
$$

wobei: $\quad R P R=\quad$ rumänische Preissteigerungsrate;

$\mathrm{IPR}=\quad$ Steigerungsrate der in Lei umgerechneten internationalen Preise.

Also:

$$
q / q=0,25 \times 134,8 \%+0,75 \times 108,3 \%=114,9 \%
$$

Dagegen sollte im Fall der Bekleidungs- und der Lederindustrie lediglich die Abwertungsrate der nationalen Währung $(108,3 \%)$ als erwartete Preissteigerungsrate eingesetzt werden, da in diesen Produktionszweigen die Maschinen und Anlagen für die Modernisierung überwiegend importiert werden müssen.

\subsubsection{Berechnung der Kapitalbereitstellungskosten in der rumänischen Textil- und Bekleidungsindustrie}

Gemäß 5.2.1. soll dabei die Formel 3.19 angewendet werden:

$$
c=q\left(r+d-\frac{q^{\prime}}{q}\right)(1-k-u z)(1-u)^{-1}(3.19)
$$

wobei:

- $\mathrm{q}=\quad$ der Preis der Kapitalgüter - soll gleich 1 eingesetzt werden; 

- $\mathrm{r}=\quad$ der kalkulatorische Zinssatz - wurde bereits in Abschnitt 5.2.1 entsprechend verschiedener Finanzierungsvarianten geschätzt, ausge- hend von der Zinskonstellation im rumänischen Bankensystem Ende 1993;
$-\mathrm{d}=\quad$ der Satz der ökonomischen Abschreibungen, dessen Wert in Abschnitt 5.2.2 gesondert für Textil-, Bekleidungs- und Lederindustrie berechnet wurde, gemäß der Altersdistribution des Kapitalstocks, die Ende 1990 galt. Da bei der Berechnung eine Zeitspanne von 5 Jahren für den Ersatz der völlig abgenutzten Maschinen angenommen wurde, soll der ursprünglich anhand von Informationen des Jahres 1990, für 1991 berechnete, ökonomische Abschreibungssatz bis 1996 gelten;
- q' $/ q=$ die Preissteigerungsrate bei TBI-spezifischen Maschinen und Anlagen, erwartet für 1994, berechnet im vorigen Abschnitt;
- $\mathrm{k}=\quad$ der Prozentsatz des Steuerabzugs für Investitionen in Rumänien; 50\%;
- $\mathbf{z}=\quad$ der Barwert der steuerlich zulässigen Abschreibungen, berechnet in Abschnitt 5.2.3, getrennt nach Eigentumsformen und Branchen (Textil, Bekleidung oder Lederware);
$-\mathrm{u}=\quad$ der Prozentsatz der Gewinnsteuer. Wie im Paragraphen 5.1 bereits dargelegt, soll bei der Berechnung der Kapitalbereitstellungskosten ein einheitlicher Steuersatz von $45 \%$ zugrundegelegt werden, da der ermäßigte Satz von $30 \%$ für Gewinne, die unter 1.000 .000 Lei (= $1.000 \mathrm{DM}$ ) liegen, praktisch aufgrund der Inflation und der kalten Progression so gut wie nicht mehr angewendet wird.

Die nach dieser Formel berechneten Kapitalbereitstellungskosten werden in Tabellen 5.8 bis 5.10 aufgeführt.

Tabelle 5.8: Kapitalbereitstellungskosten in der Textilindustrie

\begin{tabular}{||l||l|c|c|c|c|c||}
\hline Finanzierung & $\begin{array}{l}\text { Firme- } \\
\text { neigen- } \\
\text { tümer }\end{array}$ & $\mathrm{r}$ & $\mathrm{d}$ & $\mathrm{q} / \mathrm{q}$ & $\mathrm{z}$ & $\mathrm{c}$ \\
\hline \hline Kredit & privat & $86,35 \%$ & $23,27 \%$ & $114,9 \%$ & $38 \%$ & $\mathbf{- 3 , 1 6 \%}$ \\
\hline Kredit & Staat & $86,35 \%$ & $23,27 \%$ & $114,9 \%$ & $25 \%$ & $\mathbf{- 3 , 7 2 \%}$ \\
\hline Gewinne & privat & $124,5 \%$ & $23,27 \%$ & $114,9 \%$ & $34 \%$ & $\mathbf{2 0 , 7 4 \%}$ \\
\hline Gewinne & Staat & $104,6 \%$ & $23,27 \%$ & $114,9 \%$ & $23 \%$ & $\mathbf{9 , 3 8 \%}$ \\
\hline Aktien & privat & $150,7 \%$ & $23,27 \%$ & $114,9 \%$ & $32 \%$ & $\mathbf{3 8 , 2 1 \%}$ \\
\hline Aktien & Staat & $126,6 \%$ & $23,27 \%$ & $114,9 \%$ & $22,5 \%$ & $\mathbf{2 5 , 3 7 \%}$ \\
\hline
\end{tabular}


Tabelle 5.9: Kapitalbereitstellungskosten in der Bekleidungsindustrie

\begin{tabular}{||l||l|c|c|c|c|c||}
\hline \hline Finanzierung & $\begin{array}{l}\text { Firme- } \\
\text { neigen- } \\
\text { tümer }\end{array}$ & $\mathrm{r}$ & $\mathrm{d}$ & $\mathrm{q} / \mathrm{q}$ & $\mathrm{z}$ & $\mathrm{c}$ \\
\hline \hline Kredit & privat & $86,35 \%$ & $30,56 \%$ & $108,3 \%$ & $49,6 \%$ & $\mathbf{4 , 3 3 \%}$ \\
\hline Kredit & Staat & $86,35 \%$ & $30,56 \%$ & $108,3 \%$ & $39,8 \%$ & $\mathbf{5 , 0 2 \%}$ \\
\hline Gewinne & privat & $124,5 \%$ & $30,56 \%$ & $108,3 \%$ & $45,1 \%$ & $\mathbf{2 5 , 2 5 \%}$ \\
\hline Gewinne & Staat & $104,64 \%$ & $30,56 \%$ & $108,3 \%$ & $37,4 \%$ & $\mathbf{1 6 , 2 2 \%}$ \\
\hline Aktien & privat & $150,66 \%$ & $30,56 \%$ & $108,3 \%$ & $43,1 \%$ & $\mathbf{4 0 , 5 8 \%}$ \\
\hline Aktien & Staat & $126,63 \%$ & $30,56 \%$ & $108,3 \%$ & $35,4 \%$ & $\mathbf{3 0 , 2 9 \%}$ \\
\hline
\end{tabular}

Tabelle 5.10: $\quad$ Kapitalbereitstellungskosten in der Lederindustrie

\begin{tabular}{||l||l|c|c|c|c|c||}
\hline \hline Finanzierung & $\begin{array}{l}\text { Firme- } \\
\text { neigen- } \\
\text { tümer }\end{array}$ & $\mathrm{r}$ & $\mathrm{d}$ & $\mathrm{q} / \mathrm{q}$ & $\mathrm{z}$ & $\mathrm{c}$ \\
\hline \hline Kredit & privat & $86,35 \%$ & $25,6 \%$ & $108,3 \%$ & $41,6 \%$ & $\mathbf{2 , 0 8 \%}$ \\
\hline Kredit & Staat & $86,35 \%$ & $25,6 \%$ & $108,3 \%$ & $27,4 \%$ & $\mathbf{2 , 5 0 \%}$ \\
\hline Gewinne & privat & $124,5 \%$ & $25,6 \%$ & $108,3 \%$ & $37,3 \%$ & $\mathbf{2 5 , 2 4 \%}$ \\
\hline Gewinne & Staat & $104,64 \%$ & $25,6 \%$ & $108,3 \%$ & $25,5 \%$ & $\mathbf{1 5 , 3 7 \%}$ \\
\hline Aktien & privat & $150,66 \%$ & $25,6 \%$ & $108,3 \%$ & $35,4 \%$ & $\mathbf{4 2 , 1 0 \%}$ \\
\hline Aktien & Staat & $126,63 \%$ & $25,6 \%$ & $108,3 \%$ & $23,8 \%$ & $\mathbf{3 1 , 3 8 \%}$ \\
\hline
\end{tabular}

Eine wichtige Präzisierung muß hier gemacht werden: Die Berechnung der Kapitalbereitstellungskosten anhand dieser Methode beruht auf dem Stand der Ausstattung der Textil- und Bekleidungsindustrie mit Anlagevermögen, insbesondere mit Maschinen und Anlagen, wie sie derzeit gegeben ist. Die Schätzung der ökonomischen Abschreibungen geht davon aus, daß bestehende Produktionskapazitäten infolge von Investitionen wieder funktionsfähig werden. Für Investitionen in die Errichtung neuer Kapazitäten würden andere ökonomische Abschreibungen gelten. 


\subsubsection{Elastizitätsanalyse}

Die Elastizitätsanalyse der Kapitalbereitstellungskosten bezüglich einer gegebenen Steuer soll in der Berechnung ihrer relativen Änderung bestehen, die von der Variation unterschiedlicher Einflußfaktoren dieser Kosten verursacht wird.

Aus der Formel 3.19 lassen sich:

- der Zinssatz " $r$ ";

- der ökonomische Abschreibungssatz "d";

- die Preissteigerungsrate der Kapitalgüter q'/q;

- der Prozentsatz des Steuerabzugs für Investitionen "k";

- der Barwert der steuerlich erlaubten Abschreibungen "z";

- und schließlich der Gewinnsteuersatz " $u$ "

als Einflußvariablen erkennen.

Wie in Abschnitt 5.2.2 gezeigt, lassen sich die ökonomischen Abschreibungen kaum direkt von der Steuerpolitik beeinflussen. Das gleiche gilt auch für die Preissteigerungsrate der Kapitalgüter. Sie kann zwar durch die Einführung oder Abschaffung von Zöllen und Umsatzsteuern vergrößert bzw. gesenkt werden, aber sie ist von den Parametern, die die Veranlagung der Gewinnsteuer bestimmen, (Satz, Bemessungsgrundlage, Erleichterungen) völlig unabhängig.

Der Zinssatz " $r$ " muß gesondert berücksichtigt werden. Der Marktzinssatz " $i$ ", so wie er sich aus dem Gleichgewicht von Angebot und Nachfrage am Kapitalmarkt ergibt, wird nur indirekt (über makroökonomische feed-backProzesse) von der Finanzpolitik des Staates beeinflußt. Für die vorliegende Elastizitätsanalyse darf er also als ein Datum angesehen werden. Der Kalkulationszins " $r$ " dagegen ergibt sich aus dem Marktzins " $r$ " unter dem Einfluß des Gewinn-, des Dividendensteuersatzes und der Eigenschaften der entsprechenden Finanzierungsform.

Man kann also festhalten, daß die steuerlichen Parameter, die die Kapitalbereitstellungskosten direkt beeinflussen und nach denen die Elastizitätsanalyse gestaltet werden sollte, der Gewinnsteuersatz " $u$ ", der Barwert der steuerlichen Abschreibungen " $z$ " und der Satz des Steuerabzugs für Investitionen " $k$ " sind. Im folgenden wird der Einfluß der ersten zwei Parameter explizit analysiert werden, wobei der dritte als steuerpolitischer Ergänzungsparameter für die Neugestaltung der Gewinnsteuer gedacht ist.

Die Berechnung wird auch dadurch verkompliziert, daß auch der Barwert der steuerlichen Abschreibungen " $z$ " direkt von dem Steuersatz " $u$ " beeinflußt wird, weil letzterer Bestandteil des Abdiskontierungszinses " $r$ " ist. Unter expliziter Berücksichtigung der rumänischen 
Abschreibungsregelung (degressives Verfahren, Sätze hängen von der Nutzungsdauer ab) ist es praktisch unmöglich, die Kapitalbereitstellungskosten in einer überschaubaren Formel nach dem Steuersatz "u" abzuleiten. In Zusammenhang mit der Eigentumsform - und somit, mit den zugelassenen Nutzungsdauern - mit dem Produktionszweig (Textil, Bekleidung oder Leder), und mit der Finanzierungsform ergeben sich unterschiedliche Diskontierungssätze und unterschiedlich langen Abzinsungsreihen mit verschiedenen Koeffizienten.

Mathematisch ausgedruckt ist die Ableitung der Kapitalbereitstellungskosten nach " $u$ " unter der Annahme, daß " $z$ " und "r" unabhängig von " $u$ " sind:

$$
\frac{d c}{d u}=\left(r+d-\frac{q^{\prime}}{q}\right) \frac{1-z-k}{(1-u)^{2}}(5
$$

Demgemäß würde, falls $z+k$ (die Summe des Barwerts der steuerlichen Abschreibungen und des Prozentsatzes des Steuerabzugs für Investitionen) größer 1 sein sollte, der Zustand eines Steuerparadoxen erreicht: Die Steigerung des Gewinnsteuersatzes würde eine Senkung der Kapitalbereitstellungskosten bewirken. Dies ist aber nicht so einfach, da " $z$ " und " $r$ " unstetige, also nicht ableitbare, Funktionen von " $u$ " sind (siehe hierzu 5.2.1 und 5.2.3). Je nach Produktionszweig, Eigentumsform und Finanzierungsart ergeben sich also 18 verschiedene Fälle, die sich untereinander mindestens durch ein entscheidendes Merkmal Formel für die Berechnung von " $z$ ", oder für die Berechnung von " $r$ ", Wert von " $i$ " usw. unterscheiden (Tabelle 5.11).

Wie bereits erwähnt, gilt für jeden dieser Fälle eine andere Kombination von " $r$ " und " $z$ ", aber auch von " $d$ " und " $q$ '/q". Um eine Elastizitätsanalyse nach dem Gewinnsteuersatz vornehmen zu können, muß man in jedem Fall die Diskontierungssätze und die Barwerte der steuerlichen Abschreibungen, die sich für unterschiedliche Steuersätze ergeben, berechnen. Die Ergebnisse dieser Berechnungen werden in Tabellen 5.12 und 5.13 aufgeführt. Dabei wurden lediglich mögliche Senkungen des Gewinnsteuersatzes (auf 40\%, 35\%, 30\%, 25\% und $20 \%$ ) analysiert, da davon ausgegangen wurde, daß im internationalen Standortwettbewerb Rumänien sich einfach nicht leisten könnte, den ohnehin hohen Steuersatz von $45 \%$ weiter zu erhöhen, ohne schweren Investitionseinbußen hinnehmen zu müssen.

Die in Tabellen 5.12 und 5.13 angegebenen Werte wurden nun zur Kalkulation der Kapitalbereitstellungskosten "c" für die 18 vorhin definierten Fälle unter Einbeziehung unterschiedlicher Gewinnsteuersätze (von $45 \%$ bis auf 20\%) verwendet. Das Problem lautet: Wie hoch sind die Kapitalbereitstellungskosten wenn der Gewinnsteuersatz ... beträgt? Die Ergebnisse sind in Tabelle 5.14 dargestellt. 
Tabelle 5.11: $\quad$ Systematik der Fälle für die Elastizitätsanalyse

\begin{tabular}{|c|c|c|c|}
\hline Fall & Produktionszweig & Eigentum & Finanzierungsform \\
\hline 1. & Textil & privat & Kredit \\
\hline 2. & Textil & staatlich & Kredit \\
\hline 3. & Textil & privat & einbehaltene Gewinne \\
\hline 4. & Textil & staatlich & einbehaltene Gewinne \\
\hline 5. & Textil & privat & Aktienemission \\
\hline 6. & Textil & staatlich & Aktienemission \\
\hline 7. & Bekleidung & privat & Kredit \\
\hline 8. & Bekleidung & staatlich & Kredit \\
\hline 9. & Bekleidung & privat & einbehaltene Gewinne \\
\hline 10. & Bekleidung & staatlich & einbehaltene Gewinne \\
\hline 11. & Bekleidung & privat & Aktienemission \\
\hline 12. & Bekleidung & staatlich & Aktienemission \\
\hline 13. & Leder & privat & Kredit \\
\hline 14. & Leder & staatlich & Kredit \\
\hline 15. & Leder & privat & einbehaltene Gewinne \\
\hline 16. & Leder & staatlich & einbehaltene Gewinne \\
\hline 17. & Leder & privat & Aktienemission \\
\hline 18. & Leder & staatlich & Aktienemission \\
\hline
\end{tabular}

Dagegen zeigen Tabellen 5.15 und 5.16 die Art und Weise, in der die Kapitalbereitstellungskosten in den 0.g. 18 Fällen mit der Erhöhung des Barwerts der steuerlichen Abschreibungen (d.h. mit der Verbesserung der Abschreibungsbedingungen) variieren. Die Analyse wird unter Verwendung zweier verschiedener Gewinnsteuersätze unternommen, mit ähnlichen Ergebnissen: In allen Fällen erweisen sich die Kapitalbereitstellungskosten "c" nach der Ersetzung der anderen Variablen mit ihren entsprechenden Werten als eine lineare Funktion von "z", die für steigende Werte von "z" (bis auf 1) nach Null tendiert. Die für jeden Fall ermittelte Funktion $c=f(z)$ gibt den Wert von "c" in Prozent an. 
Tabelle 5.12: $\quad$ Kalkulationszinssätze " $r$ " für unterschiedliche Gewinnsteuersätze

\begin{tabular}{||c||c|c|c|c|c|c||}
\hline Fall & $\mathrm{u}=45 \%$ & $\mathrm{u}=40 \%$ & $\mathrm{u}=35 \%$ & $\mathrm{u}=30 \%$ & $\mathrm{u}=25 \%$ & $\mathrm{u}=20 \%$ \\
\hline \hline 1. & $86,35 \%$ & $94,2 \%$ & $102,05 \%$ & $109,9 \%$ & $117,8 \%$ & $125,6 \%$ \\
\hline 2. & $86,35 \%$ & $94,2 \%$ & $102,05 \%$ & $109,9 \%$ & $117,8 \%$ & $125,6 \%$ \\
\hline 3. & $124,5 \%$ & $124,5 \%$ & $124,5 \%$ & $124,5 \%$ & $124,5 \%$ & $124,5 \%$ \\
\hline 4. & $104,64 \%$ & $104,64 \%$ & $104,64 \%$ & $104,64 \%$ & $104,64 \%$ & $104,6 \%$ \\
\hline 5. & $150,66 \%$ & $148,2 \%$ & $146,2 \%$ & $144,5 \%$ & $143,1 \%$ & $141,9 \%$ \\
\hline 6. & $126,63 \%$ & $124,6 \%$ & $122,9 \%$ & $121,5 \%$ & $120,3 \%$ & $119,3 \%$ \\
\hline 7. & $86,35 \%$ & $94,2 \%$ & $102,05 \%$ & $109,9 \%$ & $117,75 \%$ & $125,6 \%$ \\
\hline 8. & $86,35 \%$ & $94,2 \%$ & $102,05 \%$ & $109,9 \%$ & $117,75 \%$ & $125,6 \%$ \\
\hline 9. & $124,5 \%$ & $124,5 \%$ & $124,5 \%$ & $124,5 \%$ & $124,5 \%$ & $124,5 \%$ \\
\hline 10. & $104,64 \%$ & $104,64 \%$ & $104,64 \%$ & $104,64 \%$ & $104,64 \%$ & $104,64 \%$ \\
\hline 11. & $150,66 \%$ & $148,2 \%$ & $146,2 \%$ & $144,5 \%$ & $143,1 \%$ & $141,9 \%$ \\
\hline 12. & $126,63 \%$ & $124,6 \%$ & $122,9 \%$ & $121,5 \%$ & $120,3 \%$ & $119,25 \%$ \\
\hline 13. & $86,35 \%$ & $94,2 \%$ & $102,05 \%$ & $109,9 \%$ & $117,75 \%$ & $125,6 \%$ \\
\hline 14. & $86,35 \%$ & $94,2 \%$ & $102,05 \%$ & $109,9 \%$ & $117,75 \%$ & $125,6 \%$ \\
\hline 15. & $124,5 \%$ & $124,5 \%$ & $124,5 \%$ & $124,5 \%$ & $124,5 \%$ & $124,5 \%$ \\
\hline 16. & $104,64 \%$ & $104,64 \%$ & $104,64 \%$ & $104,64 \%$ & $104,64 \%$ & $104,64 \%$ \\
\hline 17. & $150,66 \%$ & $148,2 \%$ & $146,2 \%$ & $144,5 \%$ & $143,1 \%$ & $141,9 \%$ \\
\hline 18. & $126,63 \%$ & $124,6 \%$ & $122,9 \%$ & $121,5 \%$ & $120,3 \%$ & $119,25 \%$ \\
\hline
\end{tabular}

Die vorliegende Elastizitätsanalyse erlaubt folgende wichtige Anmerkungen:

In Rumänien haben private Investoren bei Banken oder bei anderen Geschäften, die kurzfristige Gewinne versprechen, attraktivere Anlagemöglichkeiten als durch Investitionen in die verarbeitende Industrie. Die Kapitalbereitstellungskosten liegen bei den privaten Investoren höher, weil die Opportunitätskosten auch höher sind (siehe die Bildung der Kalkulationszinssätze). Dieses Phänomen ist in allen osteuropäischen Transformationswirtschaften zu beobachten aufgrund der höheren Unsicherheit, die kurzfristige Geschäfte fördert. Die Privatisierung der Industrie wird dadurch zusätzlich erschwert. 
Tabelle 5.13: $\quad$ Barwert der steuerlichen Abschreibungen " $z$ " für unterschiedliche Steuersätzeund dementsprechend unterschiedliche Kalkulationszinssätze

\begin{tabular}{|c|c|c|c|c|c|c|}
\hline Fall & $\mathrm{u}=45 \%$ & $\mathrm{u}=40 \%$ & $\mathrm{u}=35 \%$ & $\mathrm{u}=30 \%$ & $\mathrm{u}=25 \%$ & $u=20 \%$ \\
\hline 1. & $38 \%$ & $37 \%$ & $36 \%$ & $35,2 \%$ & $34,5 \%$ & $33,2 \%$ \\
\hline 2. & $24,9 \%$ & $24 \%$ & $23,3 \%$ & $22,7 \%$ & $22,1 \%$ & $21,6 \%$ \\
\hline 3. & $34 \%$ & $34 \%$ & $34 \%$ & $34 \%$ & $34 \%$ & $34 \%$ \\
\hline 4. & $23 \%$ & $23 \%$ & $23 \%$ & $23 \%$ & $23 \%$ & $23 \%$ \\
\hline 5. & $32,1 \%$ & $32,3 \%$ & $32,4 \%$ & $32,5 \%$ & $32,6 \%$ & $32,7 \%$ \\
\hline 6. & $21,5 \%$ & $21,7 \%$ & $21,8 \%$ & $21,9 \%$ & $21,9 \%$ & $22 \%$ \\
\hline 7. & $49,6 \%$ & $48,5 \%$ & $47,4 \%$ & $46,5 \%$ & $45,7 \%$ & $45 \%$ \\
\hline 8. & $39,8 \%$ & $38,7 \%$ & $37,7 \%$ & $36,9 \%$ & $36,1 \%$ & $35,5 \%$ \\
\hline 9. & $45,1 \%$ & $45,1 \%$ & $45,1 \%$ & $45,1 \%$ & $45,1 \%$ & $45,1 \%$ \\
\hline 10. & $37,4 \%$ & $37,4 \%$ & $37,4 \%$ & $37,4 \%$ & $37,4 \%$ & $37,4 \%$ \\
\hline 11. & $43,1 \%$ & $43,2 \%$ & $43,4 \%$ & $43,5 \%$ & $43,6 \%$ & $43,7 \%$ \\
\hline 12. & $35,4 \%$ & $35,6 \%$ & $35,7 \%$ & $35,8 \%$ & $35,9 \%$ & $36 \%$ \\
\hline 13. & $41,6 \%$ & $40,5 \%$ & $39,5 \%$ & $38,6 \%$ & $37,9 \%$ & $37,2 \%$ \\
\hline 14. & $27,4 \%$ & $26,5 \%$ & $25,7 \%$ & $25 \%$ & $24,4 \%$ & $23,9 \%$ \\
\hline 15. & $37,3 \%$ & $37,3 \%$ & $37,3 \%$ & $37,3 \%$ & $37,3 \%$ & $37,3 \%$ \\
\hline 16. & $25,5 \%$ & $25,5 \%$ & $25,5 \%$ & $25,5 \%$ & $25,5 \%$ & $25,5 \%$ \\
\hline 17. & $35,4 \%$ & $35,6 \%$ & $35,7 \%$ & $35,8 \%$ & $35,9 \%$ & $36 \%$ \\
\hline 18. & $23,8 \%$ & $24 \%$ & $24,1 \%$ & $24,2 \%$ & $24,3 \%$ & $24,3 \%$ \\
\hline
\end{tabular}

Es besteht ein geringfügiger Unterschied zwischen den Kapitalbereitstellungskosten in den verschiedenen Produktionszweigen. Die Investitionen im Textilbereich sind am kostengünstigsten, gefolgt vom Ledergewerbe und schließlich dem Bekleidungssektor. Dies ist auf die Struktur der ökonomischen Abschreibungen zurückzuführen.

Die Senkung des Gewinnsteuersatzes bringt keine sehr deutliche Senkung der Kapitalbereitstellungskosten mit sich. Die Kapitalbereitstellungskosten bleiben ziemlich hoch, selbst bei dem geringsten Steuersatz von $20 \%$ : Höchstwert 33,09\% im 11. Fall. Auch bei der Sofortabschreibung $(\mathrm{z}=1)$ bleiben die Kapitalbereitstellungskosten viel höher (zwischen $15 \%$ und $20 \%$, je nach dem Fall) bei $u=20 \%$ als bei $u=45 \%$ (zwischen 0 und $5 \%$ ). 
Tabelle 5.14: $\quad$ Elastizitätsanalyse der Kapitalbereitstellungskosten nach dem Gewinnsteuersatz "u" (Senkung)

\begin{tabular}{|c|c|c|c|c|c|c|}
\hline Fall & $\mathrm{u}=45 \%$ & $\mathrm{u}=40 \%$ & $\mathrm{u}=35 \%$ & $\mathrm{u}=30 \%$ & $\mathrm{u}=25 \%$ & $u=20 \%$ \\
\hline 1. & $-3,16 \%$ & $1,51 \%$ & $5,97 \%$ & $10,29 \%$ & $14,44 \%$ & $18,41 \%$ \\
\hline 2. & $-3,72 \%$ & $1,73 \%$ & $6,68 \%$ & $11,27 \%$ & $15,52 \%$ & $19,40 \%$ \\
\hline 3. & $20,74 \%$ & $19,94 \%$ & $19,27 \%$ & $18,69 \%$ & $18,19 \%$ & $17,75 \%$ \\
\hline 4. & $9,38 \%$ & $8,84 \%$ & $8,40 \%$ & $8,00 \%$ & $7,68 \%$ & $7,38 \%$ \\
\hline 5. & $38,16 \%$ & $34,96 \%$ & $32,46 \%$ & $30,40 \%$ & $28,72 \%$ & $27,31 \%$ \\
\hline 6. & $25,66 \%$ & $22,71 \%$ & $20,38 \%$ & $18,53 \%$ & $17,02 \%$ & $15,77 \%$ \\
\hline 7. & $4,33 \%$ & $8,39 \%$ & $12,50 \%$ & $16,56 \%$ & $20,58 \%$ & $24,53 \%$ \\
\hline 8. & $5,02 \%$ & $9,47 \%$ & $13,77 \%$ & $17,89 \%$ & $21,86 \%$ & $25,67 \%$ \\
\hline 9. & $25,25 \%$ & $24,91 \%$ & $24,61 \%$ & $24,36 \%$ & $24,14 \%$ & $23,95 \%$ \\
\hline 10. & $16,22 \%$ & $15,71 \%$ & $15,28 \%$ & $14,90 \%$ & $14,58 \%$ & $14,30 \%$ \\
\hline 11. & $40,58 \%$ & $38,42 \%$ & $36,66 \%$ & $35,24 \%$ & $34,07 \%$ & $33,09 \%$ \\
\hline 12. & $30,29 \%$ & $27,93 \%$ & $26,06 \%$ & $24,54 \%$ & $23,28 \%$ & $22,21 \%$ \\
\hline 13. & $2,08 \%$ & $6,48 \%$ & $10,77 \%$ & $14,93 \%$ & $18,94 \%$ & $22,82 \%$ \\
\hline 14. & $2,50 \%$ & $7,55 \%$ & $12,21 \%$ & $16,51 \%$ & $20,52 \%$ & $24,25 \%$ \\
\hline 15. & $25,24 \%$ & $24,44 \%$ & $23,76 \%$ & $23,18 \%$ & $22,67 \%$ & $22,23 \%$ \\
\hline 16. & $15,37 \%$ & $14,55 \%$ & $13,86 \%$ & $13,27 \%$ & $12,76 \%$ & $12,31 \%$ \\
\hline 17. & $42,10 \%$ & $39,04 \%$ & $36,64 \%$ & $34,66 \%$ & $33,04 \%$ & $31,67 \%$ \\
\hline 18. & $31,38 \%$ & $28,21 \%$ & $25,71 \%$ & $23,69 \%$ & $22,02 \%$ & $20,62 \%$ \\
\hline
\end{tabular}

Dagegen ist der Einfluß des Barwerts der steuerlichen Abschreibungen viel stärker geprägt. Im Idealfall der sofortigen Abschreibung der Anlagen $(z=100 \%)$ sind in allen Fällen die Kapitalbereitstellungskosten nahe bei 0. Die Steigung von "z" würde aber nicht nur zur Reduzierung, sondern auch zur Nivellierung der Kapitalbereitstellungskosten beitragen. Bei einem Steuersatz von $45 \%$ und $z=1$ sind alle Werte von "c" in einer Spannbreite von $5 \%$ zu finden. Das gleiche gilt für $z=1$ bei jedem Steuersatz zwischen $20 \%$ und $45 \%$. 
Tabelle 5.15: Variation der Kapitalbereitstellungskosten nach dem Barwert der steuerlichen Abschreibungen " $\mathrm{z}$ ", bei $\mathbf{u}=\mathbf{4 5 \%}$

\begin{tabular}{|c|c|c|c|}
\hline Fall & $z=40 \%$ & z steigt auf $100 \%$ & $z=100 \%$ \\
\hline 1. & $-3,07 \%$ & $c=4,32 z-4,8$ & $-0,48 \%$ \\
\hline 2. & $-3,07 \%$ & $c=4,32 z-4,8$ & $-0,48 \%$ \\
\hline 3. & $19,12 \%$ & $c=29,88-26,89 z$ & $2,99 \%$ \\
\hline 4. & $7,57 \%$ & $c=11,83-10,64 z$ & $1,19 \%$ \\
\hline 5. & $34,33 \%$ & $c=53,66-48,3 z$ & $5,36 \%$ \\
\hline 6. & $20,37 \%$ & $c=31,82-28,64 \mathrm{z}$ & $3,18 \%$ \\
\hline 7. & $5,01 \%$ & $c=7,83-7,04 z$ & $0,79 \%$ \\
\hline 8. & $5,01 \%$ & $\mathrm{c}=7,83-7,04 \mathrm{z}$ & $0,79 \%$ \\
\hline 9. & $27,21 \%$ & $c=42,51-38,26 z$ & $4,25 \%$ \\
\hline 10. & $15,65 \%$ & $c=24,45-22 z$ & $2,45 \%$ \\
\hline 11. & $42,43 \%$ & $c=66,29-59,66 z$ & $6,63 \%$ \\
\hline 12. & $28,44 \%$ & $c=44,44-40 z$ & $4,44 \%$ \\
\hline 13. & $2,12 \%$ & $c=3,32-2,99 z$ & $0,33 \%$ \\
\hline 14. & $2,12 \%$ & $c=3,32-2,99 z$ & $0,33 \%$ \\
\hline 15. & $24,32 \%$ & $c=38-34,2 z$ & $5,80 \%$ \\
\hline 16. & $12,77 \%$ & $c=19,95-17,95 z$ & $2,00 \%$ \\
\hline 17. & $39,54 \%$ & $c=61,78-55,6 z$ & $6,18 \%$ \\
\hline 18. & $25,56 \%$ & $c=39,94-35,94 z$ & $4,00 \%$ \\
\hline
\end{tabular}

Die Distribution der Kapitalbereitstellungskosten zwischen den 18 untersuchten Fällen zeigt, daß die Kreditfinanzierung viel günstiger ist als die anderen Finanzierungsformen. Im 1. und 2. Fall z.B. (Textilindustrie, Kreditfinanzierung) sind die Kapitalbereitstellungskosten sogar negativ, was auf eine Nettosubventionierung der Investitionen, die mit Kredit finanziert werden, hindeutet. Dies ist für die kleinen und mittleren, privaten, dynamischeren Unternehmen von Nachteil, die einen schwierigeren Zugang zum Kreditmarkt haben (INSTITUT FINANZEN \& STEUERN, 1978, S.20). 
Die Senkung des Gewinnsteuersatzes würde einen nivellierenden Einfluß ausüben, indem die Kapitalbereitstellungskosten bei Kreditfinanzierung erhöht und die anderen gesenkt würden.

Tabelle 5.16: Variation der Kapitalbereitstellungskosten nach dem Barwert der steuerlichen Abschreibungen " $\mathrm{z}$ ", bei $\mathbf{u}=\mathbf{2 0 \%}$

\begin{tabular}{|c|c|c|c|}
\hline Fall & $z=40 \%$ & $z$ steigt auf $100 \%$ & $z=100 \%$ \\
\hline 1. & $17,83 \%$ & $c=21,23-8,49 z$ & $12,74 \%$ \\
\hline 2. & $17,83 \%$ & $c=21,23-8,49 z$ & $12,74 \%$ \\
\hline 3. & $17,25 \%$ & $c=20,54-8,22 z$ & $12,32 \%$ \\
\hline 4. & $6,83 \%$ & $c=8,13-3,25 \mathrm{z}$ & $4,88 \%$ \\
\hline 5. & $26,39 \%$ & $c=31,42-12,57 \mathrm{z}$ & $18,85 \%$ \\
\hline 6. & $14,52 \%$ & $c=17,29-6,92 z$ & $10,37 \%$ \\
\hline 7. & $25,12 \%$ & $c=29,91-11,96 z$ & $17,95 \%$ \\
\hline 8. & $25,12 \%$ & $c=29,91-11,96 z$ & $17,95 \%$ \\
\hline 9. & $24,54 \%$ & $c=29,22-11,69 z$ & $17,53 \%$ \\
\hline 10. & $14,12 \%$ & $c=16,81-6,72 z$ & $10,09 \%$ \\
\hline 11. & $33,68 \%$ & $c=40,1-16,04 z$ & $24,06 \%$ \\
\hline 12. & $21,79 \%$ & $c=25,94-10,38 z$ & $15,56 \%$ \\
\hline 13. & $22,52 \%$ & $c=26,81-10,72 z$ & $16,09 \%$ \\
\hline 14. & $22,52 \%$ & $c=26,81-10,72 z$ & $16,09 \%$ \\
\hline 15. & $21,94 \%$ & $c=26,12-10,45 z$ & $15,67 \%$ \\
\hline 16. & $11,52 \%$ & $c=13,71-5,48 z$ & $8,23 \%$ \\
\hline 17. & $31,08 \%$ & $c=37-14,8 z$ & $22,20 \%$ \\
\hline 18. & $19,18 \%$ & $c=22,84-9,14 z$ & $13,70 \%$ \\
\hline
\end{tabular}

Da Größen wie "r", "d" und "q'/q" viel höher liegen als dies in einer stabilen Marktwirtschaft der Fall wäre, ist ihre Schätzung zwangsweise stärker mit Ungenauigkeit behaftet. Die Differenz $\mathbf{r}+\mathbf{d}-\mathbf{q}$ '/q als Residualgröße weicht dementsprechend viel stärker von einem Fall zu einem anderen ab: Im Fall der Kreditfinanzierung ist sie sogar negativ, da der Kalkulationszinssatz wegen der Gewinnsteuer viel niedriger ist als bei den anderen Finanzierungsformen. 
Schließlich stellen wir fest, daß beim gegebenen Gewinnsteuersatz von $45 \%$ die Barwerte der steuerlich zulässigen Abschreibungen nicht sehr stark von Fall zu Fall variieren (Höchstwert $\mathrm{z}=49,6 \%$ im Fall der privaten Bekleidungsunternehmen, die ihre Investitionen mit Krediten finanzieren und Tiefstwert $z=22,5 \%$ im Fall der staatlichen Textilunternehmen, die sich über Aktienemission finanzieren wollen). Dies legt die Vermutung nahe, die Kapitalbereitstellungskosten könnten wesentlich reduziert werden, ohne den Gewinnsteuersatz oder die Abschreibungsregelungen zu berühren, indem der Prozentsatz des Steuerabzugs für Investitionen "k" variiert wird. Betrachten wir Formel 3.19:

$$
c=q\left(r+d-\frac{q^{\prime}}{q}\right)(1-k-u z)(1-u)^{-1}
$$

Für $\mathrm{u}=45 \%$ und $\mathrm{z}=22,5 \%$ ist $\mathrm{uz}=10,125 \%$ und $1-\mathrm{uz}=89,875 \%$. Für $\mathrm{z}=$ $49,6 \%$ ist $\mathrm{uz}=22,32 \%$ und $1-\mathrm{uz}=77,68 \%$. Angenommen, der Prozentsatz des Steuerabzugs für Investitionen läge bei etwa $80 \%$, würde die Klammer (1-k-uz) einen sehr geringen Wert erreichen und die Kapitalbereitstellungskosten würden sich ohne andere steuerpolitischen Maßnahmen dem Wert von Null annähern.

Auf die These, daß die Erhöhung von "z" (d.h. die Verbesserung der Abschreibungsbedingungen, z.B. über eine Verkürzung der zugelassenen Nutzungsdauer oder über Beschleunigung der Degression) eine größere Senkung der Kapitalbereitstellungskosten verursacht als die Herabsetzung des Gewinnsteuersatzes, wird im folgenden näher eingegangen. Es gibt sowohl in der betriebswirtschaftlichen als auch in der volkswirtschaftlichen Literatur zahlreiche Ansätze, die die unmittelbare Bedeutung der Abschreibungen für die Wiederholung und Erweiterung der Aktivität von Unternehmen untersuchen. Gemäß FISCHER und WARNEKE (1976, S.151-152) haben Abschreibungen zweierlei Effekte. Das ist zum einen ein Finanzierungseffekt, weil sie dem Unternehmen Steuerersparnisse bzw. zinslose Steuerkredite ermöglichen, und zum anderen ein Rentabilitätseffekt, vor allem über den damit verbundenen Zinsgewinn. Eine der theoretisch bewiesenen Bedingungen einer Neutralität der Gewinnbesteuerung gegenüber den Kapitalbereitstellungskosten ist, daß der Barwert der steuerlichen Abschreibungen gleich eins sein sollte, während die Zinsen auf Fremdkapital in diesem Fall nicht mehr abzugsfähig sein dürften (BOADWAY, [1980, S.254). Nur gibt es eine einzige praktische Möglichkeit, daß $z=1$. Die Steuergesetzgebung sollte die Sofortabschreibung der beschafften Kapitalgüter gestatten. In allen anderen Fällen, in denen die Abschreibung der Kapitalgüter sich über mehrere Jahre erstreckt, sorgt der Kalkulationsszins " $r$ " dafür, daß $z<1$. Im Fall Rumäniens ist dieser Abzinsungseffekt noch stärker, da die Diskontierungssätze, bedingt durch die hohe Inflation, sehr hoch sind. 
Dieser Tatbestand widerspricht eigentlich dem ökonomischen Sinn der Abschreibungen faktische Finanzreserven zu bilden, die für die Ersetzung des völlig abgenutztes Kapitalgutes ausreichen sollen. Wenn aber der Gegenwartswert aller Abschreibungsbeträge kleiner ist als die Anschaffungs- bzw. Wiederbeschaffungskosten, werden nicht nur Grenzinvestitionen verhindert, es findet auch eine Substanzerrosion des Kapitalstocks statt, zu der die Gewinnbesteuerung wesentlich beiträgt. Daß dies in Rumänien der Fall ist, zeigen die ermittelten Werte von " $z$ ", die sich zwischen $22,5 \%$ und $49,6 \%$ befinden, obwohl die rumänische Gesetzgebung die degressive Abschreibung schon zuläßt. Das hilft aber nicht viel. Der beschleunigte Charakter der Abschreibungen könnte beliebig verstärkt werden, ohne daß " $z$ " den Wert von 1 erreicht, solange die Abschreibungen in Prozent des Anschaffungswertes berechnet und zugelassen werden. Um den Barwert der steuerlichen Abschreibungen bis auf $1 \mathrm{zu}$ erhöhen, sollte man entweder die Sofortabschreibung gestatten oder jedes Jahr die Werte der Kapitalgüter mit der Inflationsrate indexieren und die Abschreibungssumme durch die Multiplikation des geplanten Abschreibungssatzes mit dem Wiederbeschaffungswert bestimmen. In diesem Fall würde der Kalkulationszins " $r$ " dem Realzins entsprechen. Er wäre also viel kleiner als die Werte, die bisher bei der Abzinsung der Abschreibungen benutzt wurden. Falls die Realzinsen in den Indexierungskoeffizient miteingebaut wären, dann würde endlich " $z$ " den Wert eins annehmen.

Da die rumänische Gesetzgebung die Abschreibung zum Wiederbeschaffungswert in keiner Weise regelt und prinzipiell nicht erlaubt, können die Unternehmer sich auf diese Möglichkeit nicht verlassen. Das Finanzministerium hat zwar seit 1990 die Wiederbewertung (sprich: Wertindexierung) des Kapitalstocks in den staatlichen Unternehmen zweimal verordnet (zugleich wurde diese Maßnahme auch den privaten Unternehmen empfohlen). Damit wurde aber nicht der Zweck verfolgt, die Steuerlast zu senken. Es ging vielmehr um die Aufblähung der Buchwerte der staatlichen Unternehmen, um die die Verhandlungen mit potentiellen ausländischen Investoren stattfinden sollten. Der willkürliche Charakter solcher Maßnahmen erlaubt aber ihren Einbau in das Modell der Kapitalbereitstellungskosten für Rumänien nicht.

Die Möglichkeit von bestimmten Sonderabschreibungen könnte auch dazu führen, daß der Anschaffungswert, einschließlich der inflationären Wertsteigerung und der durch die Investition versäumten Zinserträge, von der gesamten Abschreibungssumme gedeckt wird. Bisher wurde in Rumänien von der Regierung von diesem Instrument nie Gebrauch gemacht.

Die Verbesserung der Abschreibungsbedingungen, d.h. die Erhöhung ihres Gegenwartwertes, führt also ausnahmslos zu einer Verbesserung der Kapitalrentabilität, aber auch zur Freisetzung von Finanzmitteln (durch Steuerersparnis) für die Fortsetzung einer Investitionskette. Außer der o.g. Methoden kann der Barwert der steuerlichen Abschreibungen " $z$ " auch durch Verkürzung der steuerlich zulässigen Nutzungsdauern erhöht werden, was sich auch 
positiv auf die Risikobereitschaft der Unternehmer auswirkt (INSTITUT FINANZEN \& STEUERN, 1978, S.53). Es darf dabei nicht vergessen werden, daß sich alle diese Maßnahmen nur dann positiv auf die Finanz- und Rentabilitätslage des Unternehmens auswirken, wenn die am Markt erwirtschafteten Überschüsse diese erhöhten Abschreibungen decken können, m.a.W., wenn das Unternehmen Cash-Flow in ausreichender Menge erwirtschaftet hat (WEICHSEL, 1964, S.21).

\subsection{Wirkungen auf die Liquidität der investierenden Unternehmen}

"Die Erfolgsbesteuerung kann zu einer Kontraktion oder Expansion der Unternehmung führen, je nachdem, ob finanzielle Begrenzungen wirksam werden oder nicht" (STROBEL, 1977, S.294). Eine Wirkungsanalyse der Gewinnbesteuerung innerhalb eines bestimmten Steuersystems darf nicht den Anspruch erheben, sie habe die wichtigsten Folgen der Gewinnsteuer erfaßt, ohne den Einfluß dieser Steuern auf die Liquidität und Finanzkraft eines Unternehmens auf irgendeine Weise zu untersuchen. Im Kapitel 4 wurde, neben dem neoklassischen Modell, auch der Liquiditätsansatz gewählt, um die Wirkungen der Gewinnund Dividendensteuer zu untersuchen. Während das erste Modell die Rentabilitätseffekte der Erfolgsbesteuerung aufzeigen soll, entfällt auf das zweite die Aufgabe, die Finanzierungseffekte derselben zu erfassen. Grob gesagt, der erste Ansatz untersucht den Einfluß der Gewinn- und Dividendenbesteuerung auf den Investitionswillen, während sich der zweite Ansatz mit den Konsequenzen für die Liquidität, d.h. für die Investitionsfähigkeit des Unternehmens, befaßt.

\subsubsection{Berechnung des maximalen Gewinnanteils, der reinvestiert werden kann}

Die erste wichtige Frage, die sich nach der Beurteilung der Rentabilität einer geplanten Investition stellt, ist, wieviel von der Investitionssumme aus eigenen Quellen finanziert werden kann, wenn wie in Rumänien das Kreditangebot begrenzt ist? In diesem Zusammenhang fragen die Entscheidungsträger im Unternehmen zuerst nach dem Höchstbetrag, der ihnen aus den erwirtschafteten Gewinnen nach Abzug der Steuern und der ausgeschütteten Dividenden zur Verfügung bleibt. Er soll in erster Linie zur Finanzierung der beabsichtigten Investition herangezogen werden.

Der Bruttogewinn setzt sich aus dem Nettogewinn und der zu zahlenden Gewinnsteuer zusammen:

$$
\mathrm{G}_{\mathrm{B}}=\mathrm{GSt}+\mathrm{G}_{\mathrm{N}}
$$


wobei:

- $G_{B}$ ist der Bruttogewinn;

- GSt ist die Gewinnsteuerschuld und

$-G_{N}$ ist der Nettogewinn.

Die privaten Unternehmen sind offiziell nicht verpflichtet Dividenden zu zahlen. Falls ihre Anteilsbesitzer einverstanden sind, dürfen sie den gesamten Betrag, der nach der Zahlung der anfallenden Gewinnsteuer und der Rückerstattung des Steuerabzugs für Investitionen bleibt, wieder investieren. In diesem Fall haben sie auch keine Dividendensteuer zu zahlen:

$$
G_{B}=u G_{B}+\operatorname{Inv}-u \times k \times \text { Inv }
$$

wobei Inv der Höchstbetrag ist, der reinvestiert werden kann. Wie schon in 5.1 gezeigt, beträgt der Prozentsatz "k" des Steuerabzugs für Investitionen zur Zeit in Rumänien 50\%, während der Gewinnsteuersatz "u" bei $45 \%$ liegt. Demzufolge:

$$
\operatorname{Inv}=71 \% \mathrm{G}_{\mathrm{B}}
$$

Den privaten Unternehmen bleibt also ein wichtiger Teil des Bruttogewinns zur Verfügung, falls sie entschlossen sind, diese Finanzierungsmöglichkeit auszuschöpfen. Allerdings wird ihnen der Betrag des Steuerabzugs für Investitionen erst am Anfang des folgenden Jahres gutgeschrieben, was den Investitionsprozeß verzögern kann.

Sei "u" der Gewinnsteuersatz und "k" der Prozentsatz des Steuerabzugs für Investitionen, dann ist die Nettosteuerschuld:

$$
\mathrm{GSt}_{\mathrm{N}}=\mathrm{u} \mathrm{G}_{\mathrm{B}}-\mathrm{ku} \operatorname{Inv}
$$

und demgemäß:

$$
G_{B}=u G_{B}-k u \text { Inv }+ \text { Inv }
$$

Darauf folgt die allgemeine Formel:

$$
\operatorname{In} v_{\max }=\frac{1-u}{1-k u} G_{B}(5.11)
$$

Die staatlichen Unternehmen dagegen müssen sich an den Regierungsbeschluß Nr.781/1991 und das anschließende Gesetz Nr.40/1992 halten, die aus dem Bruttogewinn eine Dividendenauszahlung an die Privateigentumsfonds und an den Staatseigentumsfonds als Anteilseigner 
eines staatlichen Unternehmens von mindestens $40 \%$ vorschreiben. Das Modell ändert sich also wie folgt:

$$
\mathrm{G}_{\mathrm{B}}=\mathrm{GSt}+\mathrm{D}+\mathrm{Inv}
$$

wobei $\mathrm{D}$ die Dividendenzahlung darstellt.

$$
\begin{gathered}
\text { GSt }=45 \% \mathrm{G}_{B}-22,5 \% \text { Inv } \\
D=40 \% \mathrm{G}_{\mathrm{N}}=40 \%(1-45 \%) \mathrm{G}_{\mathrm{B}}=22 \% \mathrm{G}_{\mathrm{B}} \\
\mathrm{G}_{\mathrm{B}}=45 \% \mathrm{G}_{\mathrm{B}}-22,5 \% \mathrm{Inv}+22 \% \mathrm{G}_{\mathrm{B}}+\mathrm{Inv} \\
\mathrm{G}_{B}=67 \% \mathrm{G}_{B}+77,5 \% \text { Inv } \\
\text { Inv }=42,6 \% \mathrm{G}_{B}
\end{gathered}
$$

Aus der Bruttogewinnsumme darf ein staatliches Unternehmen also höchstens $42,6 \%$ zur Finanzierung von Investitionen verwenden. Daher sind die staatlichen Unternehmen viel schlechter als die privaten gestellt. Der Staatseigentumsfonds betreibt quasi eine Politik der sozialistischen Umverteilung. Mit den von rentablen Unternehmen eingenommenen Dividenden finanziert er andere, unergiebige Betriebe.

Das Problem dabei ist der Finanzentzug bei den gewinnbringenden Unternehmen. Die Tatsache, daß diese Unternehmen Gewinne erwirtschaften, ist normalerweise ein Zeichen dafür, daß sie am Markt gut gestellt und ausreichend mit Produktionsfaktoren ausgestattet sind. Dementsprechend sollen Prozesse der intensiven Weiterentwicklung, wie z.B. der Erneuerung des Kapitalstocks, wenn nicht gefördert, dann wenigstens nicht durch den Entzug von Finanzmitteln behindert werden. Für die Höhe des Staatseigentums ist es ohne Bedeutung, ob diese Dividenden an die Eigentumsfonds gezahlt werden oder nicht, da sie, auch wenn sie beim Unternehmen verbleiben, weiterhin einen staatlichen Besitz darstellen. Sie werden nur vom Staat nicht so effizient und marktgerecht benutzt wie von den Unternehmen. Durch Nivellierung kann der Staat die Umstrukturierung und Sanierung seines Eigentums nur verzögern, wenn nicht sogar verhindern.

Das allgemeine Modell im Fall einer verbindlichen Dividendenausschüttung ist:

$$
\begin{gathered}
\mathrm{G}_{\mathrm{B}}=\mathrm{GSt}+\mathrm{D}+\mathrm{Inv} \\
\mathrm{GSt}=\mathrm{u}_{\mathrm{B}}-\mathrm{ku} \text { Inv }
\end{gathered}
$$




$$
\begin{gathered}
D=\delta\left(G_{B}-u G_{B}\right)=\delta(1-u) G_{B} \\
G_{B}=u G_{B}-k u \operatorname{Inv}+\delta(1-u) G_{B}+\operatorname{Inv} \\
\operatorname{Inv}=G_{B} \frac{(1-u)(1-\delta)}{1-k u}(5.12)
\end{gathered}
$$

Es ist anhand der Formel 5.12 leicht erkennbar, daß die Erhöhung des Prozentsatzes des Steuerabzugs für Investitionen, sowie die Herabsetzung von " $\delta$ " - dem Anteil der ausgeschütteten Dividenden - die für Investitionen frei gebliebenen Mitteln erhöhen würde. Was den Gewinnsteuersatz betrifft, gilt:

$$
\frac{\partial I n v}{\partial u}=G_{B}(1-\delta) \frac{k-1}{(1-k u)^{2}}<0, \forall u(5.13)
$$

Die Erhöhung des Gewinnsteuersatzes würde also die für Investitionen zur Verfügung stehenden Finanzmittel verringern, mit Ausnahme des Falles, wo der Steuerabzug für Investitionen bei $100 \%$ läge, also die reinvestierten Gewinne überhaupt nicht besteuert würden.

\subsubsection{Berechnung des von der Gewinnbesteuerung verursachten zusätzlichen Finanzbedarfs einer Investitionskette}

Das Modell der Investitionskette, durch die das investierende Unternehmen versucht, seine Kreditaufnahme durch Verteilung der Investitionsausgaben über mehrere Jahre zu mindern, wurde in Abschnitt 3.9 dargestellt. Im folgenden wird unter Berücksichtigung der rumänischen Gesetzgebung untersucht, um wieviel der Bedarf einer Investitionskette an fremden Finanzmitteln höher liegt, als im Fall ohne Gewinnbesteuerung.

Der Netto-Cash-Flow, den die Investitionskette ohne Besteuerung erbringt, beträgt:

$$
N C F_{0}=g \frac{t(t+1)}{2}
$$

wobei:

- $\mathrm{g}=$ die jährliche Steigerungsrate der Zahlungsüberschüsse der Investitionskette; 
$-\mathrm{t}=$ die Zeit, nach der alle Teilobjekte der Investitionskette begonnen haben, Überschüsse zu erwirtschaften (siehe Abb. 3.4).

Im folgenden wird $\mathrm{t}=5$ Jahre eingesetzt, da bei der Berechnung der ökonomischen Abschreibungen in Abschnitt 5.2 davon ausgegangen wurde, daß der Prozeß der Erneuerung des Kapitalstocks in der rumänischen TBI 5 Jahre dauert. Außerdem sei "I" die jährliche Investition, die notwendig ist, um innerhalb von 5 Jahren (wie bei der Berechnung der ökonomischen Abschreibungen) den Erneuerungsbedarf zu decken.

Die Berechnung des Netto-Cash-Flows, der unter Besteuerung zu erzielen ist, bedarf einer Cash-Flow-Analyse über 5 Jahre:

die erwirtschafteten Überschüsse seien:

$$
\mathrm{m} \mathbf{g}
$$

wobei " $\mathrm{m}$ " die Zahl des Jahres angibt (zwischen 1 und 5 Jahren)

die vom rumänischen Gesetz zugelassenen, degressiven Abschreibungen setzen sich für ein einziges Investitionsobjekt zusammen nach der Formel:

$$
\text { aI }(1-a)^{m}
$$

wobei "a" der degressive Abschreibungssatz ist, berechnet als Verhältnis zwischen dem Degressionskoeffizient $\phi$, der im neuen Abschreibungsgesetz vorgesehen ist $(2,5$ für Nutzungsdauern der Anlagegüter über 10 Jahre, 2 für Nutzungsdauern zwischen 5 und 10 Jahren und 1,5 zwischen 2 und 5 Jahren), und der durchschnittlichen gesetzlich zugelassenen Nutzungsdauer für den jeweiligen Produktionszweig (Textil, Bekleidung, Leder) " $n$ ".

dementsprechend ist die Abschreibungssumme im "m"-ten Jahr im Fall der Investitionskette kumuliert einzusetzen:

$$
\text { aI }\left[1+(1-a)+\ldots+(1-a)^{m-1}\right]
$$

die Steuerzahlung im Jahr "m" wird also:

$$
\mathrm{u}\left[\mathrm{mg}-\mathrm{I}+\mathrm{I}(1-\mathrm{a})^{\mathrm{m}}\right]
$$


das Unternehmen bekommt folgende Steuerabzüge für Investitionen jeweils im nächsten Jahr erstattet:

$$
\mathrm{ku}(1-\mathrm{u})\left[(\mathrm{m}-1) \mathrm{g}-\mathrm{I}+\mathrm{I}(1-\mathrm{a})^{\mathrm{m}-1}\right](\text { hier } \mathrm{m}=2 \ldots .5)
$$

Im Fall der besteuerten Investitionskette setzt sich der erwirtschaftete Netto-Cash-Flow (NCF, aus der Summe der jährlichen Brutto-Cash-Flows und der Steuerabzüge für Investitionen, abzüglich der Summe der jährlichen Steuerzahlungen zusammen:

$$
\begin{aligned}
& \mathrm{NCF}_{\mathrm{t}}=15 \mathrm{~g}+\mathrm{ku}(1-\mathrm{u})\left\{10 \mathrm{~g}-5 \mathrm{I}+\mathrm{I}\left[1+(1-\mathrm{a})+(1-\mathrm{a})^{2}+(1-\mathrm{a})^{3}+(1-\mathrm{a})^{4}\right]\right\}- \\
& -\mathrm{u}\left\{15 \mathrm{~g}-5 \mathrm{I}+\mathrm{I}\left[(1-\mathrm{a})+(1-\mathrm{a})^{2}+(1-\mathrm{a})^{3}+(1-\mathrm{a})^{4}+(1-\mathrm{a})^{5}\right]\right\}= \\
& =15 \mathrm{~g}+\mathrm{ku}(1-\mathrm{u})\left\{10 \mathrm{~g}-5 \mathrm{I}+\mathrm{a}^{-1} \mathrm{I}\left[1-(1-\mathrm{a})^{5}\right]\right\}-\mathrm{u}\left\{15 \mathrm{~g}-5 \mathrm{I}+\mathrm{a}^{-1} \mathrm{I}(1-\mathrm{a})\left[1-(1-\mathrm{a})^{5}\right]\right\}
\end{aligned}
$$

Der zusätzliche Finanzierungsbedarf $\mathrm{ZFB}$, den die Gewinnbesteuerung verursacht, ist eigentlich die Differenz zwischen dem Netto-Cash-Flow, den man ohne Besteuerung erzielt hätte $\left(\mathrm{NCF}_{0}\right)$ und dem tatsächlichen $(\mathrm{NCF})$.

$$
\begin{aligned}
\mathrm{ZFB}= & \mathrm{NCF}_{0}-\mathrm{NCF}_{\mathrm{t}}=\mathrm{u}\left\{15 \mathrm{~g}-5 \mathrm{I}+\mathrm{Ia}^{-1}(1-\mathrm{a})\left[1-(1-\mathrm{a})^{5}\right]\right\}-\mathrm{ku}(1-\mathrm{u})\{10 \mathrm{~g}-5 \mathrm{I}+ \\
& \left.+\mathrm{Ia}^{-1}\left[1-(1-\mathrm{a})^{5}\right]\right\}
\end{aligned}
$$

Alle diese Formeln wurden in der Aussage zusammengefaßt, daß das Unternehmen völlig frei ist, seine gesamten Nettogewinne zur Finanzierung der Investitionskette zu verwenden ohne Dividenden ausschütten zu müssen. $\mathrm{Zu}$ den einbehaltenen Gewinnen kommt im darauffolgenden Jahr auch der Steuerabzug für Investitionen hinzu, der die Liquidität des Unternehmens im laufenden Jahr verbessert und so den zusätzlichen Finanzierungsbedarf verringert. Dies kann für private Unternehmen durchaus der Fall sein, aber für die staatlichen Unternehmen trifft dies nicht $\mathrm{zu}$, da, wie im vorigen Abschnitt gezeigt wurde, letztere verpflichtet sind, an die Eigentumsfonds mindestens $40 \%$ vom Nettogewinns als Dividenden zu zahlen. Das dargelegte Modell ändert sich wie folgt:

- die Höhe des Steuerabzugs für Investitionen wird nunmehr wie folgt berechnet:

$$
\mathrm{ku}(1-\mathrm{u})(1-\delta)\left[(\mathrm{m}-1) \mathrm{g}-\mathrm{I}+\mathrm{I}(1-\mathrm{a})^{\mathrm{m}-1}\right]
$$

wobei " $\delta$ " der Prozentsatz der verbindlichen Dividendenausschüttung (zur Zeit 40\%) ist;

von dem Netto-Cash-Flow werden außerdem auch die jährlichen Dividendenzahlungen abgezogen: 


$$
\delta\left[\mathrm{mg}-\mathrm{I}+\mathrm{I}(1-\mathrm{a})^{\mathrm{m}}\right]
$$

Ebenfalls nach der Berechnung der Differenz zwischen dem neuen und dem alten, unbesteuerten Cash-Flow ergibt sich die Formel des zusätzlichen Finanzierungsbedarfs, die für die staatlichen Unternehmen gilt:

$$
\mathrm{ZFB}=(\mathrm{u}+\mathrm{d})\left\{15 \mathrm{~g}-5 \mathrm{I}+\mathrm{Ia}^{-1}(1-\mathrm{a})\left[1-(1-\mathrm{a})^{5}\right]\right\}-\mathrm{uk}(1-\mathrm{u})(1-\mathrm{d})\left\{15 \mathrm{~g}-5 \mathrm{I}+\mathrm{Ia}^{-1}\left[1-(1-\mathrm{a})^{5}\right]\right\}
$$

In den beiden erarbeiteten Formeln, sowohl für private als auch für staatliche Unternehmen, ist nach der Ableitung des zusätzlichen Finanzierungsbedarfs nicht klar, ob diese Zielgröße mit der Steigung des Steuersatzes, des Prozentsatzes des Steuerabzugs für Investitionen bzw. des degressiven Abschreibungssatzes steigt oder sinkt. Es bedarf eines bekannten Verhältnisses zwischen den erwirtschafteten Überschüssen "mg" und der jährlichen Investitionssumme "I", das eigentlich Information über die Rentabilität der Investitionskette liefern würde, um eine klare Aussage machen zu können.

Im Fall Rumäniens stellt sich genau die Frage einer Investitionskette, die möglichst schnell (bei der Berechnung der ökonomisch "richtigen" Abschreibungen wurde eine Periode von 5 Jahren angenommen) den Erneuerungsbedarf der Textil- und Bekleidungsindustrie decken sollte. Die Gewinnbesteuerung und die Verpflichtung der staatlichen Unternehmen, an die Eigentumsfonds Dividenden zu zahlen, erhöhen den Fremdkapitalbedarf, das heißt die Investitionssumme, die von den erwirtschafteten Überschüssen nicht gedeckt wird und fremdfinanziert werden muß. Der Betrag dieser Erhöhung ist der zusätzliche Finanzierungsbedarf, berechnet als Differenz zwischen dem Netto-Cash-Flow ohne und mit Besteuerung.

In Anlehnung an Kapitel 2 wird der minimale Investitionsbedarf der Textil- und Bekleidungsindustrie geschätzt, der notwendig ist, um den technischen Zustand des Anlagevermögens wieder auf ein akzeptables Niveau zu bringen (Tabelle 5.17). Dieser wird auf die zwei Eigentumsarten entsprechend ihres Gewichts im Anlagevermögen der TBI verteilt.

Es wurde weiter die optimistische Hypothese aufgestellt, die Überschüsse würden in den nächsten Jahren so stark steigen, daß sie nach dem fünften Jahr die jährliche Investitionssumme ausgleichen und von dem Zeitpunkt an die benötigten Investitionen (wie auch im Paragraphen 5.2 gezeigt, handelt es sich hier um Investitionen für die Anpassung des Sachkapitalbestands an das qualitative Weltniveau und nicht um Kapazitätserweiterungen) von den erwirtschafteten Überschüssen finanziert werden können. 
Tabelle 5.17: $\quad$ Anlageinvestitionsbedarf in der rumänischen TBI, berechnet für die kommenden 5 Jahre, in Mio. US-\$

\begin{tabular}{|c|c|c|}
\hline Produktionszweig & privat & staatlich \\
\hline \hline Textil & 47,4 & 900,6 \\
\hline Bekleidung & 7,8 & 31,2 \\
\hline Leder & 25,6 & 230,4 \\
\hline
\end{tabular}

(Quelle: Synthese des Instituts für Leichtindustrie, eigene Berechnungen)

Die jährliche Investitionssumme "I" ist also immer ein Fünftel des entsprechenden Anlageinvestitionsbedarfs für den jeweiligen Produktionszweig. Auch die jährliche Steigerungsrate der Überschüsse "g" ist ein Fünftel der jährlichen Investitionssumme "I". Damit deckt der Überschuß die Investitionssumme im fünften und letzten Jahr völlig.

Das eben dargelegte Modell wird anschließend dazu verwendet, den zusätzlichen Finanzierungsbedarf "ZFB" sowie den Anteil des zusätzlichen Finanzierungsbedarfs "ZFB\%" im Anlageinvestitionsbedarf zu ermitteln. Tabelle 5.18 gibt diese Werte für jeden Produktionszweig, strukturiert nach Eigentumsarten, an.

Unter der Annahme, daß $5 \mathrm{~g}=\mathrm{I}$, also daß nach 5 Jahren die Überschüsse die jährlichen Investitionen völlig decken, werden keine überhöhten zusätzlichen Finanzmitteln benötigt höchster absoluter Betrag: 190,6 Mio.US-\$, für die staatlichen Textilunternehmen aufgrund der höheren Kapitalintensität der Branche und der ungünstigeren Abschreibungsbedingungen; höchste relative Steigung: $21,2 \%$ bei denselben. Diese Annahme dürfte ziemlich realistisch sein. Sie entspräche einer Cash-Flow-Rentabilität von etwa $20 \%$. Im Rahmen der bisherigen Diskussion wurde erörtert, daß eine gesunde Industriepolitik den gewinnbringenden Unternehmen bessere Angebotsbedingungen gewährleisten sollte. Daher soll sich die Analyse nur auf die rentablen Unternehmen beschränken, wenn die rumänischen Unternehmen betrachtet werden sollen. Unternehmen, die Verluste erwirtschaften, werden nicht berücksichtigt.

Aus den Tabellen läßt sich ersehen, daß der relative zusätzliche Finanzierungsbedarf mit der Senkung der gesetzlichen Nutzungsdauer und mit der Verbesserung der allgemeinen Abschreibungsbedingungen (Erhöhung von "a") abnimmt. Auch der deutliche Unterschied zwischen dem zusätzlichen relativen Finanzierungsbedarf bei privaten bzw. staatlichen Unternehmen in demselben Produktionszweig ist nicht nur auf die verbindliche Dividendenausschüttung, sondern auch auf die für private Firmen kürzeren zulässigen Nutzungsdauern zurückzuführen (Weiter wird gezeigt, daß die Elastizität des ZFB gegenüber dem Dividendenausschüttungssatz am geringsten ist im Vergleich zu anderen Elastizitäten). 
Tabelle 5.18: $\quad$ Zusätzlicher Finanzierungsbedarf der Unternehmen der TBI, im Fall einer Investitionskette, die nach 5 Jahren nur noch von den Überschüssen getragen wird (in Mio. US-\$, außer "a", " $\phi$ " und " $n "$ ).

\begin{tabular}{|c|c|c|c|}
\hline Private Unternehmen: & Textil & Bekleid. & Leder \\
\hline Investitionsbedarf & 47,4 & 7,8 & 25,6 \\
\hline Jährliche Investitionssumme "I" & 9,48 & 1,56 & 5,12 \\
\hline $\begin{array}{l}\text { Gesetzliche Nutzungsdauer der } \\
\text { Anlagen " } n \text { " }\end{array}$ & $\begin{array}{r}11,28 \\
\text { Jahre }\end{array}$ & $\begin{array}{l}6,4 \\
\text { Jahre }\end{array}$ & $\begin{array}{l}10,08 \\
\text { Jahre }\end{array}$ \\
\hline Degressionskoeffizient " $\phi "$ & 2,5 & 2 & 2,5 \\
\hline $\begin{array}{l}\text { Degressiver Abschreibungssatz } \\
\text { "a" }=\phi / \mathrm{n}\end{array}$ & 0,222 & 0,3125 & 0,248 \\
\hline $\begin{array}{l}\text { Jährliche Steigung der Über- } \\
\text { schüsse "g" }\end{array}$ & 1,9 & 0,32 & 1,0 \\
\hline ZFB (in Mio. US-\$) & 1,94 & $\sim 0$ & 0,66 \\
\hline ZFB (\%) & $4,1 \%$ & $\sim 0 \%$ & $2,58 \%$ \\
\hline
\end{tabular}

\begin{tabular}{||l|c|c|c||}
\hline \hline Staatliche Unternehmen & Textil & Bekleid. & Leder \\
\hline \hline Investitionsbedarf & 900,6 & 31,2 & 230,4 \\
\hline Jährliche Investitionssumme "I" & 180,12 & 6,24 & 46,08 \\
\hline Gesetzliche Nutzungsdauer "n" & $\begin{array}{l}18,8 \\
\text { Jahre }\end{array}$ & $\begin{array}{c}10,67 \\
\text { Jahre }\end{array}$ & $\begin{array}{c}16,79 \\
\text { Jahre }\end{array}$ \\
\hline Degressionskoeffizient & 2,5 & 2,5 & 2,5 \\
\hline Abschreibungssatz "a" & 0,133 & 0,234 & 0,149 \\
\hline $\begin{array}{l}\text { Jährliche Steigungsrate der } \\
\text { Überschüsse }\end{array}$ & $\mathbf{3 6}$ & 1,25 & 9,2 \\
\hline ZFB (Mio. US-\$) & $\mathbf{1 9 0 , 6}$ & $\mathbf{0 , 4}$ & $\mathbf{3 4}$ \\
\hline ZFB (\%) & $\mathbf{2 1 , 2 \%}$ & $\mathbf{1 , 2 \%}$ & $\mathbf{1 4 , 8 \%}$ \\
\hline
\end{tabular}

Je günstiger (sprich: degressiver) die Abschreibungsmöglichkeiten sind, umso stärker verringert sich der zusätzliche Finanzierungsbedarf. Daraus ergibt sich, daß eine günstige Gestaltung der Abschreibungen sowohl für die Rentabilität der geplanten Investitionen, als auch für die Liquidität und die Eigenfinanzierungskraft der Unternehmen positive Folgen hat. Das gilt aber nur unter der Bedingung, daß das Unternehmen genug Überschüsse erwirt- 
schaftet, um seine Abschreibungen zu verdienen. Auch wurde angenommen, daß die Unternehmen schon ab dem ersten Jahr der analysierten Zeitperiode Gewinne erzielen. Für ein rumänisches Unternehmen, das schon seit einiger Zeit am Markt tätig ist, ist diese Annahme durchaus sinnvoll. Falls es sich um neugegründete Unternehmen, z.B. um Auslandsinvestitionen, handelt, trifft diese Annahme nicht mehr $\mathrm{zu}$, da neue Investitionen in der Regel nicht schon im ersten Jahr Überschüsse erzielen. Normalerweise rechnen Investoren, die sich langfristig auf einem Markt engagieren, erst nach einigen Jahren mit entscheidenden Gewinnen. Dieser spezielle Fall wird im Kapitel 7 behandelt.

Es wäre unvollständig, diese Analyse zu beenden, ohne anhand von Elastizitätsberechnungen die Parameter zu identifizieren, gegenüber denen die Selbstfinanzierungskraft der rumänischen Unternehmen in Bezug auf die technische Sanierung ihres Anlagevermögens am empfindlichsten ist. Für die Erarbeitung eines wirtschaftspolitischen Konzepts ist die Entdeckung dieser Schlüsselparameter unumgänglich, da die Effizienz des politischen Eingriffs in das Wirtschaftsgeschehen dann am höchsten ist, wenn auch die Empfindlichkeit der wirtschaftspolitischen Zielgrößen gegenüber den Instrumenten am größten ist.

Im folgenden wird untersucht, inwieweit die relative Änderung verschiedener Variablen eine stärkere oder schwächere relative Variation des zusätzlichen Finanzierungsbedarfs bewirkt. Die Elastizität des zusätzlichen Finanzierungsbedarfs gegenüber jeder Variable wird jeweils nach der Formel 5.14 berechnet. Am ergiebigsten für eine Anwendung in der Wirtschaftspolitik wären die Variablen mit den größten absoluten Elastizitäten.

$$
\varepsilon_{Z F B}^{v}=\frac{\frac{\partial Z F B}{Z F B}}{\frac{\partial v}{v}}(5.14)
$$

wobei "v" die jeweils untersuchte Variable darstellt.

Im allgemeinen Fall des jährlichen Wachstums der erbrachten Überschüsse um "g" Geldeinheiten und der jährlichen Investitionssumme "I" sind die allgemeinen Formeln (ohne $\mathrm{da}$ irgendeine Verbindung zwischen " $\mathrm{g}$ " und "I" bekannt sei):

$$
Z F B_{p r i v}=u\left[g \frac{t(t+1)}{2}-t I+I(1-a) \frac{1-(1-a)^{t}}{a}\right]-
$$




$$
-k u(1-u)\left[g \frac{t(t-1)}{2}-t I+I \frac{1-(1-a)^{t}}{a}\right](5.15)
$$

für den zusätzlichen Finanzierungsbedarf bei privaten Unternehmen und:

$$
\begin{aligned}
& Z F B_{\text {staat }}=(u+d)\left[g \frac{t(t+1)}{2}-t I+I(1-a) \frac{1-(1-a)^{t}}{a}\right]- \\
& -u k(1-u)(1-d)\left[g \frac{t(t-1)}{2}-t I+I \frac{1-(1-a)^{t}}{a}\right](5.16)
\end{aligned}
$$

Diese relativ komplizierten Ausdrücke sowie die Elastizitätsanalyse werden durch die Annahme vereinfacht, daß nach " $t$ " Jahren die Überschüsse die jährlichen Investitionen begleichen. In diesem Fall ist $I=$ gt und also:

$$
\begin{gathered}
Z F B_{p r i v}=u I\left[\frac{1-t}{2}+(1-a) \frac{1-(1-a)^{t}}{a}\right]- \\
\left.-k(1-u)\left[\frac{-1-t}{2}+\frac{1-(1-a)^{t}}{a}\right]\right\}(5.17) \\
Z F B_{\text {staat }}=I(u+\delta)\left[\frac{1-t}{2}+(1-a) \frac{1-(1-a)^{t}}{a}\right]- \\
\left.-k u(1-u)(1-\delta)\left[\frac{-1-t}{2}+\frac{1-(1-a)^{t}}{a}\right]\right\}(5.18)
\end{gathered}
$$

Die Formeln der Elastizitäten des zusätzlichen Finanzierungsbedarfs gegenüber seinen Einflußparametern ergeben sich aus Ableitungsvorgängen gemäß der Formel 5.14. In den Formeln für die Elastizitäten wurden folgende Ausdrücke verwendet: 


$$
\begin{gathered}
(1-a) \frac{1-(1-a)^{t}}{a}=A_{1} \\
\frac{1-(1-a)^{t}}{a}=A_{2} \\
\frac{1-t}{2}=T_{1} \\
\frac{-1-t}{2}=T_{2} \\
\ln (1-a) \frac{(1-a)^{t+1}}{a}=L_{1} \\
\ln (1-a) \frac{(1-a)^{t}}{a}=L_{2}
\end{gathered}
$$

Für private Unternehmen gelten:

- die Elastizität gegenüber dem Gewinnsteuersatz "u":

$$
\varepsilon_{Z F B}^{u}=\frac{T_{1}+A_{1}-k(1-2 u)\left(T_{2}+A_{2}\right)}{T_{1}+A_{1}-k(1-u)\left(T_{2}+A_{2}\right)}(5.19)
$$

- die Elastizität gegenüber der jährlichen Investitionssumme:

$$
\varepsilon_{\mathrm{ZFB}}^{I}=1(5.20)
$$

- die Elastizität gegenüber der Dauer der Investitionskette "t": 


$$
\varepsilon_{Z F B}^{t}=\frac{t\left[k(1-u)\left(0,5+L_{2}\right)-\left(0,5+L_{1}\right)\right]}{T_{1}+A_{1}-k(1-u)\left(T_{2}+A_{2}\right)}(5.21)
$$

- die Elastizität gegenüber dem degressiven Abschreibungssatz "a":

$$
\begin{gathered}
\varepsilon_{z \rightarrow b}^{a}=\frac{-1+(1-a)^{z+1}-a(t+1)(1-a)^{t}}{a\left[T_{1}+A_{1}-k(1-u)\left(T_{2}+A_{2}\right)\right]}- \\
-\frac{k(1-u)\left[-1+(1-a)^{t}-a t(1-a)^{t-1}\right]}{a\left[T_{1}+A_{1}-k(1-u)\left(T_{2}+A_{2}\right)\right]}(5.22)
\end{gathered}
$$

- die Elastizität gegenüber dem Prozentsatz des Steuerabzugs für Investitionen "k":

$$
\varepsilon_{Z F B}^{k}=\frac{1}{1-\frac{T_{1}+A_{1}}{k(1-u)\left(T_{2}+A_{2}\right)}}
$$

Ähnlich ergeben sich die analogen Elastizitäten bei den staatlichen Unternehmen, wobei es hier einen zusätzlichen Einflußparameter gibt, nämlich den Ausschüttungssatz der Dividenden:

- die Elastizität gegenüber dem Gewinnsteuersatz "u":

$$
\varepsilon_{Z F B}^{u}=\frac{u\left[T_{1}+A_{1}-k(1-\delta)(1-2 u)\left(T_{2}+A_{2}\right)\right]}{(u+\delta)\left(T_{1}+A_{1}\right)-k u(1-u)(1-\delta)\left(T_{2}+A_{2}\right)}(
$$

- die Elastizität gegenüber der jährlichen Investitionssumme:

$$
\varepsilon_{\mathrm{ZFB}}^{I}=1(5.25)
$$

- die Elastizität gegenüber der Dauer der Investitionskette " $t$ ": 


$$
\varepsilon_{\mathrm{ZFB}}^{t}=\frac{t\left[-(u+\delta)\left(+0,5+L_{1}\right)+k u(1-u)(1-\delta)\left(0,5+L_{2}\right)\right]}{(u+\delta)\left(T_{1}+A_{1}\right)-k u(1-u)(1-\delta)\left(T_{2}+A_{2}\right)}(5.26)
$$

- die Elastizität gegenüber dem degressiven Abschreibungssatz a":

$$
\begin{aligned}
& \varepsilon_{\mathrm{ZFB}}^{a}=\frac{(u+\delta)\left[-1+(1-a)^{t+1}-a(t+1)(1-a)^{t}\right]}{a\left[(u+\delta)\left(T_{1}+A_{1}\right)-k u(1-u)(1-\delta)\left(T_{2}+A_{2}\right)\right]}- \\
& -\frac{k u(1-u)(1-\delta)\left[-1+(1-a)^{t}-a t(1-a)^{t-1}\right]}{a\left[(u+\delta)\left(A_{1}+T_{1}\right)-k u(1-u)(1-\delta)\left(T_{2}+A_{2}\right)\right]}(5.27)
\end{aligned}
$$

- die Elastizität gegenüber dem Prozentsatz des Steuerabzugs für Investitionen "k":

$$
\varepsilon_{Z F B}^{k}=\frac{1}{1-\frac{(u+\delta)\left(T_{1}+A_{1}\right)}{k u(1-u)(1-\delta)\left(T_{2}+A_{2}\right)}}
$$

- schließlich, die Elastizität gegenüber dem Dividendenausschüttungssatz " $\delta$ ".

$$
\varepsilon_{Z F B}^{\delta}=\frac{\delta\left[T_{1}+A_{1}+k u(1-u)\left(T_{2}+A_{2}\right)\right]}{(u+\delta)\left(T_{1}+A_{1}\right)-k u(1-u)(1-\delta)\left(T_{2}+A_{2}\right)}(5
$$

Diese erarbeiteten, allgemeinen Formeln wurden anschließend verwendet, um die Elastizitäten der ausgewiesenen Parameter unter den heutigen Verhältnissen $(u=45 \% ; t=5$ Jahre; $k=$ $=0,5 ; \delta=0,4)$ der rumänischen TBI zu berechnen (Tabelle 5.19).

Die Ergebnisse der Elastizitätsberechnungen zeigen, daß die einzige Variable, die sowohl bei staatlichen als auch privaten Unternehmen einen starken Einfluß auf den zusätzlichen Finanzierungsbedarf ausübt, der degressive Abschreibungssatz ist. Er kann durch geringfügige Variationen die Selbstfinanzienungskraft der Unternehmen erheblich beeinträchtigen (bei Senkung) oder erleichtern (bei Steigung). Wie für die Kapitalbereitstellungskosten, spielt das Abschreibungsregime auch für die Liquidität die entscheidende Rolle (unter der Bedingung der Existenz von Überschüssen jedes Jahr, vom Anfang an!). 
Die Senkung der Dauer des Erneuerungsprozesses würde die Aufgabe der staatlichen Unternehmen mit Ausnahme der Bekleidungsindustrie (negative Elastizitäten, größer als "-1") nicht wesentlich erleichtern. Dagegen hat dieser Parameter für die private Industrie eine höhere Bedeutung. Der Gewinnsteuersatz weist bei den privaten Unternehmen immer noch eine Elastizität größer 1 auf.

Tabelle 5.19: $\quad$ Elastizitäten des zusätzlichen Finanzierungsbedarfs gegenüber seinen Einflußparametern.

\begin{tabular}{||c||c|c|c|}
\hline privat & Textil & Bekleidung & Leder \\
\hline \hline $\mathrm{a}$ & 0,222 & 0,3125 & 0,248 \\
\hline$\epsilon_{\mathrm{ZFB}}{ }^{\mathrm{u}}$ & 1,112 & 2,122 & 1,049 \\
\hline$\epsilon_{\mathrm{ZFB}}{ }^{\mathrm{I}}$ & 1 & 1 & 1 \\
\hline$\epsilon_{\mathrm{ZFB}}{ }^{\mathrm{t}}$ & $-2,246$ & 24,67 & $-4,029$ \\
\hline$\epsilon_{\mathrm{ZFB}}{ }^{\mathrm{a}}$ & $-8,59$ & $-55,196$ & $-12,1$ \\
\hline$\epsilon_{\mathrm{ZFB}}{ }^{\mathrm{k}}$ & $-0,137$ & $-1,38$ & $-0,06$ \\
\hline
\end{tabular}

\begin{tabular}{||c||c|c|c|}
\hline staatlich & Textil & Bekleidung & Leder \\
\hline \hline $\mathrm{a}$ & 0,133 & 0,234 & 0,149 \\
\hline$\epsilon_{\mathrm{ZFB}}{ }^{\mathrm{u}}$ & 0,55 & 0,539 & 0,549 \\
\hline$\epsilon_{\mathrm{ZFB}}{ }^{\mathrm{I}}$ & 1 & 1 & 1 \\
\hline$\epsilon_{\mathrm{ZFB}}{ }^{\mathrm{t}}$ & $-0,185$ & $-3,178$ & $-0,398$ \\
\hline$\epsilon_{\mathrm{ZFB}}{ }^{\mathrm{a}}$ & $-5,334$ & $-11,492$ & $-5,716$ \\
\hline$\epsilon_{\mathrm{ZFB}}{ }^{\mathrm{k}}$ & $-0,058$ & $-0,032$ & $-0,057$ \\
\hline$\epsilon_{\mathrm{ZFB}}{ }^{\delta}$ & 0,536 & 0,175 & 0,535 \\
\hline
\end{tabular}

Da diese Unternehmen kleiner sind, wäre für ihre Liquidität seine Senkung immer noch von Bedeutung. Interessanterweise würde aber die Senkung des Gewinnsteuersatzes für staatliche Unternehmen keine wesentliche Verbesserung ihrer Finanzlage bewirken. Auch gegenüber dem Ausschüttungssatz zeigt sich der zusätzliche Finanzierungsbedarf wenig empfindlich. Den geringsten Einfluß übt nach der Elastizitätsanalyse der Steuerabzug für Investitionen auf die Finanzkraft aus. 


\subsection{Möglichkeiten der Überwälzung der Gewinnsteuer}

Die Möglichkeiten einer Regierung, eine aktive Steuerpolitik zu betreiben sind durch die Unsicherheit, mit der die Inzidenz unterschiedlicher Steuern bekannt ist, eingeschränkt. Die mögliche Eingrenzung dieser Unsicherheit ist von der Kenntnis der Richtungen der steuerlichen Über- und Rückwälzungen abhängig. Eine steuerpolitische Entscheidung kann also, wenn sie den Gedanken der Überwälzungsmöglichkeiten nicht berücksichtigt, erfolglos bleiben.

Der Kern der Diskussion in dieser Arbeit ist die Frage, ob unter den Bedingungen des rumänischen wirtschaftlichen Umfeldes, die Gewinnsteuer überwälzbar ist oder nicht. Sollte sie sich als überwälzbar erweisen, müßte man sich demnach keine ernsten Gedanken über die Belastung der Unternehmen mit Erfolgsteuern machen, da diese Belastung entweder über den Preis an die Kunden weitergegeben oder über niedrigere Löhne auf die Belegschaft zurückgeleitet werden könnte.

Der heutige Stand der wissenschaftlichen Diskussion erlaubt bis heute keine klare, theoretisch fundierte Aussage darüber. Die Theorie der Steuerinzidenz liefert Ansätze in beiden Richtungen: manche behaupten, die Gewinnsteuer sei durchaus nicht überwälzbar, andere manchmal anhand des selben statistischen Materials - genau das Gegenteil. Es gibt auch Untersuchungen, die zu der Schlußfolgerung gekommen sind, die Vor- und Rückwälzungsmöglichkeiten seien vom Fall zu Fall unterschiedlich, und zwar abhängig von bestimmten Eigenschaften des Marktes und vom Zeithorizont. Obwohl diese Problematik in den Industrieländern eine der bisher am besten empirisch untersuchten ist, sind die Forscher keineswegs auf eindeutige Ergebnisse gekommen.

Die in dieser Hinsicht klassische These behauptet die Nichtüberwälzwarkeit der Gewinnsteuer. Es wird argumentiert, daß die Unternehmer die Maximierung ihrer Gewinne anstreben. Die Höhe des Gewinns im Unternehmen sei von den Variablen $\mathbf{x}, \mathbf{y}$ und $\mathbf{z}$ abhängig, die frei sind:

$$
G=G(x, y, z)
$$

Die zu zahlende Gewinnsteuer ist:

$$
\mathrm{T}_{\mathrm{G}}=\mathrm{tG}
$$

wobei " $\mathrm{t}$ " der Durchschnittssteuersatz ist. Er ist üblicherweise konstant, kann aber auch mit "G" steigen. Der Gewinn nach Steuern ist dann: 


$$
G_{n}=G[1-t G]
$$

Der Unternehmer wird versuchen, den ihm verbleibenden Gewinn zu maximieren. Solange der Grenzsteuersatz dt/dG kleiner als $100 \%$ ist, wird der Unternehmer wie folgt überlegen: Je größer "G", um so größer ist auch der nach Besteuerung verbleibende Gewinn. Die Variablen $\mathrm{x}, \mathrm{y}$ und $\mathrm{z}$ haben also beim Maximum des Bruttogewinns dieselben Werte wie bei der Maximierung des Gewinns nach Steuern. Ausbringungsmenge und Preis werden dann von der Gewinnsteuer nicht beeinflußt. In der Preistheorie werden im Fall des Monopols Preis und Ausbringungsmenge eines Produktes durch den Schnittpunkt der Grenzkosten- mit der Grenzerlöskurve bestimmt. Im klassischen Fall des Polypol-Polypsons wird der Preis als Datum angesehen und der Anbieter wird so viel produzieren, bis seine Grenzkosten den auf dem Markt herrschenden Preis gleich werden. Gerade an diese Größen knüpft die Gewinnsteuer nicht an.

Somit schmälert die Gewinnbesteuerung die Rentabilität der Investitionen unmittelbar und kann unter Umständen Schrumpfungsprozesse auslösen. In den Vereinigten Staaten wurden in den sechziger Jahren zwei bekannte Modelle entwickelt, die diese Entwicklung veranschaulichen: das sogenannte HMM-Modell (HARBERGER -McLURE - MIESZKOWS$\mathrm{KI}$ ), das sich eher mit steuerinduzierten regionalen oder sektoralen Wachstumsprozessen befaßt (es werden präferenzielle Gewinnsteuererleichterungen angenommen), und das KRZYZANIAK-Modell, das die Wachstumseffekte der Besteuerung anhand eines neoklassischen Wachstumsmodells untersucht. Unter der Annahme, daß die Gewinneinkommensbezieher eine überdurchschnittliche Sparneigung besitzen, führt eine Gewinnsteuererhöhung gemäß KRZYZANIAK zu einem negativen gesamtwirtschaftlichen Spar- und Investitionseffekt, während eine Gewinnsteuersenkung die gesamtwirtschaftliche Spar- und Investitionsquote und damit auch das Wirtschaftswachstum erhöht. Es wird davon ausgegangen, daß die gesamtwirtschaftlichen Ersparnisse in vollem Umfang investiert werden (MUSGRAVE \& KRZYZANIAK, 1963). Die Anwendung dieses Modells auf eine empirische Untersuchung der Perioden 1935-1942 und 1948-1959 in den USA ergab trotzdem langfristig eine Überwälzung von sogar 134\%. Argumentiert wurde dieses Ergebnis damit, daß sich die Gesamtkapitalrentabilität in dieser Zeit nicht verringerte, obwohl der Körperschaftssteuersatz deutlich anstieg.

In den USA wurde auch in anderen zahlreichen Studien, basierend auf statistischen Annahmen, die Überwälzung der "corporate tax" untersucht. Die wichtigste Arbeit darunter, die die These der Nichtüberwälzung bekräftigte, war die von ADELMAN (1957), die den Anteil des Bruttogewinns am Volkseinkommen für die Perioden 1922-1929 und 1946-1955 analysierte, in denen der Körperschaftssteuersatz in den USA von $12 \%$ auf $52 \%$ erhöht wurde. Dieser Anteil hätte sich bei erfolgreicher Überwälzung erhöhen müssen, er blieb 
jedoch konstant. Zum gleichen Ergebnis ist DENISON in der Analyse der Periode 1929-1952 (1954) gekommen.

Später gelangten weitere Autoren zu ähnlichen Ergebnissen: z.B. GORDON (1967), für den die Gewinnsteuer zumindest auf kurze Sicht nicht überwälzbar ist, und AGAPITOS (1977), der für die britische Industrie in der Zeit 1951-1970 vollständige Nichtüberwälzbarkeit feststellt, und zwar auf Makroebene und unter der erschwerenden Hypothese des "mark-uppricing". Die statistischen Angaben in Großbritanien in diesen 20 Jahren deuten gemäß AGAPITOS weder auf inflationäre Preisaufstöße, noch auf deflationären Lohndruck hin, die auf Gewinnsteuererhöhungen zurückzuführen wären. Schließlich wiederholt KRZYZANIAK in einem seiner neuesten Beiträge (1988) die ursprünglichen Schlußfolgerungen der Nichtüberwälzbarkeit, gestützt auf die Untersuchung der neuesten Entwicklungen in der USIndustrie.

Trotz ihrer Konsistenz mit der bei Steuerfragen sehr ergiebigen neoklassischen (Investitions)Theorie, wird heute, wegen der Unklarheit der bisherigen empirischen Ergebnisse, in der Literatur der These von der Nichtüberwälzbarkeit der Gewinnsteuer nur noch der Rang eines nützlichen Ausgangspunktes für weitergehende Überlegungen eingeräumt (siehe z.B. NOLL, 1979, S.172).

Im deutschsprachigen Raum z.B. wurde die erste Theorie, die dem klassischen Paradigma widersprach, von FÖHL (1954) erörtert. In seiner "Kritik der progressiven Einkommensbesteuerung macht FÖHL auf den Unterschied zwischen Partial- und Totalanalyse aufmerksam. In einer Wirtschaft mit unelastischem Angebot (was auf kurzer Sicht für jede Volkswirtschaft zutreffen dürfte) erhöht sich die effektive Nachfrage um den Steuerbetrag unter der Bedingung, daß die Erhebung der progressiven Einkommens- bzw. Gewinnsteuern die Ausgaben der Unternehmer nicht reduziert und der Staat diese Einnahmen gänzlich wieder ausgibt. Bei angenommenem unelastischen Angebot und konstanten Kosten schlägt sich die erhöhte Nachfrage als erhöhter Gewinn bei den Unternehmern nieder. Nach Ablauf der Multiplikatorprozesse entspricht der Nettogewinn dem Bruttogewinn in der Ausgangssituation, also wurde die Gewinnsteuer vollständig überwälzt.

Im Gegensatz zu den klassischen, partialanalytischen Modellen, die von einer gegebenen Nachfragekurve ausgehen, berücksichtigt der Ansatz von FÖHL die Dynamik des volkswirtschaftlichen Kreislaufs, indem er der von der Budgeterhöhung verursachten, gleich großen Erhöhung der effektiven Nachfrage Rechnung trägt. Die sogenannte FÖHL-Debatte war ein wichtiger Bestandteil der wissenschaftlichen Diskussion in der Steuerlehre der 50er und sogar 60er Jahre. Aus der vorwiegend in der Zeitschrift "Finanzarchiv" geführten Diskussion ergab sich eine Systematik der Bedingungen, die für eine weitgehende Überwälzung gegeben sein müßten: 
a) Die privaten Investitionen dürfen in realer Höhe durch die Steuern und Ausgaben des Staates nicht verändert und müssen gänzlich aus Mitteln des privaten Sektors finanziert werden.

b) Die wirksame Geldmenge unter Berücksichtigung der Kreislaufgeschwindigkeit muß so elastisch sein, daß die Unternehmenssteuern überwälzt werden können.

c) Der Verbrauch der Unternehmer soll nicht eingeschränkt werden.

d) Das Sparen der Arbeitnehmer darf nicht anwachsen.

e) Es muß Vollbeschäftigung herrschen.

f) Der öffentliche Haushalt muß ausgeglichen sein. (WITTMANN, 1975, S.121)

Auch im angelsächsischen Raum ist die These der Überwälzbarkeit in verschiedenen Ausmaßen der Gewinnsteuer stark vertreten worden. Interessanterweise kommen die empirischen Untersuchungen, die den Anteil des Gewinns am Volkseinkommen als Überwälzungsmaßstab verwenden, wie die von ADELMAN (1957) und DENISON (1954), zu dem Ergebnis der vollständigen Nichtüberwälzbarkeit. Diejenigen Ansätze dagegen, die auf der Dynamik der Kapitalrentabilität basieren, behaupten immer die mindestens langfristige Vollüberwälzung. CLENDENIN (siehe hierzu WITTMANN, 1975, S.118) stellte dieselbe Kapitalrentabilität in den Jahren 1926-1929, 1936-1937, 1940 und 1952-1955 (Perioden mit ähnlichen wirtschaftlichen Verhältnissen in den USA) fest, obwohl die Körperschaftssteuersätze in dieser Zeit deutlich erhöht worden sind. In bezug auf die gesamte Industrie - so argumentiert er - treffe es also zu, daß die Körperschaftssteuer überwälzt worden sei. Aber für einzelne Branchen sind die Ergebnisse sehr unterschiedlich. KRZYZANIAK (siehe oben) kalkuliert sogar einen Überwälzungsgrad von $134 \%$, basierend auf ähnlichen Überlegungen.

Auch spätere Überlegungen bestätigten die These der Überwälzung in irgendeiner Form. BRUNO (1970) ging davon aus, daß der Preis der Produkte von den Bedingungen des Zugangs eines neuen Anbieters zum Markt und nicht von den Kosten abhängig sei. Demnach kann eine Erhöhung der Gewinnsteuer in einem Oligopolmarkt mit Skalenerträgen im Gegensatz zum vollkommenen Markt sofort überwälzt werden. PENNER (1967) wies darauf hin, daß das neoklassische Modell auf eine große Aktiengesellschaft, die sich in einem oligopolistischen wirtschaftlichen Umfeld bewegt, nur begrenzt übertragbar ist. Zum einen gelten andere Regeln für die Bestimmung der angebotenen Mengen, zum anderen erfolgt die Preisbildung auch in den meisten Fällen nach Daumenkalkulationen ("mark-up pricing"). Wenn zudem auch die Unsicherheit berücksichtigt wird, läßt die allgemeine Praxis der Preisaufschläge genug Raum für die Überwälzung der Gewinnsteuer, selbst auf kurze Sicht. BEATH (1979) schlägt unter analogen Hypothesen (oligopolistisches Angebot, mark-up pricing) eine ähnliche Argumentation vor. Durch die Analyse statistischer Angaben für die USWirtschaft 1953-1973 stellt er die volle Überwälzung der Gewinnsteuer sogar auf kurze Sicht fest. Hauptgrund dafür wären unelastische Gewinnerwartungen der Unternehmen, die die Preisbildung entscheidend beeinflussen. 
Der entscheidende Schwachpunkt aller auf der Empirie gestützten Ansätze, unabhängig davon, an welche Variable (Anteil der Brutto- oder Nettogewinnmasse am Volkseinkommen, durchschnittliche Eigen- oder Gesamtkapitalrentabilität usw.) sie den Überwälzungsgrad der Körperschaftssteuer binden, oder zu welchen Ergebnissen sie kommen, ist, daß selbst die Nettogewinne von zahlreichen Faktoren und nicht allein von den Steuern beeinflußt werden. Solange der Einfluß der Körperschaftssteuer auf die Gewinne nicht von den Einflüssen anderer Faktoren isoliert werden kann, können die Aussagen über die Überwälzung empirisch nicht gesichert werden. RATCHFORD \& HAN z.B. (siehe WITTMANN, 1975, S.119) versuchten, die Unterschiede zwischen den in den 50er Jahren verfügbaren Ergebnissen (insbesondere von den Arbeiten von ADELMAN, DENISON und CLENDENIN) zu erklären. Es stellte sich heraus, daß in den untersuchten Perioden nicht nur die Körperschaftssteuersätze geändert wurden. Der Zinssatz war um $40 \%$ und mehr gefallen, während die Umschlagshäufigkeit des Kapitals zugenommen hatte. Die aus diesen beiden Faktoren resultierenden zusätzlichen Gewinne reichten offensichtlich aus, um die gestiegene Körperschaftssteuerbelastung auszugleichen.

Schließlich gibt es auch eine dritte Meinung in dieser Diskussion: danach ist die Gewinnsteuer in einer wachsenden Wirtschaft kurzfristig zwar nicht, langfristig jedoch durchaus überwälzbar. Das erste wichtige Beispiel für diesen Ansatz ist die Arbeit von OAKLAND (1972), die zum ersten Mal diese Idee durch statistische Verarbeitung langer Zeitreihen (1930-1968) in bezug auf die Bruttogewinne und die Körperschaftssteuersätze in den USA unterstützt.

Im deutschsprachigen Raum behauptet z.B. BALLARINI (1982, S.32) daß, wenn die Umsatzmaximierung anstatt der Gewinnmaximierung verfolgt wird, die Gewinnsteuerüberwälzung unter bestimmten Voraussetzungen möglich ist.

Schließlich verbindet die Referenzarbeit von EPPLER (1980) die Partialanalyse, indem ein deutsches repräsentatives Unternehmen modelliert wird, mit der Totalanalyse, indem das makroökonomische NIEHANS-Modell (1959) der deutschen Volkswirtschaft zwecks Untersuchung des "kollektiven Überwälzungsgrades" der Körperschaftssteuer benutzt wird. Ergebnis: die Überwälzung der Körperschaftssteuer in Deutschland ist bisher aufgrund einer steuergenerierten Zusatznachfrage (EPPLER, 1980, S.73) nur in den Zeiten des Aufschwungs gelungen. Bei fixierter Preis-Absatzkurve des "repräsentativen Unternehmens" wäre dagegen auch in diesem Modell eine Überwälzung der Körperschaftssteuer nicht möglich (EPPLER, 1980, S.77).

Obwohl in dem NIEHANS-Modell viele zahlenmäßige Werte der Einflußgrößen (wie: marginale Ausgabenneigung der Unternehmer, Preiselastizität der Nachfrage, Kapitalintensität usw.) strikt auf die deutsche Volkswirtschaft bezogen sind, besitzen die o.g. Ergebnisse einen 
hohen Grad wissenschaftlicher Allgemeinheit und sind mit der neoklassischen Investitionstheorie, die der vorliegenden Arbeit zugrunde liegt, durchaus vereinbar.

Angesichts der eigentlichen Frage, ob in der rumänischen TBI die Gewinnsteuer überwälzt werden könnte müssen in Anlehnung zu den vorher aufgezählten Bedingungen von WITTMAN auch folgende Fragen berücksichtigt werden:

a) Welche Marktform ist gegeben?

b) Herrscht vollkommene Kapitalmobilität (die - gegebenenfalls - die regionale oder intersektorale Steuervermeidung ermöglichen würde)?

c) Wie sieht die Preiselastizität der Nachfrage- und Angebotskurven für die Produkte der Textil- und Bekleidungsindustrie aus?

d) Wie verlaufen die Stückkosten: konstant, steigend oder sinkend (im letzten Fall ist die Steuer weniger überwälzbar)?

e) Ist die Steuer proportional oder nicht (eine progressive Steuer ist schwieriger zu überwälzen, da weniger vorausschätzbar)?

Im speziellen Fall der rumänischen TBI muß auch berücksichtigt werden, daß der Betrachtung eine kurze Periode zugrunde liegt, in der die Höhe des Angebots von den gegebenen Kapazitäten abhängt, und zugleich Kapazitätsanpassungen sogar kurzfristig erwünscht sind.

Ob die nach der Wende in neuer Form eingeführte Gewinnsteuer überwälzt wurde oder nicht, ist unmöglich zu beantworten. Wie schon gezeigt, hat die Analyse von langfristigen und zuverlässigen Zahlenreihen der amerikanischen oder britischen Volkswirtschaften jeweils nicht zu eindeutigen Ergebnissen geführt. Hinzu kommt, daß in Rumänien der Zeithorizont nicht ausreicht, um eine relevante statistische Analyse zu machen, und der durchschnittliche Gewinnsteuersatz mittlerweile wegen des Übergangs vom progressiven zum proportionalen Tarif gesunken ist. Auch erlaubt manchen Unternehmen die Monopollage, "mark-up pricing" zu betreiben. Der inflationäre Preisanstieg war zwischen Sektoren, Branchen und Produktgruppen in dieser Zeit unterschiedlich. Da die relativen Preise sich verändert haben, läßt Vieles vermuten, daß die Unternehmen beim Überwälzungsspiel in Gewinnern und Verlierern eingestuft werden könnten.

Die Frage, ob die Unternehmen der rumänischen TBI von nun an die Gewinnsteuer in ihrer heutigen Fassung zumindest teilweise überwälzen, oder eine mögliche Erhöhung der Gewinnsteuer weiterleiten könnten, kann in der heutigen rumänischen Wirtschaftskonstellation nur negativ beantwortet werden. Außer der Tatsache, daß fast alle vorhin angegebenen Bedingungen der weitgehenden Überwälzung (WITTMANN, 1975, S.121) in dem wirtschaftlichen Umfeld der rumänischen TBI unerfüllt bleiben (die Geldmenge ist infolge der antiinflationären Geldpolitik der Regierung unelastisch; die Gewinne der Unternehmer sind auch nicht so spektakulär, daß ihre Senkung ihre Ausgaben unberührt ließe; es gibt keine 
Vollbeschäftigung - dagegen befindet sich die Volkswirtschaft in der Transformationskrise; der öffentliche Haushalt ist schon defizitär), sprechen auch weitere Argumente für die Nichtüberwälzung.

Erstens sind die Finanzierungsmöglichkeiten eines rumänischen TBI-Unternehmens bei der Modernisierung seiner Kapazitäten von der Höhe des verfügbaren Gewinns abhängig. Es kann also durch Kapazitätsanpassung das Betriebsoptimum nicht schnell genug erreichen, und wegen dieses Mangels an Kapitalmobilität werden seine Überwälzungsmöglichkeiten erheblich eingeschränkt.

Zweitens ist eine Rückwälzung der Gewinnsteuer auf die Arbeitnehmer angesichts des dominierenden Staatseigentums und der Durchschnittslöhne, die sich ohnehin an der Grenze der Armut befinden, kaum denkbar.

Drittens ist die Marktlage der Unternehmen der TBI bei weitem nicht so günstig wie diejenige anderer Unternehmen, die von der geerbten Monopolstruktur der ehemaligen Planwirtschaft profitieren (vor allem in der Erzeugung von Energie, Rohstoffen und Halbfabrikaten). Auf den rumänischen Märkten der Textil-, Bekleidungs- und Lederprodukte herrscht Wettbewerb, sowohl zwischen rumänischen, als auch gegenüber ausländischen Mitanbietern.

Auch die Nachfrage für solche Produkte ist in Rumänien viel elastischer als bei Lebensmitteln oder Heizung, Wasser und Energie. Deswegen können bei TBI-Produkten Preiserhöhungen, die die Gewinnsteuer kompensieren sollten, über dem Inflationsdurchschnitt praktisch nicht durchgesetzt werden, da die Senkung der umgesetzten Mengen infolge der Verteuerung die Bruttoeinnahmen nicht steigen läßt. Die im Kapitel 2 gezeigte parallele Entwicklung der Produktion, Brutto- und Nettorenditen und Gewinnsteuern, korreliert mit den Preisindizes und der Senkung der effektiven Kaufkraft der Bevölkerung, bestätigt diese Hypothese. Auf manchen der internationalen Märkte - bzw. auf den Märkten der ehemaligen RGW-Partner Rumäniens - herrschen ähnliche Bedingungen wie in Rumänien; auf anderen Märkten ist die Konkurrenz noch stärker oder liegen die Ansprüche der Kunden viel höher. Eine Erhöhung der Gewinnsteuer, unabhängig davon wie elastisch sich Rentabilität der Investitionen und Finanzkraft der Unternehmen hiergegenüber verhalten würden, würde also von den TBIUnternehmen in voller Höhe getragen werden. 
Mihail Nedelea - 978-3-631-75036-0 Downloaded from PubFactory at 01/11/2019 09:01:58AM via free access 


\section{KAPITEL 6: GESTALTUNG UND EINFLUSS DER VERMÖGEN- UND KAPITALVERKEHRSSTEUERN}

\subsection{Gesetzlicher Rahmen}

In der rumänischen Gesetzgebung wird sowohl der Bestand an Vermögensgegenständen (damit sind bislang in Rumänien nur Grundstücke, Gebäude und Kraftfahrzeuge gemeint) als auch deren Verkehr besteuert. Diese Steuern wurden am Anfang des kommunistischen Regimes zur Enteignung der damaligen Mittelschicht benutzt, da die hohen Steuersätze nur den Besitz von Privatpersonen mit hohen Sätzen betrafen. Dagegen waren sämtliche Vermögensgegenstände der Volkseigentumsbetriebe weitgehend von diesen Steuern befreit. Deren Gebäude wurden erst 1981 von einer Steuer erfaßt, die wie die 1974 eingeführte Gebühr für die Benutzung öffentlichen Bodens von juristischen Personen, darauf abzielte, eine effizientere Nutzung der volkseigenen Immobilien zu erreichen. Erst nach der Wende (1990) sicherte die neue Regierung die Gleichstellung der natürlichen und juristischen Personen gegenüber den Bestand- und Kapitalverkehrsteuern, indem auch die juristischen Personen zu allen allgemeinen Steuern dieser Kategorie herangezogen wurden. Ein weiterer Zweck dieser Maßnahme war es, die Finanzkraft der Kreise und Gemeinden zu stärken.

Im folgenden wird nur auf die Gesetze und sonstigen Regelungen eingegangen, die die Besteuerung von juristischen Personen betreffen. Auf die Miteinbeziehung der Steuern für natürliche Personen wurde verzichtet, da die Zahl der Personenunternehmen in Rumänien zu vernachlässigen ist.

Weiter gilt allgemein für diese Bestands- und Kapitalverkehrsteuern, daß sie, gemäß den Normen Nr.150.035/16.01.1992 des Finanzministeriums über die Bilanzierung, von dem steuerpflichtigen Gewinn als Betriebskosten abzugsfähig sind.

\subsubsection{Die Gebühr für die Benutzung öffentlichen Bodens von juristischen Personen}

Diese Gebühr wird für alle Grundstücke des staatlichen Besitzes, die derzeit von Unternehmen (mit staatlichem oder privatem Kapital) verwaltet oder benutzt werden, und nicht der landoder forstwirtschaftlichen Produktion dienen, erhoben.

Erklärung: Die überwiegende Mehrheit der Unternehmen, unabhängig davon, ob mit staatlicher oder privater Mehrheitsbeteiligung, sind in Rumänien keine Eigentümer der Grundstücke, auf denen sie stehen. Nach der Wende gab es bisher keine gründliche Regelung 
der Eigentumsverhältnisse bei nichtlandwirtschaftlichen Grundstücken. Lediglich private, natürliche Personen durften bisher Eigentümer mit vollen Rechten von Grundstücken sein. Die staatlichen Unternehmen stehen logischerweise auf staatlichem Boden (1948 nationalisiert). Aber selbst privat neugegründete, kürzlich privatisierte Unternehmen, oder solche mit ausländischem Kapital sind nicht Eigentümer ihrer entsprechenden Grundstücke, sondern haben sie vom Staat in Konzession bekommen. So waren z.B. im Juni 1993 von allen bis dahin landesweit privatisierten ehemaligen staatlichen Unternehmen nur 32 zugleich Eigentümer ihrer Grundstücke. Alle andere bezahlen demnach Pachten und - zusätzlich - die oben erwähnte Gebühr. Diese Gebühr ist also das Pendant der die natürlichen Personen belastenden Grundsteuer.

Vom Standpunkt der Unternehmen aus stellt diese Gebühr zweifellos eine Grundsteuer mit Fixkostencharakter dar, und sie wird von allen für diese Arbeit relevanten Unternehmen gezahlt.

Allerdings sind die damit verbundenen Steuerzahlungen nicht hoch. Gemäß dem Gesetz Nr.69/1993 sind alle Unternehmen verpflichtet, diese Gebühr proportional zu der Fläche der von ihnen benutzten Böden jährlich zu entrichten. Dem Tarif nach ist diese "Gebühr" eine Stücksteuer. Das Gesetz sieht Beträge zwischen 20 Lei/qm und 120 Lei/qm je nach der Größe und Wirtschaftsbedeutung der Ortschaft und der Lage des Grundstücks darin vor (Kurs März 1994: $1 \mathrm{DM}=1.000$ Lei),

An dieser Stelle fällt eine Merkwürdigkeit dieses Beschlusses auf: Obwohl das gesamte Aufkommen dieser Gebühr in die Kreishaushalte fließt, dürfen die Kreisprefekturen (Vertretungen der Regierung auf Kreisebene, wie in Frankreich) lediglich die Ortschaften nach ihrer Bedeutung in die Klassen I bis IV einstufen. Dagegen ist die Eingliederung der Grundstücke in die Klassen A bis D, nach ihrer Lage in der Ortschaft, Aufgabe der Stadtpräsidien, die somit Entscheidungskraft über eine Steuer erhalten, die sie überhaupt nicht tangiert.

Gemäß der Regierungsordonanz Nr.15/19.08.1992 sind die Kreispräsidien (von der Kreisbevölkerung gewählt) - bzw. das bukarester Stadtpräsidium - berechtigt, diese Gebühr mit einem Hebesatz von $100 \%$ bis $150 \%$ zu belegen. Dadurch steigt die jährliche Belastung aufgrund dieser Gebühr zu maximal 180 Lei/qm in der Stadtmitte von Bukarest (etwa 0,18 DM/qm zum freien Währungskurs von März 1994). 


\subsubsection{Die Gebäudesteuer für juristische Personen}

Die Gebäudesteuer wird immer noch vom Gesetz Nr.25/1981, sowie neuerdings vom Regierungsbeschluß Nr.26/1992 geregelt. Demgemäß werden die gewerblichen Gebäude jährlich mit $0,75 \%$ des Fiskalwertes besteuert, falls das Unternehmen sich mehrheitlich in Staatsbesitz befindet, oder mit 1,50\%, im Fall der mehrheitlich privaten Unternehmen. Die Kreis- bzw. Stadtpräsidien können auf diese Tarife einen Hebesatz von bis zu $130 \%$ aufschlagen.

Kommentar: Der Eindruck einer tief in die wirtschaftliche Substanz eingreifenden Gebäudesteuer, den diese hohen Prozente erwecken könnten, wird von der folgenden Tatsache korrigiert: da es sich um eine Lokalsteuer handelt, wird die Steuerschuld von dem Kreis- bzw. örtlichen Finanzamt berechnet, basierend auf dem bei der Gründung des Unternehmens in den Registern eingetragenen Fiskalwert. Nach 3 Jahren anhaltender Inflation ist die Steuerschuld, die sich aus diesem Fiskalwert ergibt, faktisch unbedeutend geworden.

\subsubsection{Die Kfz-Steuer für juristische Personen}

Sie hat ihren Ursprung in der Kfz-Steuer für natürliche Personen, die vor der Wende die einzigen waren, die diese Steuer zahlten. Entsprechend der kommunistischen Auffassung, war der Besitz eines Pkw's von einer Privatperson ein Luxus.

Das Gesetz Nr.45/14.05.1992 hat die Basis dieser Steuer verbreitert, indem auch die juristischen Personen steuerpflichtig wurden. Von der Steuer sind nur die öffentlichen Institutionen und Gebietskörperschaften, sowie die Unternehmen des öffentlichen städtischen Personenverkehrs, befreit. Die Einnahmen dieser Steuer fließen in den Kreishaushalt.

Im Fall des maximal erlaubten Hebesatzes von 130\% (Regierungsordonanz Nr. 15/19.08.1992 "Über die Kreis- und Gemeindesteuern und -gebühren") belastet diese Steuer die Kraftfahrzeuge jährlich für je 500 Kubikzentimeter (oder angefangenen Teil davon) wie folgt:
- Personenkraftwagen
390 Lei
- Autobusse und Ähnliches
1170 Lei
- Lastkraftwagen
975 Lei

\subsubsection{Die Gesellschaftsteuer}

Die Gesellschaftsteuer stellt eigentlich eine Menge von Abgaben dar, die die Unternehmen anläßlich ihrer Gründung oder jeder Änderung in ihrem Statut, Stammkapital oder in ihrer 
Rechtsform, die beim Handelsregister anmeldungs- und/oder eintragungspflichtig ist, dem Handelsregisteramt (öffentliche Institution) zahlen müssen.

Kommentar:In diesem Fall handelt es sich um "versteckte" Steuern. Man könnte einwenden, daß diese Zwangsabgaben eher einen Gebührencharakter haben, da sie nicht direkt in einen öffentlichen Haushalt fließen. Dagegen spricht aber, daß ihnen keine besondere Leistung des Staates gegenüber steht (für ein Unternehmen bedeutet es keinen von einem öffentlichen Gut gestifteten Nutzen, in diesem Register eingetragen zu sein. Eher könnten sie vom Standpunkt des Staates als Beiträge für die Erhaltung des Handelsregisteramtes angesehen werden, obgleich ihr Aufkommen den Bedarf weitgehend überschreitet, was sie wiederum den Steuern annähert. Vom Standpunkt der Unternehmen stellen sie aber zweifellos Steuern mit gelegentlichem Charakter dar. Wichtiger dürften folgende Bestimmungen sein:

Bei der Eintragung ins Handelsregister müssen die neugegründeten Gesellschaften aller Rechtsformen, einschließlich der Personenunternehmen, der Gemeinschaftsunternehmen und der Töchter der ausländischen Gesellschaften, unterschiedliche Beträge entrichten (siehe Tabelle 6.1).

Für die Erhöhung des Stammkapitals gelten dieselben Kapitalklassen, wobei die Gebühren halbiert werden (z.B. für eine Erhöhung mit 9.000.000 Lei muß das Unternehmen 20.000 Lei statt 40.000 Lei bei der Eintragung dieser Änderung in das Handelsregister zahlen).

Darüber hinaus sind die Aktiengesellschaften und Kommanditgesellschaften auf Aktien verpflichtet, für jede Aktienausgabe eine Gesellschaftsteuer von $0,5 \%$ vom totalen Wert der im Prospekt angekündigten Aktien zu zahlen. Somit erhöhen sich im ersten Jahr die Kosten dieser Form von Finanzierung.

\subsubsection{Grund- und Gebäudeerwerbsteuer für juristische Personen}

Der Eigentumswechsel von Immobilien (Gebäude und Grundstücke sind für diese Arbeit interessant) zwischen juristischen Personen oder zwischen letzteren und Privatpersonen sind, gemäß des Regierungsbeschlüsses Nr.1295/13.12.1990 steuerpflichtig. Jede Änderung der Eigentumsverhältnisse eines Grundstücks oder Gebäudes bringt eine Gebühr mit sich, die laut Gesetz in progressiven Sätzen von 7\% für einen vereinbarten Entgelt bis 20.000 Lei bis $16 \%$ für einen Entgelt über 160.000 Lei gestaffelt ist.

Mit der Entwicklung der Inflation sind 160.000 Lei mittlerweile (März 1994) gleich etwa 160 DM geworden. Es gibt also keine Immobiliengeschäfte mit einem Wert unter 160.000 Lei. 
Demzufolge wird jeder An- oder Verkauf, und auch jede Schenkung, mit dem Höchstsatz von $16 \%$ besteuert.

Tabelle 6.1: Gesellschaftsteuer auf das Stammkapital

\begin{tabular}{||l|l|l||}
\hline Stammkapital & Eintragungsgebühr & Relative Belastung \\
\hline \hline 100.000 Lei(*) & 5.000 Lei & $5 \%$ \\
\hline $100.001-200.000$ Lei & 8.000 Lei & $4 \%$ bis $8 \%$ \\
\hline $200.001-1.000 .000$ Lei & 13.000 Lei & $1,3 \%$ bis $6,5 \%$ \\
\hline $1.000 .001-2.000 .000$ Lei & 20.000 Lei & $1 \%$ bis $2 \%$ \\
\hline $2.000 .001-5.000 .000$ Lei & 30.000 Lei & $0,6 \%$ bis $1,5 \%$ \\
\hline $5.000 .001-10.000 .000$ Lei & 40.000 Lei & $0,4 \%$ bis $0,8 \%$ \\
\hline über 10.000.000 Lei & 50.000 Lei & $\begin{array}{l}0,5 \% \text { bis } 0 \% \text { im } \\
\text { Grenzfall des unendli- } \\
\text { chen Stammkapitals }\end{array}$ \\
\hline
\end{tabular}

(* - das minimale, vom Gesetz zugelassene Stammkapital einer GmbH).

Kommentar: Im Fall der Schenkung kann die Steuerzahlung stark reduziert werden, indem der fiskalische Wert zur Berechnung der Steuerschuld angegeben wird. Die fiskalischen Werte der Immobilien entsprechen ihren Preisen in den siebziger Jahren, die heute zwischen 20 und 100 mal oder sogar mehr auf dem heutigen Immobilienmarkt höher liegen. Von diesem Vorteil können aber eher Privatpersonen profitieren; bei einer normalen Transaktion zwischen Firmen muß aus buchhalterischen Gründen vor dem Notar der reale Wert der Transaktion veranlagt werden und dadurch kommt die Zahllast in voller Höhe zustande. Weiter wird dieser Spielraum dadurch eingeschränkt, daß der angegebene Wert der Transaktion nicht kleiner als der Versicherungswert des verkauften Gegenstandes sein darf.

Als Ergänzung sei erwähnt, daß auch die Mehrwertsteuer hinzu kommt und die Belastung der Transaktionen erhöht. Weder in der Regierungsordonanz Nr.3/27.07.1992 "Über die Mehrwertsteuer", noch im Gesetz Nr.130/1992 mit demselben Namen, wird auf die Frage eingegangen, ob mit der Einführung der Mehrwertsteuer die Immobilienverkehrssteuer ausfällt oder nicht. Dagegen wird in denselben Verordnungen ausdrücklich bestimmt, daß der Verkauf von Immobiliengegenständen der Mehrwertsteuer mit dem Satz $18 \%$ unterstellt ist. Demzufolge liegt in diesem Fall eine Doppelbesteuerung vor. 
Allerdings belastet die Immobilienverkehrssteuer nur die bereits existierenden Gebäude, da von einem freien Verkehr von Grundstücken zwischen juristischen Personen noch nicht gesprochen werden kann (siehe hierzu Erklärungen im Abschnitt 6.1.1. und ferner, für die ausländischen Investoren, Kapitel 7). Die Errichtung z.B. einer neuen Produktionshalle ist nur der Mehrwertsteuer auf die Leistungen des Baunternehmens und sonstiger Lieferanten unterstellt.

\subsubsection{Die Steuer auf den Verkauf von Aktiva der staatlichen Unternehmen}

Diese Steuer stellt eine besondere Art von Kapitalverkehrssteuer dar. Sie wurde durch das Gesetz Nr.54/ 1.06.1992 eingeführt. Steuerpflichtig sind laut dieses Gesetzes die staatlichen Unternehmen, die über öffentliche Versteigerungsverfahren solche Teile ihres Vermögens verkaufen, die selbständig organisierte Einheiten darstellen und unabhängig funktionieren können ("Aktiva", im Sinne des Gesetzes Nr.58/14.08.1991 "Über die Privatisierung der (Handels)gesellschaften"). Damit ist also nicht der Verkauf von irgendwelchen isolierten Anlagen, Maschinen oder Gebäuden, die selbständig keine Produktionseinheit darstellen, gemeint, obschon diese auch durch Versteigerungen verkauft werden können.

Die Steuerschuld ist bei diesen Vorgängen 20\% des Verkaufswertes. Für den Fall, daß dieser Wert niedriger als der inflations- und abnutzungsangepaßte Buchwert der verkauften Aktiva ist, fällt die Steuerschuld aus. Auch wenn die Differenz zwischen den beiden Werten kleiner ist als die Steuerschuld, verringert sich letztere bis sie gleich dieser Differenz ist, so daß die dem verkaufenden Unternehmen zufließende Summe nicht wegen der Steuerzahlung allein niedriger als der o.g. Buchwert werden kann.

\subsection{Die Bedeutung der Vermögen- und Kapitalverkehrsteuern für die Investitionen}

Der Versuch, den Einfluß dieser Steuern auf die Kapitalbildung in der rumänischen (Textil)Industrie zu erfassen, soll von einer Trennung der Unternehmen in "bereits existierende" und "neu zu gründende" begleitet werden. Hierfür spielt die Eigentumsfrage nur eine untergeordnete Rolle (bei der Gebäudesteuer z.B., wo die Staatsunternehmen mit einem halbierten Steuersatz belegt sind); vielmehr ist es relevant, ob ein Unternehmen sich in der Gründungsphase befindet und demzufolge der Gesellschaftsteuer unterstellt ist, ob es Immobilien zu kaufen beabsichtigt oder vor kurzem ein Grundstück oder ein Gebäude gekauft hat, das dann für die Buchführung und das Finanzamt neubewertet werden mußte (was wiederum bei den neugegründeten Unternehmen mit höherer Wahrscheinlichkeit der Fall ist). 
Aus dem vorhin aufgeführten gesetzlichen Rahmen ergibt sich ohne weiteres, wenn man die Zahlen betrachtet, daß die Kfz-Steuer sowohl von dem Rentabilitäts- als auch von dem Liquiditätseffekt her voll zu vernachlässigen ist. Die Zahllasten zwischen $1 \mathrm{DM}$ und 5 DM pro Jahr und Fahrzeug (abgesehen von der Pflichtversicherung) machen sie zu einer Bagatellsteuer. Dasselbe gilt für die Grundsteuer.

Für die Unternehmen die schon früher gegründet worden sind, gleichgültig ob mit staatlichem oder privatem Mehrheitskapital, und keine Gebäudetransaktionen vornehmen, bedeutet auch die Gebäudesteuer keine zu erwähnende Belastung, da wie gesagt, diese aufgrund der alten Fiskalwerte der Gebäude, die diese Firmen besitzen, berechnet wird. Das ist aber nicht der Fall, wenn ein solches - oder ein neugegründetes Unternehmen, mit rumänischem oder ausländischem Kapital - ein Gebäude von einem anderen Unternehmen oder von einer Privatperson kauft. In diesem Fall muß der tatsächlich gezahlte Preis in die Bilanz eingetragen werden; zugleich wird dieser Wert auch in die Register des Finanzamtes aufgenommen. Von nun an wird das Unternehmen jährlich 0,75\% (wenn staatlich) bzw. $1,5 \%$ (wenn privat) von diesem neuen Wert des Gebäudes als Gebäudesteuer zahlen. Im hypothetischen Fall der Geldwertstabilität würde dies für das Unternehmen eine wichtige Belastung bedeuten, die sowohl Renditen als auch Liquidität mindern würde. Der Steuersatz ist ziemlich hoch und, falls der neue Fiskalwert nicht von der Inflation verzerrt wird, dann schlägt die Belastung voll zu Buche. Insbesondere in dieser Transformationszeit, in der die neue politische Macht in Rumänien sich andauernd für Marktwirtschaft und Rechtsstaat ausspricht, ist es auch zu bedauern, daß der Staat eine Diskriminierung zwischen privatem und öffentlichem Eigentum praktiziert.

Auch wenn ein Unternehmen eine neue Produktionshalle oder ein anderes Gebäude selber baut, wird der Fiskalwert demzufolge neuere Preisverhältnisse widerspiegeln und die Steuerlast wird viel höher als bei alten Gebäuden sein. Allerdings ist es fast unmöglich, diese Belastung in die Kapitalbereitstellungskosten oder in das Modell des zusätzlichen Finanzierungsbedarfs einzukalkulieren. Erstens werden Gebäude in den Firmenbilanzen nicht gesondert ausgewiesen, während beim Finanzamt und im Finanzministerium die Fiskalwerte nicht nach gewerblichen, sondern nach geographischen Kriterien geordnet sind. Das Gewicht der Gebäude im Anlagevermögen kann von daher nicht erfaßt werden. Zweitens müßte man auch darüber Informationen haben, wieviele von den existierenden Gebäuden jährlich verkauft werden - was die Aktualisierung ihrer Fiskalwerte erzwingen würde, und wieviele von den im Besitz der Unternehmen existierenden Gebäuden schon von ihrem Fiskalwert her aktualisiert worden sind.

Dieselben Argumente gelten auch für die Grund- und Gebäudeerwerbsteuer: angenommen, eine Investitionskette (gleichgültig, ob sie von einem neugegründeten oder schon bestehenden Unternehmen vorgenommen wird) würde nur aus Boden- und Gebäudeanschaffungen 
bestehen, dann würde sich der zusätzliche Finanzierungsbedarf jährlich mit $16 \% \mathrm{x}$ I, das heißt mit der Steuerlast, erhöhen. Falls die Grund- und Gebäudeinvestitionen einen Bruchteil " $\tau$ " von der gesamten jährlichen Investition "I" ausmachen, dann ist die Erhöhung des zusätzlichen Finanzierungsbedarfs, die von dieser Steuer verursacht wird, mit $16 \%$ x $\tau$ x I gleichzusetzen. Der Einfluß auf die Rentabilität ist dagegen nicht so dramatisch, da sie schon im ersten Jahr als Ausgabe abgesetzt werden kann. Von daher ist diese Steuer vielmehr als eine Umsatzsteuer zu betrachten. Immerhin belastet diese Steuer die neu zu gründenden Unternehmen stärker als die schon existierenden, was sich gewiß negativ auf Privatisierung und ausländische Investitionen auswirken kann. Ein anderer Effekt, den diese Steuer, zusammen mit den Bestimmungen der Gebäudesteuer verursacht, ist die Steuerausweichung der neuen Unternehmen, die lieber mieten oder pachten, als zu kaufen. Im Fall der Vermietung muß der Gebäudewert nicht aktualisiert werden und es fällt auch keine Gebäudeerwerbsteuer an. Die Struktur der Investitionen wird also von diesen beiden Steuern beeinflußt, das heißt daß der Anteil an Gebäuden abnimmt. Dies verlangsamt aber den Prozeß des Übergangs des Staatseigentums in private Hände, weil die Gebäude weiter in Staatsbesitz bleiben; außerdem hat an der Sanierung ihrer Bausubstanz weder der (für die meisten gewerblichen Gebäuden) staatliche Vermieter, noch der private Mieter ein Interesse, weil er nicht weiß, ob er im nächsten Jahr den Vertrag verlängern kann.

Die Wirkungen der Gesellschaftsteuer können leichter quantifiziert werden: je nach dem eingezahlten Kapital, darf die Steuer von zwischen 5\% und 0\% (im Grenzfall) als Gründungskosten in den kommenden 5 Jahren abgeschrieben werden; dementsprechend muß die Investition in eine neu gegründete Gesellschaft im schlechtesten Fall (Steuersatz 5\%) eine zusätzliche Rendite von 1\% aufs Kapital erbringen. Die Kapitalbereitstellungskosten erhöhen sich also wegen der Gesellschaftsteuer mit maximal einem Prozentpunkt. Falls die Investition mit Aktienemission finanziert wird, kommen unabhängig von der Höhe des Kapitals 0,5\% hinzu, die auch in 5 Jahren abgeschrieben werden, erhöhen also die Kapitalbereitstellungskosten mit $0,1 \%$.

Diese Steuer belastet auch die schon bestehenden Unternehmen, im Fall einer Kapitalerhöhung. Falls sie aus den einbehaltenen Gewinnen erfolgen sollte, ist die Erhöhung der Kapitalbereitstellungskosten zweimal kleiner als im Fall des neugegründeten Unternehmens (siehe die Gebührentabelle im Abs.6.1.4); im Fall einer Kapitalerhöhung über Aktienemission ist die Steigerung der Kapitalbereitstellungskosten die gleiche wie bei den neugegründeten Unternehmen.

Bei der Gesellschaftsteuer sind auch gewisse Verstoße gegen das Prinzip der Gleichmäßigkeit der Besteuerung zu vermerken: kleine Unternehmen werden proportional viel höher belastet als große Unternehmen - von daher ist sie eine regressive Steuer, die den Prozeß der kleinen 
Privatisierung negativ beeinflußt; die übrigen Formen der Finanzierung werden gegenüber der Kreditaufnahme noch mehr verteuert.

Schließlich belastet die Steuer auf den Verkauf der Aktiva der staatlichen Unternehmen die kleinen privaten Unternehmer (sowohl Rumänen als auch Ausländer), die im Rahmen der sogenannten "kleinen Privatisierung" diese Aktiva hauptsächlich über Versteigerungen gekauft haben, nicht. Der Verkaufspreis war dabei der Marktpreis, der sich infolge der Versteigerung ergeben hat. Die staatlichen Unternehmen, die diese Aktiva verkauft haben, durften die Versteigerung nicht von einem höheren Anfangspreis beginnen, als von ihren Buchwerten; auch die Konstruktion dieser Steuer (der Verkäufer darf am Ende wegen der Steuerzahlung nicht weniger für seine Aktiva als ihren Buchwert bekommen; falls der Verkaufspreis niedriger liegt, als der Buchwert einschließlich der 20\%-igen Steuer, fällt die Steuer aus) machten jegliche Überwälzung auf den Käufer unmöglich. 
Mihail Nedelea - 978-3-631-75036-0 Downloaded from PubFactory at 01/11/2019 09:01:58AM via free access 


\section{KAPITEL 7:}

\section{BESONDERHEITEN DES RUMÄNISCHEN STEUERSYSTEMS FÜR DIE AUSLÄNDISCHEN INVESTITIONEN.}

Eine Analyse der speziellen Bedingungen, denen die ausländischen Investoren ausgesetzt werden, insbesondere auf dem Fiskalgebiet, ist aus zwei Gründen angebracht:

- $\quad$ Erstens hat sich nach den politischen Umwälzungen in den osteuropäischen Ländern der internationale Wettbewerb der weniger entwickelten Länder um ausländische Kapitalinvestitionen deutlich verschärft. Den traditionellen Nettokapitalimporteuren (vor allem Entwicklungsländer) haben sich die Reformländer Osteuropas und Asiens angeschlossen. Zum Anreiz der Kapitalinvestitionen finden zwischen den interessierten Ländern "locational tournaments" statt (WHEELER \& MODY, 1992, S.57). Die Finanzmittel sind weltweit knapp geworden, und nur eine ganz geschickte Politik kann in diesem scharfen Wettbewerb die Nachfrager zum Erfolg führen.

- Zweitens stellt sich die Frage, ob die den ausländischen Investoren gewährten Erleichterungen auch effektiv sind. Insbesondere auf dem Gebiet der Steuern ist dieses Problem sehr aktuell, weil die Regierungen sehr oft zu großzügigen Steuererleichterungen neigen, ohne die anderen Bestimmungsfaktoren des internationalen Kapitalverkehrs zu berücksichtigen. Meistens sind die steuerlichen Maßnahmen die bequemsten, im Vergleich mit den Anforderungen der Kapitalgeber, die Infrastruktur aufzubauen, die Korruption zu bekämpfen oder glaubwürdige Struktur- und Eigentumsreformen zu unternehmen. Die steuerlichen Maßnahmen zum Anreiz der ausländischen Investitionen bedeuten immer Einbußen in den Haushaltseinnahmen. Es muß sichergestellt werden, daß diese Einbußen von den günstigen Folgen langfristiger Engagements der ausländischen Investoren, das heißt von der Verbesserung der wirtschaftlichen Produktionsstruktur und Erhöhung des allgemeinen Wohlstands im Empfängerland kompensiert werden.

\subsection{Wichtige gesetzlicheSonderbestimmungen betreffend die ausländischen Investitionen in Rumänien}

Der gesetzliche Rahmen der investitionsrelevanten Steuern in Rumänien wurde schon in den Abschnitten 5.1. und 5.2. vorgeführt. Daher geht es im folgenden darum, den besonderen Status der ausländischen Investoren zu präzisieren. Das Gesetz Nr.35/1991 "Über die ausländischen Investitionen", ergänzt von dem Gesetz Nr.57/1993, gewährt ihnen außer Steuervergünstigungen auch Garantien, verweigert ihnen aber wichtige, sogar entscheidende 
Rechte, wie die Anschaffung von Grund und Boden. Erkennbar ist dies auch an der äußerst spärlichen Entwicklung der ausländischen Investitionen in Rumänien (siehe das Kapitel 1).

Die folgende Kurzfassung des Gesetzes Nr.35/1991, in der der Verfasser dieser Arbeit die Ergänzungen vom Gesetz Nr.57/1993 eingebaut hat, basiert auf der deutschen Version der Rumänischen Entwicklungsagentur (1992, S.67-76). Die für diese Untersuchung wichtigsten Bestimmungen wurden ebenfalls vom Verfasser dieser Arbeit ausgewählt.

Im Sinne des Gesetzes, versteht man in Rumänien unter ausländischen Investitionen (1. Artikel):

a) die Gründung von Handelsgesellschaften, Filialen oder Niederlassungen mit ausschließlich ausländischem Kapital oder in Verbindung mit natürlichen oder juristischen rumänischen Personen, in Übereinstimmung mit den Bestimmungen des Gesetzes über die Handelsgesellschaften Nr.31/1990;

b) die Teilnahme an der Erhöhung des Gesellschaftskapitals einer schon vorhandenen Gesellschaft oder den Erwerb von Geschäftsanteilen oder Aktien einer solchen Gesellschaft, sowie auch von Obligationen oder anderen Wertpapieren;

c) die Verpachtung, Vermietung oder Übernahme der Geschäftsführung von wirtschaftlichen Tätigkeiten, Dienstleistungen, Produktionseinheiten einiger Selbstverwaltungsbetriebe oder Handelsgesellschaften;

d) den Erwerb des Eigentumsrechtes über bewegliche oder unbewegliche Güter, mit Ausnahme von Grund und Boden;

e) den Erwerb von Rechten über wirtschaftliches und geistiges Eigentum;

f) Gläubigerrechte oder andere Rechte betreffend investitionsgebundene Dienstleistungen mit wirtschaftlichem Charakter;

g) den Kauf und die Errichtung von Produktionsräumen oder anderen Gebäuden, mit Ausnahme von Wohnungen. Diejenigen, die der Investitionsabwicklung dienen, zählen nicht dazu.

Gemäß Artikel 4 können ausländische Investitionen in allen Bereichen der Industrie, der Erforschung und des Abbaus natürlicher Bodenschätze, der Landwirtschaft und Infrastruktur, des Kommunikationswesens, des Zivil- und Industriebaus, der wissenschaftlichen Forschung und der technologischen Entwicklung, des Handels, Transportwesens, Tourismus, Versicherungs- und Bankenwesens sowie anderer Dienstleistungen getätigt werden, sofern folgende Bedingungen beachtet werden:

a) Einhaltung der Umweltschutznormen;

b) Nichtbeeinträchtigung der Interessen betreffend die Sicherheit und Landesverteidigung Rumäniens;

c) Nichtbeeinträchtigung der öffentlichen Ordnung, Gesundheit und der Moral. 
Den ausländischen Investoren werden folgende Garantien gewährt:

Artikel 5: Ausländische Investitionen in Rumänien können nicht nationalisiert, enteignet, beschlagnahmt oder anderen ähnlichen Maßnahmen unterworfen werden, mit Ausnahme derjenigen, die dem öffentlichen Interessen dienen. Dabei muß das gesetzliche Verfahren eingeschaltet werden und die Zahlung einer der Investition gleichwertigen Entschädigung in angemessener Höhe und unverzüglich erfolgen.

Die Entschädigung richtet sich nach dem Marktwert der Investition zum Zeitpunkt des Ergreifens einer der unter Artikel 5 vorgesehenen Maßnahmen (Artikel 6).

Ausländische Investoren haben laut Artikel 9 das Recht:

a) an der Verwaltung der Handelsgesellschaft laut vereinbartem Vertrag und Satzung teilzunehmen;

b) ihre vertragsmäßigen Rechte und Pflichten an rumänische oder andere ausländische Investoren abzugeben;

c) die ihnen zukommenden Gewinne, ob in frei konvertibler Währung oder in Lei - nach Währungsumtausch gemäß der jeweils im Lande geltenden Umtauschregelung gänzlich ins Ausland zu transferieren (Anmerkung: nach Zahlung der 10\%-igen Dividendensteuer!);

d) Urheberrechte, Anteile für Sonderbetreuung, Begutachtungen und andere Dienstleistungen laut abgeschlossenen Verträgen ins Ausland zu transferieren;

e) jene freien Devisen ins Ausland zu transferieren, die als Folge des gänzlichen/ teilweisen Verkaufs von Aktien oder Gesellschaftsanteilen sowie auch von Obligationen oder anderer Wertpapiere entstanden sind. Das gilt auch für jene, die sich aus der Liquidation der Investitionen ergeben haben;

f) die Entschädigungssummen aus einer der Maßnahmen laut Artikel 5 in der vereinbarten Währung ins Ausland zu transferieren.

Auch unterliegen ausländische Investitionen in Rumänien laut Artikel 10 während ihrer gesamten Dauer dem in diesem Gesetz festgelegten juristischen Regime, falls ein nachträgliches Gesetz für sie keine günstigere Bedingungen vorsieht. Eine Verschärfung der Bedingungen sollte also, sofern das Gesetz Nr.35/1991 in Kraft bleibt, diejenigen Investoren, die in diese Zeit investieren, nicht berühren.

Angesichts der Steuerbegünstigungen sind folgende Bestimmungen von Bedeutung:

Artikel 12: Maschinen, Anlagen, Ausrüstungen, Fahrzeuge und irgend andere für die Investition notwendige Inportgüter, welche einen Beitrag des ausländischen Investors darstellen, sind vom Zoll befreit. 
Artikel 13: Die für die Produktion notwendigen importierten Rohstoffe, Materialien und Bestandteile sind für die ersten zwei Jahre, berechnet ab Datum der Inbetriebssetzung der Investition, vom Zoll befreit.

Artikel 14: Ausländische Investitionen sind gewinnsteuerfrei für folgende Zeiträume:

a) Investitionen in der Industrie, Landwirtschaft, Bauwesen und Erforschung und Abbau natürlicher Bodenschätze für eine Dauer von 5 Jahren ab Datum des Beginns der produktiven Tätigkeit;

b) Investitionen im Kommunikations- und Transportwesen für eine Dauer von 3 Jahren ab Beginn der betroffenen Tätigkeit;

c) für den Handels, Tourismus, Bank- und Versicherungssektor sowie für andere Dienstleistungen für eine Dauer von 2 Jahren ab Beginn der Tätigkeit.

Die Befreiung von der Gewinnsteuer gilt nur für die Investitionen, deren Wert über 10.000 US-\$ liegt. Die anderen sind den Gesetzen betreffend die rumänischen Firmen unterstellt. Für Gesellschaften mit gemischtem Kapital - rumänisch und ausländisch - wird die Zoll- und Gewinnsteuerschuld proportional um den Anteil des ausländischen Kapitals reduziert.

Artikel 15: Außer den oben vorgesehenen Gewinnsteuerbefreiungen und nach Ablauf der festgelegten Dauer werden Gewinnsteuerherabsetzungen, wie folgt, gewährt:

a) $50 \%$ für die Besteuerung jenes Gewinnes, welcher im Rahmen einer in Rumänien gegründeten Einheit für die Erweiterung und Modernisierung der technischen Ausrüstung, der Produktionsverfahren oder für die Tätigkeitserweiterung zwecks Erreichung zusätzlicher Gewinne oder für den Umweltschutz eingesetzt wird;

b) $\quad 25 \%$ falls eine der folgenden Bedingungen eingehalten wird:

mindestens 50\% des Bedarfs an Rohstoffen, Energie und Brennstoffen wird importiert;

mindestens $50 \%$ der erzeugten Produkte und Dienstleistungen werden exportiert;

über 10\% der Ausgaben werden für wissenschaftliche Forschung, Entwicklung von neuen Technologien und Schulung in Rumänien investiert;

- mindestens $50 \%$ der Anlagen und Ausrüstungen für die Erweiterung der bestehenden Investitionen oder für die Gründung neuer Investitionen, werden aus Rumänien gekauft;

mindestens 50 neue Arbeitsplätze werden durch eine neue Investition oder durch Weiterentwicklung der bestehenden Investitionen geschaffen.

Kommentar: Schließlich versucht ein Artikel die Investoren zu ermahnen, es sei nicht erwünscht, daß sie nach Ablauf der steuerfreien Zeit ihre Investitionen liquidieren und anderswohin gehen. Dieser Artikel stellt sich bei näherer Betrachtung als ein "Papiertiger" 
heraus. Es wurde vorhin (im Paragraphen 5.1) gezeigt, wie wenig effektiv ähnliche Bestimmungen gegenüber den rumänischen privaten Firmen waren: Eine Gesellschaft kann ihre Tätigkeiten einfrieren oder noch besser, keine steuerpflichtige Gewinne mehr ausweisen, ohne liquidiert $\mathrm{zu}$ werden, indem daneben eine andere gegründet wird, mit Scheineigentümern, durch die nunmehr die Geschäfte abgewickelt werden. Die neue Gesellschaft darf ruhig Gewinne machen, sie ist 5, bzw. 2 oder 3 Jahre lang von der Gewinnsteuer befreit. Ansonsten kann auch ein Konkurs inszeniert werden, wenn die Liquidation tatsächlich erfolgen muß, und dann fällt wiederum keine Steuerschuld mehr an.

Artikel 18: Falls die ausländischen Investitionen innerhalb eines Zeitraumes, der kürzer als das Doppelte der Dauer der Steuerfreiheit laut Artikel 14 ist, freiwillig liquidiert werden, sind die Investoren verpflichtet, gesetzmäßig festgelegte Steuersätze für die gesamte Funktionsdauer der Investitionen nachträglich zu zahlen. Die geschuldeten Steuern werden vorrangig aus den Liquidationserlösen der Investition oder anderen den ausländischen Investoren zukommenden Rechten gezahlt.

\subsection{Wirkungen der rumänischen steuerlichen Gesetzgebung und andere besondere Aspekte der Problematik der ausländischen Investitionen}

Angesichts der relativ kurzen Zeit, in der die vorhin dargelegte Regelung bisher angewendet wurde, ist es nicht möglich, eine empirische Überprüfung der Korrelation z.B. zwischen der Steuerfreiheit und der Dynamik der ausländischen Investitionen in Rumänien zu machen. Außerdem liegt der schleppende Verlauf dieser Investitionen die Vermutung nahe, die Steuervergünstigungen seien in den Investitionsentscheidungen ausländischer Firmen nicht der allesentscheidende Faktor, zumal Rumänien mit dem Steuererlaß im Vergleich mit den anderen osteuropäischen Ländern sehr großzügig war. Von daher wäre es äußerst schwierig, im Rahmen einer statistischen Analyse die steuerlichen Einflußfaktoren von den anderen zu trennen. Auch reicht die Zahl der wichtigen Investoren bei weitem nicht aus, um aus einer Befragung saubere Folgerungen zu ziehen.

Die theoretische und empirische Forschung hat bisher angesichts der Frage des Zusammenhangs Besteuerung - internationaler Kapitalverkehr ein umfangreiches Angebot an Ansätzen und Untersuchungen gebracht. Eine umfassende Übersicht dessen ist bei KOPITS (1976) zu finden. Anschließend wählt KOPITS aus den verschiedenen Hypothesen über das Verhalten der internationalen Firmen (z.B. die Hypothese der Größemaximierung - "manager's utility maximization" - von BAUMOL (1967) oder die Hypothese der Spielersrendite von BARLOW \& WENDER (1955) die neoklassische Hypothese der Gewinnmaximierung, die sich am besten eignet, um den Einfluß der Besteuerung auf die internationalen Kapitalbewegungen zu untersuchen. Die zahlreichen empirisch fundierten Untersuchungen über die Reaktionen der 
internationalen Firmen auf die Besteuerung in verschiedenen Ländern (KOPITS zählt 8 solche Untersuchungen nur für die Zeit zwischen 1968 und 1974 auf) zeigen, so KOPITS, daß die Kapitalbewegungen von den erwarteten Renditen in unterschiedlichen Ländern direkt, und von der Varianz dieser Renditen invers abhängig sind. Investitionen fließen zu den Standorten mit relativ hohen und konstanten Renditenerwartungen. Von daher ist nicht nur die Höhe der Besteuerung, sondern auch ihre Beständigkeit und Berechenbarkeit von beträchtlicher Bedeutung.

Allerdings deuten die empirischen Ergebnisse für die nicht-Industrieländer laut KOPITS darauf hin, daß die Erhöhung der Gewinnbesteuerung die Dividendenausschüttungen zwar in negativem Sinn, wohl aber kaum die Kapitalbereitstellungskosten bei der Muttergesellschaft beeinflußt. Tatsächlich werden für den ausländischen Investor die Bestandteile der Kapitalbereitstellungskosten vielmehr von den Gegebenheiten im Mutterland (Kalkullationszinssätze, Einkommensteuersätze, Schachtelprivilegien usw.) bestimmt. Von daher eignet sich das im Paragraphen 5.2 benutzte Modell für die Berechnung der Kapitalbereitstellungskosten bei ausländischen Investitionen nicht, zumal die meisten Nettokapitalimporteuren - so auch Rumänien - mit den wichtigsten Kapitalgeberländern Doppelbesteuerungsabkommen vereinbart haben, die eine für alle kapitalexportierenden Länder gültige Kalkulation der Abdiskontierungssätze und der steuerbedingten Ausschüttungsfaktoren unmöglich machen.

Die internationale Erfahrung der Entwicklungsländer mit der Praxis des Steuererlasses ließ bisher keine eindeutigen Folgerungen zu. Wie gesagt, die Frage: inwieweit hat der Steuererlaß die ausländischen Firmen ermuntert, in Bereiche zu investieren, in die sie sonst nicht investiert hätten?, kann in Rumänien zur Zeit nicht gründlich beantwortet werden. Aber die bisherige Entwicklung zeigt z.B. daß der Steuererlaß gerade in den Transformationsländern, wo im Zuge der Erneuerung der Gesetzgebung Schlupflöcher entstehen, die den Bürokraten erlauben, ihre Willkür durchzusetzen, kein besonders zuverlässiges Instrument der Steuerpolitik darstellt. Eine Untersuchung von BILLSBORROW und PORTER (1972) zeigt, daß falls die Berechtigung der Firmen, die Steuererlaß genießen, zu oft geprüft wird, ihre Unsicherheit erhöht wird. Damit erhöhen sich auch die Risikozuschläge, die sie in ihren Rentabilitätsrechnungen eingeben müssen. Das rumänische Gesetz sieht für unterschiedliche Geschäftsgebiete auch verschiedene Fristen für die Steuerfreiheit vor. Bei Firmen die mehrere Arten von Tätigkeiten ausüben bleibt die Einstufung in die entsprechende Kategorie der Finanzbehörde überlassen. Damit wird viel freier Raum für Ärger und Korruption geschaffen. Das klassische Beispiel in Rumänien ist die Produktion von Software, die laut rumänischen Behörden eine Dienstleistung und keine Produktion ist, und also nur 2 Jahre Steuerfreiheit (für die heimischen Gesellschaften nur 1 Jahr) genießen darf.

BILLSBORROW \& PORTER kommen auch zu dem Ergebnis, daß der Steuererlaß am wenigsten effektiv in Bereichen war, in denen es auch früher keine ausländischen Investitio- 
nen gab und es also den potentiellen Investoren an Erfahrung mangelte. Da sie auch kurzfristig keine Gewinne erwarteten, waren sie von dem Steuererlaß nicht beeindruckt.

BILLSBORROW \& PORTER schlagen auch ein Modell vor, das sich für die Untersuchung des Einflusses der befristeten Steuerfreiheit auf die ausländischen Investitionen sehr gut eignet. Im folgenden wird dieses Modell dargestellt, um anschließend für Rumänien relevante Folgerungen zu schließen. Es sei eine Firma angenommen, die eine Investition von 1 US-\$ im Jahr "0" tätigt. Jedes Jahr danach - mindestens bis auf den Planungshorizont des Investors - werden ökonomische Abschreibungen vorgenommen, so daß der reale Wert der Investition von $1 \$$ erhalten bleibt. Der erwartete reale Netto-Cash-Flow (weiterhin Bruttogewinn genannt) ist jährlich "p" US-\$.

Dieser Bruttogewinn bleibt in den ersten "a" Jahren steuerfrei und wird danach mit dem Steuersatz "u" behaftet. Der Investor berechnet, gemäß der Kapitalwertmethode, den realen Gegenwartswert seines Investitionsobjektes mittels eines Abdiskontierungszinssatzes " $r$ ", wobei der gesamte Zeithorizont der Investition mit "b" Jahren angenommen wird:

$$
G W_{a}=-1+p \int_{0}^{a} e^{-r t} d t+p(1-u) \int_{a}^{b} e^{-r t} d t(7.1)
$$

wobei: $\quad-\mathrm{t}=\quad$ die Zeit und

$-\mathrm{GW}_{\mathrm{a}}=\quad$ der Gegenwartswert der Investition mit Steuerfreiheit in den ersten "a" Jahren.

Nach Berechnung der Integrale ergibt sich:

$$
G W_{a}=\frac{1}{r}(p-r)-p u e^{-r a}-p(1-u) e^{-r b}(7.2)
$$

Effektivität eines befristeten Steuererlasses heißt, daß Investitionen, die sich ohne ihn nicht rechneten, von dem Steuererlaß allein rentabel gemacht und demzufolge vorgenommen wurden. Es würde keinen Sinn machen, den Steuererlaß zu gewähren, wenn die Investitionen sich auch ohne ihn rechnen. Im Modell bedeutet dies, daß $\mathrm{GW}_{\mathrm{a}}<0$ für $\mathrm{a}=0$ (ohne Steuererlaß) und $\mathrm{GW}_{\mathrm{a}}>0$ für $\mathrm{a}=\mathrm{b}$ (mit Steuerfreiheit für das ganze Leben der Investition). Je näher ist "a" an "b", desto mehr Investitionen werden von dem Steuererlaß rentabilisiert. Falls $\mathrm{GW}_{\mathbf{b}}$ (der Gegenwartswert im Fall der Steuerfreiheit für die ganze Lebensdauer der Investition) negativ ist, würde der Investor das Projekt auf keinen Fall unternehmen. 
Ohne Steuererlaß ist der Gegenwartswert der Investition:

$$
G W_{0}=\frac{1}{r}\left[-r+p(1-u)\left(1-e^{-r b}\right)\right](7 \cdot 3)
$$

während mit Steuerfreiheit für die ganze Lebensdauer der Gegenwartswert:

$$
G W_{b}=\frac{1}{r}\left[-r+p\left(1-e^{-r b}\right)\right](7.4)
$$

ist.

Unter welchen mathematischen Bedingungen rechnet sich dann die Investition ohne Steuererlaß im Gegensatz zu einer Investition mit Steuererlaß nicht? Es würde bedeuten:

$$
G W_{0}<0<G W_{b}(7.5)
$$

Dafür müßte:

$$
p(1-u)<\frac{r}{1-e^{-x b}}<p(7.6)
$$

In Klartext bedeutet diese Doppelbedingung, daß die Nettogewinnquote kleiner und die Bruttogewinnquote größer als ein gewisser kritischer Ausdruck sein sollten. Der Verlauf dieser kritischen Quantität - weiter CQ benannt - wird in der Abbildung 7.1 für unterschiedliche Abdiskontierungszinssätze " $r$ " und für eine Lebensdauer der Investition von 3, 5 und 10 Jahren dargestellt.

In Abb. 7.1 läßt sich klar feststellen, daß diese kritische Quantität gegenüber dem Abdiskontierungszinssatz " $r$ " sehr empfindlich, und gegenüber der Lebensdauer " $b$ " weniger empfindlich ist. Auch merkt man, daß die längerfristigen Investitionen gegenüber dem Steuererlaß weniger sensitiv sind als die kurzfristigen, die von ihm nur dann richtig profitieren können, wenn sie sehr hohe Renditen (35\%-50\%) ausweisen. 


\section{Abbildung 7.1.}

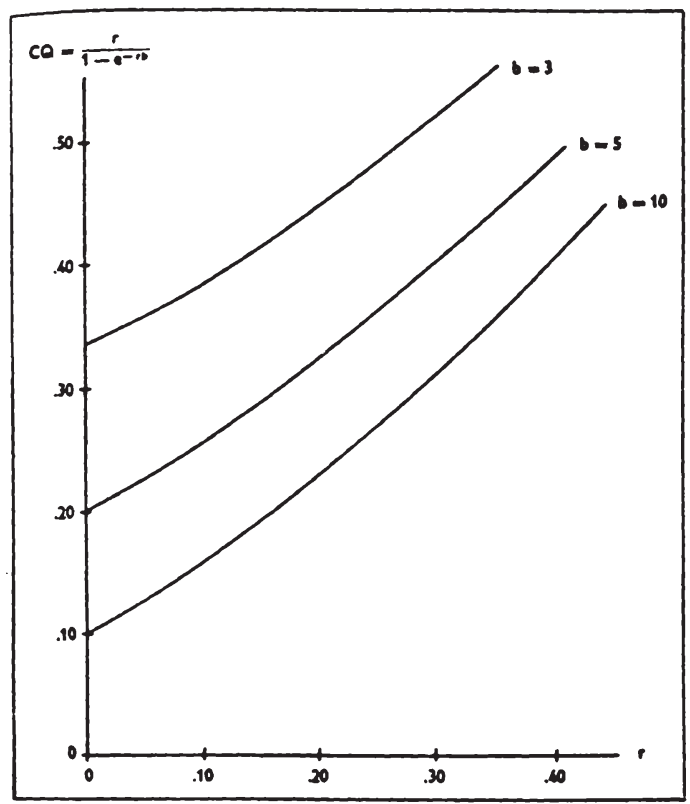

(Quelle: BILLSBORROW \& PORTER, 1972, S.409)

Die o.g. Folgerung des Modells von BILLSBORROW \& PORTER bedeutet für Länder wie Rumänien, daß die Dauer eines Steuererlasses vielmehr für diejenigen kurzfristigen Investitionen (Typ "hit and go"), die hohe Renditen schnell erbringen, als für die langfristigen Engagements in der verarbeitenden Industrie, die auf die Dauer kleinere, aber sicherere Renditen versprechen. Denn: je höher CQ liegt, desto größer ist bei irgendeiner Investition die Wahrscheinlichkeit, daß $\mathrm{p}>\mathrm{CQ}$, aber die Rentabilität nach Besteuerung $\mathrm{p}(1-\mathrm{u})<\mathrm{CQ}$, damit der Steuererlaß wirksam wird. Nehmen wir für ausländische Investitionen vereinfachend einen Abdiskontierungszinssatz $\mathrm{r}=10 \%$ an (etwa der Durchschnittswert der Dauerschuldzinsen bei internationalen Projekten einschließlich eines Risikoaufschlags). Für langfristige Investitionen $(b=10$ Jahre) liegt $C Q$ bei etwa $14 \%$. Die befristete Steuerfreiheit ist wirksam für die Investitionen bei denen "p" zwischen $C Q$ und $C Q /(1-u)$ liegt. Für $\mathrm{p}>\mathrm{CQ} /(1-u)$ ist die Investition auch ohne Steuererlaß durchaus profitabel. In unserem Fall werden von dem Steuererlaß die Investitionen, die Bruttorenditen zwischen $14 \%$ und $25 \%$ versprechen, positiv beeinflußt. Für kurzfristige Investitionen dagegen $(b=3$ Jahre, im Bereich des Handels oder der Beratung z.B.) werden sämtliche Investitionen, deren erwartete Bruttorentabilität $z$ wischen $38 \%$ und $69 \%$ rangiert, positiv beeinflußt. In den oben angedeuteten Bereichen, sowie im Banken- und Versicherungsgeschäft, sind diese Renditen in Rumänien durchaus normal. Die Vermutung liegt nahe, daß die kurzfristigen Investitionen anteilsmäßig von der befristeten Steuerfreiheit stärker als die langfristigen berührt werden, da die Bandbreite ihrer Rentabilitäten größer ist. 
Andererseits hängen die Investitionsentscheidungen nicht nur von den erwarteten Gewinnen, sondern auch von den geschätzten Risiken ab. Im Kapitel 4 wurde der Risikoansatz von DOMAR \& MUSGRAVE als notwendige Ergänzung zur neoklassischen Investitionstheorie ausgewählt. Die Übertragung dieses Modells auf den Fall Rumäniens soll im folgenden die Bedeutung anderer Instrumente der Fiskalpolitik als des Steuererlasses verdeutlichen.

Die Darstellung des Modells entspricht der Version von MUSGRAVE (1974, S.281-287). Infolge der Schätzung der erwarteten Gewinne und Risiken leitet der Investor die Kurve seiner optimalen Vermögensanlage ab. Der Punkt, an dem diese Kurve von den Indifferenzkurven "Ertrag-Risiko" desselben Investors berührt wird, ist die optimale Vermögenskombination $\mathrm{M}$ (Abb.3.1 und 3.2). Wollen wir jetzt untersuchen, auf welche Weise Investitionsentscheidungen von einer proportionalen Steuer auf das Nettoeinkommen abzüglich der Abschreibung beeinflußt werden, müssen wir zuerst die Situation betrachten, in der Verluste nicht durch in kommenden Jahren auftretenden Gewinne ausgeglichen werden können. In diesem Fall beteiligt sich der Fiskus an den Gewinnen des Investors, aber nicht an dessen Verlusten.

Vor Steuerauflage gilt für jegliche Investitionskombination folgende mathematische Erwartung:

$$
y=g-r(7.7)
$$

Das heißt, daß der Ertrag gleich den Gewinnen abzüglich den Verlusten (in einer breit gestreuten Vermögensanlage) ist. Nach Steuerauflage (u) wird Formel $7.7 \mathrm{zu}$ :

$$
y_{u}=(1-u) g-r(7.8)
$$

Bei einer Betrachtung über mehrere Jahren gilt dieselbe Gleichung für die Summen der abdiskontierten Gewinne und Verluste. Da Verluste weder im selben Jahr noch in den kommenden Jahren abgezogen werden können, wird die positive Komponente " $g$ " verringert, während die negative Komponente " $r$ " unverändert bleibt. Auch ist $y_{u}$ offensichtlich immer kleiner als $(1-u) y$, also ist der Ertrag um einen größeren Prozentsatz gesunken als es dem Steuersatz entspricht.

Die Verschiebung der Kurve der optimalen Vermögensstruktur infolge einer Steuerauflage ist in Abb.7.2 dargestellt. OGB ist die Position der Kurve der optimalen Vermögensstruktur vor Besteuerung; das Gleichgewicht liegt beim Punkt M. Durch Einführung einer Steuer werden die y-Werte (Abszissen) jedes Punktes auf der Vermögenskurve verringert. Da das Risiko unverändert bleibt, bewegt sich jeder Punkt horizontal nach links. Wenn z.B. eine $25 \%$-ige Steuer auferlegt wird, so ist die neue Kurve optimaler Vermögensstruktur $\mathrm{OG}_{25} \mathrm{~B}_{25}$, bei einer $50 \%$-iger Steuer die Kurve $\mathrm{OG}_{50} \mathrm{~B}_{50}$ usw. 
Abbildung 7.2: Gewinnsteuer ohne Verlustausgleich

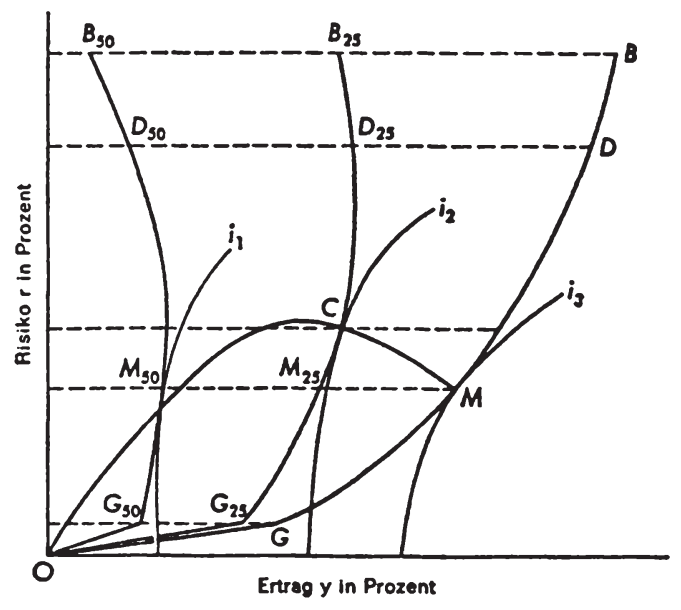

(Quelle: $\quad$ MUSGRAVE, 1974, S.283)

Die Kurve MCO stellt den Gleichgewichtspfad - die Verschiebung der optimalen Vermögenskombination - bei kontinuierlicher Erhöhung der Steuersätze dar. Bewegt man sich von $\mathbf{M}$ nach links, so steigt " $r$ " zunächst und fällt dann $a b$. Die resultierende Anpassung wird bestimmt durch das Zusammenspiel von Einkommens- und Substitutionseffekt. Der Einkommenseffekt zwingt den Investor, ein höheres Risiko zu akzeptieren, um sein Einkommen zu erhalten. Der Substitutionseffekt veranlaßt ihn dagegen, weniger zu riskieren, da die Belohnung für die Risikobereitschaft sinkt. Das Nettoergebnis kann somit sowohl in einer Erhöhung als auch in einer Verminderung des eingegangenen Risikos bestehen. Zuerst neigt der Einkommenseffekt dazu, den Substitutionseffekt zu überwiegen. Der Investor wird mehr Risiko auf sich nehmen. Früher oder später kehrt sich aber die Situation um und führt zum Abbau der risikoreicheren Investitionen (nach dem Beispiel vom Kapitel 3, Paragraphen 3.8 würde er mehr in die Tschechische Republik und weniger in Rumänien investieren) bis zu einer 100\%-igen Kassenhaltung - also keine Investitionen mehr - im Extremfall des $100 \%$-igen Steuersatzes.

Wird ein vollständiger Verlustausgleich erlaubt, dann wird der Fiskus zu einem Partner des Investoren, der an Gewinnen und Verlusten gleichermaßen teilnimmt. In diesem Fall werden sowohl erwartete Gewinne, als auch Verluste um den Steuersatz gekürzt:

$$
y_{u}=(1-u) g-(1-u) r(7.9)
$$


Es folgt:

$$
y_{u}=(1-u) y(7.10)
$$

Für alle Vermögenskombinationen wird nunmehr der Erwartungswert mit dem gleichen Prozentsatz reduziert. Die Verschiebung der Kurve der optimalen Vermögensstruktur wird für diesen Fall in Abb.7.3 dargestellt. Jeder Punkt der Kurve OGB (die Kurve der optimalen Vermögensstruktur vor Besteuerung) bewegt sich auf einer Geraden zum Nullpunkt hin. $\mathrm{OG}_{25} \mathrm{~B}_{25}$ und $\mathrm{OG}_{75} \mathrm{~B}_{75}$ sind die Kurven der optimalen Vermögensanlagen bei einer $25 \%$-igen, bzw. 75\%-igen Gewinnsteuer.

Das Gleichgewicht vor Besteuerung liegt wieder beim Punkt M. Wird eine 50\%-ige Steuer auferlegt, dann verschiebt sich die Gleichgewichtslage des Investors nach $\mathbf{M}_{50}$, obwohl sein gesamtes Vermögensportefeuille unverändert bleibt. Der Investor kann aber seine persönliche Lage verbessern, indem er ein höheres Risiko akzeptiert und sich auf der Kurve $O_{50} B_{50}$ nach oben bis zum Punkt $D_{50}$ bewegt. In diesem Fall hat er eine andere, risikoreichere Vermögensstruktur, ist aber auf eine höhere Indifferenzkurve geraten und hat somit seinen Nutzen erhöht. Wiederum bezeichnet die Kurve $\mathrm{MD}_{50} \mathrm{O}$ den Ort der optimalen Positionen zu verschiedenen Steuersätzen.

Die Steuer bringt keinen Substitutionseffekt, weil die Verluste voll ausgeglichen werden. Der Investor wird versuchen, zumindest einen Teil des Ertrags, der von der Steuer abgeschnitten wird, einzuholen. Je nach den Bedingungen kann der Punkt $\mathrm{D}_{50}$ unterhalb oder oberhalb des Punktes $M$ liegen, und der Investor kann mehr oder weniger Risiko als vor der Besteuerung auf sich nehmen. Immerhin ist $D_{50}$ von einem höheren Risiko gekennzeichnet, als das Risiko, das der Investor eingegangen wäre, wäre er bei $\mathrm{M}_{50}$ geblieben. Dies ist darauf zurückzuführen, daß der Staat einen Teil der Risiken auf sich nimmt.

Um die Bedeutung dieser Situation klar zu machen, muß man zwischen volkswirtschaftlichem und privatem Ertrag einerseits und zwischen volkswirtschaftlichem und privatem Risiko andererseits unterscheiden. Die Steuer setzt den privaten Ertrag und das private Risiko der ursprünglichen Vermögensstruktur $\mathbf{M}$ von den Koordinaten des Punktes $\mathbf{M}$ zu denen von $\mathbf{M}_{50}$. Volkswirtschaftlicher Ertrag und volkswirtschaftliches Risiko bleiben aber bei dieser speziellen Vermögenskombination im Punkt M völlig unberührt von der Steuer. Ähnlich bezeichnen die Koordinaten des Punktes $\mathrm{D}_{50}$ nur das private Risiko und den privaten Ertrag dieser neuen Vermögenskombination. Volkswirtschaftliches Risiko und volkswirtschaftlicher Ertrag der neuen Vermögenskombination sind durch die Koordinaten des Punktes D gegeben. D liegt oberhalb von M. Somit wird das volkswirtschaftliche Risiko erhöht, die individuelle Risikobereitschaft wird aber dabei auch ermuntert. Ob es in bestimmten Phasen der Entwicklung eines Landes angebracht ist, durch steuerpolitische Maßnahmen die individuelle 
Risikobereitschaft anzuregen, auch wenn dadurch das volkswirtschaftliche Risiko erhöht wird, ist eine Frage, die nicht allein mit Hilfe der ökonomischen Theorie zu beantworten ist.

Abbildung 7.3: Gewinnsteuer mit vollem Verlustausgleich

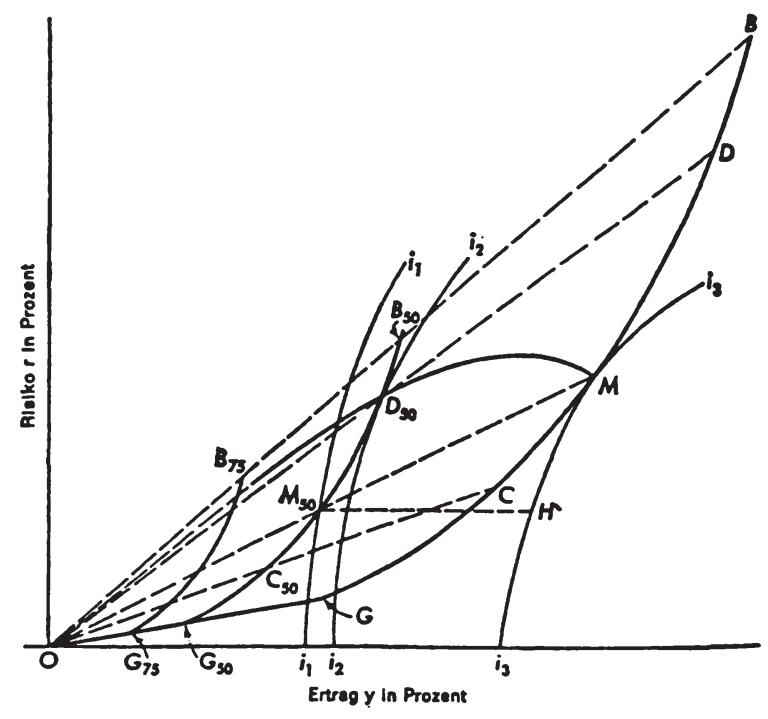

(Quelle: MUSGRAVE, 1974, S.285)

Der positive Effekt des Verlustausgleichs nicht nur auf Investitionen, sondern auch auf die laufende Produktion ist in der Literatur fast unbestritten. PENNER (1967), findet heraus, daß unter Unsicherheit sogar risikoneutrale Unternehmer die Produktion als Reaktion auf eine progressive Gewinnsteuer ohne Verlustausgleich reduzieren. Die risikoscheuen Unternehmer tun es auch in Anwesenheit einer proportionalen Gewinnsteuer. Auf jeden Fall verursachen Steuern ohne Verlustausgleich eine größere Reduktion des Outputs als die Steuern mit Verlustausgleich. Da eine steuerlich induzierte Reduktion der Produktion eine Senkung der volkswirtschaftlichen Effizienz bedeutet, bleibt die Frage offen, ob die Gesellschaft, durch die Gewährung der Möglichkeit des Verlustvortrags, nicht mehr volkswirtschaftliche Risiken auf sich nehmen sollte, um Produktion und Investition nicht zu beeinträchtigen. 
Steuerfreiheit und Risiken sind aber nicht die einzelnen Aspekte, die mit der Entscheidung, im Ausland zu investieren verbunden sind. Nachdem die Frist der Steuerfreiheit abgelaufen ist, werden nicht nur die nominellen Steuersätze - ob ermäßigt oder nicht - sondern auch die Rückstellungsmöglichkeiten und die Indexierungssysteme gegen die Inflation wichtig. Im Abschnitt 5.1 wurde gezeigt, daß obwohl das neue rumänische Buchführungssystem Rückstellungen prinzipiell zuläßt, ihre Bildung noch keiner festen Regelung unterliegt, was wiederum die Lösung von Streitfragen den Finanzbehörden allein überläßt. Es gibt auch kein festes Indexierungssystem gegen die Inflation, obwohl die Inflationsraten seit mehreren Jahren ziemlich hoch liegen. Zwar wurde 1991 und 1992 die Aufwertung der Aktiva der Unternehmen durch Regierungsbeschluß erlaubt, seitdem gab es aber keine derartige Maßnahme mehr, und weniges deutet darauf hin, daß der neuen Regierung wenigstens das Problem bewußt ist. Eine ausländische Firma, die in Rumänien eine Tochtergesellschaft gründet, sieht infolgedessen zu, wie in wenigen Jahren ihr ursprüngliches Kapital von der Inflation vernichtet wird, zumal in vielen westlichen Ländern - darunter auch Deutschland die Aufnahme in die Handelsbilanz des Konzerns (die sogenannte HB II) von indexierten Werten der Aktiva der Tochtergesellschaften aus Gründen des Gläubigerschutzes nicht erlaubt ist, ohne den Beweis vorzulegen, daß das entsprechende Sachvermögen tatsächlich zu den angegebenen Preisen veräußert werden kann. Dieser Beweis ist in Ländern wie Rumänien, mit - sowohl primär als auch sekundär - äußerst unterentwickelten Kapital-, Immobilien- und Anlagemärkten, sehr schwer zu erbringen.

Damit wird auch das Problem der Liquidationsmöglichkeit tangiert. Zwar sichert das rumänische Gesetz den ausländischen Investoren $\mathrm{zu}$, sie könnten jederzeit die Liquidationsbeträge ihrer Investitionen ins Heimatland transferieren. An wen würden sie aber ihre Anteile - bzw. ihr Sachvermögen - verkaufen, in einem Land wo der Kapitalmarkt so unterentwickelt ist, daß die Privatisierung keines nennenswerten, größeren Unternehmens bisher möglich war? Der einzige Vermögensgegenstand, der in Rumänien einigermaßen beliebig teilbar und jederzeit verkaufbar ist, ist der Boden. Er ist auch die einzige Garantie - außer den Garantien der Regierung, des Finanzministeriums oder anderer großen internationalen Banken - die ausländische Banken akzeptieren, wenn es darum geht, ein Modernisierungsprojekt in Rumänien zu finanzieren. Aber die ausländischen Investoren dürfen laut Gesetz keinen Grund und Boden erwerben; demzufolge können auch die 100\% rumänischen Unternehmen ihre Kredite vom Ausland nicht mit ihren Grundstücken garantieren, weil sie in Besitz ausländischer Banken fallen könnten. Diese Bestimmung schadet nicht nur dem internationalen Kapitalzufluß nach Rumänien, sondern auch den einheimischen Anstrengungen, den volkswirtschaftlichen Kapitalstock zu modernisieren.

Der liquidierende Investor fragt sich auch: wer garantiert, daß zu dem entsprechenden Zeitpunkt, die rumänischen Banken genug freie Devisen haben werden - das "Fixing"Verfahren wurde schon im Kapitel 1 geschildert - um die Liquidationserlöse umtauschen zu 
können? Wie lange müßten dann diese Gelder zinslos blockiert werden? Spezielle Regelungen zur Kontrolle des Währungstausches könnten jede Investitionsentscheidung, die nur auf Grundlage der Besteuerung getroffen wurde, grundsätzlich ändern (siehe hierzu auch ALWORTH, 1988). Offensichtlich ist der Ausstieg aus dem rumänischen Markt viel schwieriger als der Einstieg, und das erhöht erheblich die Risiken einer Investition.

Auch müßte man bedenken, daß die hohe Faktorbesteuerung im Gastland zu "Fiktionspreisen" zwischen Tochter- und Muttergesellschaft ermuntert. Die rumänische Lohnsteuer ist ein sehr gutes Beispiel dafür: für Monatslöhne über umgerechnet $400 \mathrm{DM}$ liegt der Steuersatz bei $60 \%$. Die Löhne der ausländischen Fach- und Führungskräfte, ohne die ein gutes Funktionieren der Tochtergesellschaft zumindest in der Anfangsphase unvorstellbar ist, werden also in Rumänien viel stärker als in ihrem Mutterland besteuert. Es gibt verschiedene Möglichkeiten, dieser konfiskatorischen Steuer auszuweichen; alle führen zur Errosion der Besteuerungsgrundlagen und - weil sie mittlerweile auch für rumänische Mitarbeiter angewendet werden - zur faktischen Senkung der Steuereinnahmen und zu Verzerrungen durch Fälschungen der Funktionen der Arbeitskosten.

Schließlich müßte man sich angesichts der heutigen Steuerregelung für ausländische Investitionen fragen, ob die wichtigeren, langfristig interessierten Investoren in Rumänien den Steuererlaß auch wirklich ausnutzen können. Mit anderen Worten, ob sie in den ersten 5, bzw.3, bzw. 2 Jahren auch tatsächlich Gewinne erwirtschaften. Da dies bei größeren Projekten normalerweise nicht der Fall ist, besteht eine große Wahrscheinlichkeit, daß die Besteuerung mit voller Kraft gerade dann einsetzt, wenn die ersten nennenswerten Erfolge sichtbar werden. Da in Rumänien der Verlustausgleich nicht erlaubt ist, kommt der Steuererlaß den wichtigeren Investoren kaum zugute. Die internationale Erfahrung mit Steuervergünstigungen zeigt (siehe BILLSBORROW \& PORTER, 1972, S.416-421, für das Beispiel Kolumbiens), daß die Firmen, die große Gewinne erwirtschaften aber keine Reinvestitionen planen, davon mehr profitieren als Firmen mit angemessenen Renditen, die auf langfristige produktive Tätigkeit ausgelegt sind. Von der Steuerfreiheit wird nur das ausländische Kapital begünstigt, das schnell ins Land gepumpt wird, mit der Absicht, es nach seiner Verwertung so schnell wie möglich wieder heraus zu kriegen. Dies ist in Rumänien aufgrund der Unvollkommenheiten des Kapitalmarktes lediglich für die Investitionen im wenig kapitalintensiven Bereich des Handels und der Dienstleistungen möglich. Der Steuererlaß fördert also nur kurzfristige Geschäfte, die meistens zur Verbesserung der volkswirtschaftlichen Produktionsstruktur nicht beitragen.

Am Ende dieser Darstellung muß wieder betont werden, daß die Steuervergünstigungen nur einen - und, nach einigen Meinungen, relativ unwichtigen - Einflußfaktor darstellen, der die internationalen Unternehmen veranlassen könnte, in einem bestimmten Land zu investieren. Die "locational theory" ist ziemlich umfangreich; eine umfassende Übersicht bieten hierfür 
WHEELER \& MODY (1992). Weiter betreiben die Autoren eine Korrelationsanalyse zwischen den ausländischen Investitionen der amerikanischen Firmen und einer Reihe von unterstellten Bestimmungsfaktoren, wie z.B.:

- den Arbeitskosten;

- den Steuervergünstigungen;

- $\quad$ der Größe des Marktes im Gastland;

- $\quad$ der Qualität der Infrastruktur;

- dem Industrialisierungsgrad;

- $\quad$ dem schon erreichten Ausmaß der ausländischen Investitionen;

- $\quad$ der politischen Einstellung gegenüber den Industrieländern;

- der Normalität der Beziehungen mit den Nachbarländern;

- $\quad$ der Bürokratie und Korruption;

- der Stabilität und Legitimität der politischen Macht, sowie der Wahrscheinlichkeit von politischen blutigen oder friedlichen Umwälzungen;

- $\quad$ der allgemeinen Einstellung gegenüber der Privatinitiative;

- der allgemeinen Vermögensverteilung;

- der Vollständigkeit und Unwidersprüchlichkeit der Gesetzgebung;

- $\quad$ den Import- und Exportrestriktionen und Regulierungen;

- $\quad$ der Existenz von Preiskontrollen;

- dem Enteignungsrisiko;

- $\quad$ der freien Konvertibilität der Währung;

- der möglichen Begrenzungen der Eigentumsrechte;

- $\quad$ der Kontrollen auf die Gewinntransfers.

Für Entwicklungsländer deuten die empirischen Ergebnisse auf die "überragende Bedeutung der Entwicklung der Infrastruktur, der Stabilität der internationalen Beziehungen, der schnellen Entwicklung der Industrie und der Expansion des Binnenmarktes. Die Länder, die diese Kriterien gut erfüllen, brauchen mit den anderen durch spezielle Anreizmaßnahmen nicht zu konkurrieren; die anderen haben dagegen wenig Chancen, von solchen "locational tournaments" zu profitieren" (WHEELER \& MODY, 1992, S.75). 
KAPITEL 8:

\section{ZUSAMMENFASSUNG UND EINIGE WIRTSCHAFTSPOLITI- SCHE FOLGERUNGEN}

Der Zweck der vorliegenden Arbeit ist festzustellen, inwieweit die Gestaltung des rumänischen Steuersystems die Kapitalbildung beeinflußt und wie durch steuerpolitische Maßnahmen die o.g. Kapitalbildung angereizt werden könnte, damit Rumänien die heutige Transformations- und Strukturkrise erfolgreich überwindet und sich auf einen günstigen Entwicklungspfad engagiert.

Im Kapitel 1 wurde dementsprechend eine Schilderung der heutigen Lage der rumänischen Volkswirtschaft vorgenommen, unter besonderer Berücksichtigung der Reformen, die nach der politischen Wende vom Ende des Jahres 1989 durchgeführt wurden. Es stellte sich heraus, daß, obwohl auf politischer Ebene entscheidende Reformen für die Demokratisierung unternommen wurden, die Umstrukturierung der Wirtschaft sich erst in ihrer Anfangsphase befindet. Die Unternehmensreform bedeutete bisher lediglich die sog. Korporatisierung der staatlichen Unternehmen, d.h. ihre Umwandlung in Aktiengesellschaften, deren Aktien sich im Besitz des Staates befinden. Dadurch wurde den staatlichen Unternehmen mehr Autonomie als in der Zentralverwaltungswirtschaft eingeräumt; immerhin wird ihnen die strategische Entscheidungsfreiheit durch zahlreiche Institutionen des Staates erheblich eingeschränkt. Der neue, demokratische Staat konnte sich bisher von den alten Aufgaben des sozialistischen Staates - als Eigentümer der überwiegenden Mehrheit des volkswirtschaftlichen Kapitals nicht abgrenzen. Im Gegenteil praktiziert er, insbesondere nach dem Amteintritt der letzten Regierung, eine Politik der verdeckten Subventionierung der nichtrentablen Unternehmen, die er durch die stetige Erhöhung des fiskalischen Druckes auf die anderen finanziert.

Dagegen versagt der Staat bei vielen der neuen Aufgaben, die ihm die neue Wirtschaftsordnung stellt. Hierzu seien vor allem die rechtliche Sicherung der Einhaltung der vertraglichen Beziehungen zwischen Wirtschaftssubjekten und die Kontrolle der Preisbildung in den staatlichen Monopolen erwähnt. Für die Übertragung des Staatseigentums in private Hände wurde bisher ebenfalls sehr wenig getan. Man kann insoweit lediglich von einer "kleinen" Privatisierung im Handels- und Dienstleistungssektor sprechen. Aus all diesen Gründen wird die Schlußfolgerung gemacht, daß die Strukturreform der rumänischen Volkswirtschaft weit hinter den politischen Reformen geblieben ist. Entsprechend der grundsätzlich freien Bildung der Preise auf den Märkten und der weitgehenden Liberalisierung des Außenhandels und des Währungskurses, befindet sich die rumänische Wirtschaft derzeit eher in der Phase des Marktsozialismus. Dies schließt aber die Existenz eines sich endogen entwickelnden Privatsektors, sogar im produzierenden Gewerbe, nicht aus. Es fehlen aber gänzlich die in 
der gegebenen Lage der rumänischen Volkswirtschaft unbedingt notwendigen angebotspolitischen Bemühungen. Es muß noch viel getan werden, damit die private Initiative in Rumänien einen fruchtbaren Boden findet.

Die Reformen wurden in Rumänien, so wie in den anderen ehemaligen Ostblockländern, von beträchtlichen wirtschaftlichen Schwierigkeiten begleitet. Im Kapitel 2 wurden diese Anpassungsprobleme am Beispiel der Textil- und Bekleidungsindustrie erörtert. Eine Faktorenausstattungsanalyse legte zuerst die Bedeutung und die Zukunftschancen dieser Branche dar. Danach wurden ihre spezifischen Entwicklungsindikatoren nach der Wende vorgeführt. Die Produktions- und Umsatzeinbrüche machten bei vielen Produktgruppen kumuliert in den letzten 3 Jahren 50\% oder mehr aus. Diese Zahl geht weit darüber hinaus, was man auf die reine Transformationskrise zurückführen könnte. Die internen und externen Ursachen dieser dramatischen Entwicklung wurden aufgezählt. Es wurde dann gefolgert, daß eine der wichtigsten Ursachen für den Verlust der Märkte und den Produktivitätrückgang der physische und moralische Verschleiß des Anlagevermögens dieser Industrie ist. Die physische Unterkapitalisierung wurde am Beispiel der Textil- und Bekleidungsindustrie veranschaulicht, aber die Lage der Produktionskapazitäten ist fast überall in der rumänischen Industrie dieselbe. Deshalb wird in der rumänischen Industrie eine verstärkte Investitionstätigkeit, die auf die Erneuerung und Modernisierung des bestehenden Sachkapitals gerichtet werden sollte, dringend benötigt.

Die theoretischen Modelle des Zusammenhangs zwischen Besteuerung und Investitionstätigkeit wurden im Kapitel 3 dargelegt und im Kapitel 4 kritisch beurteilt. Dabei ging es um die Übertragbarkeit des Modells auf die rumänische wirtschaftliche Realität, unter Berücksichtigung spezieller Gegebenheiten wie z.B. des Nichtvorhandenseins eines funktionsfähigen Kapitalmarktes. Der mikroökonomisch orientierte Ansatz der neoklassischen Investitionstheorie, nach dem die Investitionsrentabilität von den Kapitalbereitstellungskosten ("capital user costs") in entscheidendem Maße beeinflußt wird, wurde für die Untersuchung der Investitionsbereitschaft ausgewählt. Daneben wurden die Unvolkommenheiten des rumänischen Finanzmarktes berücksichtigt, indem das SCHNEIDER-Modell des Zusammenhangs zwischen Besteuerung und Liquidität der investierenden Unternehmen für die Untersuchung der Investitionsfähigkeit ausgewählt wurde. Hierbei war das Argument, daß die einbehaltenen Gewinne die wichtigste Rolle in der Finanzierung der Investitionen rumänischer Unternehmen spielen, entscheidend. Für die besondere Behandlung der ausländischen Investitionen wurde das Modell des Einflusses der Risikoeinschätzungen von DOMAR \& MUSGRAVE bestimmt. Als steuerliche Investitionsdeterminanten wurden die Gewinnsteuer, die Dividendensteuer und die verschiedenen Vermögens- und Kapitalverkehrsteuern identifiziert. 
Schließlich wurden in den Kapiteln 5, 6 und 7 die o.g. Modelle angewendet. Nach Darstellung und kritischer Beurteilung der Teile der rumänischen Gesetzgebung, die für die Besteuerung relevant sein dürften (Steuern-, aber auch Abschreibungs- und Buchführungsgesetze), erfolgte die Berechnung der Kapitalbereitstellungskosten in der rumänischen Textil-, Bekleidungs- und Lederindustrie. Dabei ergaben sich je nach Finanzierungsart und Eigentumsform 18 unterschiedliche Fälle. Die anschließende Elastizitätsanalyse fand die Parameter heraus, gegenüber denen die Kapitalbereitstellungskosten am empfindlichsten sind. Danach wurde anhand des Modells der stetigen Investitionskette (SCHNEIDER) der zusätzliche Finanzierungsbedarf berechnet, der von der Gewinnbesteuerung und von der den staatlichen Unternehmen erzwungenen Dividendenausschüttung verursacht wird. Mit anderen Worten wurde der Finanz- und Liquiditätsentzug durch Erfolgsbesteuerung, im speziellen Fall eines Textil-, Bekleidungs- oder Lederwarenunternehmens, ermittelt. Dafür wurde, basierend auf der Idee von SCHNEIDER, ein spezifisches mathematisches Modell entwickelt, das auch eine Elastizitätsanalyse ermöglicht.

Ferner wurden die Möglichkeiten der Überwälzung der Gewinnbesteuerung seitens der Textilund Bekleidungsindustrie untersucht. Dabei stellte sich heraus, daß die Chancen der Überwälzung sehr gering sind. Die Gewinnbesteuerung belastet also die Unternehmen dieser Industrie in voller Höhe.

Eine Analyse des Einflusses der vermögensartigen und Kapitalverkehrsteuern findet im Kapitel 6 statt. Dabei werden einige Ergänzungen gemacht, wie z.B. die Berechnung der Erhöhung der Kapitalbereitstellungskosten, die von der Gesellschaftssteuer verursacht wird.

Schließlich kommt im Kapitel 7 die gesonderte Analyse der Problematik der ausländischen Investitionen in Rumänien zum Ergebnis, daß die steuerfreien Fristen, die die rumänische Gesetzgebung den ausländischen Investoren gewährt, nicht die langfristigen Engagements, sondern die spekulativen Geschäfte bevorzugen. Dadurch wird eine Art von "hit and go"Kapitalismus stimuliert. Die insbesondere im Bereich des Handels investierten Mitteln werden nach ihrer Verwertung möglichst schnell aus dem Land zurückgezogen. Die Analyse anhand eines Risiko-Modells sowie eines Rentabilität-Modells, das die Effektivität des Steuererlasses ermittelt, zeigt daß man die falschen fiskalischen Instrumente eingesetzt hat.

Damit die vorliegende Untersuchung einen erhöhten praktischen Wert erhält, ist die Ergänzung ihrer beschreibenden und analytischen Teile mit einigen wirtschaftspolitischen Schlußfolgerungen angebracht. Die ziemlich hohen Werte der Kapitalbereitstellungskosten und des zusätzlichen Finanzierungsbedarfs in den unterschiedlichsten Rechenfällen lassen vermuten, die Besteuerung wäre für die Kapitalbildung in der rumänischen Textil- und Bekleidungsindustrie ein wichtiger Störungsfaktor. Die Investitionen haben sich tatsächlich 
nach der Wende sehr stolpernd entwickelt. Darin spielt die Besteuerung als rentabilitäts- und liquiditätsmindernder Faktor offensichtlich eine Rolle.

Die heutigen ungünstigen Investitionsbedingungen könnten verbessert werden, indem z.B. der Gewinnsteuersatz auf $30 \%$ herabgesetzt würde. Zugleich sollte die steuerfreie Frist für neugegründete Unternehmen abgeschafft werden und der Prozentsatz des Steuerabzugs für Investitionen unberührt bleiben. Dies würde den Trend zu einer leichteren, aber gleichmäßigeren Gewinnbesteuerung einleiten. Es ist ein wirtschaftspolitischer Fehler, durch steuerliche Diskriminierung gegen die freie Allokation der Ressourcen zu wirken. Dadurch würde auch die Entwicklung des privaten Sektors erleichtert werden, indem die kleinen, privaten Firmen mehr Spielraum für die Selbstfinanzierung ihrer Investitionen erhalten würden. Es ist bekannt, daß gerade diese kleinen Firmen einen schwierigeren Zugang zur Fremdfinanzierung haben. Die Herabsetzung des Gewinnsteuersatzes würde auch für die ausländischen Investoren ein positives Signal bedeuten. Schließlich würde die Reduzierung des Gewinnsteuersatzes - siehe die Elastizitätsanalyse im Paragraphen 5.2.6. - eine gewisse Nivellierung der Kapitalbereitstellungskosten mit sich bringen, indem die Fremdfinanzierung teurer und die Finanzierung durch Aktienemission oder einbehaltene Gewinne billiger würde.

Aber der wichtigste Schritt, der unternommen werden müßte, ist die Verbesserung der Abschreibungsbedingungen. Die Elastizität der Kapitalbereitstellungskosten sowie des zusätzlichen Finanzierungsbedarfs ist gegenüber " $z$ " - dem Barwert der steuerlich zugelassenen Abschreibungen - die höchste. Das bedeutet, daß eine kleine Erhöhung dieses Parameters eine überproportionale Senkung der beiden Indikatoren verursachen würde. Die Erhöhung des Barwerts der steuerlich zugelassenen Abschreibungen kommt nur denjenigen Unternehmen zugute, die genug Überschüsse erwirtschaften, um sich erhöhte Abschreibungen leisten zu können. Rentabilität und Wettbewerbsfähigkeit werden also zusätzlich belohnt, wodurch der Strukturwandel der rumänischen Industrie beschleunigt wird. Weiter zeigt die Elastizitätsanalyse daß die Erhöhung von " $z$ " eine erhebliche Reduzierung der Kapitalbereitstellungskosten sowie ihre Nivellierung bringt, so daß die Vorteile der Kreditfinanzierung gegenüber anderen Finanzierungsformen abnehmen.

Für die Erhöhung des Barwerts der steuerlich zugelassenen Abschreibungen müßten: die zugelassenen Nutzungsdauern der Maschinen und Anlagen mit mindestens $40 \%$ gekürzt werden. Dafür sollten neue AfA-Tabellen so schnell wie möglich eingeführt werden.

das neue Abschreibungsgesetz ergänzt werden. Damit wird die klare Definierung des Abschreibungsregimes, die Gestattung des Übergangs von der degressiven zur linearen Methode und die Einführung eines einheitlichen Degressionskoeffizients von 2,5 (siehe 5.1.6.) gemeint. 
Auch müßte das Finanzministerium gesetzlich verpflichtet werden, jährlich den Unternehmen Indexierungskoeffizienten für die Wiederbewertung ihrer Maschinen und Anlagen einzuräumen. Dadurch sollte sichergestellt werden, daß, solange die Inflation nicht unter einer bestimmten Grenze fällt, die Unternehmen ihr Sachkapital zu Wiederbeschaffungskosten abschreiben können und, somit, keine Besteuerung von Scheingewinnen erfolgt.

Einige anderen schädlichen Praktiken der Regierung und des Finanzministeriums müßten auch aufgegeben werden. Hierzu zählen insbesondere die Verordnungen, die dem Gesetz widersprechen, oder die sich so schnell ändern, daß der Planungshorizont der Unternehmen unerträglich eingeschränkt wird. Abzugsfähige Kosten sowie deren Grenzen, Möglichkeiten der Bildung des Reservefonds, der steuerfreien Rücklagen usw. müssen wenn schon jährlich, mindestens gleichzeitig mit der Billigung des Staatshaushaltes definiert werden. Im Laufe des Jahres dürfen sie nicht mehr geändert werden.

Von dem Steuerabzug für Investitionen sollten nicht nur die Sachinvestitionen, wie es im heutigen Gesetz steht, sondern auch die Beteiligungen an das Kapital anderer Unternehmen z.B. durch Aktienkauf - profitieren. Dadurch wäre die Privatisierung, im Fall des Erwerbs von Aktien der staatlichen Unternehmen durch private Firmen, erleichtert.

Schließlich sollte der Prozentsatz der obligatorischen Dividendenausschüttung bei den staatlichen Unternehmen von $40 \%$ auf höchstens $20 \%$ reduziert werden. Hier geht es zwar um keine steuerliche Maßnahme. Diese erzwungene Dividendenzahlung verringert aber die Investitionsfähigkeit bei den Unternehmen, wo sie am meisten benötigt wird. Dagegen hat der Staatseigentumsfonds, der diese Dividenden einnimmt, bisher nichts besseres gefunden, als sie bei Banken einzulegen, anstatt Modernisierungsprojekte zu finanzieren. Dem Finanzentzug bei den Unternehmen und den dadurch versäumten Modernisierungsinvestitionen steht also kein volkswirtschaftlicher Nutzen gegenüber.

In bezug auf die ausländischen Investitionen gelten auch die bisher vorgeschlagenen Maßnahmen. Eine leichtere, aber gleichmäßigere Gewinnbesteuerung ist für die ausländischen Investoren günstiger als eine Steuerfreiheit in den ersten Jahren, wenn sie sowieso keine nennenswerte Gewinne erwirtschaften, gefolgt von einer kräftigen Besteuerung wenn die Gewinne eintreten. Viel wichtiger als die Steuerfreiheit ist für die langfristig planenden Investoren die Möglichkeit des Ausgleichs der in den ersten Jahren erlittenen Verluste. Wichtigere Investitionen in der verarbeitenden Industrie werden ausländische Firmen in Rumänien nicht vornehmen, ohne daß ihnen per Gesetz einen Verlustvortrag über mindestens 5 Jahre eingeräumt wird. 
Mihail Nedelea - 978-3-631-75036-0 Downloaded from PubFactory at 01/11/2019 09:01:58AM via free access 


\section{LITERATURVERZEICHNIS}

Abel, A.B.: Dynamic Effects of Permanent and Temporary Tax Policies in a "q"-model of Investment. In: Journal of Monetary Economics, Vol.9, 1982, No.3.

Adamicek, Josef: Textil- und Bekleidungsindustrie. Tschechoslowakei. In: Osteuropaperspektiven: Industrie, Politik, Wirtschaft - Polen, Tschechoslowakei, Ungarn/ Frankfurter Allgemeine Zeitung [Hrsg.], Frankfurt am Main, 1991, S.152-156.

Adelman, M.A.: The Corporate Income Tax in the Long Run. Journal of Political Economy, 1957, S.151-157.

Agapitos, G.: Inflationary Effects of Profits Taxes with Reference to the UK Manufacturing Sector. In: Finanzarchiv, Neue Folge, Bd.35, 1976/1977, S.235-257.

Ahrens, Joachim: Die Rolle westlicher Industriestaaten bei der Transformation sozialistischer Volkswirtschaften. In: List-Forum für Wirtschafts- und Finanzpolitik, Band.19.1993, Heft 1, S.76-103.

Albach, Horst: Steuersystem und unternehmerische Investitionspolitik, Wiesbaden, 1970.

Alter, Rolf: The New Challenge in Eastern Europe: Investment and Restructuring. In: Intereconomics, Jan./ Febr. 1992, S.16-19.

Alworth, J.S.: The Finance, Investment and Taxation Decisions of Multinationals. Oxford, New York, 1988.

Anastassiou, T.A.: Tax Incentives in a Neoclassical Investment Behavior Model: Evidence from Greek Manufacturing. In: Public Finance, Vol.45, 1990, S.201-227.

Arrow, K.J.: The Economic Implications of Learning by Doing. In: Review of Economic Studies, Vol.29 (1962).

Atkinson, A.B.; Stiglitz, J.E.: Lectures on Public Economics, McGraw\& Hill, 1980.

Baan, W.: Substanz- und Ertragsteuern in der Kapitalwertmethode. In: Der Betrieb, Band 33, 1980, No.15, S.700-703 und No.16, S.746-750.

Ballarini, Klaus: Theorien der Gewinnsteuerüberwälzung. Tübingen, JCB Mohr, 1982.

Barlow, E.R.; Wender, I.T.: Foreign Investment and Taxation. New Jersey, Englewood Cliffs, 1955.

Barthel, J; Fassing, W.: Investitionsverhalten und Wirtschaftspolitik. In: Jahrbuch für Sozialwissenschaft, Bd.31, 1980, S.316-325. 
Baumol, W.J.: Business Behavior, Value and Growth. New York, Brace \& World, 1967.

Beath, J.: Target Profits, Cost Expectations and the Incidence of the Corporation Income Tax. In: The Review of Economic Studies, 1979, S.513-525.

Becker, Gernot: Inflationsbilanzierung. In: Das Wirtschaftsstudium, Nr.7/1992, S.546-548.

Beckmann, M.: Makroökonomische Untersuchungen der Auswirkungen von Steuersystemänderungen, Wiesbaden, 1970.

Begg, David; Portes, Richard: Enterprise Debt and Financial Restructuring in Central and Eastern Europe. In: European Economic Review, Nr.37/1993, S.396-407.

Bertola, Giuseppe: Irreversible Investment. Working Paper, Cambridge, Massachussets Inst. Tech., October 1987.

Billsborrow, R.E.; Porter, R.C.: The Effects of Tax Exemption on Investment by Industrial Firms in Colombia. In: Weltwirtschaftliches Archiv, 1972, S.396-426.

Boadway, R.: Corporate Taxation and Investment: A Synthesis of the Neoclassical Theory. In: Canadian Journal of Economics, 1980, S.250-266.

Böhnlein, Barbara; Heitger, Bernhard: Die neue Handelspolitik der EG gegenüber Osteuropa. In: Die Weltwirtschaft, 1991, Heft 2, S.130-145.

Borensztein, Eduardo; Demekas, Dimitri; Ostry, Jonathan: An Empirical Analysis of the Output Declines in Three Eastern European Countries. In: IMF Staff Papers, Vol.40, No.1, March 1993, S.1-31.

Bradford De Long, J.; Summers, Lawrence H.: Equipment Investment and Economic Growth. In: Quarterly Journal of Economics, Vol.106, 1991, S.445-502.

Breitenacher, Michael: Textilindustrie. Strukturwandlungen und Entwicklungsperspektiven für die achtziger Jahre. Berlin, Duncker \& Humblot, 1981.

Breitenacher, Michael: Textilindustrie im Wandel. Frankfurt am Main, Gesamttextil, 1989.

Breitenacher, Michael: Bleibt Deutschland Standort für die Textilindustrie? In: IfoSchnelldienst, Nr. 13/1992, S.24-31.

Brown, E.C.: Business Income Taxation and Investment Incentives. In: Income, Employment, and Public Policy, Essays in Honor of AH Hansen, New York, 1948.

Bruno, Michael: Stabilization and Reform in Eastern Europe. In: IMF Staff Papers, Vol.39, No.4/1992, S.741-777.

Bruno, S.: Corporate Income Tax, Oligopolistic Markets and Immediate Tax Shifting: A Suggested Theoretical Approach. In: Public Finance, No.3/1970, S.363-380. 
Busch, Berthold; Fröhlich, Hans-Peter: Westliche Unterstützung der Reformprozesse. In: Die Reformländer Mittel- und Osteuropas. Zwischenbilanz: Problemanalyse und Perspektiven. In: IW-Trends. Quartalhefte zur empirischen Wirtschaftsforschung, Nr.1/1993, S.49-70.

Calvo, Guillermo; Coricelli, Fabrizio: Output Collapse in Eastern Europe. The Role of Credit. In: IMF- Staff Papers, March 1993, S.32-52.

Calvo, Guillermo; Vegh, Carlos: Währungssubstitution in Staaten mit hoher Inflation. In: Finanzierung \& Entwicklung, März 1993.

Chenery, H.B.; Taylor, L.: Development Patterns: Among Countries and over Time. In: Review for Economics and Statistics, Vol.50, 1968, S.391-416.

Christ, C.F.: Discussion to Jorgenson. In: American Economic Review, Papers and Proceedings, May 1963, S.269-271.

Ciupagea, Constantin: Die Inflation unter drei Regierungen (rum. Sprache). In: Capital, Nr.48, 3.12.1993.

Coen, R.M.: Investment Behavior, the Measurement of Depreciation and Tax Policy. In: American Economic Review, März 1975, S.59-73.

Corbo, Vittorio: Economic Transformation in Latin America. Lessons for Eastern Europe. In: European Economic Review, No.36/1992, S.407-416.

Coricelli, Fabrizio; Milesi-Ferreti, Gian Maria: On the Credibility of "Big-Bang Programmes". In: European Economic Review, No.37/1993, S.387-395.

Cornelsen, Doris: Privatisierung in Ungarn, Polen und die Tschechoslowakei. In: Wirtschaftsreformen in Mittel- und Osteuropa: Tagungsband der Arbeitsgemeinschaft wirtschaftswissenschaftlicher Forschungsinstitute e.V. im Mai 1992 in Bonn. Berlin, Duncker \& Humblot, 1993. (Beihefte der Konjunkturpolitik, H.40), S.33-45.

Cosea, Mircea: Eine Interview für "Capital" (rum. Sprache). In: Capital, 5.02.1994, Bukarest.

Denison, E.F.: Income Tax and the Size of Distribution. In: American Economic Review, Papers and Proceedings, 1954.

DIW - Institut: Zu den Assoziationsverträgen der Europäischen Gemeinschaft mit Polen, Ungarn und der Tschechoslowakei. In: DIW-Wochenbericht, Nr. 50/1991, S.701-704.

DIW - Institut : Zur Entwicklung des Produktionspotentials in Ostdeutschland. In: DIWWochenbericht, Nr. 47/1991, S.663-668.

Dixit, Avinash: Entry and Exit Decisions under Uncertainty. In: Journal of Political Economy, Vol.97, Febr.-Dec. 1989, S.620-638. 
Döhrn, Roland; Heilemann, Ulrich: Zur allokativen Dimension. Sektorale Entwicklungsperspektiven für Ungarn, Polen und die Tschechoslowakei. In: Wirtschaftsreformen in Mittelund Osteuropa: Tagungsband der Arbeitsgemeinschaft wirtschaftswissenschaftlicher Forschungsinstitute e.V. im Mai 1992 in Bonn. Berlin, Duncker \& Humblot, 1993. (Beihefte der Konjunkturpolitik, H.40), S.51-69.

Domar, E.D.; Musgrave, R.A.: Proportional Income Taxation and Risk-Taking. In: Quarterly Journal of Economics, Vol.58, 1944, S.387-422.

Dragan, C.M.: Die neue kaufmännische Buchführung (rum. Sprache). Bukarest, Herkules Verlag, 1993.

Eckstein, Otto: Public Finance. Prentice-Hall, 1973.

Ehret, Martin; Patzig, Wolfgang: Ist eine Wiederholung des "Wirtschaftswunders" möglich? Perspektiven für die Entwicklung in den neuen Bundesländern. List-Forum für Wirtschafts- und Finanzpolitik, Heft 2, 1991, S.109-131.

Einhoff, Udo: Investitionen und Kapazitätseffekte in einzelnen Sparten der westdeutschen Textilindustrie. Opladen, Westdeutscher Verlag, 1975.

Eppler, R.: Steuerüberwälzung. Eine modelltheoretische und empirische Analyse ausgewählter Probleme der Überwälzung der Gewinnsteuern. Berlin, Duncker \& Humblot, 1980.

Feldstein, M.S.; Foot, D.K.: The Other Half of Gross Investment: Replacement and Modernization Expenditures. In: The Review of Economics and Statistics, 1971, S.49-58.

Feldstein, M.S.; Green, J.; Sheshinski, E.: Corporate Financial Policy and Taxation in a Growing Economy. In: Quarterly Journal of Economics, 1979, No.3, S.411-432.

Fischer, Lutz; Warneke, Perygrin: Besteuerung und Auslandsfinanzierung. In: Wirtschaftswissenschaftliches Studium, Heft 4, April 1976, S.145-153.

Fischer, Stanley; Gelb, Allan: The Process of Socialist Economic Transformation. In: Journal of Economic Perspectives, Vol.5, No.4, 1991, S.91-106.

Föhl, Carl: Kritik der progressiven Einkommensbesteuerung. In: Finanzarchiv, Neue Folge, Bd.14, 1953/1954, S.88-109.

Franzen, V.; Meyer, A.; Ziemer, H.: Nominalwertprinzip, Geldentwertung und Besteuerung. Bonn, Institut Finanzen und Steuern, Brief 134, 1973.

Fröhlich, Hans Peter; Link, Franz Josef: Makroökonomische Zwischenbilanz des Transformationsprozesses. In: Die Reformländer Mittel- und Osteuropas. Zwischenbilanz: Problemanalyse und Perspektiven. In: IW-Trends. Quartalhefte zur empirischen Wirtschaftsforschung. Nr.1/1993, S.15-30. 
Fromm, G.; Schink, G.R.: Aggregation and Econometric Models. In: International Economic Review, Vol.14, 1973.

Funke, M.: Tobin's q and Sectorial Investment in BRD and UK: a Pooled Cross-Section and Time-Series Study. In: Zeitschrift für Sozialwissenschaften, Berlin, 1989, S. 399-420.

Funke, M; Ryll, A.; Willenbockel, D.: Taxation and Capital Formation in West German Industries: a "q"-theory Approach. In:M Funke (Ed.): Factors in Business Investment, Berlin, 1987, S.76-103.

Gass, Liselotte: Go East to Mittelost- und Osteuropa. In: Gesamttextil, Jahrbuch der Textilindustrie, 1993, Eschborn.

Gälli, Anton: Textil- und Bekleidungsindustrie: Polen. In: Osteuropaperspektiven: Industrie, Politik, Wirtschaft - Polen, Tschechoslowakei, Ungarn/ Frankfurter Allgemeine Zeitung [Hrsg.], Frankfurt am Main, 1991, S.146-152.

Gälli, Anton: Textil- und Bekleidungsindustrie: Ungarn. In: Osteuropaperspektiven: Industrie, Politik, Wirtschaft - Polen, Tschechoslowakei, Ungarn/ Frankfurter Allgemeine Zeitung [Hrsg.], Frankfurt am Main, 1991, S.156-162.

Gälli, Anton: Nöte und Perspektiven der Textil- und Bekleidungsindustrie in Ostmitteleuropa und der GUS. In: Ifo-Schnelldienst, Nr. 30/1992, S.12-28.

Gerstenberger, W.: Investitionsbedarf in der Bundesrepublik in den achtziger Jahren. In: Kapital und Wachstum in den achtziger Jahren. Berlin, Duncker \& Humblot, 1983. (Beihefte der Konjunkturpolitik, H.30).

Görzig, Bernd; Blazejczak, Jürgen; Horn, Gustav Adolf; Kirner, Wolfgang; Schulz, Erika; Stille, Frank: Investitionen, Beschäftigung und Produktivität. Berlin, Duncker \& Humblot, 1988. (DIW-Beiträge zur Strukturforschung, Nr.108).

Gordon, R.: The Incidence of the Corporation Income Tax in US Manufacturing, 19251962. In: American Economic Review, September 1967, S.731-758.

Grigorie, Nicolae: Maßnahmen zur Bekämpfung der Steuerhinterziehung (rum. Sprache). In: Tribuna Economica, 26.03.1993, Bukarest.

Habuda, Judit: Wirtschaftliche Entwicklung und Perspektiven in Ungarn, Polen und der Tschechoslowakei. In: Ifo-Schnelldienst Nr.7/1992, S.17-22.

Hardy, D.C.; Lahiri, A.K.: Bank Insolvency and Stabilization in Eastern Europe. In: IMF Staff Papers, Vol.39, No.4, December 1992, S.778-800.

Hayashi, F.: Tobin's Marginal q and Average q: a Neoclassical Interpretation. In: Econometrica, Vol.50, Jan.1982, S.213-224. 
Hederer, G.: Die Motivation von Investitionsentscheidungen der Unternehmung, Meisenheim, 1971.

Heliwell, J.F.: Public Policies and Private Investment, Oxford, 1968.

Hendershott, P.; Cheng-Fu, S.: Investment in Producers Equipment. In: HJ Aaron \& JA Pechman [Eds.]: How Taxes Affect Economic Behavior. Washington, D.C., The Brookings Institution, 1981, S.85-129.

Hill, Hal; Suphachalasai, Suphat: The Myth of Export Pessimism (even) under the Multifiber Agreement: Evidence from Indonesia and Thailand. In: Weltwirtschaftliches Archiv, Nr.128/1992, S.310-329.

Hoanta, Nicolae: Die Kapitalisierung der Gesellschaften mit staatlichem Kapital (rum. Sprache). In: Tribuna Economică, Nr.22/1993, Bukarest.

Hoen, Herman W:; Van Leeuwen, Eliza H.: Upgrading and Relative Competitiveness in Manufacturing Trade: Eastern Europe versus the Newly Industrializing Economies. In: Weltwirtschaftliches Archiv, Nr.127/1991, S.368-379.

Inotai, Andras: Die Außenwirtschaftliche Öffnung, Handelsliberalisierung und Währungskonvertibilität. In: Wirtschaftsreformen in Mittel- und Osteuropa: Tagungsband der Arbeitsgemeinschaft wirtschaftswissenschaftlicher Forschungsinstitute e.V. im Mai 1992 in Bonn. Berlin, Duncker \& Humblot, 1993. (Beihefte der Konjunkturpolitik, H.40), S.73-82.

Institut Finanzen und Steuern: Steuerliche Maßnahmen zur Investitionförderung. Bonn, Brief 177, 1978.

International Monetary Fund: World Economic Outlook, May 1992.

International Monetary Fund: World Economic Outlook, October, 1992.

International Monetary Fund: World Economic Outlook. Interim Assesment, January 1993.

Jatzek, Hans-Georg; Leibfritz, Willy: Der Einfluß der Steuern auf die Investitionstätigkeit der Unternehmen. Berlin, Duncker \& Humblot, 1982. (Schriftenreihe des Ifo-Instituts für Wirtschaftsforschung, Bd.111).

Jorgenson, Dale W.: Capital Taxation and Investment Behavior. In: American Economic Review, Papers and Proceedings, Vol.53, 1963, S.247-259.

Jorgenson, Dale W.: Anticipations and Investment Behavior. In: The Brookings Quarterly Econometric Model of the USA, JS Duesenberry, G Fromm u.a. [Eds.], Amsterdam, 1965, S.35-92.

Jorgenson, Dale W.: Econometric Studies on Investment Behavior, a Survey. In: Journal of Economic Literature, Dec. 1971, S.1111-1147. 
Jorgenson, D.W.; Stephenson, J.A.: Investment Behavior in US Manufacturing, 1947-1960. In: Econometrica, Vol.35, 1967, S.169-187.

Katona, G.: Das Verhalten der Verbraucher und Unternehmer. Über die Beziehungen zwischen Nationalökonomie, Psychologie und Sozialpsychologie, Tübingen, 1960.

King, M.: Public Policy and the Corporation, London, 1977.

Klein, L.R.: Issues in Econometric Studies on Investment Behavior. In: Journal of Economic Litterature, 1974, S.43-49.

Klös, Hans-Peter: Privatisierung: Zwischenbilanz und Tendenzen. In: Die Reformländer Mittel- und Osteuropas. Zwischenbilanz: Problemanalyse und Perspektiven. In: IW-Trends, Quartalhefte zur empirischen Wirtschaftsforschung. Nr.1/1993, S.71-88.

Kopits, George F.: Taxation and Multinational Firm Behavior: A Critical Survey. In: International Monetary Fund Staff Papers, November 1976, S.624-673.

Kregel, J.A.; Matzner, Egon: Agenda for the Reconstruction of Central and Eastern Europe. In: Challenge, Sept./Oct. 1992, S.33-40.

Kroker, Rolf: Osteuropa auf dem Weg in die Marktwirtschaft. In: IW-Trends: Die Reformländer Mittel- und Osteuropas. Zwischenbilanz: Problemanalyse und Perspektiven. Institut der Deutschen Wirtschaft Köln. Nr.1/1993, S.3-14.

Krzyzaniak, M.; Bastani, S.: The Incidence of the US Corporation Income Tax: An Old Problem Revisited. In: Public Finance, No.2/1988, S.165-195.

Lang, Franz Peter: Short-Run Effects of Economic Reforms in Eastern Economics. In: Intereconomics, Sept./Oct. 1991, S.223-229.

Langhammer, Rolf: Die Auswirkungen der EG-Handelspolitik gegenüber Mittel- und Osteuropa. In: Wirtschaftsreformen in Mittel- und Osteuropa: Tagungsband der Arbeitsgemeinschaft wirtschaftswissenschaftlicher Forschungsinstitute e.V. im Mai 1992 in Bonn. Berlin, Duncker \& Humblot, 1993. (Beihefte der Konjunkturpolitik, H.40), S.225-249.

Leibinger, H.B.: Fiskalpolitik unter veränderten Rahmenbedingungen, Berlin, 1985.

Linotte, D.: The Fall in Industrial Output in Transition Economies: a New Interpretation. In: Working Paper 3/1992, The Leuwen Institute for Central and East European Studies.

Lionachescu, Doru: Rumänischer Staat beutet Unternehmer aus. Die Aufschiebung des neuen Buchführungssystems hat das Geschäftsklima stark beschädigt (rum. Sprache). In: Capital, 3.12.1993, Bukarest.

Lösch, Dieter: Aktueller Stand und Perspektiven des Transformationsprozesses in Albanien, Bulgarien und Rumänien. In: Wirtschaftsreformen in Mittel- und Osteuropa: Tagungsband der Arbeitsgemeinschaft wirtschaftswissenschaftlicher Forschungsinstitute e.V. im Mai 1992 
in Bonn. Berlin, Duncker \& Humblot, 1993. (Beihefte der Konjunkturpolitik, H.40), S.93118.

McDonald, Robert L., Siegel, Daniel R.: Investment and the Valuation of Firms When There Is an Option to Shut Down. In: International Economic Review, No.26, June 1985, S. 331-349.

Mellwig, W.: Sensitivitätsanalyse des steuerlichen Einflusses in der Investitionsplanung. Überlegungen zur Praktischen Relevanz einer Berücksichtigung der Steuern bei den Investitionsentscheidungen. In: Schmalenbach's Zeitschrift für Betriebswirtschaftliche Forschung, Band 32, 1980, No.1, S.16-39.

Mellwig, W.: Investition und Besteuerung. Ein Lehrbuch zum Einfluß der Steuern auf die Investitionsentscheidung, Wiesbaden, 1985.

Mihaescu, Olga: Die Umstrukturierung der Industrie als Teil der strategischen Entwicklung der rumänischen Volkswirtschaft in der Transitionsphase (rum. Sprache). Centrul de Informare şi Documentare Economiç, Bukareşt, 1993.

Meyer, J.R.; Kuh, E.: The Investment Decision - an Empirical Study, Cambridge, Ma., 1966.

Montias, J.M.: The Romanian Economy: a Survey of Current Problems. In: European Economy, Special Edition, No.2, June, 1991 (Brüssel: Commission of the European Communities), S.177-198.

Mühleck, Peter: Krise und Anpassung der deutschen TBI im Lichte der FordismusDiskussion. Frankfurt am Main, Peter Lang, 1992.

Murrel, Peter: Can Neoclassical Economics Underpin the Reform of Centrally Planned Economies? In: Journal of Economic Perspectives, Vol.5, Nr.4, 1991, S.59-76.

Musgrave, Richard A.: Finanztheorie. Studienausgabe. JCB Mohr, Tübingen, 1974.

Musgrave, R.A.; Krzyzaniak, M.: The Shifting of the Corporation Income Tax. Baltimore, John Hopkins University Press, 1963.

von Netzer, Jörg: Die deutsche Textilindustrie zwei Jahre nach der Wende: die Integration ist allmählich absehbar. In: Gesamttextil, Jahrbuch 1992, Eschborn.

Neundörfer, Konrad: Stichwort Industrialisierung: die Realität als Herausforderung. In: Gesamttextil, Jahrbuch der Textilindustrie 1992, Eschborn.

Neundörfer, Konrad; Stahr, Ernst-Heinrich [Hrsg.]: Wettbewerbsverzerrungen im TextilAußenhandel. Frankfurt/Main, Gesamttextil, 1989.

Nickell, Stephen J.: The Investment Decision of Firms, London, 1978. 
Niehans, Jürg: Die Wirkungen von Lohnerhöhungen, technischen Fortschritten, Steuern und Spargewöhnheiten auf Preise, Produktion und Einkommensverteilung. In: Schriften des Vereins für Socialpolitik, Neue Folge, Bd.17, Einkommensverteilung und technischer Fortschritt. [Hrsg.]: E Schneider, Berlin, 1959.

Noll, W.: Finanzwissenschaft. München, Vahlen, 1979.

Oakland, W.H.: Corporate Earnings and Tax Shifting in US-Manufacturing, 1930-1968. In: The Review of Economics and Statistics, 1972, S.235-244.

OECD: Industrial Policies in OECD-Countries. Annual Review, 1991.

Oppenländer, Karl-Heinz: Investitionsinduzierter technischer Fortschritt: Berechnung und Analyse für die verarbeitende Industrie der Bundesrepublik Deutschland. Berlin, Duncker \& Humblot, 1976.

Pantea, Mihaela: Das Anlagevermögen wartet auf ein neues Abschreibungsgesetz (rum. Sprache). In: Capital, 30.04.1993, Bukarest.

Penner, R.G.: Uncertainty and the Short-Run Shifting of the Corporation Tax. In: Oxford Economic Papers, No.19/1967, 1, S.99-110.

Petrea, Alecu: Wie bildet man den Reservefonds? (rum. Sprache). In: Tribuna Economica, 23.04.1993, Bukarest.

Pindyck, Robert S.: Irreversibility, Uncertainty, and Investment. In: Journal of Economic Literature, Vol. XXIX (Sept. 1991), S.1110-1148.

Pindyck, Robert S.: Irreversible Investment, Capacity Choice, and the Value of the Firm. Working Paper, Cambridge, Massachussets Inst. Tech., 1987.

Pisulla, Petra: Das Verhältnis mittel- und osteuropäischer Länder zu den internationalen Finanzorganisationen. In: Wirtschaftsreformen in Mittel- und Osteuropa: Tagungsband der Arbeitsgemeinschaft wirtschaftswissenschaftlicher Forschungsinstitute e.V. im Mai 1992 in Bonn. Berlin, Duncker \& Humblot, 1993. (Beihefte der Konjunkturpolitik, H.40), S.209-224.

Popescu, Ionut: Die Geschäftsbanken beeilen sich langsam (rum. Sprache). In: Capital, Nr.3, 21.01.1994.

Portes, Richard: Structural Reform in Central and Eastern Europe. In: European Economic Review, No.36/1992, S.661-669.

Poterba, J.; Summers, L.H.: Dividend Taxes, Corporate Investment and "Q". In: Journal of Public Economics, Vol.22, 1983, No.2.

Probst, Jürgen: Investition und Wachstum. Wachstumswirkungen der Investitionen in Industriestaaten und Entwicklungsländern. Bad Honnef, Bock + Herchen, 1978. 
Ristea, Mihai: Das neue Buchführungssystem (rum. Sprache). In: Tribuna Economica, 28.05.1993, Bukarest.

Rollo, Jim; Smith, Alasdair: EC Trade with Eastern Europe. In: Economic Policy, April 1993, S.139-182.

Romania - National Commission for Statistics: Operational Statistical Information. The Industry in September 1993. No.9, November 1993.

Romania - National Commission for Statistics: Price Statistics Bulletin, October 1993.

Romania - National Commission for Statistics: Quarterly Statistical Bulletin. No.2/1993.

Romanian Statistical Yearbook: 1991.

Romanian Statistical Yearbook: 1993.

Rudnitchi, Constantin: Offene Tore nach Europa. Bald werden die meisten rumänischen Produkte zollfrei in die EG exportiert werden können (rum. Sprache). In: Capital, Nr.5/1993, Bukarest.

Rudnitchi, Constantin: Staatseigentumsfonds trägt dem Parlament ein Privatisierungsprogramm an der Grenze zwischen Optimismus und Phantasie vor (rum. Sprache). In: Capital, Nr.48, 3.12.1993.

Rumänien - Nationaler Ausschuß für Statistik: Die Weltwirtschaft in Zahlen (rum. Sprache). August, 1993.

Rumänien - Nationaler Ausschuß für Statistik: Laufende statistische Informationen (rum. Sprache). Heft 1, Mai 1993, Bukarest.

Rumänische Entwicklungsagentur: Gesetzessammlung betreffend ausländische Investitionen in Rumänien. Bukarest, Mai 1992.

Schild, Guido: Technische Textilien - eine strategische Alternative? In: Gesamttextil, Jahrbuch 1992, Eschborn.

Schmieding, Holger: Gradualismus oder Schocktherapie? Eine Bilanz der ostmitteleuropäischen Erfahrungen. In: Wirtschaftsreformen in Mittel- und Osteuropa: Tagungsband der Arbeitsgemeinschaft wirtschaftswissenschaftlicher Forschungsinstitute e.V. im Mai 1992 in Bonn. Berlin, Duncker \& Humblot, 1993. (Beihefte der Konjunkturpolitik, H.40), S.1127.

Schneider, H.: Der Einfluß der Steuern auf die unternehmerischen Investitionsentscheidungen, Tübingen, 1964.

Schumpeter, J.: Theorie der wirtschaftlichen Entwicklung, Berlin, 1952. 
Seroussi, J.: Sorgen eines ausländischen Investors in Rumänien (rum. Sprache). In: Capital, No. 10/1993, Bukarest.

Siedenberg, A.: Investitionsorientierte Fiskalpolitik, Berlin, 1976.

Sievert, O. u.a.: Steuern und Investitionen, Band I. Europäische Hochschulschriften, Peter Lang, Frankfurt am Main, 1989.

Solow, R.M.: Wachstumstheorie. Darstellung und Anwendung. Göttingen, Vandenhoeck \& Ruprecht, 1971.

Spinanger, Dean: Kann Deutschland als Standort für die Textil- und Bekleidungsindustrie gesichert werden? In: Die Weltwirtschaft, Heft 1/1993, S.92-116.

Strobel, W.: Betriebswirtschaftliche Steuerlehre. In: Handbuch der Wirtschaftswissenschaften. [Hrsg]: W Albers u.a.. Stuttgart, Tübingen und Göttingen: Gustav Fischer, JCB Mohr und Vandenhoek \& Ruprecht, 1977.

Summers, L.H.: Taxation and Corporate Investment: a "q"-Theory Approach. In: Brookings Papers on Economic Activity, 1981, No.1, S.67-127.

Sumner, M.: Investment, q, and Taxes. In: Public Finance, Vol.44, 1989, No.2, S. 285294.

Tinbergen, J.: Statistical Evidence of the Acceleration Principle. In: Economica, May, 1938.

Tobin, J; Brainard, W.C.: Pitfalls in Financial Model Building. In: American Economic Review, Papers and Proceedings, Vol.58, May 1968, S.99-122.

Viehweg, H.G: Textil- und Bekleidungsmaschinen. Entwicklungsperspektiven bis zum Jahr 2000. In: Ifo- Schnelldienst, Nr.7/1989, S.16-23.

Wächter, H.: Unternehmungs- und Unternehmerziele im sozio-ökonomischen Feld, Göttingen, 1969.

Wagner, F.W.: Kapitalerhaltung, Geldentwertung und Gewinnbesteuerung. Berlin, Springer Verlag, 1978.

Wagner, F.W.: Das Grundmodell der Ertragsteuerwirkungen auf die Investitionsentscheidung. In: Wissenschaftliches Studium, 1979, S.67-72.

Wagner, F.W.: Die Integration der Besteuerung in die unternehmerische Planung. In: Der Betrieb, 1980, No.12, S.553-555.

Weichsel, Lothar: Beschleunigte Abschreibung, Wachstum und Konjunktur. Köln, Westdeutscher Verlag, Opladen, 1964. 
Welfens, Paul J.J.: Economic Reforms in Eastern Europe: Basic Problems, Options and Opportunities. In: Intereconomics, Sept./Oct. 1991, S.214-222.

Weydert, Jean Marie: La fiscalité et le financement des investissements des entreprises. In: Economie appliquée, Tome XXI, 1968, S.831-851.

Wheeler, David; Mody, Ashoka: International Investment Location Decisions. In: Journal of International Economics, No.33/1992, S.57-76.

Whitmore, Katherine: Banken und Finanzsysteme. Polen. In: Osteuropa-Perspektiven: Industrie, Politik, Wirtschaft - Polen, Tschechoslowakei, Ungarn / Frankfurter Allgemeine Zeitung [Hrsg.] - Frankfurt am Main, 1991, S.68-71.

Winiecki, Jan: Competitive Prospects in Eastern Europe. A Parting of the Ways. In: Intereconomics, July/ August 1991, S.187-191.

Wittmann, W.: Einführung in die Finanzwissenschaft. II. Teil: Die öffentlichen Einnahmen. Stuttgart, Gustav Fischer, 1975.

Wöhe, Günter: Steuerliche Bewertung. In: Handbuch der Wirtschaftswissenschaften. [Hrsg]: W Albers u.a.. Stuttgart, Tübingen und Göttingen. Gustav Fischer, JCB Mohr und Vandenhoek \& Ruprecht, 1980. Band 1, S.637-649.

Wöhe, G.; Bieg, H.: Grundzüge der betriebswirtschaftlichen Steuerlehre, München, 1984.

Worthington, Paula R.: Investment and Market Power. In: International Journal of Industrial Organization, No.10/1992, S.309-318. 


\title{
SOZIALÖKONOMISCHE SCHRIFTEN
}

\author{
Herausgegeben von Professor Dr. Dr. h.c. Bert Rürup
}

Band 1 Marietta Jass: Erfolgskontrolle des Abwasserabgabengesetzes. Ein Konzept zur Erfassung der Gesetzeswirkungen verbunden mit einer empirischen Untersuchung in der Papierindustrie. 1990.

Band 2 Frank Schulz-Nieswandt: Stationäre Altenpflege und "Pflegenotstand" in der Bundesrepublik Deutschland. 1990.

Band 3 Helmut Böhme, Alois Peressin (Hrsg.): Sozialraum Europa. Die soziale Dimension des Europäischen Binnenmarktes. 1990.

Band 4 Stephan RuB: Telekommunikation als Standortfaktor für Klein- und Mittelbetriebe. Telekommunikative Entwicklungstendenzen und regionale Wirtschaftspolitik am Beispiel Hessen. 1991.

Band 5 Reinhard Grünewald: Tertiärisienungsdefizite im Industrieland Bundesrepublik Deutschland. Nachweis und politische Konsequenzen. 1992.

Band 6 Bert Rürup, Uwe H. Schneider (Hrsg.): Umwelt und Technik in den Europäischen Gemeinschaften. Teil I: Die grenzüberschreitende Entsorgung von Abfällen. Bearbeitet von: Thomas Kemmler, Thomas Steinbacher. 1993.

Band 7 Mihai Nedelea: Erfordernisse und Möglichkeiten einer wachstumsorientierten Steuerpolitik in Rumänien. Dargestellt am Beispiel der Textil- und Bekleidungsindustrie. 1995. 


\section{Shengyang Zhang}

\section{Währungskonvertibilität und volkswirtschaftliche Transformation in Osteuropa}

Frankfurt/M., Berlin, Bern, New York, Paris, Wien, 1994. VIII, 218 S., 3 Abb., 17 Tab.

Europäische Hochschulschriften: Reihe 5, Volks- und Betriebswirtschaft. Bd. 1547

ISBN 3-631-46972-1 br. DM 69.--*

In der Diskussion von Entwicklungsmodellen kommt der Währungskonvertibilität eine besondere Bedeutung zu. Sie gilt als Steuergröße wie als Indikator für den Grad der Integration eines Landes in die Weltwirtschaft. Sie stellt ebenso ein zentrales Thema der Entwicklung der postsozialistischen Ökonomien in Osteuropa dar. Der Autor vertritt die Meinung, daß sich Währungskonvertibilität als ein Marktergebnis im Verlauf der Entwicklung einstellt, daß aber Maßnahmen in Richtung einer beschränkten Konvertibilität (im Sinne des IWF) den Entwicklungsund Integrationsprozeß stimulieren können.

Aus dem Inhalt: Theorie der Währungskonvertibilität . Währungspolitische Maßnahmen der Währungskonvertibilität - Beschränkte Konvertibilität

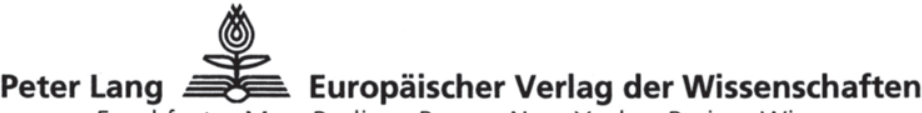

Frankfurt a.M. • Berlin - Bern - New York - Paris - Wien

Auslieferung: Verlag Peter Lang AG, Jupiterstr. 15, CH-3000 Bern 15

Telefon (004131) 9411122, Telefax (004131) 9411131

- Preisänderungen vorbehalten - *inklusive Mehrwertsteuer 